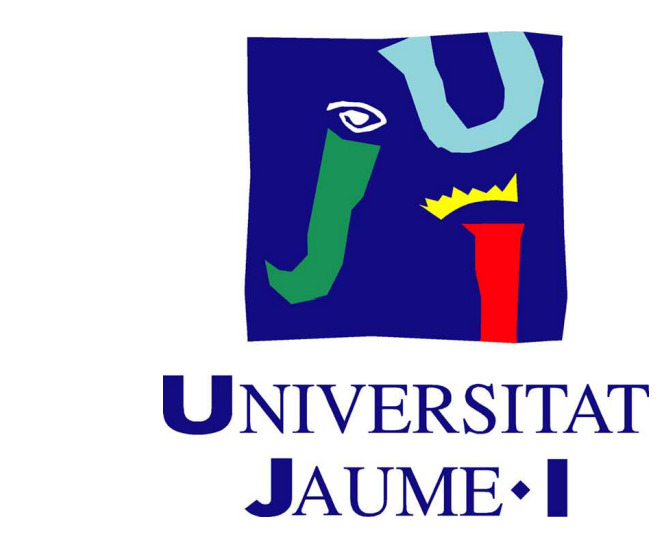

UNIVERSITAT JAUME I DE CASTELLÓ

ESCUELA SUPERIOR DE TECNOLOGÍA Y CIENCIAS EXPERIMENTALES

Departamento de Ingeniería Química

\title{
Aplicaciones estratégicas de la Nanofiltración para el tratamiento de las aguas en la industria cerámica
}

\author{
MEMORIA \\ que para optar al grado de \\ Doctor en Ingeniería Química presenta \\ Raúl CAYETANO MOLINER SALVAdOR
}

Castellón, 2017 

Enrique Sánchez Vilches, Catedrático de Ingeniería Química de la Universitat Jaume I de Castelló y André Deratani, Doctor en Ciencias Químicas y Director de Investigación en el Instituto Europeo de Membranas de Montpellier.

CERTIFICAN: Que D. Raúl Cayetano Moliner Salvador ha realizado bajo su dirección, dentro del programa de doctorado "Tecnologies Industrials, Materials i Edificació" de la Universitat Jaume I de Castellón, el trabajo que bajo el título "APLICACIONES ESTRATÉGICAS DE LA NANOFILTRACIÓN PARA EL TRATAMIENTO DE LAS AGUAS EN LA INDUSTRIA CERÁMICA" presenta en esta memoria y que constituye su tesis para optar al grado de Doctor en Ingeniería Química.

Y, para que conste a los efectos oportunos, firman el presente certificado en Castellón, a 4 de Julio de 2017.

Enrique Sánchez Vilches

Catedrático de Ingeniería Química
André Deratani

Doctor en Ciencias Químicas 

Parte de este trabajo ha sido financiado a través de tres proyectos de investigación:

- Desarrollo de una tecnología de membranas para la mejora técnica y medioambiental de la industria de la Comunidad Valenciana (IMAETA/2005/11 - IMAETB/2006/16 IMAETB/2007/19). IMPIVA - Instituto de la Pequeña y Mediana Industria de la Generalitat Valenciana.

- Advanced membrane separation technologies for boron removal in waste waters of ceramic and other manufacturing industries-NANOBORON (E!4121) European Eureka Project e IMPIVA - Instituto de la Pequeña y Mediana Industria de la Generalitat Valenciana.

- Desarrollo de procesos avanzados de Nanofiltración para la reutilización de las aguas residuales en la industria cerámica (NanoReCer). CDTI-Centro para el Desarrollo Tecnológico Industrial. 

A la meva família, per la força que em doneu i per sempre haver estat aquí. 



\section{Agradecimientos}

Este trabajo se ha llevado a cabo en el Instituto de Tecnología Cerámica de Castellón-ITC (España), en el Instituto Europeo de Membranas de Montpellier-IEM (Francia) y en varias empresas del sector cerámico de la provincia de Castellón, por lo que en primer lugar me gustaría mostrar mi agradecimiento a todas estas instituciones, especialmente a la primera, ya que es como mi casa desde hace más de una década. Gracias por poner a mi disposición medios humanos y materiales para la realización de los trabajos que han confeccionado esta tesis.

Pero sobre todo este trabajo ha sido posible por la dedicación, esfuerzo y apoyo de muchas personas a las que quiero transmitirles mi agradecimiento más sincero.

En primer lugar, quiero darles las gracias a mis directores, el Prof. Enrique Sánchez y el Prof. André Deratani. Muchas gracias a los dos por el apoyo que siempre he recibido por ambas partes para que esta tesis se hiciese realidad, así como por todos los conocimientos que me habéis trasmitido durante todos estos años. Al Prof. Enrique Sánchez quiero agradecerle la confianza que ha depositado en mí desde el principio y durante todo el tiempo que hemos trabajado juntos. Aún recuerdo aquel primer viaje que hicimos en coche hasta Montpellier y los que lo siguieron, con buena música en la space y con rueda de camión en la autopista incluida. Gracias por el apoyo a mi trabajo desde el primer día, por tus consejos, por tu experiencia, por tu dedicación y por tu inmensa ayuda, sin ella este trabajo no hubiese podido llevarse a cabo. Al Prof. Andre Deratani quiero agradecerle el trato recibido durante mis estancias en el IEM y todos los conocimientos que me ha transmitido. Merci André pour votre savoir-faire et pour partager vos connaissances sur la nanofiltration. Merci aussi pour votre amitié, car Elyane et vous êtes ma famille française.

A continuación, quiero dar las gracias a todos mis compañeros, con los que comparto el día a día en ITC y juntos conformamos el Área de Sostenibilidad. Desde su responsable hasta el último técnico que ha pasado por la Unidad de Medio Ambiente, ya que de una u otra manera habrá colaborado en este trabajo. Dentro de este equipo no puedo dejar de dar las gracias de una forma especial a la Dra. Irina Celades, por muchas razones. La primera, por animarme y contar conmigo para hacer una estancia en un centro de excelencia llamado IEM hace ahora más de 11 años, sin esta estancia este trabajo no hubiese existido. Quiero también, agradecerle la confianza puesta día a día en mí, así como todos los consejos profesionales y personales que me ha dado siempre que se los he pedido, además quiero agradecerle todas las facilidades ofrecidas para que el trabajo de redacción de esta tesis fuera lo más fácil posible. Este agradecimiento lo hago extensible a los demás responsables del Área y del Instituto.

Quiero dar las gracias a mis compañeros que como yo, estos últimos meses, han estado preparando la tesis. Gracias Ana L por estar tan atenta a todo el papeleo que la tesis lleva asociado, sin tu ayuda seguro que algo nos hubiésemos dejado. Gracias Alberto por tus consejos de formato, por lo que se debe poner y como se tiene que poner en el documento... como ya sabes, algunos de tus consejos los he seguido a raja tabla, sin embargo, a otros muchos no les he hecho ni caso. Y gracias Tica por los ánimos que me has dado cuando te comentaba que creía que no llegaba y por todo ese tiempo compartido en el despacho hasta horas intempestivas... como tu bien dices hemos logrado conocer a todo el personal de seguridad y de limpieza del ITC de estos últimos meses, que no han sido pocos. Gracias a los tres por ayudarme en todo lo que os he necesitado y por vuestra complicidad en esta "dura" tarea que es elaborar una tesis, junto a vosotros ha sido más llevadera. 
Y al resto de compañeros de Unidad: Dr. Salvador Gomar, Teresa, Alicia y Fernando, gracias por los ánimos, por vuestra ayuda y por crear un ambiente de trabajo inmejorable. Sois los mejores!!!

No puedo dejar de acordarme de otros compañeros que han estado con nosotros y que también me han tenido que echar una mano en las pruebas industriales o incluso a la hora de recoger muestras para envíame a Francia, ellos son Fran, Fabiola y Jesús. Gracias amigos.

Para terminar con los miembros del área quiero agradecer el interés y los ánimos recibidos de Papús, Ana, Sara y Salva. A éste último también le tengo que agradecer alguna figura que otra.

Y aunque no sean de nuestra área, quiero agradecer de una forma muy especial a David Lores su ayuda en todos los temas informáticos, sin ella estoy seguro que el resultado del trabajo no hubiese sido el mismo. David eres un crack como informático y mejor persona, si eso es posible. También quiero agradecer a la Dra. María Fernanda Gazulla, a la Dra. Paqui Quereda y a sus equipos por la ayuda prestada. Además, quiero darle las gracias al Prof. Sergio Mestre por echarme un cable en este segundo semestre, sin su ayuda me hubiese resultado muy difícil cumplir los plazos.

Al otro lado de los Pirineos también conocí a muchas personas y grandes compañeros que han intervenido de una forma $u$ otra en esta tesis. Quiero dar las gracias a todo el personal de IMECA en especial a Thierry y Gauthier Poudevinge, Frank Merican y Salvador Pérez por su ayuda con la planta piloto. También a todo el personal del IEM, en especial al Prof. John Palmeri por toda su ayuda con el programa Nanoflux ${ }^{\circledR}$ y a Marie Gueran por su participación en el proyecto Nanoboron. Además, quiero dar las gracias a todos los compañeros con los que coincidí en este centro durante mis diferentes estancias en el país vecino. En especial a Hafedh, por todo el tiempo que hemos pasado en el laboratorio aprendiendo muchísimas cosas de nanofiltración y por todas las experiencias vividas, merci mon frère!!!. Gracias Fatma por tu ayuda y por tus conversaciones dentro y fuera del laboratorio, eres una persona excepcional, gracias por cruzarte en mi camino amiga. Gracias Didier por esas superfotos y por las jornadas de espeleo. Por último, no quiero olvidarme de Amine y Sadika, gracias por los momentos compartidos. Merci à tous pour le bon vieux temps!!!

En los últimos años hemos trabajado con muchas empresas. A todas ellas, a sus técnicos y sus responsables quiero darles las gracias. En especial a Dídac Velilla por siempre hacernos tan fácil nuestro trabajo y sobre todo a Paco Segarra, por su profesionalidad, su intuición, su experiencia, su trato y sus ganas de probar cosas nuevas que mejoren el proceso cerámico, ha sido un auténtico placer poder trabajar contigo crack.

Y por último, pero no por ello menos importante, quiero dedicar estas líneas a las personas que están más próximas a mí, sin el apoyo de las cuales ni este trabajo ni muchos de los proyectos realizados a lo largo de mi vida hubiesen podido transformarse en realidad. Todo lo que soy se lo debo a mis padres, por este motivo esta tesis quiero dedicársela a ellos. A mi madre Juliana, porque sé que me está cuidando en todo momento y me da ánimos para afrontar cualquier reto que se me ponga por delante, también a mi padre Saturnino por forjarme como siempre lo ha hecho y por quererme tanto. También quiero darle las gracias a mi hermana Begonya por su ánimo constante y por siempre estar ahí, eres la mejor hermana que se puede tener. Tampoco me puedo olvidar de mi primo Dani, que más que un primo es como un hermano, quiero darle las gracias por ser una de esas personas con las que se puede contar, sin su ayuda muchas cosas estarían muy descuidadas.

Para terminar, tengo que dar las gracias a Carla, por estar a mi lado, por su ayuda durante estos últimos meses y por confiar en todo momento en que podía lograrlo. 
- ¡Qué extraña escena describes -dijo- y qué extraños prisioneros!

- Iguales que nosotros...

Platón

(El mito de la caverna. República, libro VII)

Tota persona ha de mirar, al llarg de la vida en 6 direccions:

Endavant, per saber cap a on va.

Endarrere, per recordar d'on ve.

A sota, per no trepitjar a ningú.

Als costats, per veure qui l'acompanya en els moments difícils.

Amunt, per saber que algú el mira i l'està cuidant. ...i per acabar, endins, per conèixer-se millor.

(No se de qui és però a mi m'ho va dir una volta la meva germana i volia que estigues a l'inici d'aquest treball) 



\section{Resumen}

El agua es un recurso natural limitado y en muchas regiones del planeta también es escaso. Por esta razón, la gestión del agua se ha convertido en una cuestión muy importante en muchos sectores industriales tradicionales consumidores de aguas y generadores de aguas residuales. El sector cerámico se encuentra dentro de estos sectores ya que consume aguas de pozo y genera aguas residuales en cantidades importantes. Además, los principales sectores cerámicos europeos, con gran importancia a nivel mundial, están ubicados en España e Italia, países de la cuenca mediterránea en los cuales existen regiones donde la escasez de recursos hídricos es un problema preocupante.

Ha sido por estos motivos por los que en el presente trabajo se ha pensado en la aplicación de la tecnología de nanofiltración (NF) a través de membranas poliméricas para ayudar a las empresas del sector cerámico en la gestión de sus aguas industriales. La nanofiltración es una técnica de separación a través de membranas cuya fuerza impulsora es un gradiente de presiones. Esta técnica se sitúa entre la ósmosis inversa (OI) y la ultrafiltración (UF), y ha tenido un importante desarrollo en las últimas décadas, principalmente por el desarrollo de los materiales con los que se fabrican las membranas. La nanofiltración presenta varias características que la hacen buena candidata para ser aplicada en el sector cerámico, como por ejemplo, la elevada retención a elementos de muy bajo peso molecular y a los iones divalentes, todo ello utilizando presiones mucho más bajas que algunas de sus técnicas competidoras como puede ser la ósmosis inversa.

Por tanto, el desarrollo de la investigación se divide en tres partes: la caracterización de las membranas utilizadas, un primer caso de estudio que ha consistido en la aplicación de la nanofiltración en la eliminación del boro de las aguas residuales generadas en la fabricación de baldosas cerámicas, y un segundo caso de estudio en el que se ha aplicado esta tecnología en la eliminación de iones divalentes en las aguas industriales utilizadas en la preparación de suspensiones cerámicas, necesarias para la elaboración del polvo atomizado.

En la primera parte del trabajo se han caracterizado cuatro membranas comerciales de nanofiltración: NF, NF-90, NF-200 y NF-270 de la marca Dow-Filmtec. Para cada una de ellas se ha determinado la permeabilidad al agua pura $\left(L_{p}^{0}\right)$, el radio de poro $\left(r_{p}\right)$ y la densidad de carga normalizada $\left(X_{i}\right)$. Los dos últimos parámetros se han calculado con la ayuda de un programa informático de modelización llamado Nanoflux ${ }^{\circledR}$ desarrollado por el Instituto Europeo de Membranas. De los resultados obtenidos se puede extraer que la membrana NF-90 puede ser la más indicada para la retención del boro, mientras que para la retención selectiva de los iones divalentes frente a los monovalentes, el comportamiento de la NF-270 parece más indicado.

Durante el primer caso de estudio se han caracterizado las aguas residuales de una empresa modelo de fabricación de baldosas cerámicas para establecer el punto de partida. Seguidamente, se han realizado ensayos de nanofiltración a escala de laboratorio para determinar la retención de boro por la membrana NF-90. Tras las pruebas de laboratorio, la tecnología se ha escalado a nivel industrial mediante pruebas piloto. Se han obtenido retenciones del boro que varían del 80 al $99 \%$. En este caso de estudio también se pretende evaluar la posibilidad de reintroducir el agua tratada en el propio proceso productivo cerámico en diferentes usos en los que en la actualidad sería 
impensable. Por tanto, con el agua obtenida tras el tratamiento, se han realizado pruebas de elaboración de esmaltes y engobes con resultados muy positivos. Para finalizar el primer caso de estudio se ha realizado un balance económico para determinar el coste del tratamiento por nanofiltración. Este coste se ha comparado con el de la ósmosis inversa, resultando ser prácticamente la mitad.

En el segundo caso de estudio, al igual que en el primero, se ha realizado una caracterización de las aguas industriales de una empresa modelo de fabricación de polvo atomizado. Tras la caracterización, se han realizado todos los ensayos necesarios a escala de laboratorio para determinar el comportamiento de la membrana NF-270 en la eliminación de los iones divalentes. Además, se han realizado ensayos del proceso cerámico a las suspensiones y productos cerámicos elaborados con las aguas nanofiltradas. Estos ensayos han determinado que las suspensiones preparadas con el permeado de las aguas industriales mejoran su comportamiento reológico considerablemente. Además, el rechazo de algunas aguas ensayadas puede utilizarse en el propio proceso productivo, ya que sus características son similares al agua residual industrial que se está actualmente utilizando para la elaboración de suspensiones cerámicas. Por este motivo, se ha decidido realizar el escalado industrial con este tipo de aguas para comprobar la viabilidad de la técnica de nanofiltración. Mediante la nanofiltración se ha podido reducir la cantidad de $\mathrm{Ca}^{2+} \mathrm{y} \mathrm{SO}_{4}{ }^{2-}$ entre $60-70 \%$ y $90-95 \%$, respectivamente. Esto se ha traducido en reducciones del $30 \%$ en el porcentaje de desfloculante añadido a las suspensiones cerámicas y un aumento de más del 1\% de la densidad de estas suspensiones. Esto puede implicar ahorros de más de $1 € /$ t de polvo atomizado elaborado con estas aguas, que en el caso de una empresa media de fabricación de polvo atomizado podría suponer un ahorro económico de unos 60000 €/año, en el caso más desfavorable. Además del ahorro económico, también se puede cuantificar importantes beneficios medioambientales ya que al disminuir la cantidad de agua a evaporar se puede ahorrar más de

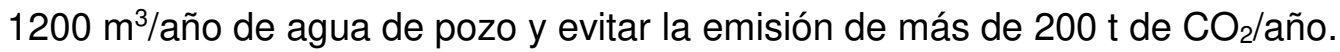




\section{Resum}

L'aigua és un recurs natural limitat i en moltes regions del planeta també és escàs. Per aquesta raó, la gestió de l'aigua s'ha convertit en una qüestió molt important en molts sectors industrials tradicionals consumidors d'aigües i generadors d'aigües residuals. El sector ceràmic es troba dins d'aquests sectors ja que consumeix aigües de pou i genera aigües residuals en quantitats importants. A més, els principals sectors ceràmics europeus, amb gran importància mundial, estan ubicats a Espanya i Itàlia, països de la conca mediterrània en els quals hi ha regions on l'escassetat de recursos hídrics és un problema preocupant.

Ha sigut per aquests motius pels quals en aquest treball s'ha pensat en l'aplicació de la tecnologia de nanofiltració (NF) a través de membranes polimèriques per a ajudar a les empreses del sector ceràmic en la gestió de les seues aigües industrials. La nanofiltració és una tècnica de separació a través de membranes la força impulsora de la qual és un gradient de pressions. Aquesta tècnica se situa entre l'osmosi inversa (OI) i la ultrafiltració (UF), i ha tingut un important desenvolupament en les últimes dècades, principalment pel desenvolupament dels materials amb els quals es fabriquen les membranes. La nanofiltració presenta diverses característiques que la fan bona candidata per a ser aplicada en el sector ceràmic, com per exemple, l'elevada retenció a elements de molt baix pes molecular i als ions divalents, tot això amb la utilització de pressions molt més baixes que algunes de les seues tècniques competidores com pot ser l'osmosi inversa.

Per tant, el desenvolupament de la investigació es divideix en tres parts: la caracterització de les membranes utilitzades, un primer cas d'estudi que ha consistit a l'aplicació de la nanofiltració en l'eliminació del bor de les aigües residuals generades en la fabricació de taulells ceràmics, i un segon cas d'estudi en el qual s'ha aplicat aquesta tecnologia en l'eliminació d'ions divalents en les aigües industrials utilitzades en la preparació de suspensions ceràmiques, necessàries per a l'elaboració de la pols atomitzada.

En la primera part del treball s'han caracteritzat quatre membranes comercials de nanofiltració: NF, NF-90, NF-200 i NF-270 de la marca Dow-Filmtec. Per a cada una d'aquestes s'ha determinat la permeabilitat a l'aigua pura $\left(L_{p}^{0}\right)$, el radi de porus $\left(r_{p}\right)$ i la densitat de càrrega normalitzada $\left(X_{i}\right)$. Els dos últims paràmetres s'han calculat amb l'ajuda d'un programa informàtic de modelització que es diu Nanoflux ${ }^{\circledR}$ desenvolupat per l'Institut Europeu de Membranes. Dels resultats obtinguts es pot extraure que la membrana NF-90 pot ser la més indicada per a la retenció del bor, mentre que per a la retenció selectiva dels ions divalents enfront dels monovalents, el comportament de la NF-270 pareix més indicat.

Durant el primer cas d'estudi s'han caracteritzat les aigües residuals d'una empresa model de fabricació de taulells ceràmics per a establir el punt de partida. A continuació, s'han realitzat assajos de nanofiltració a escala de laboratori per a determinar la retenció de bor per la membrana NF-90. Després de les proves de laboratori, la tecnologia s'ha escalat a nivell industrial mitjançant proves pilot. S'han obtingut retencions del bor que varien del 80 al 99\%. En aquest cas d'estudi també es pretén avaluar la possibilitat de reintroduir l'aigua tractada en el propi procés productiu ceràmic en diferents usos en els quals actualment seria impensable. Per tant, amb l'aigua obtinguda després del tractament, s'han realitzat proves d'elaboració d'esmalts i engalbes amb resultats molt positius. 
Per a finalitzar el primer cas d'estudi s'ha realitzat un balanç econòmic per a determinar el cost del tractament per nanofiltració. Aquest cost s'ha comparat amb el de l'osmosi inversa i ha resultat ser pràcticament la meitat.

En el segon cas d'estudi, igual que en el primer, s'ha realitzat una caracterització de les aigües industrials d'una empresa model de fabricació de pols atomitzada. Després de la caracterització, s'han realitzat tots els assajos necessaris a escala de laboratori per a determinar el comportament de la membrana NF-270 en l'eliminació dels ions divalents. A més, s'han realitzat assajos del procés ceràmic a les suspensions i productes ceràmics elaborats amb les aigües nanofiltrades. Aquests assajos han determinat que les suspensions preparades amb el permeat de les aigües industrials milloren el seu comportament reològic considerablement. A més, el rebuig d'algunes aigües assajades pot utilitzar-se en el propi procés productiu, ja que les seues característiques són semblants a l'aigua residual industrial que s'està actualment utilitzant per a l'elaboració de suspensions ceràmiques. Per aquest motiu, s'ha decidit realitzar l'escalat industrial amb aquest tipus d'aigües per a comprovar la viabilitat de la tècnica de nanofiltració. Mitjançant la nanofiltració s'ha pogut reduir la quantitat de $\mathrm{Ca}^{2+}{ }_{\text {i SO }}{ }_{4}{ }^{2-}$ entre $60-70 \%$ i 90-95\%, respectivament. Això s'ha traduït en reduccions del $30 \%$ en el percentatge de desfloculant afegit a les suspensions ceràmiques i un augment de més de l'1\% de la densitat d'aquestes suspensions. Això pot implicar estalvis de més d'1€/t de pols atomitzada elaborada amb aquestes aigües, que en el cas d'una empresa mitjana de fabricació de pols atomitzada podria suposar un estalvi econòmic d'uns $60000 € /$ any, en el cas més desfavorable. A més de l'estalvi econòmic, també es poden quantificar importants beneficis mediambientals ja que en disminuir la quantitat d'aigua que s'ha d'evaporar es poden estalviar més de 1200 m³/any d'aigua de pou i evitar l'emissió de més de 200 t de $\mathrm{CO}_{2} / a n y$. 


\section{Résumé}

L'eau est une ressource naturelle limitée et dans de nombreuses régions de la planète elle n'est pas très abondante. Pour cette raison, la gestion de l'eau est devenue une question primordiale dans de nombreux secteurs industriels traditionnels qui sont de grands consommateurs d'eau générant des volumes d'eaux usées importants. Les industries de la céramique se situent dans ce cas de figure, car elles consomment de grandes quantités d'eau mais aussi produisent des eaux usées en abondance. De plus, les principaux secteurs de la céramique en Europe, occupant une place majeure au niveau mondial, sont situés en Espagne et en Italie, pays du bassin méditerranéen dans lesquels la pénurie d'eau est un problème plus ou moins aigu suivant les régions.

En conséquence, ce travail a été conçu afin d'aider les entreprises du secteur de la céramique dans la gestion de leurs eaux industrielles par l'application d'une technologie membranaire, la nanofiltration (NF). La nanofiltration est une technique de séparation à travers des membranes polymères dont la force motrice est un gradient de pression. Cette technique est située entre l'osmose inverse (RO) et l'ultrafiltration (UF), et elle a eu un développement important durant ces dernières années, principalement grâce à la mise sur le marché de matériaux membranaires performants. La nanofiltration a plusieurs caractéristiques qui en font une bonne candidate pour une application dans le secteur de la céramique, comme par exemple, sa rétention élevée des composés de faible masse moléculaire et aussi sa sélectivité aux ions bivalents, tout en utilisant des pressions beaucoup plus faibles que des techniques concurrentes telles que l'osmose inverse.

La présentation de ce travail se divise en trois parties: la caractérisation des membranes utilisées, une première étude de cas dans laquelle la nanofiltration a été appliquée pour éliminer le bore des eaux résiduelles produites dans la fabrication des carreaux céramiques, et une seconde étude de cas dans laquelle cette technologie a été appliquée pour l'élimination des ions divalents de l'eau industrielle utilisée dans la préparation de suspensions céramiques (barbotines) précurseurs de la poudre atomisée.

Dans la première partie du travail, quatre membranes de nanofiltration commerciales ont été caractérisées: NF, NF-90, NF-200 et NF-270, toutes de la société Dow-Filmtec. Pour chacune d'entre elles, la perméabilité à l'eau pure $\left(L_{p}^{0}\right)$, le rayon de pore $\left(r_{p}\right)$ et la densité de charge normalisée $\left(X_{i}\right)$ ont été déterminés. Les deux derniers paramètres ont été calculés à l'aide d'un logiciel de modélisation appelé Nanoflux ${ }^{\circledR}$, développé à I'Institut Européen des Membranes. D'après ces résultats, il a pu être établi que la membrane NF-90 parait la membrane la plus appropriée pour la rétention du bore, alors que la membrane NF-270 semble la plus indiquée pour la rétention sélective des ions bivalents par rapport aux monovalents.

Dans la première étude de cas, des eaux résiduelles rejetées par une entreprise type de fabrication de carreaux céramiques ont été caractérisées comme point de départ. Des essais de nanofiltration à l'échelle du laboratoire ont ensuite été effectués pour déterminer la rétention du bore par la membrane NF-90. Après ces essais en laboratoire, la technologie a été évaluée au niveau industriel avec des tests sur pilote. Des rétentions du bore allant de 80 à $99 \%$ ont été obtenues. Dans ce cas, la possibilité de réutilisée l'eau traitée dans le processus de production céramique pour différents usages qui aujourd'hui n'étaient pas envisageable, a été aussi évaluée. Ainsi, des essais de 
fabrication d'émaux et d'engobes réalisés en utilisant l'eau obtenue après le traitement ont donnés des résultats très satisfaisants. Pour terminer cette première étude de cas, un bilan économique a été effectué pour déterminer le coût du traitement par nanofiltration. Ce coût comparé à celui de l'osmose inverse est d'environ égal à la moitié.

La deuxième étude de cas, comme précédemment, a débutée par la caractérisation des eaux industrielles d'une société type de production de poudre atomisée. Après cette étape, tous les tests nécessaires à l'échelle de laboratoire pour déterminer les performances de la membrane NF-270 dans l'élimination des ions bivalents ont été réalisées. Des essais ont ensuite été réalisés sur les suspensions et les produits céramique élaborés à base de l'eau nanofiltrée. Ces tests ont montré que le comportement rhéologique des suspensions préparées en utilisant le perméat de l'eau industrielle est considérablement amélioré. De plus, les rejets de la nanofiltration peuvent être utilisés dans le processus de production, car leur caractéristiques sont semblables à celles des eaux usées industrielles lesquelles sont maintenant utilisées dans la fabrication de suspensions céramiques (barbotines). La faisabilité de la technique de nanofiltration à une échelle industrielle a ensuite été évaluée avec ce type d'eau. Le traitement par nanofiltration permet de réduire la quantité des ions $\mathrm{Ca}^{2+}$ et $\mathrm{SO}_{4}{ }^{2-}$ entre $60-70 \%$ et $90-95 \%$ respectivement. En conséquence, une réduction de $30 \%$ du pourcentage de floculant ajouté aux suspensions céramiques et une augmentation de plus de $1 \%$ de la densité de ces suspensions sont attendues. Cela peut engendrer des économies de plus de $1 € / t$ de poudre atomisée élaborée avec ces eaux. Ainsi, une entreprise moyenne de fabrication de poudre atomisée pourrait voir ses coûts réduits d'environ $60000 € /$ an dans une hypothèse basse. En plus de la baisse des coûts, des avantages environnementaux importants peuvent être quantifiés, car en réduisant la quantité d'eau à évaporer un entreprise moyenne peut économiser plus de $1200 \mathrm{~m}^{3} / \mathrm{an}$ d'eau de puits et éviter l'émission de plus de 200 t de $\mathrm{CO}_{2} / \mathrm{an}$. 


\section{Abstract}

Water is a limited natural resource and in many regions of the planet, it is also scarce. Consequently, water management has become a very important issue in many traditional industrial sectors which are water consumers and wastewater generators. The ceramic sector is within these sectors because it consumes fresh water and generates wastewater in important quantities. In addition, the main European ceramic sectors, with great importance at world level, are located in Spain and Italy, Mediterranean basin countries in which there are regions where the scarcity of water resources is a worrying problem.

For these reasons, the present work has focused on the application of nanofiltration technology (NF) through polymer membranes to help ceramic companies in the management of their industrial waters. Nanofiltration is a separation technique through membranes whose driving force is a pressure gradient. This technique is situated between reverse osmosis (OI) and ultrafiltration (UF), and it has had an important development in the last decades, mainly due to the development of the materials with which the membranes are made. Nanofiltration has several features which make it a good candidate to be applied in the ceramic sector. These features are high retention to very low molecular weight elements and to divalent ions, too, all this using much lower pressures than some of its competing techniques such as reverse osmosis.

Therefore, research development is divided into three parts: the characterization of used membranes, a first study case which has consisted in the application of nanofiltration to the removal of boron from the wastewater generated in ceramic tile manufacturing, and a second study case in which this technology has been applied to the removal of divalent ions from the industrial waters used in the preparation of ceramic suspensions, which are necessary for the elaboration of the spraydry powder.

In the first part of the work, four commercial nanofiltration membranes have been characterized: NF, NF-90, NF-200 and NF-270 of the Dow-Filmtec company. For each of them, pure water permeability $\left(L_{p}^{0}\right)$, pore radius $\left(r_{p}\right)$ and normalized charge density $\left(X_{i}\right)$ have been determined. The last two parameters have been calculated with the aid of a modeling software called Nanoflux ${ }^{\circledR}$ which was developed by the European Institute of Membranes. From the results obtained, it can be deduced that the NF-90 membrane may be the most suitable one for boron retention, whereas the behavior of NF-270 membrane seems more indicated for the selective retention of the divalent ions against the monovalents.

During the first study case the wastewater of a model ceramic tile manufacturing company was characterised in order to establish the starting point. Next, laboratory-scale nanofiltration tests were performed to determine the retention of boron by the NF-90 membrane. After the laboratory tests, the technology has been scaled to industrial level by means of pilot tests. Boron retentions ranging from 80 to $99 \%$ have been obtained. In this study case, it is also evaluated the possibility of reintroducing the water treated in the production process into different uses in which it would be unthinkable nowadays. Therefore, with the water obtained after the treatment, glazes and engobes have been tested with very positive results. To end the first study case, an economic balance was 
obtained to determine the cost of the treatment by nanofiltration. This cost has been compared with reverse osmosis cost, the nanofiltration cost is almost the half of the reverse osmosis cost.

In the second case study, as in the first case, a characterization of the industrial waters of a model company dedicated to the manufacture of spray-dry powder was carried out. After the characterization, all necessary laboratory tests have been performed to determine the behavior of the NF-270 membrane in the elimination of the divalent ions. In addition, tests of the ceramic process have been carried out on suspensions and on ceramic products made with nanofiltrated waters. These tests have determined that the suspensions prepared with the permeate from the industrial waters improve their rheological behavior considerably. Moreover, the rejection of some tested waters may be also used in the production process, since its characteristics are similar to the industrial wastewater currently used for the manufacture of ceramic suspensions. For this reason, this type of water has been used to carry out industrial scaling to verify the feasibility of the nanofiltration technique. Nanofiltration has reduced the amount of $\mathrm{Ca}^{2+}$ and $\mathrm{SO}_{4}{ }^{2-}$ between $60-70 \%$ and $90-95 \%$, respectively. These results have led to reductions of $30 \%$ in the percentage of deflocculant added to the ceramic suspensions and to an increase of more than $1 \%$ in the density of these suspensions. This could imply savings of more than $1 € / t$ of spray-dry powder made with these waters, therefore in the case of a medium company, it could lead to savings of $60000 € /$ year, at the worst. In addition to economic savings, significant environmental benefits can also be quantified, since reducing the amount of water to be evaporated can save more than $1200 \mathrm{~m}^{3} /$ year of groundwater and avoid the emission of more than $200 \mathrm{t} \mathrm{CO}_{2} /$ year. 


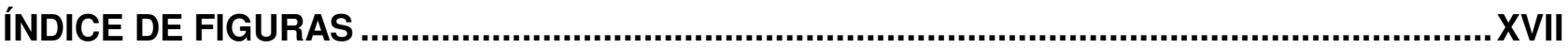

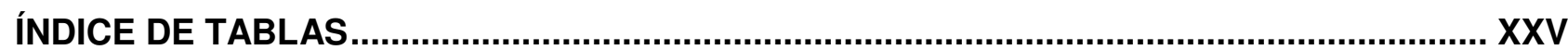

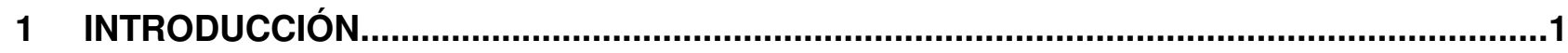

1.1 Problemática del agua en el sector cerámico ….........................................................

1.1.1 El sector de fabricación de baldosas cerámicas y subsectores afines..................4

1.1.2 Necesidad de agua en el proceso cerámico ..................................................

1.1.3 Generación, características y gestión actual de las aguas residuales procedentes de las empresas de fabricación de baldosas cerámicas ......................................... 8

1.2 El problema de la depuración del boro .............................................................15

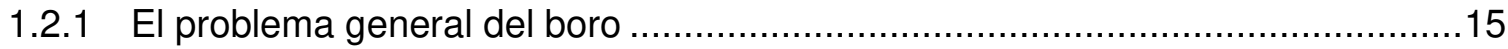

1.2.2 Química del boro..................................................................................

1.2.3 La eliminación del boro en la industria cerámica ..........................................18

1.2.4 Otras alternativas para la eliminación del boro .............................................23

1.2.5 Comparación entre las técnicas que existen para la eliminación del boro ..........25

1.3 Comportamiento reológico de las suspensiones cerámicas......................................26

1.3.1 Comportamiento de la mezcla agua - materias primas cerámicas.....................28

1.3.2 Efecto de los iones presentes en el medio dispersante .................................28

1.3.3 Desfloculación de las suspensiones cerámicas: influencia del agua utilizada ....30

1.3.4 Situación actual respecto de los tipos de agua utilizada ...................................33

1.4 Procesos de filtración a través de membranas. Nanofiltración........................................34

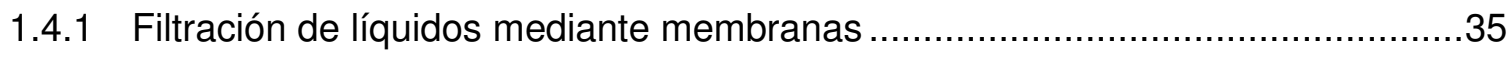

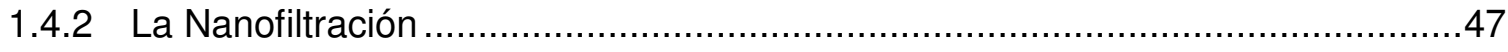

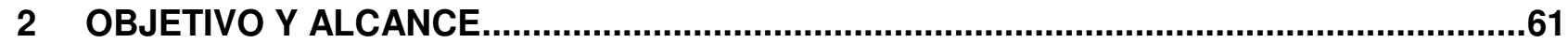

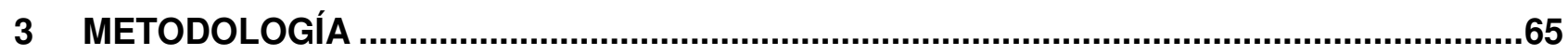

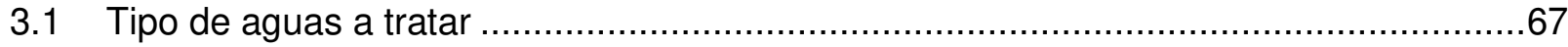

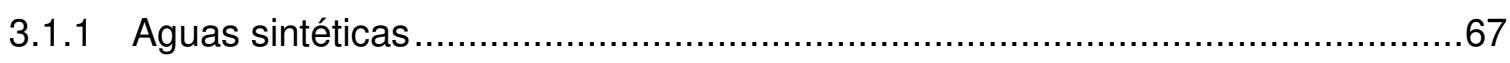

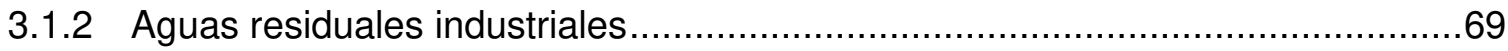

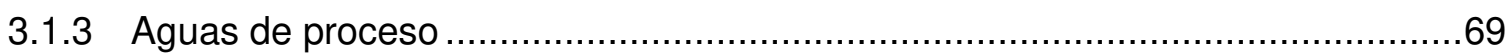

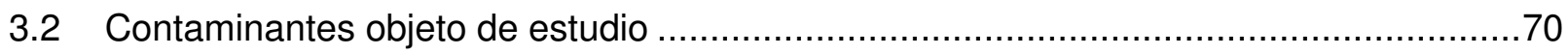

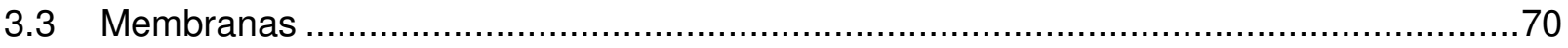

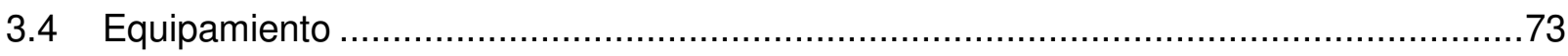


3.4.1 Plantas de filtración tangencial a escala de laboratorio ...................................73

3.4.2 Planta de filtración tangencial a escala piloto …...............................................

3.5 Análisis y determinación de diferentes parámetros de las aguas...............................81

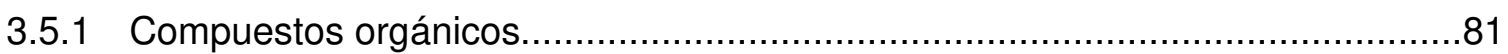

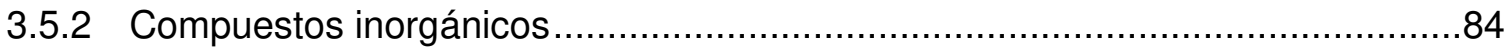

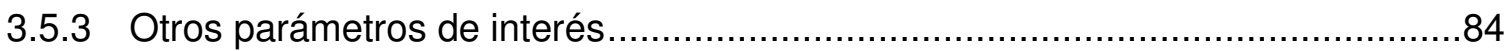

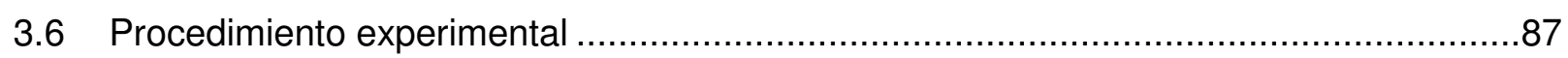

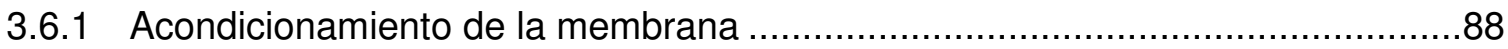

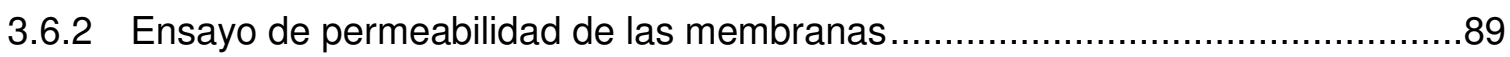

3.6.3 Cálculo de la retención ofrecida por las membranas y el grado de conversión...90

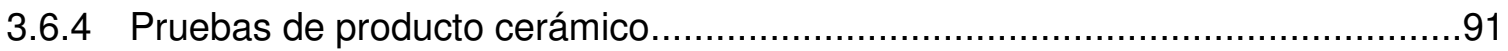

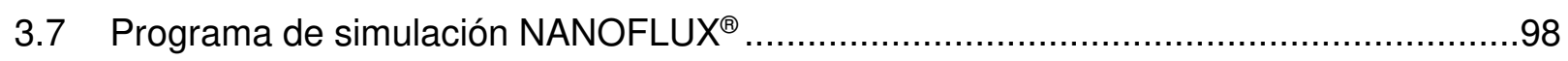

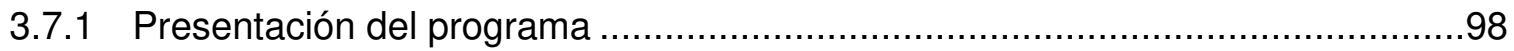

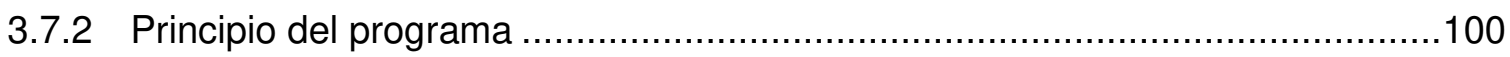

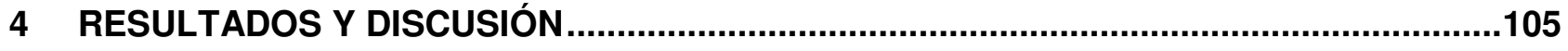

4.1 Caracterización de las membranas a escala de laboratorio ......................................107

4.1.1 Acondicionamiento de la membrana y cálculo de su permeabilidad al agua pura . 108

4.1.2 Retención de las especies neutras........................................................111

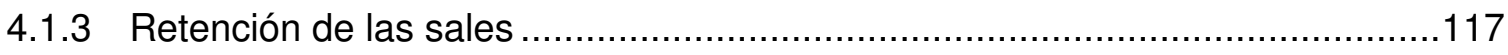

4.1.4 Elección de la membrana más adecuada para los tratamientos a realizar .......124

4.2 Eliminación del boro de las aguas residuales industriales mediante técnicas de

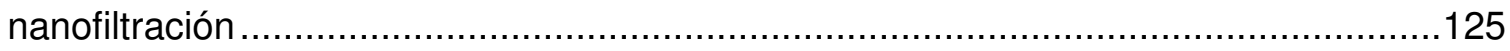

4.2.1 Caracterización de las aguas de la empresa de fabricación de baldosas..........129

4.2.2 Resultados de la nanofiltración a escala de laboratorio para la eliminación de boro 130

4.2.3 Resultados piloto en la empresa de fabricación de baldosas cerámicas 142

4.2.4 Reutilización del agua nanofiltrada en la elaboración de esmaltes y engobes..160

4.2.5 Balance económico 162

4.3 Eliminación de sales divalentes de las aguas industriales de proceso mediante técnicas de nanofiltración 163 
4.3.1 Caracterización de las aguas de proceso de la empresa de producción de polvo atomizado

4.3.2 Resultados de la nanofiltración a escala de laboratorio para la eliminación de iones divalentes

4.3.3 Resultados piloto en la empresa de producción de polvo atomizado con las aguas de pozo

4.3.4 Balance económico del tratamiento de las aguas de pozo..... 201

5 CONCLUSIONES. 205

5.1 Primer caso de estudio (eliminación del boro) …................................................207

5.2 Segundo caso de estudio (eliminación de iones divalentes) ....................................208

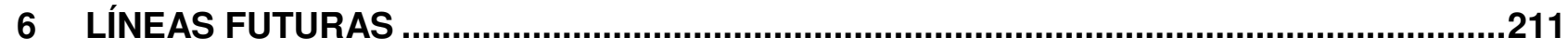

7 PROYECTOS DE INVESTIGACIÓN ..............................................................................215

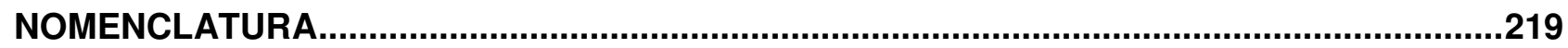

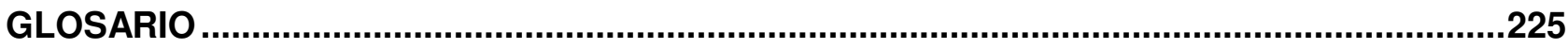

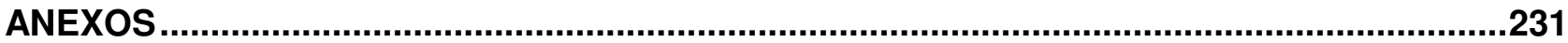

ANEXO I. Desarrollo de modelos de transporte a través de membranas de nanofiltración...233

ANEXO II. Características técnicas de las membranas de microfiltración proporcionadas por el fabricante

ANEXO III. Características técnicas de las membranas de nanofiltración proporcionadas por el fabricante 



\section{ÍNDICE DE FIGURAS}

Figura 1.1. Fabricación de baldosas cerámicas..........................................................................

Figura 1.2. Fabricación del polvo cerámico atomizado. .................................................5

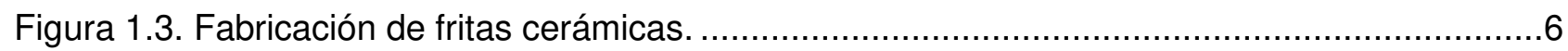

Figura 1.4. Gestión de las aguas residuales de la industria cerámica.....................................11

Figura 1.5. Porcentaje de producción de pavimento y revestimiento fabricado con pasta blanca sobre la producción total en España. .................................................................................... 12

Figura 1.6. Etapas del tratamiento físico-químico de las aguas del sector cerámico. ...................13

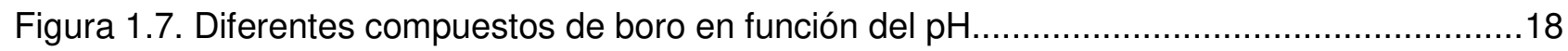

Figura 1.8. Proceso de intercambio iónico para la eliminación de boro. ........................................19

Figura 1.9. Equipo de intercambio iónico...............................................................................20

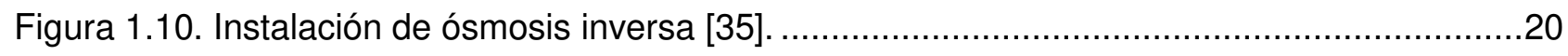

Figura 1.11. Mecanismo de transferencia a través de una membrana de ósmosis inversa [34]....21

Figura 1.12. Retención de boro y concentración de boro en el permeado en función de la presión

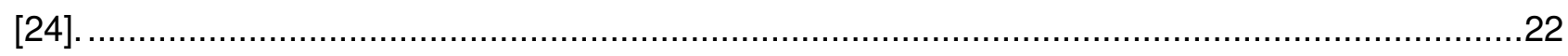

Figura 1.13. Instalación de ósmosis inversa en el sector cerámico ..........................................23

Figura 1.14. Secadero por atomización o atomizador y esquema de la etapa de secado por

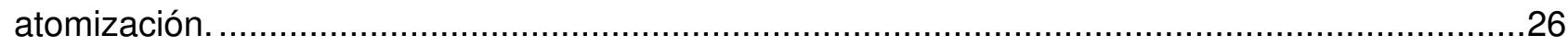

Figura 1.15. Descarga de la suspensión de un molino de laboratorio, sección de molinos de una empresa y suspensión cerámica industrial, respectivamente. ...................................................27

Figura 1.16. Modelo de la doble capa eléctrica [51] .....................................................29

Figura 1.17. Ejemplo del efecto de los desfloculantes en la viscosidad de una suspensión cerámica

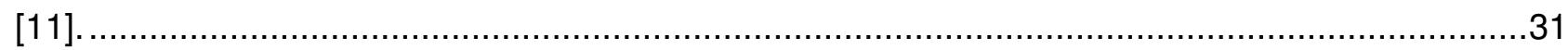

Figura 1.18. Efecto de los iones floculantes sobre la curva de desfloculación............................32

Figura 1.19. Efecto del contenido en sólidos de una suspensión cerámica sobre la curva de

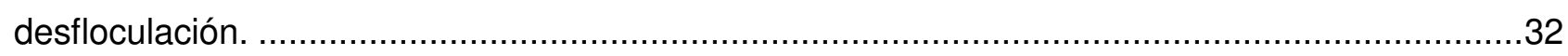

Figura 1.20. Esquema básico de la filtración a través de una membrana...................................35

Figura 1.21. Denominación de las corrientes que intervienen en una filtración............................36

Figura 1.22. Clasificación de tratamientos mediante membranas en función del radio de poro [61].

Figura 1.23. Membranas poliméricas de poliamida e imagen MEB de una membrana de PVDF...40

Figura 1.24. Membrana cerámica de SiC desarrollada en el ITC e imagen MEB de una membrana del mismo tipo. 
Figura 1.25. Imágenes MEB de varias membranas densas. 41

Figura 1.26. Fotografía realizada con el MEB de una membrana polimérica porosa.

Figura 1.27. Fotografía realizada con el MEB de una membrana polimérica asimétrica homogénea y una membrana cerámica asimétrica compuesta, respectivamente.

Figura 1.28. Membranas planas: membranas poliméricas y membranas cerámicas (elaboradas en el ITC), respectivamente.

Figura 1.29. Esquema de una membrana espiral [71] y varias membranas de este tipo.

Figura 1.30. Membranas tubulares poliméricas y cerámicas, respectivamente. .44

Figura 1.31. Membranas de fibras huecas [73]. 44

Figura 1.32. Modos de filtración: frontal y tangencial, respectivamente. 45

Figura 1.33. Esquema detallado de una filtración tangencial [75].

Figura 1.34. Configuraciones de paso único (a), discontinua (b) y alimentación y purgado (c), para procesos de filtración tangencial [75]. .46

Figura 1.35. Esquema de un corte trasversal de una membrana compuesta de nanofiltración......48

Figura 1.36. Diferentes tipos o mecanismos de ensuciamiento de las membranas. .54

Figura 1.37. Fenómeno de polarización de concentración en la interfase membrana-solución alimentación [63]. .55

Figura 1.38. Retención del boro frente a la conversión para diferentes membranas a pH 8,5 [42].57

Figura 1.39. Retención del boro frente al pH de la corriente de alimentación con una conversión del $5 \%$ con diferentes membranas [42].

Figura 1.40. Retención del calcio frente al pH de la corriente de alimentación para concentraciones que van desde 20 a $80 \mathrm{mg} / \mathrm{L}$ de $\mathrm{Ca}^{2+}[148]$.

Figura 3.1. Membranas de microfiltración (MF) tubulares. a) Membranas KLEANSEPTM 300 kD b) Detalle de las membranas KLEANSEPTM $0,1 \mu \mathrm{m}$ introducidas dentro de su cárter de filtración. ...71 Figura 3.2. Membranas de nanofiltración planas (NF-90 y NF-270) y configuración en espiral (tipo 2540), respectivamente. .72

Figura 3.3. Foto de la planta de filtración tangencial escala laboratorio del IEM. .73

Figura 3.4. Esquema descriptivo de la planta de filtración tangencial escala laboratorio del IEM. .73

Figura 3.5. Esquema del cárter que contiene la membrana [158]. .74

Figura 3.6. Planta de separación de efluentes líquidos mediante membranas a escala de laboratorio del ITC. .75

Figura 3.7. Detalle de los 3 módulos planos de filtración mediante membranas poliméricas de la planta del ITC. .76 
Figura 3.8. Planta piloto de filtración avanzada del ITC. Vista general del piloto tomada en ITC y ubicación del piloto en las empresas participantes en los casos de estudio (eliminación de compuestos de boro y sales divalentes), respectivamente. .77

Figura 3.9. Plano de la planta piloto de filtración avanzada del ITC. .78

Figura 3.10. Parte de microfiltración y detalle del cárter de membranas cerámicas desmontado. .79

Figura 3.11. Diagrama sinóptico de la parte de microfiltración.

Figura 3.12. Parte de nanofiltración, cárteres que albergan las membranas poliméricas, bombas, depósitos, conducciones y equipamiento necesario para el funcionamiento de la plana. Detalle de la introducción de una membrana en su cárter. 80

Figura 3.13. Diagrama sinóptico de la parte de nanofiltración. 81

Figura 3.14. Refractómetro interferómetrico. 82

Figura 3.15. Columna de cromatografía de exclusión estérica "Superose 12" [159]. 83

Figura 3.16. Esquema típico del montaje de la columna de cromatografía de exclusión estérica + el refractómetro [160]. 83

Figura 3.17. Espectrofotómetro, cromatografía iónica y espectrofotómetro de absorción atómica, respectivamente. 84

Figura 3.18. Conductímetro de mesa e instalado en línea en la planta piloto, respectivamente. ...85

Figura 3.19. pHmetro de mesa e instalado en línea en la planta piloto, respectivamente. .85

Figura 3.20. Turbidímetro. .86

Figura 3.21. Montaje para la determinación del SDI en el ITC. .87

Figura 3.22. Filtros después de medir el SDI. a) agua de suministro, b) y c) agua de pozo y d) agua de pozo después de microfiltrar.

Figura 3.23. Esquema de las pruebas de producto cerámico realizadas en los dos casos de estudio. 91

Figura 3.24. Molino de bolas, aplicación de un esmalte sobre una probeta cerámica y cocción de la probeta, a escala de laboratorio. .92

Figura 3.25. Molino de bolas, aplicación de un esmalte por campana y etapa de cocción, a escala industrial. 92

Figura 3.26. Esquema y fotografía del viscosímetro GALLENKAMP, así como la curva de desfloculación típica. Representación de la viscosidad frente al contenido en desfloculante. 93

Figura 3.27. Esquema de los pasos seguidos para la obtención del diagrama de compactación. .94 Figura 3.28. Esquema de los pasos seguidos para la determinación de la resistencia mecánica. 95 Figura 3.29. Esquema de los pasos seguidos para la determinación de la contracción lineal........96

Figura 3.30. Esquema de los pasos seguidos para la determinación de absorción de agua. .97 
Figura 3.31. Diagrama de gresificación.

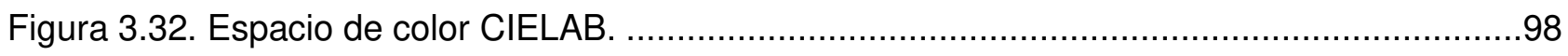

Figura 3.33. Pantalla principal del programa Nanoflux ${ }^{\circledR}$.

Figura 3.34. Interfaz del programa informático Nanoflux $^{\circledR}$ y su base de datos de compuestos neutros modelo.

Figura 3.35. Interfaz del programa informático Nanoflux $^{\circledR}$ y su base de datos de especies iónicas modelo. 102

Figura 4.1. Diagrama de flujo que muestra los pasos seguidos durante la caracterización de las membranas. 108

Figura 4.2. Permeabilidad al agua pura de las membranas NF, NF-90, NF-200 y NF-270. 109

Figura 4.3. Retención de las especies neutras por la membrana NF en función del flujo de permeado y a una temperatura de $25^{\circ} \mathrm{C}$ 112

Figura 4.4. Retención de las especies neutras por la membrana NF-90 en función del flujo de permeado y a una temperatura de $25^{\circ} \mathrm{C}$. 113

Figura 4.5. Retención de las especies neutras por la membrana NF-200 en función del flujo de permeado y a una temperatura de $25^{\circ} \mathrm{C}$. 113

Figura 4.6. Retención de las especies neutras por la membrana NF-270 en función del flujo de permeado y a una temperatura de $25^{\circ} \mathrm{C}$

Figura 4.7. Retención en función del flujo de permeado para la membrana NF. Línea continua: modelización de Nanoflux ${ }^{\circledR}$, puntos discontinuos: resultados experimentales.

Figura 4.8. Retención en función del flujo de permeado para la membrana NF-90. Línea continua: modelización de Nanoflux ${ }^{\circledR}$, puntos discontinuos: resultados experimentales.

Figura 4.9 Retención en función del flujo de permeado para la membrana NF-200. Línea continua: modelización de Nanoflux ${ }^{\circledR}$, puntos discontinuos: resultados experimentales. 116

Figura 4.10. Retención en función del flujo de permeado para la membrana NF-270. Línea continua: modelización de Nanoflux ${ }^{\circledR}$, puntos discontinuos: resultados experimentales. 116

Figura 4.11. Retención de $\mathrm{NaCl}$ en función del flujo de permeado a $25^{\circ} \mathrm{C}$ para una disolución $0,01 \mathrm{M}$. 118

Figura 4.12. Retención de $\mathrm{MgSO}_{4}$ en función del flujo de permeado a $25^{\circ} \mathrm{C}$ para una disolución de $0,01 \mathrm{M}$.

Figura 4.13. Retención en función del flujo de permeado a $25^{\circ} \mathrm{C}$ de la membrana NF para las disoluciones $\mathrm{NaCl}$ 0,01M y $\mathrm{MgSO}_{4}$ 0,01M; trazo continuo: predicción del modelo Nanoflux ${ }^{\circledR}$, puntos discontinuos: resultados experimentales. 120 
Figura 4.14. Retención en función del flujo de permeado a $25^{\circ} \mathrm{C}$ de la membrana NF-90 para las disoluciones $\mathrm{NaCl}$ 0,01M y $\mathrm{MgSO}_{4}$ 0,01M; trazo continuo: predicción del modelo Nanoflux ${ }^{\circledR}$, puntos discontinuos: resultados experimentales.

Figura 4.15. Retención en función del flujo de permeado a $25^{\circ} \mathrm{C}$ de la membrana NF-200 para las disoluciones $\mathrm{NaCl}$ 0,01M y $\mathrm{MgSO}_{4}$ 0,01M; trazo continuo: predicción del modelo Nanoflux ${ }^{\circledR}$, puntos discontinuos: resultados experimentales. 122

Figura 4.16. Retención en función del flujo de permeado a $25^{\circ} \mathrm{C}$ de la membrana NF-270 para las disoluciones $\mathrm{NaCl}$ 0,01M y $\mathrm{MgSO}_{4}$ 0,01M; trazo continuo: predicción del modelo Nanoflux ${ }^{\circledR}$, puntos discontinuos: resultados experimentales. 123

Figura 4.17. Esquema del proceso productivo de una empresa de producción de baldosas cerámicas sin etapa de atomización y gestión de sus aguas, así como la actuación prevista en este caso de estudio.

Figura 4.18. Diagrama de flujo de las aguas en una empresa modelo de fabricación de baldosas cerámica sin etapa de atomización. 127

Figura 4.19. Diagrama de flujo de los pasos seguidos en el primer caso de estudio (eliminación del boro). 128

Figura 4.20. Retención del boro en función del $\mathrm{pH}$ y del flujo de permeado. NF-90 plana, $\mathrm{C}_{\mathrm{aB}}=10$ $\mathrm{mg} / \mathrm{L}$ y $\mathrm{Q}_{\mathrm{a}} \approx 9 \mathrm{~L} / \mathrm{min}$. 131

Figura 4.21. Retención del boro en función del $\mathrm{pH}$ y del caudal de permeado. NF-90 plana, $\mathrm{C}_{\mathrm{aB}}=1$ $\mathrm{mg} / \mathrm{L}$ y $\mathrm{Q}_{\mathrm{a}} \approx 9 \mathrm{~L} / \mathrm{min}$. .133

Figura 4.22. Retención del boro en función del $\mathrm{pH}$ y del flujo de permeado. NF-90 plana, $\mathrm{C}_{\mathrm{aB}}=100$ $\mathrm{mg} / \mathrm{L}$ y $\mathrm{Q}_{\mathrm{a}} \approx 9 \mathrm{~L} / \mathrm{min}$. . 134

Figura 4.23. Variación de la retención del boro en función del pH y de la presión. NF-90 plana, $\mathrm{C}_{\mathrm{aB}}=10 \mathrm{mg} / \mathrm{L}$ y $\mathrm{Q}_{\mathrm{a}} \approx 9 \mathrm{~L} / \mathrm{min}$. 135

Figura 4.24. Retención del boro en función del $\mathrm{pH}$ y del flujo de permeado. NF-90 en espiral, $\mathrm{C}_{\mathrm{aB}}=10$ $\mathrm{mg} / \mathrm{L}$ (trazo continuo), $\mathrm{C}_{\mathrm{aB}}=100 \mathrm{mg} / \mathrm{L}$ (trazo discontinuo) y $\mathrm{Q}_{\mathrm{a}} \approx 7,00 \mathrm{~L} / \mathrm{min}$. 136

Figura 4.25. Retención del boro de una membrana NF-90 espiral en función del flujo de permeado a partir de agua residual sometida a un tratamiento físico-químico y microfiltrada. $\mathrm{C}_{\mathrm{B}}=13,2 \mathrm{mg} / \mathrm{L}$, $\mathrm{pH}=11, \mathrm{Q}_{\mathrm{a}}=7 \mathrm{~L} / \mathrm{min}$ (trazo continuo) y $\mathrm{Q}_{\mathrm{a}}=4 \mathrm{~L} / \mathrm{min}$ (trazo discontinuo). 139

Figura 4.26. Retención del boro por una membrana NF-90 en espiral en función del flujo de permeado a partir de agua residual sin un tratamiento físico-químico pero microfiltrada. $\mathrm{C}_{\mathrm{a} B}=17,6$ $\mathrm{mg} / \mathrm{L}, \mathrm{pH}=11, \mathrm{Q}_{\mathrm{a}}=7 \mathrm{~L} / \mathrm{min}$ (trazo continuo) y $\mathrm{Q}_{\mathrm{a}}=4 \mathrm{~L} / \mathrm{min}$ (trazo discontinuo). 140

Figura 4.27. Extracto del historial de la variación de la permeabilidad en la membrana NF90 espiral a $25^{\circ} \mathrm{C}$.

Figura 4.28. Imágenes del traslado y ubicación de la planta piloto hasta la empresa de fabricación de baldosas cerámicas. 
Figura 4.29. Imágenes de las membranas cerámicas de MF KLEANSEPTM 300 kD y KLEANSEPTM $0,1 \mu \mathrm{m}$, respectivamente. En el segundo caso dentro de su cárter.

Figura 4.30. Imágenes de membranas poliméricas NF-90 en espiral tamaño 2540. Varias membranas antes de su utilización (izquierda) y detalle de una membrana introduciéndose en su cárter (derecha).

Figura 4.31. Esquema del tratamiento en continuo a través de membranas de las aguas residuales de la empresa de fabricación de baldosas cerámicas. 145

Figura 4.32. Vista superior de la balsa donde se almacena el agua después del tratamiento físicoquímico. 146

Figura 4.33. Vista superior del depósito de MF (izquierda) con agua sucia en el fondo antes de la MF y depósito de NF (derecha) medio lleno con agua trasparente (amarillenta) después de la MF (y antes de la etapa de NF). 146

Figura 4.34. Permeabilidad de las membranas cerámicas KLEANSEP ${ }^{T M} 300$ kD e influencia del FCV. 148

Figura 4.35. Permeabilidad de las membranas cerámicas KLEANSEP ${ }^{\mathrm{TM}} 0,1 \mu \mathrm{m}$ e influencia del FCV. 150

Figura 4.36. Filtros después de la prueba del SDI. 152

Figura 4.37. Tanque de la planta piloto donde se recoge el agua antes y después de la microfiltración.

Figura 4.38. Representación de las retenciones obtenidas en función de la presión ensayada a pH 9,5 .

Figura 4.39. Representación de la retención del boro obtenida en función de la presión ensayada a $\mathrm{pH} 11$. 156

Figura 4.40. Estabilización de las membranas KLEANSEPTM 300 kD previa a la prueba en continuo. 157

Figura 4.41. Representación gráfica de los datos de producción frente al tiempo de la etapa de NF. 159

Figura 4.42. Piezas decoradas con el esmalte de referencia STD. 161

Figura 4.43. Proceso de aplicación del engobe elaborado con las aguas nanofiltradas. 161

Figura 4.44. Esquema del proceso productivo de una empresa de producción de polvo atomizado, actuaciones previstas en el estudio y los resultados esperados (flechas verdes)..... 164

Figura 4.45. Diagrama de flujo de las aguas de una empresa tipo de preparación de polvo atomizado (producción: 600 t/día)...... 165

Figura 4.46. Diagrama de flujo de los pasos seguidos en el segundo caso de estudio (eliminación de sales divalentes). 167 
Figura 4.47. Viscosidad de las suspensiones preparadas con aguas sintéticas nanofiltradas y sin tratar frente al contenido en desfloculante.

Figura 4.48. Viscosidad de suspensiones preparadas con aguas residuales frente al contenido en desfloculante.

Figura 4.49. Densidad de la pieza en crudo frente a la presión de prensado.

Figura 4.50. Contracción lineal y absorción de agua frente a la temperatura de cocción. 178

Figura 4.51. Disminución de la conductividad frente a la presión aplicada en la nanofiltración del agua residual. 179

Figura 4.52. Disminución de la conductividad frente a la presión aplicada en la nanofiltración del agua de pozo.

Figura 4.53. Viscosidad frente al contenido en desfloculante de las suspensiones elaboradas con agua de pozo.

Figura 4.54. Prueba de concentración de una muestra de agua residual industrial mediante nanofiltración.

Figura 4.55. Viscosidad frente al contenido en desfloculante para diferentes densidades de las suspensiones cerámicas elaboradas con las aguas del ensayo de concentración de las aguas residuales.

Figura 4.56. Prueba de concentración de una muestra de agua de pozo mediante nanofiltración. 186

Figura 4.57. Viscosidad frente al contenido en desfloculante de las suspensiones elaboradas con agua residual y con los rechazos obtenidos de la nanofiltración del agua residual y del agua de pozo en los ensayos de concentración.

Figura 4.58. Traslado hasta la empresa de fabricación de polvo atomizado de la planta de nanofiltración del ITC y ubicación en la empresa.

Figura 4.59. Filtros utilizados en el ensayo de SDI. 191

Figura 4.60. Un módulo, una membrana NF-270 2540. 192

Figura 4.61. Dos módulos con dos membranas NF-270 2540 en serie con recirculación. 193

Figura 4.62. Tres módulos con tres membranas NF-270 2540, 2 membranas en paralelo +1 en serie con recirculación. .194

Figura 4.63. Tres módulos con tres membranas NF-270 2540 en serie con recirculación. 195

Figura 4.64. Planta piloto y tanques de almacenamiento del agua nanofiltrada. 197

Figura 4.65. Esquema general del tratamiento en continuo de las aguas en la empresa de fabricación de polvo atomizado.

Figura 4.66. Flujo de permeado obtenido con las 3 membranas NF-270 en serie y conductividad del permeado en función del tiempo. 
Figura 4.67. Comparativa de los resultados de las pruebas reológicas entre el agua de producción y el agua nanofiltrada en la prueba industrial. .

200 


\section{ÍNDICE DE TABLAS}

Tabla 1.1. Valores promedio de la carga contaminante del agua residual del sector cerámico antes y después del tratamiento físico-químico convencional. ...................................................14

Tabla 1.2. Límites de concentración de boro en diferentes tipos de aguas................................17

Tabla 1.3. Parámetros físicos del boro. ...................................................................... 17

Tabla 1.4. Desventajas de los métodos empleados habitualmente frente a la nanofiltración.........25

Tabla 1.5. Presiones de trabajo y permeabilidades más habituales de los procesos de filtración a

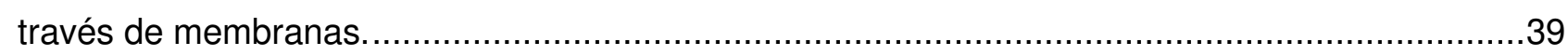

Tabla 3.1. Compuestos neutros y algunas de sus propiedades [151][152][153][154][155]...........68

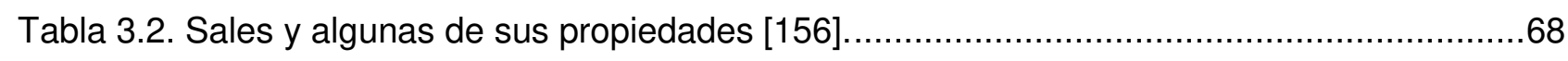

Tabla 3.3. Especificaciones de las membranas de MF proporcionadas por el fabricante. ............71

Tabla 3.4. Especificaciones de las membranas de NF proporcionadas por el fabricante..............72

Tabla 3.5. Métodos y equipos utilizados en los análisis de las especies inorgánicas de las aguas

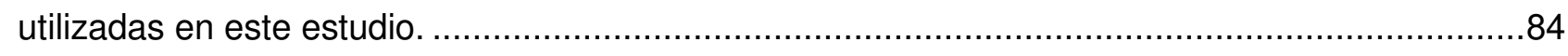

Tabla 4.1. Permeabilidad al agua pura de las membranas (media de las dos últimas $L_{p}^{0}$ del

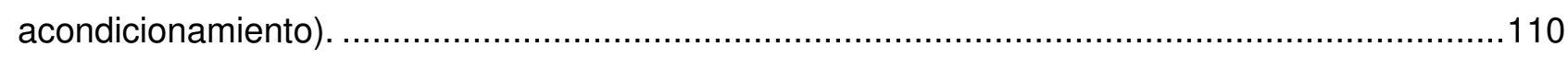

Tabla 4.2. Radios de poro $\left(r_{p}\right)$ de las membranas calculadas a partir de Nanoflux ${ }^{\circledR} \ldots \ldots \ldots \ldots \ldots \ldots . . . . . .117$

Tabla 4.3. Densidades de carga electroestática normalizadas $\left(X_{i}\right)$ calculadas con ayuda del

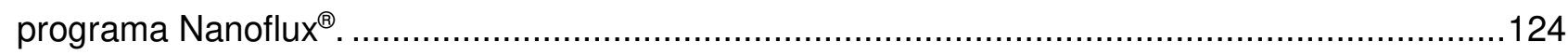

Tabla 4.4. Análisis químicos de varias muestras de agua de la empresa en la que se va a realizar el primer caso de estudio.

Tabla 4.5. Parámetros que imposibilitan el vertido al alcantarillado municipal y los límites legales.

Tabla 4.6. Retenciones, flujos conseguidos y presiones aplicadas a diferente $\mathrm{pH}\left(\mathrm{C}_{\mathrm{aB}}=10 \mathrm{mg} / \mathrm{L}\right)$.

Tabla 4.7. Retenciones, flujos conseguidos y presiones aplicadas a diferente $\mathrm{pH}\left(\mathrm{C}_{\mathrm{aB}}=1 \mathrm{mg} / \mathrm{L}\right) .133$ Tabla 4.8. Retenciones, flujos conseguidos y presiones aplicadas a diferente $\mathrm{pH}\left(\mathrm{C}_{\mathrm{aB}}=100 \mathrm{mg} / \mathrm{L}\right)$.

Tabla 4.9. Retenciones y flujos conseguidos a diferente $\mathrm{pH}$ (Concentraciones medias y altas de B en la alimentación).

Tabla 4.10. Resultados obtenidos en los ensayos de nanofiltración de un agua residual industrial (después de un tratamiento físico-químico y una microfiltración) con la membrana NF-90. 139

Tabla 4.11. Resultados de los ensayos de nanofiltración de un agua residual industrial (sin tratamiento físico-químico y una microfiltración) con la membrana NF-90. 140 
Tabla 4.12. FCV y parámetros de control para la membrana KLEANSEPTM 300 kD. 149

Tabla 4.13. FCV y parámetros de control para las membranas KLEANSEPTM $0,1 \mu \mathrm{m}$. 150

Tabla 4.14. Evaluación de la capacidad de ensuciamiento del agua de la empresa mediante ensayo SDI y turbidez del agua, antes y después del pretratamiento.

Tabla 4.15. Ensayos a diferentes presiones con la membrana NF-90 y agua de balsa a pH 9,5.154

Tabla 4.16. Ensayos a diferentes presiones con la membrana NF-90 agua de balsa, aprox. pH 11.

Tabla 4.17. Condiciones de trabajo para una de las pruebas en continuo 158

Tabla 4.18. Resultados de boro y rendimiento de la filtración en continuo...... 159

Tabla 4.19. Comparación entre los costes de un tratamiento de ósmosis inversa y uno de nanofiltración.

Tabla 4.20. Análisis químicos de varias muestras de aguas residuales recogidas a lo largo de varios meses.

Tabla 4.21. Análisis químicos de dos muestras de agua de pozo recogidas a lo largo de varios meses.

Tabla 4.22. Resultados de las pruebas de nanofiltración con aguas sintéticas a diferentes presiones.

Tabla 4.23. Resultados de las curvas de desfloculación de las suspensiones preparadas con aguas sintéticas.

Tabla 4.24. Resultados de la prueba de nanofiltración con las aguas residuales reales a varias presiones. 173

Tabla 4.25. Composición de gres porcelánico esmaltado GPE.

Tabla 4.26. Resultados de las curvas de desfloculación de la suspensión (GPE) con el agua residual sin tratar y con el agua residual nanofiltrada.

Tabla 4.27. Resultados de las pruebas con piezas crudas fabricadas con polvo atomizado proveniente de suspensiones cerámicas elaboradas con aguas nanofiltradas y sin tratar. 176

Tabla 4.28. Resultados de las pruebas realizadas en piezas cocidas fabricadas con polvo atomizado proveniente de suspensiones cerámicas elaboradas con aguas nanofiltradas y sin tratar (propiedades a una absorción de agua del 1\%)......

Tabla 4.29. Resultados de flujo y disminución de la conductividad en el ensayo de nanofiltración del agua residual.

Tabla 4.30. Resultados de flujo y disminución de la conductividad en el ensayo de nanofiltración del agua de pozo.

Tabla 4.31. Resultados de las curvas de desfloculación de las suspensiones cerámicas con agua de pozo y agua nanofiltrada. 
Tabla 4.32. Análisis de las aguas de inicio, el permeado y el rechazo de la prueba de concentración con aguas residuales. 184

Tabla 4.33. Resultados de las curvas de desfloculación de las aguas utilizadas en el ensayo de concentración. 185

Tabla 4.34. Resultados de las curvas de desfloculación de las suspensiones cerámicas elaboradas con agua residual de proceso utilizada por la empresa y el rechazo obtenido después de los ensayos de nanofiltración (ensayos de concentración) 187

Tabla 4.35. Resultados de las pruebas de SDI y método de obtención. 190

Tabla 4.36. Prueba en discontinuo a diferentes presiones con agua de pozo y una configuración de 1 membrana NF270 tipo 2540 192

Tabla 4.37. Prueba en discontinuo a diferentes presiones con agua de pozo y una configuración de 2 membranas NF270 en serie con recirculación. 193

Tabla 4.38. Prueba en discontinuo a diferentes presiones con agua de pozo y una configuración de 2 membranas en paralelo +1 membrana en serie $(2+1)$ con recirculación (membranas todas ellas NF-270 2540). 194

Tabla 4.39. Prueba en discontinuo a diferentes presiones con agua de pozo y una configuración de 3 membranas en serie NF270 $(1+1+1)$ con recirculación.

Tabla 4.40. Condiciones de trabajo. Agua de pozo, sistema de 3 membranas en serie NF270 $(1+1+1)$ con recirculación. 198

Tabla 4.41. Análisis químicos de las muestras tomadas durante la realización de la prueba de nanofiltración en continuo. Agua de pozo, sistema 3 membranas NF270 en serie $(1+1+1)$ con recirculación. 199

Tabla 4.42. Datos desglosados de los costes de operación. 201

Tabla 4.43. Resultados de los balances económicos. 203

Tabla 4.44. Disminución de la emisión de $\mathrm{CO}_{2}$. 204 

1 INTRODUCCIÓN 

La tecnología de membranas es un método avanzado de tratamiento de aguas. Mediante la utilización de este tipo de procesos puede eliminarse iones y moléculas presentes en disoluciones líquidas. La selección de la membrana más adecuada depende de la separación deseada y a su vez dependerá, tanto de la composición del agua a tratar, como del grado de purificación que se quiere alcanzar. La nanofiltración (NF), técnica que ha tenido un gran desarrollo recientemente, presenta ventajas significativas si se compara con otros procesos que también utilizan membranas. La nanofiltración permite una retención casi completa de los iones polivalentes y de los compuestos orgánicos de pesos moleculares relativamente pequeños, además, dependiendo de la membrana y de las condiciones de trabajo, también se puede conseguir un buen rechazo de los iones monovalentes. Todo ello utilizando presiones de trabajo mucho más bajas que la ósmosis inversa (OI). Por todas estas ventajas se ha considerado como una técnica que podría tener una aplicación importante en algunas etapas del proceso productivo del sector cerámico.

\subsection{Problemática del agua en el sector cerámico}

La gestión del agua se ha convertido en una cuestión cada vez más crítica en la mayoría de los sectores industriales tradicionales, debido a la gran cantidad de agua que consumen, así como la gran cantidad de agua residual que producen. En el caso de la industria de fabricación de baldosas cerámicas, la mayoría de las aguas residuales provienen de las operaciones de lavado de las instalaciones usadas para la preparación y la aplicación de esmaltes y otros acabados estéticos [1]. Además, se utiliza una cantidad considerable de agua limpia (generalmente, agua subterránea proveniente de pozos que las propias empresas disponen en sus instalaciones) para la preparación de los esmaltes y otras aplicaciones decorativas. Por tanto, como el agua se ha convertido en un recurso cada vez más limitado, la industria cerámica tiene que encontrar la solución para reducir su consumo, así como para reutilizar de una forma más eficiente las aguas residuales generadas en sus procesos productivos.

La composición de las aguas residuales de la industria cerámica varía ampliamente y puede contener sólidos en suspensión y electrólitos de naturaleza muy diversa, así como sustancias orgánicas que provienen, en su mayoría, de los aditivos utilizados en la decoración de las baldosas [2]. Sin embargo, los tratamientos que se utilizan actualmente (tratamientos generalmente físicoquímicos de coagulación-floculación) no son totalmente eficaces, en particular cuando se trata de: compuestos orgánicos no-biodegradables que aumentan la DQO del agua, ciertos iones tales como cationes alcalinos y alcalinotérreos, compuestos de boro, cloruros, sulfatos... Este tratamiento poco efectivo de las aguas residuales hace imposible su reutilización en el mismo proceso de producción, excepto en la preparación de las suspensiones cerámicas necesarias para la obtención de polvo atomizado que se utiliza para fabricar la matriz o soporte de las baldosas cerámicas (no todas las empresas disponen de esta etapa del proceso productivo) o como agente de limpieza en aquellas operaciones que no se requiera una calidad del agua muy elevada (limpieza de suelos, limpieza de algunas líneas de esmaltado...) [3]. Incluso, después de los tratamientos indicados, el agua residual tiene una calidad tan baja que en la mayoría de casos no cumple ni con los requisitos técnicos necesarios para que las aguas puedan ser reutilizadas en etapas distintas que no sean la elaboración de suspensiones cerámicas u operaciones de limpieza, ni mucho menos con los 
requisitos legales para ser vertida al alcantarillado. Por tanto, esta agua necesita una gestión externa o un tratamiento adicional, que supone un alto coste económico para las empresas y/o un impacto ambiental.

\subsubsection{El sector de fabricación de baldosas cerámicas y subsectores afines}

El sector de fabricación de baldosas cerámicas en España se encuentra concentrado en la provincia de Castellón (sobre el 95\% de las empresas a nivel nacional). Además, dentro de la provincia, esta industria se localiza preferentemente en el denominado coloquialmente "triángulo del azulejo" formado por las localidades de l'Alcora, Onda y Villarreal, que en conjunto representan un área geográfica de apenas unos $400 \mathrm{~km}^{2}$ [4].

La industria de baldosas cerámicas representa un sector de gran importancia socioeconómica en España, y en particular, como se ha indicado, en la provincia de Castellón. Después de experimentar crecimientos espectaculares en la pasada década (la producción aumentó más de un $50 \%$ pasando de producir 400 millones de $\mathrm{m}^{2}$ en 1995 a 609 millones de $\mathrm{m}^{2}$ en 2005) [5] también sufrió como ningún otro sector, el impacto de la crisis (la producción se redujo en más de un 46\% en 2009 hasta valores de 324 millones de $\mathrm{m}^{2}$ ) [6]. Actualmente, España es el cuarto país productor mundial de baldosas cerámicas por detrás de China, Brasil e India y por delante de Italia, con una producción de 492 millones de $\mathrm{m}^{2}$ en 2016. Además, es el segundo exportador mundial por detrás de China. Esta actividad se realiza en unas 160 empresas que crean 15000 empleos directos y más de 7000 indirectos [7][8].

Otro subsector industrial muy importante relacionado directamente con el sector de baldosas cerámicas, es el de fabricación de fritas y esmaltes cerámicos. En la actualidad, España es líder mundial en la fabricación de fritas cerámicas ( 1 millón y medio de toneladas al año) y muchas de las 25 empresas que componen este sector tienen centros de producción y/o distribución en otros países (Italia, Brasil, Indonesia, China, México, India, Marruecos...), convirtiéndose en verdaderas multinacionales, generando más de 3600 puestos de trabajo directos en 2016 [9]. Aunque el presente trabajo se centre en las aguas de las empresas productoras de baldosas cerámicas y por extensión, en las empresas de producción de polvo atomizado, ya que son las empresas encargadas de la preparación/conformación de la principal materia prima de las baldosas cerámicas; el subsector de fabricación de fritas y esmaltes también se encuentra afectado por el problema de la gestión del agua [10].

\subsubsection{Necesidad de agua en el proceso cerámico}

El ciclo tecnológico del proceso cerámico se compone de diversas etapas en las que las materias primas se transforman en producto acabado. 


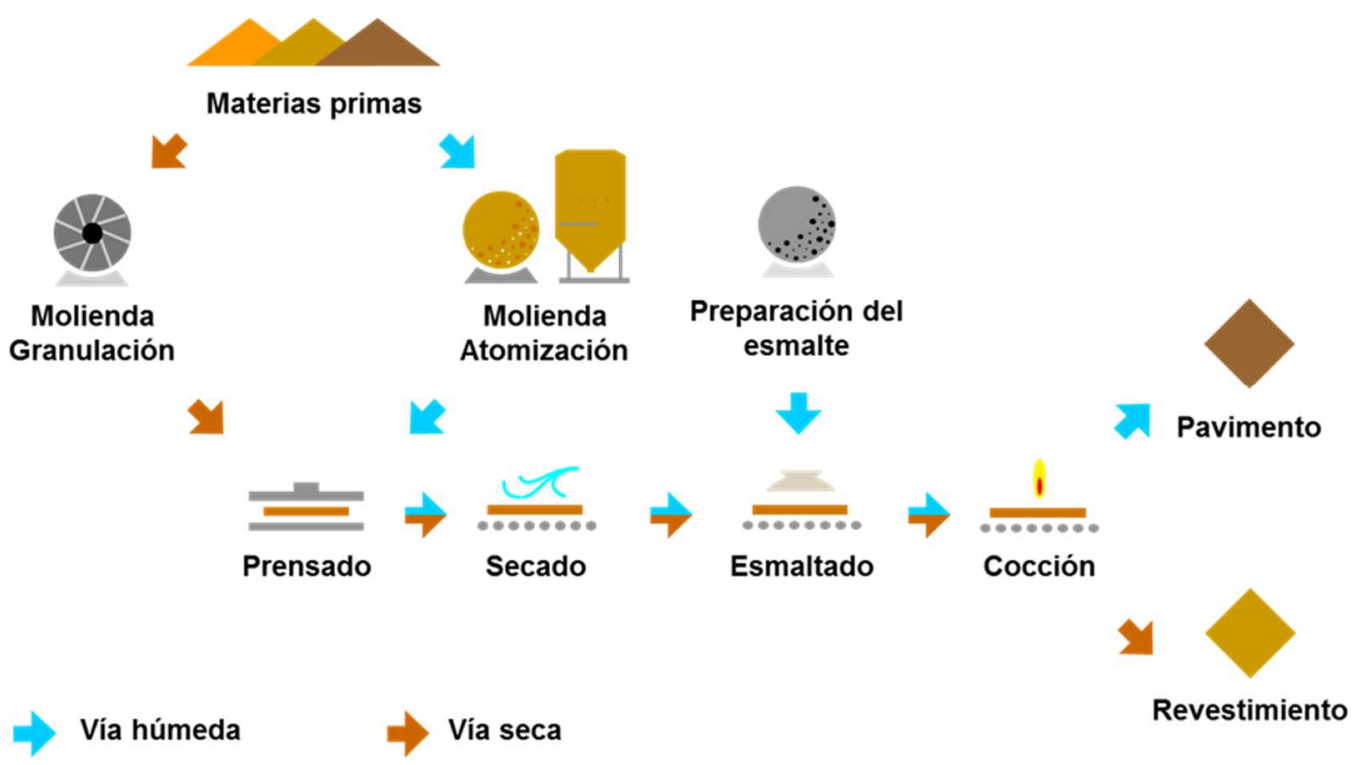

Figura 1.1. Fabricación de baldosas cerámicas.

En la Figura 1.1 se muestra el proceso productivo para la fabricación de baldosas por vía húmeda y por vía seca, ya que son los dos procedimientos que actualmente pueden utilizarse para la obtención de este producto [11]. Sin embargo, hay que decir que menos de un $4 \%$ de las baldosas producidas en España son fabricadas vía seca, mientras que el resto, más del $96 \%$, se fabrican vía húmeda. Este proceso de fabricación se caracteriza por que las materias primas cerámicas son molturadas con un gran contenido en agua para obtener una suspensión cerámica, que posteriormente será secada por atomización, tal como se esquematiza en la Figura 1.2.

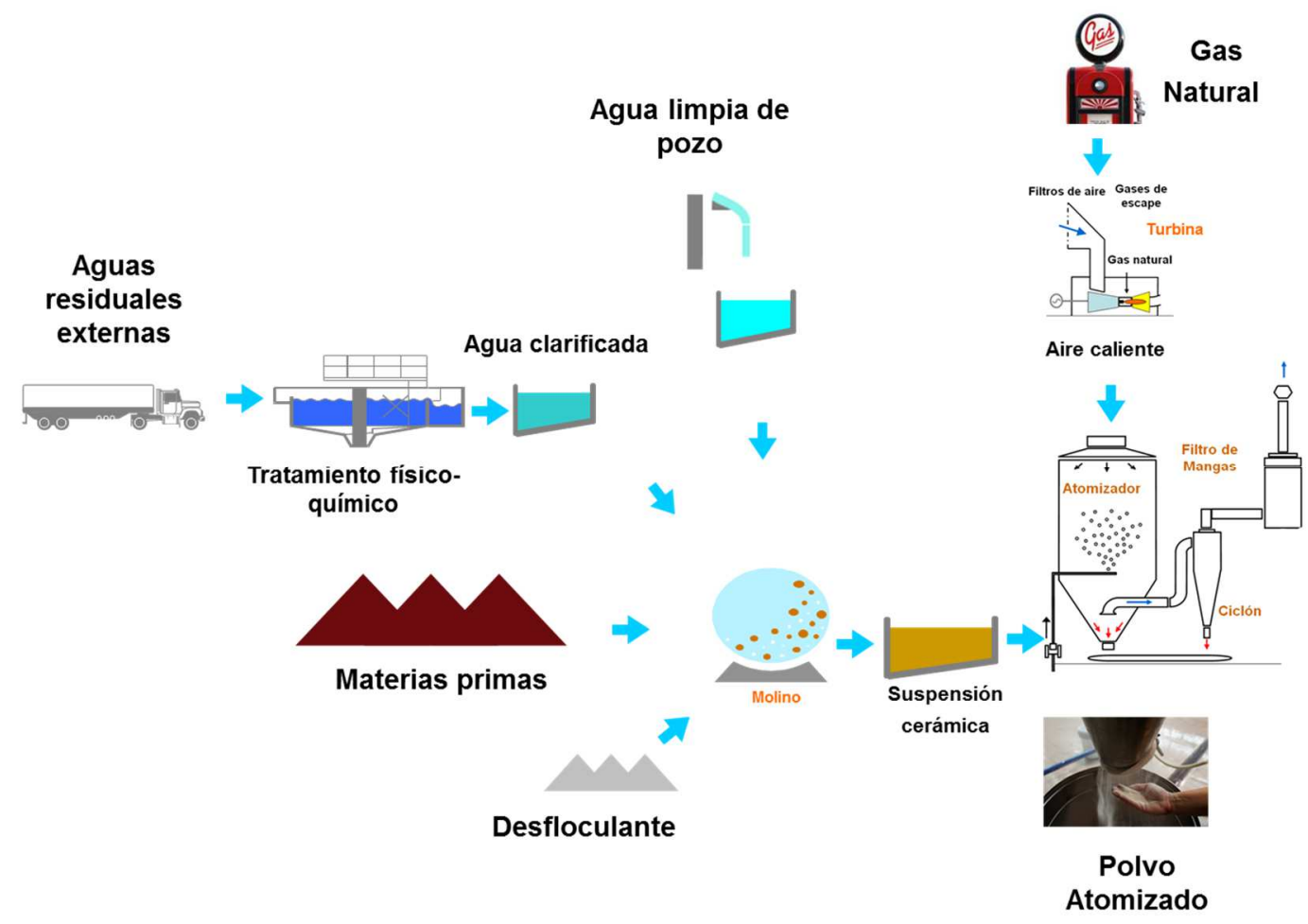

Figura 1.2. Fabricación del polvo cerámico atomizado. 
El agua en la fabricación del polvo atomizado vía húmeda adquiere una importancia crucial desde el principio y en todas las etapas del proceso.

En la Figura 1.3 también se muestra un esquema del proceso de fabricación de las fritas cerámicas. Aunque en este esquema se muestre la posibilidad del enfriamiento de la frita por aire, la inmensa mayoría de las fritas son enfriadas mediante la utilización de agua, por este motivo, este elemento adquiere una gran importancia en este proceso productivo.

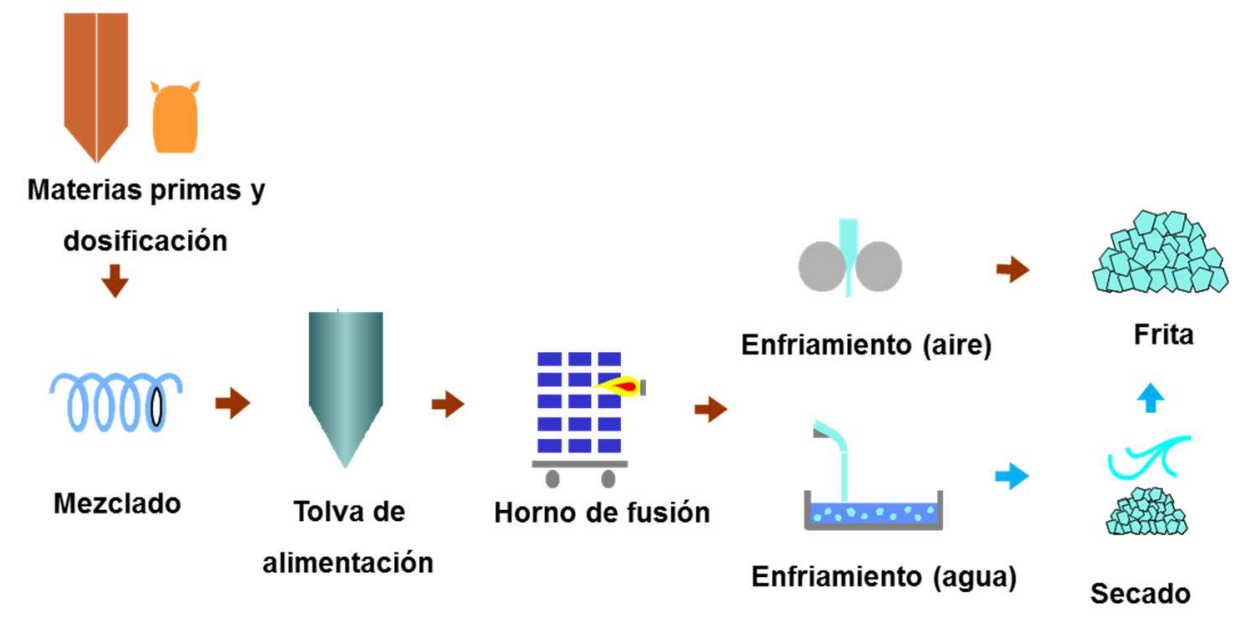

Figura 1.3. Fabricación de fritas cerámicas.

En casi todas las etapas de los procesos mencionados, el agua juega un papel importante y puede tener las siguientes funciones, las cuales determinan el destino final de la misma [12]:

a) Como materia prima (agua limpia de pozo y agua residual)

El agua se utiliza como materia prima en la preparación de las composiciones para fabricar el polvo atomizado que más tarde será utilizado para la elaboración de los soportes cerámicos (molienda vía húmeda), en humectación de la composición preparada por vía seca, en preparación de esmaltes y en la humectación de piezas para la posterior aplicación de esmaltes. Según a cuál de estos usos vaya destinada el agua utilizada como materia prima, su calidad podrá ser una u otra.

El agua utilizada en la preparación de suspensiones cerámicas destinadas a la elaboración de soportes cerámicos puede ser agua residual industrial procedente de otras etapas del proceso productivo o puede ser agua limpia (generalmente de pozo, aunque también podría ser de red pública si la empresa no dispone de éste). La calidad del agua necesaria dependerá de diferentes variables, si el polvo atomizado es de coloración roja esta composición admitirá un agua de menor calidad y por tanto podría aprovechar el agua residual de otras etapas para llevar a cabo la molturación vía húmeda y elaboración de la suspensión cerámica. Si la composición es de un polvo atomizado de coloración blanca puede admitir menos cantidad de agua residual o en su caso tiene que ser sometida a algún tipo de depuración (tratamiento físico-químico de coagulación-floculación, generalmente). Si el producto que se pretende obtener es un polvo atomizado para la elaboración de productos cerámicos sin esmaltar en muchas ocasiones solamente se podrá utilizar agua limpia como materia prima. En ambos casos, si no hay suficiente cantidad de agua residual se aportará 
agua limpia para la correcta elaboración de la suspensión cerámica (ver el esquema representado en la Figura 1.2).

Por otro lado, tanto el agua utilizada para la elaboración de esmaltes, como la utilizada para la humectación de piezas que utilizan todas las empresas de fabricación de baldosas cerámicas, son aguas limpias, que generalmente son subterráneas y provenientes de pozos perforados en las propias parcelas donde se ubican las fábricas.

Este consumo de agua prácticamente no comporta generación alguna de aguas residuales, ya que el agua utilizada como materia prima es emitida totalmente a la atmósfera por evaporación, en las distintas fases del proceso: atomización, secado, esmaltado y cocción. Las necesidades de agua para estos fines son muy variables.

b) Como agente de lavado

El agua se utiliza como agente de lavado de las instalaciones de preparación de las composiciones para el soporte y de los esmaltes, así como para la limpieza de las líneas y equipos de esmaltado.

Los consumos de agua de estas operaciones son muy variables, ya que se realizan manualmente, y dependen además del tipo de producto fabricado, de las instalaciones, de los hábitos y modos de trabajar de cada empresa... Los consumos en estas operaciones son [13]:

- Preparación de composiciones para el soporte cerámico (vía húmeda): 1 - 2 L/m²

- Preparación y aplicación de esmaltes: 4 -12 L/m²

El agua de lavado generada en la preparación de composiciones para el soporte cerámico por vía húmeda, es poco importante, además se puede reciclar fácilmente para la preparación de las propias suspensiones cerámicas.

Sin embargo, el agua de lavado generada en la preparación y aplicación de esmaltes constituye la principal fuente de aguas residuales de la industria cerámica y es el agua en la cual se centra el problema de las aguas residuales de la industria de fabricación de baldosas cerámicas [14].

Como el caso anterior, según donde se esté realizando la limpieza se podrá utilizar un agua con calidades diferentes. Mientras que para la limpieza de las secciones de preparación de suspensiones cerámicas para la elaboración de polvo atomizado y el baldeo de los suelos en las líneas de esmaltado, pueden ser utilizadas aguas residuales industriales clarificadas sometidas a algún tratamiento de clarificación (como se ha dicho el más utilizado es un físico-químico de coagulación-floculación), en otras operaciones como la limpieza de molinos y equipamientos que están en contacto directo con esmaltes y otros aditivos utilizados para la decoración, no se utiliza en la actualidad otra agua que no sea agua limpia.

c) Como fluido para intercambio de calor y retención de partículas en sistemas de depuración de efluentes gaseosos

El agua se utiliza como vehículo de intercambio de calor en operaciones de refrigeración de prensas y otros equipos, también en operaciones de pulido y biselado en la fabricación de gres porcelánico, además en este último caso, a su vez funciona como agente de arrastre de partículas. 
También se utiliza en el fritado de vidriados cerámicos, donde se enfría la masa fundida directamente sobre agua.

Además, el agua puede utilizarse como agente de retención de partículas en sistemas de depuración de efluentes gaseosos. Estos equipos (abatidores vía húmeda) son utilizados principalmente a la salida de los secaderos por atomización [15].

El consumo de agua en estos casos se limita a las pérdidas por evaporación y a las purgas del circuito, que constituyen las únicas aguas residuales de estas operaciones, pues se intenta conseguir la recirculación total. Sin embargo, hay que mencionar que las aguas procedentes de las purgas de estos sistemas cerrados presentan elevadas concentraciones de diferentes elementos. En el caso de las aguas de purga procedentes del circuito de refrigeración del fritado de vidriados cerámicos destinadas a la decoración de baldosas, se pueden encontrar casos en los que además del elevado contenido en sales, la concentración de boro es más de 20 veces el límite legal de vertido. Por otro lado, en el caso de las aguas de purga procedentes de la etapa de pulido y biselado se pueden encontrar conductividades muy elevadas, esto es consecuencia de la gran cantidad de sales que se disuelven debido a la fricción y desgaste que existe entre las muelas y las baldosas que se están mecanizando.

En cuanto a la calidad de las agua utilizadas con estos fines hay que mencionar que, tanto en enfriamiento de fritas, como en las operaciones de pulido y biselado, como en la refrigeración de prensas, el agua utilizada en la actualidad es agua limpia que va ensuciándose o evolucionando a medida que aumentan los ciclos de recirculación. Sin embargo, el agua utilizada en sistemas de depuración de gases sí que puede ser agua residual industrial clarificada.

\subsubsection{Generación, características y gestión actual de las aguas residuales procedentes de las empresas de fabricación de baldosas cerámicas}

\subsubsection{Generación y características del agua residual}

Como se ha comentado anteriormente, en la industria de fabricación de baldosas cerámicas, las aguas residuales provienen principalmente de las aguas generadas en el lavado de las instalaciones de preparación y aplicación de esmaltes. Todas estas aguas de limpieza se dirigen mediante canaletas hacia colectores que generalmente, originarán una única corriente de aguas residuales para cada planta.

Los caudales, así como las características de estas aguas residuales son muy heterogéneos, principalmente porque las operaciones de lavado de equipos y baldeo de suelos siempre son realizadas manualmente por los operarios que trabajan en estas secciones del proceso productivo. Además, también van a estar influenciados por el número de aplicaciones que se utilicen y la frecuencia de cambio de modelos producidos.

Sin embargo, y teniendo en cuenta la heterogeneidad que se puede encontrar en las aguas residuales mencionadas, se puede extraer varias características generales que todas ellas comparten. Así, las aguas residuales del sector de fabricación de baldosas cerámicas, presentan 
turbidez y color a causa de las partículas de fritas, esmalte y mineral arcilloso que están en suspensión. Si se tiene en cuenta su composición química, en estas aguas se pueden encontrar [3]:

- Sólidos en suspensión: arcillas, restos de fritas y esmaltes, así como otras materias primas insolubles en general.

- Aniones y cationes en disolución: sulfatos, cloruros, $\mathrm{Na}^{+}, \mathrm{Mg}^{2+}, \mathrm{Ca}^{2+} \ldots$

- Metales pesados en disolución y/o suspensión, principalmente derivados del Pb y Zn.

- Compuestos de boro.

- Materia orgánica: vehículos serigráficos, colas, tintas y demás aditivos orgánicos generalmente utilizados en la etapa de decoración del proceso productivo de los materiales cerámicos, o incluso en su caso, aditivos utilizados en la etapa de depuración de las aguas residuales (coagulantes y floculantes).

La proporción de estos elementos en las aguas residuales industriales va a depender, entre otras variables, de los diferentes tipos y composición de los esmaltes, así como de los vehículos, tintas y demás materiales de decoración aplicados, además de la cantidad de agua utilizada para estas labores de limpieza.

Los tratamientos tradicionalmente empleados por la industria cerámica para la depuración de sus aguas residuales son capaces de eliminar algunas de las sustancias presentes en las mismas. Sin embargo, existen algunos contaminantes que, por sus características, presentan mayor grado de dificultad a la hora de su eliminación, por tanto, se necesita tratamientos más efectivos (de todos estos tratamientos se hablará más adelante).

Algunos elementos presentes en las aguas residuales a los que se hace referencia tienen límites muy estrictos en la legislación de vertidos [16]. Sin embargo, otros muchos, aunque no resultan problemáticos a la hora de verterlos si no superan los límites legales establecidos, ocasionarían diferentes problemas en el caso que tuviese que reutilizarse el agua que los contiene. Algunos de estos elementos y los problemas que ocasionan se detallan a continuación:

- Los compuestos orgánicos. Estos compuestos proceden de los aditivos de naturaleza orgánica utilizados durante todo el proceso productivo. Estos compuestos no se logran eliminar de las aguas residuales con los tratamientos actualmente utilizados, basados principalmente en procesos físico-químicos de coagulación-floculación. La persistencia de dichos compuestos, incluso en aquellas aguas tratadas, da lugar a su descomposición y, en consecuencia, a la generación de malos olores y de otros problemas de índole técnico que en muchas ocasiones dificultan la reutilización de las aguas depuradas en el propio proceso productivo, tanto como materia prima o como agente de limpieza [17].

- Diferentes iones y sales. Generalmente las aguas residuales procedentes de las industrias de fabricación de baldosas y de fritas tienen un gran contenido de iones en disolución, como por ejemplo $\mathrm{Na}^{+}, \mathrm{Mg}^{2+}, \mathrm{Ca}^{2+}, \mathrm{Cl}^{-}, \mathrm{SO}_{4}{ }^{2-} \ldots$ Estos elementos son los causantes de que la conductividad del agua sea muy elevada y pueden producir diferentes problemas (reológicos, de eflorescencias, defectos superficiales en el vidriado...) a la hora de reutilizar aguas con elevadas concentraciones de los mismos. 
- El boro y sus compuestos. El boro es el contaminante que mayor número de problemas ocasiona en el sector de fabricación de baldosas en cuanto al tratamiento de aguas se refiere. Este elemento y sus compuestos están presentes en las materias primas utilizadas en los vidriados de los productos fabricados por la industria cerámica, por tanto, pasan a sus aguas residuales con facilidad en las operaciones de limpieza de las líneas de esmaltado. La eliminación de estos compuestos de las aguas residuales es muy compleja [18], debido principalmente a su elevada solubilidad en el agua y a su reducido tamaño molecular [19]. Por esta razón, para su eliminación es necesario aplicar, además de un tratamiento físicoquímico de coagulación-floculación, tratamientos terciarios, como posteriormente se describirá [1].

\subsubsection{Gestión actual de las aguas residuales procedentes de las empresas de fabricación de baldosas cerámicas}

Una vez conocido el principal origen de las aguas residuales industriales de este sector y sus principales características, se describirá la gestión que las empresas hacen actualmente de sus aguas residuales.

Actualmente, la mayor parte de las empresas dedicadas a la fabricación de baldosas cerámicas tienen vertido cero. Esto quiere decir que las aguas residuales procedentes de sus plantas, o son introducidas en la etapa de preparación de las suspensiones cerámicas para elaboración de polvo atomizado, donde el agua se ha de evaporar en el proceso de atomización, o bien son reutilizadas, después de haberlas sometido a un tratamiento físico-químico sencillo [14], como agente de limpieza en aquellas operaciones donde la calidad que se exige al agua no es muy elevada.

Por tanto, la situación actual respecto a la gestión de las aguas residuales es la siguiente:

- Reciclado directo, es decir, reciclado en el proceso de preparación de materias primas del soporte (molienda y posterior atomización) sin ningún tipo de tratamiento o después de un tratamiento físico-químico sencillo.

En el caso que la empresa de fabricación de baldosas cerámicas no disponga de etapa de atomización (más del $80 \%$ de las empresas del sector), ya que adquiere el polvo atomizado a empresas externas de fabricación de este producto, las aguas residuales tendrán que ser transportadas hasta alguna empresa que si disponga de esta etapa. Estas empresas son principalmente plantas que solamente se dedican a la fabricación de polvo atomizado (en adelante llamadas atomizadores). El transporte desde la planta donde se generan las aguas residuales hasta el atomizador se realiza a través de conducciones directas, si la empresa generadora y la receptora están cerca, o a través de camiones cisterna en la mayoría de los casos, ya que las empresas generadoras están bastante alejadas de las empresas de atomización.

- Reciclado en operaciones de limpieza de las instalaciones de la propia empresa generadora, tras un proceso no demasiado riguroso de depuración de las mismas (tratamientos físico-químicos de coagulación-floculación, generalmente). 
En la Figura 1.4 se puede observar un esquema de la gestión actual de las aguas residuales de la industria cerámica.

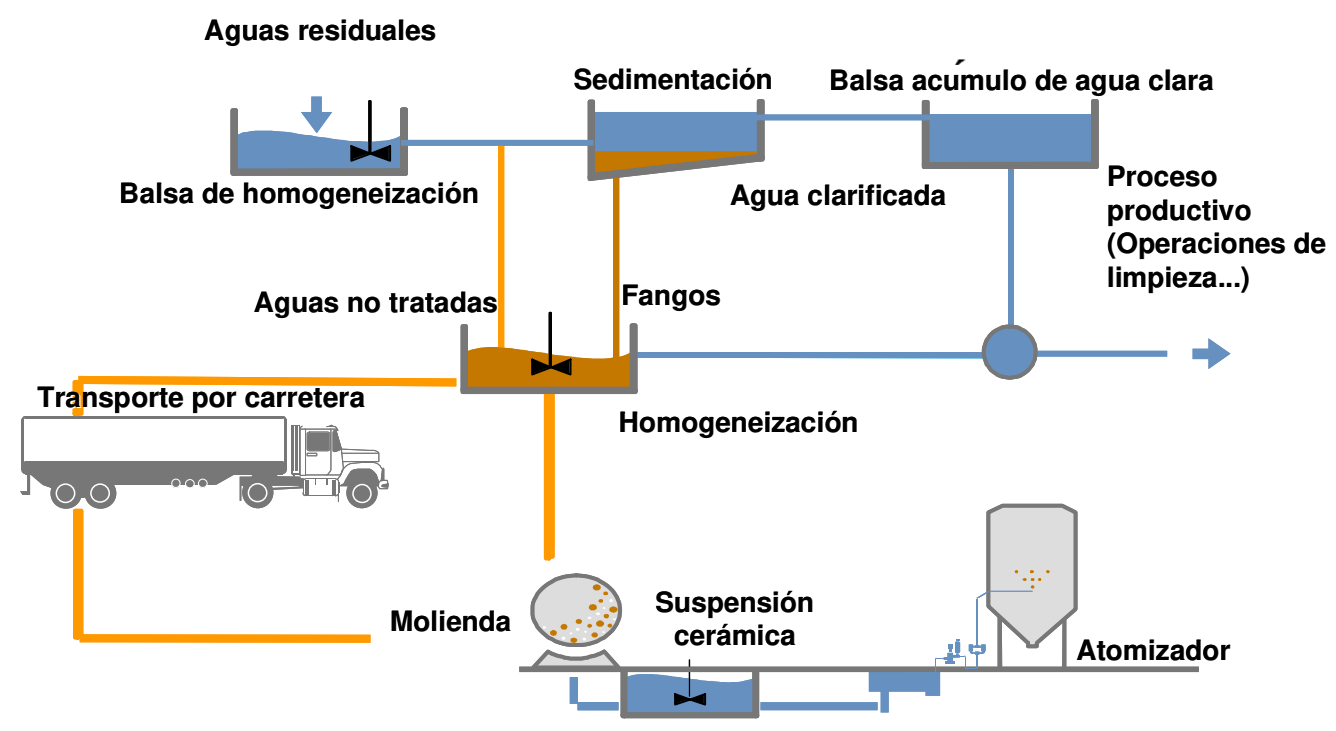

Figura 1.4. Gestión de las aguas residuales de la industria cerámica.

Por último, también cabe mencionar que existe un pequeño porcentaje de empresas que depuran de forma más exhaustiva sus aguas residuales industriales (mediante tratamientos terciarios, generalmente) hasta que todos sus parámetros cumplan los límites establecidos por la legislación, de esta forma poder verterlas directamente al alcantarillado.

El grado de implantación de las dos primeras opciones enumeradas anteriormente (reciclado directo o en labores de limpieza) es muy importante en la actualidad. No obstante, en el caso del reciclado directo merece la pena mencionar que el porcentaje de aguas residuales recirculadas, aun siendo muy elevado, depende también de las características del tipo de baldosa a fabricar y, en consecuencia, de sus exigencias de calidad. Así, por ejemplo, el porcentaje de aguas residuales que pueden ser utilizadas para la elaboración del polvo atomizado necesario para la fabricación de baldosas cerámicas de pasta roja puede ser del 100\%. Sin embargo, este porcentaje puede reducirse (incluso ser 0) para la fabricación de algunas baldosas cerámicas de pasta blanca no esmaltadas, en los que generalmente las exigencias de calidad son mayores [3]. Por esa razón, ya existen atomizadores que están limitando la entrada de aguas residuales externas por no tener suficiente capacidad para absorber todas las aguas residuales que les llegan de las empresas consumidoras del polvo atomizado que fabrican.

En este sentido, y puesto que en estos últimos años la producción de baldosas de pasta blanca, en particular de gres porcelánico, está creciendo de forma significativa respecto a las de pasta roja, tal y como se muestra en la Figura 1.5 (desde el año 2000 ha aumentado de un 17\% a más de un 40\%) [8], se plantea un problema de excedente de aguas residuales para el que se tendrá que buscar una solución: depurar para reutilizarlas en otras etapas del proceso o verterlas cumpliendo los límites que marca la legislación. Por lo tanto, en casi todos los casos se necesitará de un tratamiento previo de las aguas residuales. 


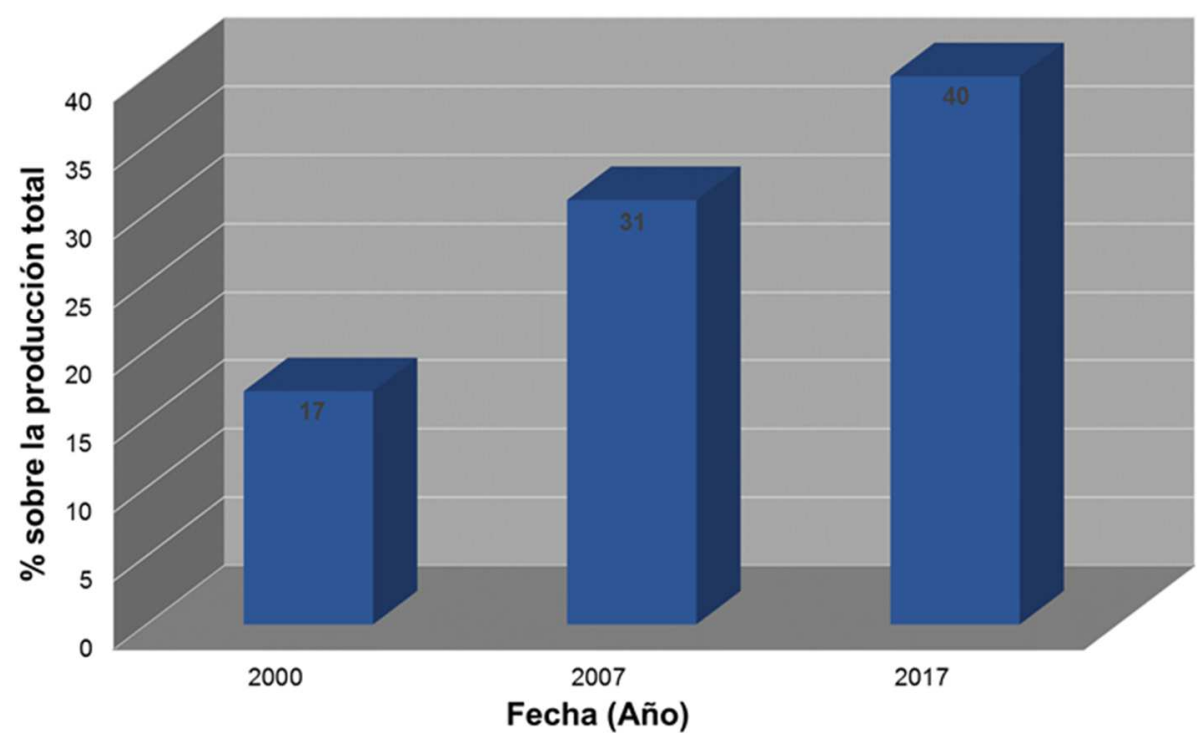

Figura 1.5. Porcentaje de producción de pavimento y revestimiento fabricado con pasta blanca sobre la producción total en España.

Además, el reciclado actual en las plantas de atomización conlleva el problema de las necesidades de transporte de las aguas residuales desde la instalación donde se generan hasta la planta de atomización, ya que, de las aproximadamente 160 empresas de fabricación de baldosas cerámicas de la provincia de Castellón, solo unas 25 empresas poseen planta de atomización. Por lo tanto, esta forma de gestión supone para las empresas un coste bastante elevado, además del impacto medioambiental ocasionado por el transporte por carretera.

\subsubsection{Tratamientos habituales y depuración de las aguas residuales de la industria cerámica}

Los sistemas de tratamiento tradicionalmente utilizados para la depuración de las aguas residuales procedentes de la industria cerámica, se pueden dividir en dos tipos [3][12]: tratamientos físicoquímicos y tratamientos terciarios.

\section{Tratamiento físico-químico}

Estos tratamientos consisten en una serie de etapas compuestas de procesos físicos de sedimentación y homogeneización, así como de procesos químicos de coagulación, neutralización y floculación [20][21].

Este tratamiento es muy efectivo para la eliminación de sólidos en suspensión, así como de algunos metales de las aguas residuales de la industria cerámica y presenta gran flexibilidad en lo que se refiere a la secuencia de etapas que la componen. La Figura 1.6 muestra un esquema general de las diferentes etapas de un tratamiento físico-químico en la industria cerámica. 


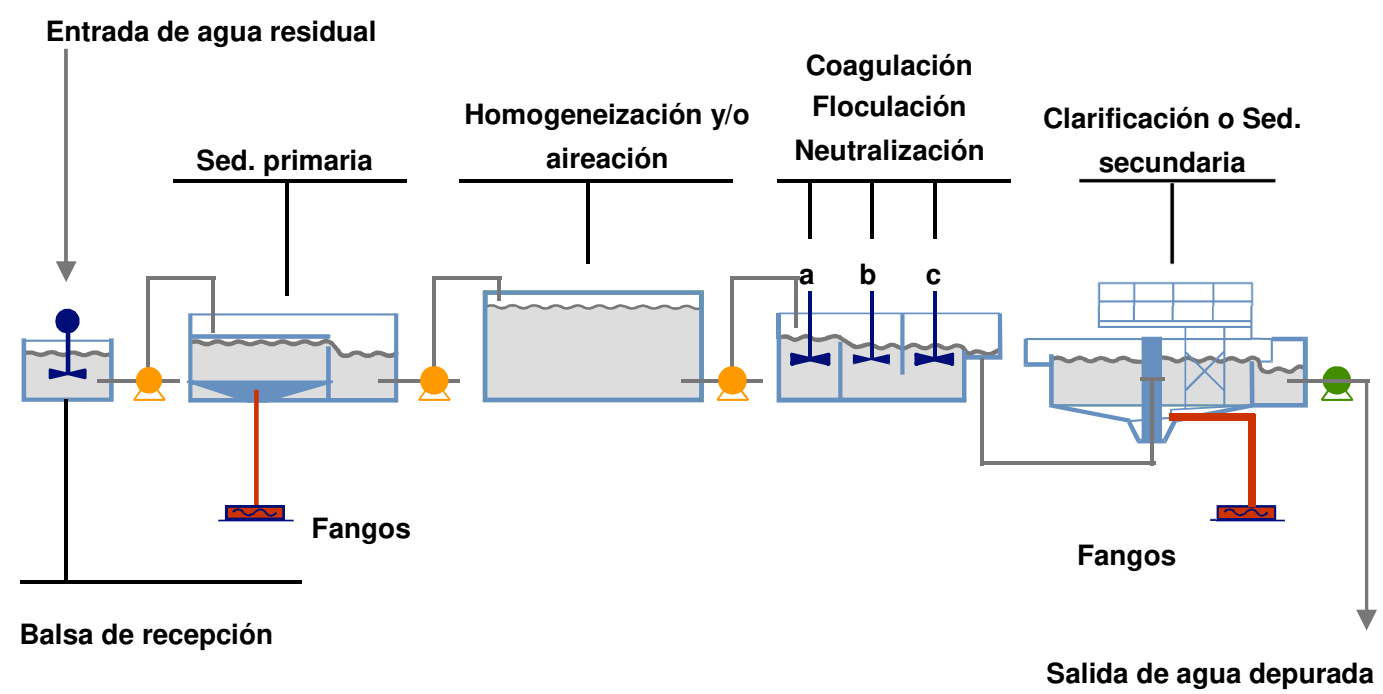

Figura 1.6. Etapas del tratamiento físico-químico de las aguas del sector cerámico.

A continuación, se va a profundizar en cada una de las etapas realizando una breve explicación de cada una de ellas [12][14]:

- Balsa de recepción o de acúmulo: Las aguas residuales de las diferentes etapas del proceso productivo son recogidas en esta balsa a través de canaletas y colectores donde habrá una primera homogeneización.

- Sedimentador: El agua residual es trasvasada desde la balsa de recepción hasta el sedimentador, en el que se realizará la separación de las partículas de mayor tamaño. Los lodos resultantes de esta operación serán tratados externamente. Esta etapa en muchas empresas es omitida, por tanto las aguas pasan directamente a las otras etapas.

- Balsa de homogeneización: Después de la sedimentación, el agua es trasvasada hasta una balsa agitada con el fin de conseguir cierta uniformidad en el agua residual y regular la alimentación de la balsa de reacción posterior.

- Balsa de reacción: El agua procedente de la balsa de homogeneización es bombeada hasta la balsa de reacción. Esta balsa estará constituida por tres reactores agitados. En el primero se introduce el coagulante. Aunque el coagulante más utilizado actualmente por las empresas es el policloruro de aluminio, también pueden utilizarse otros como $\mathrm{FeCl}_{3} \circ \mathrm{Al}_{2} \mathrm{SO}_{4}$. El efecto del coagulante consiste en desestabilizar las cargas eléctricas de las partículas coloidales suspendidas, favoreciendo su acercamiento y aglomeración. En el segundo reactor tiene lugar la neutralización por adición de $\mathrm{Ca}(\mathrm{OH})_{2} \circ \mathrm{NaOH}$, ya que la adición de coagulantes acidifica el medio. Por último, el agua pasa al tercer reactor donde se realiza la adición de floculantes. Estos floculantes son sustancias de alto peso molecular, solubles en agua y con un número elevado de centros activos donde se fijan las partículas por mecanismos de adsorción para la formación de los flóculos fácilmente sedimentables.

- Clarificador: después del proceso de coagulación-neutralización-floculación el agua pasa a un clarificador donde se eliminan los sólidos originados en el proceso. El agua, una vez aclarada, es eliminada por la parte alta del clarificador para su posterior reutilización en 
operaciones de limpieza, generalmente. Los fangos son extraídos por la parte inferior del equipo y serán gestionados externamente con las aguas residuales no tratadas en la empresa.

Sin embargo, estos tratamientos físico-químicos no son capaces de depurar todos los contaminantes presentes en las aguas residuales. Hay elementos, como el caso del boro, que no pueden ser eliminados mediante estas técnicas y siguen estando presentes después de la aplicación de este tratamiento. A parte del problema del boro, estas aguas tratadas presentan otros problemas que no se solucionan con los tratamientos físico-químicos:

- Iones en disolución: $\mathrm{SO}_{4}{ }^{2-}, \mathrm{Mg}^{2+}, \mathrm{Ca}^{2+}, \mathrm{Na}^{+}, \mathrm{Cl}^{-} \ldots$

- Materia orgánica: problemas de descomposición, de olores...

En la Tabla 1.1 se recogen los valores promedio de la carga contaminante del agua residual del sector cerámico antes y después de un tratamiento físico-químico estándar como el que se acaba de describir.

Tabla 1.1. Valores promedio de la carga contaminante del agua residual del sector cerámico antes y después del tratamiento físicoquímico convencional.

\begin{tabular}{|c|c|c|}
\hline Parámetro & Antes del tratamiento & Después del tratamiento \\
\hline $\mathrm{pH}$ & $7-9$ & $7,6-8,6$ \\
\hline Conductividad $(\mu \mathrm{S} / \mathrm{cm})$ & $1000-4000$ & $800-4000$ \\
\hline $\mathrm{DBO}_{5}\left(\mathrm{mg} / \mathrm{L}\right.$ de $\left.\mathrm{O}_{2}\right)$ & $40-1500$ & $40-350$ \\
\hline $\mathrm{DQO}\left(\mathrm{mg} / \mathrm{L}\right.$ de $\left.\mathrm{O}_{2}\right)$ & $500-3000$ & $70-2000$ \\
\hline Sólidos en suspensión (mg/L) & $1-20000$ & $1-100$ \\
\hline Cloruros (mg/L) & $200-1500$ & $100-1400$ \\
\hline Sulfatos (mg/L) & $200-1500$ & $100-1000$ \\
\hline Fluoruros (mg/L) & $0,1-2$ & $0,1-1$ \\
\hline Boro (mg/L) & $1-80$ & $1-80$ \\
\hline Calcio (mg/L) & $50-500$ & $50-150$ \\
\hline Magnesio (mg/L) & $10-100$ & $10-40$ \\
\hline Sodio (mg/L) & $200-1200$ & $100-1000$ \\
\hline Potasio (mg/L) & $10-50$ & $5-30$ \\
\hline
\end{tabular}


Como se puede observar en la Tabla 1.1, existe una gran variabilidad en la composición de carga contaminante de las aguas residuales del sector cerámico, tanto antes, como después del tratamiento físico-químico. Por un lado, el tratamiento apenas modifica el contenido en iones en disolución, como pone de manifiesto el dato de conductividad. Puesto que el límite de vertido es $3000 \mu \mathrm{S} / \mathrm{cm}$, pueden existir casos en los que el agua residual tratada supere este límite. Por otro lado, tampoco es un tratamiento efectivo ni para eliminar materia orgánica, ni para la eliminación de boro, tal como se ha comentado anteriormente. En lo que se refiere al contenido de sólidos en suspensión, el tratamiento es eficaz, como cabría esperar, aunque el grado de eficacia depende en gran medida de las características del agua residual alimentada al tratamiento, así como de las del propio tratamiento.

\section{Tratamiento terciario}

Estos tratamientos son utilizados con un objetivo en concreto, la eliminación del boro de las aguas residuales, dada la ineficacia del tratamiento físico-químico convencional [22]. Como se ha observado, en función del tipo de producto fabricado, la concentración de boro presente en las aguas residuales puede ser importante, siendo en muchas ocasiones más elevada que los límites actualmente establecidos por la legislación de vertido (3 mg/L de B) [16] (Directiva 91/271/EEC).

Las alternativas desarrolladas actualmente para la eliminación de este elemento se basan en la utilización de resinas de intercambio iónico o bien en procesos de ósmosis inversa. De ambas técnicas se hablará con más detalle en el apartado 1.2.3 La eliminación del boro en la industria cerámica.

\subsection{El problema de la depuración del boro}

\subsubsection{El problema general del boro}

El boro no se encuentra como elemento libre en la naturaleza. Todos los compuestos de boro que se hallan en la naturaleza, en general tienen enlaces de boro-oxígeno. Por esta razón, el boro está presente principalmente como boratos o compuestos de ácido bórico [23].

La mayor parte del boro encontrado en la tierra se encuentra en los océanos y en depósitos continentales naturales [24].

El contenido de boro en el agua de mar es bastante importante, se encuentra entre 4 y $7 \mathrm{mg} / \mathrm{L}$, mientras que por lo general es inferior a $0,3 \mathrm{mg} / \mathrm{L}$ en las aguas subterráneas y superficiales. Estas cantidades pueden ser localmente más altas debido a depósitos naturales cercanos o factores antropológicos. Los boratos y el ácido bórico son altamente solubles en agua [25].

Existen importantes depósitos continentales en Estados Unidos, Turquía, Chile... pero Estados Unidos y Turquía representan más del $80 \%$ de la producción mundial de boro [26]. Existen diferentes especies minerales con una gran cantidad de boro, como tincal, colemanita, kernita, ulexita, hidroboracita y szaibelita. El porcentaje de boro difiere en cada mineral, siendo los primeros cuatro los minerales más utilizados para la obtención de este elemento [27]. 
Los compuestos de boro más utilizados en la industria son los boratos y el ácido bórico. Los principales compuestos derivados de estos minerales son el borax pentahidratado $\left(\mathrm{Na}_{2} \mathrm{O} \cdot 2 \mathrm{~B}_{2} \mathrm{O}_{3} \cdot 5 \mathrm{H}_{2} \mathrm{O}\right)$, borax decahidratado $\left(\mathrm{Na}_{2} \mathrm{O} \cdot 2 \mathrm{~B}_{2} \mathrm{O}_{3} \cdot 10 \mathrm{H}_{2} \mathrm{O}\right)$, ácido bórico $\left(\mathrm{H}_{3} \mathrm{BO}_{3}\right)$, borax anhidro $\left(\mathrm{Na}_{2} \mathrm{O} \cdot 2 \mathrm{~B}_{2} \mathrm{O}_{3}\right)$, y ácido bórico anhidro $\left(\mathrm{B}_{2} \mathrm{O}_{3}\right)[27]$.

Debido a sus propiedades el boro, principalmente en forma de ácido bórico y sus derivados, se utiliza como materia prima en muchos procesos industriales. El boro se puede encontrar en fertilizantes e insecticidas por su carácter micronutriente-tóxico. Este elemento también se puede encontrar en la industria de recubrimientos superficiales por su carácter ácido-base y su capacidad tamponante. La capacidad de este elemento para formar poliestructuras y su bajo coeficiente de dilatación térmica hacen que sea la base de los vidrios borosilicatados, de la fibra de vidrio y de determinados esmaltes. Este es el uso industrial más extendido, además del uso por el que se utiliza en la industria cerámica. Su carácter refractario y su acción disolvente sobre óxidos metálicos hacen que este elemento sea utilizado también en soldadura y en la industria de la metalurgia. Otro de los usos del boro que por su porcentaje es importante, ya que sigue a su uso en la industria del vidrio y derivados, es el de fabricación de detergentes, ya que este elemento presenta una acción blanqueante y acondicionadora del agua que favorecen el trabajo de jabones y tensoactivos. También puede encontrarse en la industria nuclear, en la industria química, en la industria del automóvil... [28].

Entre las características del boro y sus compuestos también está la de ser muy soluble en el agua, de ahí sus problemas para ser separado. Por este motivo, la contaminación por el boro es hoy en día uno de los problemas medioambientales que afecta a las aguas superficiales de todo el mundo, en concreto, existen estudios que muestran concentraciones muy altas de este contaminante en algunos ríos europeos, generalmente en los ríos que están cerca de núcleos industriales importantes [29]. En particular, existen puntos en el levante español (cuenca del Júcar y Segura) en los que la concentración de la industria cerámica es importante, donde la concentración de boro es elevada [28].

El boro es un elemento necesario para el crecimiento de las plantas, pero eso sí, en porcentajes muy pequeños, ya que la presencia de cantidades superiores a las que la planta necesita lo convierten en tóxico. Alguno de los cultivos más sensibles a la presencia de boro en las aguas de riego son los cítricos y los kiwis, que no deben ser regados con aguas con elevadas concentraciones de este elemento. Hay que mencionar que el cultivo de cítricos es el cultivo más extendido por todo el levante español [30][31]. Según diferentes estudios, el boro también puede influir en el funcionamiento normal de las EDAR, ya que puede resultar tóxico o inhibidor de los procesos de síntesis y descomposición biológica que tienen lugar en estas estaciones de depuración [32].

El boro puede llegar a los seres humanos a partir de los alimentos y del agua potable, y también puede ser tóxico si se inhala a través de las vías respiratorias y/o se absorbe por contacto cutáneo. El consumo a largo plazo afecta principalmente al sistema reproductivo masculino y aumenta el riesgo de cáncer. Existen límites establecidos, tanto en la legislación vigente, como recomendaciones hechas por organizaciones tales como la Organización Mundial de la Salud [33]. 
Por tanto, existen varios límites y recomendaciones diferentes para este elemento dependiendo del tipo de agua (potable, de riego, residual...) y la legislación involucrada (legislación europea, legislación nacional o legislación regional).

En la Tabla 1.2 se recopilan algunos de estos límites.

Tabla 1.2. Límites de concentración de boro en diferentes tipos de aguas.

\begin{tabular}{|c|c|c|}
\hline Tipo de agua & Especificaciones & $\begin{array}{l}\text { Límite } \\
\text { (mg/L) }\end{array}$ \\
\hline \multirow{2}{*}{$\begin{array}{l}\text { Agua potable } \\
\text { para el consumo } \\
\text { humano }\end{array}$} & $\begin{array}{c}\text { Unión Europea } \\
\text { (98/83/CE } 3 \text { Noviembre 1998) [30] }\end{array}$ & 1 \\
\hline & Organización Mundial de la Salud (OMS) [24] & 0,3 \\
\hline \multirow{2}{*}{ Agua de regadío } & General [31] & $1-2$ \\
\hline & Cítricos y Kiwis [30] & $<0,3$ \\
\hline \multirow[t]{2}{*}{ Aguas residuales } & $\begin{array}{c}\text { Descarga a Estación de Depuración de Aguas } \\
\text { Residuales (EDAR), vertidos a red municipal de } \\
\text { saneamiento [16] } \\
\text { Directiva 91/271/EEC }\end{array}$ & 3 \\
\hline & $\begin{array}{c}\text { Descarga directa (suelo, ríos...) (Autorizaciones } \\
\text { Ambientales Integradas (AAI) concedidas por la } \\
\text { Generalitat Valenciana) }\end{array}$ & 1 \\
\hline
\end{tabular}

\subsubsection{Química del boro}

El boro tiene el símbolo químico $\mathrm{B}$, el número atómico 5 y la masa atómica de $10.811 \mathrm{Da}$. Es el único elemento no metálico del Grupo III de la tabla periódica. El radio molecular del ácido bórico y el coeficiente de difusión del boro se muestran en la Tabla 1.3.

Tabla 1.3. Parámetros físicos del boro.

\begin{tabular}{|c|c|}
\hline Parámetros & Valores \\
\hline $\mathrm{r}_{22 \mathrm{BO}^{-}}$ & $2,26 \pm 0,01 \AA$ \\
\hline Coeficiente de difusión del boro & $810^{-9} \mathrm{~m}^{2} / \mathrm{s}$ \\
\hline
\end{tabular}

El ácido bórico y los boratos son los principales derivados de boro encontrados en el agua. La química del ácido bórico está dominada por el carácter ácido débil de este compuesto [26]. La forma en la que el boro está presente en el agua cambia de ácido bórico a borato, dependiendo del pH. 
Por tanto, se pueden encontrar las siguientes reacciones de equilibrio:

$$
\begin{array}{ll}
\mathrm{H}_{3} \mathrm{BO}_{3} \leftrightarrow \mathrm{H}_{2} \mathrm{BO}_{3}{ }^{-}+\mathrm{H}^{+} & \mathrm{pKa}=9,14 \\
\mathrm{H}_{2} \mathrm{BO}_{3}^{-} \leftrightarrow \mathrm{HBO}_{3}{ }^{2-}+\mathrm{H}^{+} & \mathrm{pKa}=12,74 \\
\mathrm{HBO}_{3}{ }^{2-} \leftrightarrow \mathrm{BO}_{3}{ }^{3-}+\mathrm{H}^{+} & \mathrm{pKa}=13,80
\end{array}
$$

La Figura 1.7 muestra los diferentes porcentajes de las especies de boro que pueden encontrarse en solución acuosa en función del pH. A pH 7, se observa que todo el boro está en la forma de ácido bórico. Mientras que a pH 8, el ácido bórico comienza a disociarse a la forma iónica. A pH 9,14, el porcentaje de ácido bórico es sólo del 50\%. Por lo tanto, en algunas técnicas de eliminación de boro, esta eliminación dependerá en gran medida del pH [34][35].

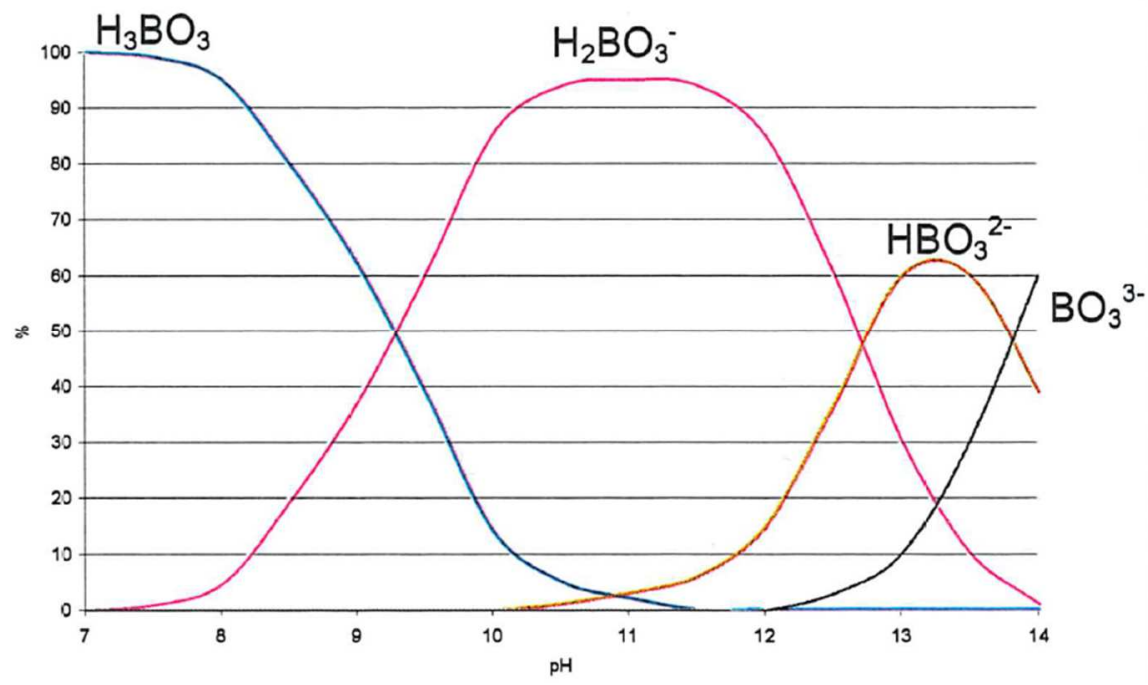

Figura 1.7. Diferentes compuestos de boro en función del pH.

La fracción de ácido bórico es el parámetro crítico que influirá de forma importante a la hora de eliminar este elemento. Esto se debe a que el ácido bórico es una molécula neutra, mientras que los boratos son especies cargadas en las que se puede aprovechar esa carga para aumentar la eficacia de la técnica de separación.

\subsubsection{La eliminación del boro en la industria cerámica}

El boro está presente en la industria cerámica porque es una materia prima de las fritas y de los esmaltes utilizados en la decoración de las baldosas cerámicas [27]. Por tanto, este elemento se va a encontrar en las aguas residuales que han estado en contacto con estos productos.

Como puede observarse en la Tabla 1.1 la concentración de boro en las aguas de la industria cerámica puede encontrarse entre valores de 1-80 mg/L de B, incluso estos valores podrían llegar a ser muy superiores en el caso de las aguas de refrigeración de las fritas, ya que están en un circuito cerrado y en contacto directo con el material fundido cuyas materias primas contienen boro (ver Figura 1.3).

Como se ha mencionado anteriormente, en el caso de la provincia de Castellón se concentra un elevado número de empresas cerámicas (> 90\% de la producción nacional; alrededor de 160 
empresas). Esta elevada concentración industrial, conlleva, por un lado, una elevada necesidad de agua y por otro, una generación de aguas residuales importante. Si a este hecho, se le une que la provincia de Castellón también se caracteriza por contener extensas zonas de cultivo de cítricos, es evidente que el riesgo de contaminación por boro es de especial relevancia en esta zona de España.

Las alternativas desarrolladas actualmente para la eliminación de este elemento en la industria cerámica de la provincia de Castellón se basan en la utilización de resinas de intercambio iónico o bien en procesos de ósmosis inversa.

\subsubsection{Intercambio iónico}

Los tratamientos de intercambio iónico se basan en un intercambio de iones entre dos electrolitos o entre una solución electrolítica y un complejo. Generalmente, los intercambiadores de iones son sólidos que llevan grupos funcionales cargados. Los intercambiadores de iones típicos son resinas de intercambio iónico (resinas porosas o geles poliméricos), zeolitas, montmorillonita, arcilla...

Estas sustancias son intercambiadores catiónicos, que intercambian cationes, o intercambiadores aniónicos, que intercambian aniones, aunque también hay intercambiadores anfóteros, que son capaces de intercambiar simultáneamente cationes y aniones.

Los intercambiadores de iones pueden ser de diferentes tipos, pueden ser no selectivos o tener preferencias de unión por ciertos iones o clases de iones, dependiendo de su estructura química. Esto puede depender del tamaño de los iones, su carga, o su estructura.

Para el caso concreto de la eliminación del boro existen varias resinas específicas y muy selectivas para la eliminación de este elemento, algunas de las cuales son: Amberlite IRA 743 (cuyo grupo funcional se basa en N-metil-glucamina), Wofatit MK 51, Amberlite XE-243, Duolite ES 371, Diaion CRB 02, Uniselec UR 3500 y Purolite S 108 [26][36][37][38].

En el caso de las aplicaciones de esta tecnología en el sector cerámico para la eliminación del boro, estas plantas están constituidas por una columna rellena de resinas de intercambio iónico, un grupo automático de regeneración de las mismas con un ácido y una base fuerte, así como contenedores para la recogida de los líquidos de la regeneración. Su funcionamiento consiste en la realización de ciclos sucesivos, compuestos por etapas de tratamiento del agua, regeneración de la resina y drenaje después de cada lavado (ver Figura 1.8).

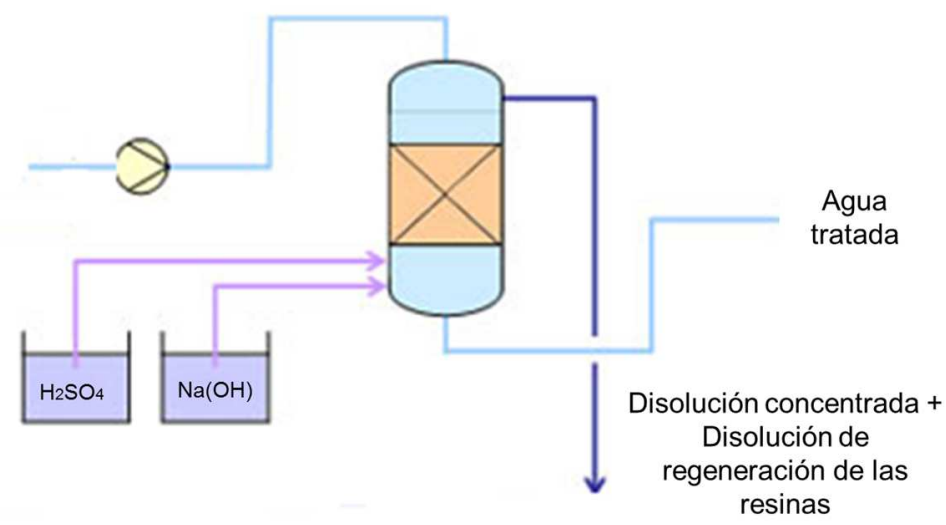

Figura 1.8. Proceso de intercambio iónico para la eliminación de boro. 
Además, antes de ser alimentadas a la columna donde se alojan las resinas, las aguas residuales tratadas incluso después del tratamiento físico-químico que habitualmente es aplicado a las aguas residuales del sector cerámico, deben someterse a un pretratamiento para eliminar los posibles sólidos en suspensión y la materia orgánica, ya que de lo contrario se podría alterar el funcionamiento de la columna, aumentando las pérdidas de carga y reduciendo la superficie de intercambio efectiva.

En la Figura 1.9 se puede observar una planta de eliminación de boro por intercambio iónico.

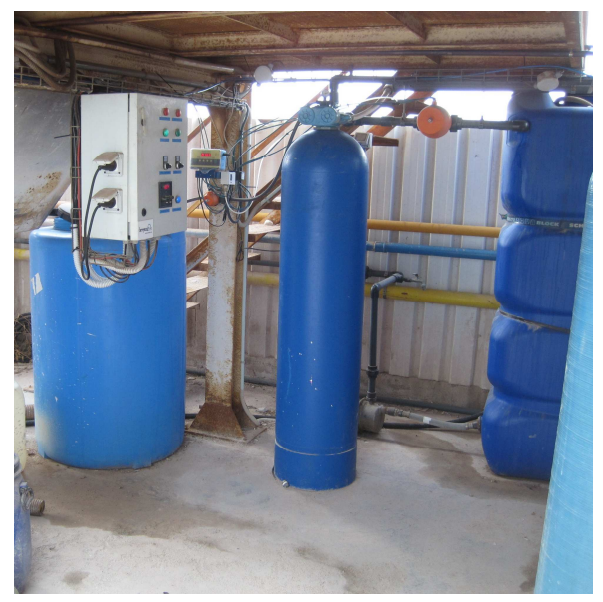

Figura 1.9. Equipo de intercambio iónico.

Aunque los rendimientos obtenidos hasta la fecha son buenos ( $>94 \%)$ el proceso presenta serios inconvenientes que hace que no pueda ser considerado como la mejor alternativa para la solución del problema, como posteriormente se describirá (apartado 1.2.5 Comparación entre las técnicas que existen para la eliminación del boro).

\subsubsection{2 Ósmosis inversa.}

La ósmosis inversa $(\mathrm{Ol})$ es un tratamiento que consiste en obligar a las moléculas de agua a atravesar la membrana desde una región de alta concentración a una región de baja concentración de soluto mediante la aplicación de una presión superior a la presión osmótica. La presión es, por lo tanto, la fuerza impulsora del transporte. En la Figura 1.10 se puede observar una planta de osmosis inversa.

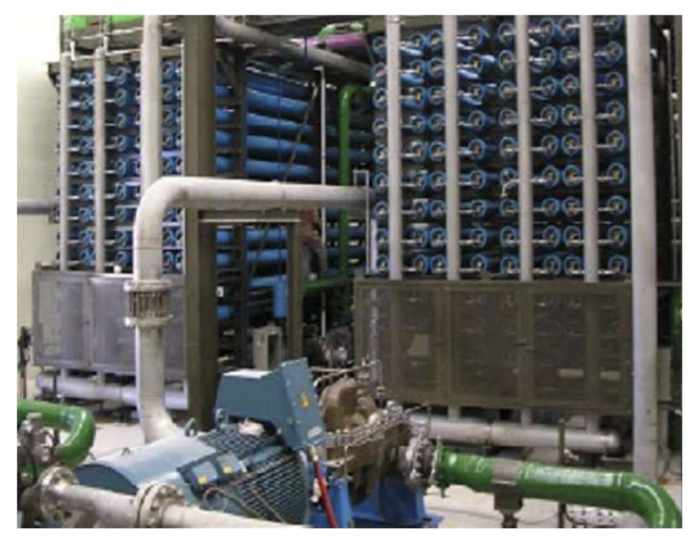

Figura 1.10. Instalación de ósmosis inversa [35]. 
El mecanismo de transporte utilizado por esta técnica es la disolución-difusión a través de una barrera densa sin poros predefinidos, que es la membrana. En la Figura 1.11 se muestra cómo el agua atraviesa la membrana de ósmosis inversa y pasa de la solución concentrada a la solución diluida.

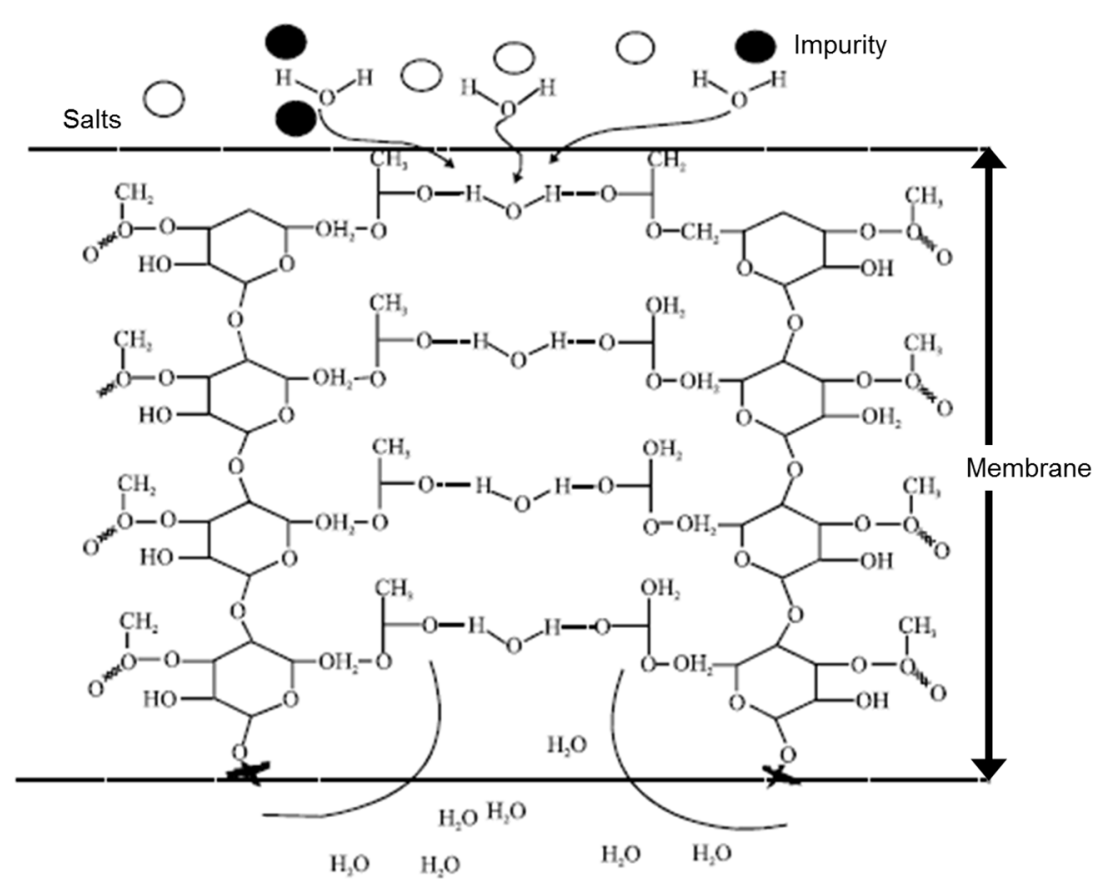

Figura 1.11. Mecanismo de transferencia a través de una membrana de ósmosis inversa [34].

La ósmosis inversa es una de las técnicas más ampliamente utilizada para la eliminación del boro y existen varias membranas que funcionan bien para esta aplicación: SW30HR-380, SW30HR-320, SW30-380, SW30-400 y BW30LE-400 de Dow-Filmtec, así como ESPA-1, 320 ESPA-2, 5760 SWC3 y 160 CPA3 de Hydronautic o X-FLOW WFC 0995 de Pentair [30][39][40][41].

Los parámetros de proceso más importantes para obtener elevadas retenciones del boro son: el tipo de membrana, el pH, la temperatura y la presión de trabajo.

\section{Retención del boro en función del tipo de membrana}

Hay diferencias considerables entre diferentes membranas. Si por ejemplo se comparan las membranas BW30LE-440 y la SW30HR-380, la retención de boro a pH 8 es del 55\% y 90\% respectivamente. Sin embargo, se pueden observar algunas diferencias importantes en la presión de trabajo y en el flujo resultante, ya que la membrana BW30LE-440 trabaja a $P=10,7$ bar con un flujo de $1,81 \mathrm{~m}^{3} / \mathrm{h}$, mientras que la membrana SW30HR-380 trabaja a $\mathrm{P}=55$ bar con un flujo de 0,95 $\mathrm{m}^{3} / \mathrm{h}$. Estas diferencias se deben principalmente a la química y al comportamiento frente a una determinada disolución de cada una de las membranas [30][42].

\section{Retención del boro en función del pH}

Otro parámetro del proceso muy importante es el pH. A valores de pH más altos, la retención de boro mejora significativamente. Esto es debido a que a pH más elevados la concentración de las especies del boro que se encuentran en forma de boratos es mayor (ver apartado 1.2.2 Química del boro) y por tanto estas especies cargadas son más retenidas que las especies neutras. En la región 
de $\mathrm{pH}$ donde el ácido bórico se disocia hacia los boratos hay una mejora sustancial con cada unidad de aumento de $\mathrm{pH}$. Por tanto, a pH elevado la retención aumentará.

\section{Retención del boro en función de la temperatura [30]}

La temperatura tiene una fuerte influencia sobre el valor de $\mathrm{pKa}$ y $\mathrm{pKb}$ del boro. Se ha observado que en el intervalo de temperaturas de 10 a $45^{\circ} \mathrm{C}$, el pKa varía de 8,7 a 9,7, este cambio en el pKa se traduce en una presencia más importante de $\mathrm{H}_{2} \mathrm{BO}_{3}{ }^{-}$y por lo tanto, una mejor retención de boro.

Además, el efecto del desplazamiento del pK se ve reforzado por el efecto general del aumento del paso de sal a través de las membranas en la dirección de altas temperaturas. Esto se debe a que la permeabilidad de la membrana, tanto para el disolvente (agua) como para los solutos (boro y otros elementos), es una función de la temperatura.

\section{Retención del boro en función de la presión}

En la Figura 1.12 se muestra la dependencia de la concentración del boro en el permeado y la retención de este elemento en función de la presión de operación. Como se puede observar, la retención del boro tiende a aumentar cuando la presión aumenta.

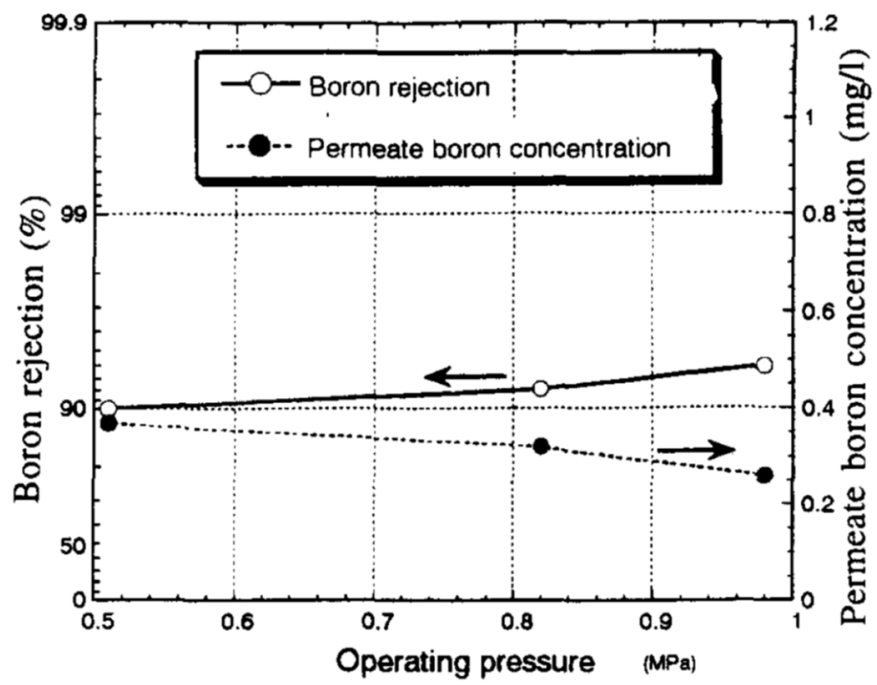

Figura 1.12. Retención de boro y concentración de boro en el permeado en función de la presión [24].

La membrana usada en este caso ha sido la ES10-D4 y las características de la disolución empleada en el ensayo han sido de un pH de 10 y una concentración de boro de $1 \mathrm{mg} / \mathrm{L}$ [24].

Los tratamientos de ósmosis inversa en el sector cerámico, al igual que los tratamientos de intercambio iónico, también se llevan a cabo mediante ciclos formados por diferentes etapas. La presión de operación de este tratamiento oscila sobre los 40 bares, esto implica un elevado consumo de energía [12]. 
En la Figura 1.13 se observa una fotografía de una planta de ósmosis inversa instalada en el sector cerámico.

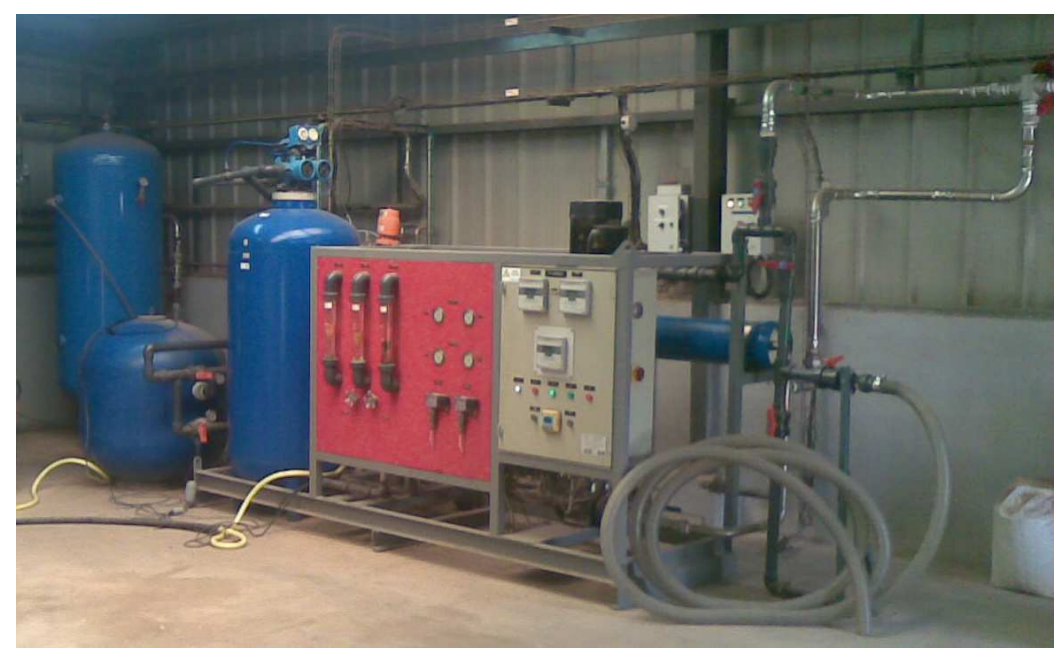

Figura 1.13. Instalación de ósmosis inversa en el sector cerámico.

\subsubsection{Otras alternativas para la eliminación del boro}

Los tratamientos más comúnmente utilizados para la eliminación del boro son el intercambio iónico y la ósmosis inversa, ya descritos anteriormente. Sin embargo, aunque no existen referencias de la utilización de otros tratamientos para la eliminación del boro en la industria cerámica, existen alternativas a las ya mencionadas no tan conocidas ni utilizadas para la eliminación de este contaminante presente en diferentes tipos de aguas.

Por tanto, a continuación se hará referencia a los tratamientos alternativos al intercambio iónico y a la ósmosis inversa para la eliminación del boro, además se explicará brevemente cada uno de ellos.

\section{Electrodiálisis}

La electrodiálisis (ED) es un proceso en el que los iones se transportan de una solución a otra a través de membranas permeables bajo la influencia de un gradiente de potencial.

Las cargas eléctricas de los iones permiten que sean conducidos a través de las membranas fabricadas a partir de polímeros de intercambio iónico. La aplicación de una tensión eléctrica entre dos electrodos extremos genera el campo requerido para llevar a cabo este transporte. Por tanto, el campo eléctrico es la fuerza impulsora de la filtración. Puesto que las membranas utilizadas en la electrodiálisis son capaces de transportar selectivamente iones que tienen una carga positiva o negativa y rechazar iones de la carga opuesta, la purificación tiene lugar mediante un mecanismo de intercambio iónico [43].

Este tratamiento también puede utilizarse para la eliminación de boro. Sin embargo, si se utiliza este tratamiento con este fin, hay que tener en cuenta que existen iones con mayor movilidad que los boratos, tales como $\mathrm{Cl}^{-}$y $\mathrm{SO}_{4}{ }^{2-}$, por lo tanto, es necesario eliminarlos antes que los boratos, ya que de lo contrario la eficiencia de eliminación de boro y los flujos son muy bajos en presencia de altas cantidades de cloruros y sulfatos. Por lo tanto, los estudios sobre esta materia sugieren que se debe 
usar la electrodiálisis en dos etapas para la eliminación del boro. En la primera etapa, se debe eliminar aproximadamente $80 \%$ de los cloruros, sulfatos y otros iones (tales como $\mathrm{Ca}^{2+}, \mathrm{Mg}^{2+} \ldots$ ) a $\mathrm{pH}$ ácido (aproximadamente $\mathrm{pH}$ 3). Estos iones se eliminan con el fin de aumentar la eficiencia de eliminación de boro y evitar que algunos iones puedan precipitar si el $\mathrm{pH}$ aumenta en la segunda etapa. En la primera etapa, el transporte de boro es despreciable porque el pH no es suficiente para disociar el ácido bórico en compuestos cargados. En la segunda etapa, el pH se eleva hasta el intervalo 9-10, y hasta 97\% del boro se puede eliminar de una disolución de alimentación de 70 $\mathrm{mg} / \mathrm{L}$ de boro [44][45][46].

\section{Adsorbentes inorgánicos}

Algunos iones metálicos adsorben boro y precipitan como hidróxidos metálicos. Los adsorbentes más estudiados son $\mathrm{Fe}(\mathrm{OH})_{3}, \mathrm{Al}(\mathrm{OH})_{3}, \mathrm{Mg}(\mathrm{OH})_{2}, \mathrm{Ni}(\mathrm{OH})_{2}$ y $\mathrm{Zn}(\mathrm{OH})_{2}$. La eliminación de boro puede ser alta, pero siempre es necesario controlar la temperatura y el $\mathrm{pH}$.

La principal ventaja es que, en algunos casos, se consigue una importante eliminación de boro (95\%). Sin embargo, el método puede implicar riesgos ambientales (dependiendo del adsorbente) y puede tener un coste elevado [27].

\section{Extracción con solvente}

Este método es muy eficaz como método de laboratorio, siendo los compuestos más ampliamente utilizados los compuestos orgánicos hidroxilados [47].

La principal ventaja es la posibilidad de trabajar de forma continua y automática. Las desventajas de esta técnica son la complejidad del equipo, la solubilidad en agua de los compuestos orgánicos (riesgo ambiental) y el alto costo de estos compuestos.

\section{Precipitación con álcalis}

Este método se basa en la adición de $\mathrm{NaOH}$ o $\mathrm{CaO}$. El objetivo es conseguir niveles de pH en los que el contaminante no sea soluble en agua. La eliminación de contaminantes se produce por precipitación. La principal desventaja es la baja eficiencia [48].

Estos tres últimos tratamientos son mucho menos eficientes a bajas concentraciones que los procesos explicados anteriormente y tienen mayores costes de operación. Sin embargo, en el caso de concentraciones muy altas de boro, puede ser útil combinar estas técnicas con procesos más efectivos a concentraciones bajas [27].

\section{Nanofiltración}

La nanofiltración es un tratamiento que puede ser aplicado para la eliminación del boro [42]. Al igual que la ósmosis inversa, es un tratamiento con membranas cuya fuerza impulsora es un gradiente de presión. Por los resultados y las ventajas que ofrece este tratamiento frente a sus competidores (Ver apartado 1.2.5 Comparación entre las técnicas que existen para la eliminación del boro), la nanofiltración puede ser una buena solución para la eliminación del boro en la industria cerámica, por tanto es la técnica que se ha utilizado en este trabajo, en la cual se profundizará en el apartado 1.4.2 La Nanofiltración. 


\subsubsection{Comparación entre las técnicas que existen para la eliminación del boro}

En Tabla 1.4 se recogen algunas de las desventajas de los tratamientos más utilizados en el sector cerámico para la eliminación del boro y las ventajas que se le suponen a la nanofiltración que ha sido la técnica elegida en este estudio para la eliminación de este elemento.

Tabla 1.4. Desventajas de los métodos empleados habitualmente frente a la nanofiltración.

\begin{tabular}{|c|c|c|}
\hline $\begin{array}{l}\text { Método de } \\
\text { depuración }\end{array}$ & $\begin{array}{l}\text { Desventajas de los métodos de } \\
\text { depuración actuales }\end{array}$ & Ventajas de la nanofiltración \\
\hline \multirow{5}{*}{$\begin{array}{l}\text { Planta de } \\
\text { intercambio } \\
\text { iónico }\end{array}$} & Las resinas utilizadas son caras & $\begin{array}{l}\text { Con la nanofiltración no son } \\
\text { necesarias las resinas y las } \\
\text { membranas tienen una vida útil } \\
\text { considerable }\end{array}$ \\
\hline & $\begin{array}{l}\text { Para la regeneración de las resinas se } \\
\text { utiliza sustancias ácidas y básicas fuertes, } \\
\text { por tanto, la utilización de este tipo de } \\
\text { sustancias implica una problemática que } \\
\text { hace necesarias medidas de seguridad } \\
\text { para su manipulación }\end{array}$ & $\begin{array}{l}\text { Las membranas no se han de } \\
\text { regenerar, solamente limpiar } \\
\text { cuando su eficiencia descienda }\end{array}$ \\
\hline & $\begin{array}{c}\text { El coste de esta regeneración es elevado, } \\
\text { por tanto, la utilización de este método } \\
\text { también [49] }\end{array}$ & $\begin{array}{c}\text { Con los procesos de nanofiltración } \\
\text { se pretende abaratar } \\
\text { considerablemente los costes }\end{array}$ \\
\hline & $\begin{array}{c}\text { El proceso de depuración es lento, ya que } \\
\text { ha de pasar por muchas fases }\end{array}$ & $\begin{array}{l}\text { Los tiempos de operación sin } \\
\text { limpiezas ni interrupciones pueden } \\
\text { ser largos }\end{array}$ \\
\hline & $\begin{array}{l}\text { Método muy selectivo que sólo elimina el } \\
\text { boro. Por tanto, no sería posible reutilizar } \\
\text { el agua en el propio proceso productivo }\end{array}$ & $\begin{array}{l}\text { Además del boro elimina otros } \\
\text { contaminantes y confiere al agua } \\
\text { tratada una calidad para poder ser } \\
\text { reutilizada en el propio proceso } \\
\text { productivo }\end{array}$ \\
\hline $\begin{array}{l}\text { Planta de } \\
\text { ósmosis } \\
\text { inversa }\end{array}$ & $\begin{array}{l}\text { Las presiones utilizadas pueden ser del } \\
\text { orden de } 40 \text { bar, por tanto, a la utilización } \\
\text { de este método se le asocia un consumo } \\
\text { de energía y un coste de las instalaciones } \\
\text { elevado, ya que se requiere equipamiento } \\
\text { capaz de trabajar a presiones altas [12] }\end{array}$ & $\begin{array}{l}\text { Las presiones utilizadas son, como } \\
\text { máximo de } 15 \text { bar, por esta razón, } \\
\text { el consumo de energía y el coste } \\
\text { de las instalaciones requeridas por } \\
\text { esta tecnología es muy inferior. } \\
\text { Pudiendo tener buenos resultados } \\
\text { a presiones menores de } 6 \text { bar [50] }\end{array}$ \\
\hline
\end{tabular}




\subsection{Comportamiento reológico de las suspensiones cerámicas}

Prácticamente la totalidad de las baldosas cerámicas fabricadas en España (más del 95\% de la producción está ubicada en la Comunidad Valenciana) utilizan procesos de molienda de materias primas vía húmeda. Es decir, las materias primas cerámicas más un pequeño porcentaje de productos químicos que actúan como dispersantes (desfloculantes) se molturan con agua en molinos de bolas para obtener una suspensión cerámica que, más tarde, es secada en grandes secaderos por atomización (ver Figura 1.14) para obtener el polvo atomizado seco que se utilizará para la fabricación de baldosas cerámicas prensadas. Este proceso necesita gran cantidad de agua para la molienda de las materias primas y gran cantidad de energía térmica (normalmente gas natural) para el secado de la suspensión generada, con sus consiguientes emisiones asociadas de $\mathrm{CO}_{2}$ a la atmósfera.
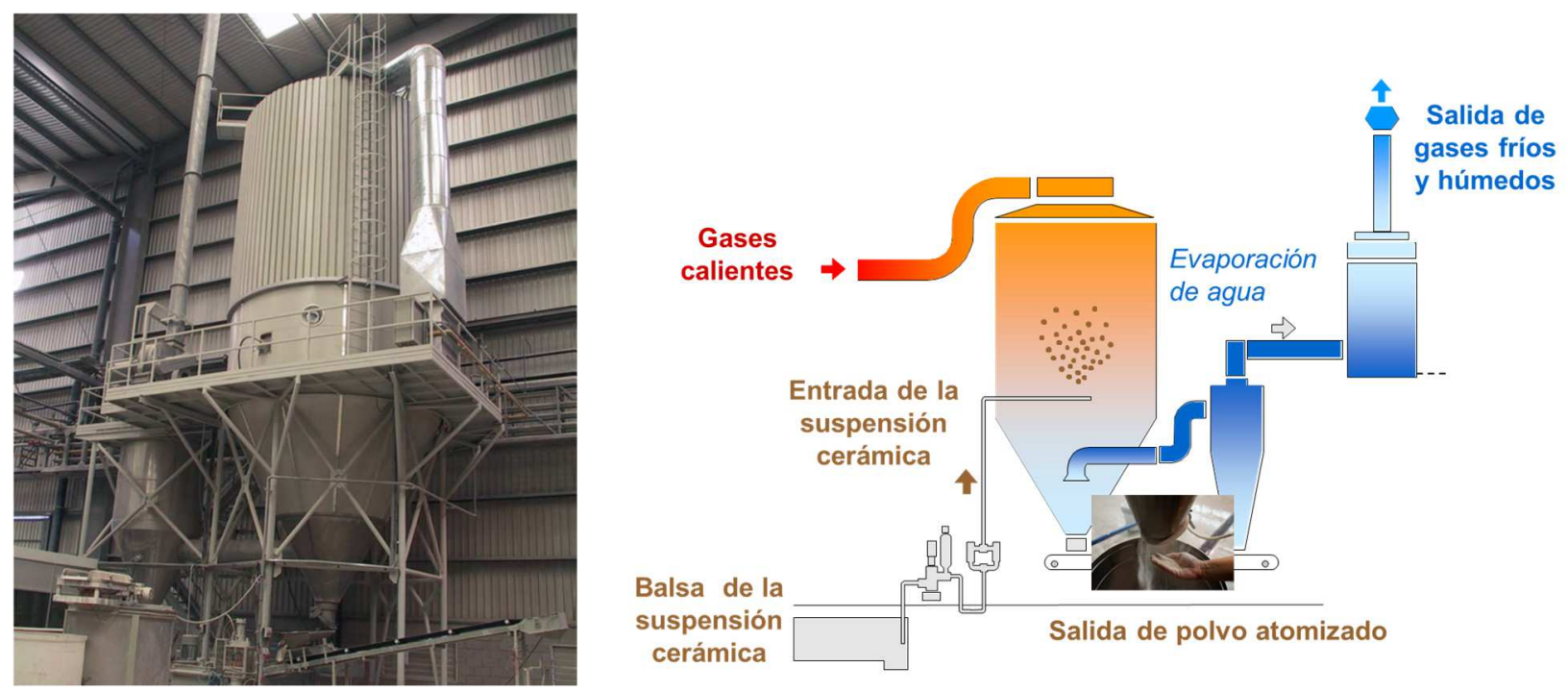

Figura 1.14. Secadero por atomización o atomizador y esquema de la etapa de secado por atomización.

Además, como se ha comentado en el apartado 1.1.3 Generación, características y gestión actual de las aguas residuales procedentes de las empresas de fabricación de baldosas cerámicas, actualmente las empresas dedicadas a la elaboración de polvo atomizado son las grandes gestoras de las aguas residuales generadas en todo el sector cerámico, ya que estas empresas utilizan las aguas residuales de los procesos de fabricación de baldosas para elaborar su producto atomizado.

Teniendo en cuenta, que según la definición aceptada por la IUPAC, la reología es el estudio del flujo y deformación de la materia bajo la influencia de una fuerza mecánica o la definición recogida en el Diccionario Esencial de las Ciencias de la Real Academia de las Ciencias Exactas, Físicas y Naturales que la define como el estudio de la deformación y el flujo de la materia, especialmente el flujo de fluidos no newtonianos [51], y que la elaboración de las suspensiones cerámicas es uno de los primeros pasos del proceso productivo, no es difícil pensar que las propiedades reológicas de éstas tendrán especial importancia en el sector cerámico. Este punto solamente se centrará en la primera parte del proceso productivo, por tanto, se profundizará en los aspectos reológicos que afectan a las suspensiones cerámicas que se prepararan para la fabricación de baldosas cerámicas. En etapas posteriores de preparación de esmaltes y engobes, así como en las etapas de 
decoración, el comportamiento reológico de las suspensiones también es sumamente importante, pero estas etapas no están dentro del ámbito de estudio de este trabajo.

El comportamiento reológico de la suspensión influye de forma directa sobre todas las etapas de preparación, así como en las propiedades del polvo atomizado cerámico obtenido (tamaño y porosidad de los gránulos) después del secado por atomización [11].

La molienda de materias primas será la primera fase del proceso productivo cerámico (ver Figura 1.1 y Figura 1.2 ) cuyo rendimiento estará directamente ligado a la viscosidad y al contenido en sólidos de la suspensión, ya que la descarga de los molinos y el posterior tamizado son dos etapas críticas fuertemente influenciadas por estos parámetros (ver Figura 1.15).
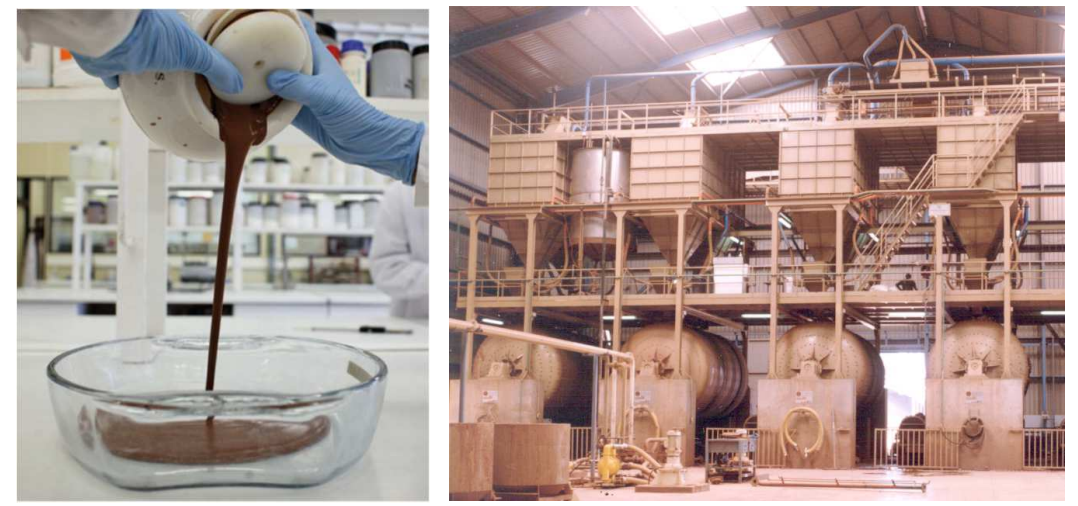
Figura 1.15. Descarga de la suspensión de un molino de laboratorio, sección de molinos de una empresa y suspensión cerámica industrial, respectivamente.

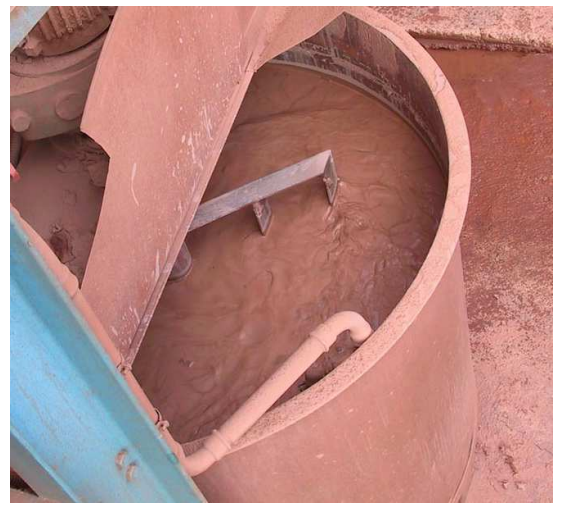

\section{政}

Si el contenido en sólidos es muy alto puede que la viscosidad de la suspensión sea tan elevada que la operación de vaciado de los molinos y el tamizado de la suspensión cerámica no pueda llevarse a cabo de forma correcta. Actualmente, en el sector cerámico las concentraciones de sólidos más comunes varían entre 58\% y 72\% (en peso) [52] y las viscosidades entre 300 y 1500 $\mathrm{cP}$. Por otro lado, la agitación de las balsas donde se almacena la suspensión cerámica antes de su secado y su bombeo hasta el atomizador están también directamente relacionados con su viscosidad.

Además de los problemas físicos que se pueden dar en la planta a causa de las propiedades reológicas de la suspensión, la rentabilidad de un proceso de secado por atomización está relacionada directamente con su contenido en sólidos, ya que aumentará cuanto más incremente este parámetro. Al aumentar el contenido en sólidos, la razón kg agua/kg sólido seco en el alimento se reduce, lo que se traduce en una reducción en el consumo específico del atomizador (kcal/kg de sólido atomizado) con el consiguiente ahorro en el consumo de gas natural y la reducción de las emisiones de $\mathrm{CO}_{2}$, así como un incremento de la producción de polvo atomizado.

Por consiguiente, el porcentaje óptimo agua-sólido es un parámetro relacionado directamente con los aspectos económicos de las etapas de molienda y atomización, por tanto se tiene que favorecer una suspensión con una máxima fluidez y estabilidad, con el mínimo contenido en agua posible. A continuación se profundizará y se explicará brevemente varios mecanismos para actuar sobre las suspensiones cerámicas con el objetivo de obtener el máximo contenido en sólidos y la mínima 
viscosidad posible. Aunque uno de los métodos más extendidos en la industria cerámica para aumentar la concentración de sólidos es la adición de agentes químicos que actúen como desfloculantes, no es el único método tal y como se verá más adelante.

\subsubsection{Comportamiento de la mezcla agua - materias primas cerámicas}

Por tanto, para comprender mejor las características y el comportamiento de las suspensiones cerámicas se tendrá que profundizar en el sistema agua-arcilla. Propiedades de los minerales arcillosos tan importantes como son la plasticidad o el poder suspensionante se pueden apreciar cuando estos materiales son mezclados con el agua, de tal forma que es conveniente considerar el sistema arcilla-agua en su conjunto para poder entenderlas.

Las arcillas naturales que se dispersan en agua tienen tendencia a formar aglomerados si no están debidamente desfloculadas. Estos aglomerados pueden formar suspensiones con un comportamiento excesivamente viscoso que no son aptas en la industria cerámica. Cuando las partículas arcillosas son dispersadas en una suspensión líquida, permanecen suspendidas y no sedimentan, forman lo que se denomina un sistema coloidal. Por tanto, un sistema coloidal está formado por dos fases, una fase dispersa formada por sólidos finamente divididos y una fase liquida continua.

En general, las partículas que componen la fase dispersa de un sistema coloidal son menores de 1 $\mu \mathrm{m}$, siendo frecuente que su tamaño esté comprendido entre 0,2 y 0,005 $\mu \mathrm{m}$. Estas partículas están sometidas a diversas clases de fuerzas: cinéticas, de Van der Waals, electrostáticas, estéricas e hidrodinámicas. De tal modo que los sistemas coloidales son extremadamente sensibles a todas las interacciones que pueden deberse a esas fuerzas. Por tanto, el balance de estas fuerzas sobre las partículas arcillosas determinará la tendencia a su aglomeración o dispersión en un líquido [51].

\subsubsection{Efecto de los iones presentes en el medio dispersante}

Para una mejor comprensión de los sistemas coloidales se considera apropiado profundizar en el concepto de micela coloidal [11], ya que la forma de la distribución de las cargas alrededor de una partícula es sumamente importante para entender el comportamiento de estos sistemas.

Existen varios modelos para explicar el comportamiento de las partículas coloidales, uno de ellos es el modelo de Stern [53][54] con alguna modificación (modelo de la doble capa eléctrica).

Las cargas electrostáticas existentes en la superficie de las partículas coloidales provocan la formación de una interfase (partícula-medio dispersante) cargada, donde se desarrolla una doble capa eléctrica como resultado de la presencia de cargas superficiales que son compensadas, cerca de la superficie, por una distribución desigual de iones de carga opuesta (contra-iones) e iones de la misma carga (co-iones) [55].

El potencial eléctrico de una partícula coloidal varía en función de la distancia a su superficie, tal como puede observarse en la Figura 1.16. Se puede apreciar que el potencial eléctrico decrece en función de la acumulación en las proximidades de la interfase de iones de signo opuesto llamados contra-iones. 


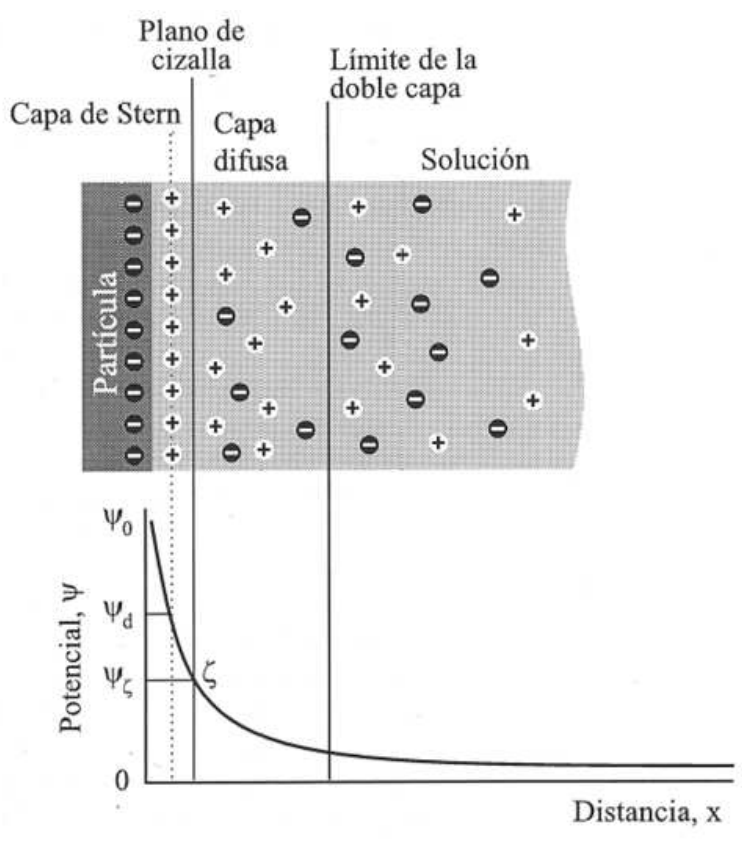

Figura 1.16. Modelo de la doble capa eléctrica [51].

En el modelo de Stern se indica que una fracción de los contra-iones se adsorbe enérgicamente formando una monocapa muy cerca de la superficie, a esta capa se le denomina capa de Stern. Los demás contra-iones se diseminan alrededor de la partícula de forma difusa, su concentración disminuirá de forma exponencial a medida que la distancia a la partícula aumente [56]. El potencial que existe en la superficie de la partícula coloidal se le denomina potencial de Nerst $\left(\Psi_{0}\right)$, denominándose potencial de Stern $\left(\Psi_{\mathrm{d}}\right)$ al que se encuentra en el límite externo de la capa adsorbida.

Si las moléculas del medio dispersante tienen carácter polar también serán adsorbidas, de esta forma, existirá otra capa de moléculas próxima a la superficie de las partículas que también es retenida. En el caso de los líquidos en general, a esta capa se le denomina liosfera, mientras que si el medio dispersante es el agua a esta capa se la denomina hidrosfera. Más allá de esta capa, las moléculas del líquido dispersante están libres de las fuerzas ejercidas por la partícula coloidal, por tanto presentarán movimiento térmico sin orientación influenciada por la superficie de la partícula. Por tanto, a todo el conjunto formado por la hidrosfera más la capa de Stern se le denomina micela coloidal. De modo que cuando la partícula se mueve, la micela coloidal se mueve con ella. El límite entre la liosfera y el líquido libre se comporta como un plano de cizalla y el potencial en dicho plano se denomina potencial zeta $\left(\Psi_{\zeta}\right)$. Este potencial será un poco inferior al potencial de Stern, ya que este plano de cizalla se sitúa en la parte exterior del límite del plano de Stern, pero muy próximo al mismo [57].

El potencial zeta es sumamente importante en la estabilidad de los sistemas coloidales. Cuando dos partículas cargadas eléctricamente se acercan éstas tienden a repelerse, este fenómeno está causado por la superposición de sus campos eléctricos. La repulsión entre dos partículas cargadas será más intensa cuanto mayor sea el valor absoluto del potencial zeta. En los sistemas arcillaagua, un aumento del potencial zeta y, por tanto, de las fuerzas repulsivas, se traducirá en una 
mayor dispersión de las partículas en el agua, es decir, se favorecerá la desfloculación del sistema coloidal y en consecuencia su estabilidad.

El potencial zeta varía según el tipo y la concentración de los contra-iones. Estos dos factores serán responsables que el espesor de la doble capa varíe, sin embargo la distancia que existe entre la superficie de la partícula y el plano de cizalla se mantendrá siempre constante. Así, en bajas concentraciones, los iones monovalentes y alcalinos $\left(\mathrm{Li}^{+}, \mathrm{Na}^{+}, \mathrm{K}^{+} \ldots\right)$ proporcionan un potencial zeta alto debido a que el espesor de la doble capa es grande, por el contrario, los iones divalentes y polivalentes $\left(\mathrm{Ca}^{2+}, \mathrm{Mg}^{2+}, \mathrm{Ba}^{2+}, \mathrm{Al}^{3+} \ldots\right)$, debido a su mayor carga eléctrica y menor tamaño, reducen el espesor de esta doble capa, proporcionado un potencial inferior. Del mismo modo, si se aumenta la concentración de cualquier ion se reducirá el potencial zeta, ya que si la concentración de los contra-iones aumenta el espesor de la doble capa disminuirá.

\subsubsection{Desfloculación de las suspensiones cerámicas: influencia del agua utilizada}

La tendencia a la floculación o desfloculación de una suspensión cerámica dependerá del balance de fuerzas atractivas o repulsivas a las que se encuentren sometidas las partículas. Cuando la doble capa que está rodeando a las partículas coloidales se solapa con la doble capa de otra partícula hay una repulsión, que vendrá determinada por el espesor de dicha doble capa y el potencial zeta de la partícula. Si las fuerzas de repulsión son superiores a las fuerzas de atracción de Van der Waals se obtendrá una suspensión coloidal desfloculada y estable. Sin embargo, si estas fuerzas de repulsión no superan a las de Van der Waals se favorecerá la formación de agregados y por tanto la floculación de la suspensión cerámica [55]. En consecuencia, para aumentar el grado de desfloculación de una suspensión hay que actuar sobre estas fuerzas existentes entre las partículas.

Como las fuerzas atractivas de Van der Waals dependen de la masa y separación de las partículas, así como de la constante dieléctrica del medio de la suspensión, no es fácil actuar sobre ellas, por tanto no es sobre este tipo de fuerzas sobre las que se ha de intervenir para influir en la desfloculación de las suspensiones coloidales cerámicas. Sin embargo, existen diferentes mecanismos para actuar sobre las fuerzas de repulsión electroestática o estérica [11]. Uno de estos mecanismos consistirá en aumentar las fuerzas de repulsión mediante la modificación de la carga superficial de las partículas cerámicas, lo que se podrá llevar a cabo con relativa facilidad si se cambia el pH del medio. Pero este mecanismo no es el que se perseguirá en este trabajo.

Otro mecanismo muy efectivo para aumentar la estabilidad de las suspensiones cerámicas, y posiblemente el más utilizado en el sector cerámico en la actualidad, se basa en la introducción de compuestos desfloculantes. Estos compuestos se adsorben en la superficie de las partículas para proporcionar a la partícula un elevado volumen, de esta forma se produce una fuerte repulsión de tipo estérico. Además, también es común que estos compuestos tengan carácter iónico, de este modo pueden modificar la carga en la superficie de la partícula y, por tanto, también las fuerzas de repulsión electrostáticas.

El objetivo de añadir electrolitos desfloculantes a las suspensiones cerámicas que se tienen que secar por atomización no es otro que el de favorecer una gran concentración de sólidos con la mejor fluidez y estabilidad posible. Los desfloculantes más utilizados son el carbonato sódico, el 
tripolifosfato sódico, el metasilicato sódico y una serie de compuestos comerciales formados por mezclas de silicatos, fosfatos, huminatos, poliacrilatos y otros polímeros. En la Figura 1.17 se puede observar un ejemplo de cómo afecta a la viscosidad de una suspensión cerámica la adición de determinados desfloculantes. En esta gráfica también se puede apreciar que no todos los aditivos funcionan de la misma forma, además la cantidad de estos compuestos que se tiene que añadir para reducir la viscosidad de la suspensión también varía de unos aditivos a otros.

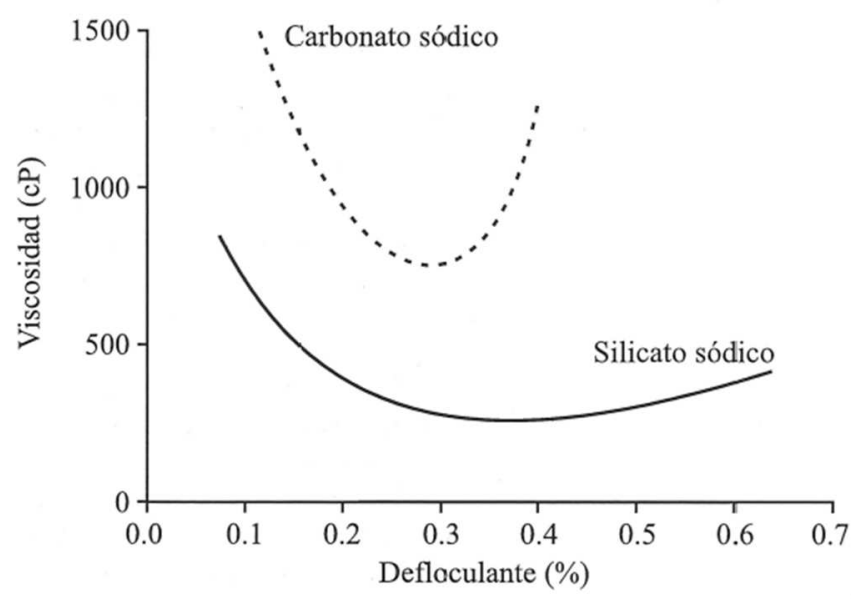

Figura 1.17. Ejemplo del efecto de los desfloculantes en la viscosidad de una suspensión cerámica [11].

Cada empresa del sector cerámico que prepara sus materias primas utiliza un desfloculante o mezcla de desfloculantes determinado, según características de sus materias primas y sus aguas de proceso, por tanto es difícil determinar que desfloculantes son los más utilizados, lo que sí que es fácil reseñar es que el precio de prácticamente todos ellos ha ido aumentando con los años.

Por último, se abordará el efecto de los iones presentes en la suspensión sobre el potencial zeta y en consecuencia sobre la capacidad de desflocular-flocular una determinada suspensión. Existe una serie dispuesta por Hofmeister donde se ordenan iones en función de su capacidad de desfloculación [51]. Estas series, ordenadas en grado creciente de capacidad de desfloculación son:

$$
\begin{gathered}
\mathrm{Al}^{3+}<\mathrm{Ba}^{2+}<\mathrm{Ca}^{2+}<\mathrm{Mg}^{2+}<\mathrm{NH}_{4}^{+}<\mathrm{K}^{+}<\mathrm{Na}^{+}<\mathrm{Li}^{+} \text {(Cationes) } \\
\text { Citrato }<\mathrm{SO}_{4}{ }^{2-}<\mathrm{Cl}^{-}<\mathrm{NO}_{3}{ }^{-} \text {(Aniones) }
\end{gathered}
$$

Debido a su carga, los cationes floculantes son adsorbidos por las partículas con mayor fuerza que los iones desfloculantes, este hecho hace que su posterior desplazamiento sea muy complicado. Como puede observarse en las series de Hofmeister existen iones más floculantes que otros, como regla general los iones multivalentes son los que tienen un comportamiento más floculante $\left(\mathrm{Al}^{3+}\right.$, $\mathrm{Ba}^{2+}, \mathrm{Ca}^{2+}, \mathrm{Mg}^{2+}$, Citrato, $\left.\mathrm{SO}_{4}{ }^{2-} \ldots\right)$. Por tanto, la presencia de estos iones en las suspensiones cerámicas influirá negativamente en sus condiciones reológicas. Concretamente, cuanta más presencia de iones divalentes $\left(\mathrm{Ca}^{2+}, \mathrm{Mg}^{2+}\right.$ y $\left.\mathrm{SO}_{4}{ }^{2-}\right)$ en el agua, mayor viscosidad se obtendrá para una determinada suspensión cerámica y un mayor contenido en desfloculante será necesario para alcanzar el mínimo en la viscosidad (ver Figura 1.18). El objetivo en todo proceso cerámico es 
conseguir que el contenido de desfloculante sea el más bajo posible (desf $f_{\min }$ ) para una determinada viscosidad mínima $\left(\mu_{\min }\right)$ de trabajo correspondiente al mínimo de la curva de desfloculación tal como se describe en la Figura 1.18, y además el contenido en sólidos de la suspensión sea lo más elevado posible. Normalmente, a nivel industrial se ha de trabajar en la zona del mínimo de la curva de desfloculación, ya que se corresponde con las condiciones reológicas de máxima estabilidad (mínima variación de viscosidad con el tiempo).

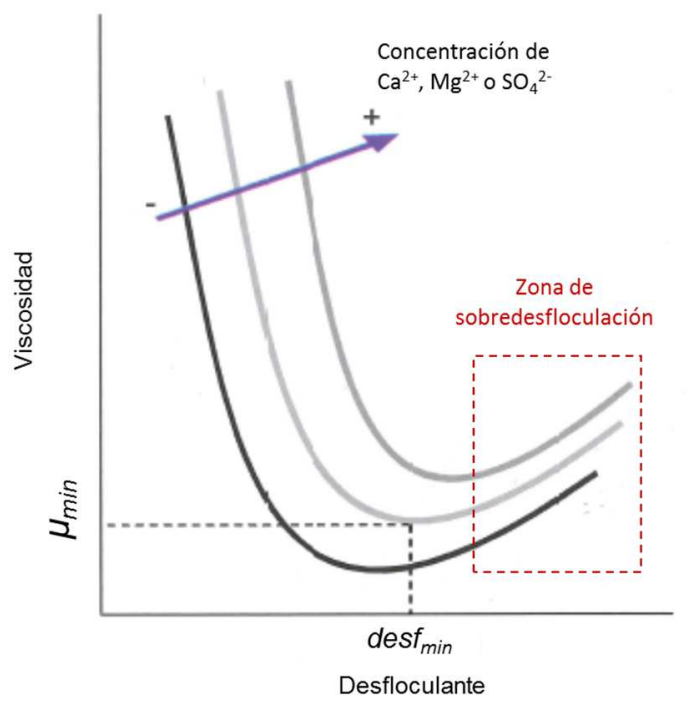

Figura 1.18. Efecto de los iones floculantes sobre la curva de desfloculación.

Por otro lado, la presencia de electrolitos divalentes afectará directamente al contenido en sólidos que es posible alcanzar en la suspensión cerámica, tal como se deduce al comparar la Figura 1.19 donde se observa el efecto del contenido en sólidos sobre la curva de desfloculación de una determinada suspensión cerámica y la Figura 1.18 que se ha comentado anteriormente. Es decir, la presencia de iones floculantes disminuye la concentración de sólidos que es posible alcanzar en una determinada suspensión cerámica.

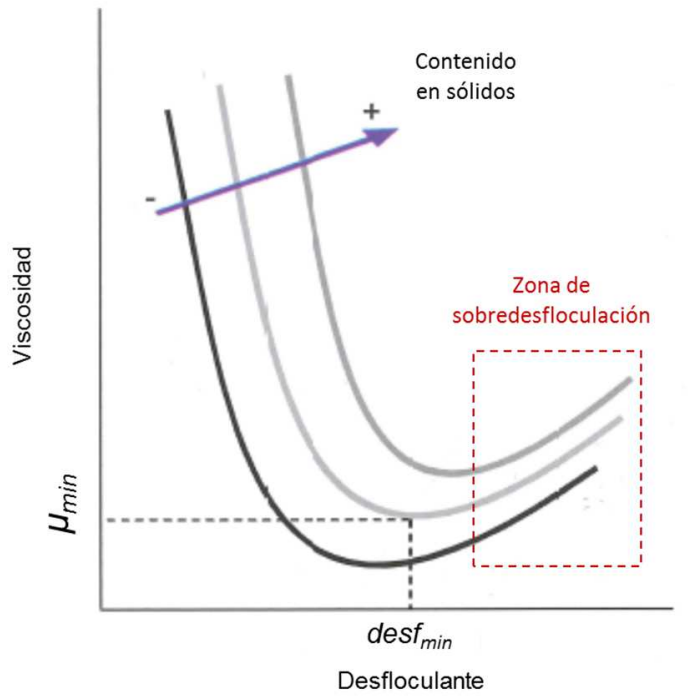

Figura 1.19. Efecto del contenido en sólidos de una suspensión cerámica sobre la curva de desfloculación. 
Para lograr desplazar los iones floculantes se puede añadir sustancias desfloculantes o se puede eliminar de la solución los iones floculantes. Sin embargo, hay que tener en cuenta que la adición de un electrolito en exceso, incluso siendo un electrolito con carácter desfloculante, puede reducir el potencial zeta, produciendo un fenómeno de sobredesfloculación y obtener justamente los efectos contrarios a los perseguidos, tal como se puede observar en las zonas marcadas en rojo en la Figura 1.18 y en la Figura 1.19. Por este motivo, el mejor método consiste en la eliminación de los cationes floculantes de la suspensión. Existen varios métodos para la eliminación de estos iones floculantes como pueden ser métodos de precipitación o métodos en los que estos iones son introducidos en un complejo [11]. Sin embargo, en este trabajo se ha pensado en la utilización de una tecnología de nanofiltración a través de membranas como es la nanofiltración para conseguir este objetivo. Además, la eliminación de iones floculantes también potenciará la acción dispersante de los compuestos añadidos como desfloculantes.

\subsubsection{Situación actual respecto de los tipos de agua utilizada}

Por tanto, una vez conocido con más detalle el comportamiento reológico de las suspensiones cerámicas y los factores que más les afectan, se realizará una breve descripción de la situación actual de las empresas que trabajan con estas suspensiones cerámicas para la elaboración del polvo atomizado necesario para la fabricación de las baldosas cerámicas y se analizará donde se puede actuar con la aplicación de la tecnología escogida en este trabajo.

En la actualidad existen dos tipos de empresas que preparan polvo atomizado para la fabricación de baldosas cerámicas: las que procesan polvo atomizado de coloración roja (por los óxidos de hierro de las materias primas), denominadas también de pasta roja, y las de coloración blanca (materias primas con menor contenido de óxidos cromóforos), denominadas de pasta blanca. Generalmente, las aguas residuales industriales procedentes de las empresas del sector cerámico son utilizadas por las empresas de atomización de pasta roja en su proceso productivo como líquido de molienda y como materia prima para la elaboración de sus suspensiones sin haberlas antes sometido a ningún tratamiento de depuración, ya que la pasta roja permite el uso de aguas que contengan iones cromóforos. Sin embargo, esta práctica no es posible en las empresas que fabrican polvo atomizado de coloración blanca, donde la coloración final es un parámetro de calidad a tener en cuenta. Por este motivo, las empresas de este último tipo que son capaces de absorber aguas residuales tienen que, al menos, someterlas a un tratamiento físico-químico de coagulaciónfloculación. Los lodos secos obtenidos en esta operación se almacenan para ir introduciéndolos en las composiciones de los productos atomizados que lo permitan.

Los tratamientos de depuración físico-químicos de coagulación-floculación de las aguas residuales industriales son bastante efectivos para la eliminación de los sólidos presentes en las aguas gestionadas tal y como se ha visto con anterioridad, sin embargo, estos métodos de depuración no son efectivos para la eliminación de iones disueltos y por tanto, las aguas clarificadas tienen una alta concentración en electrolitos y una elevada conductividad (ver Tabla 1.1. del apartado 1.1.3.3 Tratamientos habituales y depuración de las aguas residuales de la industria cerámica). Esta agua será la que se utilizará para la molturación de las materias primas y la elaboración de las suspensiones. Como se ha comentado en repetidas ocasiones en esta introducción, uno de los 
parámetros característicos de las suspensiones cerámicas es el contenido en sólidos, que tiene que ser lo más elevado posible para maximizar el rendimiento del proceso de atomización. Este parámetro viene limitado por la viscosidad. En efecto, la viscosidad tiene influencia en la molienda, descarga de molinos, bombeo de la suspensión cerámica al atomizador, resistencia a la agitación en las balsas... De ahí que el comportamiento reológico de la suspensión cerámica sea tan importante en las empresas de atomización.

Los iones presentes en el agua utilizada en la elaboración de las suspensiones cerámicas influirán de forma notable en los parámetros descritos en el párrafo anterior, especialmente, los iones divalentes, que intervienen negativamente en la desfloculación de la mezcla, ya que tienen el efecto contrario, es decir, actúan como floculantes enérgicos. Por tanto, a mayor contenido en este tipo de iones, mayor cantidad de desfloculante hay que introducir en la mezcla para alcanzar las condiciones reológicas adecuadas, como se ha explicado a lo largo del apartado 1.3. Comportamiento reológico de las suspensiones cerámicas. Es decir, a mayor contenido de iones divalentes, mayor cantidad de desfloculante, mayor viscosidad y menor contenido en sólidos de la suspensión cerámica, por tanto menor rendimiento del atomizador, mayor consumo energético (gas natural) y mayores emisiones de $\mathrm{CO}_{2}$.

Por tanto, en este punto es donde se centra el interés y el objetivo del presente trabajo, ya que se pretende eliminar del agua industrial utilizada en la elaboración de las suspensiones cerámicas el máximo contenido posible en iones divalentes, con el objetivo final de optimizar el comportamiento reológico de las suspensiones cerámicas que se han de preparar para su posterior atomización. Es por ello que se propone estudiar técnicas, nunca antes utilizadas en el sector, capaces de actuar sobre estos elementos, concretamente la técnica de nanofiltración a través de membranas poliméricas.

\subsection{Procesos de filtración a través de membranas. Nanofiltración}

Las membranas semipermeables son hoy en día utilizadas en numerosas aplicaciones industriales para controlar selectivamente los intercambios de materia entre medios diferentes. Estos procesos se utilizan para valorizar o para depurar los componentes de una mezcla, por tanto, cada vez son más importantes en el ámbito del tratamiento de las aguas. Varias razones justifican esta tendencia:

- Las normas de calidad del agua potable, así como las que hacen referencia a los límites de vertido de aguas residuales, son cada vez más severas. Por tanto, los métodos clásicos no son suficientemente eficaces para responder a estas normas y hay que buscar otro tipo de tratamientos.

- $\quad$ En los métodos clásicos se utiliza, en general, una mayor cantidad de reactivos químicos, si lo comparamos con los tratamientos a través de membranas.

- Los progresos tecnológicos hacen que los métodos de filtración a través de membranas sean cada vez más competitivos.

- El principio de estos tratamientos consiste en extraer físicamente los contaminantes, no en eliminarlos químicamente. 
En este apartado se presentarán conceptos teóricos importantes para una mejor comprensión de los tratamientos de filtración a través de membranas, y se profundizará concretamente en la nanofiltración. Por tanto, en un primer lugar se hablará de los principios de operación de los métodos de filtración a través de membranas. Tras la introducción en el campo de las membranas, se abordarán las características de la nanofiltración y se hablará de sus principales aplicaciones.

\subsubsection{Filtración de líquidos mediante membranas}

La purificación del agua mediante tratamientos a través de membranas comenzó a ser importante en los años 60, principalmente a causa del buen comportamiento que ofrecían las membranas sintéticas. Los procesos de separación por medio de membranas tienen las siguientes ventajas: son económicamente eficientes, se trata de procesos poco agresivos con el medio ambiente y se pueden considerar como tecnologías limpias, ya que no necesitan productos químicos adicionales, su funcionamiento es relativamente sencillo, no son demasiado sensibles a variaciones en la composición del alimento y permiten conseguir agua tratada de elevada calidad. Sin embargo, no ha sido hasta estos últimos años cuando los tratamientos con membranas se han empezado a aplicar en la depuración de aguas residuales. El desarrollo de la tecnología de las membranas para esta nueva aplicación ha sido posible gracias a numerosos avances en el campo de la elaboración de los materiales utilizados en su fabricación.

Una membrana se puede definir como una barrera selectiva que separa dos fases, tal como se ilustra en la Figura 1.20.

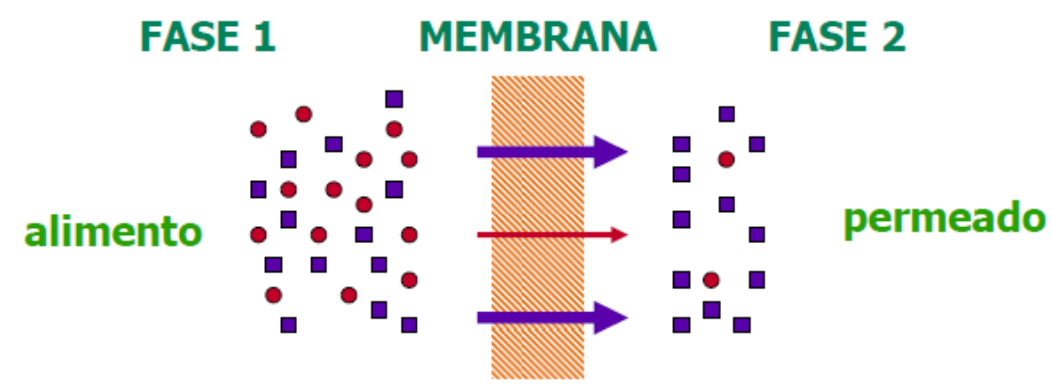

fuerza impulsora

$\Delta c_{,} \Delta \mathbf{P}, \Delta \mathrm{T}, \Delta \mathrm{E}$

Figura 1.20. Esquema básico de la filtración a través de una membrana.

El transporte de las especies de una fase a otra está restringido de manera selectiva, debido a las diferentes propiedades físicas y/o químicas que existen entre la membrana y las especies implicadas [43]. Los sólidos y los compuestos dispersos o disueltos en la fase de alimentación serán retenidos total o parcialmente en el rechazo, mientras que el permeado será la fase libre de los compuestos retenidos (ver Figura 1.21). 


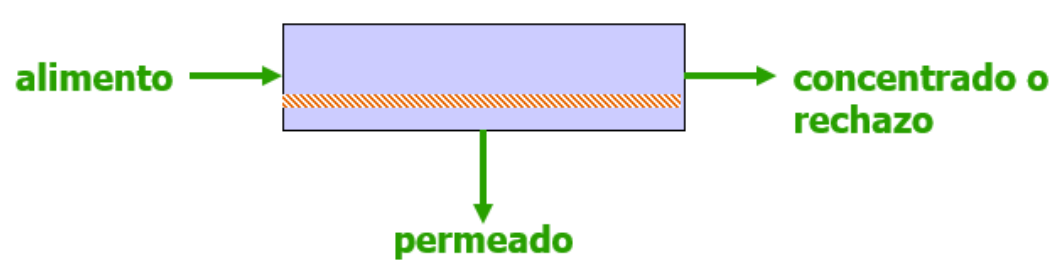

Figura 1.21. Denominación de las corrientes que intervienen en una filtración.

La forma, el tamaño y la carga de las diferentes especies son las características principales que determinarán si son retenidas o no por la membrana. El transporte a través de las membranas puede estar originado por distintas fuerzas impulsoras tales como la presión $(\Delta \mathrm{P})$, un campo eléctrico $(\Delta \mathrm{E})$ o un gradiente de concentración $(\Delta c)$ (ver Figura 1.20), siendo los procesos cuya fuerza impulsora es la presión los más desarrollados en el caso del tratamiento de agua a través de membranas.

\subsubsection{Conceptos básicos relacionados con la filtración a través de membranas}

Existen numerosas definiciones en los procesos de filtración a través de membranas que es útil aclarar porque se han utilizado con mucha frecuencia en el presente trabajo. Por tanto, a continuación se dará una definición de alguno de ellos:

El flujo volumétrico de permeado $\left(J_{v}\right)$ se define como la relación entre la producción de permeado y la superficie activa de la membrana correspondiente, sus unidades son habitualmente $L /\left(h \cdot \mathrm{m}^{2}\right)$. Para una producción de permeado determinada, la superficie de membrana dependerá del flujo elegido. El flujo óptimo corresponde a un compromiso entre el control del ensuciamiento u obturación de la membrana ("fouling"), el consumo energético y el coste de inversión. Con el aumento del flujo de permeado, el ensuciamiento u obturación, la frecuencia de limpieza y la presión de trabajo también aumentan, en cambio los costes de inversión bajan.

La presión transmembrana o diferencia de presión $(\Delta P)$ es la diferencia de presión que existe entre las dos caras de la membrana, es decir entre la presión de la corriente alimentación $\left(P_{a}\right)$ y la presión de la corriente del permeado $\left(P_{p}\right)$. Su unidad es el bar. Esta diferencia de presión es la fuerza impulsora responsable de la filtración a través de la membrana.

La diferencia de presión osmótica $(\Delta \pi)$ puede definirse como la diferencia entre la presión osmótica de la alimentación y la presión osmótica del permeado. Su unidad de medida también es el bar.

La permeabilidad hidráulica $\left(L_{P}\right)$ es el flujo de permeado dividido por la presión neta de impulsión ("Net Driving Pressure"- NDP), que es la diferencia entre la presión transmembrana y la presión osmótica, sus unidades son $\mathrm{L} /\left(\mathrm{h} \cdot \mathrm{m}^{2}\right.$ ·bar). Expresa el comportamiento de la membrana con respecto a la permeabilidad al agua. Sólo depende de la membrana, la temperatura y el estado de obturación de la membrana. La permeabilidad de la membrana al agua pura normalizada con relación a una temperatura fija $\left(L_{P}^{0}\right)$, permite comparar distintas membranas. El seguimiento de este parámetro sirve para determinar y verificar el estado de las membranas. 
El Peso Molecular de Corte (PMC) (término que en inglés se denomina "Molecular Weight CutOff"-MWCO), es el peso molecular de las moléculas que son retenidas por una membrana al $90 \%$ [58]. Generalmente este parámetro se expresa en Dalton (Da).

Factor de Concentración Volumétrica (FCV), variable que se define como la relación entre el caudal de alimentación y el caudal de concentrado o rechazo.

El grado de retención o retención $\left(\boldsymbol{R}_{\boldsymbol{i}}\right)$ es un parámetro que puede ser utilizado para cuantificar la selectividad de la membrana a una determinada especie. Por tanto, este parámetro cuantifica la retención que una membrana ofrece a una especie $\boldsymbol{i}$ presente en la disolución que se alimenta al sistema de filtración. En la bibliografía se puede encontrar expresado en tanto por cien o tanto por uno [43][59]. Por consiguiente, un $\boldsymbol{R}_{\boldsymbol{i}}$ de un $100 \%$ o de 1 significaría que la membrana retiene a la especie $\boldsymbol{i}$ en su totalidad. Mientras que si $\boldsymbol{R}_{\boldsymbol{i}}$ es de $0 \%$ o 0 en tanto por uno, la membrana no es capaz de retener ninguna molécula o partícula de la especie $\boldsymbol{i}$ determinada.

El grado de conversión o conversión $(S)$ (en inglés: "yield") se define como la relación entre el caudal de permeado y el caudal de alimentación [43]. Este parámetro suele expresarse en tanto por cien. Por tanto, si se obtiene un grado de conversión de un $80 \%$, significará que de cada $100 \mathrm{~L}$ alimentados a un sistema de filtración, $80 \mathrm{~L}$ pasarán a través de la membrana en forma de permeado.

\subsubsection{Clasificación de tratamientos mediante membranas}

A continuación, se describe los diferentes tipos de procesos de filtración a través de membranas más comúnmente utilizados en el tratamiento de líquidos, cuya fuerza impulsora para el transporte de materia a través de la membrana es la presión. Según lo comentado anteriormente, la membrana actuará como un tamiz. En consecuencia, el trasporte selectivo a través de este medio filtrante está principalmente regido por la diferencia entre el tamaño de la especie disuelta y el de los poros de la membrana. La siguiente clasificación de los procesos que utilizan membranas se realizará teniendo en cuenta el tamaño (radio) de poro de la membrana $\left(r_{p}\right)$ : microfiltración, ultrafiltración, nanofiltración y ósmosis inversa (ver Figura 1.22) [60]. 


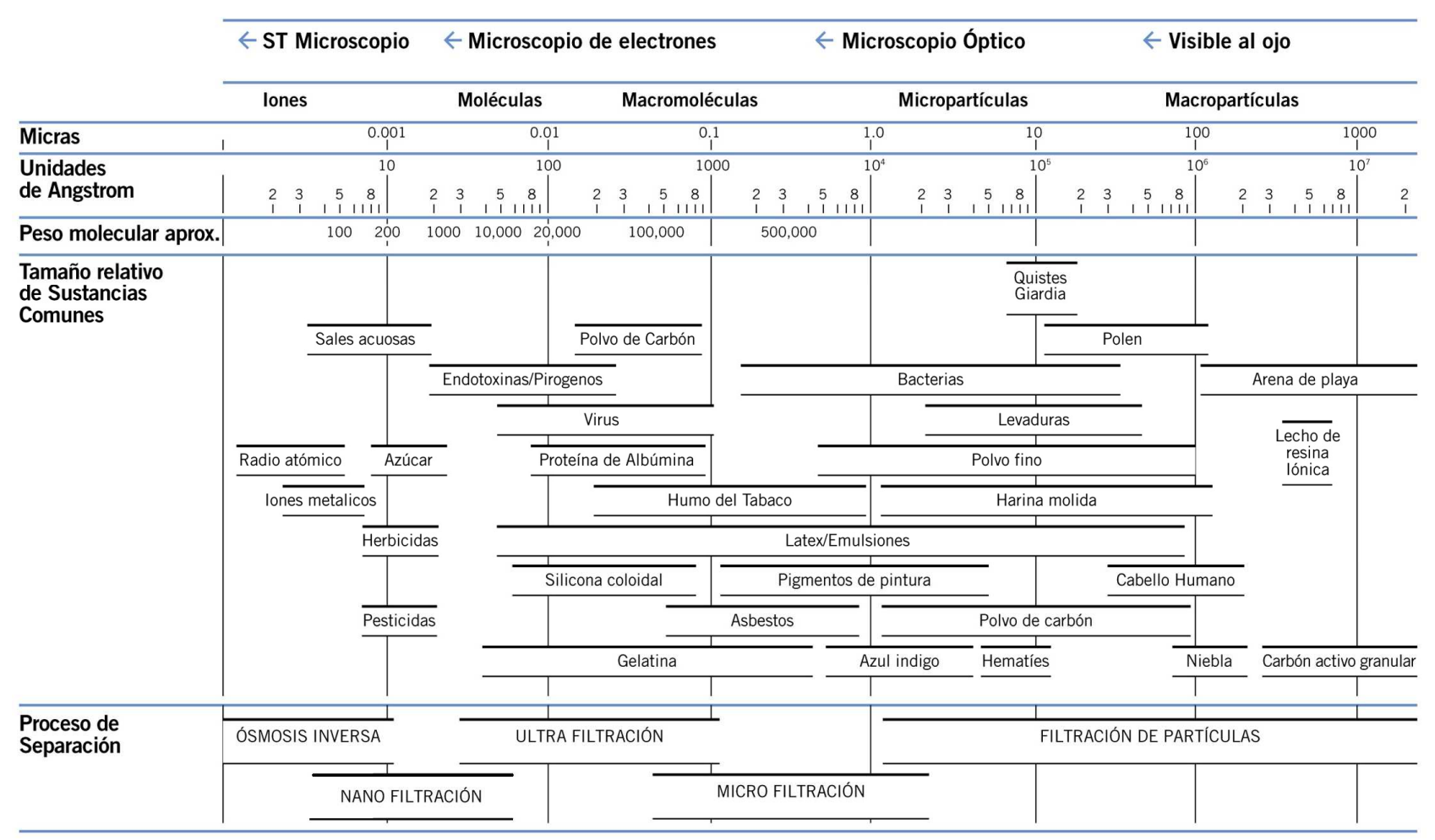

Figura 1.22. Clasificación de tratamientos mediante membranas en función del radio de poro [61].

Las membranas de Microfiltración (MF) se caracterizan por tener un $r_{p}$ que oscila entre 0,05 y $3 \mu \mathrm{m}$ y una gran permeabilidad. En los procesos de MF la presión aplicada es baja (entre 0,1 y 2,5 bar) y las diferentes especies son retenidas por su tamaño. Por tanto, solamente las especies de tamaño mayor que el tamaño del poro de la membrana serán retenidas. Las membranas de MF retienen, principalmente, sólidos en suspensión, partículas grandes, coloides, y algunos microorganismos como las bacterias. Los procesos que utilizan membranas de MF son, con diferencia, los más extensamente utilizados y sus principales aplicaciones son la clasificación, desinfección y también se utilizan como pretratamientos para eliminar las partículas grandes de una corriente antes de que lleguen a las etapas que utilizan membranas de diámetros de poro más pequeños.

Las membranas de Ultrafiltración (UF) tienen un $r_{p}$ inferior (entre 2 y $100 \mathrm{~nm}$ ) y una permeabilidad más baja que las membranas de MF. Por consiguiente, los procesos de UF requerirán unas presiones de trabajo más elevadas (entre 0,5 y 5 bar) que en el caso de los procesos de MF. En este caso, también es la diferencia de tamaño el principal mecanismo implicado en la retención de las diferentes especies presentes en la corriente alimento. Estas membranas pueden retener pequeñas bacterias, virus y macromoléculas solubles como las proteínas.

El proceso de Nanofiltración (NF) es una técnica, intermedia entre la UF y la ósmosis inversa (OI), con un desarrollo más reciente. Las membranas de NF tienen un radio de poro menor de $5 \mathrm{~nm}$. En este caso, además del impedimento estérico, hay diferentes interacciones debidas al reducido tamaño del poro de las membranas. De este modo, el mecanismo de transporte se explica principalmente por efectos de tamaño y por efectos eléctricos (exclusión de Donnan), entre otros [62]. Existe un equilibrio entre la superficie cargada de la membrana y la disolución. Por esta razón, muchas especies iónicas son rechazadas por la membrana, incluso especies de tamaño más 
pequeño que el $r_{p}$ de la membrana. El intervalo de presiones en el que trabaja esta técnica suele estar comprendido entre 3-20 bar.

Finalmente, las membranas de ósmosis inversa $(\mathrm{Ol})$ consisten en una barrera densa sin poros definidos. El mecanismo de transporte es, por lo tanto, totalmente diferente y se cree que tiene lugar según un mecanismo de disolución-difusión [63]. En este caso, la permeabilidad es mucho más baja que para las membranas anteriormente citadas. Por otra parte, las especies cargadas que están presentes en la corriente alimento son casi totalmente retenidas. Sin embargo, hay que destacar que, generalmente, la Ol requiere elevadas presiones de trabajo (hasta 120 bar). El consumo de energía de esta técnica puede ser bastante importante y dependerá, principalmente, de la presión osmótica de la corriente alimento.

A continuación, se resumen en una tabla los intervalos de presión de trabajo y las permeabilidades más habituales de los procesos de filtración a través de membranas que se acaban de explicar [43]:

Tabla 1.5. Presiones de trabajo y permeabilidades más habituales de los procesos de filtración a través de membranas.

\begin{tabular}{|c|c|c|c|c|}
\hline & MF & UF & NF & OI \\
\hline $\begin{array}{c}\text { Presión mínima/máxima de trabajo } \\
\text { (bar) }\end{array}$ & $0,1-2,5$ & $0,5-5$ & $3-20$ & $5-120$ \\
\hline $\begin{array}{c}\text { Permeabilidad de la membrana } \\
\left(\mathrm{L} / \mathrm{m}^{2} \mathrm{~h} \text { bar }\right)\end{array}$ & $>50$ & $10-50$ & $1-25$ & $0,05-1,5$ \\
\hline
\end{tabular}

\subsubsection{Tipos de membranas y geometría de sus módulos}

Existen muchos tipos de membranas diferentes y para clasificarlas se pueden tener en cuenta ciertas características comunes, por tanto algunas de estas clasificaciones pueden ser por naturaleza química, o por su porosidad, estructura de fabricación... A continuación se profundizará en alguna de estas clasificaciones.

\section{Según su naturaleza química}

Las membranas se pueden elaborar a partir de diversos materiales. Por un lado, los polímeros orgánicos han sido los materiales más desarrollados para la fabricación de membranas denominadas poliméricas u orgánicas. Algunos de los polímeros más utilizados para la elaboración de membranas son acetato de celulosa (CA), nitrato de celulosa (CN), cloruro de polivinilo (PVC), fluoruro de polivinilideno (PVDF), politetrafluoroetileno (PTFE), polisulfonas/poliéter sulfonas (PSf/PES), polipropileno (PP), polietileno (PE), poliimidas (PI), poliacrilonitrilo (PAN), poliamidas aromáticas... [64][43].

En la Figura 1.23 se puede observar una fotografía donde hay varias membranas de poliamida junto a una imagen MEB de otra membrana polimérica de PVDF, donde puede observarse la microestructura de la misma. 

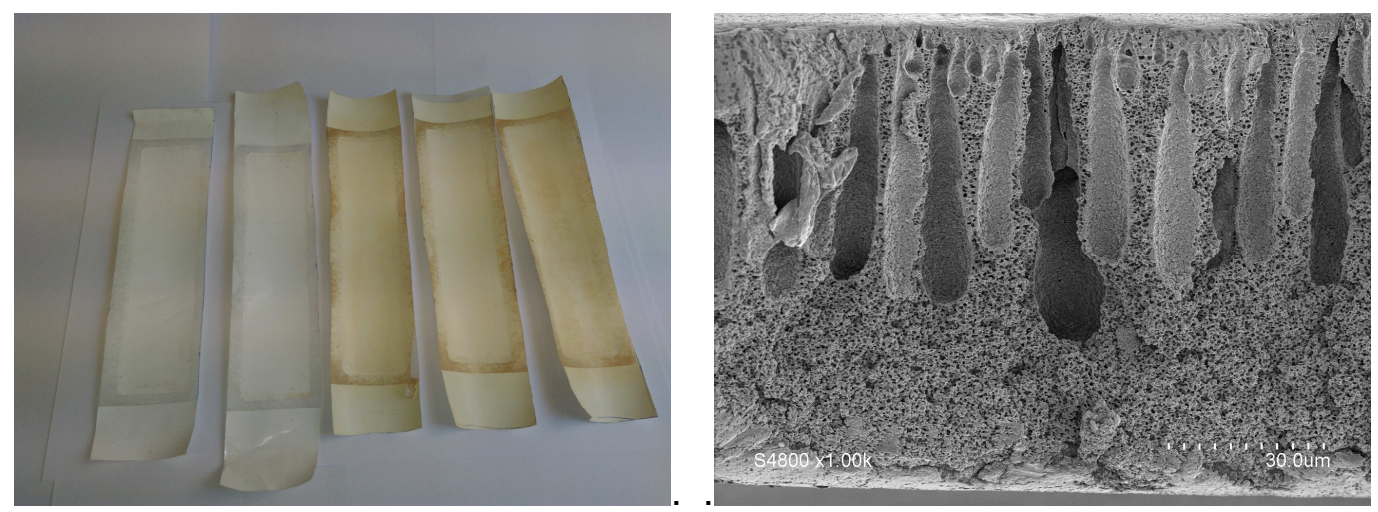

Figura 1.23. Membranas poliméricas de poliamida e imagen MEB de una membrana de PVDF.

Por otro lado están las membranas cerámicas, membranas que pueden ser utilizadas en procesos donde se requiera una elevada estabilidad térmica, química y mecánica. Estas membranas se pueden preparar por técnicas de sol-gel y sinterización. Compuestos como alúmina $\left(\mathrm{Al}_{2} \mathrm{O}_{3}\right)$, sílice $\left(\mathrm{SiO}_{2}\right)$, circona $\left(\mathrm{ZrO}_{2}\right)$, carburo de silicio $(\mathrm{SiC})$ y titania $\left(\mathrm{TiO}_{2}\right)$ son las materias primas más comúnmente utilizadas en la fabricación de las membranas cerámicas [65][63]. Aunque la principal desventaja de las membranas cerámicas es su alto coste de producción, se utilizan a menudo en procesos de MF en el sector de la alimentación, donde se requieren ciclos de esterilización. Además, es muy común encontrar membranas cerámicas tubulares multicanal para aumentar la superficie de filtración (ver Figura 1.24).
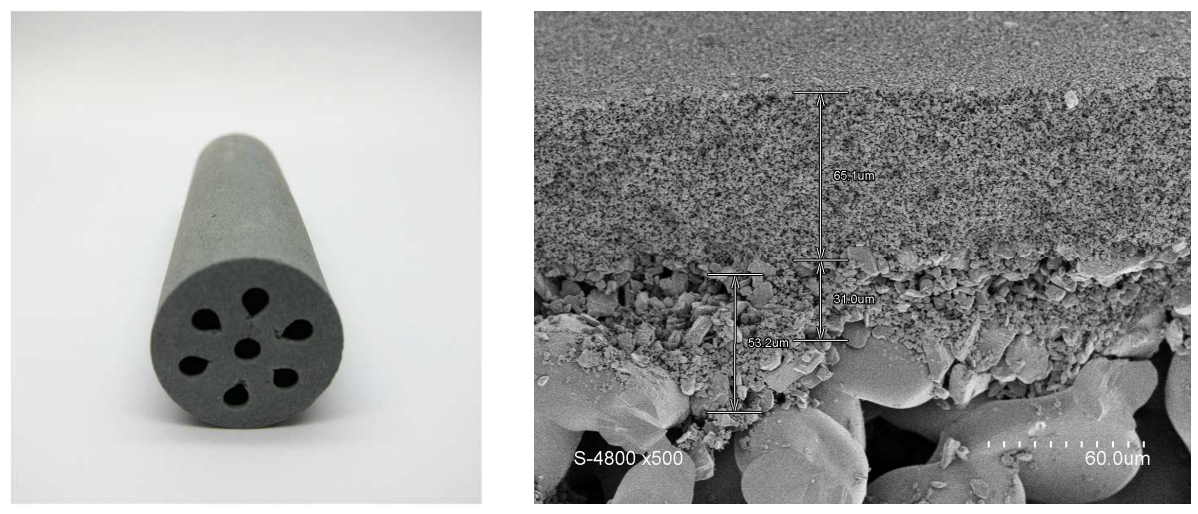

Figura 1.24. Membrana cerámica de SiC desarrollada en el ITC e imagen MEB de una membrana del mismo tipo.

Dentro de las membranas inorgánicas, también se pueden encontrar membranas metálicas y de vidrio. Las primeras son fabricadas generalmente por sinterizado de polvos metálicos de wolframio, molibdeno, níquel, hierro, aluminio, platino, cobre, plata, oro... Su principal aplicación es la purificación o la separación de gases [66]. Mientras que las segundas se obtienen a partir de óxidos de silicio $\left(\mathrm{SiO}_{2}\right)$ más aditivos tales como compuestos de fósforo, boro y sodio que conferirán a las membranas propiedades distintas en cada caso [67].

\section{Según su porosidad}

Si se tiene en cuanta la porosidad de las membranas existen las membranas densas, que consisten en un film sin poros a través del cual el permeado fluye por difusión bajo el efecto de una fuerza impulsora. La separación de los compuestos de una mezcla dada está directamente ligada 
a su coeficiente de difusión y solubilidad a través de la membrana. Por este motivo, una membrana densa puede separar compuestos de tamaño similar si su solubilidad y difusión a través de esa membrana son diferentes (ver Figura 1.25).
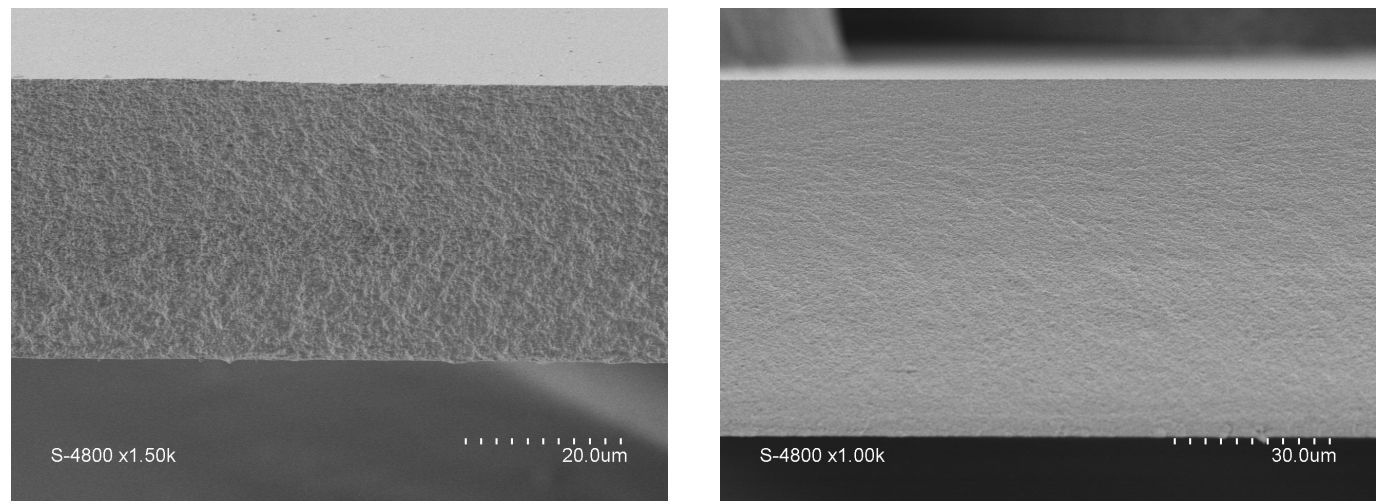

Figura 1.25. Imágenes MEB de varias membranas densas.

Y por otro lado, se pueden encontrar las membranas porosas. Estas membranas son similares por su estructura a los filtros convencionales con diámetros de poros superiores a un micrómetro, sin embargo, para considerarse membranas porosas el tamaño de sus poros tiene que ser considerablemente menor (ver Figura 1.26). La selectividad de estas membranas vendrá determinada especialmente por el tamaño de poro y su dispersión. Además, la naturaleza del material de fabricación también afectará a otras propiedades de la membrana y por tanto, también a su comportamiento frente a una disolución determinada [68].

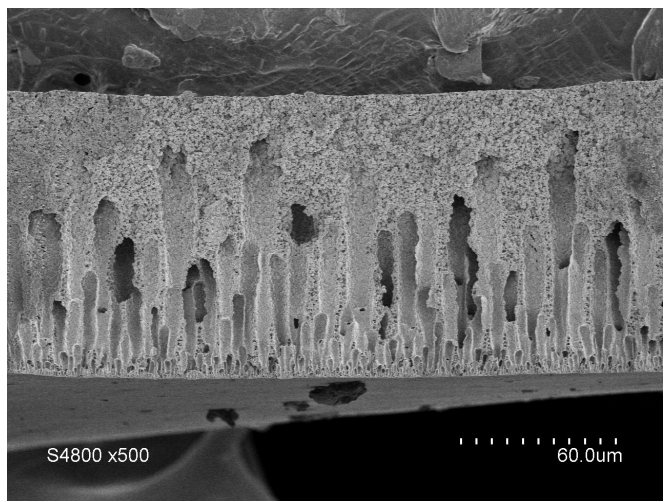

Figura 1.26. Fotografía realizada con el MEB de una membrana polimérica porosa.

\section{Según su estructura de fabricación}

Si se tiene en cuenta la estructura de las membranas se pueden encontrar membranas simétricas y asimétricas, además dentro de estas últimas se pueden hacer varias distinciones.

Así, las membranas simétricas son las que a lo largo de todo el ancho de la membrana están compuestas por el mismo material y presentan las mismas propiedades. De tal forma que sus propiedades morfológicas (diámetro de poro, porosidad, tortuosidad...) y sus propiedades funcionales (permeabilidad, retención...) no dependen de la cara de la membrana utilizada.

Sin embargo, generalmente las membranas tienen que ser muy finas para obtener permeabilidades altas. Por tanto, para hacerlas compatibles con su uso industrial esa membrana fina y por 
consiguiente de baja resistencia, tiene que estar acoplada sobre un soporte poroso mecánicamente más resistente. Es aquí donde se pueden encontrar las membranas asimétricas que tendrán propiedades morfológicas y/o funcionales distintas a lo largo del espesor de la misma. Los beneficios ofrecidos por este tipo de membranas en términos de resistencia mecánica y en permeabilidad son tales que la mayoría de procesos de separación comerciales que utilizan membranas emplean este tipo de membranas.

Las membranas asimétricas pueden ser homogéneas o compuestas [64]. Generalmente, si son homogéneas estarán formadas por el mismo material, aunque las capas exteriores tendrán propiedades distintas a las interiores. Por otro lado, si son compuestas los materiales que formarán las diferentes capas de la membrana serán también distintos (ver Figura 1.27). Pero todas ellas se caracterizan por tener la primera capa en la superficie de la membrana generalmente muy fina, su espesor es mucho menor comparado con la capa o las capas inferiores. Esta capa es la que proporciona las características de funcionalidad de la membrana, por tanto será la responsable de su permeabilidad, selectividad y porcentaje de retención a un determinado elemento [69]. La capa o las capas sobre las que se sitúa esta primera capa selectiva son las que realizan la función de soporte con propiedades mecánicas y porosidades muy superiores a la capa fina. Por lo general, esta capa de soporte no tiene ninguna influencia sobre la funcionalidad de la membrana.
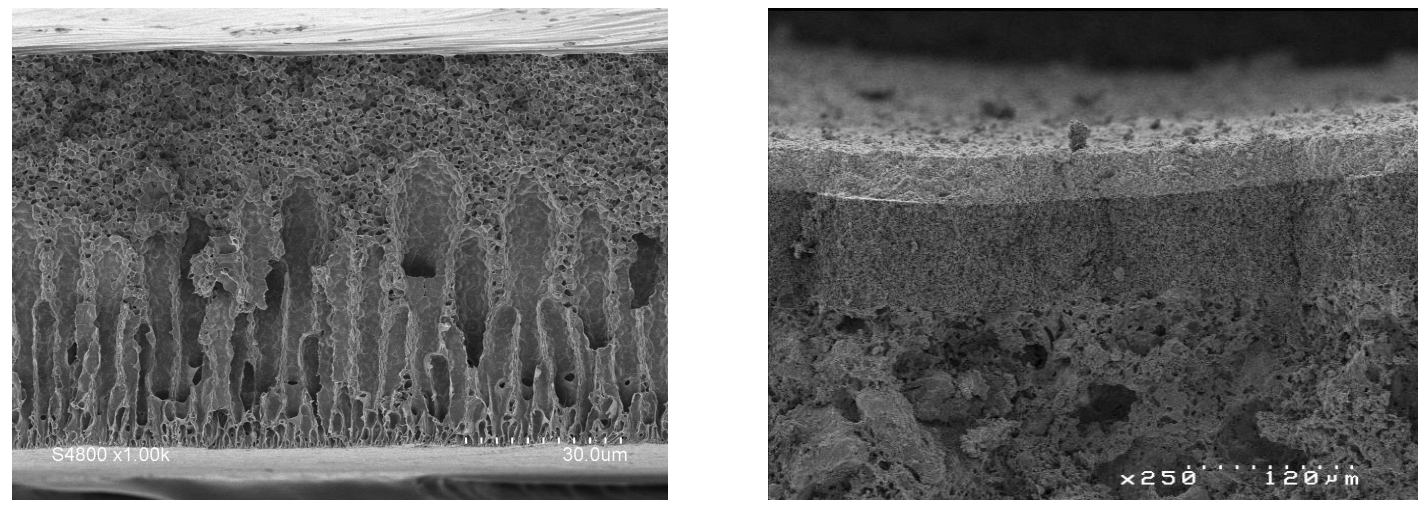

Figura 1.27. Fotografía realizada con el MEB de una membrana polimérica asimétrica homogénea y una membrana cerámica asimétrica compuesta, respectivamente.

En este punto también hay que hablar de las membranas que presentan carga eléctrica. La principal característica de este tipo de membranas es que, tanto la superficie, como las paredes de los poros, están cargados positiva o negativamente. Las membranas que están cargadas positivamente favorecen el paso de los aniones, mientras que las cargadas negativamente favorecen el paso de los cationes. Por tanto, la separación con este tipo de membranas, además de por la dimensión de sus poros, también tiene lugar por la repulsión de los iones de la misma carga. Por este motivo, por ejemplo, los iones monovalentes son menos retenidos que los divalentes o la selectividad disminuye cuando en las disoluciones existe una fuerza iónica elevada. Se puede encontrar este tipo de membranas en electrodiálisis, pero también en nanofiltración.

\section{Según su configuración}

Una vez conocidos cuales son los principales tipos de membrana existentes en la actualidad, también se ha de abordar las configuraciones en las que se pueden encontrar estas membranas. 
Las membranas para su aplicación industrial tienen que disponerse en módulos que reagrupan uno o varios elementos básicos. Los distintos tipos de módulos se diferencian por diversas características como por ejemplo el coste de instalación, la superficie filtrante del módulo, el consumo de energía por unidad volumétrica de permeado producido, la susceptibilidad al ensuciamiento, la facilidad de lavado y la aptitud para trabajar en unas condiciones de proceso dadas (temperatura, viscosidad, presión, flujo, $\mathrm{pH}$, resistencia a condiciones de lavado...). En cuanto al tipo de configuraciones existentes, se pueden encontrar principalmente cuatro tipos diferentes: membranas planas, en espiral, tubulares y de fibras huecas [63][70].

Las membranas planas representan la configuración más comúnmente utilizada en el laboratorio para ensayar el comportamiento de una membrana dada con una disolución o suspensión determinada (ver Figura 1.28). Sin embargo, también pueden ser utilizadas de forma industrial dispuestas de manera similar a los filtros-prensa. Esta disposición confiere una gran flexibilidad a la instalación y un buen acceso a las membranas para su limpieza y su sustitución en caso de ruptura o colmatación. Sin embargo, estas configuraciones son poco eficaces a flujos de alimentación muy elevados, se colmatan fácilmente y generalmente necesitan pretratamientos.
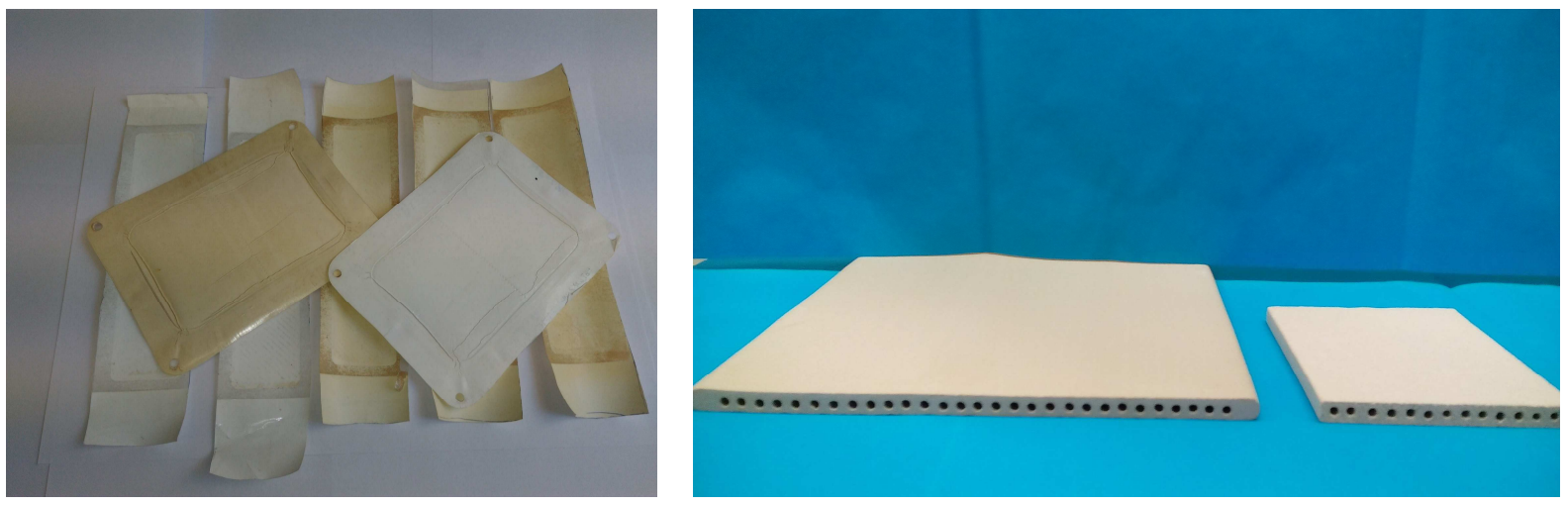

Figura 1.28. Membranas planas: membranas poliméricas y membranas cerámicas (elaboradas en el ITC), respectivamente.

Los módulos de membranas en espiral están compuestos de un tubo perforado sobre el que se enrollan una membrana y un separador de plástico tal y como se muestra en la Figura 1.29.
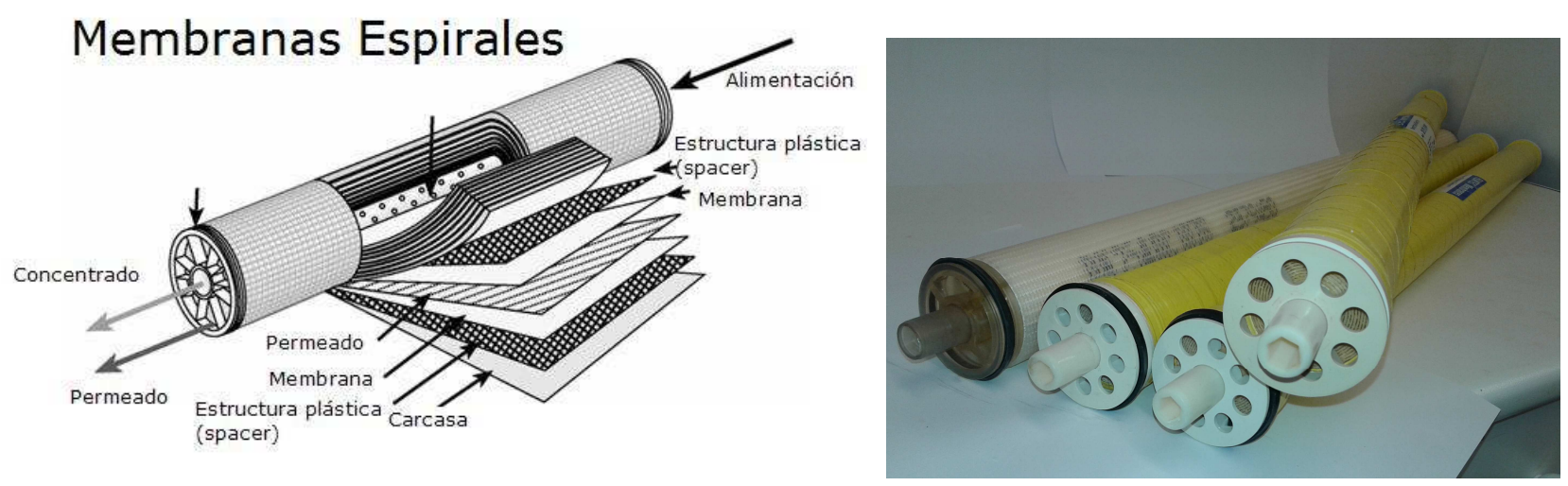

Figura 1.29. Esquema de una membrana espiral [71] y varias membranas de este tipo. 
Esta disposición es de las más compactas y adecuadas para los tratamientos de alta presión. Sin embargo, la limpieza y desinfección en estos módulos es más compleja y la velocidad de operación es limitada.

Las membranas tubulares son las que se conforman en forma de tubo, tal y como su nombre indica (ver Figura 1.30). Es común disponer este tipo de membranas de forma paralela en el interior de cárteres metálicos. Generalmente, el permeado atraviesa la membrana desde el interior al exterior y se recoge en el interior del cárter. Estos sistemas también son muy flexibles a la hora de aplicar etapas de limpieza (incluso es posible hacer lavados en contra dirección del flujo habitual de operación de la membrana) y en muchas ocasiones son poco propensas a la colmatación. Sus principales desventajas son el coste y la baja superficie filtrante por módulo. Por este último motivo y para aumentar la superficie filtrante es habitual encontrar membranas cerámicas multicanal. El módulo tubular es generalmente la configuración elegida para las membranas cerámicas [72].
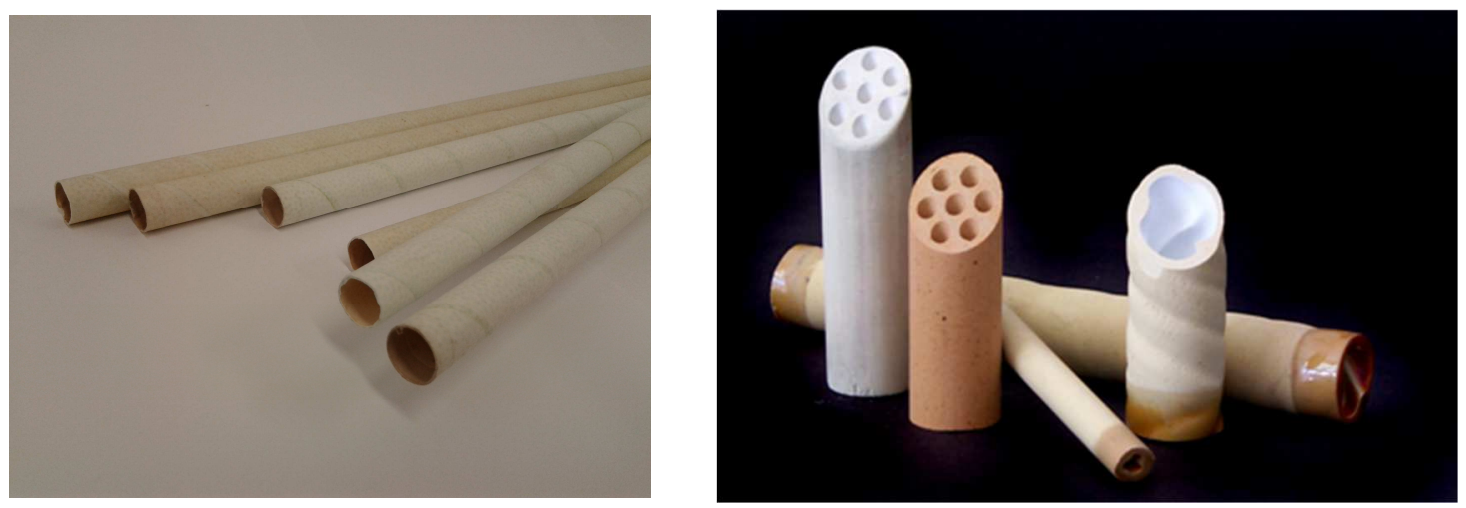

Figura 1.30. Membranas tubulares poliméricas y cerámicas, respectivamente.

Las membranas de fibra hueca se disponen agrupadas dentro de un cárter tal y como se puede apreciar en la Figura 1.31. La capa selectiva estará situada al interior o al exterior de cada una de las fibras, según donde se recoja el permeado y por donde circule la disolución alimento. Estos sistemas son muy compactos, de bajo coste y especialmente adecuados para fluidos de baja viscosidad con poco riesgo de obstrucción. Se recomienda un pre-filtro, justamente para evitar posibles colapsos. Estas membranas son muy utilizadas industrialmente, debido a su elevada superficie activa por unidad de volumen.
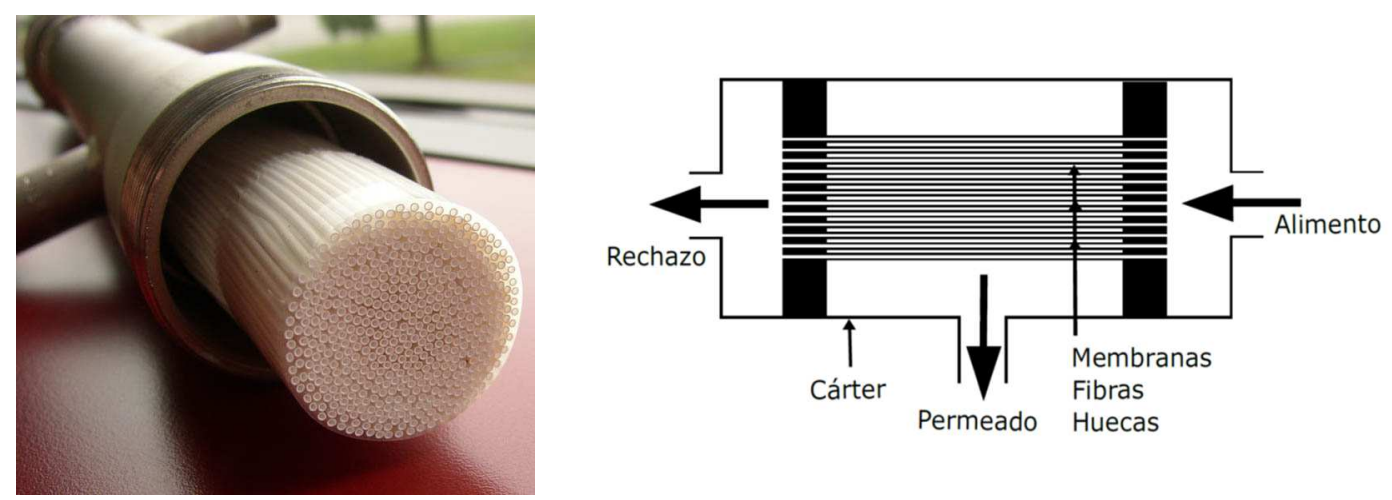

Figura 1.31. Membranas de fibras huecas [73]. 


\subsubsection{Modos de filtración a través de membranas}

En los procesos de filtración con membranas cuya fuerza impulsora de la filtración es la presión existen varios métodos de filtración: frontal y tangencial. En la filtración frontal (Figura 1.32), la acumulación de materia en la superficie de la membrana obstruye la filtración. Este modo de filtración se realiza de forma discontinua y es utilizado principalmente a escala de laboratorio. En la filtración tangencial (Figura 1.32), el alimento-rechazo circula tangencialmente a la membrana, esto permite disminuir la formación de la capa de sustancias retenidas en la superficie de la membrana y por tanto, disminuye su colmatado u obstrucción. Este modo de filtración puede operar de forma continua y es el modo más utilizado industrialmente [74].
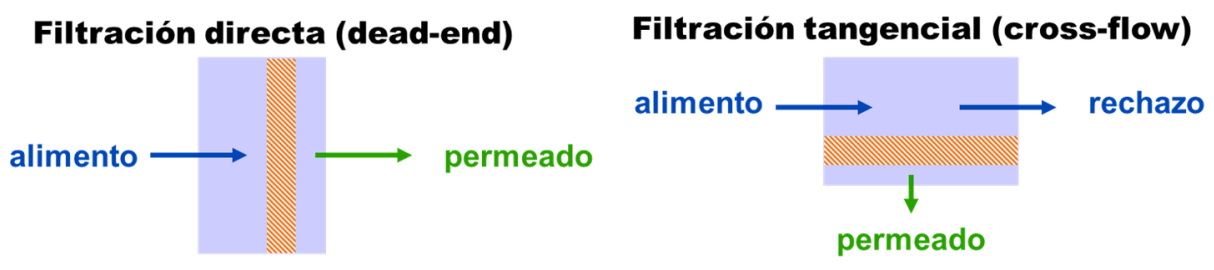

Figura 1.32. Modos de filtración: frontal y tangencial, respectivamente.

En el modo tangencial, el líquido de alimentación entra en el módulo y se divide en dos corrientes. El permeado corresponde a la corriente que atraviesa la membrana, mientras que la corriente restante es el rechazo. El permeado contiene las especies que pasan a través de la membrana, mientras que el rechazo alberga las especies retenidas por ésta. En la Figura 1.33 se puede observar con más detalle una filtración tangencial, que es la utilizada a lo largo de todo el estudio.

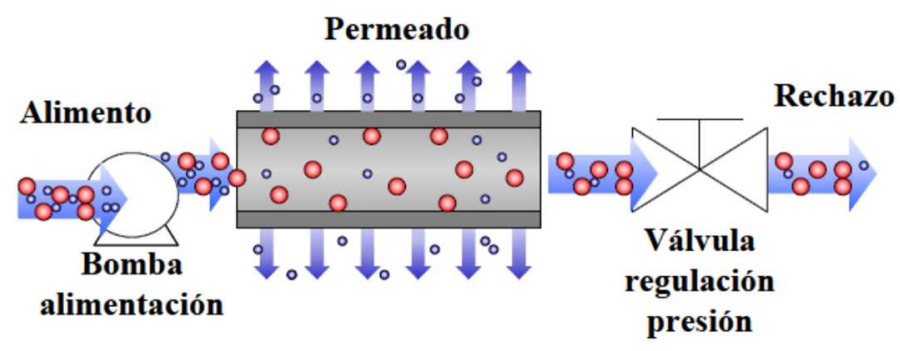

Figura 1.33. Esquema detallado de una filtración tangencial [75].

En el modo tangencial existen, a su vez, varias configuraciones diferentes de filtración, siendo tres las configuraciones más importantes (ver Figura 1.34): paso único o continua ("single-pass"), discontinua ("batch"), y alimentación y purgado o semi-continua ("feed-and-bleed") [75]. Según el objetivo perseguido con la filtración se puede utilizar una configuración u otra.

En la configuración de paso único o continua ("single-pass") la corriente de permeado y la corriente de rechazo son separadas a la salida del módulo de filtración y pueden alimentar (por separado) otros procesos o incluso otros módulos de filtración. Esta es la forma de operar de muchas instalaciones industriales y de muchas desalinizadoras. El principal inconveniente de esta configuración es que resulta difícil obtener el caudal de permeado deseado en un solo paso, por esta razón se necesitan áreas de membrana elevadas. Con estas configuraciones no se pueden obtener grados de conversión elevados, a menos que se enlacen varios módulo en serie [43]. 
En la configuración discontinua ("batch"), toda la corriente rechazo se recircula al depósito que alberga la disolución alimento. En estos casos también se puede añadir una corriente de recirculación parcial, como se indica con la línea punteada de la Figura 1.34 [43]. La concentración de la corriente de alimentación aumenta a medida que se va extrayendo permeado del circuito. Esta configuración es utilizada en instalaciones industriales a pequeña escala y también es la solución más adecuada para realizar una concentración [59].

Existe una configuración mezcla de las dos anteriormente descritas, a ésta se le denominada configuración de alimentación-purgado o semi-continua ("feed-and-bleed"). En este caso, a medida que el permeado es extraído, se reintroduce la misma cantidad de alimento, de esta forma el volumen es constante durante la filtración. Además, se puede recircular una parte de la corriente rechazo. Esta configuración se usa en aplicaciones a gran escala y son diseñadas como multietapa para de este modo reducir en la medida de lo posible el área de membranas que el sistema necesita.
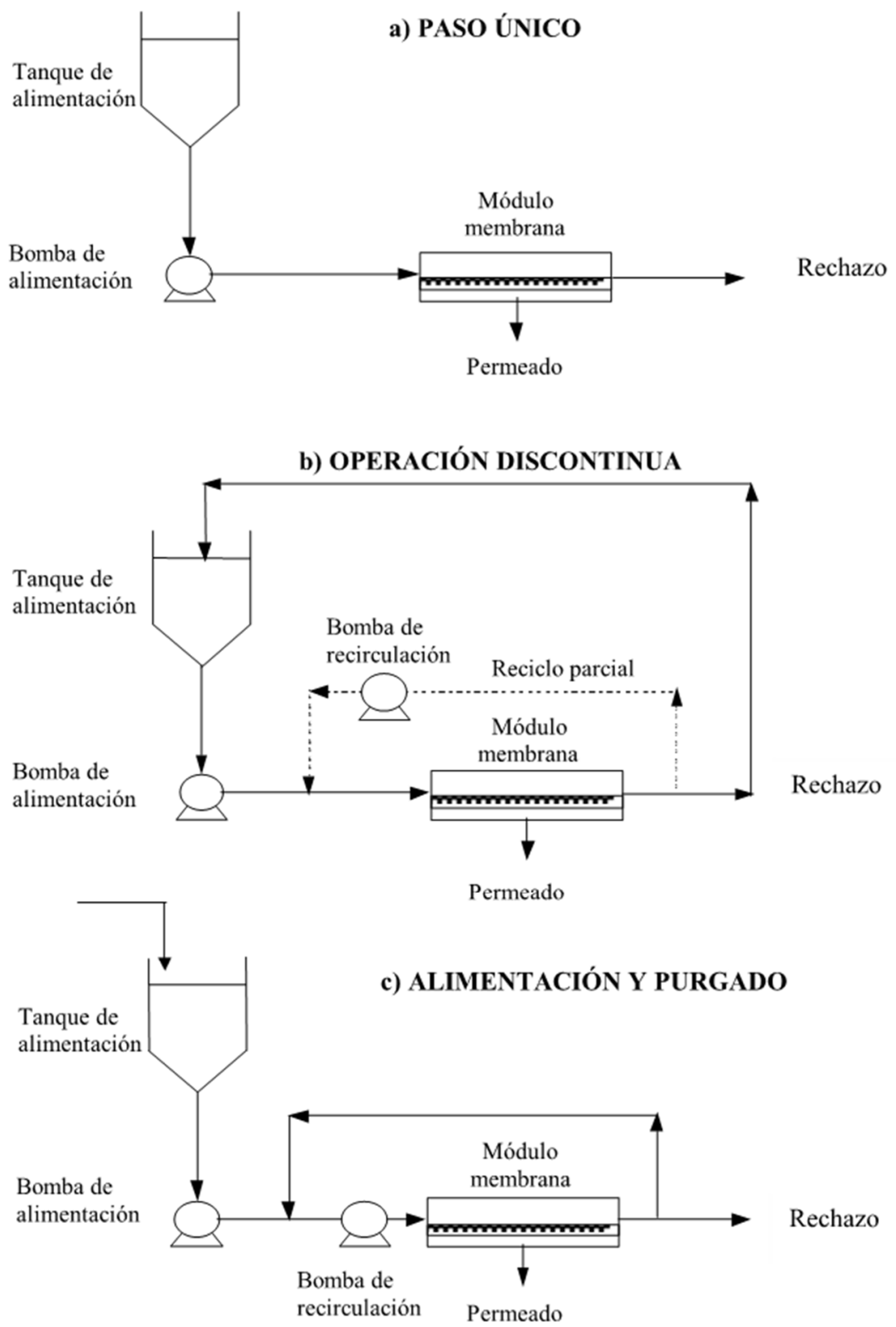

Figura 1.34. Configuraciones de paso único (a), discontinua (b) y alimentación y purgado (c), para procesos de filtración tangencial [75]. 


\subsubsection{La Nanofiltración}

Según lo visto en la Figura 1.22, la nanofiltración es una técnica de separación situada entre la ósmosis inversa y la ultrafiltración. Inicialmente, las membranas de nanofiltración fueron consideradas como membranas de ósmosis inversa, con la diferencia de estar fabricadas de tal forma que los poros fuesen más grandes para aumentar la permeabilidad [76], pero hoy en día se considera una técnica diferente ya que los mecanismos de transporte de ambas técnicas son distintos.

Con la ósmosis inversa, la ultrafiltración y la microfiltración, la nanofiltración forma parte de los procesos de filtración a través de membranas cuya fuerza impulsora es un gradiente de presión, que para esta técnica variará entre 3 y 20 bar.

Como también se ha mencionado en puntos anteriores, la nanofiltración se caracteriza principalmente por un mecanismo de transporte basado, no solamente en los efectos estéricos (o de tamaño), sino también en la carga, tanto de las diferentes especies que se quieren eliminar, como de la propia membrana, este hecho conlleva las siguientes implicaciones:

- Los compuestos neutros son retenidos a causa del impedimento estérico debido al tamaño del poro de la membrana.

- Los iones polivalentes (por ejemplo $\mathrm{Ca}^{2+}, \mathrm{Mg}^{2+}, \mathrm{SO}_{4}{ }^{2-}, \mathrm{PO}_{4}{ }^{3-} \ldots$ ), retenidos fácilmente, sufren una separación selectiva, mientras que los iones monovalentes son solamente parcialmente retenidos [77].

- Parte de las especies cargadas (especies monovalentes) pueden pasar a través de la membrana, esto hace que disminuya la diferencia de presión osmótica de un lado al otro de la membrana.

- Las presiones de trabajo son más bajas que las utilizadas en la ósmosis inversa, además se obtiene un mayor caudal de permeado. Todo esto hace que la nanofiltración sea una técnica más eficiente energéticamente si se compara con la ósmosis inversa.

La aparición de la nanofiltración en el contexto industrial es muy reciente y coincide prácticamente con el desarrollo de los materiales de las membranas con nanoestructuras específicas adaptadas para la separación a escala nanométrica.

Las especies afectadas por la nanofiltración tienen tamaños cercanos a los de la molécula de agua y serán o no retenidos por estas membranas, cuyos radios de poro varían de 0,3 a $5 \mathrm{~nm}$ aproximadamente, mediante mecanismos de selectividad mixta basados a la vez en la carga y en el tamaño de las moléculas.

La mayoría de las membranas de nanofiltración disponibles comercialmente son poliméricas y tienen una morfología asimétrica compuesta (varias capas de diferentes materiales) [78]. La capa activa en las membranas de nanofiltración y de ósmosis inversa se forma generalmente durante un post-tratamiento de las membranas de microfiltración y de ultrafiltración, usando un polímero (generalmente del tipo poliamida) diferente al de la matriz, dando como resultado las membranas compuestas [79]. La morfología de este tipo de membranas puede observarse en la Figura 1.35. 


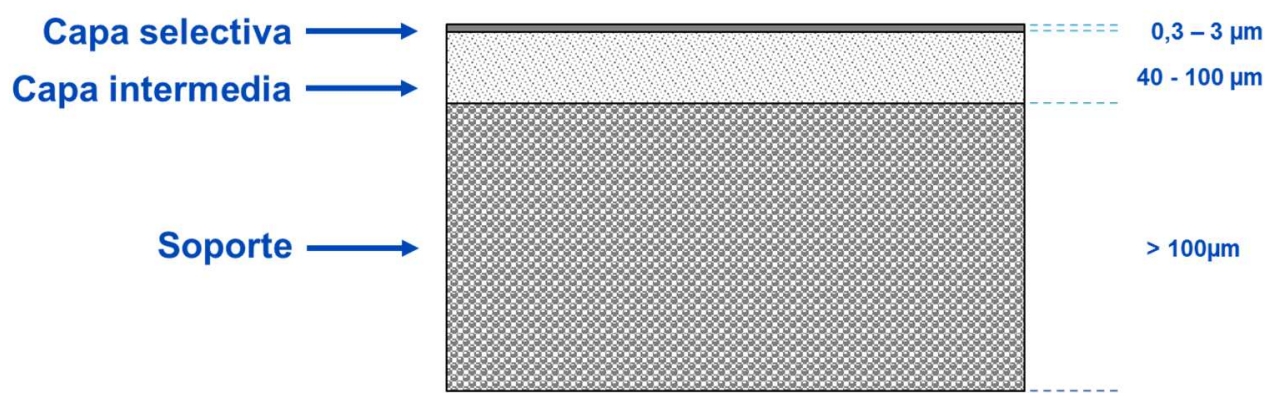

Figura 1.35. Esquema de un corte trasversal de una membrana compuesta de nanofiltración.

En algunas aplicaciones, la selectividad de la nanofiltración entre moléculas de tamaños similares es la clave del éxito del proceso de separación con membranas, permitiendo un paso elevado de iones monovalentes y reteniendo prácticamente la totalidad de los iones multivalentes. De este modo, la membrana de nanofiltración, reduce el incremento del gradiente de presión osmótica a la que contribuyen las sales monovalentes. Por tanto, como resultado, es posible obtener una mayor cantidad de producción de permeado [80] a presiones no muy elevadas y por consiguiente, con consumos energéticos menos importantes que la ósmosis inversa.

Una vez se ha explicado de forma general en que consiste la nanofiltración, sus principales características si se comparan con las técnicas más próximas y las características estructurales típicas de este tipo de membranas, se abordarán los mecanismos y modelos que actualmente están más aceptados para describir y comprender como se efectúa el transporte a través de estas membranas. Además, se nombrarán algunas de las principales aplicaciones de esta tecnología y se profundizará en las aplicaciones que se le quiere dar en este estudio.

\subsubsection{Transporte a través de las membranas de nanofiltración}

En este apartado en primer lugar se tratará de explicar los mecanismos que tienen lugar en el trasporte de materia a través de las membranas de nanofiltración y en segundo lugar, se abordarán los modelos teóricos que se han desarrollado para modelizar el transporte a través de este tipo de membranas.

\subsection{Mecanismos de transporte a través de una membrana de nanofiltración}

La nanofiltración es una técnica de separación a través de membranas que intentará separar mezclas de moléculas e iones de tamaños pequeños y muy similares. Generalmente, las mezclas serán líquidas y se intentará separar el disolvente de algunos de los solutos disueltos en el mismo. Por tanto, se podrá distinguir entre el transporte del disolvente y el transporte del soluto a través de la membrana propiamente dicha.

Al trasporte de disolvente le afectarán principalmente dos factores. Por un lado, la permeabilidad de la membrana, que estará directamente relacionada con el tipo de membrana [81]. Esta permeabilidad en el caso de las membranas de nanofiltración generalmente no es demasiado elevada, por tanto el flujo del permeado estará condicionado por esa permeabilidad. Y por otro lado, el trasporte del disolvente estará condicionado por la presión osmótica de las disoluciones retenidas. Esta presión osmótica también estará condicionada por las especies disueltas y su concentración. 
Por tanto, cuanto mayor sea la diferencia de concentraciones entre el rechazo y permeado, mayor será la presión osmótica y en consecuencia, el trasporte de disolvente no será favorecido.

Por lo que respecta al transporte de los solutos, en la actualidad, todavía no existen teorías del todo claras que expliquen completamente su transporte y, por lo tanto, tampoco se puede explicar completamente la selectividad de las membranas de nanofiltración. Se han propuesto numerosos enfoques, pero ningún de ellos ha sido capaz de describir completamente y de manera simple los mecanismos que intervienen en estos procesos. Sin embargo, se está de acuerdo en una serie de aspectos, que intentan describir el funcionamiento general de estas membranas. Uno de estos aspectos en los que varios autores coinciden es que la retención de los solutos se debe a efectos estéricos (tamaño de poro y del soluto a retener) y a efectos de carga (tanto de la carga de la superficie de la membrana e interior de los poros como de la carga de los solutos) [82][74][83][84]. Por tanto, para comprender mejor el comportamiento y la selectividad de una membrana porosa es indispensable determinar, no solamente sus características estructurales (radio de poro medio, distribución de tamaño de poro, tortuosidad...), sino también sus características eléctricas superficiales, tales como la carga o el potencial de la superficie de la pared de los poros. En cada uno de estos efectos se profundizará a continuación.

Sin lugar a duda, un efecto estérico tiene una gran importancia en la retención de todas las moléculas. Este efecto está claro cuando se trata de moléculas neutras, sin embargo, en los elementos o moléculas cargadas a este efecto se tiene que añadir el efecto carga. Por tanto, el tamaño de la especie a filtrar en relación al tamaño de poro de la membrana utilizada va a condicionar la retención de la misma. Desde hace mucho tiempo se han invertido esfuerzos para esclarecer la selectividad de las membranas porosas usando modelos hidrodinámicos de transporte impedido [85]. En los años 30 Ferry ya desarrolló estudios muy influyentes de los que se derivan factores de impedimento para el transporte convectivo a partir de consideraciones estéricas [86]. En estos estudios se relaciona la retención con los radios medios de las moléculas y de los poros de la membrana y se describe relativamente bien las variaciones de retención con el tamaño o la masa molar de las moléculas. Los estudios de Ferry se realizaron para membranas porosas de ultrafiltración, por tanto pueden existir algunas diferencias entre estas membranas y las de nanofiltración con poros mucho más estrechos.

Por consiguiente, y a modo de resumen, la relación entre el tamaño de la especie filtrada y el diámetro de poro de la membrana va a condicionar la retención del soluto. Por tanto, si el tamaño es superior al diámetro del poro de la membrana, el soluto será retenido por la membrana. Mientras que si el tamaño de este soluto es muy inferior al diámetro de poro de la membrana éste pasará a través de ella sin ningún tipo de problema. En cambio, si el tamaño del soluto es próximo al diámetro de poro de las membranas, intervendrá lo que se denomina mecanismo de difusión impedida, término que define cuando la difusión de un soluto es fuertemente ralentizada en el seno de un poro cuyo diámetro es próximo al tamaño del propio soluto [85].

El segundo gran efecto que se va a encontrar en el trasporte de los solutos a través de las membranas de nanofiltración será el efecto de la carga. Generalmente, las membranas de nanofiltración cuando están en contacto con la disolución que tienen que filtrar presentan cargas en 
la superficie y en el interior de sus poros [87][88][82], además, en la mayoría de las ocasiones esta carga es negativa [89][90]. Por tanto, cuando los solutos también poseen cargas, en estos casos, al citado fenómeno de exclusión estérica se han de sumar fenómenos suplementarios relacionados con las cargas, tanto de la membrana, como del propio soluto.

El equilibrio entre la membrana cargada y la solución en contacto con ella se caracteriza por un potencial denominado potencial de Donnan, causante de la retención de algunos elementos cargados. Este mecanismo también llamado exclusión de Donnan permite la retención de algunos iones cuyo tamaño es menor al tamaño de poro de la membrana [91][92]. Los iones portadores de cargas idénticas a las membranas son repelidos por la membrana, y sus contraiones también son rechazados, para mantener la electroneutralidad del fluido. La exclusión será tanto más fuerte cuanto más alta sea la densidad de carga de la membrana.

Además, intervienen otros fenómenos electroestáticos, ya que en el caso de las membranas también se puede aplicar los fenómenos descritos en el apartado 1.3.2 Efecto de los iones presentes en el medio dispersante, ya que la presencia de cargas en la superficie de un sólido sumergido en una disolución tiene una influencia en la distribución espacial de las especies cargadas presentes en la disolución en el entorno de la superficie del sólido. Como se dijo en el apartado anteriormente mencionado, las fuerzas electroestáticas ocasionadas por la carga superficial del sólido, en este caso la membrana, atraen las especies de carga opuesta y repelen las de la misma carga. De esta manera, el potencial electroestático ejercido por la carga superficial en el sólido varia progresivamente en el seno de una zona llamada "doble capa eléctrica". Al igual que pasaba con la micela coloidal, uno de los modelos más comúnmente utilizados para describir la estructura de la doble capa eléctrica es el de Stern [56]. Este modelo sugiere que esta reorganización de cargas en la superficie de la membrana y también en la superficie del interior de los poros conduce a la formación de dos zonas distintas, la capa compacta más cercana al sólido (capa de Stern) y la capa más externa denominada capa difusa. El espesor de la primera permanecerá prácticamente invariable, mientras que el de la segunda variará según las características de la disolución. Por ejemplo, el espesor variará notablemente con la fuerza iónica de la disolución, cuando ésta última aumente el espesor de la capa difusa disminuirá. El espesor de la capa difusa se considera generalmente igual a una dimensión denominada longitud de Debye. Esta magnitud es un parámetro útil para estimar el alcance de las interacciones electrostáticas. Se utiliza con frecuencia la relación del radio medio de poro de una membrana y la longitud de Debye para estimar la parte ocupada por la capa difusa en el interior de un poro (en esta comparación se puede determinar que parte del poro está influenciada por las cargas eléctricas y que parte del mismo es eléctricamente neutra) [82]. Esta relación, denominada también radio electrocinético, indica si la doble capa eléctrica se ha formado completamente en el interior de los poros o si, por el contrario, se superponen las cargas y el efecto de doble capa disminuye [53]. Tanto en la superficie de la membrana propiamente dicha, como en la superficie de los poros, existirán estas interacciones electroestáticas. Por consiguiente, en la retención de las especies cargadas, parece ser que el espesor de la doble capa eléctrica (longitud de Debye) a nivel de las paredes del poro con respecto al radio de poro, tiene una gran importancia en el efecto carga a la hora de retener o no un determinado soluto cargado. 
Por lo anteriormente explicado se deduce que, la naturaleza de las sales (aniones y cationes, mono, di o trivalentes) desempeña un papel muy importante en la selectividad de las membranas. La fuerza iónica, así como el pH de la disolución, pueden actuar sobre la carga superficial del material de la membrana. Por tanto, los datos relativos a la selectividad de las membranas de nanofiltración son muy dependientes de las condiciones para las cuales se obtuvieron, y deben extrapolarse con prudencia. Por esta razón, a menudo son necesarias diferentes pruebas experimentales para validar estas extrapolaciones.

Cuando se tienen disoluciones complejas en las que coexisten diferentes especies, tanto cargadas como las que no lo están, todas ellas participan en el transporte. Por tanto, pueden aparecer entonces fenómenos mixtos, todavía no del todo claros, que hacen que el transporte de una sal pueda influir sobre el de otra, o también que el transporte de una molécula neutra pueda influir sobre el de una especie cargada, además de otros muchos efectos [43]. Sin embargo, todavía no se tiene clara una explicación para estos fenómenos y no se cesa en el empeño de encontrar modelos que tengan en cuenta todos los fenómenos que interviene en un proceso de nanofiltración.

\subsection{Modelos de transporte a través de membranas de nanofiltración}

Todo proceso de modelización persigue la predicción del comportamiento de un sistema dado. En el caso concreto de la nanofiltración, el objetivo principal de la modelización es el de relacionar la concentración de un soluto cualquiera " $i$ " presente en la corriente de alimentación $\left(c_{a i}\right)$ y la presión transmembrana aplicada $(\Delta P)$ con la concentración de ese soluto en el permeado $\left(c_{p i}\right)$ y el flujo volumétrico $\left(J_{v}\right)$. Si se conocen las concentraciones de la disolución de alimentación y las concentraciones del permeado se puede calcular la retención $\left(R_{i}\right)$ que la membrana ofrece a un determinado soluto " $i$ " [93]. Por tanto, lo único que se pretende es relacionar los parámetros que se conocen antes de la filtración (composición y propiedades de la disolución más las propiedades de la membrana) y prever los resultados de la nanofiltración extrayendo parámetros característicos de la filtración, como son la retención a un soluto dado, así como el flujo de permeado, entre otros (presión, caudal, pH, temperatura, concentración...) [94]. Parámetros estos que pueden determinar la viabilidad o no de uno de estos tratamientos a la hora de resolver un problema dado.

Dependiendo de las características de la membrana y de las propiedades de los solutos, se pueden proponer diferentes modelos. Existen modelos sencillos que consideran una membrana como un material poroso con poros bien definidos y que no tiene en cuenta el efecto carga y en cambio, existen otros modelos que intentan introducir en sus cálculos el efecto de las cargas [95].

Los mecanismos de transporte de las especies químicas iónicas y solutos no cargados, a través de membranas de nanofiltración, son de especial interés en la modelización de este tipo de filtración. Por tanto, aunque no sea el objetivo principal de este trabajo, se enunciarán, sin mayores pretensiones, algunos modelos utilizados para el estudio del transporte a través de membranas de nanofiltración. Algunos de los cuales ya han sido utilizados en la ósmosis inversa y la ultrafiltración.

En primer lugar hay modelos desarrollados para modelizar el comportamiento de solutos rígidos en forma de esferas no cargadas dentro de poros cilíndricos, como por ejemplo el modelo de transporte impedido ("Hindered Transport Theory"-HTT). Este modelo puede aplicarse a estructuras de poros 
más complejas introduciendo un factor de tortuosidad. Además, tiene en cuenta interacciones hidrodinámicas y estéricas entre los solutos y los poros [85][59]. Este modelo es uno de los que utiliza el programa de simulación que se ha utilizado en este estudio para la caracterización de las membranas como posteriormente se describirá (ver apartado 3.7 Programa de simulación NANOFLUX ${ }^{\circledR}$.

También se ha utilizado el análisis termodinámico para conocer los coeficientes de transporte, aplicando el modelo no lineal de Spliegler-Kedem [96][97][98]. Este modelo se utilizó también en procesos de recuperación de sal a partir de salmueras y plantas de decoloración de la industria del azúcar. Algunos investigadores utilizan los modelos (SHP) ("Steric-Hindrance Pore”) [99] y (TMS) (Teorell-Meyer-Sievers), para describir el transporte de solutos cargados a través de membranas de nanofiltración, para ello se acepta que la capa activa de la membrana tiene sus poros cargados. También se ha utilizado el modelo (SC) (“Space-Charge") para predecir la retención de las sales en capilares cargados [100]. También ha sido empleado en la nanofiltración uno de los modelos más extensamente admitido en la ósmosis inversa, el modelo de disolución-difusión (SDM), [101][102][103].

Sin embargo, el modelo que ha alcanzado un mayor desarrollo y difusión para explicar el transporte de solutos en nanofiltración, es sin lugar a duda, el modelo de Nernst-Planck [104][105][106].

El modelo "Donnan-Steric-Pore" (DSPM), incorpora efectos de carga y estéricos en el transporte de iones a través de la membrana a la ecuación extendida de Nernst-Planck, así como los efectos de la polarización por concentración. Este modelo se puede utilizar para la predicción de flujos de permeado y rechazo en mezclas multicomponentes [107][108]. Se puede utilizar una variante del anterior, denominado "Steric Electric and Dielectric Exclusion" (SEDE), para describir la transferencia de electrolitos y solutos no cargados. Este modelo se basa en la ecuación extendida de Nernst-Planck que incorpora los términos de difusión, electromigración y convección en los poros de la membrana, así como los impedimentos naturales de difusión y convección de especies en el interior de la membrana [109].

De igual forma que el modelo DSPM, el modelo homogéneo "Hindered Electro Transport" (HET), desarrollado por el Dr. John Palmeri y sus colaboradores, considera un mecanismo de exclusión de los solutos cargados incluyendo los efectos estéricos y eléctricos [83]. Entre las diferencias que se pueden encontrar entre estos dos modelos figura la elección del tamaño representativo de los iones: el modelo DSPM utiliza el radio de Stokes mientras que el modelo HET utiliza el radio de la estructura cristalina (o radio de Pauling) [110][83][111]. Este modelo es otro de los que utiliza el programa de simulación que se ha utilizado en este estudio para la caracterización de las membranas como también se describirá posteriormente (ver apartado 3.7 Programa de simulación NANOFLUX ${ }^{\circledR}$.

El modelo HET es interesante ya que es relativamente sencillo y presenta una buena capacidad para tener en cuenta los efectos electrostáticos y estéricos del transporte a través de las membranas de nanofiltración. Los parámetros de los iones presentes en este modelo son: la concentración de un determinado ion en la alimentación $\left(c_{i a}\right)$, su valencia $\left(z_{i}\right)$, su radio $\left(r_{i}\right)$ y su coeficiente de difusión en el medio continuo que tiene que atravesar (dependiente de la temperatura) $\left(D_{i}\right)$. A su vez la 
membrana será caracterizada por tres parámetros: el radio de poro $\left(r_{p}\right)$, la permeabilidad hidráulica al agua pura $\left(L_{p}^{0}\right)$ y la densidad de carga efectiva de la membrana $\left(X_{m}\right)$. Para un nanoporo dado, $X_{m}$ depende de la naturaleza de la disolución del electrolito filtrado, mientras que $r_{p}$ y $L_{p}^{0}$ son considerados como dos parámetros fijos dependientes de la membrana.

Para una mejor comprensión de los modelos de transporte a través de las membranas de nanofiltración en el Anexo I se ha profundizado en varios de ellos. Se han explicado varios modelos simples de transporte, así como también otros más complejos como son el modelo "Hindered Transport Theory" (HTT) y el modelo "Hindered Electro Transport" (HET), que son los modelos utilizado por el programa informático que se ha empleado en este estudio para modelizar el comportamiento de las membranas utilizadas.

\subsubsection{Fenómenos limitantes de la nanofiltración}

Existen diferentes fenómenos que afectan negativamente, tanto al flujo de permeado a través de las membranas, como en la retención esperada de determinados solutos. En este apartado se abordarán dos de los fenómenos limitantes más característicos de la nanofiltración como son el ensuciamiento ("fouling" en inglés) y la polarización por concentración [43][63][74].

\section{Ensuciamiento o "fouling"}

El ensuciamiento o "fouling" en membranas se define como una acumulación de materia en la interfase membrana/disolución alimentación o el interior de los propios poros de la membrana. Este ensuciamiento puede ser reversible o irreversible, según si después de una operación de limpieza es posible recuperar una permeabilidad de la membrana igual a la inicial, antes de su ensuciamiento. Las consecuencias más negativas de este ensuciamiento son una disminución considerable de la permeabilidad y una variación de la selectividad de la membrana con el transcurso del tiempo.

Se pueden distinguir entre diferentes tipos o mecanismos de ensuciamiento cuando se habla de filtración a través de membranas [43]. A continuación se profundiza en varios de ellos:

- Ensuciamiento por adsorción: fenómeno físico-químico que se debe a diferentes interacciones entre algunos elementos presentes en la disolución de alimentación y la superficie de la membrana o incluso el interior de los poros de la membrana.

- Ensuciamiento por formación de una torta: se trata de una acumulación de partículas en la superficie de la membrana. Este tipo de ensuciamiento tiene algunas variantes, como puede ser el ensuciamiento por el desarrollo de un biofilm, ya que la acumulación de materia en la superficie de la membrana muchas veces crea condiciones favorables para la proliferación de micro-organismos en forma de biofilms.

- Ensuciamiento por bloqueo de poros: se trata de la obstrucción mecánica completa de los poros que implica una disminución del número de poros disponibles en la membrana. Este tipo de ensuciamiento será causado por partículas mucho mayores que el diámetro del poro, por tanto estos elementos son mucho más fáciles de eliminar que los elementos con dimensiones parecidas al diámetro de poro que pueden penetrar en el interior del propio poro. 
- Ensuciamiento por obstrucción de los poros: si el tamaño de las partículas es más pequeño que los diámetros de los poros presentes en las membranas, estas partículas pueden penetrar en el interior de los poros y pueden ir obstruyéndolos progresivamente. Este tipo de ensuciamiento muchas veces es irreversible ya que los ciclos de limpieza no logran eliminarlo completamente.

En la Figura 1.36 se puede encontrar un esquema de los diferentes tipos o mecanismos de ensuciamiento de la membrana:

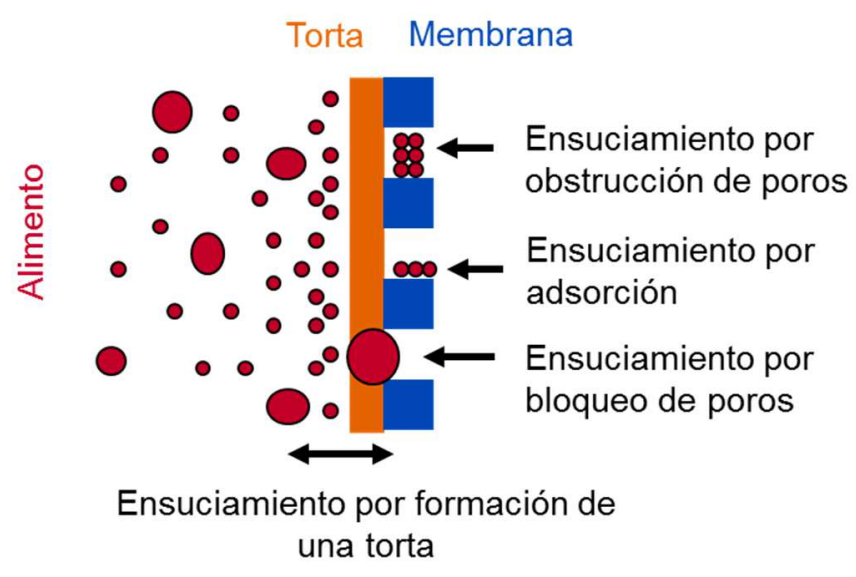

Figura 1.36. Diferentes tipos o mecanismos de ensuciamiento de las membranas.

En general, todos estos tipos de ensuciamiento se dan al mismo tiempo, por tanto el ensuciamiento es una combinación de todos ellos.

Existen numerosos estudios dirigidos al análisis y eliminación del ensuciamiento de las membranas, ya que es un factor limitante de todos los procesos donde interviene este tipo de filtración [112][113][114].

\section{Polarización por concentración}

En un proceso de nanofiltración, el disolvente y los solutos son impulsados por convección hacia la membrana, todo ello bajo la influencia de un gradiente de presión como fuerza impulsora. Los solutos retenidos se acumulan en la superficie de la membrana creando un gradiente de concentración que genera un flujo de difusión del soluto en contracorriente al sentido de la filtración que intenta equilibrar las concentraciones. Además, sea el que sea el régimen de circulación del fluido en el seno del sistema de filtración (generalmente turbulento), existe en la interfase membrana-disolución alimentación una zona de circulación donde el régimen de circulación es laminar. Por tanto, se establece una capa cercana a la membrana de espesor $\delta$ donde existe un perfil de concentraciones denominada "capa límite" [115]. Este fenómeno inherente a los procesos de separación por membranas se le denomina polarización por concentración [116][117][118]. En la Figura 1.37 se muestra un esquema de este fenómeno. 


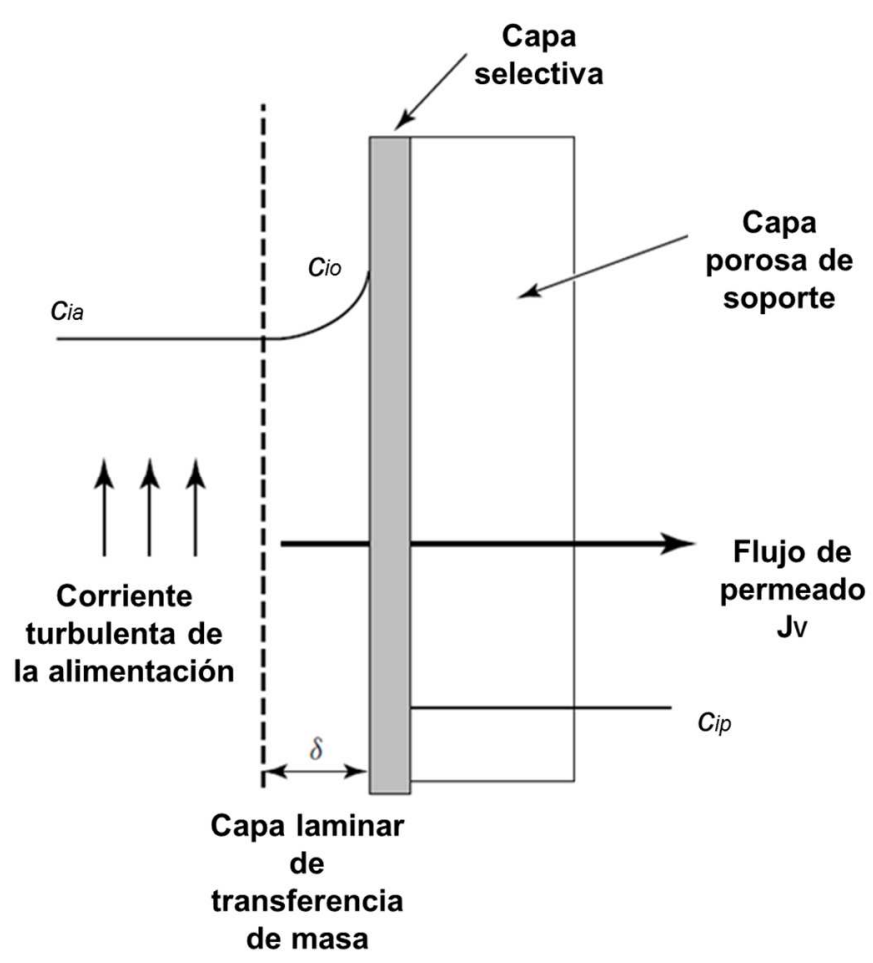

Figura 1.37. Fenómeno de polarización de concentración en la interfase membrana-solución alimentación [63].

El fenómeno de polarización de concentración lleva asociado una disminución del flujo de permeado y muchas veces, una variación de la retención de determinadas especies.

Generalmente, la polarización de concentración es un fenómeno reversible. Sin embargo, este fenómeno puede traer otros asociados. Por ejemplo, en el caso de la filtración de sales, se puede superar el límite de solubilidad en la superficie de la membrana y pueden formarse precipitados cristalinos. En el caso que se estén separando macromoléculas, se puede formar una capa de gel sobre la membrana que puede comportarse como una capa suplementaria que tanto soluto como disolvente tienen que atravesar. En todos estos casos tan extremos, el flujo de permeado disminuirá considerablemente [88][119][120].

La polarización de concentración puede depender de varios factores, entre ellos: la velocidad de circulación de la disolución de alimentación, la viscosidad del disolvente, las características de los solutos, la hidrodinámica en las proximidades de la membrana... [63].

\subsubsection{Aplicaciones industriales de la nanofiltración}

Actualmente, la nanofiltración tiene usos muy diversos en distintos sectores industriales, como por ejemplo, en tratamientos [79]:

a) De aguas para el consumo:

- Potabilización [121].

- Ablandamiento de agua [122].

- Agua para embotellado [123].

- Desalinización [124][125]. 
b) De protección del medioambiente [126][127]:

- Ablandamiento de agua para torres de enfriamiento.

- Ajuste de los parámetros de vertido de efluentes residuales y/o reutilización cuando es posible.

- Tratamientos de efluentes de la industria metalúrgica.

- Reciclado de efluentes coloreados y tintas, en el sector textil [128][129][130][131][132] y papelero [133][134][135].

- Eliminación de virus y bacterias de un fluido.

- Eliminación de DQO de una corriente líquida [136].

c) Para el sector petro-químico [137][138].

d) Para el sector de la alimentación, de las bebidas y de los lácteos [139][140].

- Lavado cáustico en cerveza y otras bebidas [141].

- Separación de azúcares.

- Reciclado de efluentes de regeneración de intercambio iónico.

- Reciclado de agua de lavado en alimentos.

- Desmineralización de suero [74].

- Desmineralización de zumos.

e) Para el sector farmacéutico [139].

\subsubsection{Aplicaciones industriales de la nanofiltración en el sector cerámico abordadas en este estudio}

El hecho de pensar en las técnicas de nanofiltración para el tratamiento de las aguas industriales del sector cerámico, es debido a las principales ventajas que esta tecnología ofrece sobre otros procesos convencionales. Estas ventajas son, entre otras:

- Bajo consumo energético con respecto a otras técnicas de depuración (como por ejemplo la ósmosis inversa).

- En principio, no es necesario añadir otros compuestos para llevar a cabo la depuración.

- La separación puede realizarse de forma continua.

- Las técnicas de membranas pueden combinarse fácilmente con otras operaciones básicas.

- Retención de elementos o iones de reducidas dimensiones y selectividad de los iones divalentes frente a los monovalentes.

En concreto, como se ha apuntado con anterioridad, en este trabajo se plantea la utilización de la técnica de nanofiltración a través de membranas para la eliminación del boro y de los compuestos divalentes de algunas de las aguas industriales generadas y/o utilizadas en el sector de la fabricación de baldosas cerámicas.

\section{Eliminación del boro usando la técnica de nanofiltración}

La nanofiltración no ha sido una técnica comúnmente utilizada para la eliminación del boro. Cuando se ha tenido que utilizar técnicas de filtración a través de membranas para la eliminación de este elemento, siempre se ha pensado en la ósmosis inversa [142][143]. Sin embargo, hay ciertos 
estudios, no demasiados por el momento, que han sugerido que utilizando membranas de nanofiltración se pueden obtener resultados similares a los obtenidos con la ósmosis inversa para la eliminación del boro [42][144], pero con la ventaja de utilizar una menor presión y por consiguiente, un consumo de energía más bajo. Como en el caso de la ósmosis inversa, los parámetros más importantes en la nanofiltración son el tipo de membrana utilizada, el pH, la temperatura y la presión.

Si se tiene en cuanta las membranas utilizadas, en la Figura 1.38 se muestra diferentes intervalos de retención obtenidos con algunas membranas de ósmosis inversa (BW-30 y TW-30) y también con otras membranas de nanofiltración (NF-90 y NF-45), que se han utilizado para el tratamiento de aguas procedentes de lixiviados de vertederos. La retención de la membrana de nanofiltración NF-45 no es muy elevada pero la que ofrece la membrana NF-90 también de nanofiltración, se aproxima a las retenciones obtenidas con las membranas de ósmosis inversa.

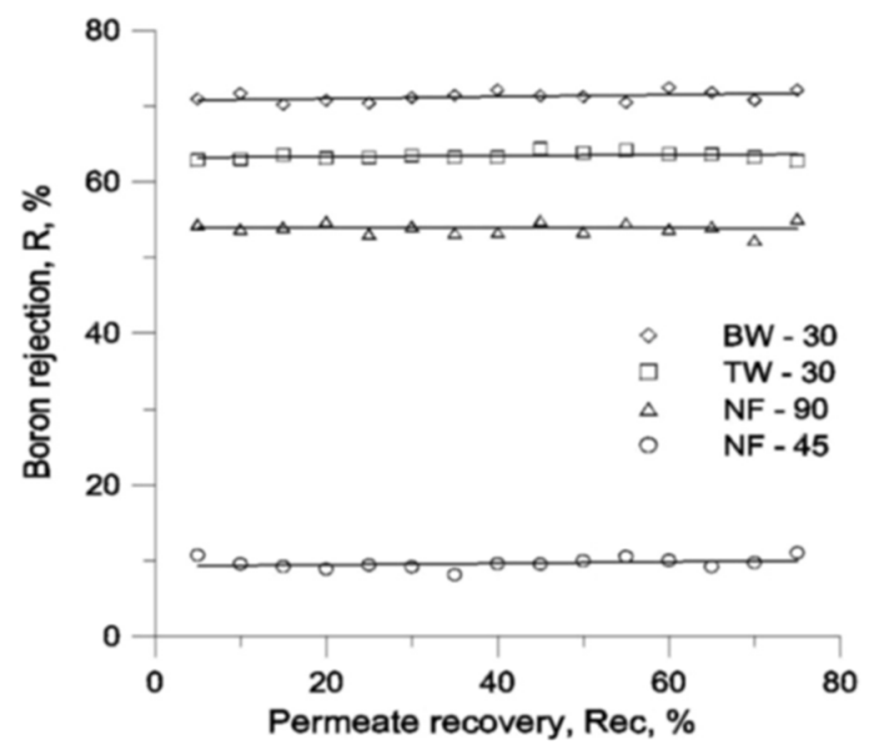

Figura 1.38. Retención del boro frente a la conversión para diferentes membranas a pH 8,5 [42].

Como se ha comentado, la influencia del pH también es determinante a la hora de retener el boro por técnicas de filtración avanzada [144]. En la Figura 1.39 se puede observar claramente que la retención del boro ofrecida por las diferentes membranas examinadas en ese estudio no difiere demasiado a pH alto de 11. La retención para las membranas BW-30, TW-30 y NF-90 fue de 98,4, 97,6 y $97,2 \%$, respectivamente. En este estudio, la concentración de boro en el agua tratada (agua procedente del lixiviado de un vertedero) fue de $25,4 \mathrm{mg} / \mathrm{L}$. Por tanto, una membrana de nanofiltración como es la NF-90 permite obtener resultados similares de retención de boro a los obtenidos con las membranas de ósmosis inversa, cuando el pH utilizado es elevado. 


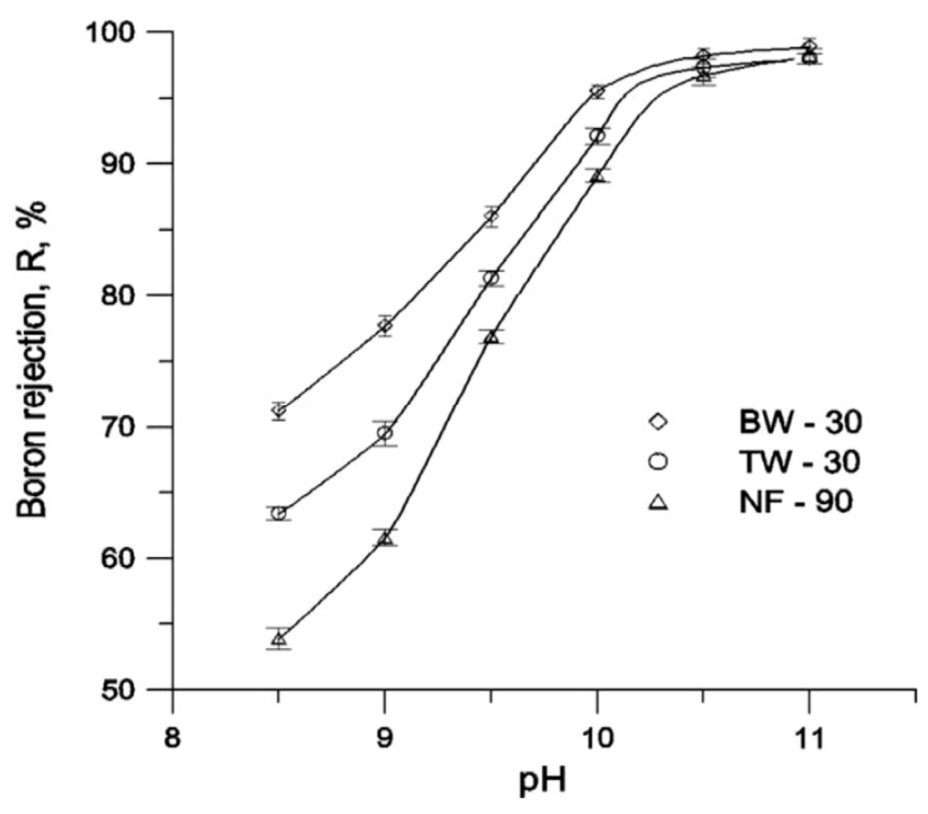

Figura 1.39. Retención del boro frente al pH de la corriente de alimentación con una conversión del 5\% con diferentes membranas [42].

La nanofiltración tiene las mismas ventajas y desventajas técnicas que se pueden encontrar en la ósmosis inversa. Sin embargo, como se acaba de mostrar, a pH elevado, la nanofiltración puede ser más efectiva, ya que se podrán conseguir flujos de permeado más elevados y similares retenciones del boro a presiones de trabajo inferiores, con el consiguiente ahorro de energía.

\section{Eliminación de compuestos divalentes usando la técnica de nanofiltración}

Una de las características principales de la técnica de nanofiltración es la mayor capacidad de separar iones divalentes o polivalentes frente a los iones monovalentes. Puesto que para muchas etapas del proceso productivo cerámico se tiene que utilizar suspensiones cerámicas concentradas lo más desfloculadas posible y estos iones divalentes y polivalentes causan muchos problemas (ver el apartado 1.3.3 Desfloculación de las suspensiones cerámicas), esta técnica se revela como una técnica muy apropiada para mejorar las características reológicas de estas suspensiones cerámicas industriales. Esta técnica no ha sido ensayada hasta la fecha con aguas industriales del sector cerámico.

Al igual que con el caso del boro, existen algunos trabajos en los que se ha estudiado la eliminación de iones divalentes o polivalentes de una disolución acuosa e insisten en la capacidad de las membranas de nanofiltración de retener los iones divalentes frente a los monovalentes [145][146][147].

Concretamente, si se tiene en cuenta el calcio, se pueden encontrar trabajos [148] donde mediante la utilización de membranas de nanofiltración (MPF-34 de Weizmann) se obtiene retenciones del ion calcio que varían entre $65-78 \%$ a pH 7-8, para concentraciones en la disolución de alimentación de 20 a $80 \mathrm{mg} / \mathrm{L}$ de $\mathrm{Ca}^{2+}$. 


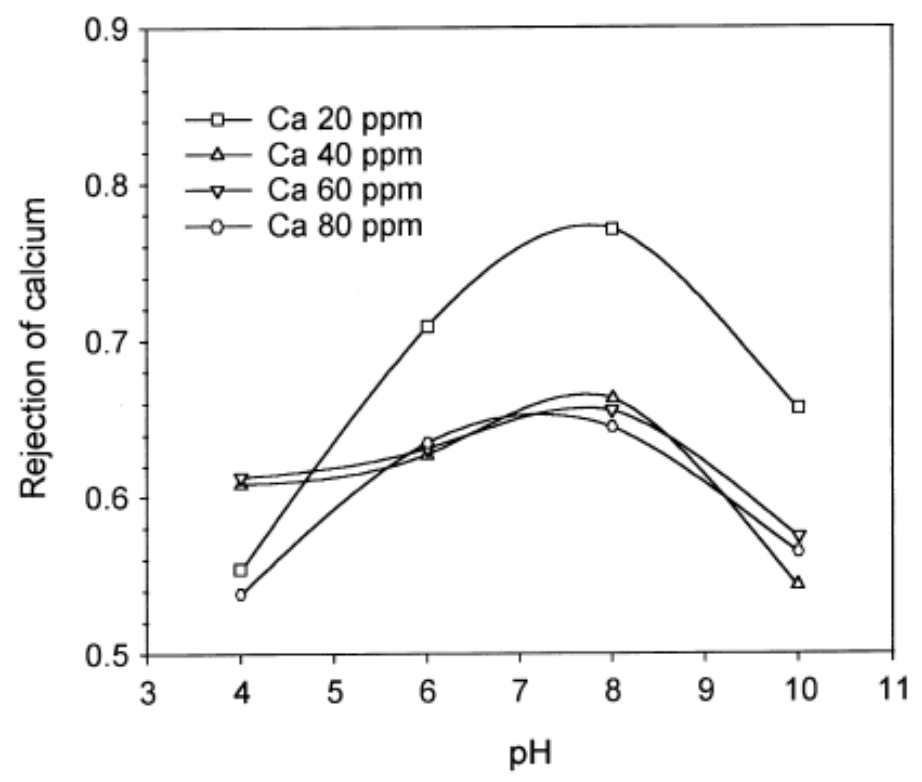

Figura 1.40. Retención del calcio frente al pH de la corriente de alimentación para concentraciones que van desde 20 a $80 \mathrm{mg} / \mathrm{L}$ de $\mathrm{Ca}^{2+}[148]$.

De igual forma, en varios trabajos también se profundiza en la eliminación de los iones sulfato de determinadas disoluciones acuosas. En [81] la retención encontrada por las membranas de nanofiltración NF-90 y NF-270 es del 95\% y 94\% de media, respectivamente. Estas retenciones son obtenidas con disoluciones de alimentación que contienen concentraciones de sulfatos que varían de 500 a 2000 mg/L. Mientras que en [145] la retención del sulfato de sodio con la membrana NF90 es de más del 99\% cuando se parte de una concentración de alimentación de 60000 mg/L.

Existen otros trabajos que profundizan en la eliminación de los sulfatos mediante técnicas de nanofiltración [149][150] y todos ellos están en la misma línea en cuanto a retenciones y parámetros de trabajo. 

2 OBJETIVO Y ALCANCE 

El objetivo del presente trabajo ha sido el de estudiar, desarrollar y aplicar una tecnología de membranas emergente, como es la nanofiltración, para tratar las aguas industriales de la industria del sector cerámico.

Este estudio ha tenido varias finalidades, por este motivo se han tratado varios tipos de agua. Por un lado, cuando se ha trabajado con aguas residuales procedentes de una fábrica de elaboración de baldosas cerámicas, la finalidad ha sido la de obtener un agua libre de los elementos contaminantes que superen los límites establecidos por la legislación vigente para poder ser vertidas. Sin embargo, se ha querido ir más lejos, y una vez tratada esta agua se ha analizado la posibilidad de poder reutilizarla en diferentes etapas del proceso, donde actualmente esto no es posible debido al incumplimiento de los requisitos de calidad necesarios. Por otro lado, cuando se ha tratado el agua industrial de proceso utilizada en una empresa de fabricación de polvo atomizado (agua residual industrial y agua limpia de pozo), se ha considerado ésta como una materia prima más, por tanto lo que se ha pretendido es mejorar su calidad, eliminando los elementos que afecten negativamente a las etapas donde se está utilizando, y por tanto, mejorar los procesos productivos donde ella interviene.

En cuanto al sector industrial, se ha considerado oportuno trabajar con el sector cerámico porque es un sector manufacturero tradicional de la Comunidad Valenciana con elevado peso a nivel nacional y mundial. Además, no se tiene constancia de la utilización de la nanofiltración en este sector a diferencia de otros sectores tradicionales como pueden ser la alimentación, el textil o el papelero.

A continuación se profundizará en la estructura que se ha elegido para llevar a cabo esta investigación. En primer lugar, la meta inicial de este trabajo ha sido la del estudio y caracterización de varias membranas poliméricas de nanofiltración para su posterior aplicación estratégica en la gestión de las aguas industriales de la industria cerámica mediante dos casos de estudio. Por tanto, una vez caracterizadas las membranas se han abordado dos objetivos en la tesis:

a) La eliminación, mediante técnicas de nanofiltración, de los compuestos de boro, ya que su presencia en las aguas residuales, incluso después de ser sometidas a tratamientos físicoquímicos, impide su reaprovechamiento o vertido. Por otra parte, su eliminación con las técnicas utilizadas en la actualidad (resinas de intercambio iónico y ósmosis inversa, principalmente) tiene asociado un coste económico muy elevado.

b) Eliminación o reducción, también por medio de esta tecnología, de la concentración de iones divalentes presentes en las aguas industriales de proceso. De esta forma, se podrá conseguir una calidad adecuada de las aguas tratadas para hacer más eficientes los procesos productivos donde ellas intervienen. Estos iones divalentes son $\mathrm{Ca}^{2+}, \mathrm{SO}_{4}{ }^{2-}$ y $\mathrm{Mg}^{2+}$ principalmente, que entre otros elementos son los causantes de la elevada conductividad del agua. Los iones mencionados, por su poder floculante, confieren características al agua que hacen menos eficientes algunas etapas del proceso productivo, como es el caso de la obtención del polvo atomizado utilizado para la fabricación de baldosas cerámicas. Por tanto, mediante un tratamiento de nanofiltración de las aguas utilizadas en la elaboración de suspensiones cerámicas para este proceso, se pretende mejorar el rendimiento de la etapa 
de atomización, así como disminuir el impacto ambiental asociado a las emisiones de $\mathrm{CO}_{2}$ y el consumo de compuestos químicos desfloculantes.

En ambos casos se ha realizado un balance económico con el objeto de analizar si la aplicación de esta tecnología de nanofiltración puede aportar beneficios económicos al sector.

En resumen, los objetivos finales del estudio son:

- Mejora en la reutilización de aguas residuales e industriales del sector cerámico.

- Mejora de la productividad y la eficiencia de algunas etapas del proceso productivo.

- Reducción de costes de producción.

- Minimización del consumo energético y la reducción del impacto ambiental asociado al proceso productivo.

Todos estos aspectos son sumamente importantes para trabajar en la sostenibilidad de los procesos productivos industriales. 
3 METODOLOGÍA 

En esta sección se describe la metodología experimental que ha sido utilizada para llevar a cabo todas las acciones necesarias para realizar el presente trabajo. Por tanto, en este apartado se ha realizado una descripción de los tipos de aguas tratadas, las membranas utilizadas, el equipamiento necesario, las técnicas de caracterización empleadas, así como la metodología de ensayo que se ha seguido a lo largo del estudio.

\subsection{Tipo de aguas a tratar}

En el presente estudio se ha trabajado con tres tipos de aguas: aguas sintéticas, aguas residuales industriales y aguas de proceso. En los siguientes apartados se ha profundizado en cada uno de ellos.

\subsubsection{Aguas sintéticas}

Se han utilizado aguas sintéticas a lo largo del estudio en diferentes ocasiones. En primer lugar, para la caracterización de las membranas se han utilizado disoluciones acuosas con diferentes compuestos. Los compuestos utilizados han sido seleccionados según el tipo de membrana (según la retención principalmente) y siempre teniendo en cuanta los compuestos que están dentro de la base de datos del programa informático Nanoflux ${ }^{\circledR}$ que se ha utilizado para caracterizar y extraer información del comportamiento de las membranas (Ver apartado 3.7 Programa de simulación NANOFLUX ${ }^{\circledR}$ ). A continuación se puede encontrar más información sobre estos compuestos:

\section{Compuestos neutros}

Los compuestos neutros se han elegido en función de su peso molecular, cuanto mayor sea el radio de poro de la membrana mayor tendrá que ser la masa molar de las sustancias que se utilicen para caracterizar dicha membrana. El flujo de permeado y la retención ofrecida por cada una de las membranas a cada compuesto neutro serán utilizados para estimar el radio de poro de la membrana mediante el programa informático Nanoflux ${ }^{\circledR}$. 
Los compuestos neutros utilizados y algunas de sus propiedades se han recopilado en la Tabla 3.1.

Tabla 3.1. Compuestos neutros y algunas de sus propiedades [151][152][153][154][155].

\begin{tabular}{|c|c|c|c|}
\hline Compuesto & $\begin{array}{c}\text { Masa molar } \\
(\mathrm{g} / \mathrm{mol})\end{array}$ & $\begin{array}{c}\text { Radio de Stokes } \\
(\mathrm{nm})\end{array}$ & $\begin{array}{c}\text { Coeficiente de } \\
\text { difusión a } 25^{\circ} \mathbf{C} \\
\left(\mathrm{m}^{2} / \mathrm{s}\right)\end{array}$ \\
\hline 1-Propanol & 60,1 & 0,223 & $1,1 \cdot 10^{-9}$ \\
\hline $\begin{array}{c}\text { 2-Propanol o alcohol } \\
\text { isopropílico }\end{array}$ & 60,1 & 0,241 & $1,02 \cdot 10^{-9}$ \\
\hline Etilenglicol & 62 & 0,212 & $1,15 \cdot 10^{-9}$ \\
\hline Glicerina & 92 & 0,260 & $0,94 \cdot 10^{-9}$ \\
\hline Arabinosa & 150 & 0,323 & $0,76 \cdot 10^{-9}$ \\
\hline Glucosa & 180 & 0,365 & $0,67 \cdot 10^{-9}$ \\
\hline Sacarosa & 342 & 0,47 & $0,52 \cdot 10^{-9}$ \\
\hline
\end{tabular}

\section{Compuestos cargados/sales}

Se han utilizado diferentes sales para caracterizar las membranas estudiadas. El flujo de permeado y la retención ofrecida por cada una de las membranas a cada sal han sido utilizados para estimar la densidad de carga superficial de cada una de las membranas mediante el programa informático Nanoflux ${ }^{\circledR}$. Las sales utilizadas y algunas de sus propiedades se recogen en la Tabla 3.2.

Tabla 3.2. Sales y algunas de sus propiedades [156].

\begin{tabular}{|c|c|c|c|c|}
\hline Compuesto & $\begin{array}{c}\text { Masa molar } \\
(\mathbf{g} / \mathrm{mol})\end{array}$ & $\begin{array}{c}\text { Radio de } \\
\text { Stokes } \\
(\mathrm{nm})\end{array}$ & $\begin{array}{c}\text { Radio de } \\
\text { Pauling } \\
(\mathrm{nm})\end{array}$ & $\begin{array}{c}\text { Coeficiente de } \\
\text { difusión a } 25^{\circ} \mathrm{C} \\
\left(\mathrm{m}^{2} / \mathrm{s}\right)\end{array}$ \\
\hline $\mathrm{Mg}^{2+}$ & 24,31 & 0,347 & 0,065 & $0,706 \cdot 10^{-9}$ \\
\hline $\mathrm{Na}^{+}$ & 22,99 & 0,184 & 0,095 & $1,334 \cdot 10^{-9}$ \\
\hline $\mathrm{SO}_{4}{ }^{2-}$ & 96,07 & 0,230 & 0,290 & $1,065 \cdot 10^{-9}$ \\
\hline $\mathrm{Cl}^{-}$ & 35,45 & 0,121 & 0,181 & $2,032 \cdot 10^{-9}$ \\
\hline
\end{tabular}

En segundo lugar, además de las aguas sintéticas realizadas para caracterizar las membranas y antes de trabajar con las aguas reales de los casos de estudio, también se han elaborado aguas 
sintéticas imitando a las reales para someterlas al tratamiento de nanofiltración, analizar el comportamiento de las membranas y los resultados obtenidos. En el primer caso de estudio se ha utilizado el ácido bórico $\left(\mathrm{H}_{3} \mathrm{BO}_{3}\right)$ y el hidróxido de sodio $\mathrm{Na}(\mathrm{OH})$ como modificador de $\mathrm{pH}$. Mientras que en el segundo caso de estudio, se ha utilizado cloruro sódico ( $\mathrm{NaCl}$ ), bicarbonato sódico $\left(\mathrm{NaHCO}_{3}\right)$ y sulfato de calcio dihidratado $\left(\mathrm{CaSO}_{4} \cdot 2 \mathrm{H}_{2} \mathrm{O}\right)$.

El agua para realizar las disoluciones, así como la que se utiliza para calcular la permeabilidad de las membranas de nanofiltración al agua pura, es agua proporcionada por un sistema MILLI-Q Millipore, de esta forma se ha asegurado un agua ultrapura durante todo el estudio, evitando perturbaciones que podrían ocasionar las posibles impurezas presentes en el agua.

\subsubsection{Aguas residuales industriales}

Como se ha comentado con anterioridad (ver apartado 1.1.3.1 Generación y características del agua residual) son las operaciones de limpieza de las secciones de preparación y aplicación de esmalte las que generan la mayor parte de aguas residuales en el sector cerámico. En cuanto a la composición química, éstas se caracterizan por la presencia de: sólidos en suspensión, iones disueltos, metales pesados en disolución y/o suspensión, compuestos de boro en cantidades más o menos variables y materia orgánica.

Las concentraciones de estos elementos dependen del tipo y la composición de los esmaltes involucrados y del volumen de agua utilizado en las etapas de limpieza, ya que generalmente estas etapas de limpieza se realizan de forma manual [12].

En este trabajo, en el primer caso de estudio se ha trabajado con el agua residual generada por una empresa de fabricación de baldosas cerámicas en cuyas características se profundizará al comienzo del apartado en el que se abordará el caso de estudio.

\subsubsection{Aguas de proceso}

En el segundo caso de estudio se ha trabajado con las aguas de proceso de una empresa de producción de polvo atomizado. El agua de proceso se denomina al agua utilizada como materia prima para la elaboración de cada uno de los sub-productos necesarios para producir el producto acabado final. Por consiguiente, se ha trabajado tanto con aguas residuales después de un tratamiento físico-químico, como con aguas de pozo, ya que las empresas dedicadas a este fin utilizan estos dos tipos de aguas para la producción del polvo atomizado (ver Figura 1.2 y el apartado 1.1.3.2 Gestión actual de las aguas residuales procedentes de las empresas de fabricación de baldosas cerámicas). Estas empresas en primer lugar, utilizan toda el agua residual que ellos mismos generan junto a las aguas residuales de otras empresas que se dedican a la elaboración de baldosas cerámicas, cuyo vertido es cero gracias a este tipo de empresas que introducen sus aguas residuales de nuevo en el proceso productivo. Sin embargo, generalmente los atomizadores son deficitarios de agua y por tanto, además de utilizar todas las aguas residuales que poseen, necesitan de agua limpia de pozo para alcanzar la producción de polvo atomizado requerido. Además, para la fabricación de determinados polvos atomizados de alto valor añadido utilizados en la elaboración de baldosas no esmaltadas no se pueden utilizar aguas residuales para la 
preparación de la suspensión cerámica que precede a dicho polvo atomizado. Por estas razones, se ha decidido considerar al agua de producción como una materia prima más, confiriéndole la importancia que realmente tiene y tratar de mejorar su calidad. Por este motivo, se ha trabajado tanto con las aguas residuales, como con el agua de pozo, ya que ambos tipos son utilizadas por las empresas para la elaboración de las suspensiones cerámicas necesarias para la obtención del polvo atomizado.

\subsection{Contaminantes objeto de estudio}

Los contaminantes en los cuales se ha focalizado el trabajo en los dos casos de estudio industriales reales han sido el boro y los iones divalentes:

- Boro: Los compuestos de boro se utilizan como materia prima en un gran número de procesos industriales entre los que se encuentra la industria cerámica [157]. La presencia de boro es bastante habitual en las aguas residuales de la industria cerámica y su contenido puede oscilar entre 1-80 mg/L (ver Tabla 1.1). Su presencia incluso en aguas clarificadas después de tratamientos físico-químicos impide su vertido. La presencia de este contaminante en estas aguas se debe a la elevada solubilidad de este elemento y su reducido tamaño iónico, características que no facilitan su eliminación con las técnicas de tratamiento más habituales en el sector cerámico.

- Iones divalentes: Entre otros factores, una alta conductividad iónica asociada a la presencia de algunas sales impide la reutilización de las aguas residuales. Incluso en aguas limpias de proceso, las elevadas concentraciones de algunos iones hacen disminuir considerablemente la eficiencia de los procesos productivos. Especialmente en el campo de la cerámica, los iones divalentes son altamente floculantes por lo tanto, hay que contrarrestar su efecto con la adición de desfloculantes con el consiguiente perjuicio económico para el proceso [11][51].

\subsection{Membranas}

El tratamiento en torno al cual gira este trabajo es la nanofiltración que es la técnica de filtración avanzada a través de membranas que, debido a su elevada selectividad, más se ha desarrollado en estos últimos años en el ámbito industrial.

Sin embargo, antes de realizar la nanofiltración, sobre todo a escala industrial, es aconsejable someter a las aguas a un pretratamiento previo para eliminar posibles sólidos en suspensión y otros elementos que puedan dañar las membranas del tratamiento principal. Por tanto, en este estudio se han utilizado membranas de microfiltración en el pretratamiento de las aguas y membranas de nanofiltración en el tratamiento propiamente dicho.

En la etapa de microfiltración se han utilizado dos tipos diferentes de membranas cerámicas tubulares multicanal, ambas de la marca comercial Orelis. En el anexo II se puede encontrar una ficha técnica con todas las características que el fabricante proporciona de estas membranas y en la Tabla 3.3 se compilan algunas de ellas. 
Tabla 3.3. Especificaciones de las membranas de MF proporcionadas por el fabricante.

\begin{tabular}{|c|c|c|c|c|}
\hline Membrana & $\begin{array}{c}\text { Número de } \\
\text { canales }\end{array}$ & $\begin{array}{c}\text { Diámetro de } \\
\text { canales }(\mathrm{mm})\end{array}$ & $\begin{array}{c}\text { Superficie } \\
\text { filtrante }\left(\mathrm{m}^{2}\right)\end{array}$ & Umbral de corte \\
\hline $\begin{array}{c}\text { KLEANSEPTM } \\
0,1 \mu \mathrm{m}\end{array}$ & 19 & 3,5 & 0,245 & $0,1 \mu \mathrm{m}$ \\
\hline $\begin{array}{c}\text { KLEANSEPTM } \\
300 \mathrm{kD}\end{array}$ & 52 & 2,2 & 0,52 & $300 \mathrm{kDa}$ \\
\hline
\end{tabular}

Los $0,1 \mu \mathrm{m}$ de la membrana KLEANSEPTM $0,1 \mu \mathrm{m}$ hacen referencia al tamaño medio del diámetro de poro de la membrana. En cambio la cifra 300 kD de la membrana KLEANSEPTM $300 \mathrm{kD}$, hace referencia al Peso Molecular de Corte (PMC) (término que en inglés se denomina "Molecular Weight Cut-Off"-MWCO). Por tanto, en este caso la membrana sería capaz de retener el $90 \%$ de las moléculas presentes en una disolución cuyo peso molecular fuese de 300000 Dalton (Da). El Peso Molecular de Corte (PMC), junto al diámetro de poro, son los dos parámetros más utilizados para clasificar las membranas de micro y ultrafiltración.

Estas membranas cerámicas solamente se han utilizado en los ensayos a nivel planta piloto. En los ensayos de laboratorio no se sometía a las aguas a ningún pretratamiento. Ya que las cantidades a filtrar no eran muy grandes y las membranas utilizadas después de cada serie de ensayos generalmente eran desechadas.
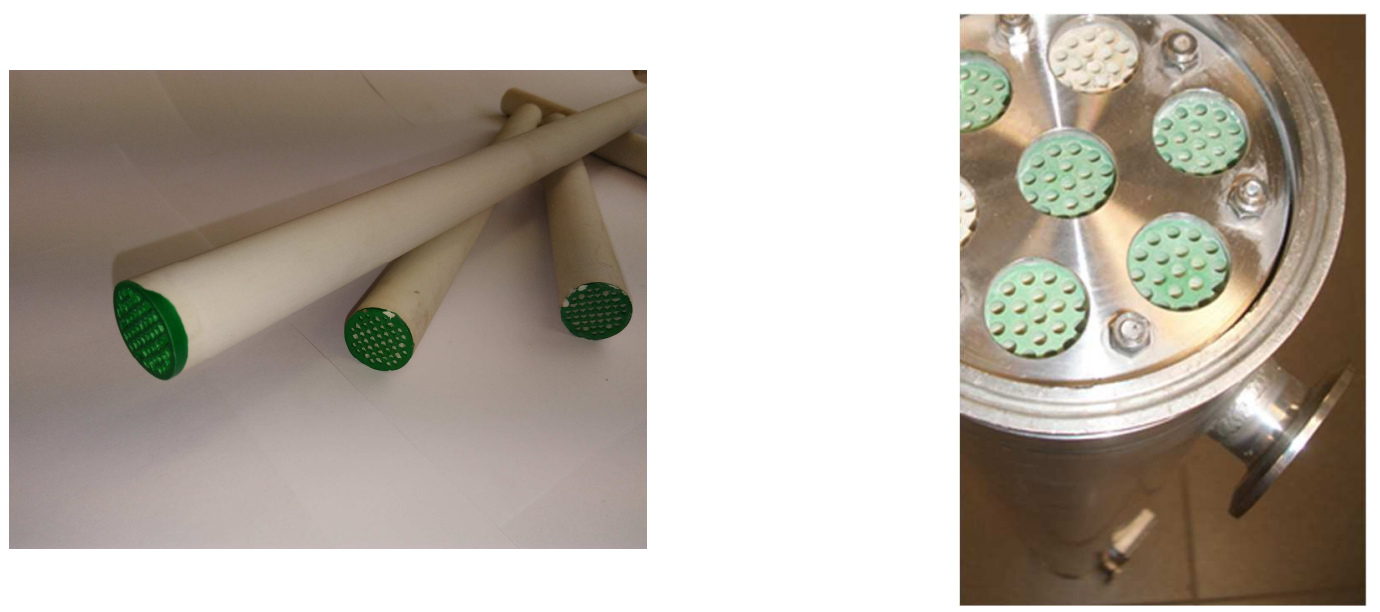

Figura 3.1. Membranas de microfiltración (MF) tubulares. a) Membranas KLEANSEPTM 300 kD b) Detalle de las membranas KLEANSEPTM 0,1 $\mu$ m introducidas dentro de su cárter de filtración.

En cuanto a las membranas de nanofiltración, normalmente están constituidas por tres partes, cada una de ellas tiene un papel particular:

- $\quad$ Un soporte macroporoso que ofrece una buena resistencia mecánica y que permite flujos elevados de líquidos (Definición de la dimensión de los poros en los medios porosos según la IUPAC (International Union of Pure and Applied Chemistry): microporos: $\mathrm{d}<2 \mathrm{~nm}$, mesoporos : $2 \mathrm{~nm}<\mathrm{d}<50 \mathrm{~nm}$ y macroporos : $\mathrm{d}>50 \mathrm{~nm}$ [43]). 
- Una o más capas intermedias, meso o macroporosas, que garantizan la conexión entre el soporte y la capa activa.

- Una capa activa en la cual se produce la separación por nanofiltración. El grosor de esta capa es pequeño, a menudo inferior al micrómetro con diámetros de poros del orden del nanómetro $(\mathrm{nm})$. La distribución de tamaño de estos poros es muy estrecha. Permite garantizar a la vez elevados flujos de líquidos y una importante selectividad de separación (entre las disoluciones eléctricamente cargadas y las disoluciones no cargadas). Más allá de esta morfología común, las membranas de nanofiltración poseen características físicas y químicas específicas vinculadas a su naturaleza orgánica.

Concretamente, en este trabajo se han utilizado cuatro membranas de nanofiltración diferentes, todas ellas de la marca Dow Filmtec. En el Anexo III se detalla las características y especificaciones técnicas de las membranas ofrecidas por el fabricante, algunas de ellas se recogen en la Tabla 3.4.

Tabla 3.4. Especificaciones de las membranas de NF proporcionadas por el fabricante.

\begin{tabular}{|c|c|c|c|}
\hline Membrana & $\begin{array}{c}\text { Material de la } \\
\text { Membrana }\end{array}$ & $\begin{array}{c}\text { Flujo de permeado } \\
\left.\text { (L/(h }^{2} \text { bar }\right)\end{array}$ & $\begin{array}{c}\text { Retención de } \text { MgSO }_{4} \\
(\%)\end{array}$ \\
\hline NF & Polipiperazina amida & 6,76 & $>98$ \\
\hline NF-90 & Poliamida & 8,68 & $>97$ \\
\hline NF-200 & Poliamida & 7,11 & $>97$ \\
\hline NF-270 & Poliamida & 10,68 & $>97$ \\
\hline
\end{tabular}

Nota: El flujo de permeado y la retención están basadas en las condiciones de trabajo siguientes: $2000 \mathrm{ppm} \mathrm{MgSO}_{4}, 25^{\circ} \mathrm{C}$ y $15 \%$ recuperación. Los flujos de permeado para elementos individuales pueden variar entre $-15 \% /+50 \%$.

En los ensayos a nivel de laboratorio se han utilizado membranas planas, mientras que en los ensayos en planta piloto se han utilizado membranas industriales en espiral. En la Figura 3.2 se pueden observar varias imágenes con estas membranas.
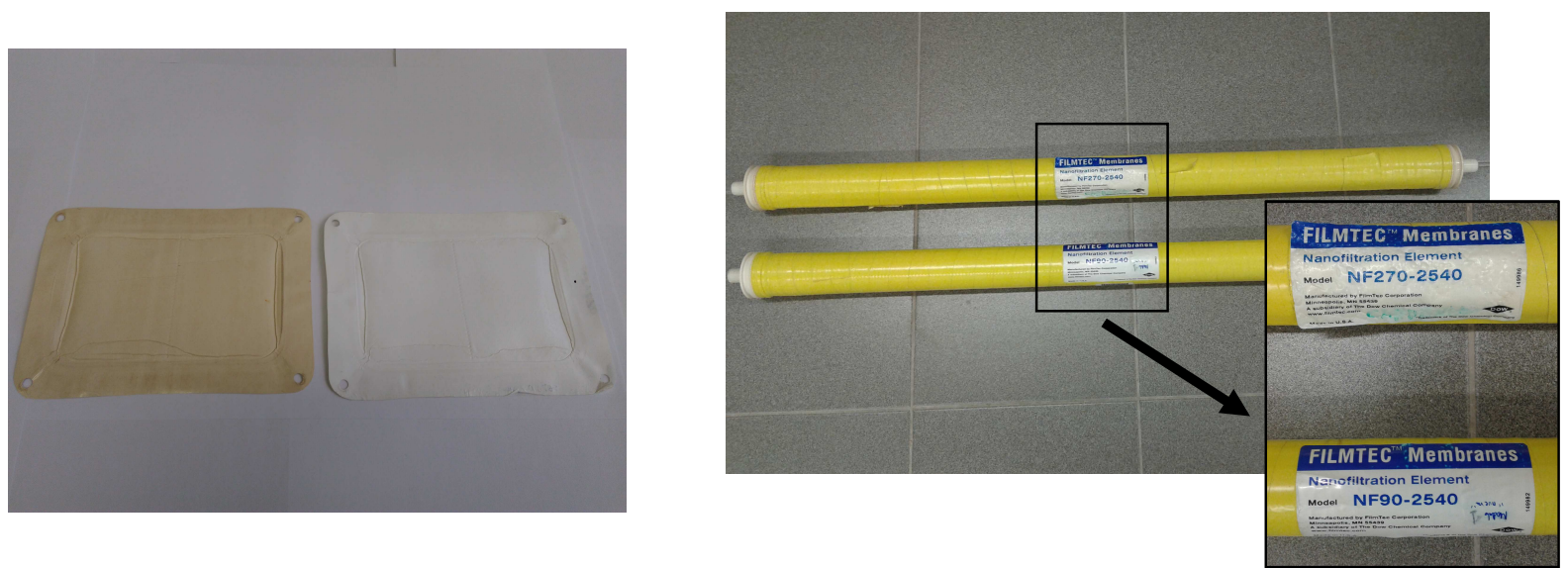

Figura 3.2. Membranas de nanofiltración planas (NF-90 y NF-270) y configuración en espiral (tipo 2540), respectivamente. 


\subsection{Equipamiento}

El equipamiento utilizado para la realización de este trabajo tiene un peso muy importante en el mismo. Además, como se ha trabajado a escala de laboratorio y a escala industrial, se ha tenido que ir adaptando el equipamiento a cada una de las situaciones.

Todos los equipos, independientemente de la escala que se trate, tienen en común los siguientes elementos: tanque/s de alimentación, bomba/s de circulación o sistema que aplique una diferencia de presión, manómetros de control de presión, caudalímetros, termómetros, cárteres para alojar las membranas, sistemas toma muestras y sistemas de captación de datos.

\subsubsection{Plantas de filtración tangencial a escala de laboratorio}

La caracterización de las membranas se realizó en el Instituto Europeo de Membranas de Montpellier (Francia) (en adelante IEM). Por tanto, se utilizó un equipo de filtración de este centro que consiste en una unidad de filtración tangencial que funciona en circuito cerrado (Figura 3.3 y Figura 3.4), dónde la corriente rechazo y la corriente permeada filtrada se recirculan en el depósito de alimentación, con el fin de mantener constante la concentración de la solución de alimentación.

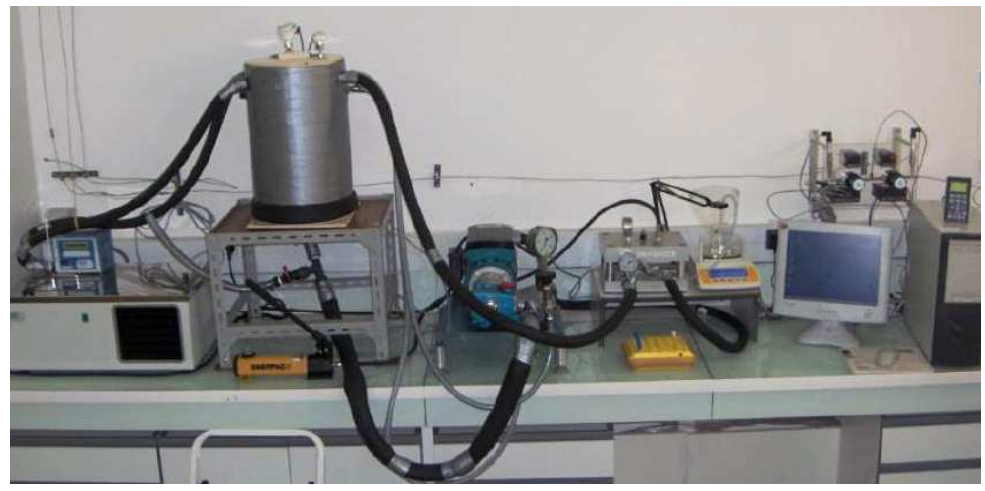

Figura 3.3. Foto de la planta de filtración tangencial escala laboratorio del IEM.

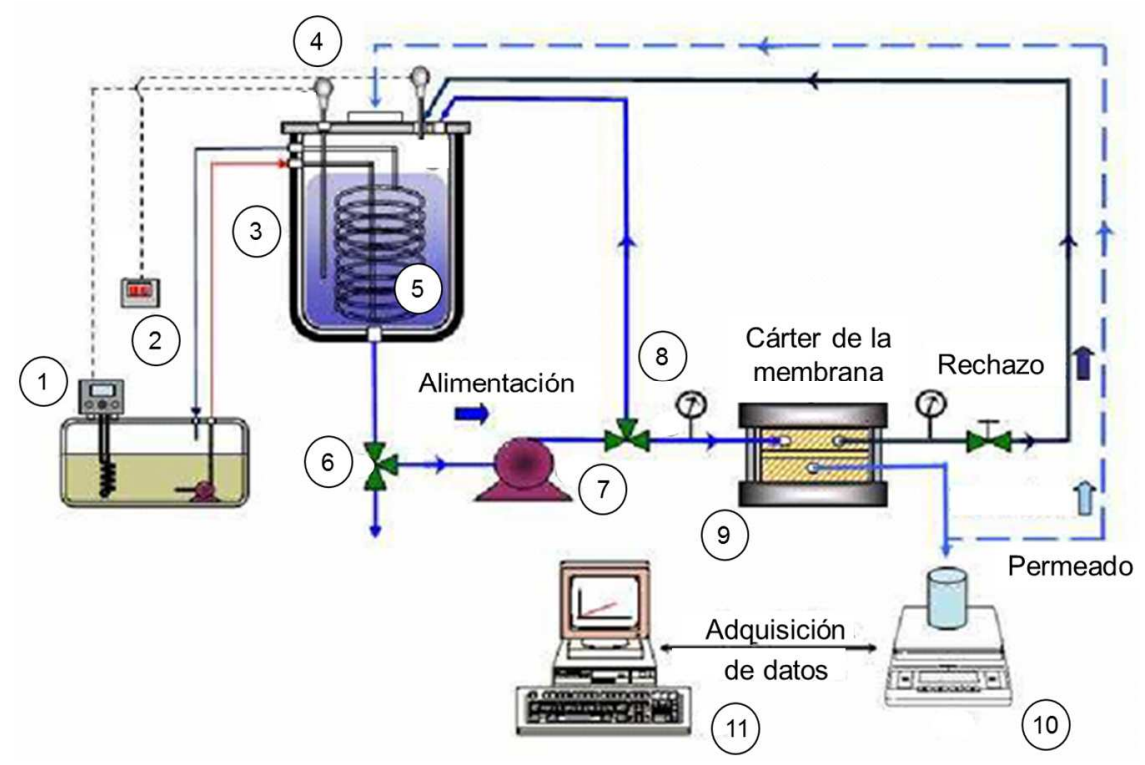

1- Criotermostato de circulación

2- Controlador de temperatura

3- Deposito cilíndrico calorifugado

4- Sonda de temperatura

5- Serpentín

6- Válvula

7- Bomba volumétrica

8- Manómetro

9- Módulo de nanofiltración tangencial

10- Balanza de precisión

11- Ordenador captador de datos (PC)

Figura 3.4. Esquema descriptivo de la planta de filtración tangencial escala laboratorio del IEM. 
El modulo o cárter que contiene la membrana de nanofiltración es una célula a presión de acero inoxidable (modelo SEPA-CF OSMONICS), este módulo tiene en su interior una membrana plana colocada entre dos mallas de plástico, una se llama de alimentación y la otra de circulación (Figura 3.5). Estas mallas permiten que la difusión de la materia sobre toda la superficie de la membrana sea uniforme. La superficie activa de la membrana es de $133 \mathrm{~cm}^{2}$.

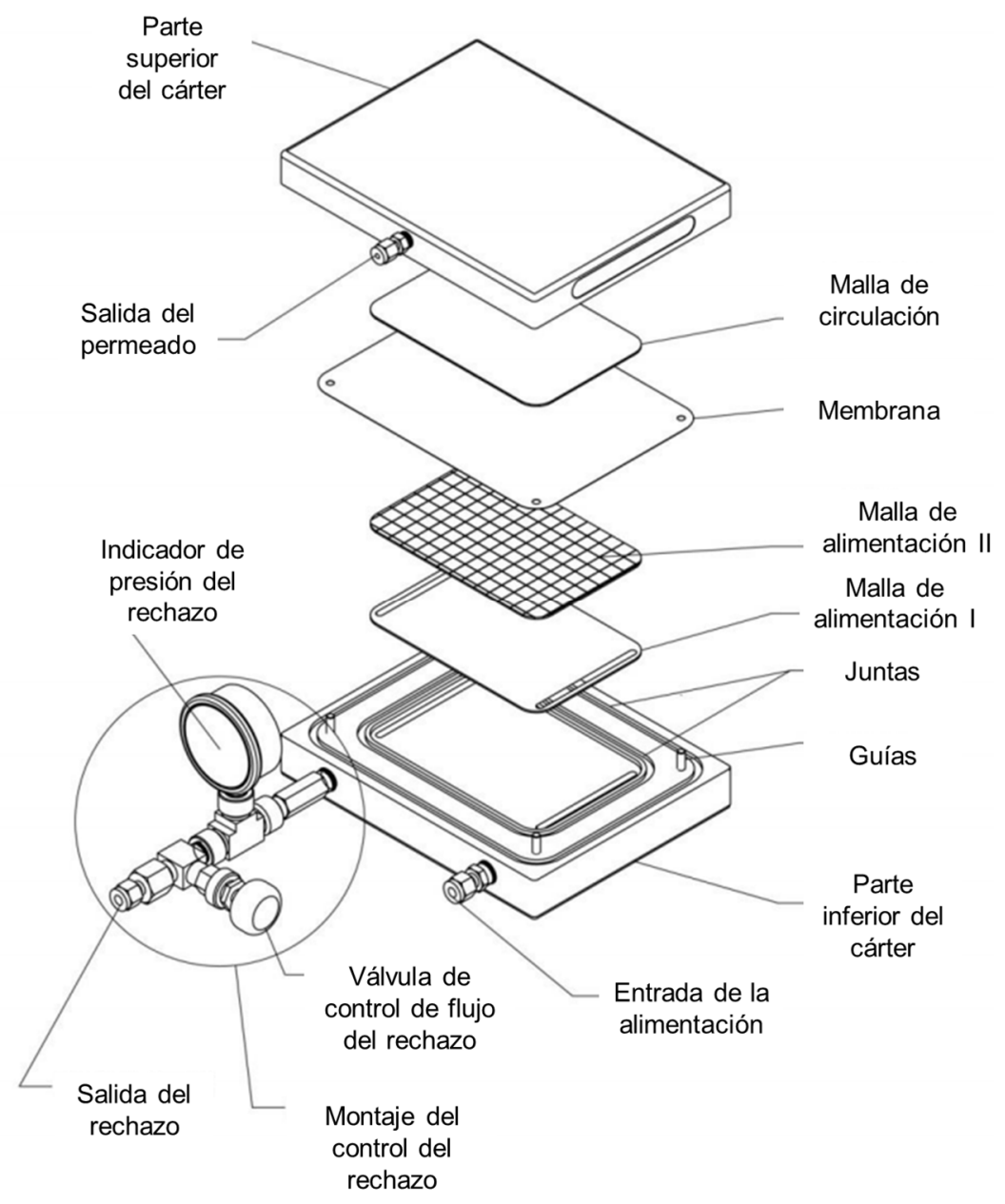

Figura 3.5. Esquema del cárter que contiene la membrana [158].

El fluido a tratar (disolución acuosa) se almacena en el depósito o tanque cilíndrico de PVC con capacidad de 30 litros. Las tuberías de la instalación son de PVC trenzado ( $P_{\max }=20$ bar). La circulación del fluido está impulsada por una bomba volumétrica CAT PUMPS 231 de 9 L/min (con una presión máxima de 40 bar), impulsada por un motor con variador de velocidad (VSM 011 de BROOK HANSEN) de 1,1 kW. Para variar la alimentación, existe una válvula que permitía modificar la presión aplicada a la membrana, esta presión se determina por medio de dos manómetros.

Hay que destacar que todos los componentes del dispositivo son de materiales inertes como teflón o acero inoxidable. Así se reducen la adsorción y las pérdidas de reactivos por interacción entre materiales. La calefacción o el enfriamiento del líquido de alimentación se realiza por medio de un serpentín de acero inoxidable, colocado en el interior del tanque. Un criotermostato de circulación de agua Frigiterm-10 P-SELECTA, garantiza la regulación y la circulación de agua que abastece el serpentín. El control de la temperatura está asegurado por medio de dos sondas de temperatura 
PT100. Una de ellas está en el interior del tanque y conectada al criotermostato. Y la otra está, conectada a un indicador numérico WEST 6010 para controlar la temperatura del rechazo. Con el fin de reducir al máximo las pérdidas térmicas el conjunto de la tubería y el tanque están aislados con una envoltura aislante de poliuretano.

La medida del flujo de permeado se efectúa por pesada. Para ello se utiliza una balanza SARTORIUS CP323S conectada a un PC encargado de la adquisición de los datos por medio del programa informático WINWEDGE.

Las pruebas a escala de laboratorio en cada uno de los casos de estudio (eliminación de compuestos de boro y sales divalentes) se realizaron en el Instituto de Tecnología Cerámica (en adelante ITC), por tanto, se utilizó el equipamiento que en este centro se dispone y que a continuación se describe. El equipo de filtración avanzada a escala de laboratorio del ITC es homólogo al del IEM y está equipado con varios módulos que permiten utilizar membranas de diferentes tipos. Una fotografía de este equipo puede observarse en la Figura 3.6:

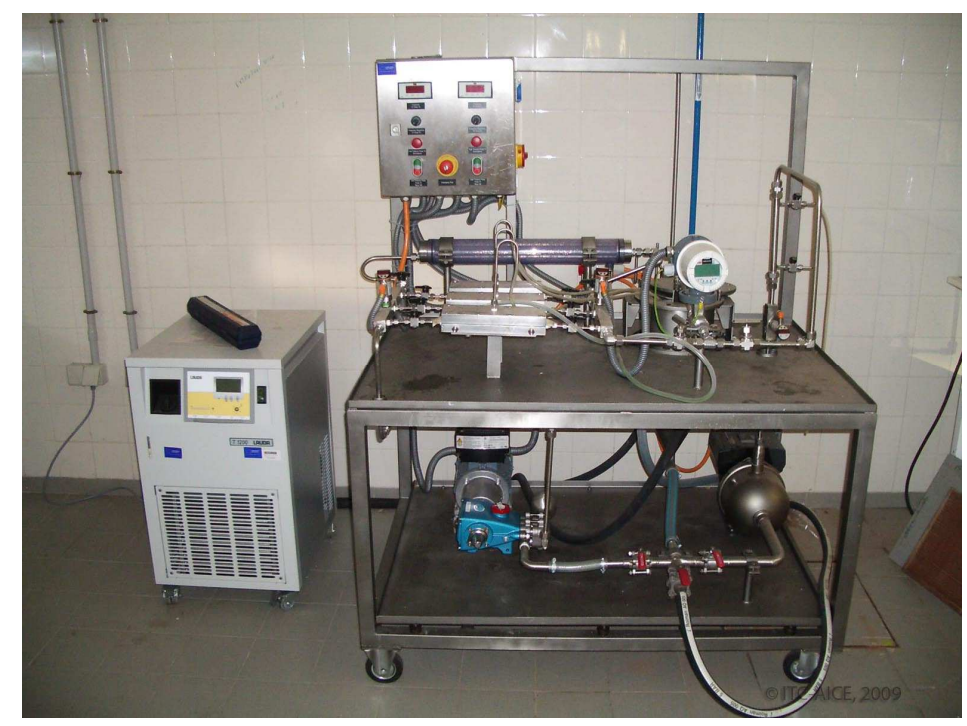

Figura 3.6. Planta de separación de efluentes líquidos mediante membranas a escala de laboratorio del ITC.

Esta planta se puede dividir en dos partes o bloques, la parte que funciona a altas presiones y la parte de baja presión. En las pruebas de laboratorio realizadas en el ITC solamente se ha utilizado la parte de alta presión, ya que es la que permite realizar los ensayos de nanofiltración. La parte de alta presión (3 a 30 bar) puede utilizar tres módulos planos de filtración, tal y como se aprecia en la Figura 3.7. En estos módulos se utilizan membranas poliméricas (como por ejemplo las NF-90 y NF-270 caracterizadas en el equipo anterior), con una superficie activa de $96 \mathrm{~cm}^{2}$ por módulo.

Esta parte está equipada con una bomba de pistón capaz de proporcionar elevadas presiones al sistema, además incluye manómetros para controlar la presión de trabajo.

Por último, el equipo dispone de un termocriostato externo que calorífuga el depósito donde se introduce la muestra que se ha de filtrar, de esta forma se mantiene en todo momento la temperatura de la disolución controlada. La temperatura es un parámetro que puede influir de forma decisiva en 
la filtración, por este motivo es muy importante tener un dispositivo capaz de controlar y modificar, si es necesario, la temperatura a la cual se realizan los ensayos.

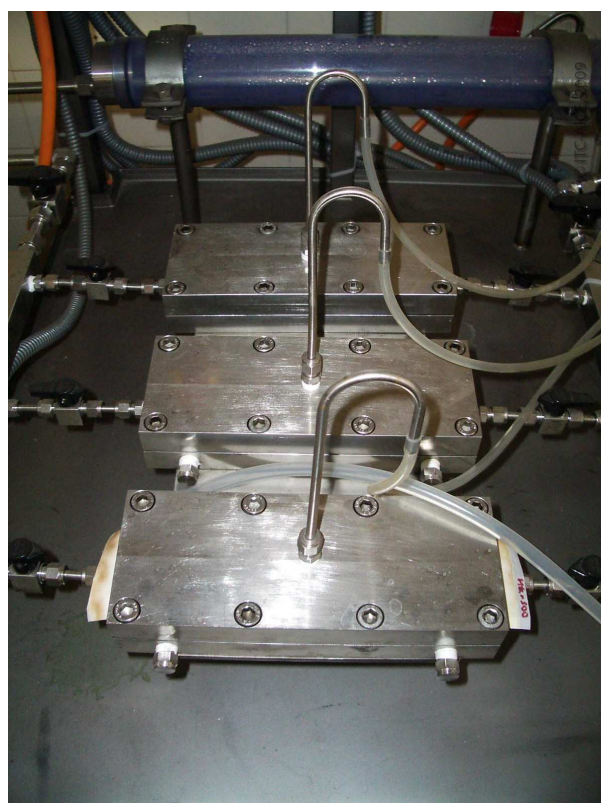

Figura 3.7. Detalle de los 3 módulos planos de filtración mediante membranas poliméricas de la planta del ITC.

Otras características técnicas son las siguientes:

- Depósito de alimentación: de 2 a 8 L de disolución.

- Intervalo de temperaturas en el que se puede trabajar: 1 a $40^{\circ} \mathrm{C}$.

- Intervalo de presión de alimentación: 0 a 30 bar.

- Intervalo de frecuencia de la bomba de circulación de la disolución: 0 a $50 \mathrm{~Hz}$.

Por tanto y resumiendo, las pruebas a escala de laboratorio en los casos de estudio, se han realizado de forma discontinua, con una instalación de laboratorio capaz de albergar membranas planas poliméricas y que opera de forma tangencial. El modo de funcionamiento de esta instalación del ITC es exactamente el mismo que el de la instalación del IEM, por este motivo no se ha considerado oportuno una descripción tan detallada.

\subsubsection{Planta de filtración tangencial a escala piloto}

Después de haber trabajado a escala de laboratorio, se han realizado pruebas de filtración a una escala superior mediante la utilización de una planta piloto capaz de albergar membranas comerciales.

Para la realización de las pruebas a escala piloto se ha utilizado la instalación que el ITC tiene para llevar a cabo este tipo de trabajos de filtración avanzada. Esta planta piloto puede observarse en la Figura 3.8. 

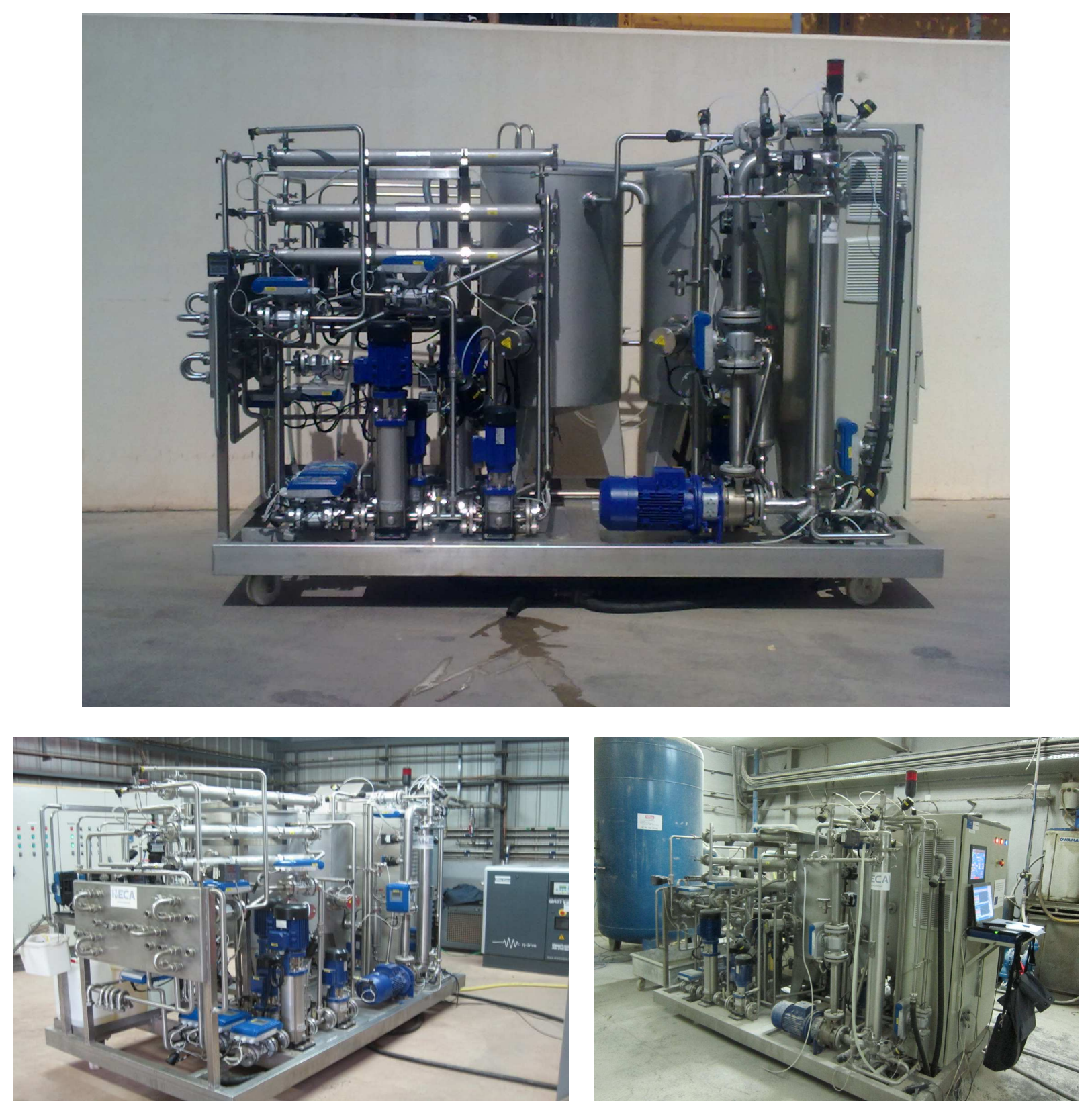

Figura 3.8. Planta piloto de filtración avanzada del ITC. Vista general del piloto tomada en ITC y ubicación del piloto en las empresas participantes en los casos de estudio (eliminación de compuestos de boro y sales divalentes), respectivamente.

En la Figura 3.9 se puede observar un plano proporcionado por la empresa encargada de la construcción de la planta piloto en el que se puede apreciar todas las partes que componen este equipo y la interconexión entre cada una de ellas. 


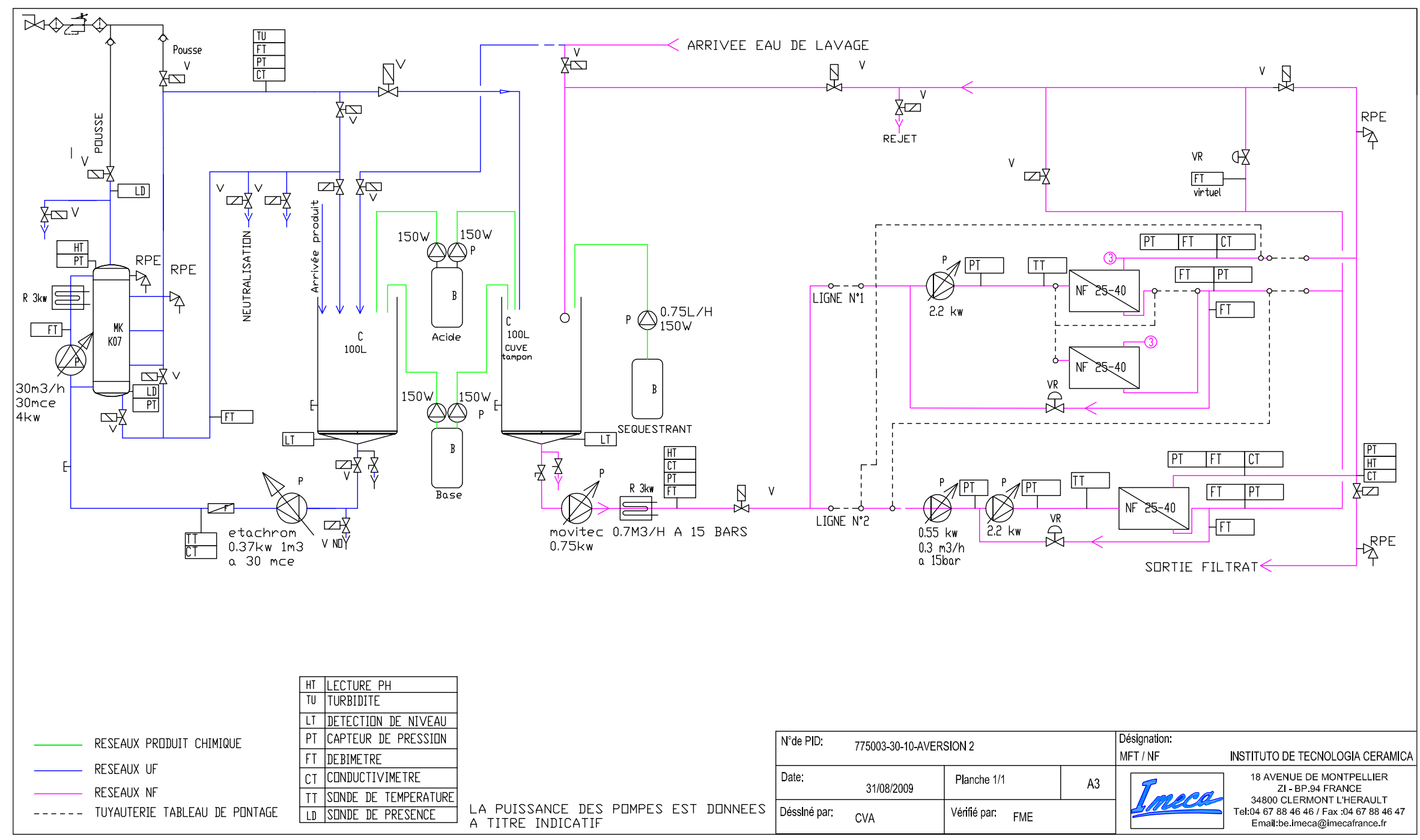

Figura 3.9. Plano de la planta piloto de filtración avanzada del ITC. 
Esta planta piloto de filtración consta de dos partes bien diferenciadas. En primer lugar se puede encontrar una etapa de pretratamiento o parte de microfiltración, ésta consta de un módulo donde se pueden colocar hasta siete membranas cerámicas de microfiltración (Ver Figura 3.10). La parte de microfiltración es capaz de operar a presiones que oscilan entre 1 y 4 bar.
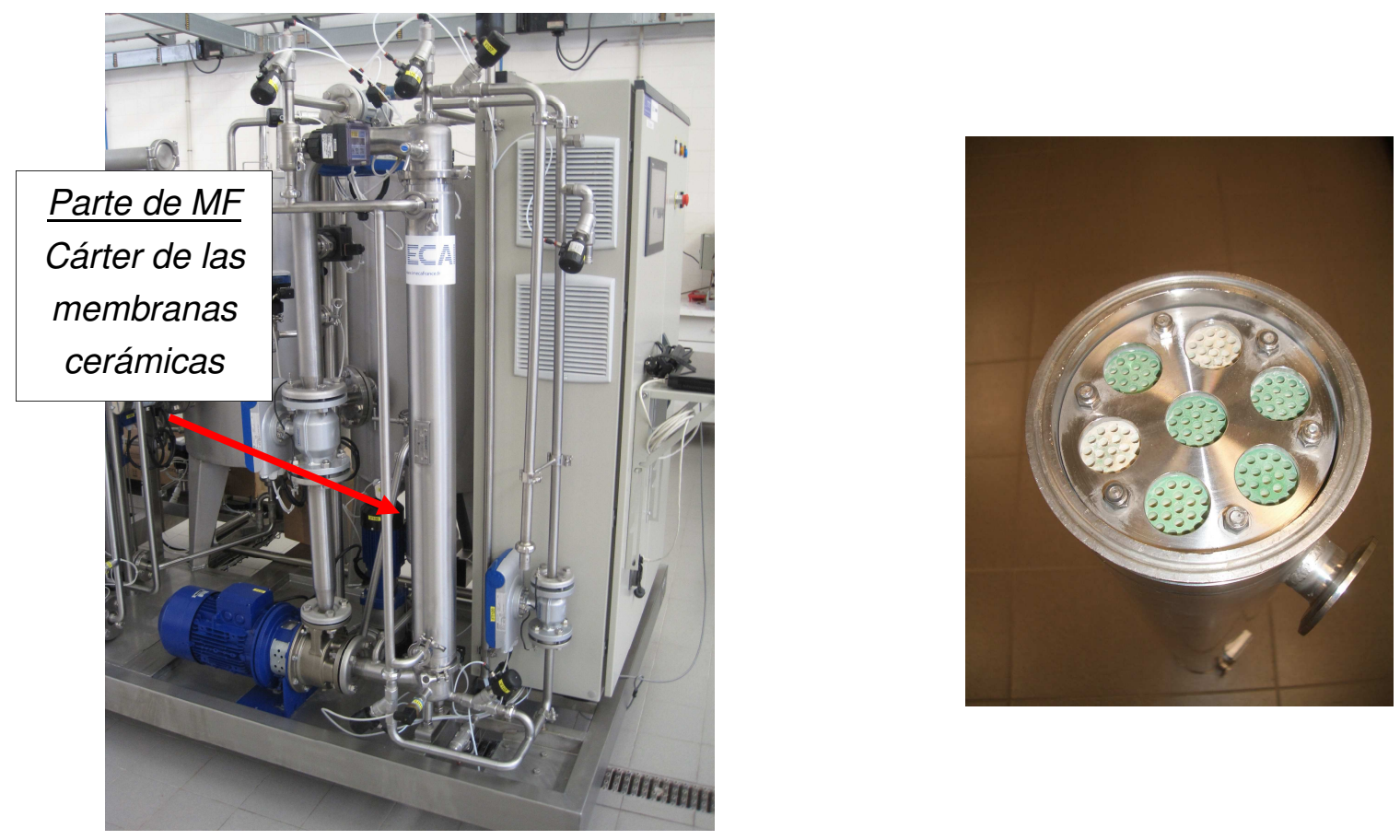

Figura 3.10. Parte de microfiltración y detalle del cárter de membranas cerámicas desmontado.

A continuación, se muestra la Figura 3.11 donde se puede observar el diagrama sinóptico de la parte de microfiltración.

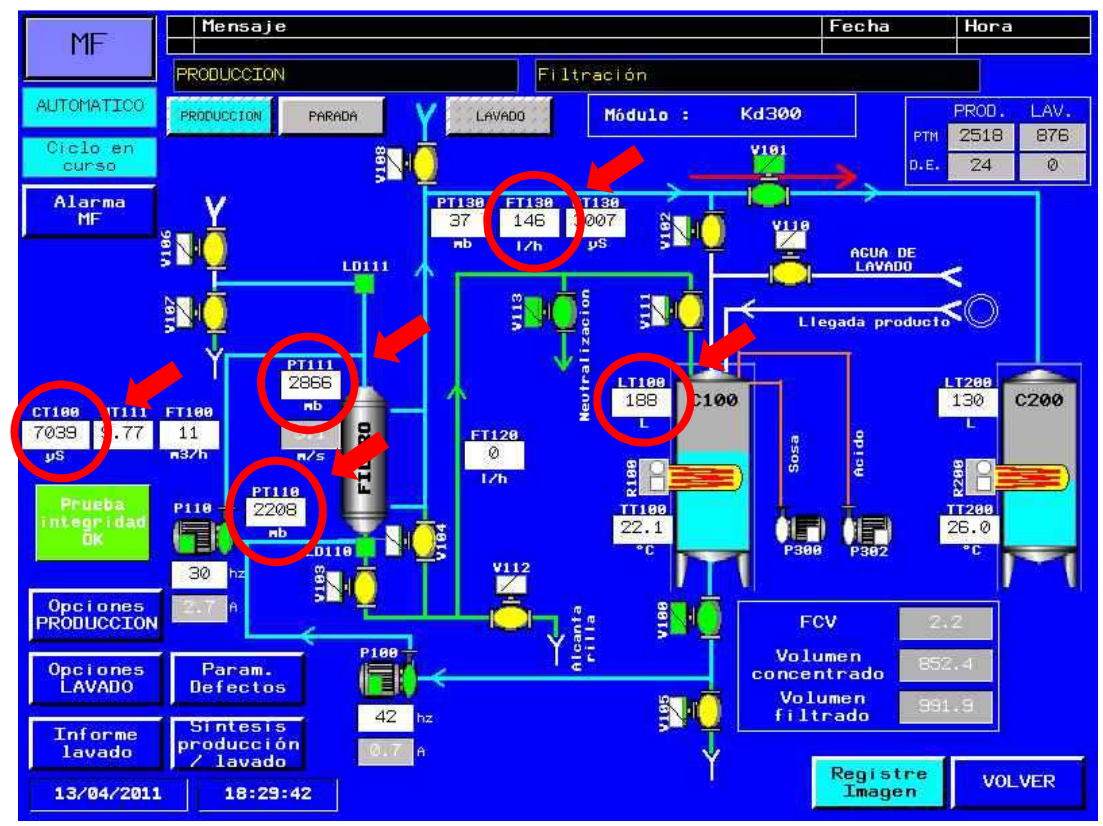

Figura 3.11. Diagrama sinóptico de la parte de microfiltración. 
Este sinóptico es el que el operador de la planta piloto puede ver en todo momento y es la interfaz máquina-operador que le permite seguir los parámetros de control durante el funcionamiento de la planta. Algunos de estos parámetros están marcados en rojo en la figura a modo de ejemplo: presiones de trabajo (PT100 y PT111), caudal de permeado (FT130), nivel del tanque que alimenta la etapa de microfiltración (LT100), conductividad del agua de producción (CT100)...

Sin embargo, el núcleo importante de la planta piloto es la parte de nanofiltración, donde se pueden utilizar simultáneamente tres membranas poliméricas en espiral de tipo 2540 en configuraciones muy diversas (en serie, en paralelo y combinaciones de ambas). La parte de nanofiltración puede trabajar a presiones comprendidas entre 4 y 20 bar.

Toda la planta piloto está equipada con instrumentos de medida en línea para la determinación de las variables necesarias que permiten el seguimiento en continuo de la filtración, así como de un sistema informático de captación de datos para el registro de dichas variables. La instalación dispone de varios caudalímetros, conductímetros, termómetros, manómetros, medidores de $\mathrm{pH}, \mathrm{y}$ electroválvulas, todos ellos conectados a un autómata que es el responsable de coordinar todas las partes de la planta piloto para llevar a cabo los diferentes ensayos (ver Figura 3.12).
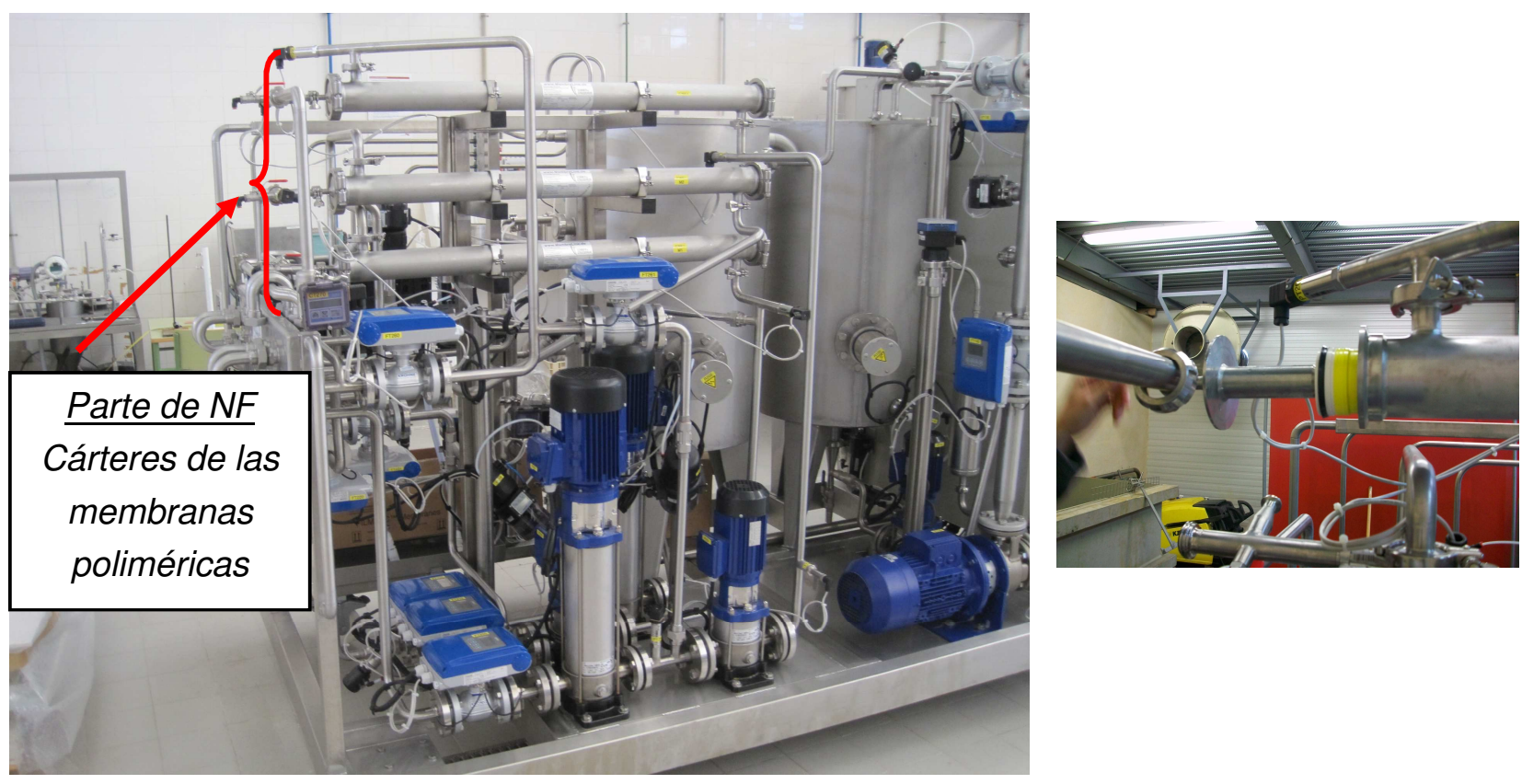

Figura 3.12. Parte de nanofiltración, cárteres que albergan las membranas poliméricas, bombas, depósitos, conducciones y equipamiento necesario para el funcionamiento de la plana. Detalle de la introducción de una membrana en su cárter.

Al igual que en la parte de la microfiltración, la planta piloto también ofrece una interfaz máquinaoperador muy cómoda para el control de todos los parámetros de la parte de nanofiltración. A continuación, en la Figura 3.13 se puede observar su diagrama sinóptico. Alguno de los parámetros que el operador puede seguir se resaltan en rojo en la figura: nivel del tanque (LT200) que alimenta la etapa de nanofiltración y alberga el permeado procedente de la etapa de microfiltración, pH del agua de producción (HT200), temperatura del agua de producción que pasa por la membranas (TT250), caudal de alimentación (FT200), presiones de trabajo (PT251 y PT260), caudal de 
permeado (FT280), caudal de rechazo (FT 260), conductividad de la alimentación (CT200) y la del permeado (CT280)...

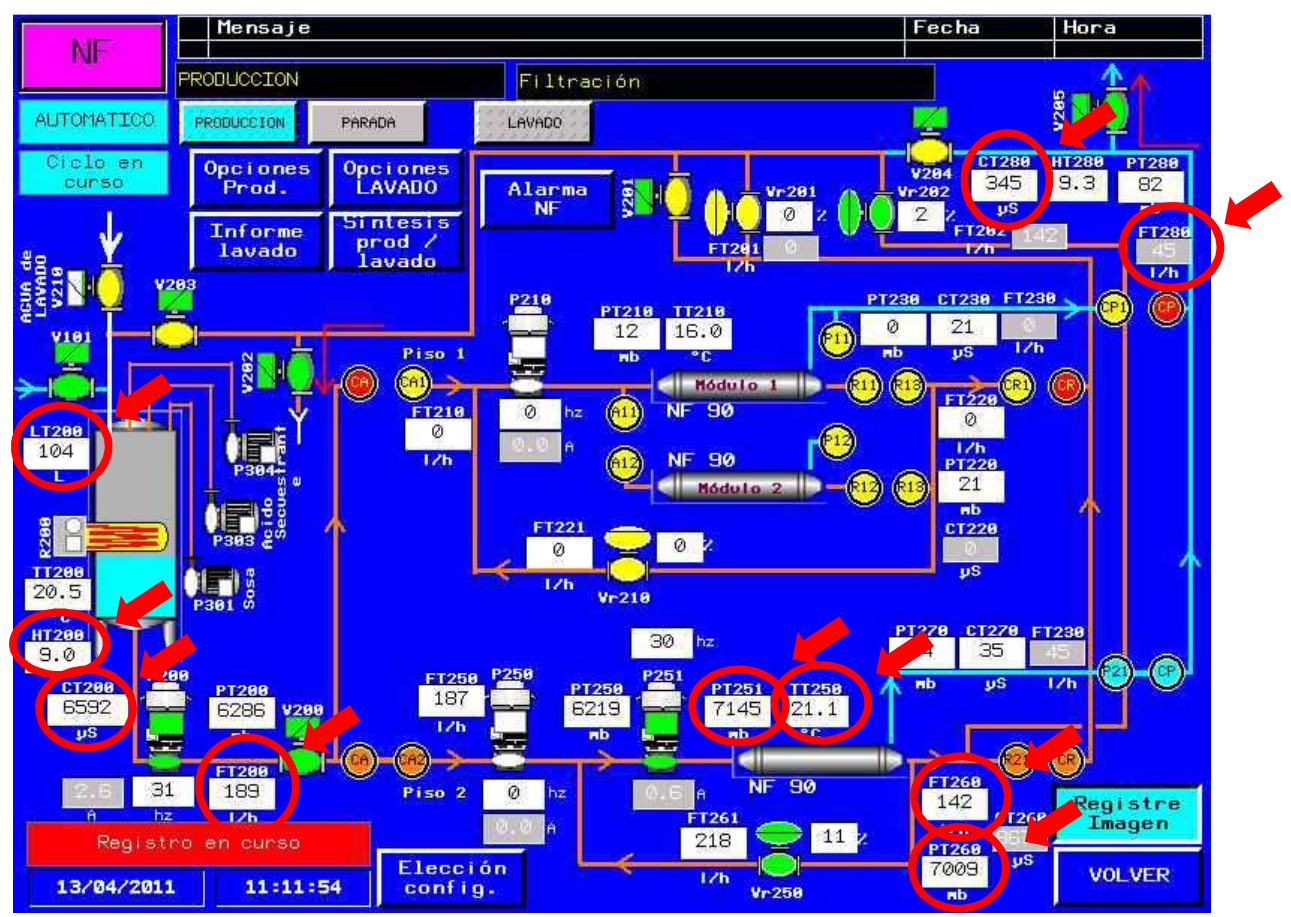

Figura 3.13. Diagrama sinóptico de la parte de nanofiltración.

\subsection{Análisis y determinación de diferentes parámetros de las aguas}

En este punto se hace referencia a los distintos métodos utilizados para la realización de los análisis y determinación de los diferentes parámetros necesarios para la realización de las tareas de este trabajo.

\subsubsection{Compuestos orgánicos}

Se utilizan diferentes métodos de análisis según el tipo de muestra que debe analizarse. Si se tienen muestras de disoluciones neutras con un único polímero, se puede utilizar la refractometría. Si por el contrario, se tiene una mezcla de polímeros, se utiliza la cromatografía de exclusión estérica. En este apartado también se recogerá una breve explicación de la determinación de la DQO.

\section{Refractometría}

El refractómetro interferométrico es un detector extremadamente sensible y estable el cual mide la diferencia de índice de refracción entre el líquido que debe analizarse y un líquido de referencia (en este caso es agua pura). El índice de refracción se mide a una longitud de onda fija y una temperatura ajustable fija. El equipo utilizado fue un Optilab DSP de Wyatt Technology Corporation (ver Figura 3.14). 


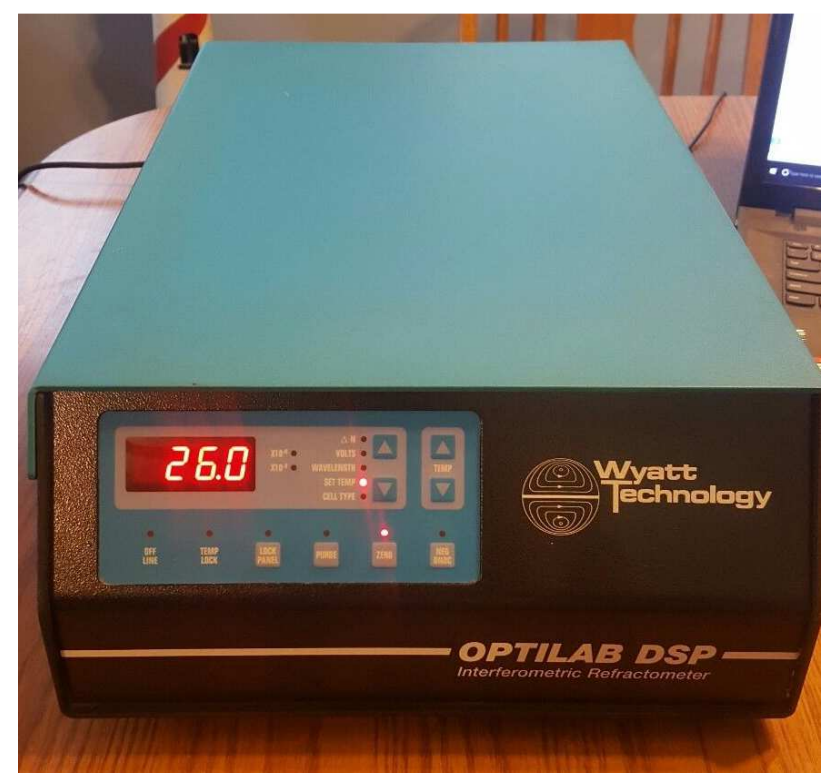

Figura 3.14. Refractómetro interferómetrico.

Este método de análisis permite conocer la concentración de los compuestos neutros utilizados en la caracterización de las membranas presentes en las muestras del permeado y en la disolución de partida, de esta forma se puede calcular la retención que la membrana ofrece a estos compuestos. Con ayuda de una jeringuilla, se inyectan las distintas muestras del permeado recogidas. Los refractogramas obtenidos (intensidad en voltios en función del tiempo en minutos) presentan picos terminados en una zona plana cuya altura es directamente proporcional a la concentración del componente medido.

Cada muestra se inyecta 3 veces para tener 3 picos, la media de las alturas de los picos representados en el refractograma será el valor a tener en cuenta. La medida de estos picos se realiza mediante un programa informático según los siguientes pasos:

- fijación de una línea de base para cada serie de picos.

- medida de la altura e intensidad de los picos.

- determinación de la concentración con ayuda de una curva de calibrado.

\section{Cromatografía de exclusión estérica}

Se llama cromatografía de exclusión estérica ("Size Exclusión Chromatography"-SEC) a un tipo de cromatografía líquida. Contrariamente a los métodos de cromatografía convencional, el fenómeno físico que permite la separación de las distintas macromoléculas que se pretenden analizar no se basa en la afinidad química con el soporte, sino simplemente en el tamaño de las macromoléculas (su volumen hidrodinámico).

El elemento clave que distingue la cromatografía de exclusión estérica de la cromatografía de fase líquida ordinaria es que las columnas se llenan con un material caracterizado por una distribución de poros moleculares de tamaños diferentes. Las moléculas de polímero entran y salen de estos poros según su tamaño. Las más grandes no entran en los poros y en consecuencia pasan más rápidamente a través de la columna. Las más pequeñas entran en todos los poros y por lo tanto 
tardan más tiempo para cruzar la columna. Hay pues, una separación según la dimensión de los polímeros. En este estudio se utilizó la columna Superose 12 de GE Healthcare (ver la Figura 3.15).

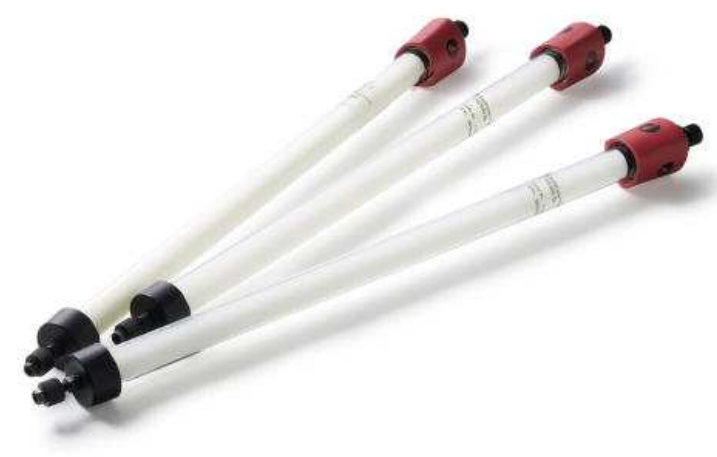

Figura 3.15. Columna de cromatografía de exclusión estérica "Superose 12"[159].

En la salida de la columna hay instalado algún tipo de equipo detector (viscosímetro, fotómetro, refractómetro...) que cuantifica el número de moléculas que salen de la columna en función del tiempo. En este caso el detector que se instaló es un refractómetro, tal y como se observa en la Figura 3.16.

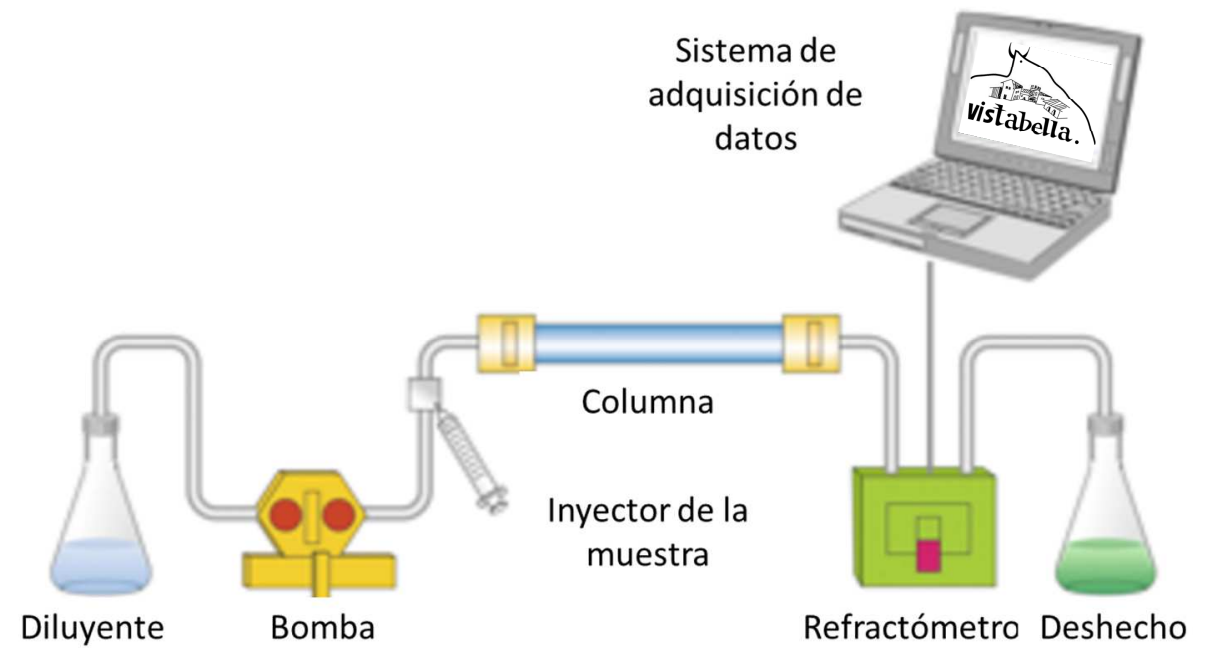

Figura 3.16. Esquema típico del montaje de la columna de cromatografía de exclusión estérica + el refractómetro[160].

\section{Determinación de la Demanda Química de Oxígeno (DQO)}

La DQO es la cantidad de oxígeno consumido para la oxidación total de los constituyentes orgánicos a productos inorgánicos. La determinación de la DQO se ha realizado según la norma UNE 77004/89. 


\subsubsection{Compuestos inorgánicos}

Los métodos que se han utilizado en el análisis de las distintas especies inorgánicas presentes en las aguas con las que se ha trabajado se detallan en la Tabla 3.5.

Tabla 3.5. Métodos y equipos utilizados en los análisis de las especies inorgánicas de las aguas utilizadas en este estudio.

\begin{tabular}{|l|l|}
\hline \multicolumn{1}{|c|}{ Parámetros o especies } & \multicolumn{1}{|c|}{ Método } \\
\hline Compuestos de B & $\begin{array}{l}\text { Método de la azometina-H por espectrofotometría de UV-VIS. } \\
\text { Utilizando un espectrofotómetro modelo UV-160 A de la firma } \\
\text { SHIMADZU. }\end{array}$ \\
\hline $\mathrm{SO}_{4}{ }^{2-} \mathrm{y} \mathrm{Cl}^{-}$ & $\begin{array}{l}\text { Cromatografía iónica. Utilizando un cromatógrafo modelo "ICS- } \\
1000 \text { " de la firma DIONEX }\end{array}$ \\
\hline $\mathrm{Na}^{+}, \mathrm{Ca}^{2+} \mathrm{y} \mathrm{Mg}^{2+}$ & $\begin{array}{l}\text { Espectrofotometría de absorción atómica UNE 77-056. Utilizando } \\
\text { un espectrofotómetro modelo AAnalyst 400 de Perkin Elmer }\end{array}$ \\
\hline $\begin{array}{l}\text { Sólidos en suspensión } \\
(\text { arcillas, esmaltes...) }\end{array}$ & Norma UNE-EN 872 \\
\hline
\end{tabular}

En la Figura 3.17 se recopilan las fotografías de los equipos mencionados en la Tabla 3.5.
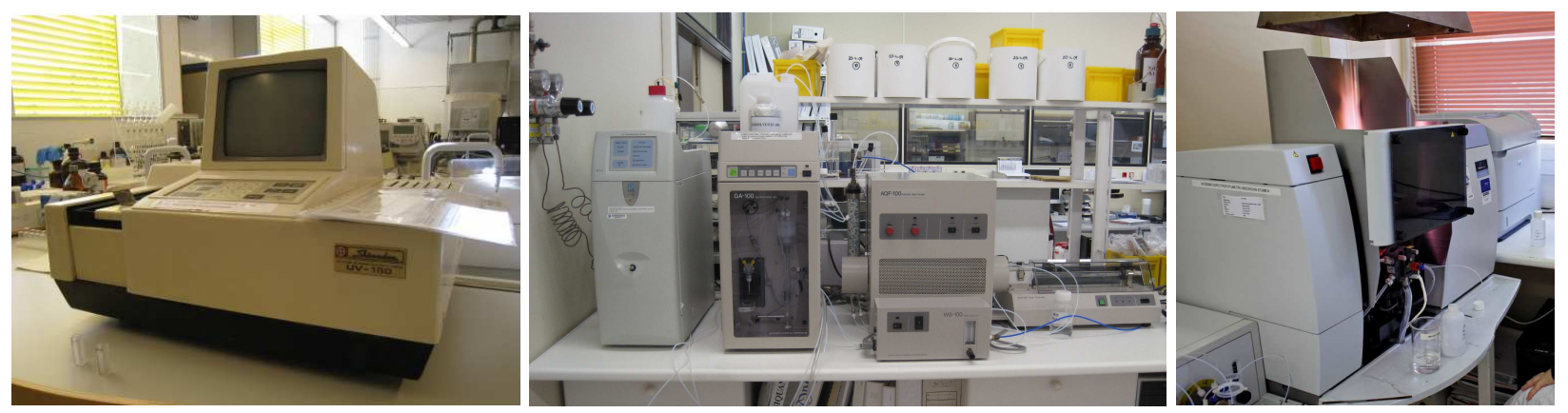

Figura 3.17. Espectrofotómetro, cromatografía iónica y espectrofotómetro de absorción atómica, respectivamente.

\subsubsection{Otros parámetros de interés}

Además de los compuestos orgánicos e inorgánicos de las muestras también se han tenido que analizar otros parámetros complementarios a lo largo de todo el trabajo. A continuación se profundizará en cada uno de ellos.

\subsubsection{Determinación de la conductividad}

La determinación de la conductividad se ha realizado con equipamiento diferente si se trata de los ensayos a escala laboratorio o a escala piloto, ya que en estos últimos la conductividad es medida directamente por los conductímetros instalados en línea en la propia instalación piloto. Por tanto, en los ensayos a escala laboratorio la conductividad se ha llevado a cabo por medida directa sobre la 
muestra, utilizando un conductímetro CRISSON. En cambio, en los ensayos a escala piloto, los conductímetros utilizados son de la marca BÜRKERT serie 8226 instalados en línea en el propio equipo (ver Figura 3.18).
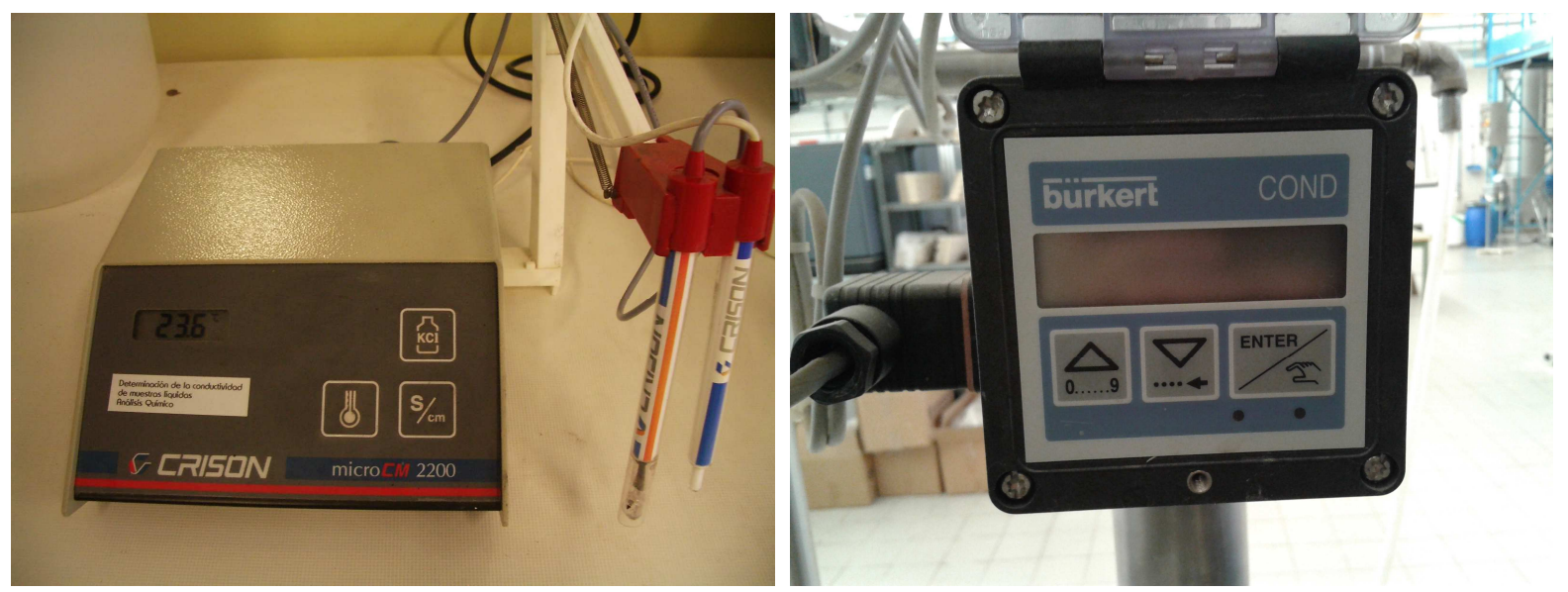

Figura 3.18. Conductímetro de mesa e instalado en línea en la planta piloto, respectivamente.

\subsubsection{Determinación del pH}

De la misma forma que la conductividad, el $\mathrm{pH}$ se ha medido con diferentes $\mathrm{pHmetros}$ dependiendo si los ensayos son a escala de laboratorio o a escala piloto. Por tanto, en los primeros casos este parámetro ha sido medido según la norma ASTM D1293 utilizando un pHmetro CRISSON modelo 2002. Mientras que en los ensayos a escala piloto, el pH ha sido medido en línea por pHmetros 8205 BÜRKERT (ver Figura 3.19).
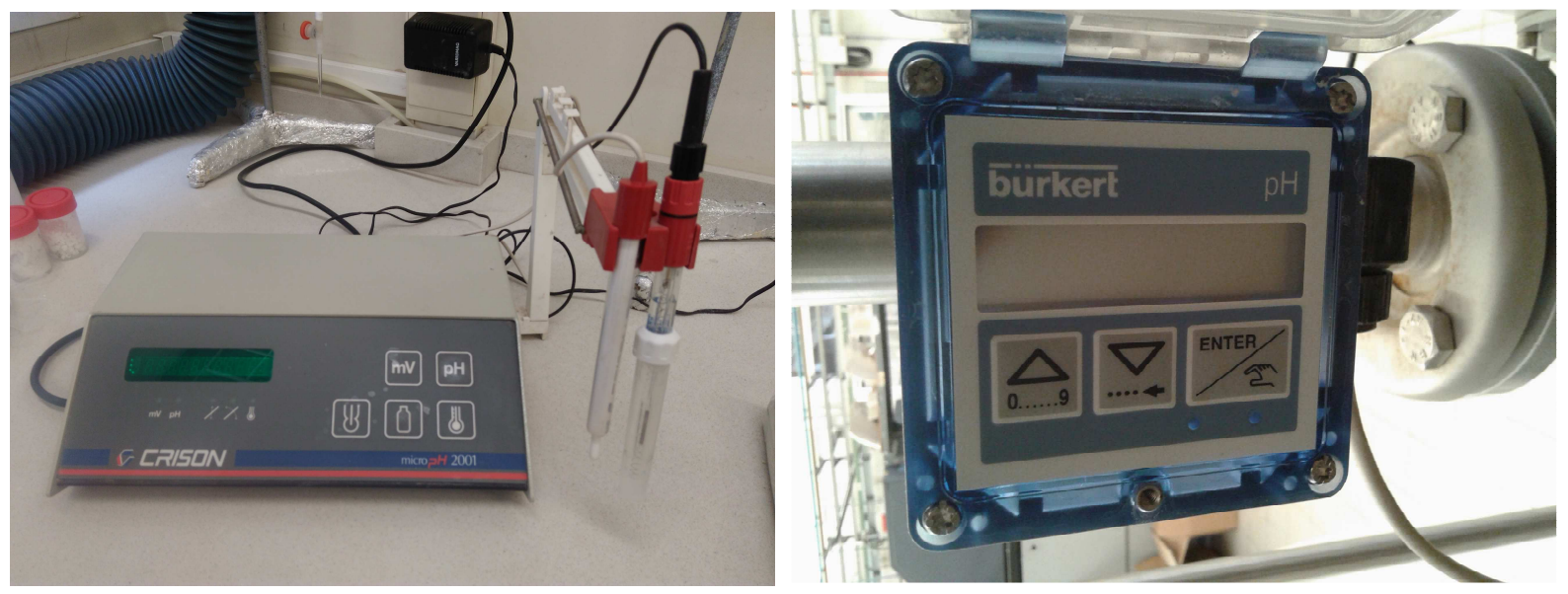

Figura 3.19. pHmetro de mesa e instalado en línea en la planta piloto, respectivamente.

\subsubsection{Determinación de la turbidez}

Para la medida de turbidez se utiliza una fuente de luz infrarroja, el haz de luz es medido por el detector con un ángulo de $90^{\circ}$, que permite medir a través de 3 rangos de medida. El equipo utilizado ha sido un turbidímetro PC Compact de la marca AQUA LYTIC (ver Figura 3.20). 


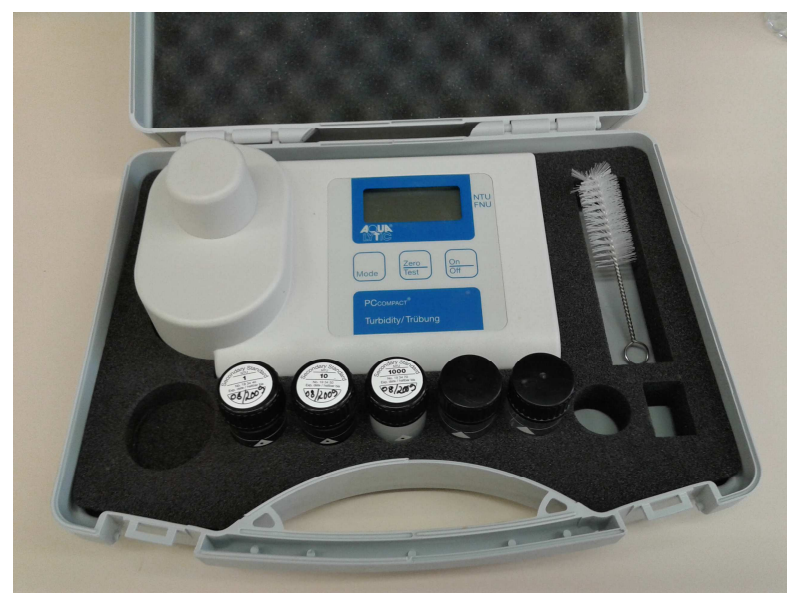

Figura 3.20. Turbidímetro.

\subsubsection{Determinación del índice de "ensuciamiento" de las membranas (SDI)}

El índice de densidad de sedimentos ("Silt Density Index" - SDI) o índice de "ensuciamiento" es un procedimiento sencillo desarrollado para estimar el grado de bloqueo o "ensuciamiento" de las membranas debido a la contaminación en forma de partículas coloidales, que comúnmente incluyen bacterias, arcillas... Este método es ampliamente aceptado en la industria, dado que principalmente mide la concentración de partículas o materia coloidal [63].

El procedimiento de SDI determina la caída en el flujo a través de una membrana de $47 \mathrm{~mm}$ de diámetro cuyo tamaño de poro es de 0,45 $\mu \mathrm{m}$. Los poros son susceptibles de ser obstruidos por la materia coloidal y por tanto el flujo a través de la membrana disminuye.

Para determinar el valor de SDI siguiendo la norma americana ASTM D418 se tiene que medir el tiempo requerido para filtrar un volumen fijo de $500 \mathrm{~mL}$ de agua a través de una membrana de 47 $\mathrm{mm}$ de diámetro y un tamaño de poro de $0,45 \mu \mathrm{m}$, con una presión constante de 2 bar. La diferencia entre el tiempo inicial y el tiempo de una segunda medida después de 15 minutos representa el valor de SDI. La fórmula para el cálculo de este índice es la siguiente:

$$
S D I_{t_{T}}=\frac{\left(1-\frac{t_{i}}{t_{f}}\right)}{t_{T}} \cdot 100
$$

donde:

$t_{i}$ : tiempo inicial requerido para recoger $500 \mathrm{~mL}$ de muestra (s).

$t_{f}$ : tiempo final requerido para recoger $500 \mathrm{~mL}$ de muestra después del tiempo de prueba (s).

$t_{T}$ : tiempo total transcurrido durante la prueba (generalmente son 15 minutos) (min).

En la Figura 3.21 y en la Figura 3.22 se puede observar el montaje del ITC para medir este parámetro y las membranas utilizadas en varios ensayos en uno de los casos industriales estudiados en este trabajo, respectivamente. 


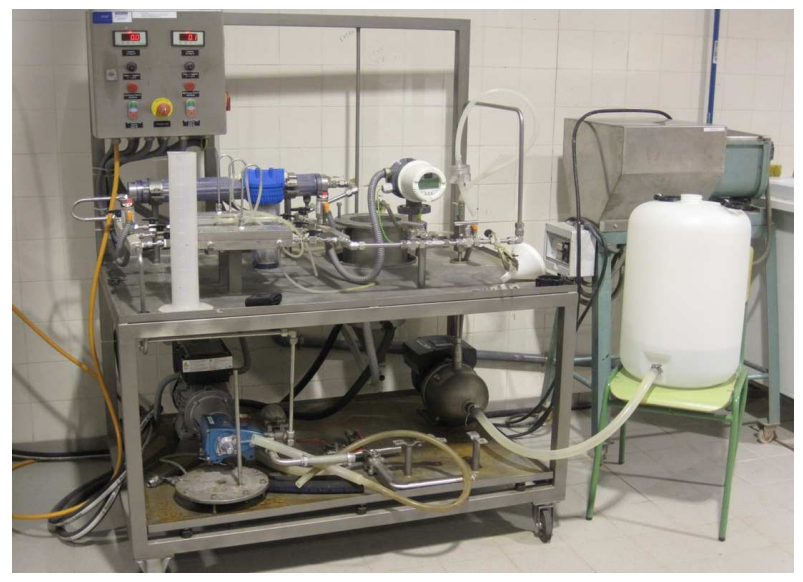

Figura 3.21. Montaje para la determinación del SDI en el ITC.

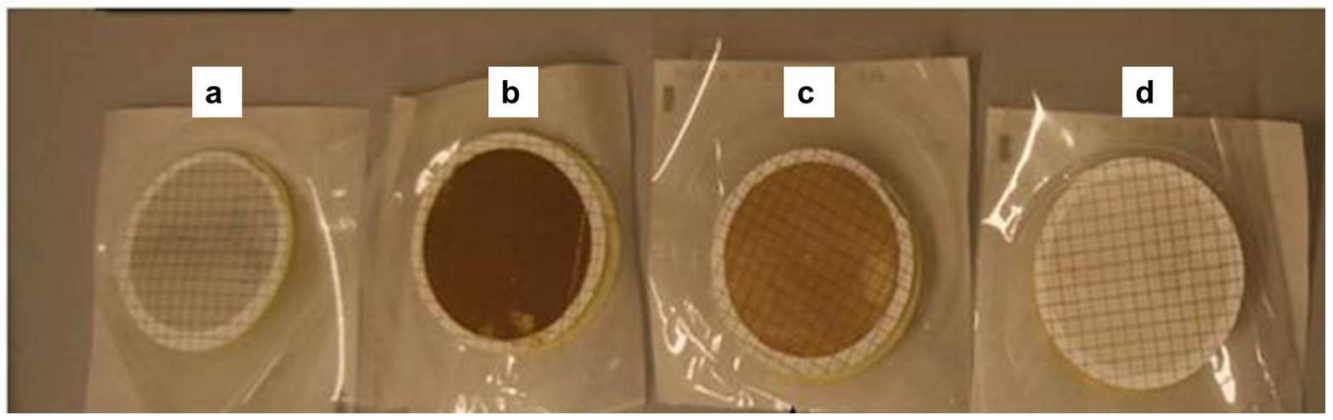

Figura 3.22. Filtros después de medir el SDI. a) agua de suministro, b) y c) agua de pozo y d) agua de pozo después de microfiltrar.

\subsection{Procedimiento experimental}

El procedimiento experimental que se ha seguido durante los ensayos realizados con las membranas es el que se detalla a continuación:

- Acondicionamiento de la membrana.

- Determinación de la permeabilidad de la membrana al agua pura.

- Medida del flujo de permeado, cálculo de la retención a los elementos de interés proporcionada por las membranas, así como el cálculo de la conversión alcanzada por el tratamiento para los dos casos de estudio (eliminación de compuestos de boro y eliminación de iones divalentes).

En la parte de caracterización de las membranas utilizadas en este estudio se ha empleado un software informático llamado Nanoflux ${ }^{\circledR}$ para modelizar el comportamiento de las membranas [111] y extraer datos referentes a la estructura de la membrana y sus interacciones con la disolución que se tiene que nanofiltrar, de esta forma es posible elegir las membranas cuyas características mejor se adapten a los objetivos perseguidos. Para la realización de esta caracterización se han realizado varios ensayos de nanofiltración con cada una de las membranas y unas disoluciones con unos compuestos determinados (compuestos neutros y sales cargadas, ver apartado 3.1.1 Aguas sintéticas). Los flujos de permeado y las retenciones ofrecidas por las membranas para cada uno de los compuestos son introducidas en el programa informático Nanoflux ${ }^{\circledR}$ y éste proporciona 
información referente a la membrana después de una modelización de su comportamiento. Una introducción básica al programa se realizará en el apartado 3.7 Programa de simulación NANOFLUX ${ }^{\circledR}$.

Una vez realizada la caracterización de las diferentes membranas de nanofiltración, se ha elegido las membranas que mejores características han demostrado para ser aplicadas a escala industrial, abordando directamente diferentes problemas que tienen en materia de aguas algunas empresas del sector cerámico, intentado aportar soluciones para mejorar sus procesos productivos actuales. Concretamente, se han aplicado las técnicas de nanofiltración en dos casos de estudio. En primer lugar, en la eliminación de compuestos de boro de las aguas residuales generadas en una empresa de producción de baldosas cerámicas, y en segundo lugar, en la eliminación de iones divalentes en las aguas de producción de una empresa de elaboración de polvo atomizado.

Para llevar a cabo el estudio de los casos planteados, se ha trabajado en primer lugar con aguas sintéticas a escala laboratorio con membranas planas y/o en espiral para comprobar que la tecnología funcionaba y permitía conseguir los objetivos marcados. Tras comprobar que la tecnología es viable con las aguas sintéticas, se contactó con las empresas donde se tenía que realizar la implementación de la nanofiltración para que proporcionasen aguas industriales para ver si los resultados eran comparables. Por último, se ha realizado el escalado a nivel industrial, para ello en todos los casos la planta piloto industrial que dispone el ITC ha sido trasladada hasta las propias instalaciones industriales de las empresas para trabajar "in situ" con sus aguas industriales.

Además, en estos casos de estudio aplicados a situaciones reales, después de la filtración se han realizado pruebas de producto, utilizando el agua obtenida después del tratamiento para estudiar la viabilidad de reutilización del agua tratada en el propio proceso productivo cerámico o la mejora del proceso cuando se utiliza el agua tratada.

Por último, después de comprobar la viabilidad del tratamiento se ha realizado un balance económico, para de esta forma, analizar si la aplicación de esta técnica de filtración avanzada puede aportar beneficios económicos a las empresas donde se han realizado los trabajos, y por extensión al sector cerámico en general.

En los próximos apartados se profundizará en las partes del procedimiento experimental llevado a cabo con las membranas y en las pruebas con el producto cerámico producido durante los dos casos de estudio realizados en las empresas.

\subsubsection{Acondicionamiento de la membrana}

Cuando las membranas son nuevas o han sido reutilizadas después de un periodo de almacenamiento, el primer paso que hay que realizar antes de utilizarlas normalmente es un buen acondicionamiento. El acondicionamiento tiene que realizarse por varios motivos. Uno de ellos es para eliminar los restos de productos de conservación que pueden haber en la superficie y en el interior de los poros de las membranas, tanto si son nuevas como si han sido almacenadas con las disoluciones de conservación indicadas para cada membrana. Otro de los motivos es el de compactar la membrana sometiéndola a una presión superior a la de trabajo, ya que no hay que olvidar que las membranas de nanofiltración utilizadas en este estudio son poliméricas y al 
someterlas a presiones elevadas pueden compactarse y variar ligeramente su morfología. Este acondicionamiento puede realizarse de varias formas, sin embargo el método más utilizado y el que se ha empleado en este estudio, es someter a las membranas a uno o varios ciclos de filtración con agua pura a una presión ligeramente superior a la máxima presión de trabajo y como mínimo durante 1 hora de duración por cada ciclo (siempre teniendo precaución de no superar la presión máxima de trabajo de la membrana establecida por el fabricante). A estos ciclos se les denominará ciclos de acondicionamiento. Después de cada uno de estos ciclos se realizará un ensayo para determinar la permeabilidad al agua pura de la membrana, tal y como se explicará en el apartado 3.6.2 Ensayo de permeabilidad de las membranas. Se realizarán tantos ciclos de acondicionamiento como sea necesario para que dos permeabilidades al agua pura medidas consecutivamente entre ciclos de acondicionamiento no varíen entre si más de un $5 \%$, de esta forma se comprueba que la membrana es estable.

\subsubsection{Ensayo de permeabilidad de las membranas}

Tras cada ciclo de acondicionamiento de la membrana, la permeabilidad al agua pura es el ensayo que se ha realizado para caracterizar la membrana. La ley de Darcy o ecuación del flujo volumétrico para el agua pura estipula que el flujo de permeado $\left(J_{v}\right)$ es proporcional a la permeabilidad hidráulica $\left(L_{p}\right)$ y a la presión efectiva $(\Delta P-\sigma \Delta \pi)$ :

$$
J_{V}=L_{p}(\Delta P-\sigma \Delta \pi)
$$

donde:

$J_{v}$ : Flujo de permeado $\left(\mathrm{L} / \mathrm{h} \mathrm{m}^{2}\right)$.

$L_{p}$ : Permeabilidad hidráulica de la membrana ( $\mathrm{L} / \mathrm{h} \mathrm{m}^{2}$ bar).

$\Delta P$ : Presión transmembrana (bar).

$\sigma$ : Coeficiente de reflexión.

$\Delta \pi$ : Diferencia de presión osmótica (bar).

En ausencia de soluto, cuando se utiliza agua pura, la presión osmótica es nula, por lo que la ecuación (3.2) se transforma en la ecuación:

$$
J_{V}=L_{p}^{0} \Delta P
$$

Todos estos conceptos ya han sido introducidos en el apartado 1.4.1.1 Conceptos básicos relacionados con la filtración a través de membranas. Así pues, la representación $J_{v}=f(\Delta P)$ debe dar una línea recta cuya pendiente obtenida es la permeabilidad al agua pura de la membrana $\left(L_{p}^{0}\right)$ [43].

Por tanto, para calcular la permeabilidad al agua pura para una membrana determinada se medirá el flujo de permeado obtenido a varias presiones (generalmente, a 5, 8, 11 y 15 bar), una vez obtenido el flujo se representará frente a la presión aplicada en cada caso y la pendiente resultante de esta representación será el parámetro buscado. Por tanto, se realizarán pruebas para determinar 
la permeabilidad al agua pura durante el acondicionamiento de las membranas, una vez acondicionada y tras los ciclos de limpieza realizados tras los ensayos más severos, de esta forma se puede comprobar si las características de la membrana han cambiado.

\subsubsection{Cálculo de la retención ofrecida por las membranas y el grado de conversión}

Durante todo el desarrollo del proyecto se calcularán varios parámetros en cada uno de los ensayos realizados con las membranas, ya que estos indicarán la idoneidad del tratamiento de nanofiltración para alcanzar los objetivos previstos. Estos parámetros serán la retención ofrecida por la membrana a un determinado elemento o compuesto y el grado de conversión o relación entre el caudal de alimentación y el caudal de permeado.

A continuación se profundiza en cada uno de estos parámetros:

\section{Retención}

La retención se calcula mediante la siguiente fórmula:

$$
R=\frac{c_{a}-c_{p}}{c_{a}}=1-\frac{c_{p}}{c_{a}}
$$

donde:

$c_{a}$ : Concentración de la disolución de alimentación (g/L).

$c_{p}$ : Concentración del permeado $(\mathrm{g} / \mathrm{L})$.

El objetivo de las técnicas de separación a través de membranas es que la retención de los elementos que se quieren separar sea lo más elevada posible. Por esta razón se ha de analizar el parámetro que interesa controlar antes y después del tratamiento. La retención es un parámetro adimensional, sin embargo se puede expresar en tanto por cien (\%) o en tanto por uno [43][63].

\section{Conversión}

La conversión se calcula mediante la siguiente fórmula:

$$
S=\frac{Q_{p}}{Q_{a}}
$$

donde:

$Q_{a}:$ Caudal de alimentación $(\mathrm{L} / \mathrm{h})$.

$Q_{p}$ : Caudal de permeado (L/h).

Interesa que este parámetro sea lo más alto posible, ya que esto significará que la cantidad de agua proveniente del rechazo será pequeña y la cantidad de agua libre de elementos que se quieren eliminar es máxima. Al igual que la retención, este parámetro se puede expresar en tanto por cien (\%) o en tanto por uno [43][161]. 


\subsubsection{Pruebas de producto cerámico}

En los dos casos de estudio que se han llevado a cabo en este trabajo se han realizado pruebas de producto cerámico con las aguas nanofiltradas. En el primer caso para comprobar la viabilidad de la reutilización de las aguas residuales nanofiltradas en el propio proceso productivo. Mientras que en el segundo caso, se han realizado pruebas con las aguas de proceso (aguas residuales y aguas de pozo) para evaluar las propiedades reológicas de las suspensiones cerámicas preparadas con las aguas nanofiltradas y para comprobar la viabilidad de la utilización de esas suspensiones para la fabricación de baldosas cerámicas. Todas estas pruebas se explican a continuación en los siguientes apartados, y además en la Figura 3.23. se puede observar un esquema con todas ellas.
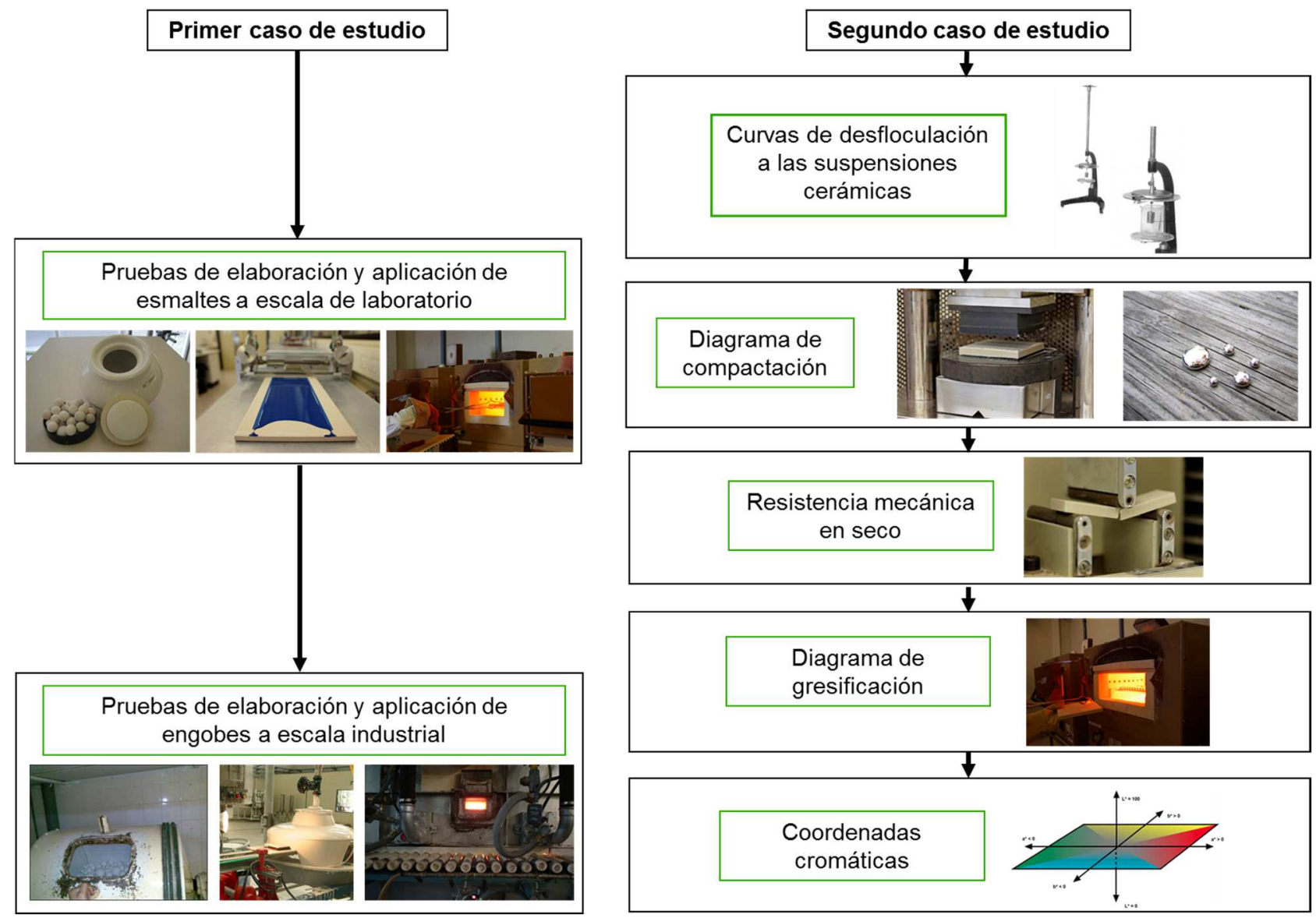

Figura 3.23. Esquema de las pruebas de producto cerámico realizadas en los dos casos de estudio.

\subsubsection{Pruebas de producto cerámico en el primer caso de estudio}

Una vez nanofiltrada el agua residual, se elaboraron diferentes engobes y esmaltes cerámicos. Para determinar si éstos son aptos para poder ser utilizados en la decoración de baldosas cerámicas se compararon varias probetas decoradas con esmaltes y engobes elaborados con las aguas tratadas y otras decoradas con los mismos esmaltes y engobes elaborados con las aguas de suministro que la empresa utiliza habitualmente para esos propósitos (aguas limpias de pozo). Hasta el momento, la reutilización de aguas residuales en la elaboración de esmaltes y engobes no es una práctica realizada en el sector cerámico, por tanto si los resultados son positivos se podría conseguir ahorros considerables en el consumo de agua. 
En primer lugar, se realizaron pruebas a nivel de laboratorio, elaborándose cantidades de estos productos que oscilan entre 2-3 L. Para ello, se utilizaron molinos de bolas de laboratorio donde se molturaron las materias primas con las aguas indicadas en cada caso. Una vez obtenidos los esmaltes se aplicaron sobre probetas de laboratorio y se cocieron en un horno de laboratorio simulando un ciclo de cocción industrial (ver Figura 3.24).
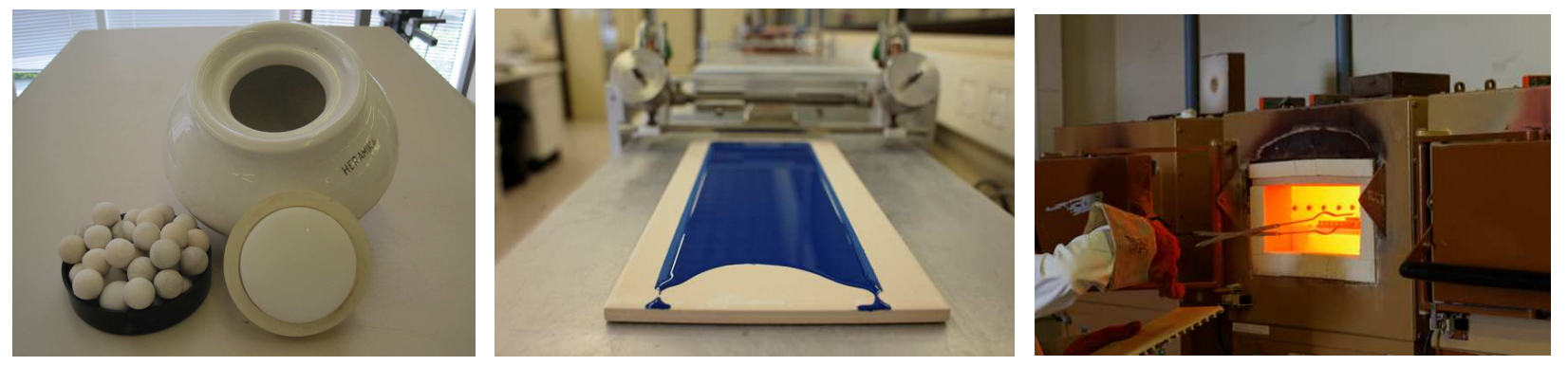

Figura 3.24. Molino de bolas, aplicación de un esmalte sobre una probeta cerámica y cocción de la probeta, a escala de laboratorio.

Posteriormente, se realizó una prueba a escala industrial. Para la cual se elaboraron $200 \mathrm{~L}$ del engobe (capa intermedia entre el soporte cerámico y el esmalte) de referencia de la empresa donde se realiza el estudio. Para ello, se utilizaron los molinos de bolas discontinuos más pequeños que la empresa dispone a escala industrial. El engobe obtenido se aplicó sobre baldosas estándar en las líneas de esmaltado de la fábrica, exactamente igual que con el resto de engobes que se aplican habitualmente. En este caso se utilizó $50 \%$ de agua nanofiltrada y $50 \%$ de agua limpia de pozo para la elaboración del engobe. Tras su aplicación, las baldosas en las que se aplicó estos engobes, se decoraron con los esmaltes correspondientes, se secaron y se cocieron como el resto de las baldosas de la producción normal de la fábrica. En esta prueba de producto a escala industrial, además de analizar los resultados finales del engobe en las piezas cocidas, también se determinó la densidad y la cantidad de suspensión de engobe aplicada a cada pieza, como se hace normalmente en la práctica industrial (ver Figura 3.25).
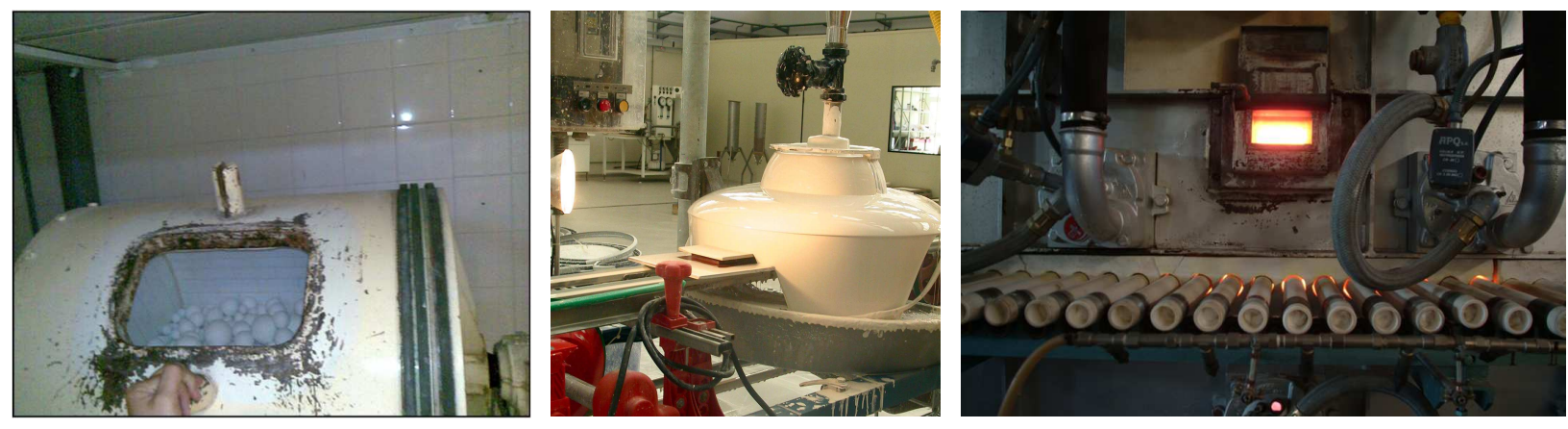

Figura 3.25. Molino de bolas, aplicación de un esmalte por campana y etapa de cocción, a escala industrial.

\subsubsection{Pruebas de producto cerámico en el segundo caso de estudio}

Como se ha mencionado en repetidas ocasiones el objetivo perseguido en el segundo caso de estudio fue el de reducir el contenido de iones divalentes de las aguas de producción de una empresa de fabricación de polvo atomizado, con el fin de mejorar el comportamiento reológico de las suspensiones elaboradas con éstas. 
Para evaluar el comportamiento reológico se han determinado las curvas de desfloculación típicamente realizadas para el control industrial de éste. Este ensayo se describe a continuación.

\section{Curvas de desfloculación}

Para la realización de las curvas de desfloculación se prepararon suspensiones a partir de diferentes composiciones cerámicas molturadas vía húmeda con cada una de las aguas estudiadas, determinándose la variación que experimenta la viscosidad con el porcentaje de desfloculante añadido. La medida de la viscosidad se realiza con un viscosímetro GALLEMKAMP de hilo de torsión del ํㅜ 30 utilizando un cilindro de $1,75 \mathrm{~cm}$ de diámetro (ver Figura 3.26).

El objetivo del ensayo consiste en determinar el contenido de desfloculante para el que la curva de viscosidad frente al contenido de desfloculante, alcanza su valor mínimo tal como se puede observar en la Figura 3.26. En el apartado 1.3.3 Desfloculación de las suspensiones cerámicas: influencia del agua utilizada ya se emplearon estas curvas (ver Figura 1.18 y Figura 1.19) para explicar la influencia de los iones divalentes y el contenido en sólidos en una suspensión cerámica.
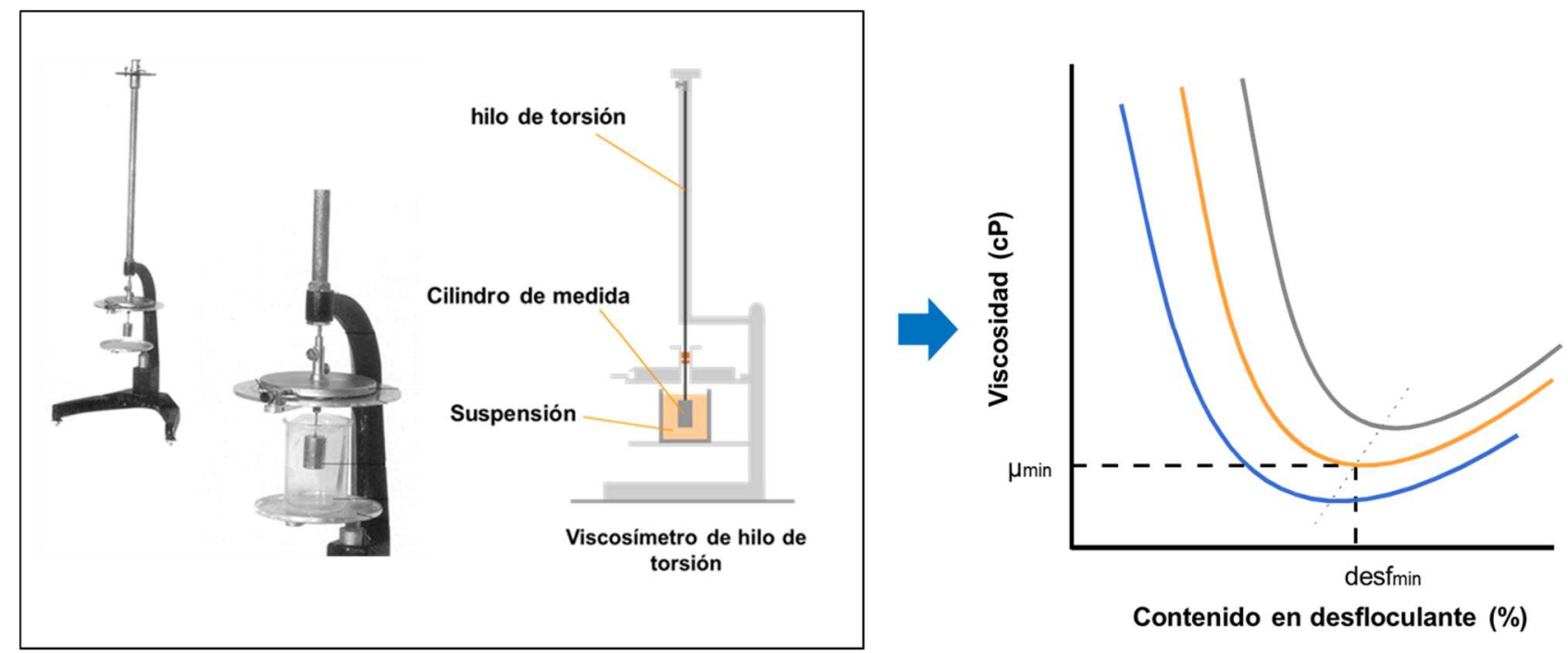

Figura 3.26. Esquema y fotografía del viscosímetro GALLENKAMP, así como la curva de desfloculación típica. Representación de la viscosidad frente al contenido en desfloculante.

Para la realización de este ensayo se prepara una suspensión a un determinado contenido en sólidos sobre la que se añade sucesivamente desfloculante hasta que con al menos 2 adiciones, el valor de la viscosidad es igual o superior al anterior valor medido. El desfloculante empleado fue una mezcla compuesta por un $25 \%$ de tripolifosfato sódico y un $75 \%$ de metasilicato sódico.

Además, también se prepararon probetas de baldosas cerámicas utilizando polvo atomizado elaborado con agua nanofiltrada para comprobar si las baldosas fabricadas con esta agua tenían las mismas propiedades que las fabricadas con polvo atomizado elaborado con aguas de proceso sin nanofiltrar. A estas probetas se les han realizado varios ensayos típicos del proceso cerámico. Ensayos que se resumen seguidamente.

\section{Diagrama de compactación}

Para determinar el diagrama de compactación, se conformaron probetas cilíndricas (de $4 \mathrm{~cm}$ de diámetro y aproximadamente $7 \mathrm{~mm}$ de espesor) a una humedad del 5,5\% (base seca) y a diferentes 
presiones de prensado. Las probetas se secaron a $110^{\circ} \mathrm{C}$ en una estufa eléctrica de laboratorio, con recirculación de aire. Posteriormente, se pesaron y se determinó su densidad aparente en seco por el método de inmersión en mercurio. La presión de prensado se regula directamente en la prensa y para determinar la densidad aparente de las piezas prensadas se utiliza la siguiente fórmula [162]:

$$
D_{a p}=\frac{m d_{H g}}{e_{p}}
$$

donde:

$D_{a p}:$ densidad aparente de la probeta seca o cocida $\left(\mathrm{g} / \mathrm{cm}^{3}\right)$.

$m$ : masa de la probeta seca o cocida $(\mathrm{g})$.

$e_{p}$ : empuje probeta seca o cocida sumergida en el mercurio $(\mathrm{g})$.

$d_{H g}:$ densidad del mercurio $=13,53 \mathrm{~g} / \mathrm{cm}^{3}$.

En la Figura 3.27 se pueden observar los pasos seguidos hasta la obtención del diagrama de compactación.

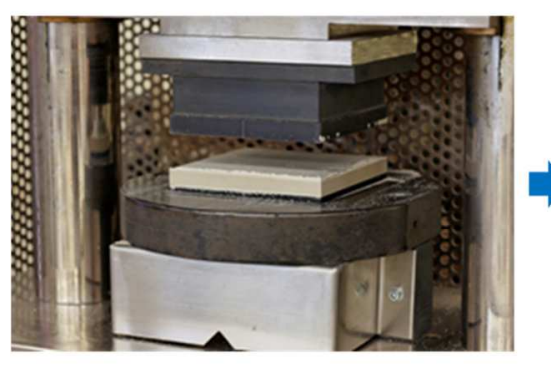

Conformado por prensado

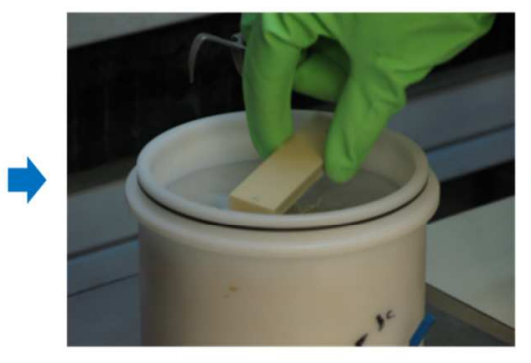

Densidad aparente por inmersión en mercurio

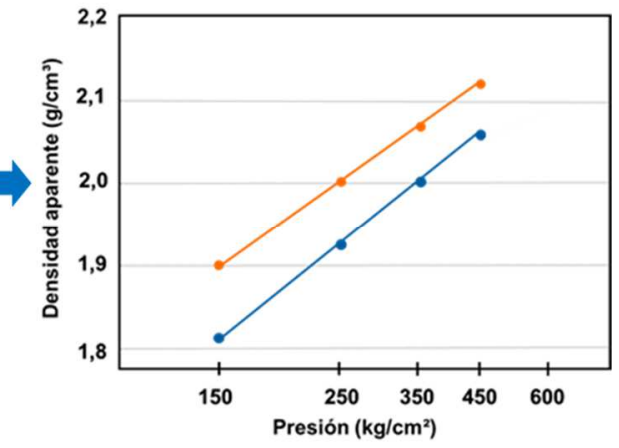

Figura 3.27. Esquema de los pasos seguidos para la obtención del diagrama de compactación.

\section{Resistencia mecánica en seco}

La resistencia mecánica en seco se determinó mediante flexión por tres puntos de apoyo. Para ello se conformaron probetas prismáticas de $80 \mathrm{~mm}$ de longitud, $20 \mathrm{~mm}$ de anchura y aproximadamente $7 \mathrm{~mm}$ de espesor por prensado unidireccional, a una humedad de prensado del 5,5\% (base seca) y a la presión necesaria para obtener una densidad aparente en seco de 1,95 g/ $\mathrm{cm}^{3}$. Las probetas fueron secadas en una estufa eléctrica de laboratorio con recirculación de aire a $110^{\circ} \mathrm{C}$. Posteriormente, se pesaron de nuevo y se determinó su densidad aparente por el método de inmersión en mercurio.

Antes de la realización de los ensayos las probetas se introdujeron en un desecador a vacío el tiempo necesario para que alcanzasen la temperatura ambiente (15 minutos aproximadamente), con el objeto de que su hidratación fuese mínima.

Los ensayos se realizaron en una máquina de ensayos mecánicos a una velocidad de deformación constante de $1 \mathrm{~cm} / \mathrm{min}$. El dispositivo de flexión mediante tres puntos de apoyo consta de dos bordes 
de apoyo inferiores (soportes) por lo general cilíndricos, sobre los que se sitúa la probeta, y un apoyo superior, también cilíndrico, mediante el cual se aplica la carga. La resistencia mecánica a la tracción de una pieza sometida a un ensayo de flexión por tres puntos de apoyo viene dada por la siguiente expresión [11]:

$$
\sigma_{m s}=\frac{3 F_{\max } L}{2 b e^{2}}
$$

donde:

$\sigma_{m s}:$ resistencia mecánica en seco $\left(\mathrm{kg} / \mathrm{cm}^{2}\right)$.

$F_{\text {max }}$ : fuerza máxima antes de la rotura o carga de rotura $(\mathrm{kg})$.

$L$ : distancia entre apoyos $(\mathrm{cm})$.

$b$ : anchura de la probeta $(\mathrm{cm})$.

$e$ : espesor de la probeta $(\mathrm{cm})$.

En la Figura 3.28 se pueden observar los pasos seguidos para la determinación de la resistencia mecánica de las probetas cerámicas en crudo.
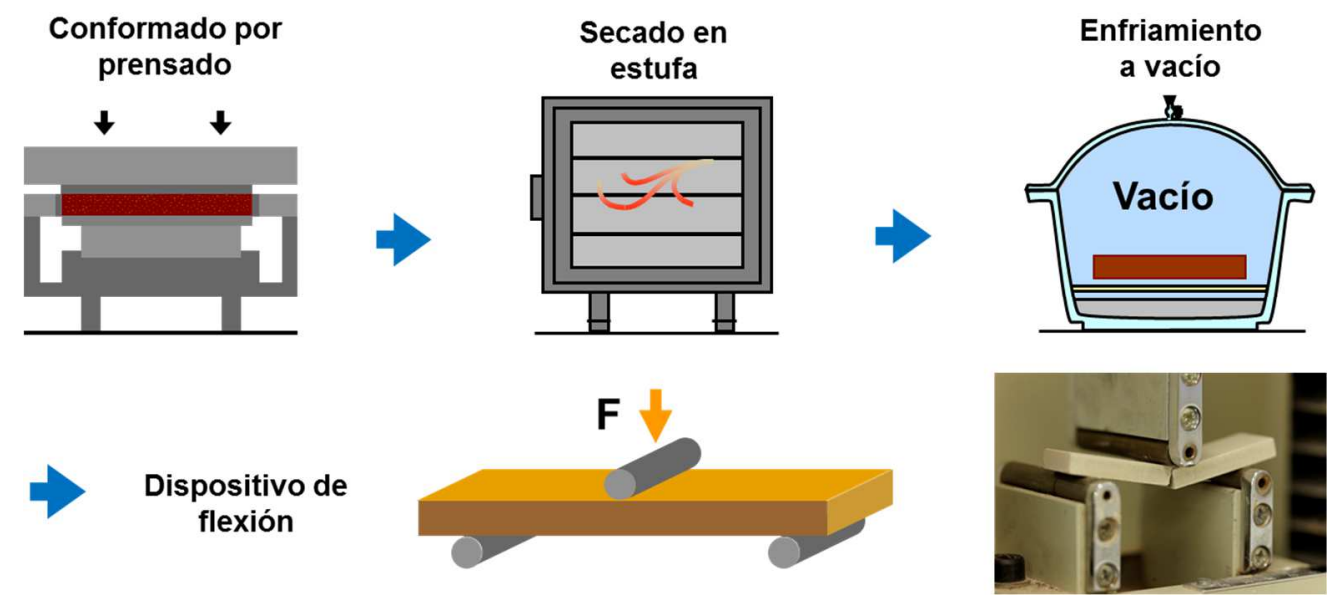

Figura 3.28. Esquema de los pasos seguidos para la determinación de la resistencia mecánica.

\section{Diagrama de gresificación}

Para determinar el diagrama de gresificación, se conformaron probetas cilíndricas (de $4 \mathrm{~cm}$ de diámetro y aproximadamente $7 \mathrm{~mm}$ de espesor) por prensado unidireccional, a una humedad de prensado del $5,5 \%$ (base seca) y a la presión necesaria para obtener una densidad aparente en seco de $1,95 \mathrm{~g} / \mathrm{cm}^{3}$.

Las probetas se secaron a $110^{\circ} \mathrm{C}$ en una estufa eléctrica de laboratorio, con recirculación de aire. Posteriormente, se pesaron, se midió su diámetro y se determinó su densidad aparente por el método de inmersión en mercurio, tras lo cual se cocieron a diferentes temperaturas en un horno eléctrico de laboratorio con un ciclo rápido de cocción y un tiempo de permanencia a la máxima temperatura de 6 minutos. La velocidad de calentamiento fue de $25^{\circ} \mathrm{C} / \mathrm{min}$. 
Una vez cocidas, las probetas se pesaron de nuevo, determinándose su densidad aparente por el método indicado anteriormente. La contracción de cocción se evaluó por diferencia entre el diámetro en seco y en cocido, definiéndose este parámetro en base seca. Para ello se utilizó la siguiente ecuación [162]:

$$
C L=\frac{L_{S}-L_{c}}{L_{S}} \cdot 100
$$

donde:

$C L$ : contracción lineal (\%).

$L_{S}$ : diámetro o longitud de la probeta seca $(\mathrm{mm})$.

$L_{C}$ : diámetro o longitud de la probeta cocida $(\mathrm{mm})$.

Un esquema de los pasos seguidos para la determinación de la contracción lineal se puede observar en la Figura 3.29.

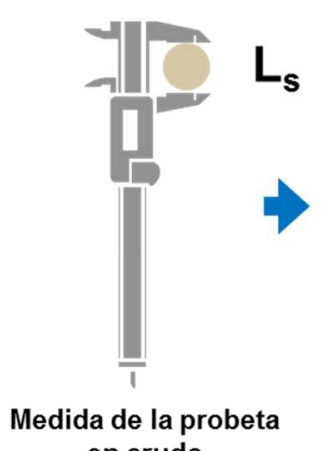
en crudo

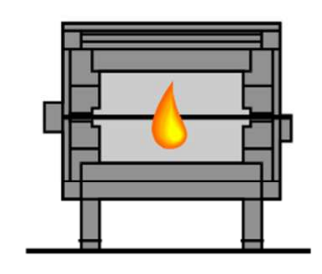

Cocción

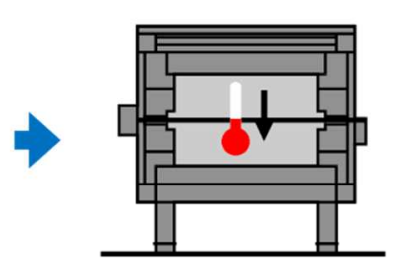

Enfriamiento

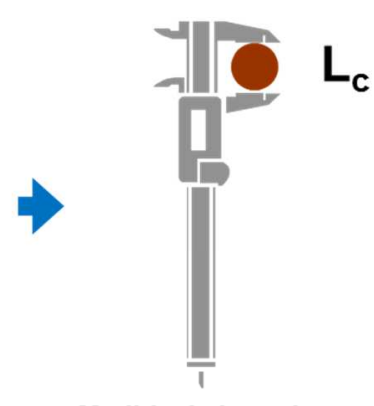

Medida de la probeta cocida

Figura 3.29. Esquema de los pasos seguidos para la determinación de la contracción lineal.

La absorción de agua se calculó midiendo la ganancia de peso experimentada por las probetas al introducirlas en agua en ebullición por un período de dos horas. La ecuación utilizada en este caso ha sido [162]:

$$
A A=\frac{m_{h}-m_{c}}{m_{c}} \cdot 100
$$

donde:

$A A$ : absorción de agua (\%).

$m_{h}$ : masa de la probeta cocida y húmeda $(\mathrm{g})$.

$m_{c}$ : masa de la probeta cocida $(\mathrm{g})$.

Al igual que en los casos anteriores, en la Figura 3.30 se puede observar un esquema de los pasos seguidos para la determinación de la absorción de agua. 


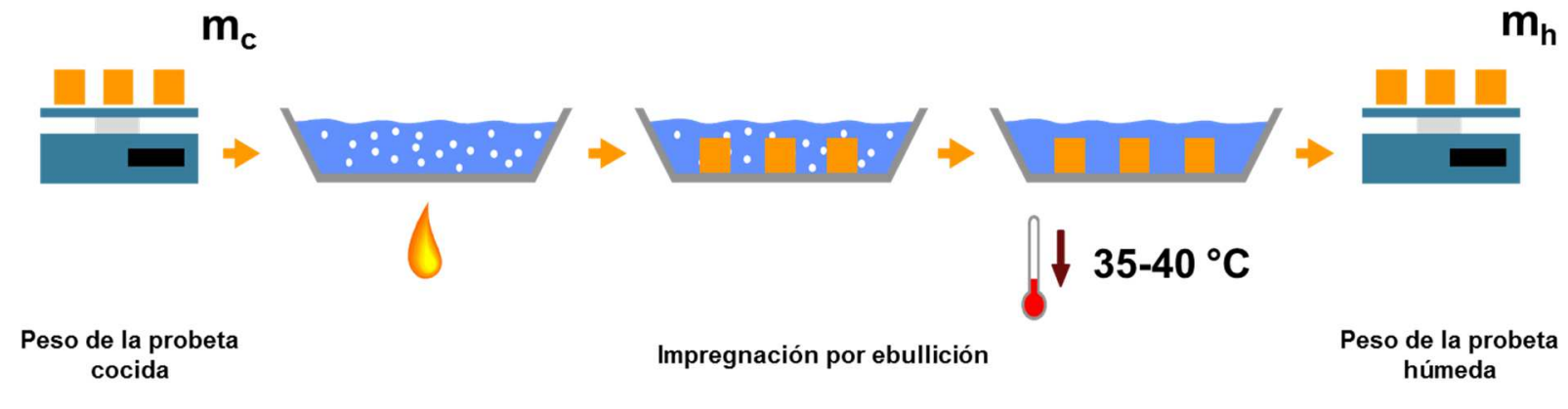

Figura 3.30. Esquema de los pasos seguidos para la determinación de absorción de agua.

A la representación de la contracción lineal y la absorción de agua de una pieza cerámica se le denomina diagrama de gresificación. Un ejemplo de este tipo de diagramas puede observarse en la Figura 3.31.

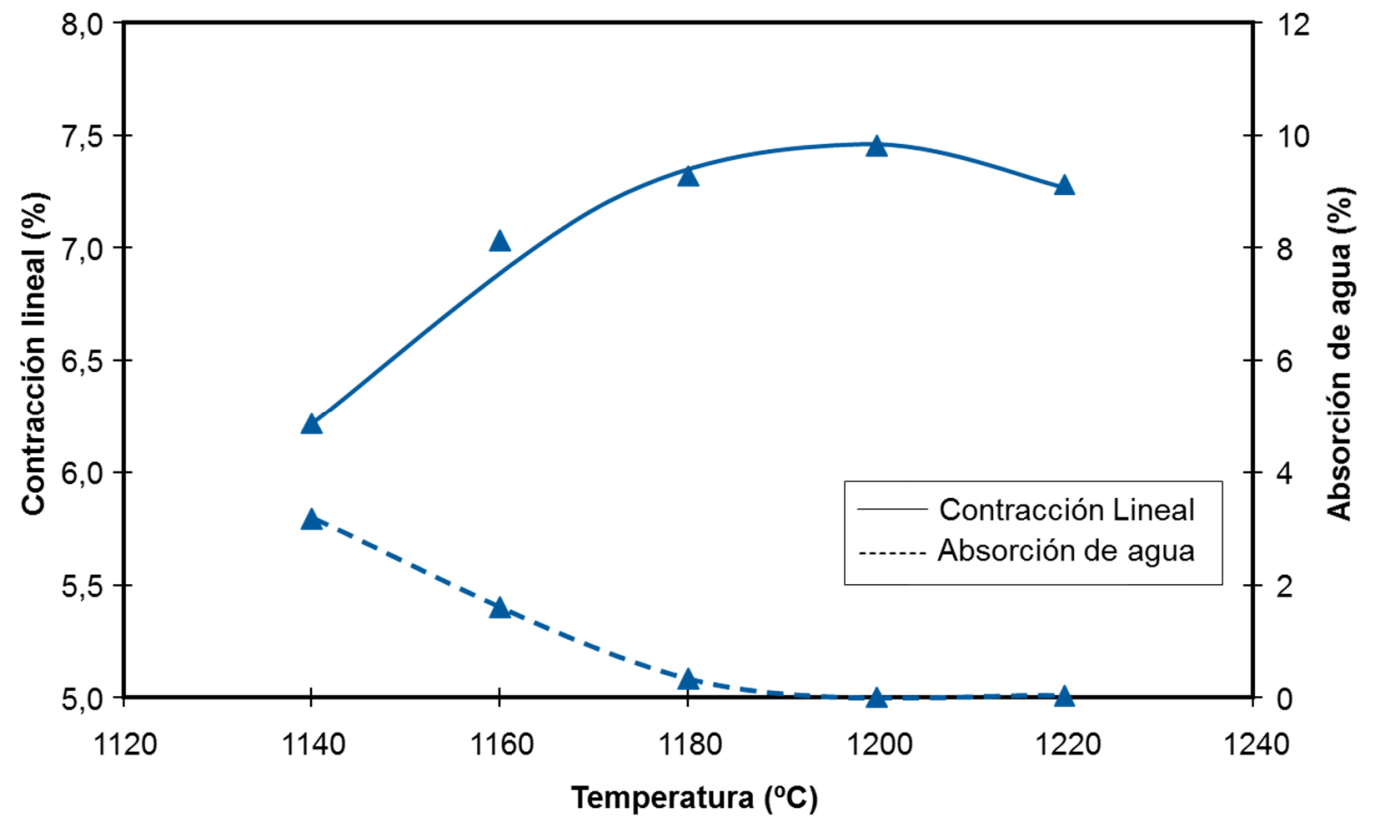

Figura 3.31. Diagrama de gresificación.

\section{Coordenadas cromáticas}

Para comparar el color de las probetas realizas con las diferentes aguas se utilizó el espacio de color denominado CIE $1976 \mathrm{~L}^{*}, \mathrm{a}^{*}$ y b* (CIELAB). Este espacio de color se basa en representar en coordenadas rectangulares las magnitudes $L^{*}, a^{*}$ y $b^{*}$ que poseen un significado relacionable con características observables del color [11]:

- $\quad L^{*}$ : indica la posición en el eje blanco $\left(L^{*}=100\right)$ negro $\left(L^{*}=0\right)$.

- $\quad a^{*}$ : indica la posición en el eje rojo $\left(a^{*}>0\right)$ verde $\left(a^{*}<0\right)$.

- $\quad b^{*}$ : indica la posición en el eje amarillo $\left(b^{*}>0\right)$ azul $\left(b^{*}<0\right)$.

En la Figura 3.32 se puede observar una representación donde se ilustra el espacio de color denominado CIELAB. 


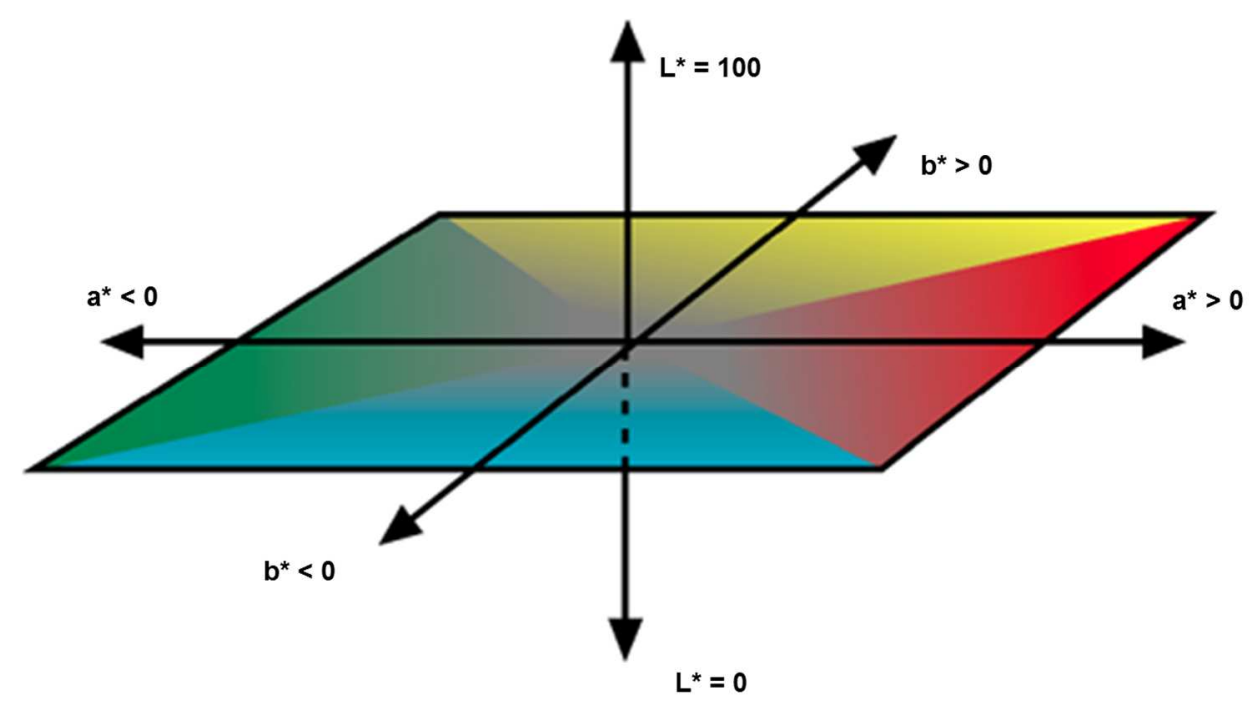

Figura 3.32. Espacio de color CIELAB.

Las coordenadas cromáticas $\left(L^{*}, a^{*}\right.$ y $\left.b^{*}\right)$ se determinaron en un espectrofotómetro de reflectancia difusa, utilizando un iluminante tipo $\mathrm{D}_{65} \mathrm{y}$ un observador standard $\mathrm{a} 10^{\circ}$.

Todos estos ensayos típicos del proceso cerámico se han realizado a probetas fabricadas con polvo atomizado elaborado con aguas nanofiltrada y sin nanofiltrar, de forma que se puedan comparar los resultados obtenidos con ambas probetas.

\subsection{Programa de simulación NANOFLUX ${ }^{\circledR}$}

\subsubsection{Presentación del programa}

En nanofiltración, además de la membrana propiamente dicha, la retención de los solutos depende de las características de la disolución que se está tratando (concentración, pH...), condiciones y parámetros de trabajo (velocidad de circulación, presión transmembrana...), así como de las interacciones membrana/disolución. Estudiar experimentalmente todos los factores que afectan a la nanofiltración aplicada a disoluciones complejas implicaría numerosos ensayos. Para ahorrar tiempo y esfuerzo, se puede recurrir a la simulación por modelos matemáticos. Sin embargo, los mecanismos de transporte en nanofiltración son muy complejos, tan complejos que hasta el momento, ningún modelo matemático ha podido modelizar todas las interacciones entre los solutos y la propia membrana (ver 1.4.2.1 Transporte a través de las membranas de nanofiltración). Un buen modelo coherente que explique los fenómenos que tienen lugar en la nanofiltración tiene que ser en primer lugar fiable, es decir, ser capaz de reproducir los resultados experimentales. Además, tiene que tener capacidad suficiente para predecir el comportamiento de las membranas de nanofiltración.

Nanoflux ${ }^{\circledR}$ es un programa informático desarrollado por el Dr. John Palmeri y sus colaboradores [83][111] en el Instituto Europeo de Membranas (IEM) de Montpellier (Francia) para modelizar y simular el trasporte de solutos a través de membranas de nanofiltración [163]. En la Figura 3.33 se puede ver la pantalla principal de este programa informático. 


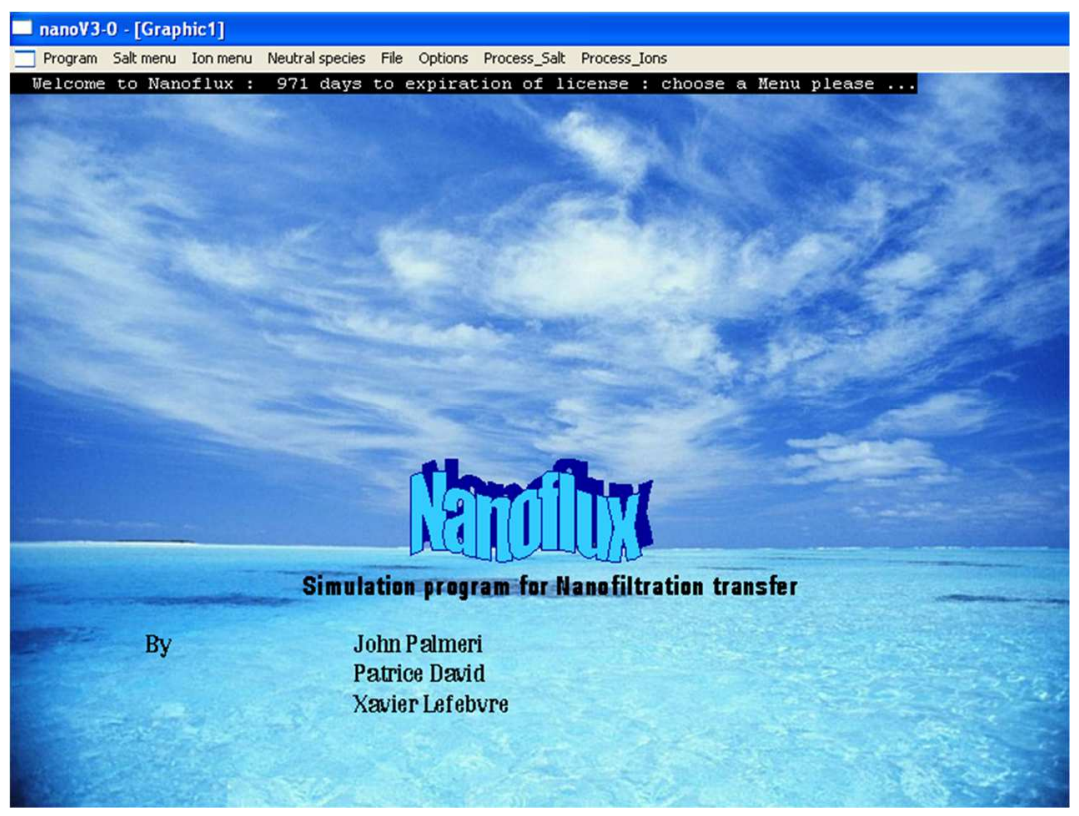

Figura 3.33. Pantalla principal del programa Nanoflux ${ }^{\circledR}$.

Por medio de este programa se puede profundizar en la caracterización de las membranas y obtener previsiones de su comportamiento frente a la disolución que se tiene que tratar [164]. Por tanto, puede utilizarse para caracterizar las membranas de nanofiltración, calculando el radio de los poros y la densidad de carga superficial de las membranas.

Por consiguiente, con este programa informático será posible optimizar un proceso por medio de la determinación de los mejores parámetros de funcionamiento del tratamiento, una vez obtenidos estos datos, Nanoflux ${ }^{\circledR}$ permitirá el dimensionamiento de una instalación de nanofiltración.

De forma resumida, las características más importantes de este programa informático son las siguientes:

- Es posible predecir el rendimiento de filtración de las membranas para disoluciones simples o mezclas complejas de moléculas neutras e iones, como por ejemplo: agua de mar, agua superficial, agua de pozo o incluso aguas residuales.

- Permite calcular, a partir de datos de entrada de alimentación (composición, pH, presión aplicada...), todos los datos necesarios de salida del proceso de nanofiltración (retención de iones y moléculas neutras, flujos...), todo ello para módulos simples de una sola membrana o hasta para plantas con múltiples módulos y varias membranas cada uno.

- Es posible obtener resultados de simulación rápidos y fiables mediante la combinación simultánea de los robustos algoritmos matemáticos y la base de datos interna de Nanoflux ${ }^{\circledR}$ que contiene las principales membranas comerciales. Esta base de datos se actualiza periódicamente, adjuntando nuevas membranas y nuevos solutos [164]. El programa ha sido probado y validado usando estudios de casos reales [95].

- Es fácil de usar, debido a su interfaz de usuario, ergonómica e intuitiva. Este programa de modelización es una herramienta que puede ser utilizada en la toma de decisiones cuando se trata de elegir de forma económica la membrana adecuada y optimizar los procesos de nanofiltración. Por tanto, este programa puede utilizarse para minimizar los difíciles y 
costosos estudios piloto, reduciendo así el coste total y el tiempo necesario para elegir la membrana apropiada [2], así como la ampliación y explotación de plantas de nanofiltración.

En consecuencia, Nanoflux ${ }^{\circledast}$ intenta llenar un hueco en los métodos de predicción y optimización del funcionamiento de la nanofiltración que ha surgido debido a la complejidad de los procesos fundamentales de transporte de los iones. Posiblemente, este hueco ha retrasado el desarrollo general de la nanofiltración. Por consiguiente, este programa es una herramienta muy útil para:

- Ayudar a las empresas y a los investigadores a caracterizar membranas y mejorar las prestaciones de las mismas.

- Desarrollar métodos para comprender mejor la relación entre el material de la membrana y sus propiedades de filtración.

- Informar a los posibles clientes de las potencialidades de una membrana, incluso antes de realizar costosas pruebas experimentales.

- Reducir el tiempo y el coste en la elección de la tecnología de membranas apropiada para solucionar un problema industrial de filtración, permitiendo un rápido retorno de la inversión.

- Enseñar a estudiantes e ingenieros la ciencia de las membranas a través de herramientas de simulación.

\subsubsection{Principio del programa}

Nanoflux ${ }^{\circledast}$ es un programa informático que para determinar los diferentes parámetros referentes a los procesos de nanofiltración se basa en la correlación entre resultados experimentales y los modelos teóricos de trasporte de materia a través de las membranas de nanofiltración.

El método que Nanoflux ${ }^{\circledR}$ utiliza para la modelización consiste en estimar, en primer lugar, el tamaño del poro de la membrana según la retención de moléculas neutras modelo [83][111]. Por tanto, el radio efectivo de los poros $\left(r_{p}\right)$ es estimado por el ajuste del modelo HTT ("Hindered Transport Theory") con los resultados experimentales de retención de los solutos neutros en función del flujo volumétrico [85][165][166] (ver el ANEXO I. Desarrollo de modelos de transporte a través de membranas de nanofiltración). La retención esperada a un flujo elevado depende sólo de la relación existente entre el tamaño del soluto y el del poro de la membrana.

En la práctica, los solutos neutros son seleccionados en la interfaz del programa informático. A partir de valores arbitrarios que se dan al diámetro de poro $\left(r_{p}\right)$, el programa calcula con la ayuda del modelo teórico correspondiente a los solutos neutros las curvas teóricas de retención sobre la misma gráfica. El programa calcula por ajuste con los resultados experimentales de las retenciones (anteriormente introducidas en el programa) los valores óptimos del radio de poro $\left(r_{p}\right)$ ajustado por cálculos numéricos. Por tanto, el radio de poro $\left(r_{p}\right)$ de la membrana es estimado a partir de la retención de los compuestos neutros modelo. En la Figura 3.34, se puede observar una imagen que el programa Nanoflux ${ }^{\circledast}$ muestra de la base de datos donde almacena los compuestos neutros modelo. En esta pantalla se pueden elegir los compuestos con los que en cada caso interese trabajar. 


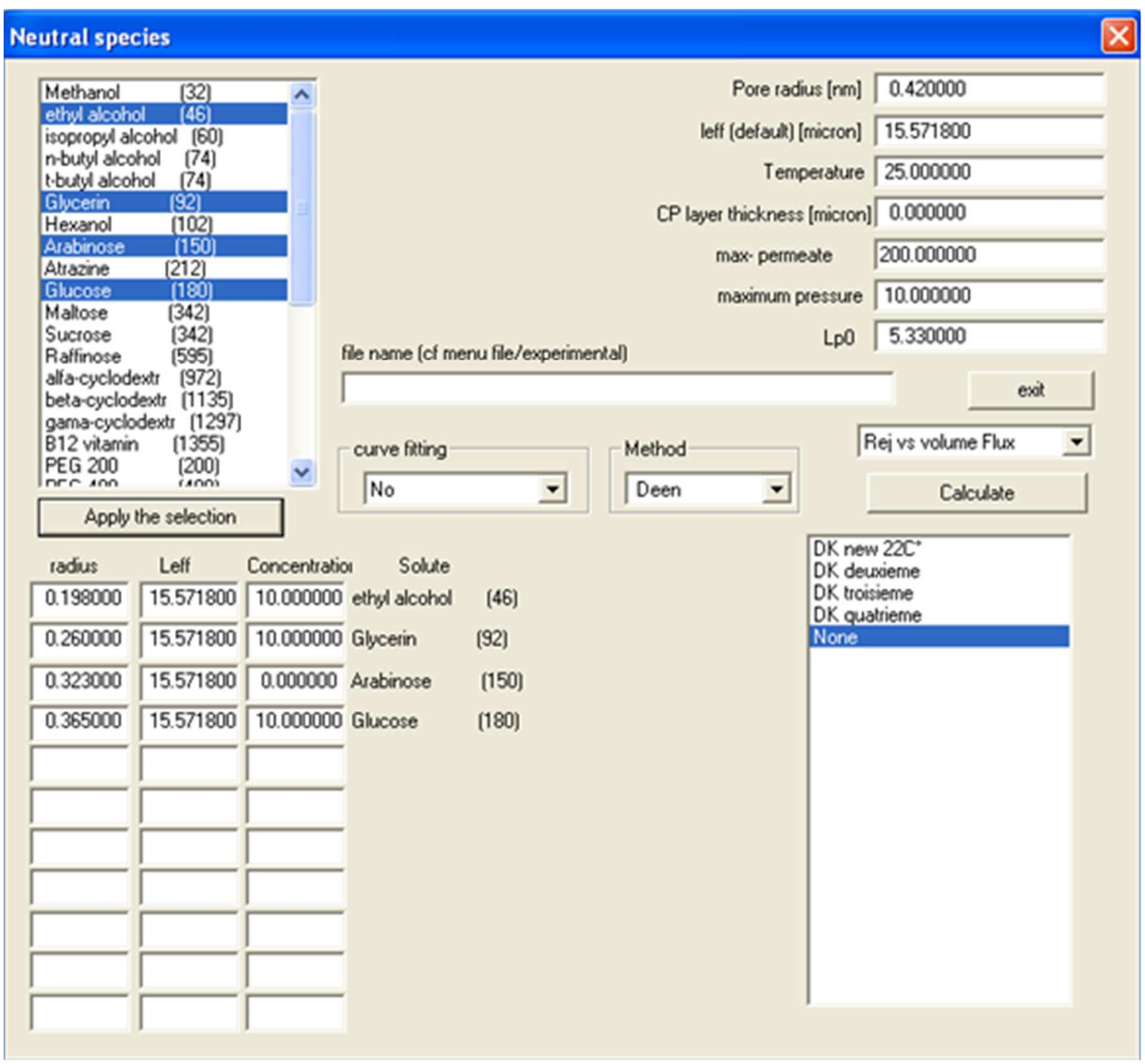

Figura 3.34. Interfaz del programa informático Nanoflux ${ }^{\circledR}$ y su base de datos de compuestos neutros modelo.

La densidad de carga de la membrana $\left(X_{m}\right)$ o la densidad de carga normalizada $\left(X_{i}=X_{m} / \sum c_{a i}\right)$ se estiman indirectamente por ajuste del modelo hibrido HETT ("Hindered Electro Transport Theory") con los resultados experimentales de la retención de las sales en función del flujo volumétrico (ver el ANEXO I. Desarrollo de modelos de transporte a través de membranas de nanofiltración). La retención esperada con un flujo elevado, depende de la relación entre el tamaño del ion y el tamaño del poro de la membrana, de la relación entre la movilidad intra-membrana del coión y de su contraión y de la densidad de carga de la membrana.

Para que el valor ajustado de la densidad de carga de la membrana $\left(X_{m}\right)$, represente fielmente la densidad de carga real de la membrana, es necesario que no tengan lugar otras interacciones que no sean las electroestáticas y las estéricas.

En la práctica, se estudia la retención que ofrece la membrana a diferentes sales simples $(\mathrm{NaCl}$, $\mathrm{MgSO}_{4}, \mathrm{Na}_{2} \mathrm{SO}_{4}, \mathrm{CaCl}_{2}$ ), cada sal es seleccionada a partir de la interfaz correspondiente del programa (ver Figura 3.35). 


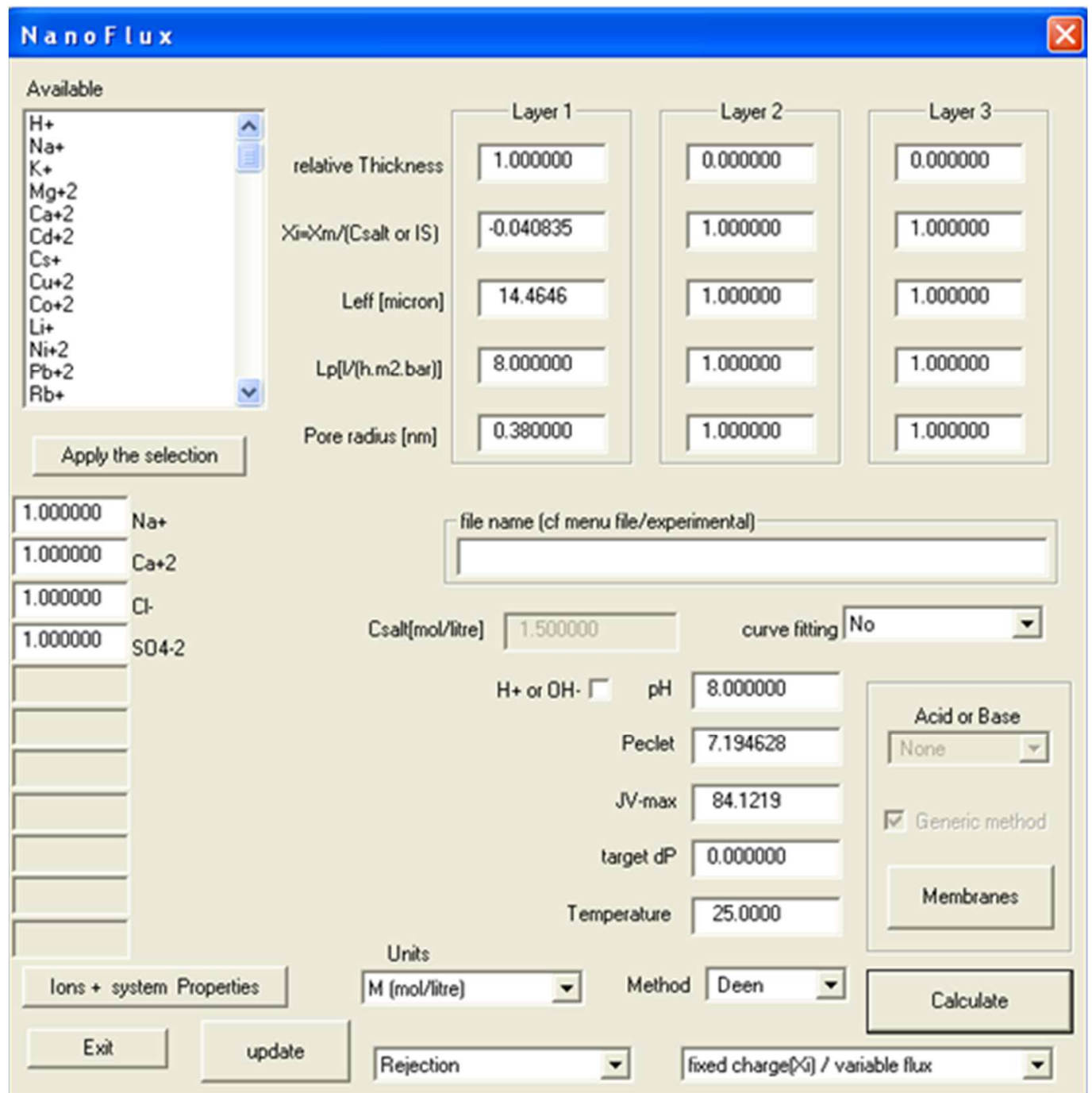

Figura 3.35. Interfaz del programa informático Nanoflux ${ }^{\circledR}$ y su base de datos de especies iónicas modelo.

Además, son introducidos también en el programa el valor de $\mathrm{pH}, c_{a i}$ (concentración de la corriente alimento de las especies $i$ ) y el $r_{p}$ (radio de poro de la membrana ofrecido por el programa a partir de los resultados obtenidos con las disoluciones de compuestos neutros). Por un lado, los resultados experimentales obtenidos con estas sales son analizadas por el programa Nanoflux ${ }^{\circledR}$ a través de un procedimiento numérico de ajuste utilizando la base de datos interna del programa que contiene valores de radio de la molécula en forma cristalina, la carga iónica y el coeficientes de difusión, además de un conjunto de parámetros de entrada ajustable por el usuario, de esta forma, determinar los valores óptimos de la densidad de carga y espesor de la membrana que caracterizan el par membrana/sal. Y por otro lado, las predicciones teóricas de la retención de los iones presentes en una disolución son obtenidas tras resolver numéricamente las ecuaciones extendidas de NernstPlank para el flujo de iones. Los valores de los parámetros mejor ajustados, los cuales minimizan las diferencias entre las retenciones experimentales y teóricas, varían en función de la concentración de la sal y del pH de la corriente alimento. Cuanto más precisos sean estos dos parámetros, mejor será la previsión hecha por el modelo. Por tanto, el programa Nanoflux ${ }^{\circledR}$ determina la densidad de carga y el espesor efectivo de la membrana para mezclas de sales como 
una función del pH, de la fuerza iónica y de la concentración de la corriente alimento usando las anteriores consideraciones [167].

La retención y el flujo de permeado para mezclas complejas de varios iones se pueden predecir de una forma aproximada utilizando la base de datos interna de las sales simples [83][111].

Por tanto, Nanoflux ${ }^{\circledR}$ puede ser la base de un método experimental y teórico combinado para caracterizar, simular y optimizar el comportamiento de membranas de nanofiltración en las que el efecto carga es importante. 

4 RESULTADOS Y DISCUSIÓN 



\subsection{Caracterización de las membranas a escala de laboratorio}

Las membranas de nanofiltración que se van a utilizar en este estudio son membranas orgánicas de la empresa Dow-Filmtec. En concreto, son las membranas NF, NF-90, NF-200 y NF-270 (ver apartado 3.3 Membranas). Se decidió estudias estas membranas porque cuando se inició este trabajo estas cuatro membranas constituían toda la serie de nanofiltración de Dow-Filmtec, compañía de reconocido prestigio dentro de la filtración a través de membranas. Además, de alguna de ellas ya se disponían de datos bibliográficos acerca de su comportamiento en diferentes escenarios.

Es necesario realizar una caracterización de las membranas comerciales utilizadas, ya que la información proporcionada por el fabricante no es muy extensa (ver ANEXO III. Características técnicas de las membranas de nanofiltración proporcionadas por el fabricante). Los datos del fabricante en ningún caso hacen referencia al grado de retención de las especies no cargadas, y solamente ofrecen datos muy generales de la retención que las membranas presentan a alguna sal. Por esta razón, lo que se pretende en este apartado es obtener más información referente a cada una de las membranas para poder anticiparse, en la medida de lo posible, al comportamiento que éstas tendrán ante una disolución alimento determinada.

Por lo tanto, para caracterizar las membranas, en primer lugar, se han acondicionado las membranas y se ha calculado su permeabilidad al agua pura $\left(L_{p}^{0}\right)$. Seguidamente, se ha determinado el radio de poro $\left(r_{p}\right)$ de las membranas. Para ello se han realizado ensayos experimentales de nanofiltración con cada una de las membranas utilizando disoluciones acuosas con determinadas especies modelo no cargadas. A partir de los datos experimentales obtenidos, se ha modelizado el comportamiento de la membrana mediante el programa informático Nanoflux ${ }^{\circledR}$ y se ha obtenido el radio de poro de cada una de las membranas. El programa informático Nanoflux ${ }^{\circledR}$ conoce la masa molar, el radio de Stokes, así como el coeficiente de difusión de todas las especies modelo no cargadas que se han utilizado. Por último, se ha determinado la densidad de carga normalizada $\left(X_{i}\right)$ de las membranas ante varias disoluciones acuosas dadas. Para ello también se han realizado ensayos experimentales de nanofiltración, pero esta vez con disoluciones acuosas con varias sales modelo. Con los resultados experimentales obtenidos en estos ensayos de nanofiltración y por medio del programa Nanoflux ${ }^{\circledR}$, se ha modelizado el comportamiento de las membranas para obtener su densidad de carga normalizada $\left(X_{i}\right)$ frente a estas disoluciones. El programa Nanoflux ${ }^{\circledR}$ tiene en su base de datos toda la información necesaria de las especies cargadas modelo utilizadas.

Tanto las especies neutras como las sales empleadas en los ensayos experimentales, así como algunas de sus principales características, pueden encontrarse en el apartado 3.1 Tipo de aguas a tratar.

Para una mejor comprensión de las acciones realizadas en este apartado, en la Figura 4.1 se muestra un diagrama de flujo donde se pueden observar los pasos seguido para la caracterización de las membranas. 


\section{CARACTERIZACIÓN DE LAS MEMBRANAS}

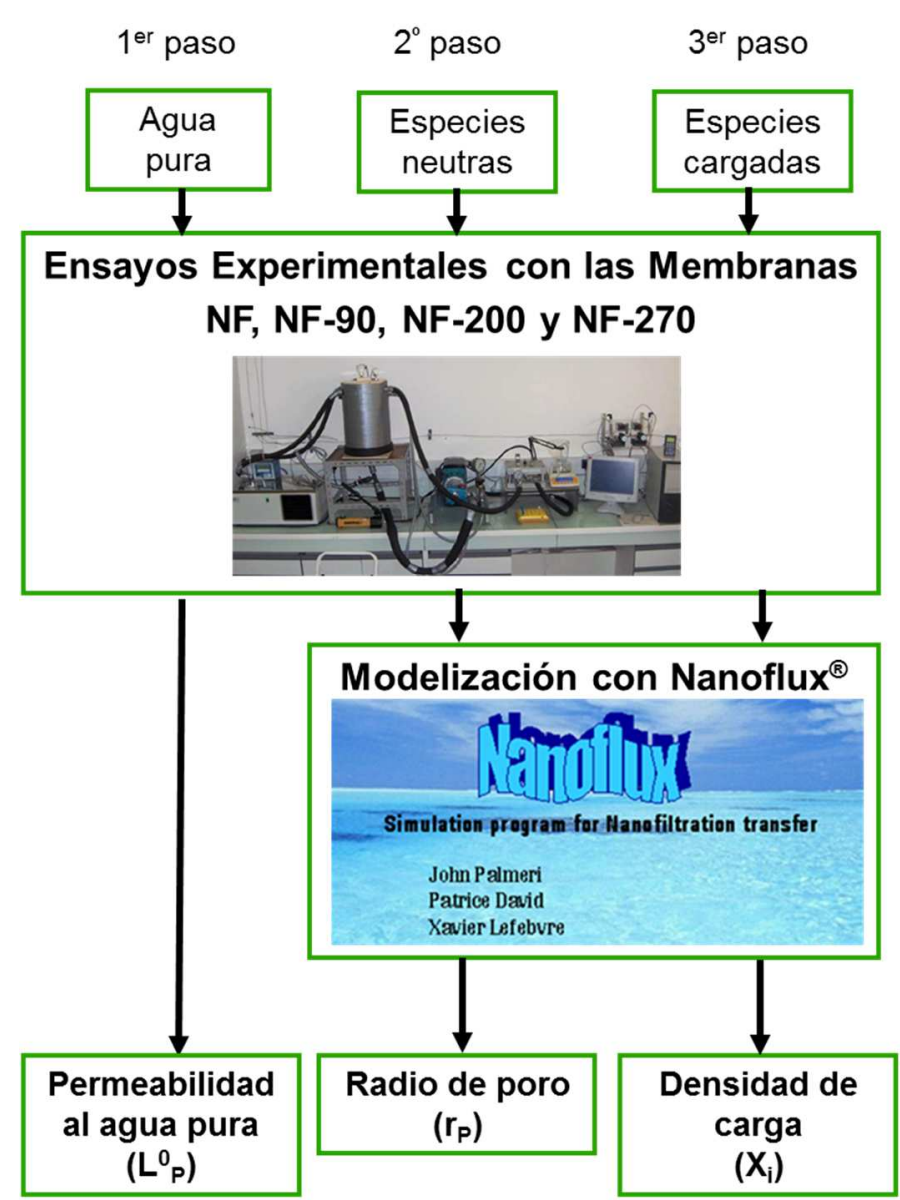

Figura 4.1. Diagrama de flujo que muestra los pasos seguidos durante la caracterización de las membranas.

Para hacer las distintas pruebas con estas membranas se siguió exactamente el procedimiento descrito en apartado 3.6 Procedimiento experimental. Antes de realizar los ensayos experimentales con las disoluciones sintéticas, se acondicionaron las membranas. Para la realización de todas las pruebas necesarias para la caracterización de las membranas a escala de laboratorio se han utilizado membranas planas y el equipamiento de laboratorio que el IEM dispone en sus instalaciones (ver 3.4.1 Plantas de filtración tangencial a escala de laboratorio).

\subsubsection{Acondicionamiento de la membrana y cálculo de su permeabilidad al agua pura}

Para la caracterización de las membranas se ha partido de membranas planas nuevas. Por tanto, el primer paso ha sido acondicionarlas para eliminar posibles restos de productos conservantes, hidratarlas y compactarlas (ver apartado 3.6.1 Acondicionamiento de la membrana). Tras cada ciclo de acondicionamiento se ha determinado la permeabilidad al agua pura de la membrana. Este ensayo ha permitido conocer la evolución del acondicionamiento, además de conocer este parámetro propiamente dicho una vez se considere que la membrana esté completamente acondicionada. La permeabilidad al agua pura es uno de los parámetros que se ha utilizado para caracterizar las membranas que se han utilizado [43]. 
La ley de Darcy estipula que el flujo de permeado $\left(J_{v}\right)$ es proporcional a la permeabilidad hidráulica $\left(L_{p}^{0}\right)$ y a la presión transmembrana $(\Delta P)$ cuando se utiliza agua pura, por tanto no hay solutos a separar. Así pues, la representación de $J_{v}=f(\Delta P)$ debe dar una recta cuyo valor es la permeabilidad $\left(L_{p}^{0}\right)$ de la membrana al agua pura.

Por tanto, después de cada ciclo de acondicionamiento realizado a cada una de las membranas se ha medido el flujo de permeado al agua pura a distintas presiones $(5,8,11$ y 15 bar) y a una temperatura de $30^{\circ} \mathrm{C}$ para de esta forma calcular su permeabilidad. Los ciclos de acondicionamiento y la medida de la permeabilidad se han repetido hasta encontrar resultados similares (variación de $\pm 5 \%$ ), de esta forma se comprueba que la membrana está acondicionada y es estable. Se ha calculado este parámetro después de cada ensayo con las distintas disoluciones para ver si las características de la membrana permanecen constantes.

A continuación, se representa en la Figura 4.2 un gráfico donde se puede observar la permeabilidad al agua pura obtenida durante el acondicionamiento de cada membrana y después de la utilización de cada una de ellas con una disolución acuosa de especies neutras, este último dato se ha puesto para demostrar que la membrana sigue siendo estable después de la primera utilización, esto será así hasta que se colmate o tenga algún problema que haga que tenga que desecharse y sustituirse por otra nueva.

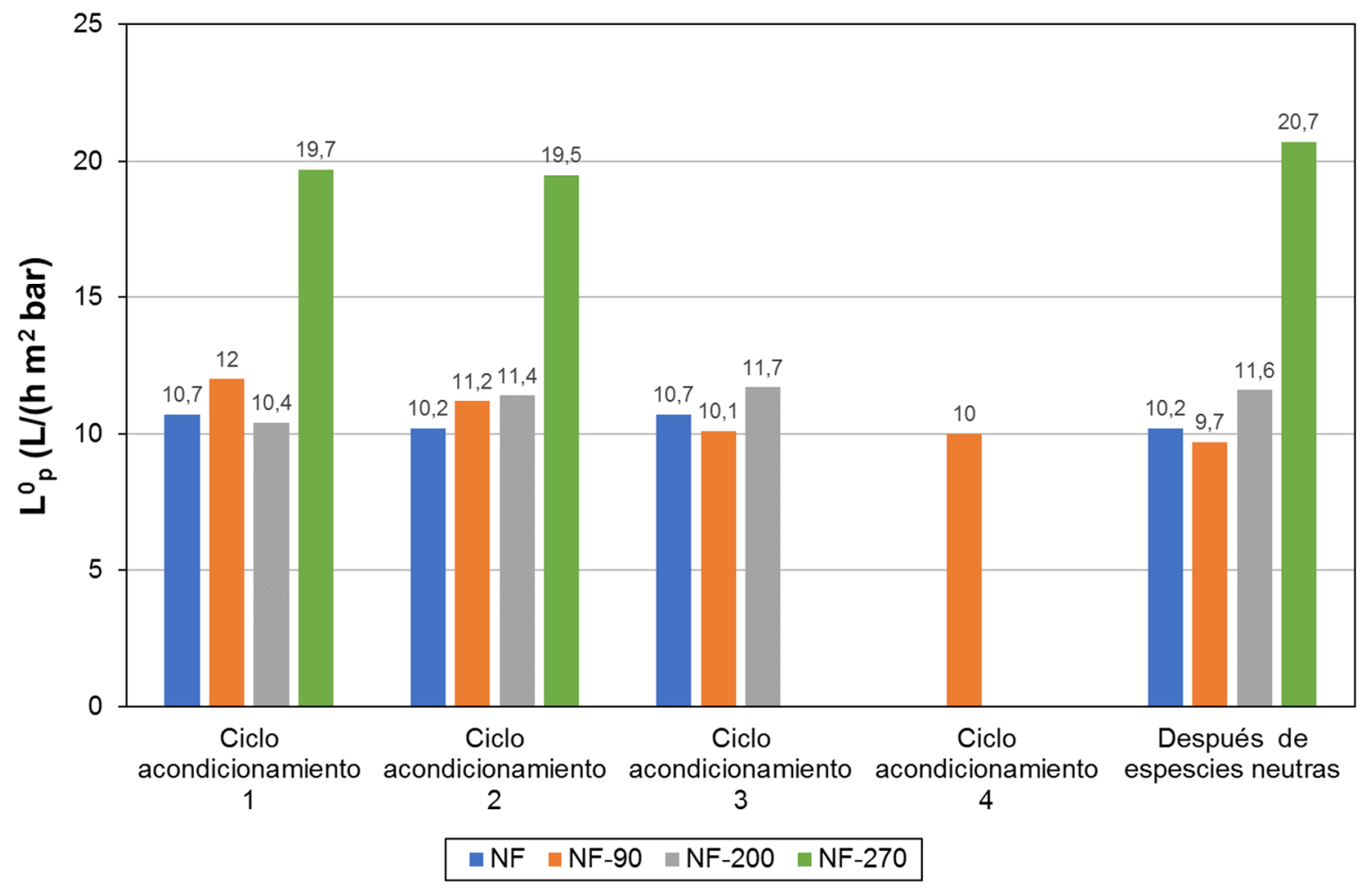

Figura 4.2. Permeabilidad al agua pura de las membranas NF, NF-90, NF-200 y NF-270.

Como puede observarse en la Figura 4.2, para acondicionar la membrana NF hicieron falta 3 ciclos de acondicionamiento, obteniéndose una permeabilidad al agua pura después de cada uno de ellos de 10,7 L/(h $\mathrm{m}^{2}$ bar), 10,2 L/( $\mathrm{h} \mathrm{m}^{2}$ bar) y 10,7 L/( $\mathrm{h} \mathrm{m}^{2}$ bar $)$, respectivamente. También puede observarse la permeabilidad obtenida después del ensayo realizado con especies neutras que es 
de 10,2 L/(h $\mathrm{m}^{2}$ bar). El hecho de obtener la misma permeabilidad ( $\left.\pm 5 \%\right)$, permite comprobar que la membrana permanece estable y no ha sufrido ningún cambio, además demuestra que la membrana no ha sufrido obturación de ningún tipo y que la limpieza ha sido correcta.

En el caso de la membrana NF-90 para su completo acondicionamiento han sido necesarios 4 ciclos, ya que las primeras permeabilidades obtenidas variaban entre ellas más de un $5 \%$. Las permeabilidades obtenidas en la etapa de acondicionamiento han sido $12,0 \mathrm{~L} /\left(\mathrm{h} \mathrm{m}^{2}\right.$ bar), 11,2 $\mathrm{L} /\left(\mathrm{h} \mathrm{m}^{2}\right.$ bar), 10,1 L/(h $\mathrm{m}^{2}$ bar) y 10,0 L/( $\mathrm{h} \mathrm{m}^{2}$ bar), respectivamente. Después del ensayo realizado con soluciones neutras, la permeabilidad obtenida ha sido de $9,80 \mathrm{~L} /\left(\mathrm{h} \mathrm{m}^{2}\right.$ bar), permeabilidad que demuestra que la membrana es estable después del ensayo.

Por lo que respecta a la membrana NF-200 han hecho falta 3 ciclos, al igual que ocurrió con la membrana NF. Las permeabilidades obtenidas han sido $10,5 \mathrm{~L} /\left(\mathrm{h} \mathrm{m}^{2}\right.$ bar $), 11,5 \mathrm{~L} /\left(\mathrm{h} \mathrm{m}^{2}\right.$ bar) y 11,7 $\mathrm{L} /\left(\mathrm{h} \mathrm{m}^{2}\right.$ bar), respectivamente. Al igual que en los casos anteriores, la permeabilidad obtenida después de los ensayos realizados con las disoluciones de especies neutras también muestra que la membrana no ha sufrido ningún cambio.

En el caso de la membrana NF-270 solamente se han necesitado dos ciclos para que se pueda considerar la membrana acondicionada, ya que las permeabilidades obtenidas después de estos dos primeros ciclos han sido similares. Permeabilidades de $19,7 \mathrm{~L} /\left(\mathrm{h} \mathrm{m}^{2}\right.$ bar) y $19,5 \mathrm{~L} /\left(\mathrm{h} \mathrm{m}^{2}\right.$ bar), respectivamente. La permeabilidad obtenida después del ensayo con la disolución sintética de especies neutras $\left(20,6 \mathrm{~L} /\left(\mathrm{h} \mathrm{m}^{2}\right.\right.$ bar)), muestra que la membrana sigue siendo estable después del ensayo realizado.

Además, también se puede ver en la gráfica representada en la Figura 4.2, que el acondicionamiento de las membranas se da por finalizado cuando las permeabilidades de las mismas variaban menos de un $5 \%$ entre un ensayo y el precedente.

Si se considera la permeabilidad de las membranas como la media entre las dos últimas permeabilidades obtenidas en la etapa de acondicionamiento, se obtienen los resultados recogidos en la Tabla 4.1, considerándose la permeabilidad al agua pura de cada una de las membranas.

Tabla 4.1. Permeabilidad al agua pura de las membranas (media de las dos últimas $L_{p}^{0}$ del acondicionamiento).

\begin{tabular}{|c|c|c|c|c|}
\hline \multirow{2}{*}{} & \multicolumn{4}{|c|}{ Tipo de membrana } \\
\cline { 2 - 5 } & NF & NF-90 & NF-200 & NF-270 \\
\hline $\begin{array}{c}\text { Permeabilidad al agua } \\
\text { pura } L_{p}^{0}\end{array}$ & \multirow{2}{*}{ (L/h m mar $^{2}$ ba, } & 10,1 & 11,6 & 19,6 \\
\hline
\end{tabular}

Como se aprecia en la tabla, la membrana NF-90 es la menos permeable, mientras que la membrana NF-270 es la más permeable. Estos resultados confirman los datos que el fabricante proporciona para cada una de las membranas y que están recogidos en la Tabla 3.4 del apartado 3.3 Membranas. Las permeabilidades calculadas y las proporcionadas por el fabricante no coinciden, ya que las permeabilidades calculadas en el presente trabajo se han obtenido para el 
agua pura a $30^{\circ} \mathrm{C}$ y el fabricante las proporciona para una disolución acuosa de 2000 ppm de $\mathrm{MgSO}_{4}$ a $25^{\circ} \mathrm{C}$. Sin embargo, se puede observar la misma tendencia.

Si sólo se tuviese en cuenta la producción de permeado, la membrana más conveniente es la NF270 , pero es posible que sea una de las que mayor radio de poro tenga, por tanto, puede que no sea la más indicada para obtener la retención más elevada de los contaminantes estudiados.

\subsubsection{Retención de las especies neutras}

\subsubsection{Ensayos experimentales con las disoluciones de las especies neutras}

Estos ensayos con especies neutras de tamaño conocido se han realizado para caracterizar la membrana y para obtener más información sobre su comportamiento. Si se conoce la retención y el flujo del permeado para una disolución dada, se puede determinar el radio de poro $\left(r_{p}\right)$ de la membrana con la ayuda de la modelización realizada por el programa informático Nanoflux ${ }^{\circledR}$.

Por tanto, se han efectuado diferentes ensayos en el laboratorio con disoluciones sintéticas de especies neutras para calcular su grado de retención. Las disoluciones tenían una concentración de $1 \mathrm{~g} / \mathrm{L}$. Las especies neutras elegidas son especies modelo con el radio de Stokes conocido (radio de la especie en su forma cristalina) y que se encuentran en la base de datos del programa informático. La retención de estas especies es utilizada por Nanoflux ${ }^{\circledR}$ para el cálculo del radio de poro de las membranas. Los compuestos elegidos para preparar la disolución sintética han sido la glucosa, la sacarosa, la glicerina y la arabinosa, y en algunos casos además se ha utilizado también el etilenglicol, el 1-propanol y el alcohol isopropílico o 2-propanol. Las características de todos estos compuestos se recogen en el punto 3.1 Tipo de aguas a tratar.

La retención que cada membrana ofrece a estas moléculas en función del flujo de permeado se representa en las figuras que van de la Figura 4.3 a la Figura 4.6. En estas gráficas se observan las curvas características de la retención $(R)$ (en tanto por uno) que la membrana ofrece para cada molécula frente al caudal de permeado $\left(J_{v}\right)$. Cada punto representado en las gráficas corresponde a la retención obtenida de forma experimental que la membrana ofrece a cada especie neutra a $25^{\circ} \mathrm{C}$ y para una presión determinada. En este caso se partió de 3 bar de presión y se llegó hasta 15 bar, pasando por 5, 7, 9 y 12 bar.

En la Figura 4.3 se observa la retención que la membrana NF ofrece a estas sustancias neutras. Y se observa que la retención a la sacarosa, glucosa y arabinosa está por encima del 90-95\% cuando la retención es constante con respecto al flujo y presión (en adelante meseta). Por otro lado, la retención del glicerol oscila en torno al $80 \%$. 


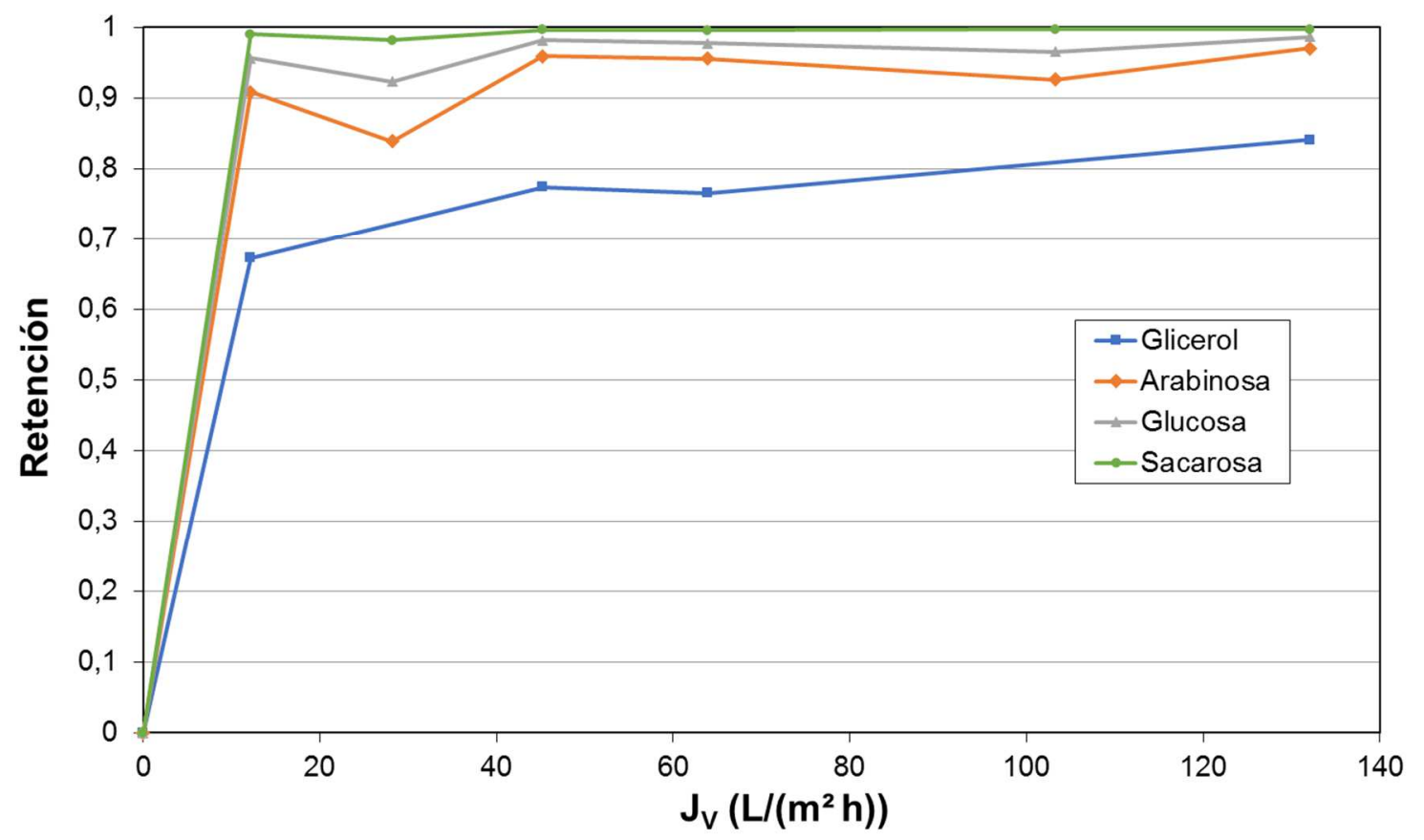

Figura 4.3. Retención de las especies neutras por la membrana NF en función del flujo de permeado y a una temperatura de $25^{\circ} \mathrm{C}$.

En la Figura 4.4 se representa la retención que ofrece la membrana NF-90 y como puede observarse la retención ofrecida a la sacarosa, a la glucosa y a la arabinosa es del 100\%, incluso a presiones bajas (3 bar). La retención del glicerol se mueve en torno al 95\% una vez llegados a la meseta. Como se puede observar en la gráfica, en este caso se utilizó también etilenglicol y alcohol isopropílico o propanol-2, para de esta forma disponer de datos suficientemente espaciados para obtener una buena modelización con el programa Nanoflux ${ }^{\circledR}$. La retención del alcohol isopropílico oscila en torno al $80 \%$ una vez se ha llegado a la meseta y la del etilenglicol es superior al $50 \%$ en sus puntos más elevados. 


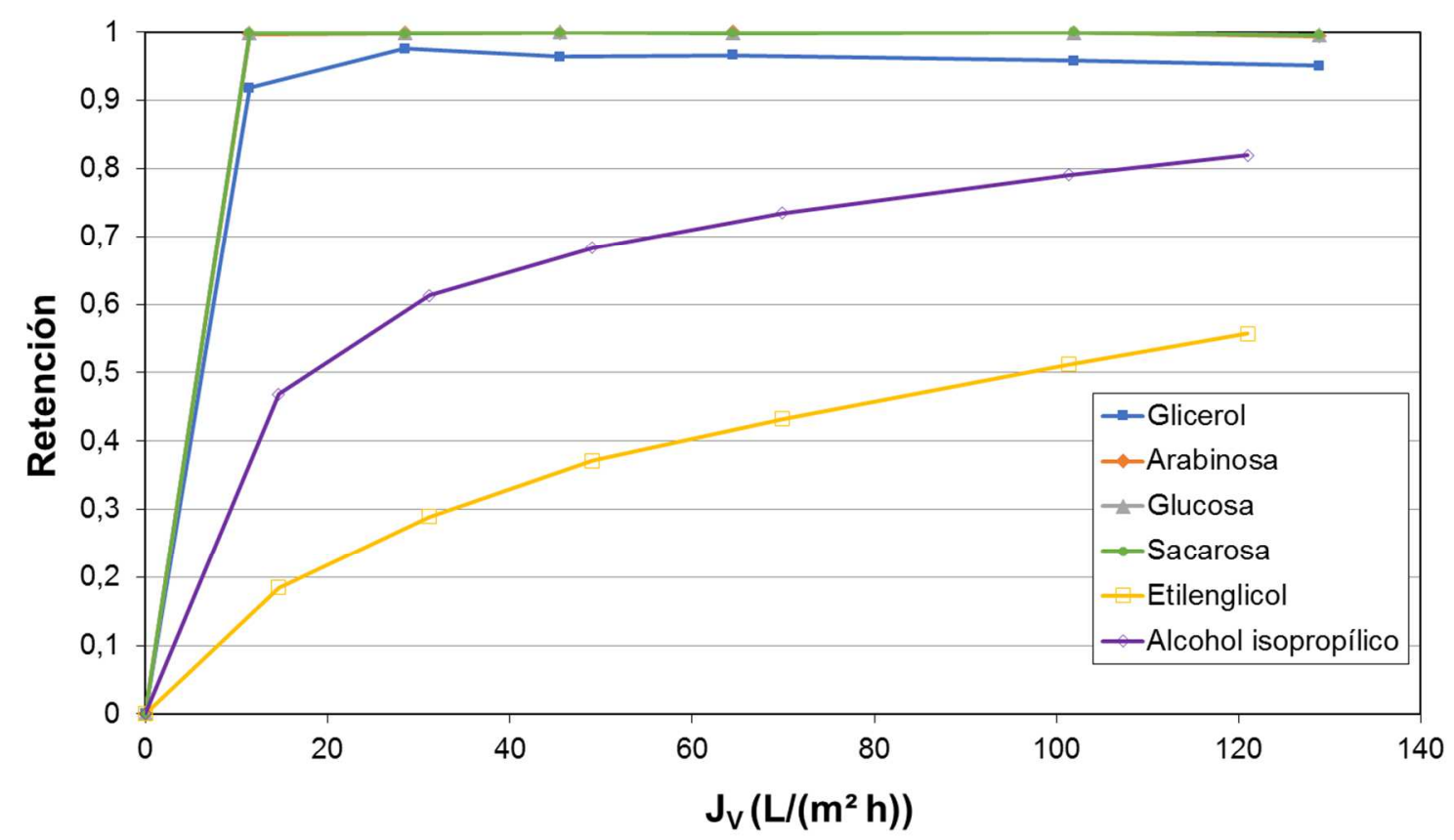

Figura 4.4. Retención de las especies neutras por la membrana NF-90 en función del flujo de permeado y a una temperatura de $25^{\circ} \mathrm{C}$.

La retención que ofrece la membrana NF-200 a las especies neutras se puede observar en la Figura 4.5. En este caso se ha utilizado la glucosa, la arabinosa y el 1-propanol. La retención que la membrana ofrece a la glucosa en la meseta es superior al 95\%, la de la arabinosa se mueve en torno al $95 \%$ y por último la del 1-propanol es del $30 \%$.

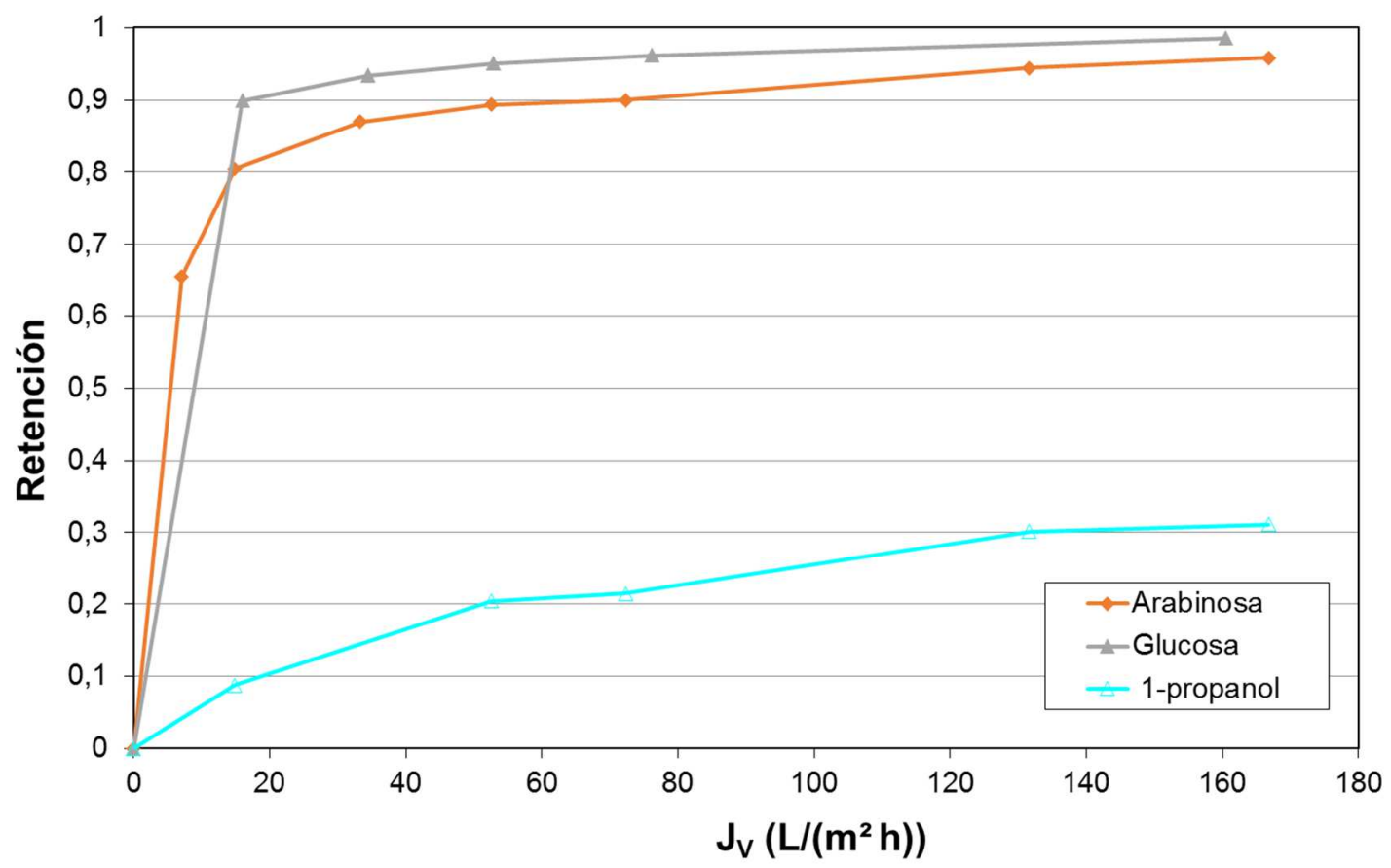

Figura 4.5. Retención de las especies neutras por la membrana NF-200 en función del flujo de permeado y a una temperatura de $25^{\circ} \mathrm{C}$. 
En la gráfica de la Figura 4.6 se representa la retención que la membrana NF-270 ofrece a las especies neutras estudiadas. Concretamente, se puede ver que la retención a la sacarosa es del $100 \%$ una vez alcanzada la meseta. La retención de la glucosa y de la arabinosa es superior al $95 \%$, mientras que la retención del glicerol varía entre 85 y $90 \%$.

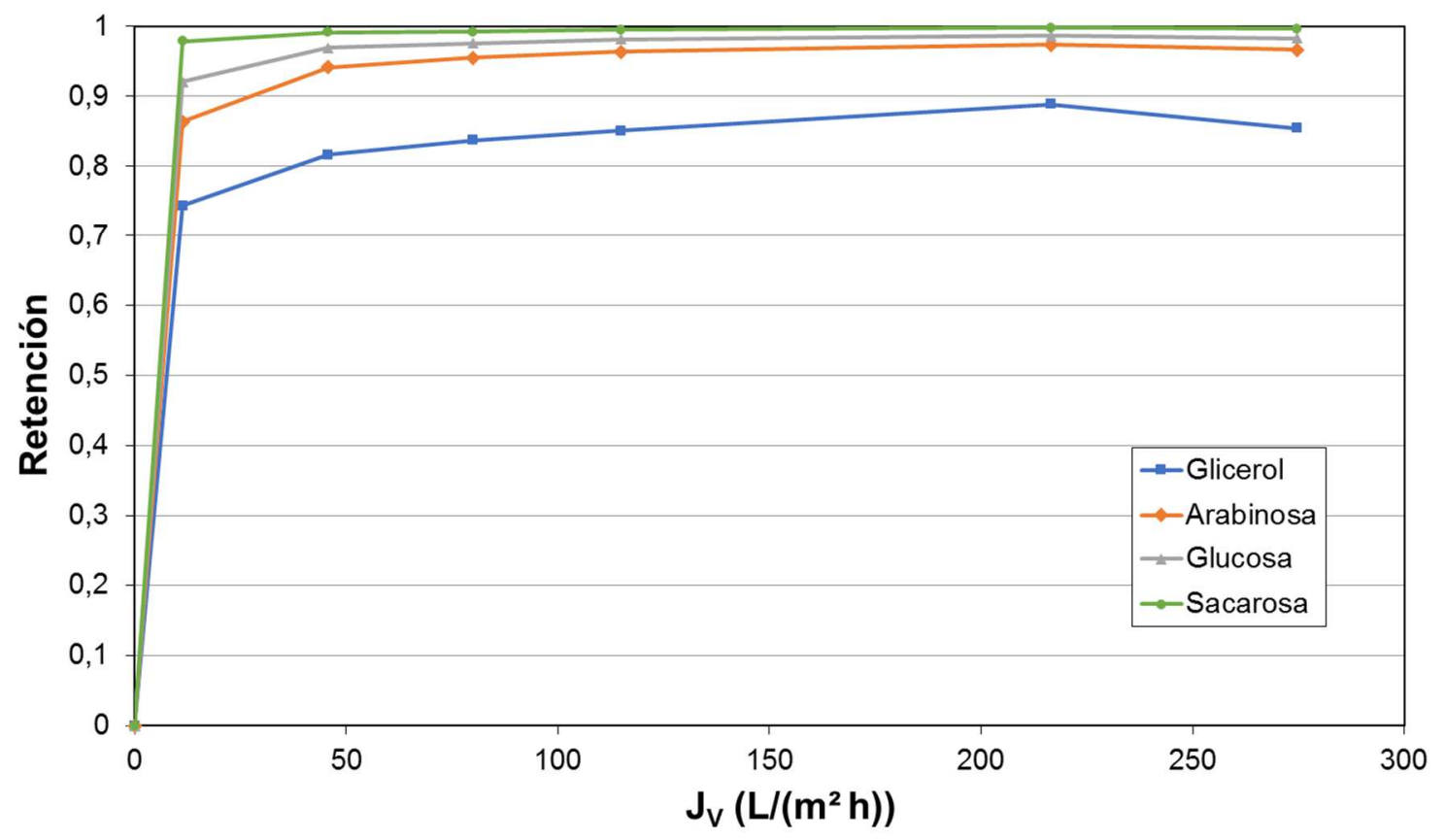

Figura 4.6. Retención de las especies neutras por la membrana NF-270 en función del flujo de permeado y a una temperatura de $25^{\circ} \mathrm{C}$.

A la vista de los resultados obtenidos se observa que la membrana que mayor retención ofrece a las especies estudiadas es la NF-90 y la que posiblemente peor comportamiento presenta es la NF200, a la espera de contrastar los resultados experimentales con los obtenidos en la modelización con el programa Nanoflux ${ }^{\circledR}$.

Tal y como se ha mencionado anteriormente, los resultados obtenidos experimentalmente se introducen en el programa informático Nanoflux ${ }^{\circledR}$, para que éste modelice el comportamiento de las membranas y calcule el radio de poro que más se ajuste a los resultados experimentales obtenidos.

\subsubsection{Modelización del radio de poro $\left(r_{p}\right)$ de la membrana mediante el programa informático Nanoflux ${ }^{\circledR}$.}

Con esta modelización se pretende obtener el radio de poro para cada una de las membranas estudiadas. Por tanto, para que el programa Nanoflux ${ }^{\circledR}$ modelice el comportamiento de las membranas y pueda calcular el radio de poro de las mismas, hay que introducirle los valores experimentales de retención y flujo volumétrico obtenidos con las disoluciones sintéticas de especies neutras, junto a la concentración inicial de la alimentación, el pH de la disolución y la temperatura de filtración. Después, el programa proporcionará unas representaciones gráficas de la retención $(R)$ para cada compuesto frente al flujo de permeado $\left(J_{v}\right)$. En estas representaciones se pueden observar puntos que corresponden a los datos experimentales que han sido introducidos y líneas continuas que corresponden a la modelización que realiza el programa informático. Las 
gráficas obtenidas por el programa Nanoflux ${ }^{\circledR}$ pueden observarse en las figuras que van desde la Figura 4.7 hasta la Figura 4.10. El radio de poro calculado para cada membrana, junto con otros parámetros que no se utilizarán en este trabajo, se puede observar en los datos que el programa proporciona en la parte superior derecha de las gráficas (dato rodeado con un círculo rojo).

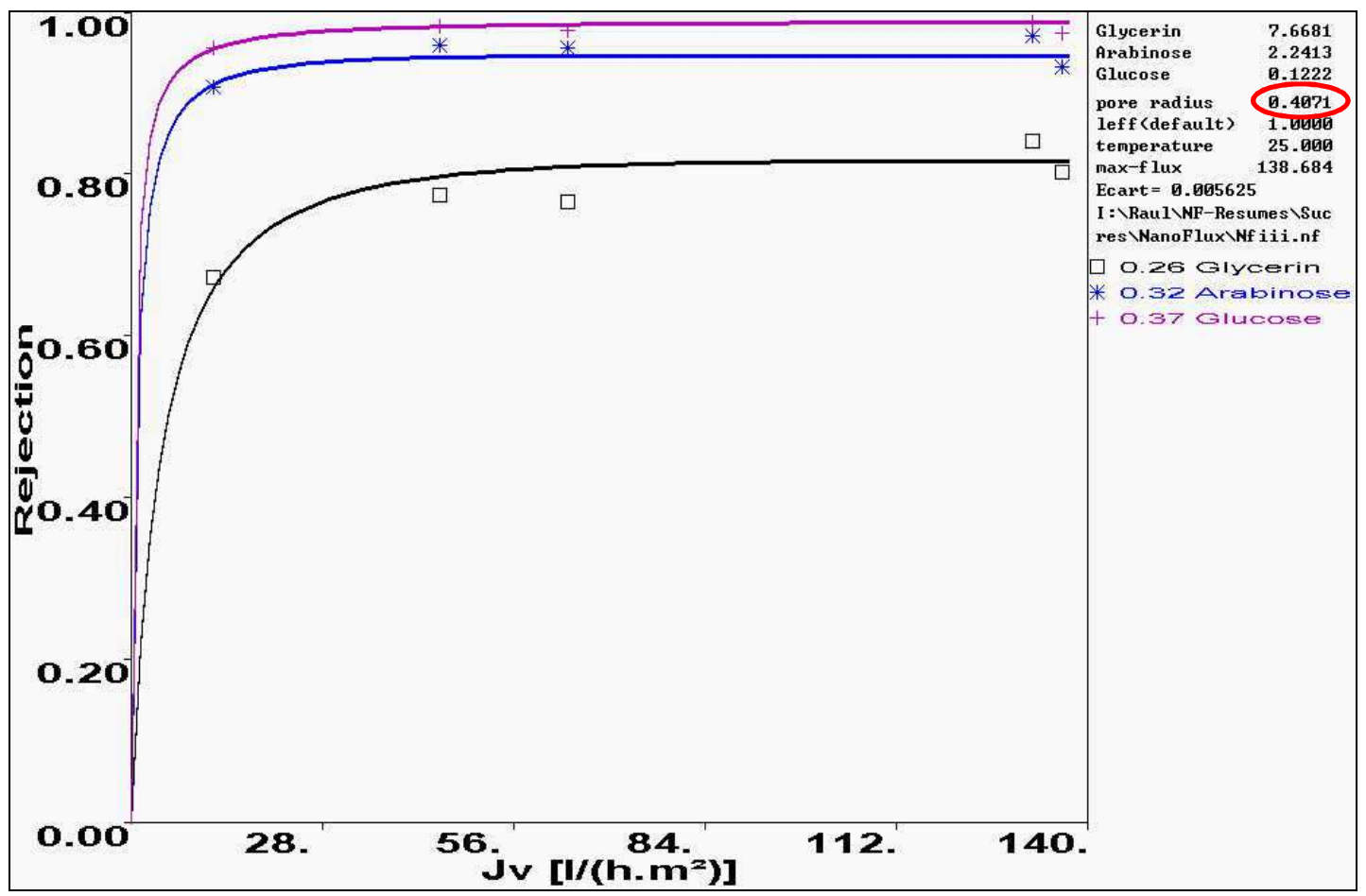

Figura 4.7. Retención en función del flujo de permeado para la membrana NF. Línea continua: modelización de Nanoflux ${ }^{\circledR}$, puntos discontinuos: resultados experimentales.

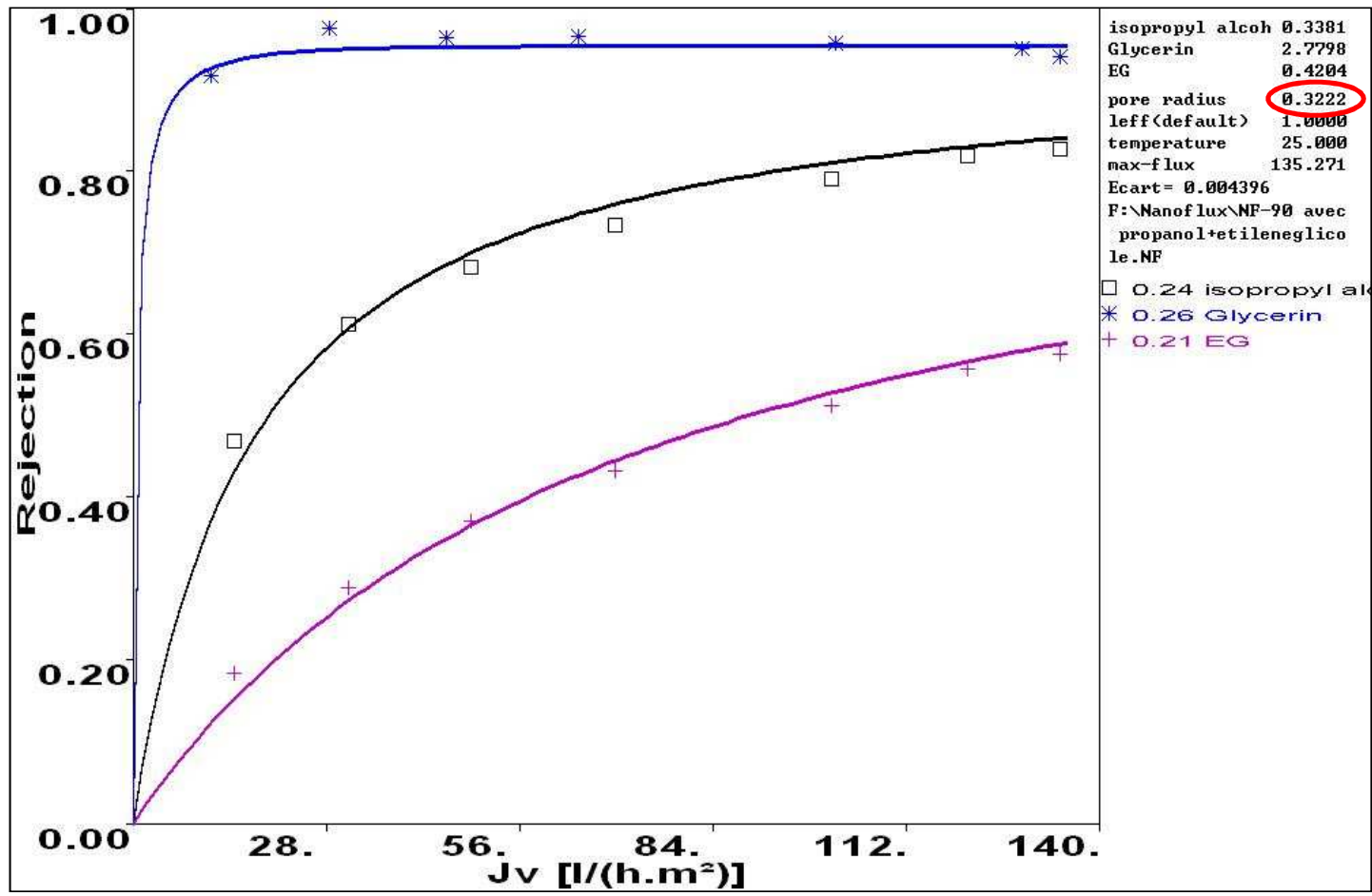

Figura 4.8. Retención en función del flujo de permeado para la membrana NF-90. Línea continua: modelización de Nanoflux ${ }^{\circledR}$, puntos discontinuos: resultados experimentales. 


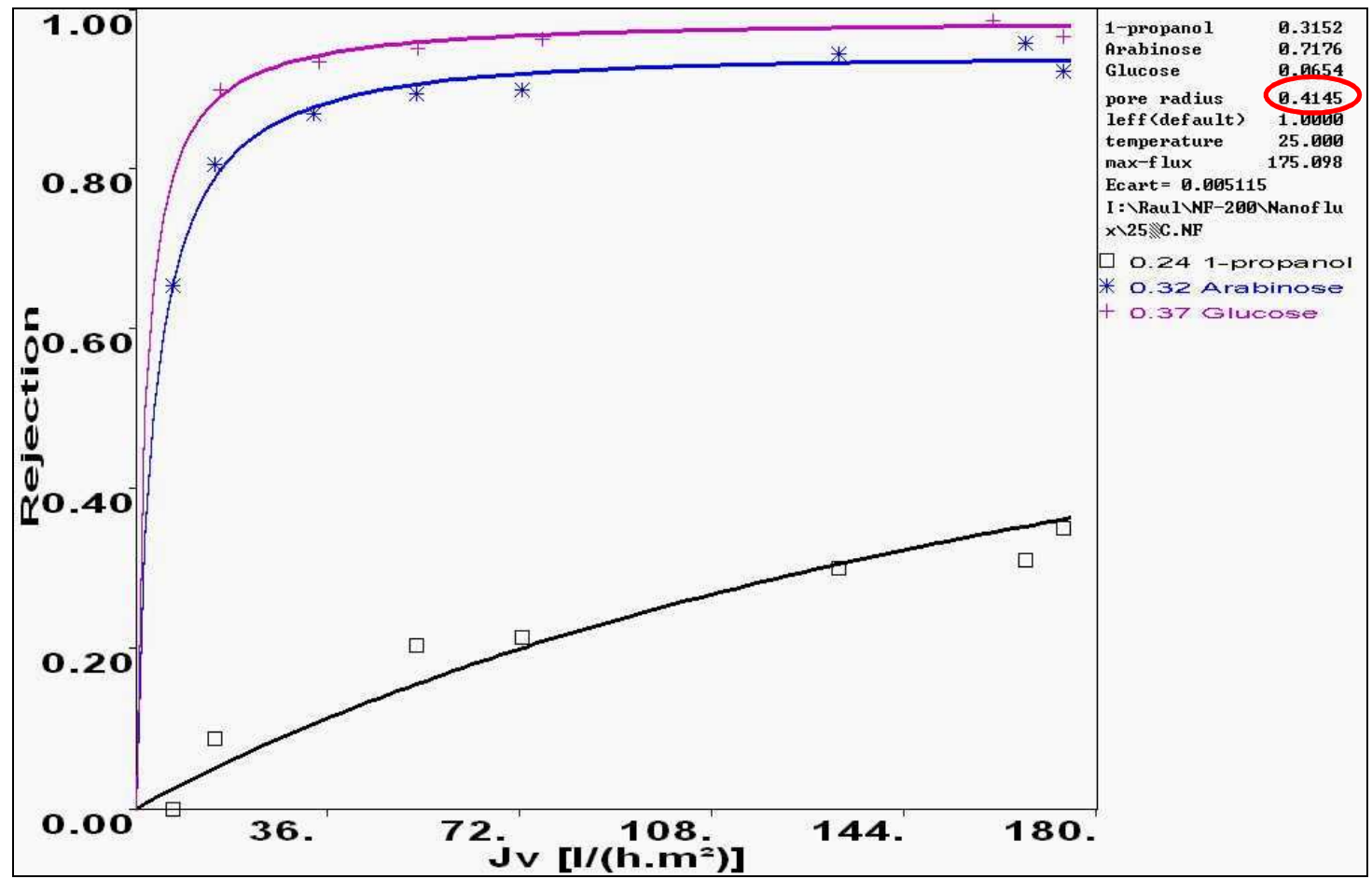

Figura 4.9 Retención en función del flujo de permeado para la membrana NF-200. Línea continua: modelización de Nanoflux ${ }^{\circledR}$, puntos discontinuos: resultados experimentales.

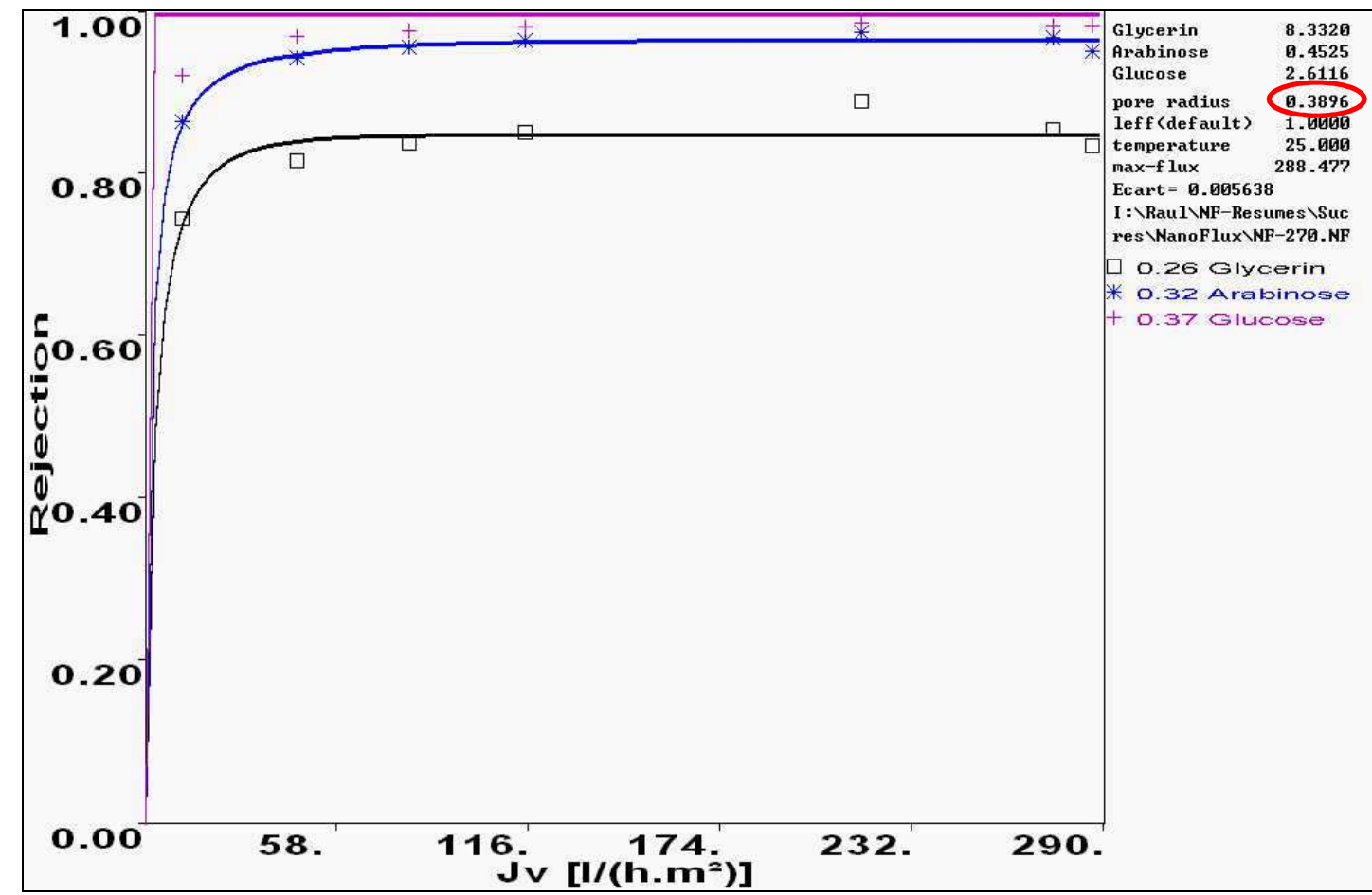

Figura 4.10. Retención en función del flujo de permeado para la membrana NF-270. Línea continua: modelización de Nanoflux ${ }^{\circledR}$, puntos discontinuos: resultados experimentales.

Si se observan las gráficas obtenidas, puede apreciarse la buena relación que existe entre los datos experimentales y las curvas calculadas por el programa informático. Por tanto, cabe esperar que los radios de poro proporcionados por el programa se ajusten a la realidad. Esto no podría afirmarse 
si el programa informático no hubiese ajustado durante su modelización curvas próximas a los datos experimentales.

En la Tabla 4.2 se recopilan los radios medios de los poros de las membranas calculados mediante el programa informático Nanoflux ${ }^{\circledR}$ :

Tabla 4.2. Radios de poro $\left(r_{p}\right)$ de las membranas calculadas a partir de Nanoflux ${ }^{\circledast}$.

\begin{tabular}{|c|c|c|}
\hline Membrana & $\mathrm{T}\left({ }^{\circ} \mathrm{C}\right)$ & $r_{p}(\mathrm{~nm})$ \\
\hline $\mathrm{NF}$ & 25 & 0,41 \\
\hline $\mathrm{NF}-90$ & 25 & 0,32 \\
\hline $\mathrm{NF}-200$ & 25 & 0,42 \\
\hline
\end{tabular}

Como puede observarse en la Tabla 4.2, el radio de poro $\left(r_{p}\right)$ más pequeño es el de la membrana NF-90, este hecho explica que esta membrana tenga una retención a las moléculas neutras con las que se ha trabajado mayor que la ofrecida por las demás membranas utilizadas, tal y como se ha visto en la Figura 4.4 y en la Figura 4.8. También puede estar relacionado con el hecho que la permeabilidad de la membrana al agua pura es menor para la membrana NF-90 que para el resto de membranas estudiadas. Las membrana NF, NF-200 y NF-270, presentan un radio de poro $\left(r_{p}\right)$ similar y mayor que la membrana NF-90 [168].

\subsubsection{Retención de las sales}

\subsubsection{Ensayos experimentales con las disoluciones de las sales}

Una vez determinados los radios medios de poro de las membranas con las que se ha trabajado y siguiendo con la caracterización de las mismas, se procedió a estudiar la retención que las membranas ofrecen a algunos iones (todos ellos están presentes en las aguas industriales del sector cerámico con las que se ha trabajado en los casos de estudio reales del presente trabajo). De este modo se pretende establecer cuál es la densidad de carga superficial de cada membrana para algunas disoluciones conocidas. Por tanto, conociendo la retención $(R)$ a determinados iones y el flujo de permeado $\left(J_{v}\right)$ para unas disoluciones dadas, se puede determinar la densidad de carga normalizada de la membrana $\left(X_{i}\right)$ con la ayuda de la modelización del programa informático Nanoflux ${ }^{\circledR}$.

Para llevar a cabo esta parte de la caracterización, se han preparado dos disoluciones acuosas con diferentes sales. Concretamente se han utilizado $\mathrm{NaCl}$ y $\mathrm{MgSO}_{4}$ con una concentración igual a $0,01 \mathrm{M}$. Los ensayos de nanofiltración se han realizado a una temperatura constante de las disoluciones de $25^{\circ} \mathrm{C}$ y las presiones aplicadas han sido de 2, 3, 4, 7, 11, 14 y 16 bar. 


\section{Retención del cloruro de sodio}

En la gráfica de la Figura 4.11 se representa la retención que las cuatro membranas estudiadas ofrecen a una disolución de $\mathrm{NaCl}$ 0,01M en función del flujo de permeado.

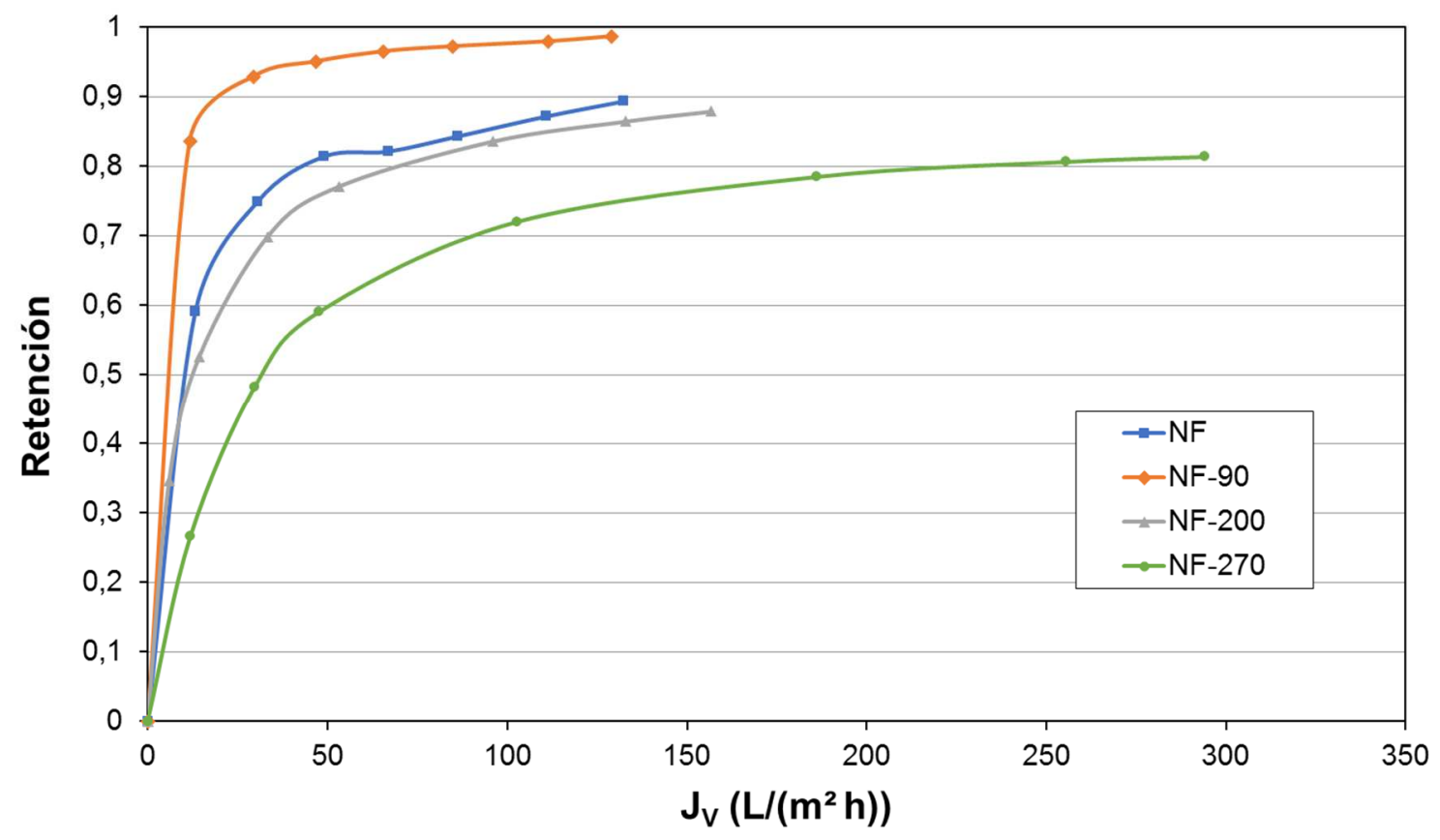

Figura 4.11. Retención de $\mathrm{NaCl}$ en función del flujo de permeado a $25^{\circ} \mathrm{C}$ para una disolución $0,01 \mathrm{M}$.

Como puede observarse, la membrana NF-90 es la que ofrece una retención más elevada a los iones monovalentes (en torno a $97 \%$ cuando la retención llega a la meseta), siendo la que menor retención ofrece a este tipo de iones la membrana NF-270 (en torno a $80 \%$ en la meseta). Las membranas NF y NF-200 ofrecen una retención entre el 85 y 90\% al NaCl. La retención de la membrana NF-90 es muy elevada para los iones monovalentes, esta membrana tiene un comportamiento próximo a las membranas de ósmosis inversa.

\section{Retención de sulfato de magnesio}

De la misma forma que en el caso precedente, se ha estudiado el comportamiento de las membranas frente a una disolución de $\mathrm{MgSO}_{4}$ 0,01M. Los resultados se pueden observar en la Figura 4.12. 


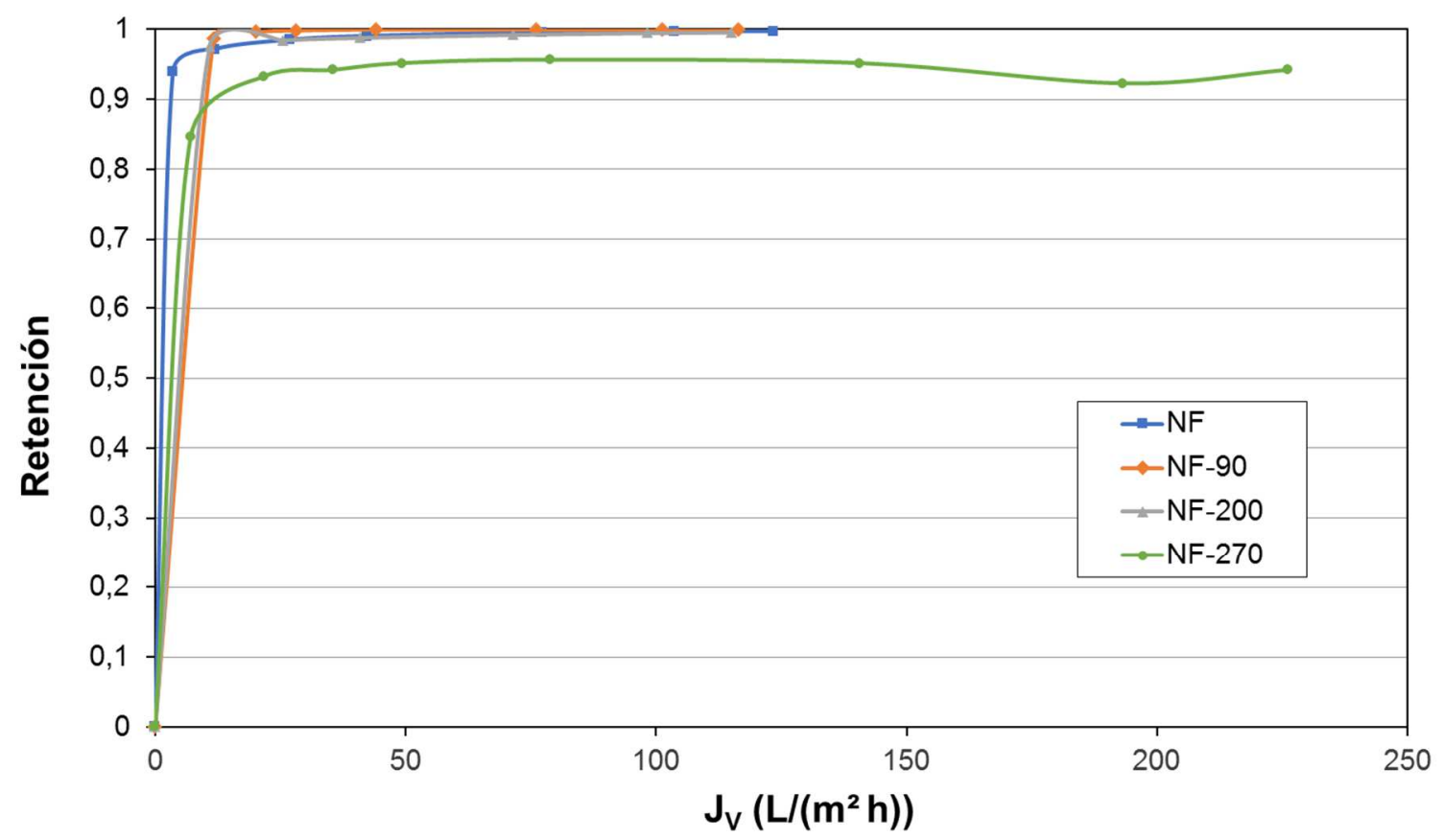

Figura 4.12. Retención de $\mathrm{MgSO}_{4}$ en función del flujo de permeado a $25^{\circ} \mathrm{C}$ para una disolución de $0,01 \mathrm{M}$.

Como era de esperar, los iones divalentes han sido mucho más retenidos por todas las membranas estudiadas. Por tanto, se ha obtenido retenciones del compuesto $\mathrm{MgSO}_{4}$ de prácticamente el $100 \%$ para las membranas NF, NF-90 y NF-200. Mientras que para la membrana NF-270, la retención para este compuesto se ha estabilizado en torno al $95 \%$.

\subsubsection{Modelización de la densidad de carga electroestática normalizada $\left(X_{i}\right)$ de las membranas mediante el programa informático Nanoflux ${ }^{\circledR}$}

Como en el caso de las disoluciones elaboradas con los compuestos neutros, los resultados experimentales obtenidos con las disoluciones elaboradas con las sales han sido introducidas en el programa informático Nanoflux ${ }^{\circledR}$ para determinar la densidad de carga normalizada $\left(X_{i}\right)$ de las membranas para unas determinadas condiciones de trabajo. Además, también se han introducido la concentración inicial de la alimentación, el pH de la disolución, la temperatura de filtración y el radio de poro para cada una de las membranas obtenido en el apartado anterior. Seguidamente y al igual que en el caso de las disoluciones elaboradas con los compuestos neutros, Nanoflux ${ }^{\circledR}$ ha proporcionado unas gráficas en las que representa la retención $(R)$ ofrecida por la membrana obtenida de forma experimental (en forma de puntos), junto a la modelización que realiza el programa (representada en forma de líneas continuas). Estas gráficas obtenidas con el programa Nanoflux ${ }^{\circledR}$ se recopilan en las figuras que van desde la Figura 4.13 a la Figura 4.16. La densidad de carga normalizada $\left(X_{i}\right)$ para cada membrana calculada por el programa informático se puede observar, rodeada por un círculo rojo, en la parte superior derecha da cada una de las gráficas. 
NF
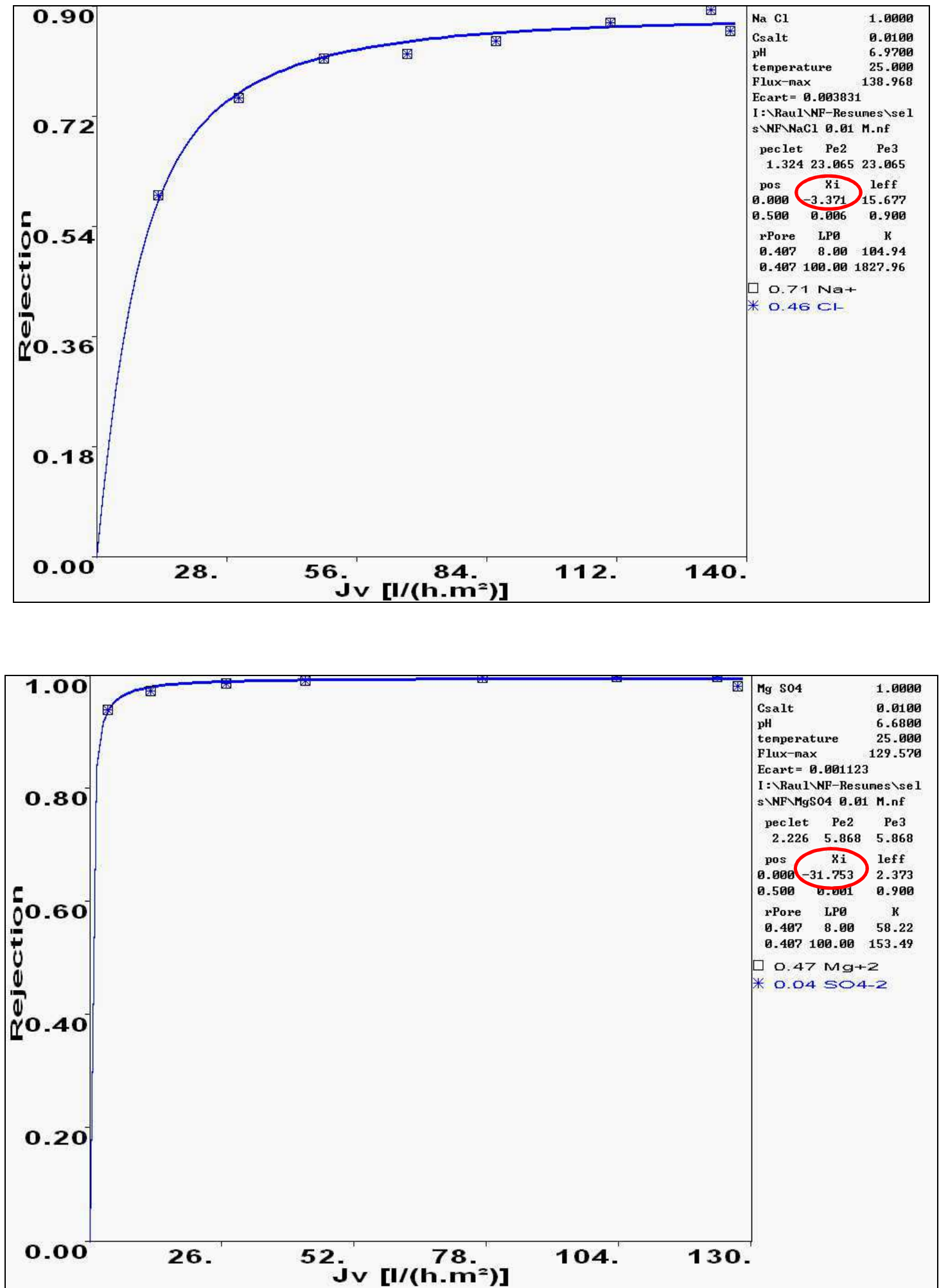

Figura 4.13. Retención en función del flujo de permeado a $25^{\circ} \mathrm{C}$ de la membrana $\mathrm{NF}$ para las disoluciones $\mathrm{NaCl} 0,01 \mathrm{M}$ y $\mathrm{MgSO}_{4} 0,01 \mathrm{M}$; trazo continuo: predicción del modelo Nanoflux ${ }^{\circledR}$, puntos discontinuos: resultados experimentales. 


\section{NF-90}
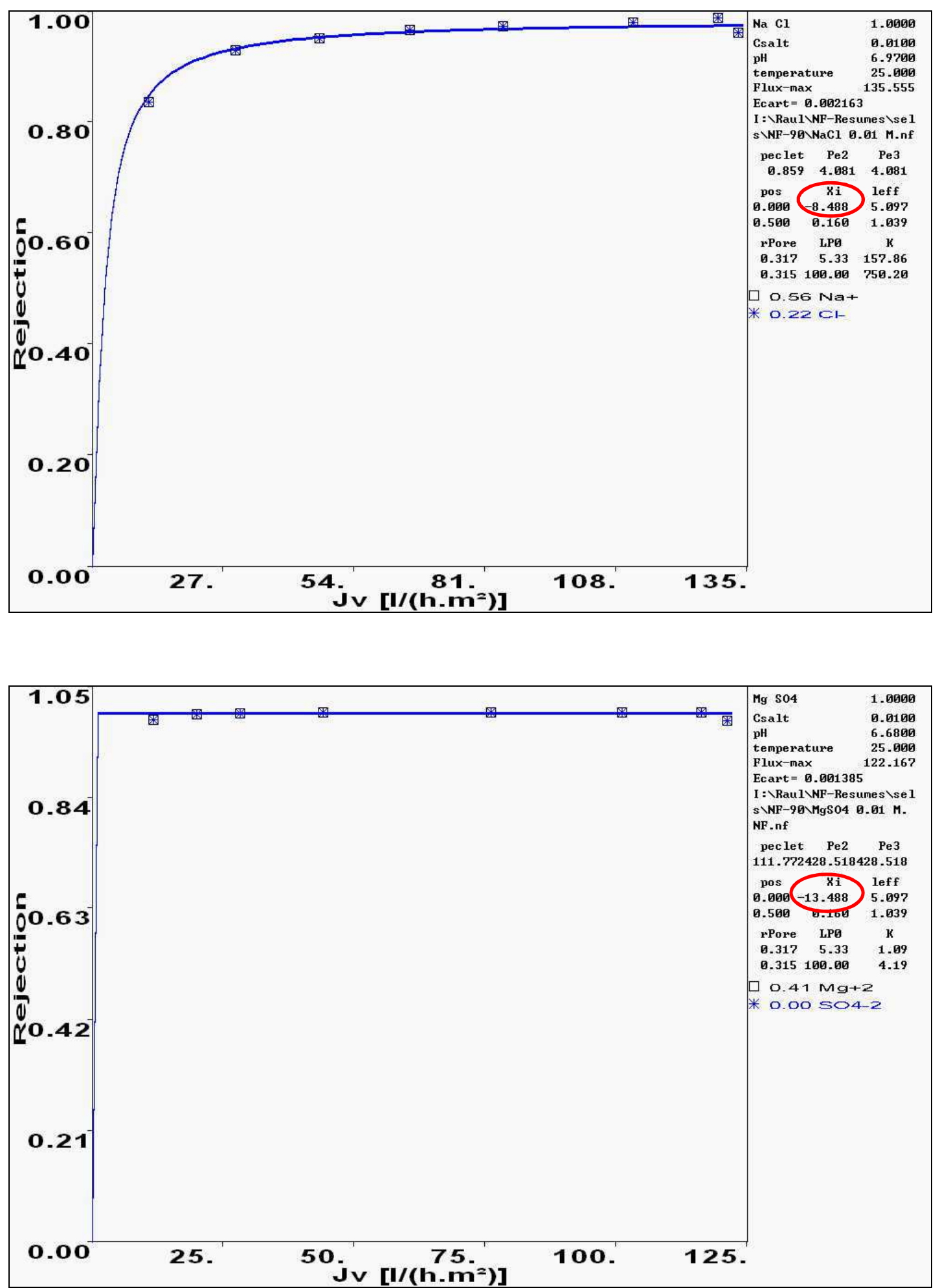

Figura 4.14. Retención en función del flujo de permeado a $25^{\circ} \mathrm{C}$ de la membrana NF-90 para las disoluciones $\mathrm{NaCl} 0,01 \mathrm{M} \mathrm{y} \mathrm{MgSO}_{4}$ 0,01M; trazo continuo: predicción del modelo Nanoflux ${ }^{\circledR}$, puntos discontinuos: resultados experimentales. 
NF-200
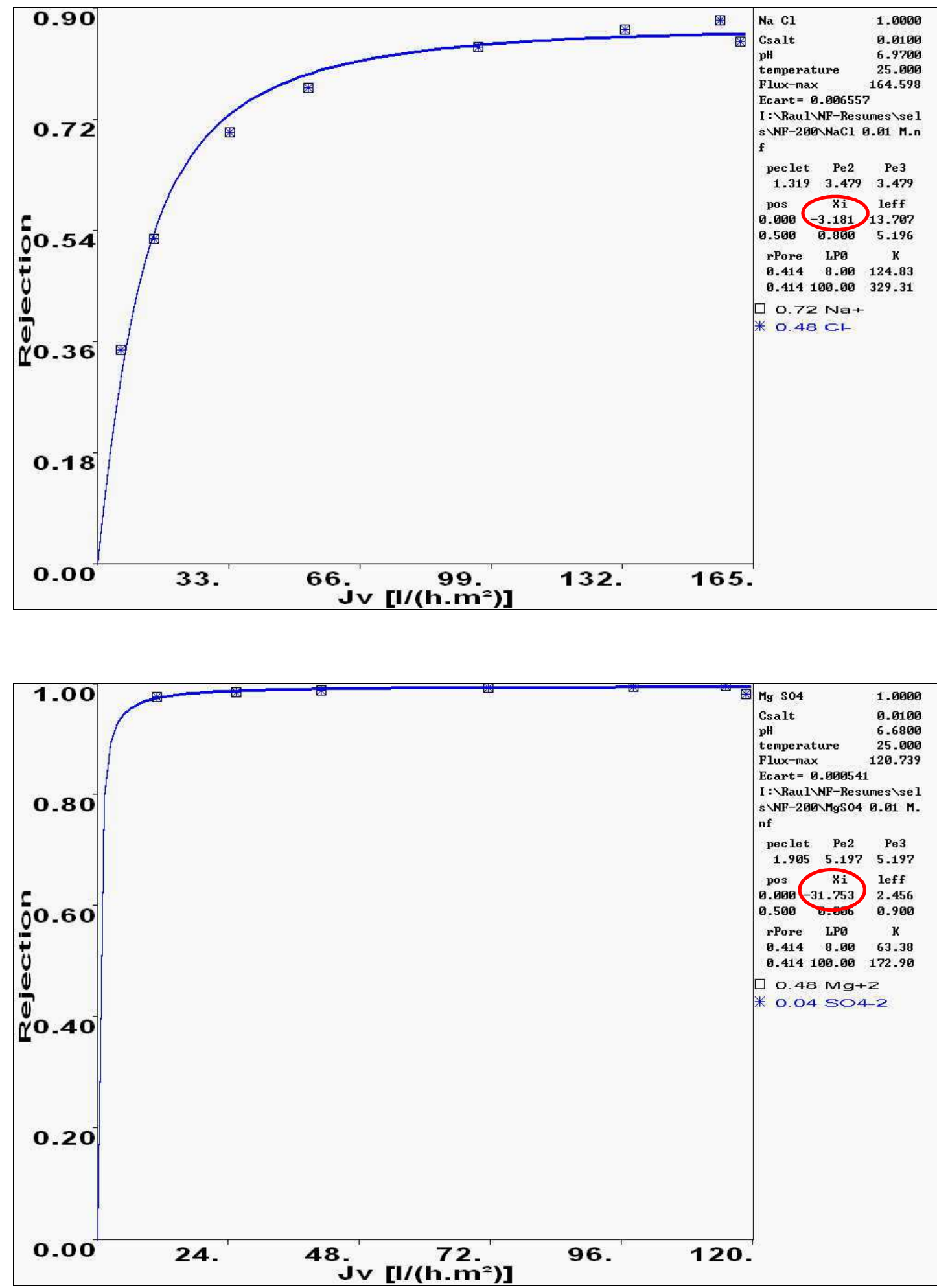

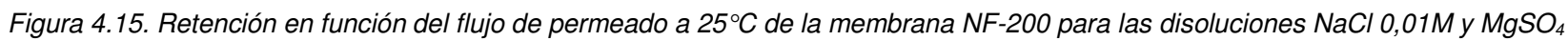
0,01M; trazo continuo: predicción del modelo Nanoflux ${ }^{\circledR}$, puntos discontinuos: resultados experimentales. 


\section{NF-270}
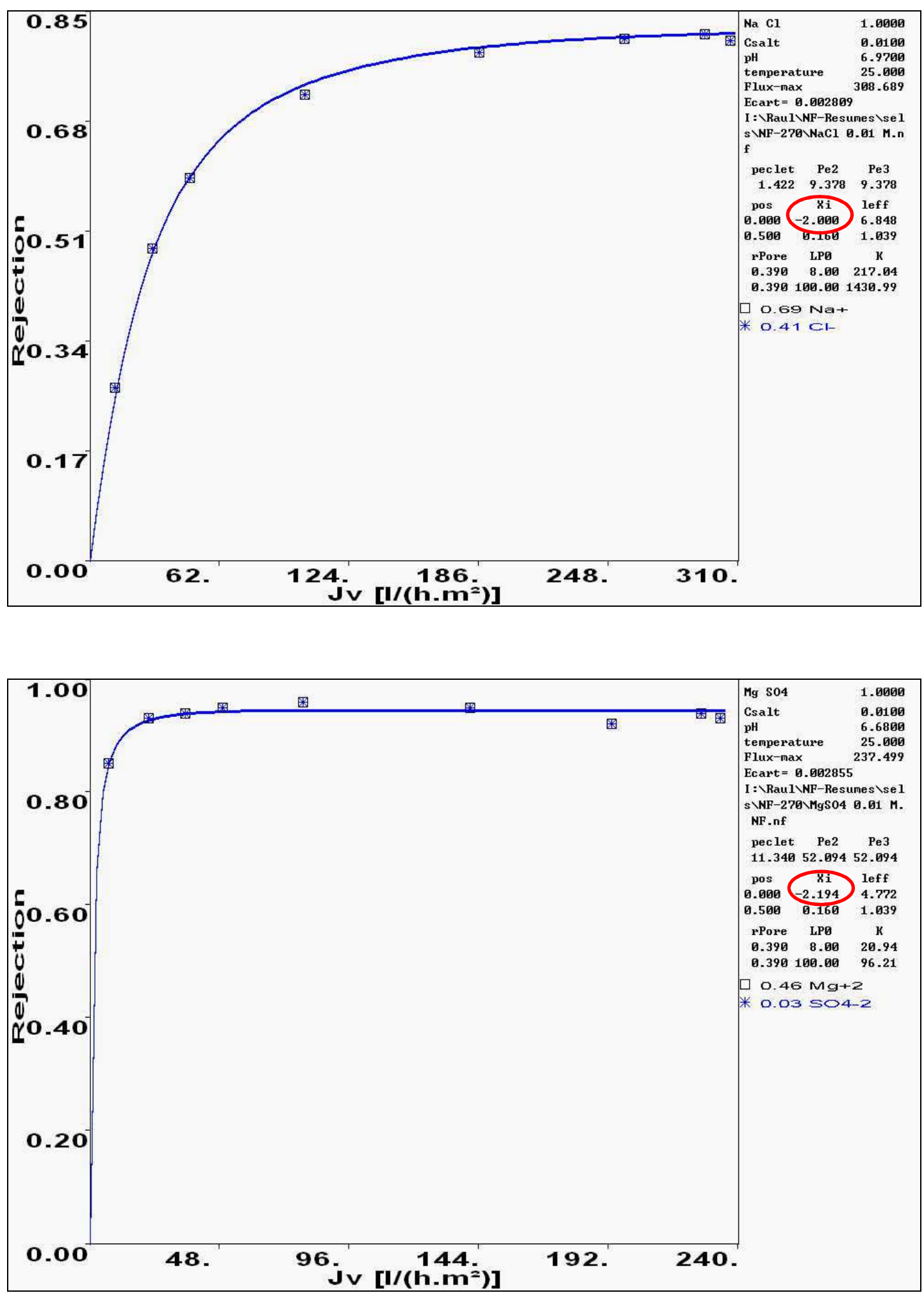

Figura 4.16. Retención en función del flujo de permeado a $25^{\circ} \mathrm{C}$ de la membrana $\mathrm{NF}-270$ para las disoluciones $\mathrm{NaCl} 0,01 \mathrm{M} \mathrm{y} \mathrm{MgSO}_{4}$ 0,01M; trazo continuo: predicción del modelo Nanoflux ${ }^{\circledR}$, puntos discontinuos: resultados experimentales. 
En la Tabla 4.3 se recopilan todos los datos referentes a la densidad de carga normalizada $\left(X_{i}\right)$ modelizados por el programa informático Nanoflux ${ }^{\circledR}$ :

Tabla 4.3. Densidades de carga electroestática normalizadas $\left(X_{i}\right)$ calculadas con ayuda del programa Nanoflux ${ }^{\circledR}$.

\begin{tabular}{|c|c|c|c|c|}
\hline & NF & NF-90 & NF- 200 & NF-270 \\
\hline $\mathrm{NaCl} 0,01 \mathrm{M}$ & $-3,371$ & $-8,488$ & $-3,181$ & $-2,000$ \\
\hline $\mathrm{MgSO}_{4} 0,01 \mathrm{M}$ & $-31,753$ & $-13,488$ & $-31,753$ & $-2,194$ \\
\hline
\end{tabular}

Todas las membranas presentan una carga negativa tal y como ocurre en muchas membranas de nanofiltración, según se confirma en la bibliografía consultada [90][150]. La membrana que exhibe menor densidad de carga en todas las situaciones es la NF-270. Además, si se observan las gráficas en las que se representa la retención frente al flujo de permeado a diferentes presiones (ver la Figura 4.11 y la Figura 4.12), donde se comparan los cuatro tipos de membranas, también se ha comprobado que la membrana NF-270 es la que presenta menor retención de las cuatro. Por tanto, la densidad de carga de la membrana estará relacionada con la retención que las membranas presentan frente a las especies cargadas [90][169].

\subsubsection{Elección de la membrana más adecuada para los tratamientos a realizar}

Si se tiene en cuanta la permeabilidad al agua pura de las membranas caracterizadas (ver Tabla 4.1), se puede observar que la membrana NF-270 es la que presenta una mayor permeabilidad (19,6 L/h m² bar), siendo la NF-90 la que muestra una permeabilidad más baja (10,1 L/h m² bar). Desde el punto de vista de la productividad de las membranas, la permeabilidad es un parámetro muy importante, ya que cuanto más permeable es una membrana mayor cantidad de permeado puede producir y por tanto, una mayor cantidad de agua puede tratar. Como puede observarse en todas las gráficas donde aparece el flujo de permeado obtenido con la membrana NF-270 (Figura 4.6, Figura 4.10, Figura 4.11, Figura 4.12 y Figura 4.16) el flujo de permeado es mucho mayor para esta membrana que para el resto. Sin embargo, también hay que tener en cuenta otros parámetros, como la retención de los elementos que se quieran separar, así como la selectividad que una membrana puede ofrecer a unas determinadas especies $u$ otras [43].

La retención a las especies neutras ha sido utilizada para determinar el radio de poro de las membranas (ver Tabla 4.2) y de las cuatro membranas caracterizadas, la membrana NF-90 tiene el radio de poro más pequeño $(0,32 \mathrm{~nm})$. Mientras que las otras 3 membranas tienen radios de poro algo mayores. Por tanto, si se tiene en cuenta el tamaño de la especie a separar, la membrana que retendrá especies más pequeñas será la NF-90. Por esta razón, si las especies que se quieren eliminar presentan tamaños iónicos pequeños, se tendría que utilizar esta membrana. Además, si se tiene en cuenta la carga de las especies, también habrá que contemplar el efecto de la densidad de carga presente, tanto en la superficie de la membrana, como en los poros de la misma.

Las pruebas con las sales monovalentes y divalentes han permitido conocer el comportamiento de las membranas frente a estas especies y relacionarlo con las densidades de carga que las membranas adquieren frente a estas disoluciones. Si se observan los resultados obtenidos en las 
figuras que van desde la Figura 4.13 a la Figura 4.16 y recopilados en la Tabla 4.3, se puede advertir que la membrana NF-270 presenta menor densidad de carga que las otras membranas caracterizadas en todos los ensayos, y por tanto también menor retención, tanto a las especies monovalentes como divalentes. Sin embargo, en este punto hay que realizar una apreciación, en el caso de las especies divalentes, aunque presenta retenciones menores que las demás membranas, esta retención es elevada, ya que supera ampliamente el 95\%. En cambio, si se tiene en cuenta las retenciones ofrecidas a las especies monovalentes, ésta membrana presenta la más baja (en torno a 80\%). Estos datos implican que, frente a las especies divalentes, la membrana NF-270 es la más selectiva de todas las membranas caracterizadas.

Por tanto, una vez analizados los resultados obtenidos en la caracterización de las membranas estudiadas, se ha decidido utilizar la membrana NF-90 para la eliminación del boro de las aguas residuales. Como se ha visto (ver apartado 1.2 El problema de la depuración del boro) el boro se encuentra en las aguas residuales de la industria cerámica a pH 7 en forma de ácido bórico $\left(\mathrm{H}_{3} \mathrm{BO}_{3}\right)$. El tamaño molecular de esta especie es muy reducido, por tanto se necesita una membrana con el radio de poro lo más pequeño posible. Además, se modificará el $\mathrm{pH}$ del agua que se tenga que nanofiltrar para desplazar el equilibrio y que el ácido bórico se transforme en ion borato, de esta forma además de las propiedades estéricas de la membrana, poder aprovechar el efecto de carga de las mismas para aumentar la retención de estas especies. Por estas razones, la membrana NF90 será la más indicada para este primer caso de estudio con aguas industriales.

Por otra parte, se utilizará la membrana NF-270 en el segundo caso de estudio para la eliminación de iones divalentes de las aguas industriales de una empresa dedicada a la elaboración de polvo atomizado. Como se ha comentado con anterioridad (ver apartado 1.1 Problemática del agua en el sector cerámico y apartado 1.3.3 Desfloculación de las suspensiones cerámicas), estas empresas utilizan el agua para la elaboración de las suspensiones cerámicas que más tarde secan por atomización para obtener el polvo atomizado. En este proceso los iones divalentes, y en especial el $\mathrm{Ca}^{2+}$ y el $\mathrm{SO}_{4}{ }^{2-}$, ejercen un fuerte efecto floculante que hace aumentar la viscosidad de las suspensiones cerámicas y disminuir la productividad del atomizador. Para contrarrestar este efecto floculante en las suspensiones cerámicas es necesario el consumo de una mayor cantidad de sustancias desfloculantes y además, si se floculan las suspensiones cerámicas, el contenido en sólidos de las mismas disminuye, por tanto, es necesario una cantidad superior de energía para secar la suspensión más diluida que tendrá como resultado una producción de polvo atomizado menor. Además, se ha comprobado que los iones monovalentes no tienen un efecto tan perjudicial para la elaboración de estas suspensiones cerámicas [11], por estas razones, se ha elegido la membrana NF-270 que es la más selectiva con los iones divalentes y por tanto se considera que podrá ofrecer unos resultados más positivos que las otras membranas caracterizadas.

\subsection{Eliminación del boro de las aguas residuales industriales mediante técnicas de nanofiltración}

Esta parte del trabajo se centra en la eliminación, mediante técnicas de nanofiltración, de los compuestos de boro presentes en las aguas residuales del sector cerámico. Tal como se ha comentado en la introducción, la presencia de este elemento en las aguas residuales de las 
empresas de elaboración de baldosas cerámicas impide su vertido, ya que el boro persiste en ellas incluso después de ser sometidas a tratamientos físico-químicos de coagulación-floculación (este tratamiento no es efectivo para este contaminante y es el más utilizado en el sector cerámico para eliminar sólidos en suspensión y algunos metales).

Paralelamente a la eliminación del boro, que es el principal objetivo de esta etapa del trabajo, con la utilización de la técnica de nanofiltración se eliminará o reducirá la concentración de otras sustancias contaminantes presentes en las aguas residuales. De esta forma, se pretende alcanzar los requisitos de calidad necesarios para la reutilización del agua residual. Por tanto, se ha hecho especial hincapié en la eliminación de los compuestos orgánicos, que son causantes de malos olores y de defectos en las baldosas cerámicas fabricadas. Así como también, en la eliminación de diferentes iones como son $\mathrm{SO}_{4}{ }^{2-}, \mathrm{Mg}^{2+}, \mathrm{Ca}^{2+}, \mathrm{Na}^{+}, \mathrm{Cl}^{-} \ldots$, causantes de la elevada conductividad del agua que la inhabilita a la hora de reutilizarla en el proceso productivo.

Concretamente, la empresa en la que se ha realizado el estudio (empresa de fabricación de baldosas cerámicas) no disponen de etapa de atomización y las aguas residuales son generadas en la etapa de preparación y aplicación de esmaltes (Figura 4.17). Esta empresa somete a un tratamiento físico-químico una parte de las aguas residuales que genera y el resto lo gestiona externamente a través de una empresa de fabricación de polvo atomizado. El agua obtenida después del tratamiento físico-químico es un agua con baja concentración de partículas y de metales, sin embargo, la calidad no es buena, ya que el contenido en sales disueltas, materia orgánica y boro son muy elevados. Esta agua clarificada es recirculada al interior de la fábrica, pero por las características anteriormente mencionadas, solamente se puede reutilizar en la limpieza de suelos, instalaciones o equipamientos que no estén en contacto con materiales susceptibles de ser contaminados.

Paralelamente a este tratamiento, la empresa de fabricación de baldosas gestiona a diario externamente entre 15 y $20 \mathrm{~m}^{3}$ de agua residual. Para ello, la transporta mediante camiones cisterna hasta una empresa de atomización cercana. En estas empresas, el agua residual se utilizará para la fabricación de polvo atomizado que más tarde servirá para la fabricación de baldosas cerámicas (ver apartado 1.1.3 Generación, características y gestión actual de las aguas residuales procedentes de las empresas de fabricación de baldosas cerámicas).

Como se ha comentado con anterioridad, esta agua es gestionada externamente porque no puede ser reutilizada en el propio proceso productivo, ni tampoco puede ser vertida al alcantarillado municipal, ya que incluso, después de ser sometida a un tratamiento físico-químico, la concentración de algunos parámetros del agua residual supera los límites establecidos por la legislación vigente. Por este motivo, y para revertir esta situación, se ha pensado en la incorporación de un tratamiento terciario como es la nanofiltración.

En la Figura 4.17 se esquematiza de forma simplificada el proceso productivo de una empresa modelo similar a la empresa en la que se van a realizar las pruebas, donde se puede ver la gestión actual de las aguas. Además, también se introduce el tratamiento propuesto en este estudio, así como el punto exacto donde se tiene que ubicar. 


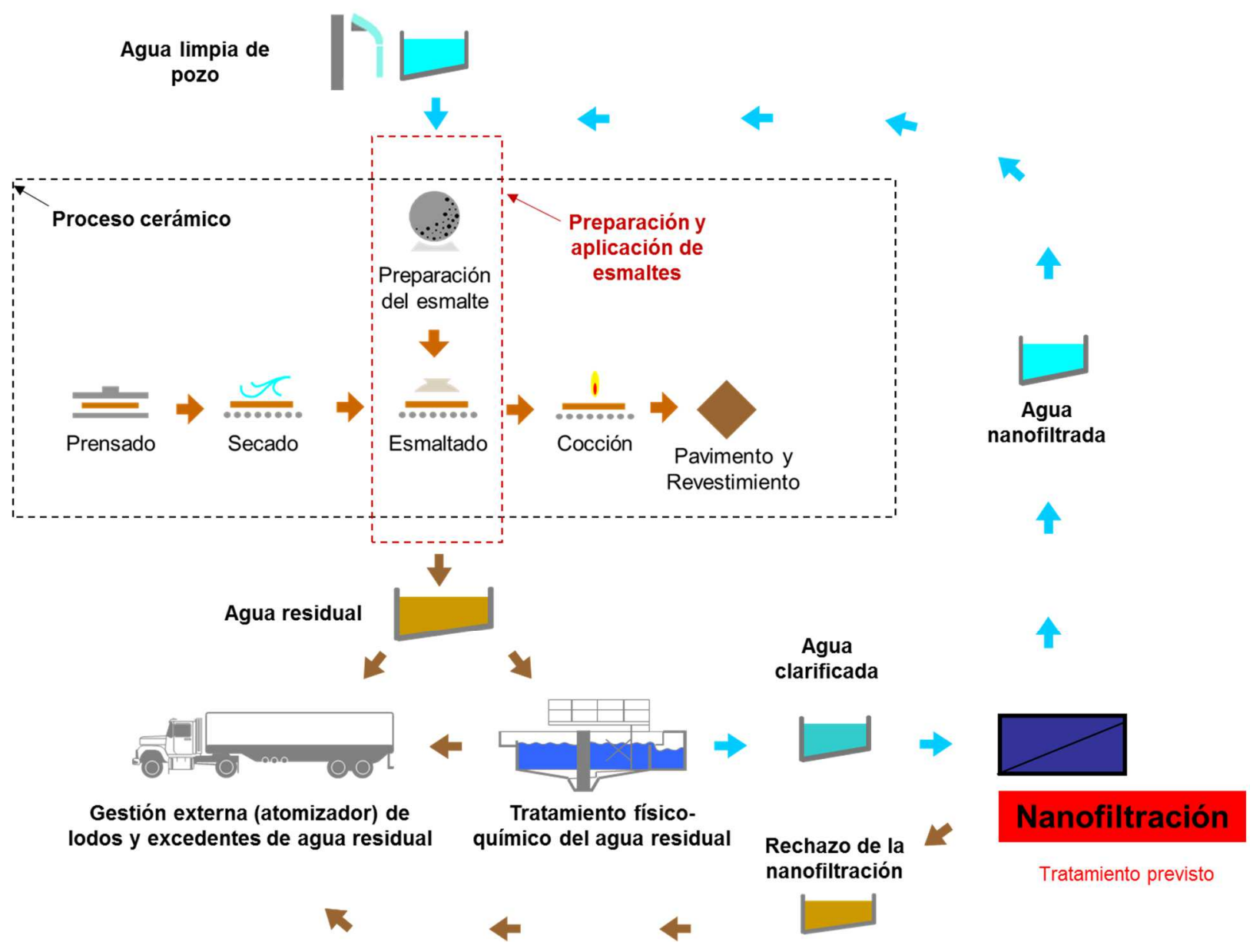

Figura 4.17. Esquema del proceso productivo de una empresa de producción de baldosas cerámicas sin etapa de atomización y gestión de sus aguas, así como la actuación prevista en este caso de estudio.

Además, en la Figura 4.18 se ilustra un diagrama de flujo donde se puede observar las cantidades de agua que una empresa modelo de este tipo puede necesitar y gestionar.

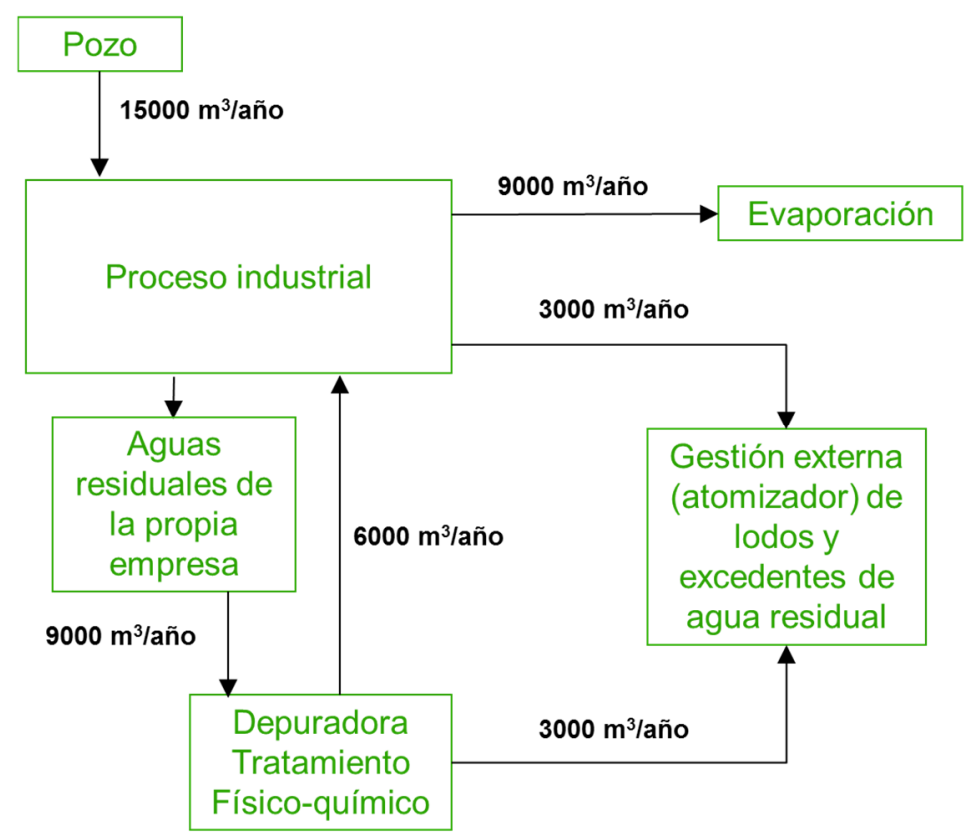

Figura 4.18. Diagrama de flujo de las aguas en una empresa modelo de fabricación de baldosas cerámica sin etapa de atomización. 
Por tanto, como se ha avanzado anteriormente, en este caso de estudio se ha aplicado un tratamiento de nanofiltración con la membrana NF-90 para la eliminación del boro de las aguas residuales resultantes del tratamiento físico-químico. La elección de esta membrana para el propósito perseguido ya ha sido explicada anteriormente (ver apartado 4.1.4 Elección de la membrana más adecuada para los tratamientos a realizar).

Una vez explicado los objetivos y el tipo de empresa con la que se va a trabajar, el primer paso realizado ha sido una caracterización de las aguas de la empresa, de este modo se conoce el punto de partida y las características del agua residual con la que se ha tenido que trabajar. Seguidamente, se han recopilado los resultados obtenidos en todas las pruebas de nanofiltración realizadas a nivel de laboratorio con aguas sintéticas y reales. Tras las pruebas a escala de laboratorio, se han abordado las pruebas a escala industrial con las aguas residuales reales de la empresa, con el objetivo de comprobar si esta técnica es capaz de eliminar el boro de esta corriente líquida. Este caso de estudio en concreto, se ha finalizado con varios ensayos de caracterización de producto cerámico para analizar la viabilidad de la reutilización del agua nanofiltrada en la fabricación de engobes y esmaltes para la decoración de las baldosas cerámicas (algo inviable con las aguas residuales tratadas solamente mediante un tratamiento físico-químico), además de un estudio económico que compara el coste de varias tecnologías de eliminación de boro.

En el esquema representado en la Figura 4.19 se detalla un diagrama de flujo donde se compila de forma resumida todos los pasos seguidos en este primer caso de estudio.

\section{PASOS SEGUIDOS DURANTE EL PRIMER CASO DE ESTUDIO (ELIMINACIÓN DEL BORO)}

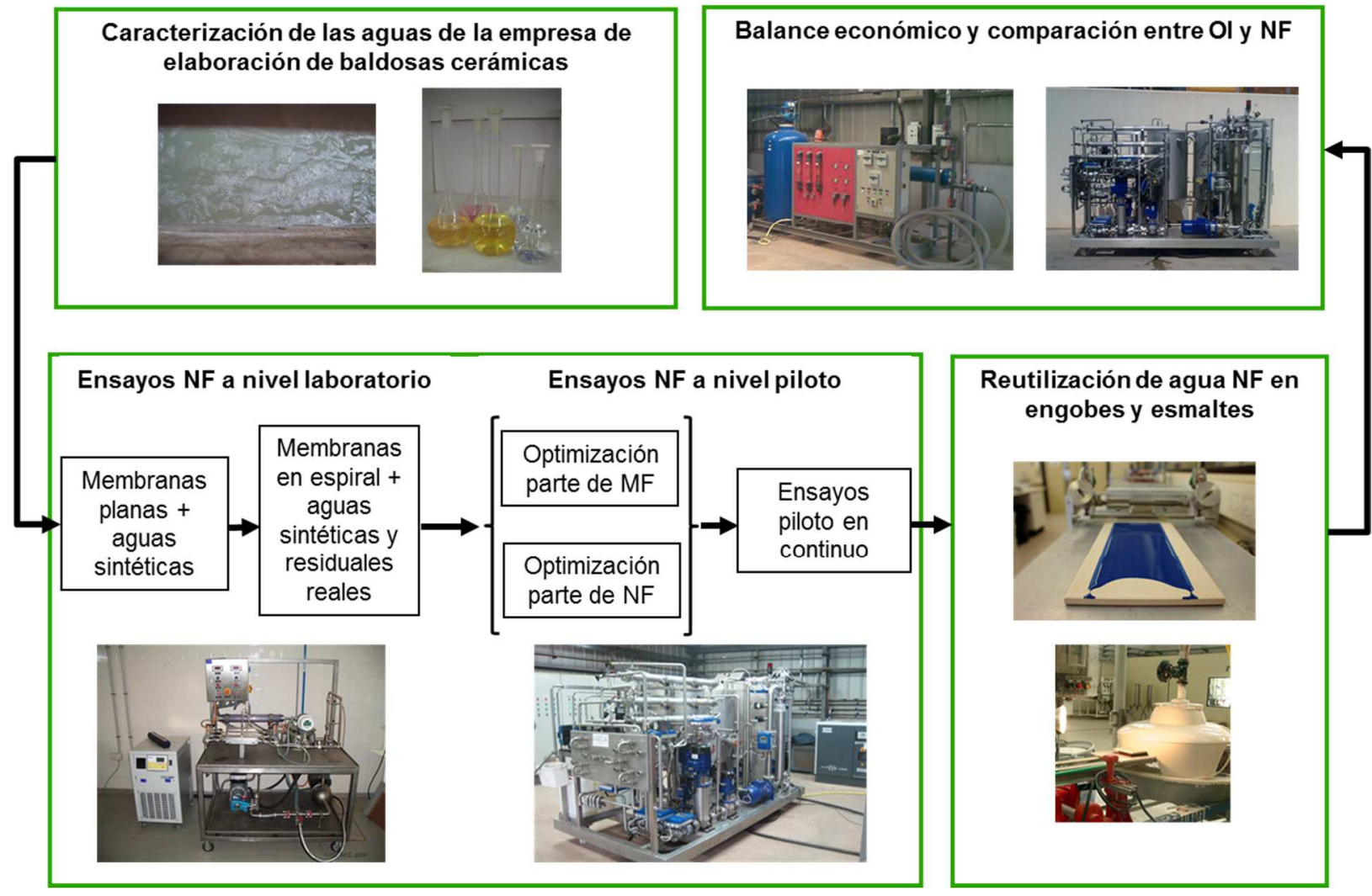

Figura 4.19. Diagrama de flujo de los pasos seguidos en el primer caso de estudio (eliminación del boro). 


\subsubsection{Caracterización de las aguas de la empresa de fabricación de baldosas}

Se dispone de varios análisis de las aguas de esta empresa, tanto del agua limpia procedente del pozo, como de las aguas residuales antes y después de ser sometidas a un tratamiento físicoquímico de coagulación-floculación, es decir del agua residual bruta y agua residual clarificada, respectivamente.

Tabla 4.4. Análisis químicos de varias muestras de agua de la empresa en la que se va a realizar el primer caso de estudio.

\begin{tabular}{|c|c|c|c|c|c|c|}
\hline \multirow[t]{2}{*}{ Parámetros } & \multicolumn{2}{|c|}{$\begin{array}{c}\text { Agua residual antes } \\
\text { del F-Q (agua } \\
\text { residual bruta) }\end{array}$} & \multicolumn{3}{|c|}{$\begin{array}{l}\text { Agua residual después del F-Q } \\
\text { (agua residual clarificada) }\end{array}$} & \multirow{2}{*}{$\begin{array}{c}\text { Agua } \\
\text { limpia de } \\
\text { pozo }\end{array}$} \\
\hline & $\begin{array}{l}\text { Muestra } \\
\text { R1-1 }\end{array}$ & $\begin{array}{c}\text { Muestra } \\
\text { R1-2 }\end{array}$ & $\begin{array}{c}\text { Muestra } \\
\text { R1-3 }\end{array}$ & $\begin{array}{c}\text { Muestra } \\
\text { R1-4 }\end{array}$ & $\begin{array}{l}\text { Muestra } \\
\text { R1-5 }\end{array}$ & \\
\hline $\mathrm{pH}$ & 7,8 & 7,7 & 8,6 & 8,3 & 8,3 & 7,5 \\
\hline $\begin{array}{l}\text { Conductividad } \\
\qquad(\mu \mathrm{S} / \mathrm{cm})\end{array}$ & 2990 & 4300 & 2685 & 3570 & 5540 & 1169 \\
\hline $\mathrm{DQO}\left(\mathrm{mg} / \mathrm{L} \mathrm{O}_{2}\right)$ & 1474 & - & 1316 & 1166 & 709 & $<30$ \\
\hline $\begin{array}{l}\text { Sólidos en } \\
\text { suspensión } \\
\text { (mg/L) }\end{array}$ & 980 & 88500 & - & 69 & 4 & - \\
\hline Cloruros (mg/L) & 436 & & 461 & 955 & 986 & 55 \\
\hline Sulfatos (mg/L) & 214 & - & 874 & 274 & 280 & 274 \\
\hline Boro (mg/L) & 9 & 17,6 & 11,1 & 6,2 & 13,2 & 0,4 \\
\hline Calcio (mg/L) & 115 & - & 128 & 109 & 71 & 139 \\
\hline Magnesio (mg/L) & 24 & - & 35 & 31 & 17,7 & 31 \\
\hline Sodio (mg/L) & 416 & - & 400 & 716 & 748 & 29 \\
\hline Potasio (mg/L) & 21 & - & 17 & 38,4 & 50 & 1,3 \\
\hline Cinc $(m g / L)$ & 0,1 & - & 0,4 & 0,2 & - & 0,5 \\
\hline Hierro (mg/L) & - & - & $<0,1$ & $<0,1$ & - & 0,2 \\
\hline Plomo (mg/L) & - & - & 0,3 & $<0,1$ & - & $<0,1$ \\
\hline Mercurio ( $\mu \mathrm{g} / \mathrm{L})$ & - & - & 3 & 3,7 & - & $<2$ \\
\hline
\end{tabular}


El principal problema que tiene la empresa, en cuanto a la gestión del agua, es la elevada cantidad de aguas residuales que se han de tratar externamente. Como se ha mencionado anteriormente, muchos de los parámetros medidos en el agua residual no cumplen con los requisitos mínimos para ser vertidas al alcantarillado municipal. Incluso después del tratamiento físico-químico existen parámetros que no cumplen con la legislación, tal como se indica en la Tabla 4.5.

Tabla 4.5. Parámetros que imposibilitan el vertido al alcantarillado municipal y los límites legales.

\begin{tabular}{|c|c|c|}
\hline Parámetros & $\begin{array}{c}\text { Agua después } \\
\text { tratamiento físico- } \\
\text { químico }\end{array}$ & $\begin{array}{c}\text { Límites de vertido a la } \\
\text { EDAR [16] }\end{array}$ \\
\hline Conductividad $(\mu \mathrm{S} / \mathrm{cm})$ & $3570-5540$ & 3000 \\
\hline Boro $(\mathrm{mg} / \mathrm{L})$ & $6,2-17,6$ & 3 \\
\hline D.Q.O $\left(\mathrm{mg} \mathrm{de} \mathrm{O}_{2} / \mathrm{L}\right)$ & $1166-1474$ & 1000 \\
\hline
\end{tabular}

La empresa tampoco puede reutilizar las aguas clarificadas después del tratamiento físico-químico para otro fin que no sea el de baldeo de suelos y limpieza de equipos que no estén en contacto con productos que puedan ser estropeados. No pudiendo emplear esta agua para otros usos que consumen mucha agua en la empresa como por ejemplo, la elaboración de engobes, esmaltes o limpieza de molinos o equipos que estén en contacto con esmaltes o productos susceptibles de ser contaminados. La alta conductividad y el alto contenido en sales de estas aguas desestabilizaría los esmaltes y los engobes, floculándolos y no permitiendo una buena aplicación. Además, el valor alto de DQO indica materia orgánica que produciría defectos superficiales en las baldosas decoradas con los esmaltes y engobes preparados con estas aguas.

Por tanto, el objetivo principal de la actuación en esta empresa es el de disminuir la cantidad de aguas residuales que tiene que gestionar externamente. Por tanto, la situación ideal sería reducir la cantidad de agua que tendría que transportarse al atomizador y obtener aguas depuradas capaces de ser utilizadas en cualquier etapa del proceso productivo de la empresa (preparación de esmaltes, limpieza de molinos, limpieza de pantallas de decoración...). Sin embargo, si esta situación no pudiera alcanzarse y las aguas obtenidas no tuviesen las características necesarias para poder reutilizarse, la otra opción sería reducir las aguas que hay que tratar externamente y obtener agua depurada que cumpliese con los requisitos necesarios para poder ser vertida al alcantarillado municipal sin ningún riesgo para el medio receptor.

\subsubsection{Resultados de la nanofiltración a escala de laboratorio para la eliminación de boro}

\subsubsection{Ensayos de nanofiltración realizados con membranas planas}

Como se ha descrito anteriormente (ver apartado 4.1.4 Elección de la membrana más adecuada para los tratamientos a realizar) la membrana que mejores características ha ofrecido para la retención de este elemento será la membrana NF-90. 
Además, teniendo en cuanta la composición de las aguas residuales de las empresas españolas del sector cerámico y afines (ver el punto 1.1.3.1 Generación y características del agua residual), más las características del agua residual de la empresa de fabricación de baldosas cerámicas con las que se va a trabajar, se decidió que a escala laboratorio se prepararían disoluciones sintéticas de diferentes concentraciones de boro: 100, 10 y $1 \mathrm{mg} / \mathrm{L}$. De esta manera, se estudiará el comportamiento de la membrana utilizada con disoluciones que abarcan las diferentes concentraciones que se pueden encontrar en este sector industrial. Las membranas utilizadas en estos primeros ensayos han sido planas y el equipamiento ha sido el que el ITC tiene para trabajar a esta escala (ver apartado 3.4.1 Plantas de filtración tangencial a escala de laboratorio).

Teniendo en cuanta toda la información recopilada en la introducción referente al comportamiento del boro con respecto al pH (ver el apartado 1.2 El problema de la depuración del boro), se ha decidido hacer los ensayos de laboratorio a diferentes valores de $\mathbf{p H}(6,7,8,9,10$ y 11) para verificar los datos de la bibliografía y el comportamiento de la membrana, de esta forma poder identificar cuáles son las mejores condiciones de trabajo para la máxima retención de este elemento. Para la modificación del pH se ha utilizado $\mathrm{NaOH}$ en las cantidades requeridas en cada caso.

\section{$10 \mathrm{mg} \mathrm{de} \mathrm{B/L}$}

Con la concentración de $\mathbf{1 0} \mathbf{~ m g ~ d e ~ B / L ~ s e ~ r e a l i z a r o n ~ f i l t r a c i o n e s ~ a ~ p r e s i o n e s ~ d i f e r e n t e s ~ d e ~ 3 , ~ 5 , ~ 7 , ~}$ 10, 12 y 15 bar trabajando a pH de 6, 7, 8, 9, 10 y 11. Además, la temperatura de trabajo ha sido de $25^{\circ} \mathrm{C}$ durante todos los ensayos. En torno a esta concentración se encuentra el boro en las aguas industriales de la empresa caso de estudio. La retención conseguida a cada pH en función del flujo volumétrico de permeado puede observarse en la gráfica de la Figura 4.20.

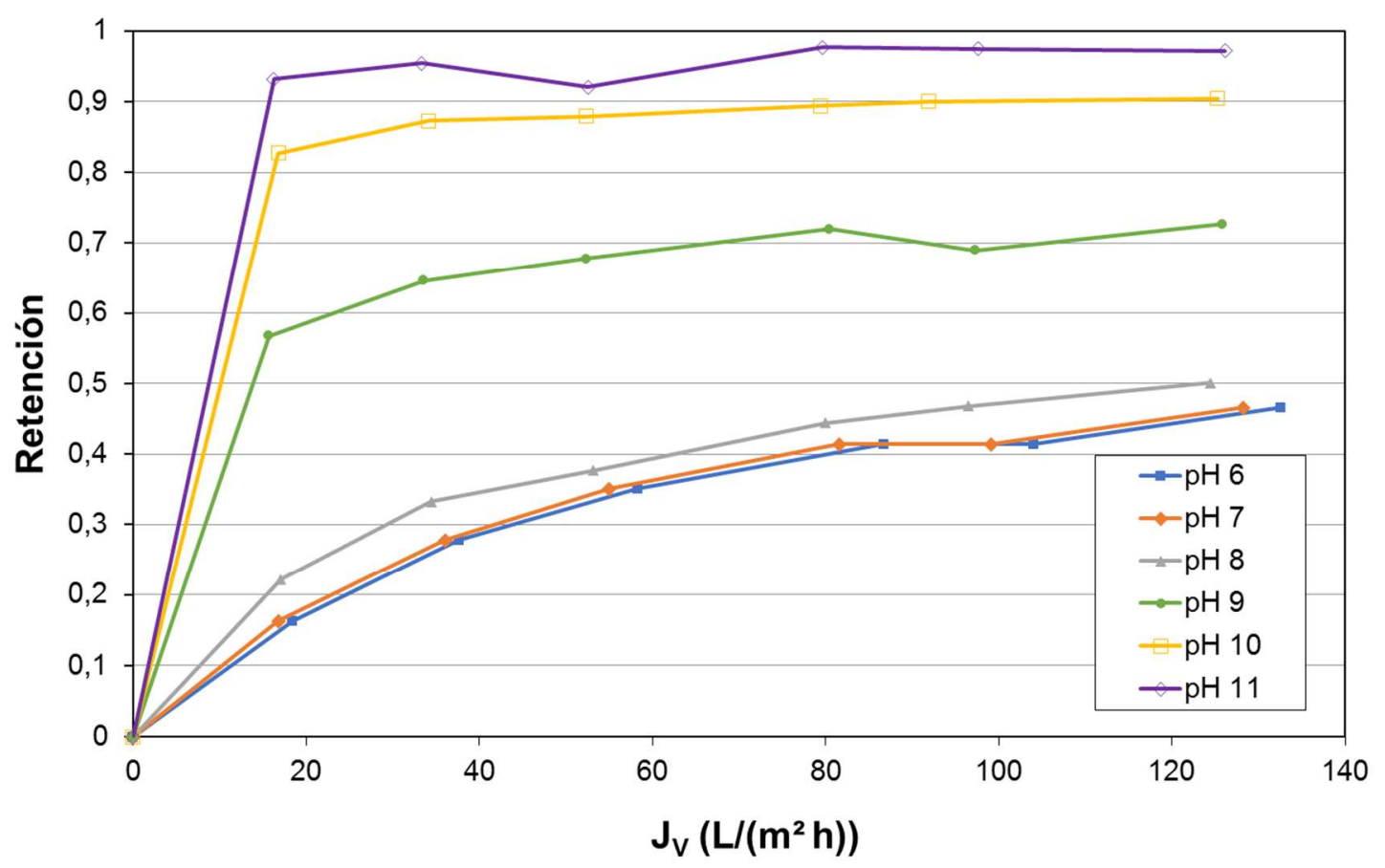

Figura 4.20. Retención del boro en función del $\mathrm{pH}$ y del flujo de permeado. NF-90 plana, $c_{a B}=10 \mathrm{mg} / \mathrm{L}$ y $Q_{a} \approx 9 \mathrm{~L} / \mathrm{min}$. 
Algunos datos relevantes de esta representación se detallan en la Tabla 4.6. Uno de estos datos es la retención $(R)$ alcanzada cuando se llega a la meseta (es decir, cuando la retención es contante y no varía prácticamente con el aumento de la presión). También se han recopilado el flujo y la presión mínima con la que se llega a esa meseta.

Tabla 4.6. Retenciones, flujos conseguidos y presiones aplicadas a diferente $\mathrm{pH}$ ( $\mathrm{C}_{a B}=10 \mathrm{mg} / \mathrm{L}$ ).

\begin{tabular}{|c|c|c|c|}
\hline pH & $\begin{array}{l}\text { Retención del boro } \\
(\%)\end{array}$ & $\begin{array}{l}\text { Flujo mínimo para alcanzar la } \\
\text { meseta } \\
\qquad\left(L / \mathrm{m}^{2} \mathrm{~h}\right)\end{array}$ & $\begin{array}{c}\text { Presión mínima para alcanzar } \\
\text { la meseta } \\
\text { (bar) }\end{array}$ \\
\hline 6 & 41 & 87 & $10-12$ \\
\hline 7 & 41 & 82 & $10-12$ \\
\hline 8 & 47 & 97 & 12 \\
\hline 9 & 72 & 80 & 10 \\
\hline 10 & 87 & 34 & $3-5$ \\
\hline 11 & 95 & 33 & $3-5$ \\
\hline
\end{tabular}

Se puede observar claramente que las retenciones a $\mathrm{pH} \approx 6,7$ y 8 son bastante parecidas, pero bajas (<50\%). Sin embargo, la retención aumenta de forma considerable a partir de $\mathrm{pH} 9$.

\section{$1 \mathrm{mg}$ de $B / L$}

Después de analizar los resultados obtenidos con la disolución de $10 \mathrm{mg}$ de $\mathrm{B} / \mathrm{L}$ se decidió que en el caso de la disolución de $\mathbf{1} \mathbf{~} \mathbf{m g}$ de $\mathbf{B} / \mathbf{L}$ no se trabajaría a todos los $\mathrm{pH}$ ensayados en el caso precedente para optimizar el número de experimentos, por tanto se realizaron los ensayos con un $\mathrm{pH}$ de 6 (la retención obtenida ha sido la menos importante y del orden de las obtenidas a pH 7 y 8), también se ha realizado el ensayo a pH 9 (la retención en el caso precedente ha sido intermedia) y por último se ha trabajado a $\mathrm{pH} 11$ ( $\mathrm{pH}$ al cual la retención ha sido máxima). Además, en este caso se ha realizado ensayos a presiones algo más bajas que en los casos anteriores para poder ver la tendencia de la retención ofrecida por la membrana a presiones menores y de esta forma poder analizar la posibilidad de trabajar a bajas presiones si ya se obtienen buenos resultados, concretamente se ha trabajado a 2, 3, 4, 5, 7, 10, 12 y 15 bar. Se cree conveniente realizar los ensayos con una disolución a baja concentración de boro para estudiar el comportamiento de estas membranas en el caso que se tuviese que trabajar con una corriente diluida.

Los datos de retención frente al caudal de permeado obtenido durante la realización de estos ensayos se representan en la gráfica de la Figura 4.21. 


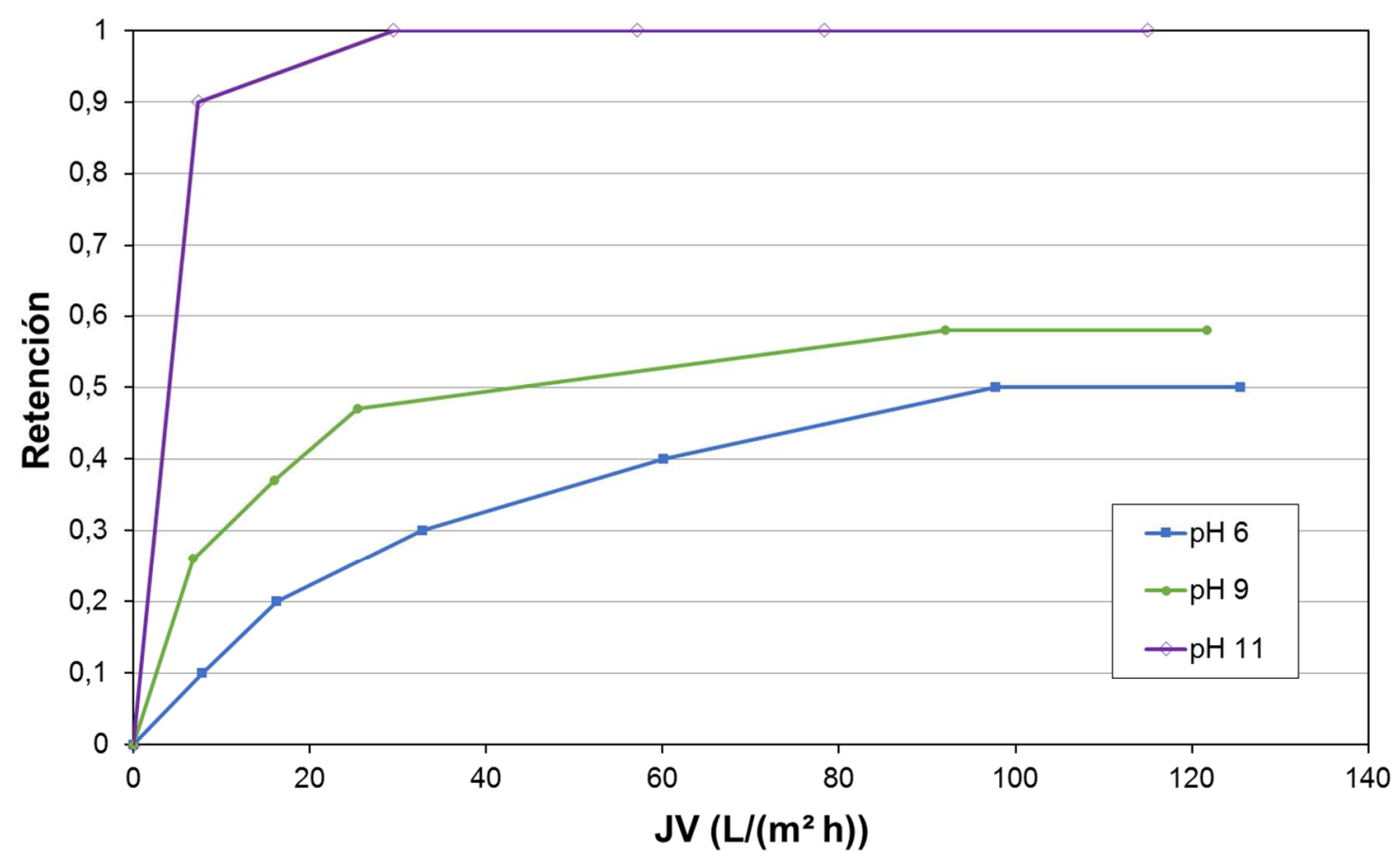

Figura 4.21. Retención del boro en función del $\mathrm{pH}$ y del caudal de permeado. NF-90 plana, $c_{a B}=1 \mathrm{mg} / \mathrm{L}$ y $Q_{a} \approx 9 \mathrm{~L} / \mathrm{min}$.

En la Tabla 4.7 se recopilan los datos más representativos de la gráfica anterior.

Tabla 4.7. Retenciones, flujos conseguidos y presiones aplicadas a diferente $\mathrm{pH}\left(\mathrm{c}_{a B}=1 \mathrm{mg} / \mathrm{L}\right)$.

\begin{tabular}{|c|c|c|c|}
\hline $\mathrm{pH}$ & $\begin{array}{c}\text { Retención del boro } \\
(\%)\end{array}$ & $\begin{array}{c}\text { Flujo mínimo para alcanzar } \\
\text { la meseta } \\
\left(\mathrm{L} / \mathrm{m}^{2} \mathrm{~h}\right)\end{array}$ & $\begin{array}{c}\text { Presión mínima para alcanzar } \\
\text { la meseta } \\
(\text { bar })\end{array}$ \\
\hline 6 & 50 & 98 & $12-15$ \\
\hline 9 & 58 & 92 & 12 \\
\hline 11 & 100 & 25 & $4-5$ \\
\hline
\end{tabular}

Los resultados obtenidos en esta ocasión siguen la misma tendencia que en el caso anterior. Sin embargo, la retención obtenida a pH 9 es menor que en el caso de la disolución con una concentración de $10 \mathrm{mg}$ de B/L. Sin embargo, la retención obtenida a pH 11 ha sido más elevada (prácticamente del 100\%). Siendo más o menos la misma retención la obtenida a un pH 6 si se compara con la concentración anterior.

\section{$100 \mathrm{mg} \mathrm{de} \mathrm{B/L}$}

Se han realizado las mismas pruebas que para la disolución de $1 \mathrm{mg}$ de B/L pero esta vez aumentando la concentración de boro a $\mathbf{1 0 0} \mathbf{~ m g ~ d e ~ B / L ~ d e ~ l a ~ d i s o l u c i o ́ n ~ s o m e t i d a ~ a ~ n a n o f i l t r a c i o ́ n . ~}$ Esta concentración es la máxima cantidad que se podrá encontrar en algunas empresas relacionadas con el sector cerámico (ver punto 1.1.3.1 Generación y características del agua 
residual), por tanto, se cree conveniente observar el comportamiento de las membranas a esta concentración de boro. Los resultados obtenidos se han representado en la Figura 4.22.

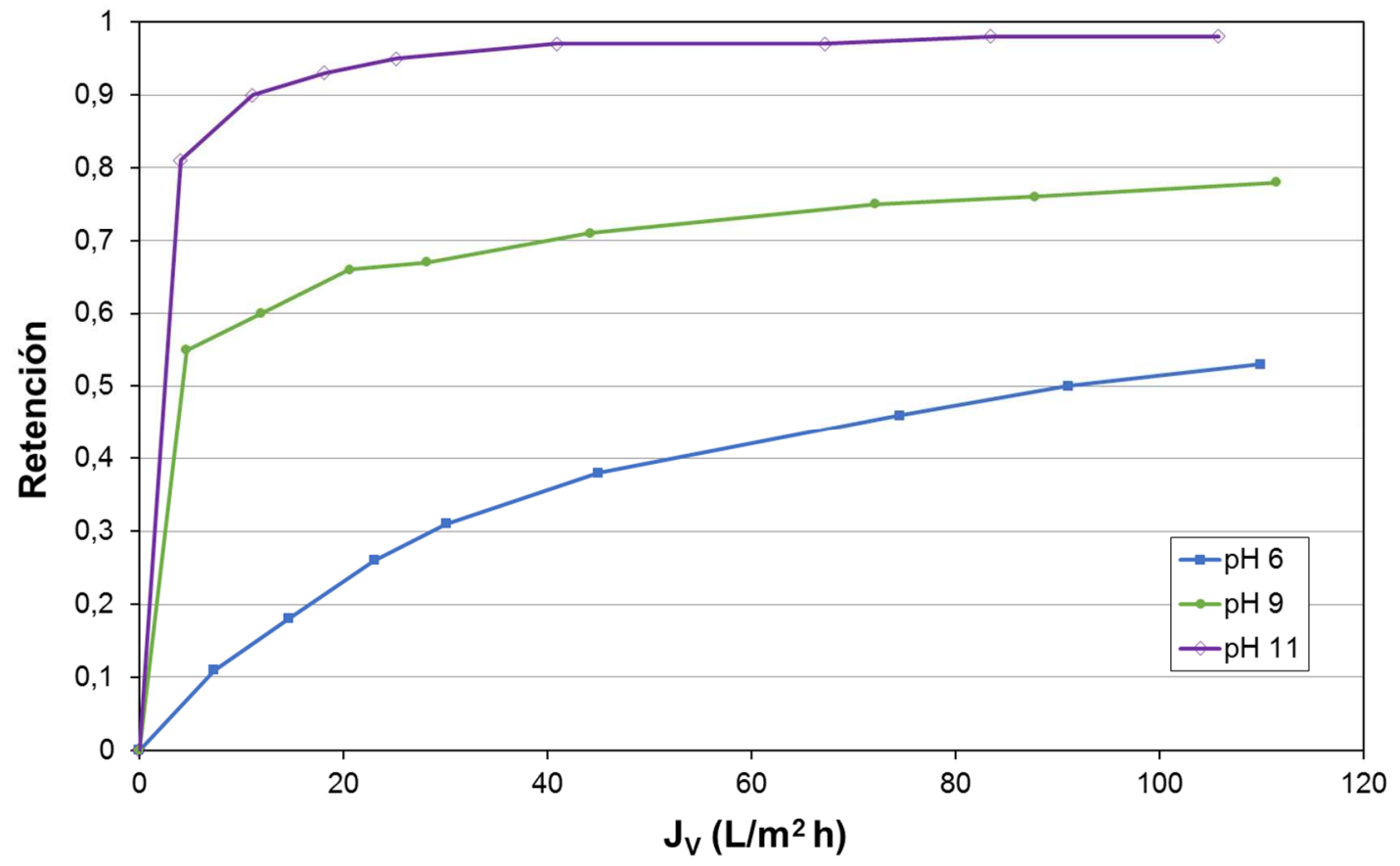

Figura 4.22. Retención del boro en función del $\mathrm{pH}$ y del flujo de permeado. NF-90 plana, $c_{a B}=100 \mathrm{mg} / \mathrm{L}$ y $Q_{a} \approx 9 \mathrm{~L} / \mathrm{min}$.

En la Tabla 4.8. se recopilan los datos más representativos de la gráfica anterior.

Tabla 4.8. Retenciones, flujos conseguidos y presiones aplicadas a diferente $\mathrm{pH}\left(\mathrm{C}_{\mathrm{aB}}=100 \mathrm{mg} / \mathrm{L}\right)$.

\begin{tabular}{|c|c|c|c|}
\hline $\mathrm{pH}$ & $\begin{array}{c}\text { Retención del boro } \\
(\%)\end{array}$ & $\begin{array}{c}\text { Flujo mínimo para } \\
\text { alcanzar la meseta } \\
\left(\mathrm{L} / \mathrm{m}^{2} \mathrm{~h}\right)\end{array}$ & $\begin{array}{c}\text { Presión mínima para alcanzar la } \\
\text { meseta } \\
\text { (bar) }\end{array}$ \\
\hline 6 & 53 & 110 & $12-15$ \\
\hline 9 & 78 & 90 & 12 \\
\hline 11 & 98 & 40 & 7 \\
\hline
\end{tabular}

Los resultados obtenidos son muy próximos a los obtenidos con la disolución de $10 \mathrm{mg}$ de B/L, observándose la misma tendencia en cuanto a la variación de la retención con el pH.

\section{Retención del boro en función del pH a diferentes presiones}

Si se representa la retención al boro ofrecida por la membrana NF-90 en función del pH para varias presiones de trabajo, a una temperatura constante de $25^{\circ} \mathrm{C}$ y trabajando con una disolución de alimentación con una concentración de $10 \mathrm{mg}$ de B/L, tal y como se hace en la Figura 4.23, se puede observar que la presión ejercida sobre la membrana y el pH de la solución de alimentación tienen un importante efecto sobre la retención del boro. 
En efecto, para un mismo $\mathrm{pH}$, cuanto mayor sea la presión, la retención es más importante. Esto es particularmente cierto para $\mathrm{pH}$ bajos, es decir cuando el $\mathrm{pH}$ es menor de 8, que es cuando las moléculas en las que está presente el boro están poco ionizadas. La diferencia en la retención obtenida a diferentes presiones tiende a desaparecer cuando las moléculas portadoras de este elemento están en forma ionizada, es decir, cuando el pH es superior a 9 (ver punto 1.2.2 Química del boro).

En cuanto al efecto del $\mathrm{pH}$, se aprecia que a pH menor de 8 la retención prácticamente no varía con este parámetro. A partir de $\mathrm{pH} 8$, cuanto más se aumenta el $\mathrm{pH}$ de la solución, mejor es la retención del boro. La máxima retención para la membrana NF-90 se alcanza a $\mathrm{pH}=11$. A pH superior a 11 se estaría fuera del intervalo de trabajo de este tipo de membranas (ver Anexo III), por tanto no es recomendable trabajar a $\mathrm{pH}$ superior. La retención conseguida con esta membrana, no sólo es causa de los efectos estéricos debidos al reducido tamaño de los poros de la membrana, sino que también es debida a la repulsión electroestática entre los iones borato y la superficie de la membrana de nanofiltración, la cual se encuentra cargada negativamente a este pH (ver Tabla 4.3) [82][30][42].

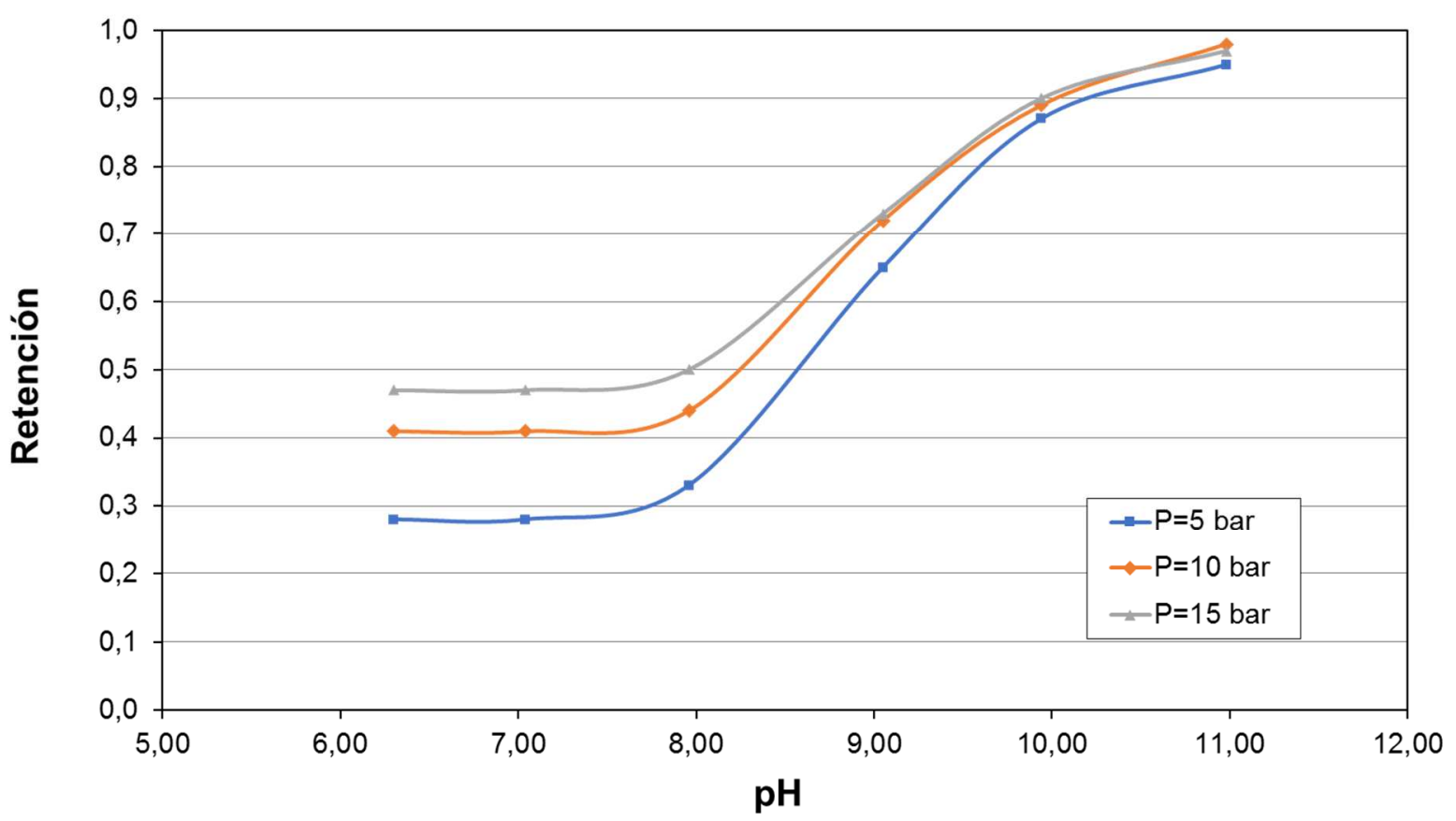

Figura 4.23. Variación de la retención del boro en función del pH y de la presión. NF-90 plana, $c_{a B}=10 \mathrm{mg} / \mathrm{L}$ y $Q_{a} \approx 9 \mathrm{~L} / \mathrm{min}$.

\subsubsection{Ensayos de nanofiltración realizados con membranas en espiral}

Hasta este momento, en todos los ensayos realizados se han utilizado membranas planas, que es la configuración más utilizada en los ensayos a escala de laboratorio. Como los objetivos de este estudio son la implementación de la nanofiltración en la industria cerámica, se cree necesario hacer un escalado y utilizar configuraciones de membrana más comunes a nivel industrial (ver punto 1.4.1.3 Tipos de membranas y geometría de sus módulos). Por tanto, los ensayos de retención del boro han sido repetidos utilizando esta vez membranas NF-90 en espiral, ya que realmente son las membranas construidas en esta configuración las que se utilizan en instalaciones industriales [74]. 
De esta forma, se pretende verificar que los resultados obtenidos con las membranas planas son escalables a la configuración en espiral. En este caso se han utilizado módulos de dimensiones 2540 (ver Anexo III) y el equipamiento utilizado ha sido el que dispone el ITC para tal fin (ver punto 3.4.2 Planta de filtración tangencial a escala piloto). En primer lugar, se ha trabajado con disoluciones sintéticas para ver si se repetían los resultados obtenidos con las membranas planas y seguidamente ya se han realizado ensayos con aguas residuales procedentes de la empresa para estudiar el comportamiento de estas membranas frente a este tipo de aguas residuales reales. Hay que tener en cuenta que en estas aguas ya no solamente están presentes los compuestos de boro, existen multitud de otros elementos que interaccionarán con la membrana en el proceso de nanofiltración.

\section{Solución sintética de boro}

En la realización de estos ensayos de nanofiltración se ha trabajado a temperatura constante de $25^{\circ} \mathrm{C}$ y las presiones de trabajo han sido de 4, 5, 7, 10 y 13 bar. El caudal de alimentación a la membrana ha sido igual a $Q_{a}=7 \mathrm{~L} / \mathrm{min}$. Los resultados de la retención del boro a diferentes $\mathrm{pH}$ y concentraciones medias (10 mg/L de B) y altas (100 mg/L de B) obtenidas con la membrana NF-90 con configuración en espiral a $Q_{a} \approx 7 L / m i n$ son representados en la Figura 4.24.

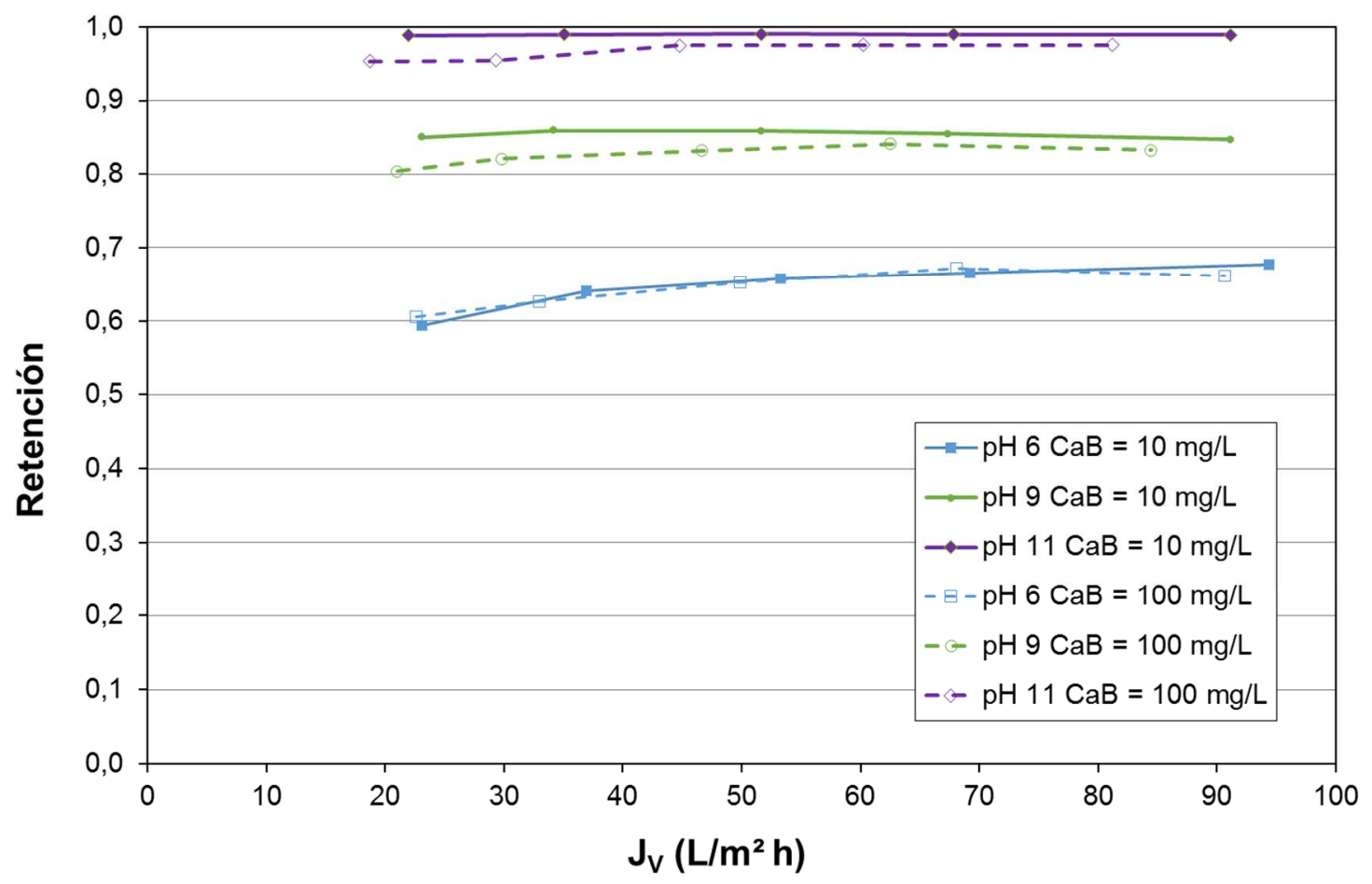

Figura 4.24. Retención del boro en función del $\mathrm{pH}$ y del flujo de permeado. NF-90 en espiral, $c_{a B}=10 \mathrm{mg} / \mathrm{L}$ (trazo continuo), $c_{a B}=100$ $\mathrm{mg} / \mathrm{L}$ (trazo discontinuo) y $Q_{a} \approx 7,00 \mathrm{~L} / \mathrm{min}$.

Además, en la Tabla 4.9 se han recopilado los datos más representativos de la representación gráfica anterior. 
Tabla 4.9. Retenciones y flujos conseguidos a diferente $\mathrm{pH}$ (Concentraciones medias y altas de $B$ en la alimentación).

\begin{tabular}{|c|c|c|c|c|}
\hline \multirow{2}{*}{$\begin{array}{c}\mathrm{C}_{\mathrm{aB}} \\
(\mathrm{mg} / \mathrm{L})\end{array}$} & $\mathrm{pH}$ & $\begin{array}{c}\text { Retención del } \\
\text { boro } \\
(\%)\end{array}$ & $\begin{array}{c}\text { Flujo mínimo para alcanzar } \\
\text { la meseta } \\
\left(\mathrm{L} / \mathrm{m}^{2} \mathrm{~h}\right)\end{array}$ & $\begin{array}{c}\text { Presión mínima para } \\
\text { alcanzar la meseta } \\
(\text { bar })\end{array}$ \\
\hline \multirow{2}{*}{10} & 6 & 65 & 37 & 5 \\
\cline { 2 - 6 } & 9 & 85 & 23 & 4 \\
\cline { 2 - 6 } & 11 & 99 & 22 & 5 \\
\hline \multirow{2}{*}{100} & 6 & 64 & 33 & 5 \\
\cline { 2 - 6 } & 9 & 83 & 30 & 4 \\
\hline
\end{tabular}

La concentración de boro no tiene una influencia muy marcada sobre la retención de esta membrana, ya que observamos aproximadamente la misma retención a $\mathrm{C}_{\mathrm{aB}}=10 \mathrm{mg} / \mathrm{L}$ que a $\mathrm{C}_{\mathrm{aB}}$ $=100 \mathrm{mg} / \mathrm{L}$. Por otro lado, si se compara las retenciones obtenidas con las membranas planas (ver Tabla 4.6 para concentraciones medias y Tabla 4.8 para concentraciones altas) se puede observar que las retenciones obtenidas con las membranas en espiral son del mismo orden o incluso superiores.

La meseta constante se alcanza a un flujo de permeado y presión poco elevados, incluso antes que con las membranas planas. Además, se puede comprobar que el flujo y la presión mínimos para llegar a la meseta desciende cuando aumenta el $\mathrm{pH}$, este es debido a que a $\mathrm{pH}$ elevado las moléculas portadoras del boro están en su totalidad en forma de boratos y por lo tanto cargadas eléctricamente, este hecho hace que la nanofiltración sea más efectiva a presiones más bajas.

Por tanto, con estos ensayos se puede observar que existe un buen escalado de las membranas planas a las membranas en espiral. Aunque, pequeñas diferencias entre los resultados obtenidos con las membranas planas y con las membranas en espiral pueden ser debidas a dos causas principalmente:

- Puede existir un cierto grado de heterogeneidad en la fabricación de las membranas, por tanto, los posibles efectos de esa heterogeneidad son menores cuanto más grande es la superficie utilizada. Por esta razón, siempre es más representativo de la realidad el trabajar con membranas en espiral que con membranas planas a nivel de laboratorio, ya que generalmente en este último caso la superficie de la membrana es mucho menor.

- Una hidrodinámica diferente, ya que aunque el modo de filtración es tangencial tanto cuando se utilizan las membranas planas como cuando se utilizan las membranas en espiral, el espesor y tipo de espaciadores entre el fluido y la membrana puede influir en la filtración propiamente dicha. 


\section{Efluentes industriales}

Después de haber comprobado que las membranas en forma de espiral reproducían con bastante exactitud el comportamiento frente a una disolución sintética de boro si son comparadas con las membranas planas, se decidió pasar a utilizar estas membranas con aguas industriales reales. La empresa de fabricación de baldosas cerámicas fue la encargada de proporcionar las aguas residuales para realizar estos ensayos. En un caso se cogieron aguas de antes del tratamiento físico-químico cuya concentración en boro fue de 13,2 mg/L, y en otro caso se cogió la muestra después de haber pasado por dicho tratamiento, en la que la concentración de boro fue de 17,6 $\mathrm{mg} / \mathrm{L}$. La concentración de boro no es la misma en ambas muestras porque se tomaron en diferentes días. Esta variabilidad en la concentración confirma la heterogeneidad y variabilidad que tienen las aguas residuales del sector cerámico, tal y como se comentó en el apartado 1.1.3 Generación, características y gestión actual de las aguas residuales procedentes de las empresas de fabricación de baldosas cerámicas. En ambos casos, las muestras se sometieron a una microfiltración antes de aplicar el tratamiento de nanofiltración, con el fin de alargar la vida útil de las membranas y aumentar la eficiencia del tratamiento principal.

A continuación se pueden observar por separado los resultados obtenidos con las aguas recogidas antes y después del tratamiento físico-químico. De esta forma poder analizar si este tratamiento es realmente necesario sabiendo que antes de la nanofiltración se va a realizar un pretratamiento de microfiltración. Los ensayos se han realizado a temperatura constante de $25^{\circ} \mathrm{C}$ y las presiones a las que se ha trabajado han sido 4, 6, 9 y 13 bar. El pH al cual se han realizado estos ensayos es de 11 , ya que como se ha visto anteriormente es al pH que mejores resultados se han obtenido.

a) Utilización de la membrana NF-90 en la nanofiltración de un agua residual pretratada mediante un tratamiento físico-químico y una posterior microfiltración.

En esta ocasión también se trabajó a varias velocidades de alimentación, ya que al ser aguas industriales reales se pensó que posiblemente a velocidades más altas no se depositaría suciedad en la superficie de la membrana evitando el "fouling" y no se favorecería la polarización por concentración en la superficie de la membrana. A mayor velocidad de la disolución de alimentación mayor turbulencia en la superficie de la membrana y por consiguiente se minimiza tanto el "fouling" como la polarización por concentración [43][117][118][120][63] (ver punto 1.4.2.2 Fenómenos limitantes de la nanofiltración).

En la Figura 4.25 se representan los datos obtenidos en uno de los ensayos de nanofiltración del agua pretratada mediante un tratamiento físico-químico y una posterior microfiltración. 


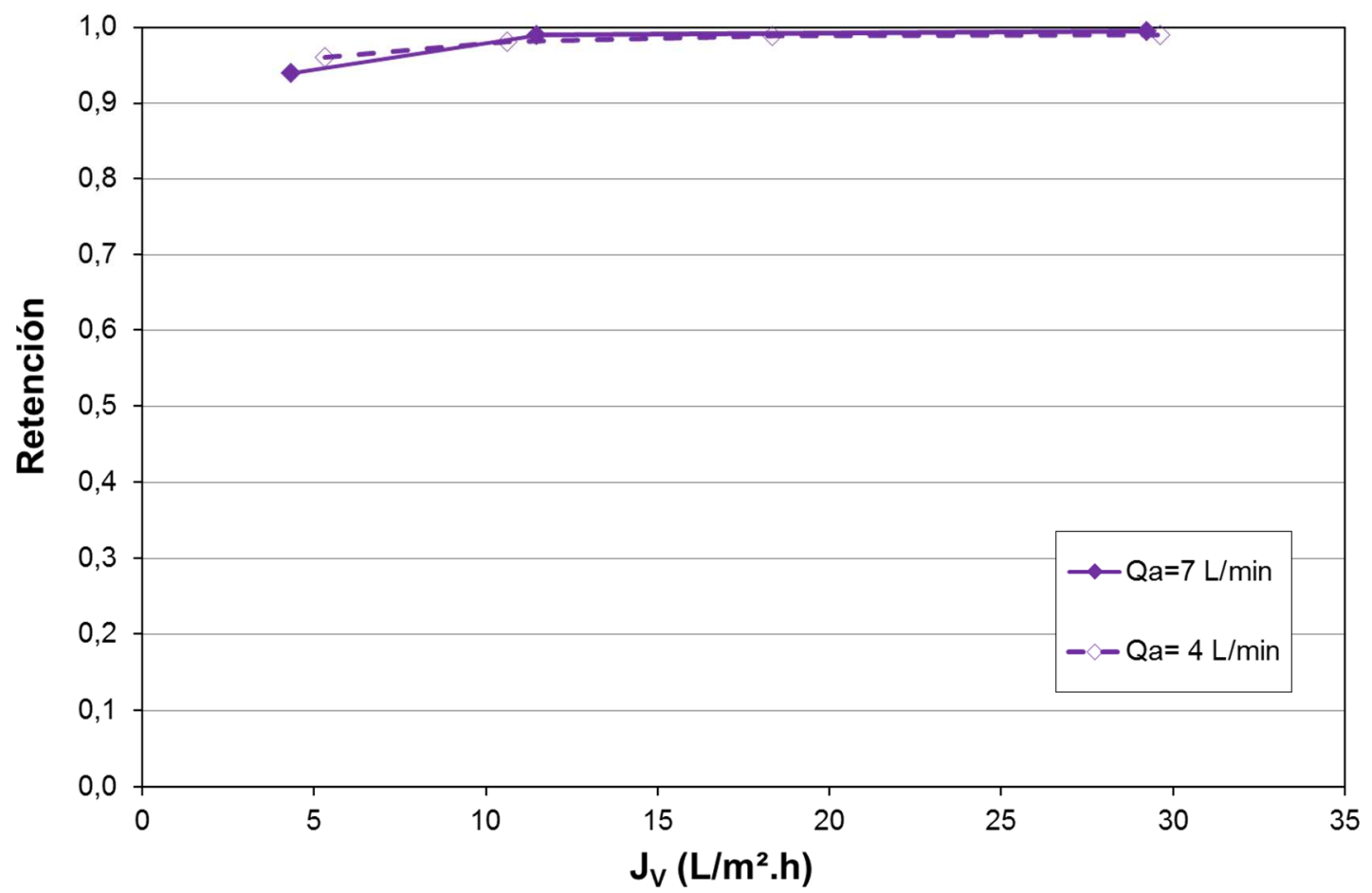

Figura 4.25. Retención del boro de una membrana NF-90 espiral en función del flujo de permeado a partir de agua residual sometida a un tratamiento físico-químico y microfiltrada. $c_{a B}=13,2 \mathrm{mg} / \mathrm{L}, p H=11, Q_{a}=7 \mathrm{~L} / \mathrm{min}$ (trazo continuo) y $Q_{a}=4 \mathrm{~L} / \mathrm{min}$ (trazo discontinuo).

Se puede observar que la retención de boro se mantiene constante trabajando tanto a un caudal de alimentación de $4 \mathrm{~L} / \mathrm{min}$ como a $7 \mathrm{~L} / \mathrm{min}$. Por tanto, parece que la velocidad de alimentación no será un parámetro que afecte drásticamente a la retención del boro.

Trabajando a pH 11 la retención del boro es de alrededor del 99\%, a presiones muy bajas (6 bar) y por tanto, también a caudales de permeado no muy elevados. Como se observa en la Tabla 4.10.

Tabla 4.10. Resultados obtenidos en los ensayos de nanofiltración de un agua residual industrial (después de un tratamiento físicoquímico y una microfiltración) con la membrana NF-90.

\begin{tabular}{|c|c|c|c|c|}
\hline pH & $\begin{array}{c}\text { Retención del } \\
\text { boro } \\
(\%)\end{array}$ & $\begin{array}{c}\text { Flujo mínimo para } \\
\text { alcanzar la meseta } \\
\left(\mathrm{L} / \mathrm{m}^{2} \text { h) }\right.\end{array}$ & $\begin{array}{c}\text { Presión mínima para } \\
\text { alcanzar la meseta } \\
(\text { bar })\end{array}$ & $\begin{array}{c}\text { Caudal de } \\
\text { alimentación } \\
(\mathrm{L} / \mathrm{min})\end{array}$ \\
\hline \multirow{2}{*}{11} & 11 & 6 & 7 \\
\cline { 2 - 5 } & 99 & 10 & 6 & 4 \\
\hline
\end{tabular}

b) Utilización de la membrana NF-90 en la nanofiltración de un agua residual microfiltrada sin pretratamiento físico-químico.

Se creyó conveniente realizar un ensayo con un agua residual industrial sin haberla sometido al tratamiento físico-químico, de esta forma se podría observar si este tratamiento afecta a la retención del boro y al funcionamiento general del tratamiento de nanofiltración. De esta forma, analizar si sería posible prescindir del tratamiento físico-químico de las aguas residuales ya que antes de la 
nanofiltración se tiene que realizar un pretratamiento de microfiltración. Los resultados obtenidos se pueden observar en la Figura 4.26.

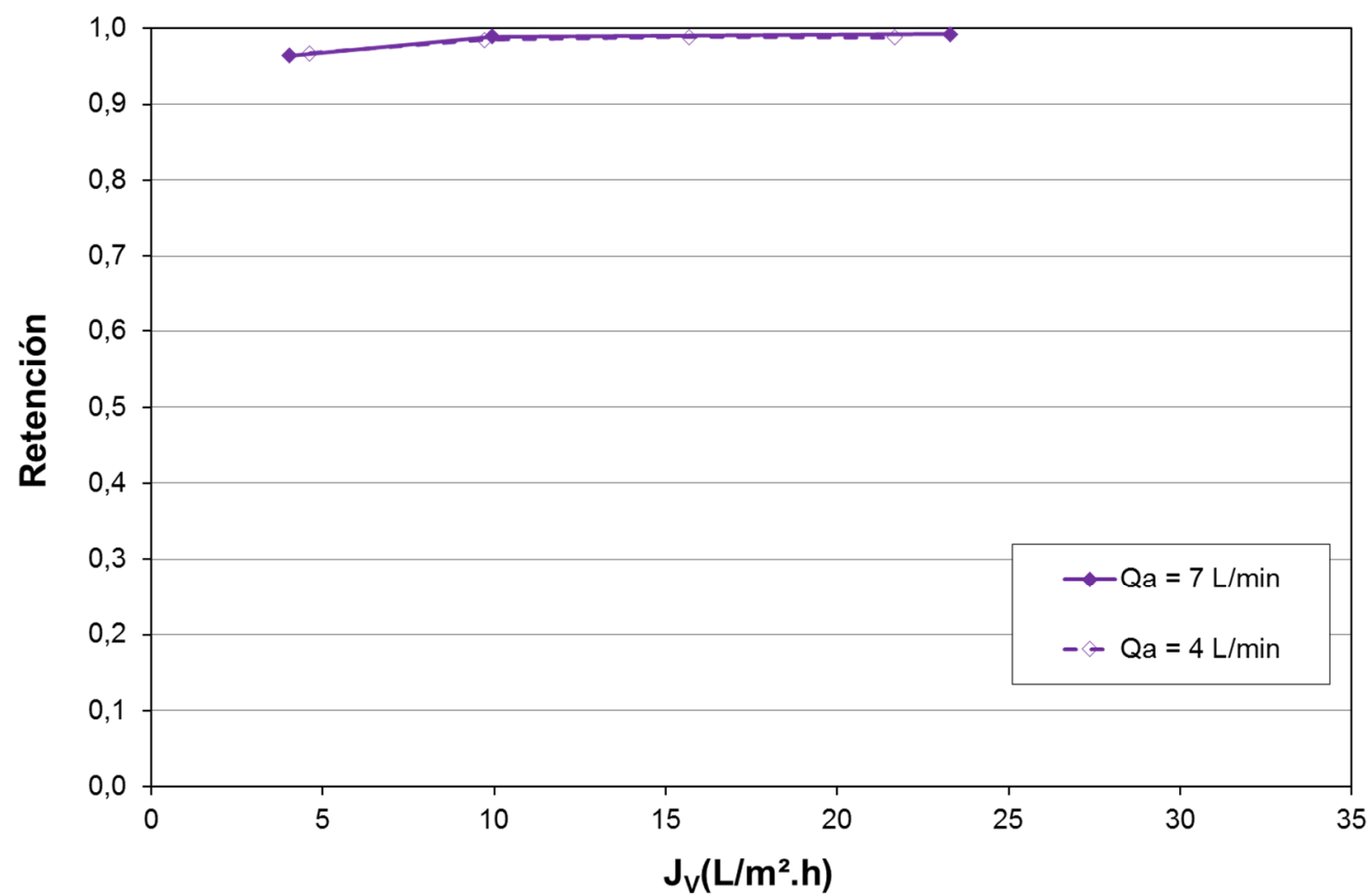

Figura 4.26. Retención del boro por una membrana NF-90 en espiral en función del flujo de permeado a partir de agua residual sin un tratamiento físico-químico pero microfiltrada. $c_{a B}=17,6 \mathrm{mg} / \mathrm{L}, \mathrm{pH}=11, Q_{a}=7 \mathrm{~L} / \mathrm{min}$ (trazo continuo) y $Q_{a}=4 \mathrm{~L} / \mathrm{min}$ (trazo discontinuo).

La retención del boro no se ve afectada por el hecho de que el agua haya sido o no sometida a un tratamiento físico-químico. Tampoco en este caso la velocidad de alimentación afecta a la retención.

Tabla 4.11. Resultados de los ensayos de nanofiltración de un agua residual industrial (sin tratamiento físico-químico y una microfiltración) con la membrana NF-90.

\begin{tabular}{|c|c|c|c|c|}
\hline \multirow{2}{*}{$\mathrm{pH}$} & $\begin{array}{c}\text { Retención del } \\
\text { boro } \\
(\%)\end{array}$ & $\begin{array}{c}\text { Flujo mínimo para } \\
\text { alcanzar la meseta } \\
\left(\mathrm{L} / \mathrm{m}^{2} \mathrm{~h}\right)\end{array}$ & $\begin{array}{c}\text { Presión mínima para } \\
\text { alcanzar la meseta } \\
(\text { bar })\end{array}$ & $\begin{array}{c}\text { Caudal de } \\
\text { allimentación } \\
(\mathrm{L} / \mathrm{min})\end{array}$ \\
\hline \multirow{2}{*}{11} & 10 & 6 & 7 \\
\cline { 2 - 5 } & 99 & 10 & 6 & 4 \\
\hline
\end{tabular}

Como puede observarse al comparar los resultados recogidos en la Tabla 4.10 y en la Tabla 4.11, los resultados de retención del boro son idénticos cualquiera que sea el pretratamiento sufrido por el efluente. Así mismo, tampoco parece existir influencia entre la retención del boro y el caudal de alimentación del agua residual a los módulos de filtración si éste varía entre 4 y $7 \mathrm{~L} / \mathrm{min}$. Sin embargo, si se comparan las gráficas de la Figura 4.25 y la Figura 4.26 parece ser que el flujo de permeado ha disminuido cuando se han nanofiltrado las aguas que no han estado sometidas al tratamiento físico-químico. Para comprobar este hecho con más detalle se ha realizado una comparación de la permeabilidad de la membrana con las aguas tratadas. 
c) Variación de la permeabilidad de la membrana de nanofiltración con el agua alimentada.

Los efluentes industriales están muy cargados debido a que contienen partículas en suspensión (arcilla, feldespatos, esmaltes...), muchos electrolitos y en muchas ocasiones, materia orgánica procedente de los aditivos utilizados en la etapa de decoración de los productos cerámicos, así como los utilizados en la etapa de depuración de las propias aguas residuales (coagulantes y floculantes) (ver apartado 1.1 Problemática del agua en el sector cerámico).

Las características de estos efluentes hacen que las membranas de nanofiltración sean obstruidas por las partículas coloidales y la materia orgánica, fenómeno que se describe con el termino anglosajón "fouling" (ver apartado 1.4.2.2 Fenómenos limitantes de la nanofiltración) [112][113][114]. Este fenómeno produce:

- Una disminución del flujo de permeado y del rendimiento de la membrana.

- La creación de una torta en la superficie de la membrana.

- El aumento de la presión trans-membrana para lograr el mismo rendimiento.

En la Figura 4.27 se representa en azul la permeabilidad de la membrana NF-90 al agua pura, en naranja la permeabilidad de la membrana obtenida para las aguas residuales sometidas a un tratamiento físico-químico y a una microfiltración, y por último, en verde, la permeabilidad de la membrana obtenida para las aguas residuales solamente sometidas a un proceso de microfiltración.

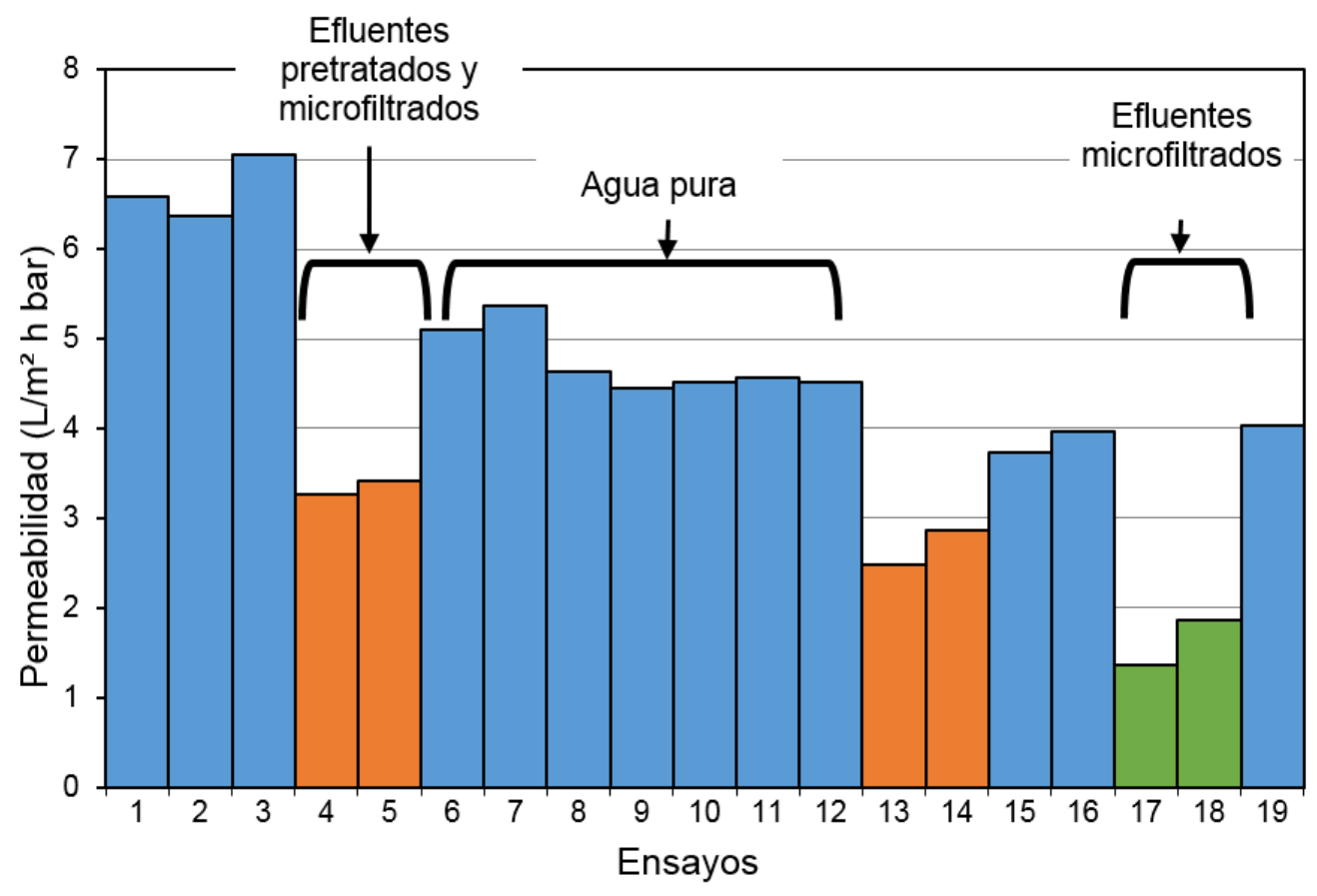

Figura 4.27. Extracto del historial de la variación de la permeabilidad en la membrana NF90 espiral a $25^{\circ} \mathrm{C}$.

Es normal que la permeabilidad de la membrana descienda considerablemente cuando se trabaja con aguas residuales si se compara con la permeabilidad obtenida con el agua pura (ver ensayos 4, 5, 13, 14, 17 y 18 de la Figura 4.27). Este comportamiento es lógico, ya que el agua pura está libre de toda sustancia que interfiera en el paso del disolvente a través de la membrana. Sin embargo, también se puede observar en esta representación, que el tratamiento de esta agua residual con la membrana NF-90 causa la disminución de la permeabilidad de la membrana al agua 
pura, ya que antes del primer tratamiento (ensayos 4 y 5) la permeabilidad al agua pura era alrededor de $7 \mathrm{~L} / \mathrm{m}^{2} \mathrm{~h}$ bar, mientras que después de este primer tratamiento la permeabilidad al agua pura descendió en torno a 4,5-5 L/m² $\mathrm{h}$ bar. Además, un lavado con agua pura (práctica habitual después de utilizar las membranas con disoluciones sintéticas o disoluciones que ensucien poco) no basta para recuperar la permeabilidad inicial de la membrana. Es necesario efectuar un ciclo de lavado agua-base-agua-ácido-agua-base-agua con el fin de eliminar el efecto del ensuciamiento de la membrana. Sin embargo, incluso con este lavado no se consiguió recuperar la permeabilidad inicial, ya que en muchos casos el "fouling" no es completamente reversible (ver apartado 1.4.2.2 Fenómenos limitantes de la nanofiltración). En estos casos, incluso sin haber recuperado totalmente la permeabilidad inicial, se tiene que continuar utilizando la membrana si aún permite conseguir los objetivos previstos. Sin embargo, estos ensayos muestran que se tendrán que realizar ciclos de limpieza más frecuentes para no colmatar de forma irreversible la membrana. En este caso, se ha limpiado la membrana y se ha medido su permeabilidad después de cada ensayo.

Los ensayos 17 y 18 muestran un fuerte descenso de la permeabilidad. Este descenso es debido a la presencia de biofilm en los efluentes. Estas muestras tuvieron que ser almacenadas durante varios días sin realizar el ensayo de nanofiltración, por este motivo y sabiendo que en las muestras existe materia orgánica, se favoreció la proliferación de micro-organismos que formaron biofilms que podían apreciarse en la propia agua y después en las entradas de la membrana (ver apartado 1.4.2.2 Fenómenos limitantes de la nanofiltración). Este hecho, unido a que la muestra no fue sometida a un tratamiento físico-químico, son los motivos por los que la permeabilidad desciende de esta forma tan considerable. Por tanto, se puede observar con la realización de estos ensayos que es sumamente importante la realización de pretratamientos antes del tratamiento de nanofiltración, e intentar que el tiempo de residencia del agua a tratar en los depósitos de almacenamiento previos al tratamiento sea lo más corto posible para evitar fenómenos de "fouling" en la membrana.

\subsubsection{Resultados piloto en la empresa de fabricación de baldosas cerámicas}

Para llevar a cabo el estudio de nanofiltración con las aguas residuales industriales de la empresa de fabricación de baldosas cerámicas se ha trabajado con las aguas residuales que la empresa obtiene después de haberlas sometido a su tratamiento físico-químico.

El equipamiento de filtración con membranas utilizado en esta ocasión ha sido la planta piloto que el ITC dispone para trabajar a nivel industrial (ver apartado 3.4.2 Planta de filtración tangencial a escala piloto). En la Figura 4.28 se ilustra el traslado de la planta piloto hasta las instalaciones de la fábrica y su ubicación durante el tiempo que duraron las pruebas. 

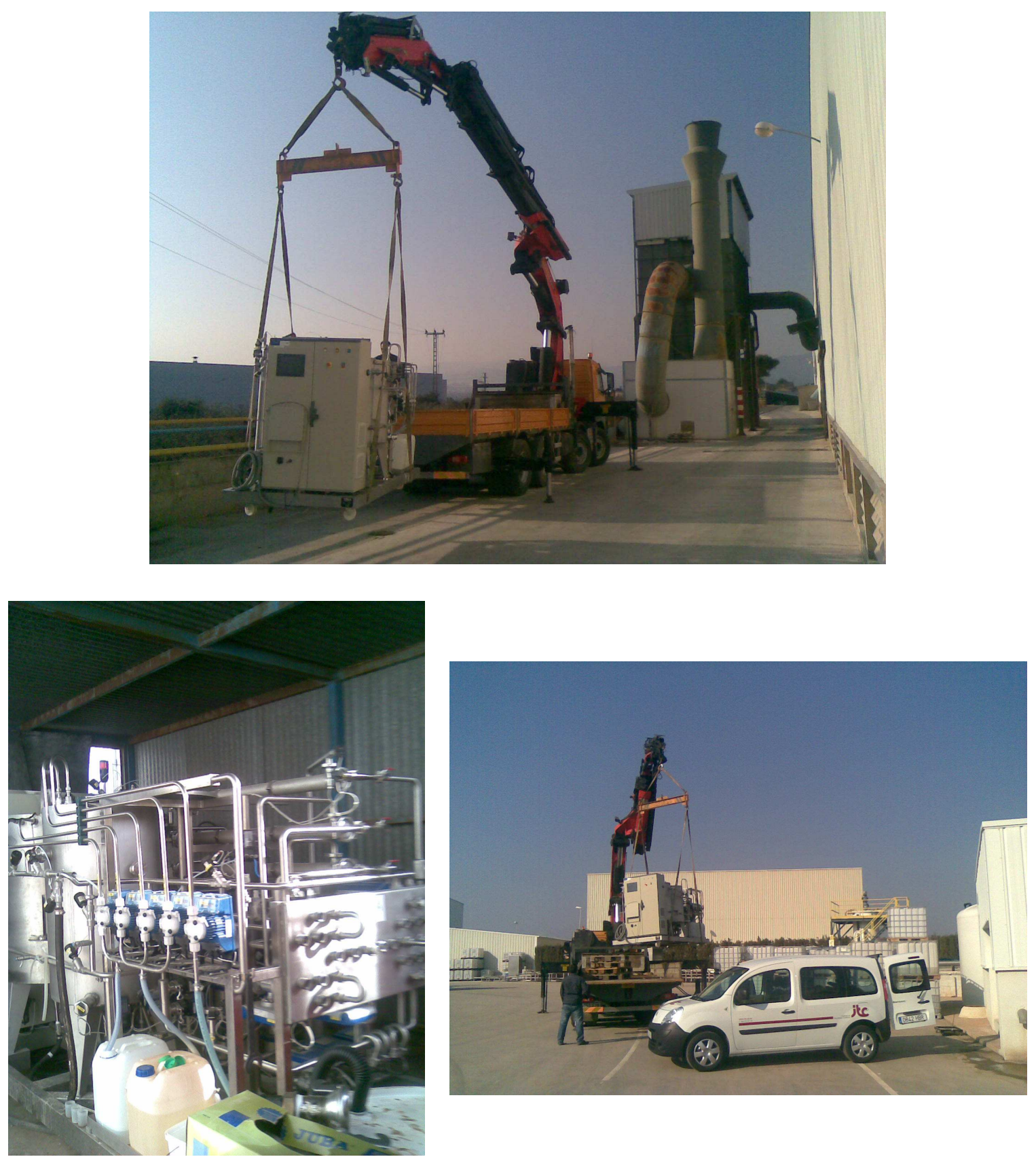

Figura 4.28. Imágenes del traslado y ubicación de la planta piloto hasta la empresa de fabricación de baldosas cerámicas.

En primer lugar, al agua de partida se le ha aplicado un pretratamiento de microfiltración a través de membranas cerámicas KLEANSEPTM 300 kD y KLEANSEPTM $0,1 \mu \mathrm{m}$ de la marca Orelis, antes de aplicarle el tratamiento de nanofiltración, de esta forma evitar obturaciones, alargar la vida útil de las membranas y aumentar el rendimiento del tratamiento principal que en este caso es la nanofiltración. En la Figura 4.29 se pueden observar varias fotografías donde se ilustran las membranas cerámicas utilizadas en este pretratamiento. 

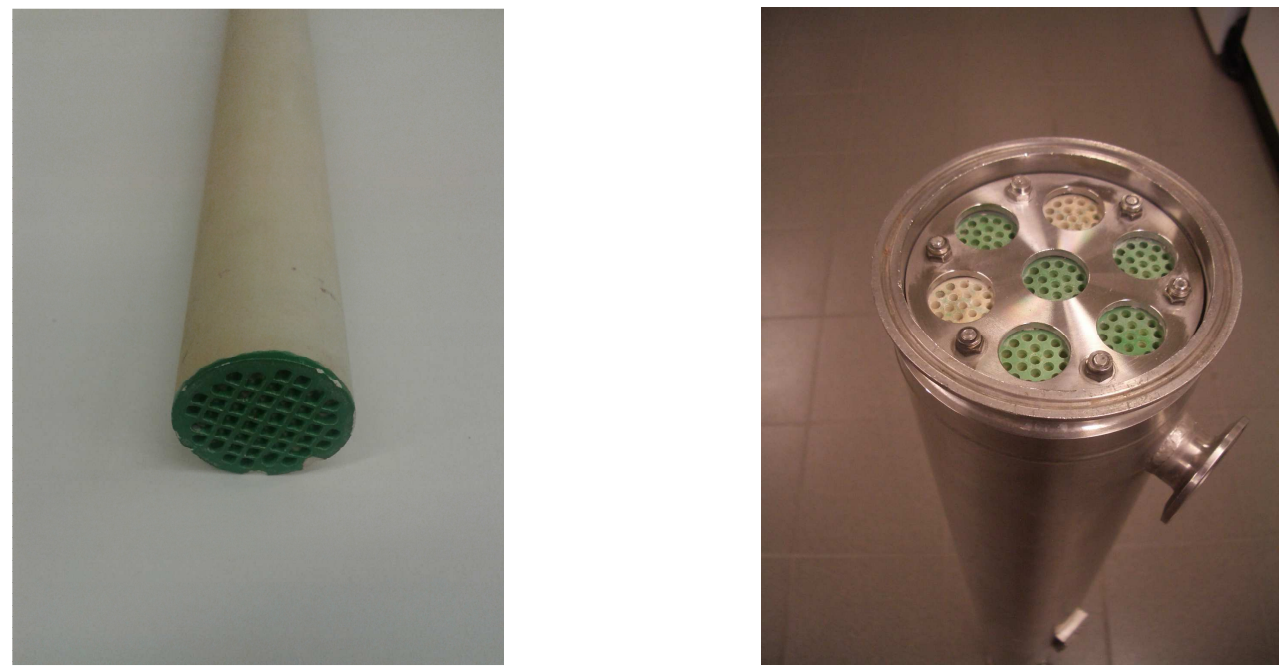

Figura 4.29. Imágenes de las membranas cerámicas de MF KLEANSEP ${ }^{T M} 300$ kD y KLEANSEP ${ }^{T M} 0,1 \mu m$, respectivamente. En el segundo caso dentro de su cárter.

Se ha considerado oportuno trabajar con dos tipos de membranas de microfiltración de diámetro de poro diferente para ver cuál de los dos tipos es más efectivo con las aguas procedentes de la industria cerámica. El hecho de probar estos dos tipos de membranas se debe a la inexistencia de datos experimentales, ya que hasta el momento se desconoce si alguna empresa de fabricación de baldosas cerámicas ha utilizado esta técnica para el tratamiento de sus aguas residuales. Las membranas han sido tubulares multicanal (ver Figura 4.29) cuyas características se pueden encontrar en la Tabla 3.3 del apartado 3.3 Membranas y en el Anexo II. Concretamente, se ha utilizado el cárter con las 7 membranas cerámicas que se puede observar en la Figura 4.29.

Las membranas de nanofiltración que se han utilizado en esta ocasión, al igual que en las pruebas a escala de laboratorio, son las membranas NF-90 de Dow-Filmtec, que han sido las que mejores resultados han ofrecido para la eliminación del boro de todas las membranas estudiadas. Se han utilizado membranas comerciales de configuración en espiral del tipo 2540 como puede apreciarse en la Figura 4.30, donde se pueden observar varias membranas antes de su utilización, así como un detalle de una de las membranas introduciéndose en el cárter que la ha albergado en la planta piloto durante las pruebas de nanofiltración. Sus características pueden encontrarse en la Tabla 3.4 del apartado 3.3 Membranas y en el Anexo III. En este caso, aunque la planta piloto tiene la posibilidad de trabajar con tres membranas dispuesta en diferentes configuraciones, solamente se ha utilizado una membrana NF-90 de tipo 2540, ya que en la ubicación de la empresa de fabricación de baldosas donde tenía que estar la planta piloto no se podía disponer de caudales superiores de agua residual para poder abastecer otras configuraciones con más membranas. 

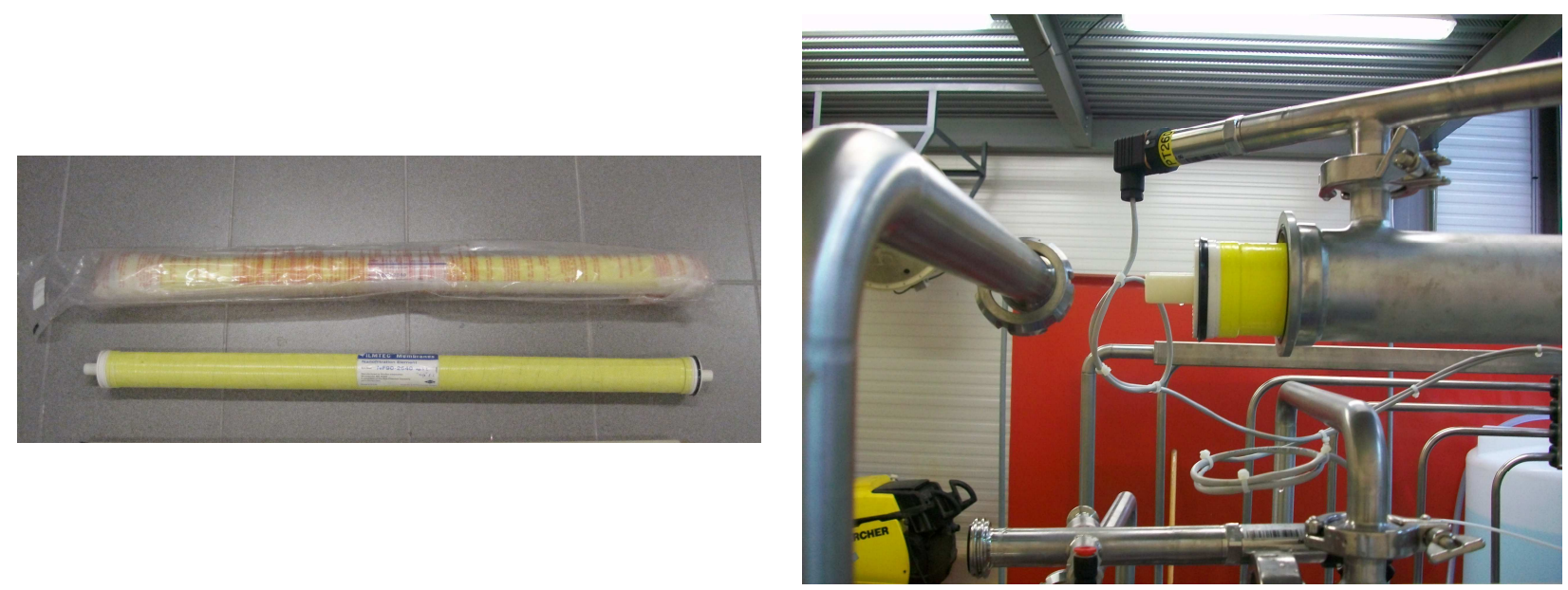

Figura 4.30. Imágenes de membranas poliméricas NF-90 en espiral tamaño 2540. Varias membranas antes de su utilización (izquierda) y detalle de una membrana introduciéndose en su cárter (derecha).

En la Figura 4.31 se puede observar un diagrama de flujo en el que se esquematiza el tratamiento a través de membranas al que se van a someter las aguas residuales industriales.

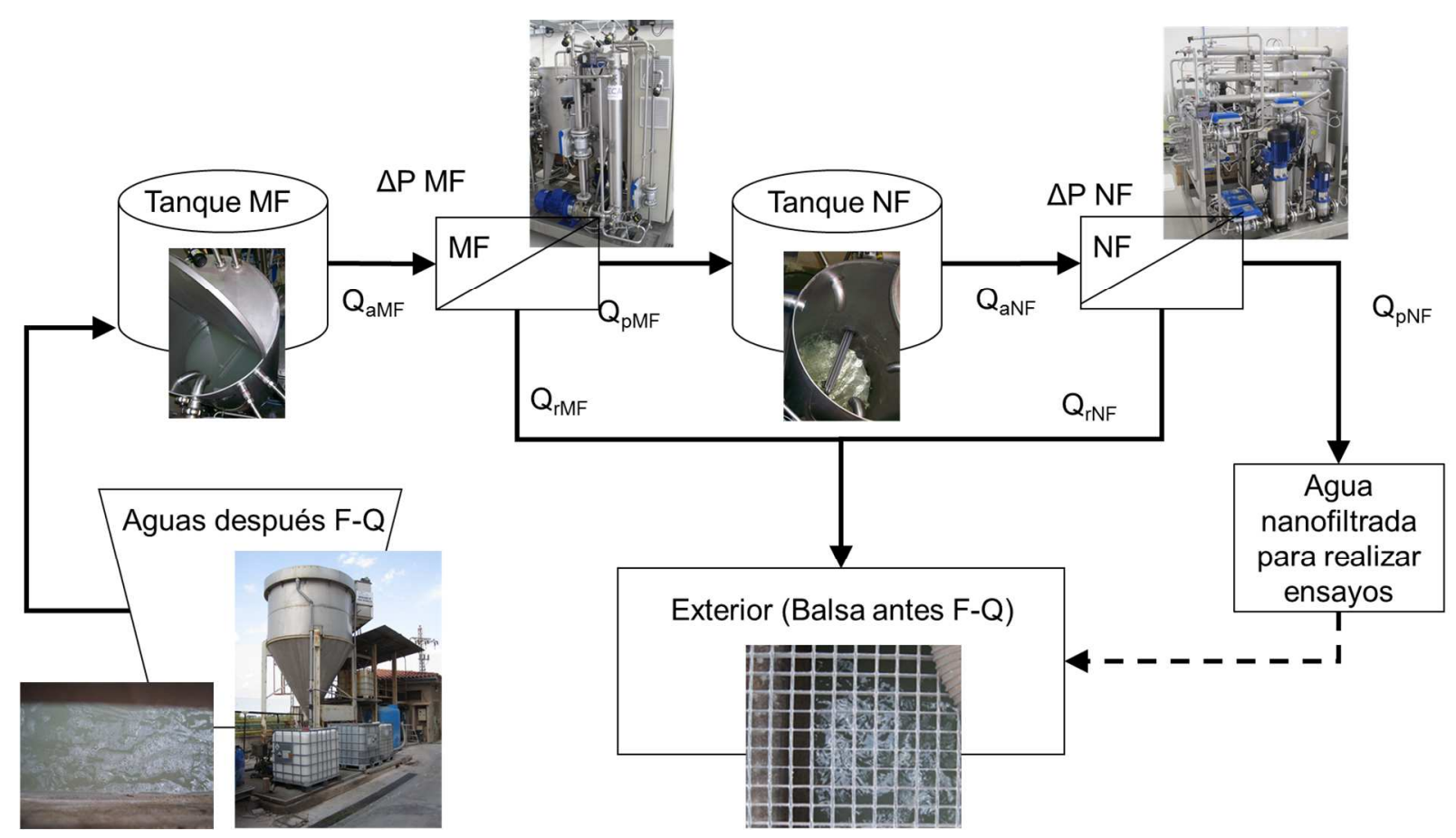

Figura 4.31. Esquema del tratamiento en continuo a través de membranas de las aguas residuales de la empresa de fabricación de baldosas cerámicas.

El punto de partida del tratamiento será la balsa de almacenamiento de las aguas tratadas después del tratamiento físico-químico que la empresa aplica a sus aguas residuales (ver Figura 4.32) 

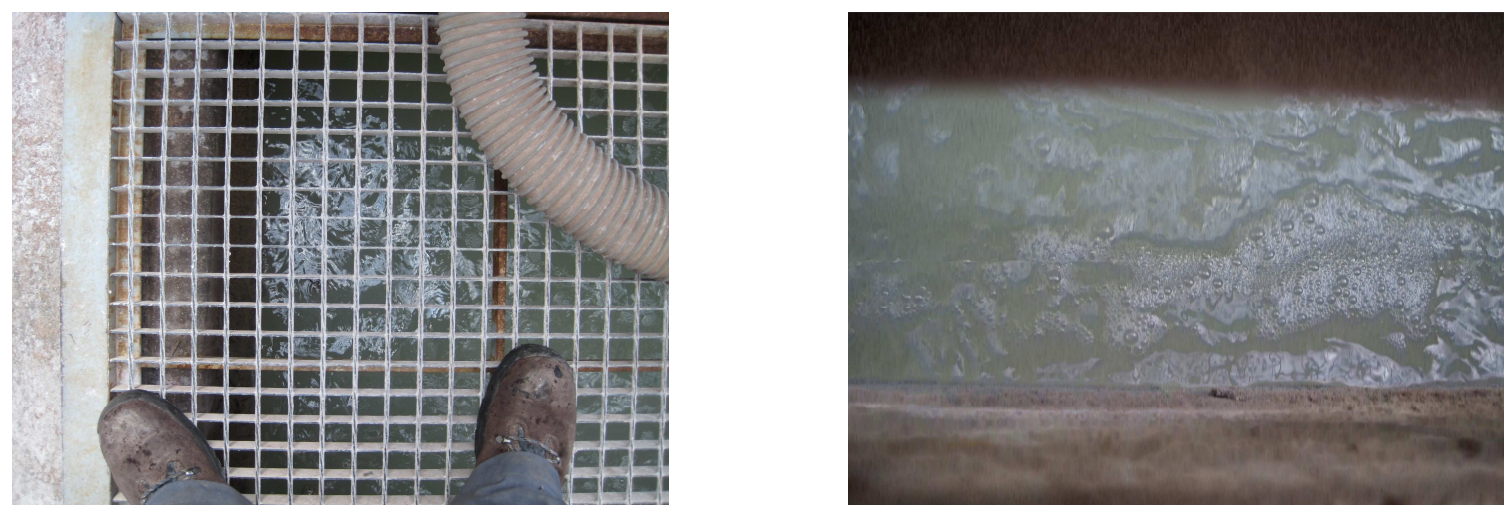

Figura 4.32. Vista superior de la balsa donde se almacena el agua después del tratamiento físico-químico.

Esta agua residual resultante de la aplicación del tratamiento físico-químico habitual de la empresa (a partir de ahora agua de balsa) será introducida en el primer depósito de la planta piloto de filtración tal y como puede observarse en el diagrama de flujo de la Figura 4.31. Este depósito alimenta a la etapa de microfiltración (depósito de microfiltración). El agua microfiltrada pasa al segundo depósito de la planta piloto que alimenta a la etapa de nanofiltración (depósito de nanofiltración), mientras que la corriente rechazo es enviada de nuevo a la balsa inicial. En la Figura 4.33 se puede ver una fotografía tomada con el agua sin microfiltrar y el agua microfiltrada, la primera es alimentada a la etapa de microfiltración y la segunda se alimenta a la etapa de nanofiltración.

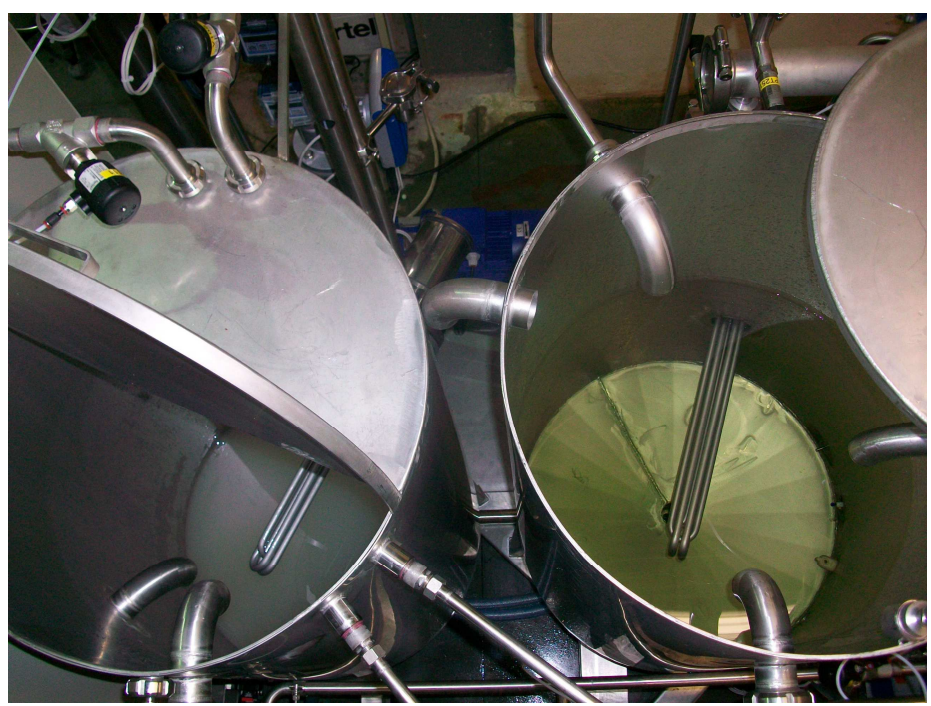

Figura 4.33. Vista superior del depósito de MF (izquierda) con agua sucia en el fondo antes de la MF y depósito de NF (derecha) medio lleno con agua trasparente (amarillenta) después de la MF ( $y$ antes de la etapa de NF).

Una vez el agua de partida ha sido pretratada con el tratamiento de microfiltración y ya trasvasada al depósito de nanofiltración, ya puede iniciarse la nanofiltración propiamente dicha. La corriente de permeado del tratamiento puede ser recogida en los recipientes indicados para comprobar la eficiencia y eficacia del tratamiento, así como para realizar las pruebas de producto pertinentes. Mientras que la corriente de rechazo, al igual que en el caso del pretratamiento, puede ser reintroducida en la balsa de inicio. 
Como se ha comentado con anterioridad, la planta piloto es muy flexible y puede trabajar en circuito cerrado, es decir todas las corrientes de salida (permeado y rechazo) pueden ser reintroducidas en su depósito de partida para poder siempre trabajar en condiciones constantes.

A continuación, se ha realizado una recopilación de las pruebas y resultados obtenidos en la optimización del pretratamiento de microfiltración y del tratamiento propiamente dicho de nanofiltración.

\subsubsection{Optimización del pretratamiento de microfiltración a escala piloto}

En este apartado se han realizado los ensayos oportunos para optimizar el pretratamiento de microfiltración. Esta etapa ha de ser capaz de proporcionar suficiente agua pretratada con la mínima calidad necesaria para que el tratamiento de nanofiltración se lleve a cabo sin problemas.

Por tanto, se han realizado los ensayos oportunos para, en primer lugar, conocer el caudal de agua microfiltrada que la planta puede ofrecer y, en segundo lugar, establecer las condiciones de trabajo para que la etapa de microfiltración sea estable en el tiempo. Los dos parámetros de trabajo más importantes que se han de determinar son el caudal de permeado capaz de producir esta etapa y la presión de trabajo necesaria para producir este caudal.

Además, este tipo de tratamientos funciona de forma discontinua, concretamente en régimen de alimentación y purgado (ver Figura 1.34). El agua de alimentación al sistema de microfiltración circula en circuito cerrado. Es decir, el permeado se extrae continuamente y se dirige al tanque que alimentará a la etapa de nanofiltración, mientras que el rechazo se recircula a la cabeza del sistema para volver a ser microfiltrado. Al mismo tiempo, se realizan purgas periódicas para que la corriente de alimentación no se concentre demasiado. También se va aportando continuamente agua nueva al sistema para remplazar el agua permeada y las purgas del circuito que se tienen que ir realizando, de esta forma el volumen en el bucle de la microfiltración siempre es el mismo. Por tanto, es una práctica habitual en este tipo de tratamientos determinar la frecuencia de desconcentración del bucle de filtrado (purgas) para que la etapa de microfiltración se colmate lo más lentamente posible y no de problemas a la instalación. Esta desconcentración simplemente consistirá en eliminar parte del agua que está recirculando alrededor de las membranas cerámicas, de esta forma se pretende evitar que se vaya concentrado continuamente y acabe colmatando las membranas. En primer lugar, se ha elegido como variable que determine en qué momento se ha de realizar la desconcentración del bucle la variable FCV (Factor de Concentración Volumétrica), variable que se define como la relación entre el caudal de alimentación y el caudal de rechazo:

$$
F C V=\frac{Q_{a}}{Q_{r}}
$$

donde $Q_{a}$ es el caudal de alimentación de la operación de microfiltración y $Q_{r}$ es el caudal de rechazo. Esta variable es una de las más utilizadas cuando se operan instalaciones industriales. Se han probado varios FCV que varían desde 20 hasta valores de 3, es decir desde desconcentraciones de bucle muy frecuentes a menos frecuentes. Por lo tanto, cuando la relación entre el caudal de alimentación y el caudal de rechazo llegue al FCV introducido en los parámetros 
de control de la planta piloto, el autómata que regula el funcionamiento del equipo desconcentrará el bucle de la microfiltración.

Además, se ha trabajado con dos membranas diferentes, por un lado, la membrana cerámica KLEANSEPTM 300 kD y, por otro, la membrana cerámica KLEANSEPTM 0,1 $\mu$ m (ver Tabla 3.4 en el apartado 3.3 Membranas o Anexo II). De esta forma, se pretende estudiar si alguna de las dos tiene un comportamiento mejor que la otra con las aguas residuales industriales del sector cerámico. Por tanto, se ha determinado el caudal de permeado que se puede obtener con cada una de ellas y la calidad del agua microfiltrada que se consigue después de este pretratamiento. Para determinar la eficacia del pretratamiento de microfiltración y la calidad del agua obtenida se ha determinado el parámetro denominado SDI "Silt Density Index" (ver apartado 3.5.3.4 Determinación del índice de "ensuciamiento" de las membranas (SDI)) y se ha medido la turbidez.

\section{Membranas cerámicas KLEANSEPTM 300 kD}

Los resultados obtenidos en la optimización de la membrana de microfiltración KLEANSEP ${ }^{\text {TM }} 300$ kD se pueden observar en la Figura 4.34 en la que se representa la permeabilidad frente al tiempo de filtración, donde se ve claramente la variación de esta propiedad durante el trascurso de la filtración. También se expresan los cambios de FCV que se han realizado durante el ensayo.

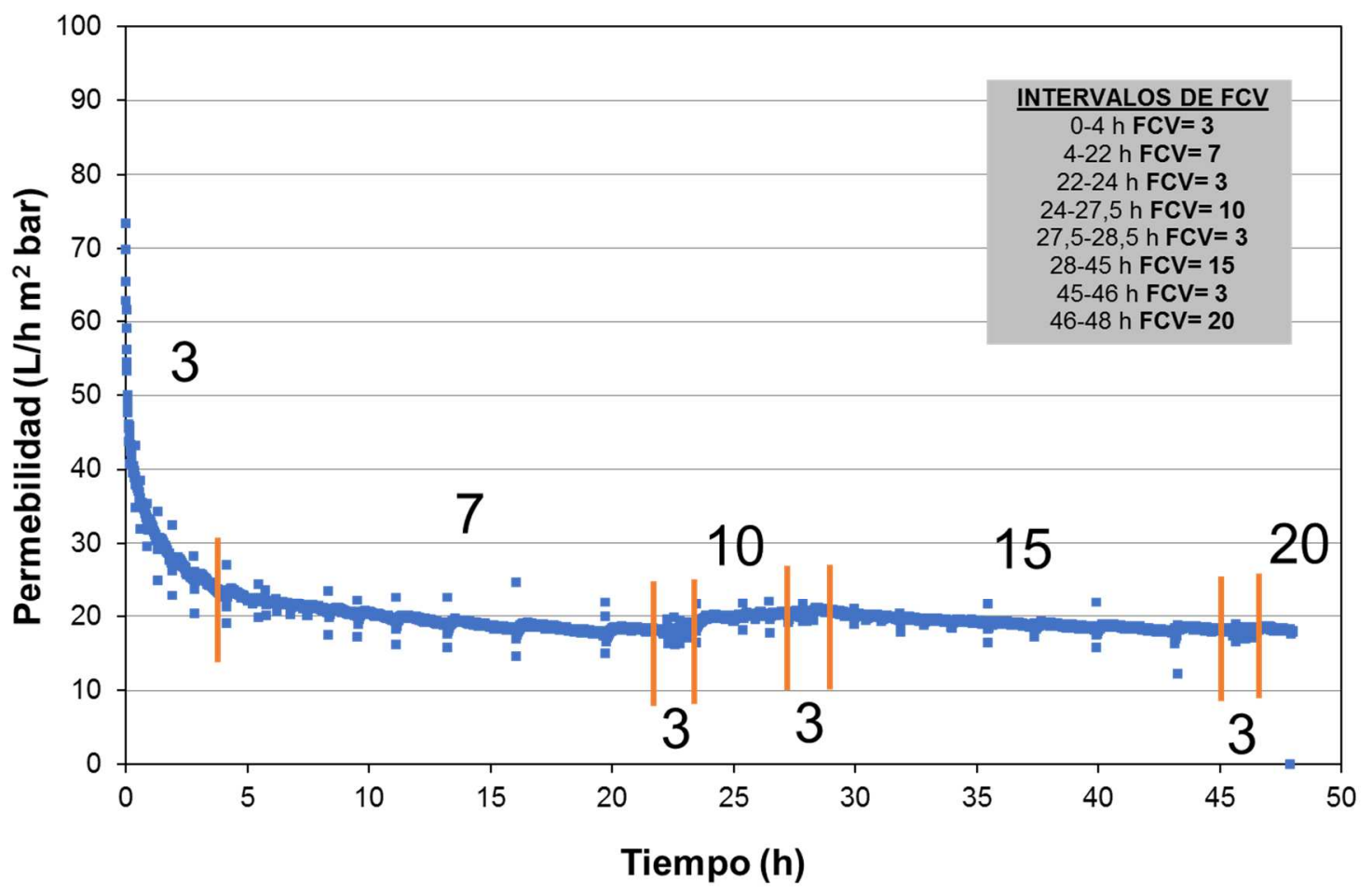

Figura 4.34. Permeabilidad de las membranas cerámicas KLEANSEPTM 300 kD e influencia del FCV.

Los cambios de permeabilidad con el tiempo son considerables hasta llegar a la meseta constante que varía entre los 18-20 L/h $\mathrm{m}^{2}$ bar. En este tramo constante se puede observar que los cambios de FCV no tienen una influencia muy marcada en la permeabilidad.

Esta curva es típica del acondicionamiento de las membranas de microfiltración, ya que al principio sufren una caída drástica de la permeabilidad por la acumulación de partículas en la superficie de la membrana que forman una torta. Esta torta es la responsable de esta caída tan importante de la 
permeabilidad [43]. Cuando esa torta se estabiliza, se llega a una meseta donde la permeabilidad permanece constante con una ligera tendencia decreciente por el progresivo ensuciamiento de la membrana hasta que la presión transmembrana supera un límite prefijado, momento en el que se tiene que proceder a realizar una limpieza de la membrana.

En la Tabla 4.12 se ha recopilado los resultados de caudal de permeado y permeabilidad obtenidos a presión contante y FCV variable. Esta tabla confirma que la variación en la frecuencia de desconcentración del bucle de la microfiltración asociada al intervalo de FCV que va desde 3 a 20 no afecta de una manera notable a la permeabilidad de la membrana, ya que cuando se ha alcanzado la meseta, la permeabilidad permanece constante en $18 \mathrm{~L} / \mathrm{h} \mathrm{m}^{2}$ bar.

Tabla 4.12. FCV y parámetros de control para la membrana KLEANSEPTM 300 kD

\begin{tabular}{|c|c|c|c|}
\hline $\begin{array}{c}\text { Presión } \\
\text { (bar) }\end{array}$ & $\begin{array}{c}\text { Caudal de permeado } \\
(\mathrm{L} / \mathrm{h})\end{array}$ & $\begin{array}{c}\text { Permeabilidad } \\
\left(\mathrm{L} / \mathrm{h}^{2} \text { bar }\right)\end{array}$ & FCV \\
\hline \multirow{10}{*}{} & 158 & 32 & 3 \\
\cline { 2 - 4 } & 100 & 20 & 3 \\
\cline { 2 - 4 } & 99 & 19 & 10 \\
\cline { 2 - 4 } & 116 & 20 & 3 \\
\cline { 2 - 4 } & 116 & 19 & 3 \\
\cline { 2 - 4 } & 93 & 18 & 20 \\
\cline { 2 - 4 } & 96 & 18 & 10 \\
\hline
\end{tabular}

\section{Membranas cerámicas KLEANSEP ${ }^{\mathrm{TM}} 0,1 \mu \mathrm{m}$}

Tras los ensayos realizados con las membranas KLEANSEPTM 300 kD se cambia el cárter por el de las membranas KLEANSEPTM $0,1 \mu \mathrm{m}$. Al igual que en el caso anterior, se ha calculado la permeabilidad que ofrecen estas membranas para esta agua en concreto y además se ha estudiado si los cambios en el FCV tienen algún efecto sobre la permeabilidad.

En la Figura 4.35 se representa la permeabilidad frente al tiempo de filtración. En esta ocasión, se representa los datos una vez la permeabilidad ya es constante y ha alcanzado la meseta, que es cuando se realizarán las variaciones de FCV para analizar si existe alguna relación entre los dos parámetros con este tipo de aguas. La permeabilidad alcanza la meseta en torno a los 21 $\mathrm{L} / \mathrm{h} \mathrm{m}^{2}$ bar. En la gráfica, también se expresan los cambios de FCV que se han realizado durante el ensayo. Con el fin de simplificar el número de ensayos a diferentes FCV y visto que a frecuencias 
elevadas de desconcentración del bucle no se obtienen mejores permeabilidades, el intervalo de FCV que se ha estudiado con estas membranas ha sido de 2 a 10.

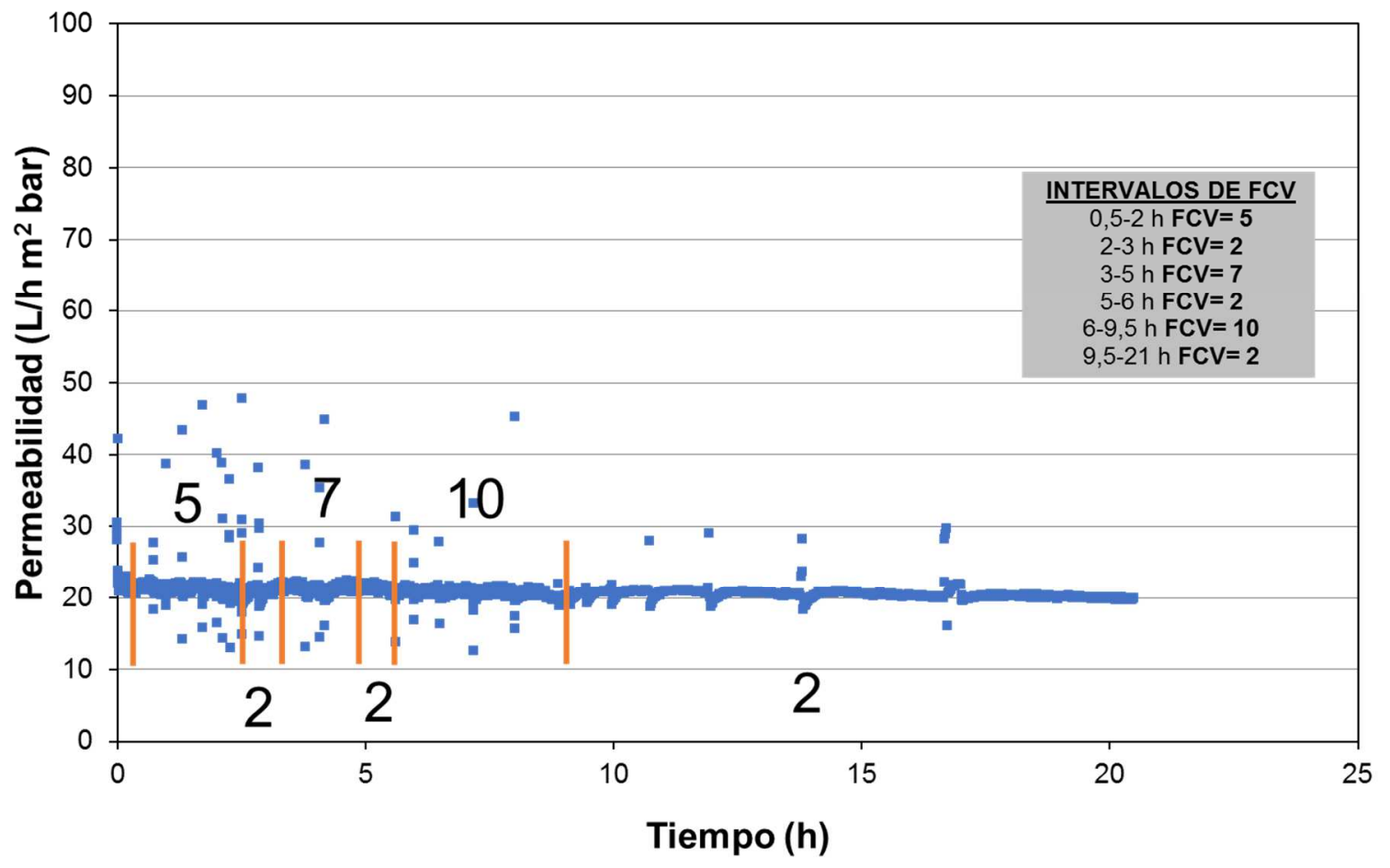

Figura 4.35. Permeabilidad de las membranas cerámicas KLEANSEP ${ }^{T M} 0,1 \mu m$ e influencia del FCV.

En este caso, también se puede observar en la gráfica que los cambios de FCV entre 2 y 10, al igual que pasaba con las membranas KLEANSEP ${ }^{\mathrm{TM}} 300 \mathrm{kD}$, tampoco tienen una influencia muy marcada en la permeabilidad.

En la Tabla 4.13 y a modo de recopilación de datos se recogen los resultados obtenidos de caudal de permeado y permeabilidad para una presión constate de 2,5 bar a distintos FCV:

Tabla 4.13. FCV y parámetros de control para las membranas KLEANSEPTM $0,1 \mu \mathrm{m}$.

\begin{tabular}{|c|c|c|c|}
\hline $\begin{array}{c}\text { Presión } \\
\text { (bar) }\end{array}$ & $\begin{array}{c}\text { Caudal de permeado } \\
(\mathrm{L} / \mathrm{h})\end{array}$ & $\begin{array}{c}\text { Permeabilidad } \\
\left(\mathrm{L} / \mathrm{h}^{2} \text { bar }\right)\end{array}$ & FCV \\
\hline \multirow{6}{*}{2,5} & 80 & 22 & 5 \\
\cline { 2 - 4 } & 80 & 21 & 2 \\
\cline { 2 - 4 } & 84 & 21 & 2 \\
\cline { 2 - 4 } & 80 & 21 & 10 \\
\cline { 2 - 4 } & 85 & 21 & 2 \\
\hline
\end{tabular}


Los datos recogidos en la Tabla 4.13 confirman lo observado en la gráfica representada en la Figura 4.35 y no se detecta ninguna variación importante de la permeabilidad durante el trascurso de la filtración con las variaciones del FCV.

Por tanto, de estos datos se desprende que lo importante es que exista una desconcentración del bucle de microfiltración que evite la colmatación de las membranas, sin embargo, parece que la frecuencia con que se vaya a hacer, siempre que esté dentro de la frecuencia establecida por el intervalo 2 - 20 de FCV, no tiene demasiada importancia. Por tanto, en estos casos industriales se ha trabajado con un FCV igual a 10.

Una vez compilados los resultados obtenidos con los dos tipos de membrana, se puede analizar cuál de ellas es la más adecuada para el uso concreto que se le quiere dar en este caso de estudio. Por consiguiente, si se tiene en cuanta la permeabilidad de las membranas obtenida con esta agua residual se puede observar que son muy próximas en los dos casos. Cuando esta propiedad alcanza la meseta, y por tanto es constante, se obtiene una permeabilidad en torno a los $18 \mathrm{~L} / \mathrm{h} \mathrm{m}^{2}$ bar (a $25^{\circ} \mathrm{C}$ ) para las membranas KLEANSEP ${ }^{T M} 300 \mathrm{kD}$, mientras que para las membranas KLEANSEP ${ }^{\mathrm{TM}}$ $0,1 \mu \mathrm{m}$ la permeabilidad es un poco superior y se encuentra en torno a los $21 \mathrm{~L} / \mathrm{h} \mathrm{m}^{2}$ bar $\left(\mathrm{a} 25^{\circ} \mathrm{C}\right)$. Al estar tan próximas las permeabilidades es necesario considerar otros parámetros para determinar cuál es la mejor membrana para el tratamiento que se propone. Estos parámetros serán el SDI y la turbidez del agua después del pretratamiento de microfiltración [170][171]. Los ensayos a este respecto se recopilarán en el siguiente apartado.

\section{SDI “Silt Density Index" de las aguas microfiltradas}

Para determinar que membrana de microfiltración es la más efectiva y por tanto la que se utilizaría en las pruebas industriales con la planta piloto se determinó el SDI (ver el apartado 3.5.3.4 Determinación del índice de "ensuciamiento" de las membranas (SDI)) y también la turbidez del agua después del pretratamiento de microfiltración. En la Tabla 4.14 se muestran los resultados obtenidos en los ensayos para la determinación del SDI y de la turbidez, tanto del agua de balsa, como del agua microfiltrada.

Tabla 4.14. Evaluación de la capacidad de ensuciamiento del agua de la empresa mediante ensayo SDI y turbidez del agua, antes y después del pretratamiento.

\begin{tabular}{|c|c|c|c|}
\hline Muestra & $\mathrm{SDI}_{15}$ & $\mathrm{~T}^{\mathrm{a}}\left({ }^{\circ} \mathrm{C}\right)$ & Turbidez (NTU) \\
\hline \multirow{2}{*}{ Agua de balsa } & 6,2 & 18,4 & 64 \\
\cline { 2 - 4 } & $>6,0$ & 18 & 53 \\
\hline \multirow{2}{*}{ Agua MF KLEANSEP } & & - \\
\hline Agua MF KLEANSEP $300 \mathrm{kD}$ & $3,5 / / 1,7$ & 18,6 & 1 \\
\cline { 2 - 4 } & $4,6 / / 2,0$ & $22,7 / / 22,5$ & $<1$ \\
\hline
\end{tabular}




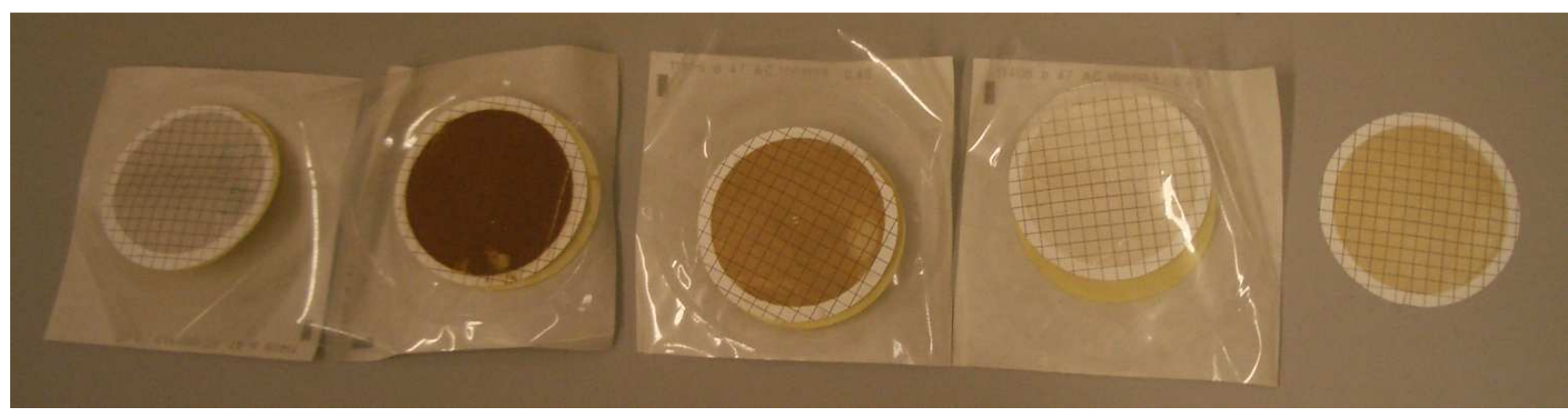

Figura 4.36. Filtros después de la prueba del SDI.

A la vista de los resultados obtenidos, se puede observar que la turbidez del agua de balsa de la empresa, que oscila entre 53 y 64 NTU, desciende considerablemente después del tratamiento de microfiltración, situándose este en torno a 1 NTU.

Por consiguiente, la microfiltración ha sido capaz de eliminar gran parte de las partículas causantes de la turbidez del agua de balsa. En la imagen recogida en la Figura 4.37, puede verse los dos tanques de la planta piloto. En el tanque de la izquierda se recibe el agua de balsa procedente de la balsa que almacena el agua después del tratamiento físico-químico, por tanto el agua que se aprecia en la imagen es el agua antes de la microfiltración. Mientras que en el tanque de la derecha, se almacena el agua ya pretratada por el tratamiento de microfiltración. Esta agua será la que se alimentará al tratamiento de nanofiltración para la eliminación del boro. Como puede observarse en la imagen, la eliminación de sólidos en suspensión y por tanto la reducción de la turbidez tras el pretratamiento de microfiltración son muy efectivos.

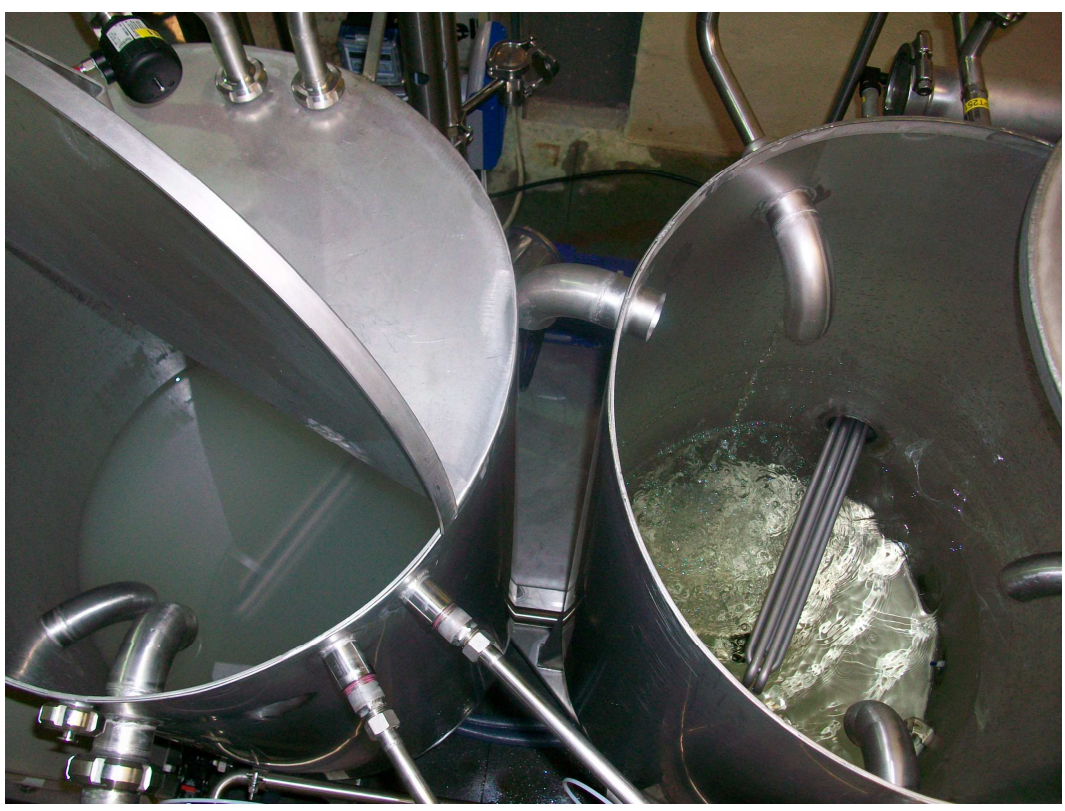

Figura 4.37. Tanque de la planta piloto donde se recoge el agua antes y después de la microfiltración.

En cuanto al SDI, se puede observar que con las membranas de microfiltración KLEANSEPTM 300 kD este parámetro es menor que el SDI obtenido con las membranas KLEANSEP ${ }^{\mathrm{TM}} 0,1 \mu \mathrm{m}$. Al tener el diámetro de poro más pequeño, esta membrana logrará una mejor retención de las partículas que provocan el ensuciamiento de las membranas. Ambas membranas logran obtener 
una corriente de agua con un SDI menor de 5, característica que es recomendable que cumplan las aguas que van a ser sometidas a un tratamiento de nanofiltración [172] (ver también Anexo III), ya que a SDI superiores pueden aparecer problemas de "fouling" en dichas membranas. Sin embargo, el SDI obtenido con la membrana KLEANSEP ${ }^{\mathrm{TM}} 0,1 \mu \mathrm{m}(\mathrm{SDI}=4,8)$ está muy próximo a este límite.

Por tanto, después de analizar los resultados de permeabilidad, turbidez y SDI obtenidos con las membranas KLEANSEP ${ }^{\mathrm{TM}} 300 \mathrm{kD}$ y KLEANSEP ${ }^{\mathrm{TM}} 0,1 \mu \mathrm{m}$ se eligió la primera de ellas. Sobre todo, porque a permeabilidades y turbidez del agua tratada similares, los SDI del agua microfiltrada obtenida con la membrana KLEANSEPTM 300 kD son más pequeños, ya que incluso se pueden encontrar valores de SDI $<3$.

\subsubsection{Optimización del tratamiento de nanofiltración a escala piloto}

Tras la optimización del pretratamiento de microfiltración se ha realizado los ensayos de nanofiltración en discontinuo para optimizar dicho tratamiento. Por tanto, estos ensayos se realizaron con la membrana NF-90, trabajando a varias presiones $(4,5,7,10$ y 15 bar) y modificando el $\mathrm{pH}(9,5$ y 11$)$.

Con estas pruebas se pretende optimizar las condiciones de trabajo para realizar las pruebas de producción industrial de nanofiltración en continuo con las aguas de la empresa en sus propias instalaciones.

A continuación, se muestran los resultados de los ensayos realizados a diferentes presiones y con varios $\mathrm{pH}$. En primer lugar, se ha abordado el ensayo realizado en condiciones reales sin modificación del $\mathrm{pH}$, que ha sido exactamente de 9,5. Mientras que en segundo lugar, se han recogido los resultados del ensayo en el que se ha ajustado el pH a 11 mediante la adición de hidróxido sódico al $25 \%$ en la cuba de alimentación de la nanofiltración.

Se tomaron muestras de agua de alimentación, de permeado (a las distintas presiones de trabajo) y de rechazo para analizarlas, de este modo controlar la eficiencia del tratamiento.

En la Tabla 4.15 se muestran los resultados obtenidos en el ensayo en el que no se ha modificado el $\mathrm{pH}$ del agua residual. En esta tabla se recogen los análisis obtenidos para el boro, cloruros, sulfatos, sodio y calcio, además del rendimiento obtenido para las presiones de: 4, 5, 7,10 y 15 bar respectivamente. 
Tabla 4.15. Ensayos a diferentes presiones con la membrana NF-90 y agua de balsa a pH 9,5.

\begin{tabular}{|c|c|c|c|c|c|c|c|c|c|c|c|}
\hline \multirow{2}{*}{$\begin{array}{l}\text { Parámetros } \\
\text { Medidos }\end{array}$} & \multirow{2}{*}{$\begin{array}{l}\text { Agua } \\
\text { Inicial } \\
\text { Valor }\end{array}$} & \multicolumn{2}{|c|}{$\begin{array}{l}\text { NF90 } \\
4 \text { bar }\end{array}$} & \multicolumn{2}{|c|}{$\begin{array}{l}\text { NF90 } \\
5 \text { bar }\end{array}$} & \multicolumn{2}{|c|}{$\begin{array}{l}\text { NF90 } \\
7 \text { bar }\end{array}$} & \multicolumn{2}{|c|}{$\begin{array}{l}\text { NF90 } \\
10 \text { bar }\end{array}$} & \multicolumn{2}{|c|}{$\begin{array}{l}\text { NF90 } \\
15 \text { bar }\end{array}$} \\
\hline & & Valor & $\mathbf{R}(\%)$ & Valor & $\mathbf{R}(\%)$ & Valor & $\mathrm{R}(\%)$ & Valor & $\mathbf{R}(\%)$ & Valor & $\mathbf{R}(\%)$ \\
\hline $\mathrm{pH}$ & 9,4 & 9,7 & & 9,7 & & 9,6 & & 9,4 & & 9,2 & \\
\hline$B(m g / L)$ & 14 & 8 & 43 & 7 & 50 & 5,7 & 59 & 4,8 & 66 & 4,2 & 70 \\
\hline $\mathrm{Ca}^{2+}(\mathrm{mg} / \mathrm{L})$ & 69 & 0,6 & 99 & - & - & 0,5 & 99 & - & - & 1,3 & 98 \\
\hline $\mathrm{SO}_{4}{ }^{2-}(\mathrm{mg} / \mathrm{L})$ & 282 & 6,6 & 98 & - & - & 5 & 98 & - & - & 0,6 & 99 \\
\hline $\mathrm{Cl}^{-}(\mathrm{mg} / \mathrm{L})$ & 1025 & 32 & 97 & - & - & 5,7 & 99 & - & - & 4,2 & 99 \\
\hline $\mathrm{Na}^{+}(\mathrm{mg} / \mathrm{L})$ & 834 & 24 & 97 & - & - & 13 & 98 & - & - & 8 & 99 \\
\hline
\end{tabular}

Por otro lado, en la Figura 4.38 se puede observar la representación de las retenciones obtenidas para todos los parámetros analizados frente a la presión aplicada durante el tratamiento.

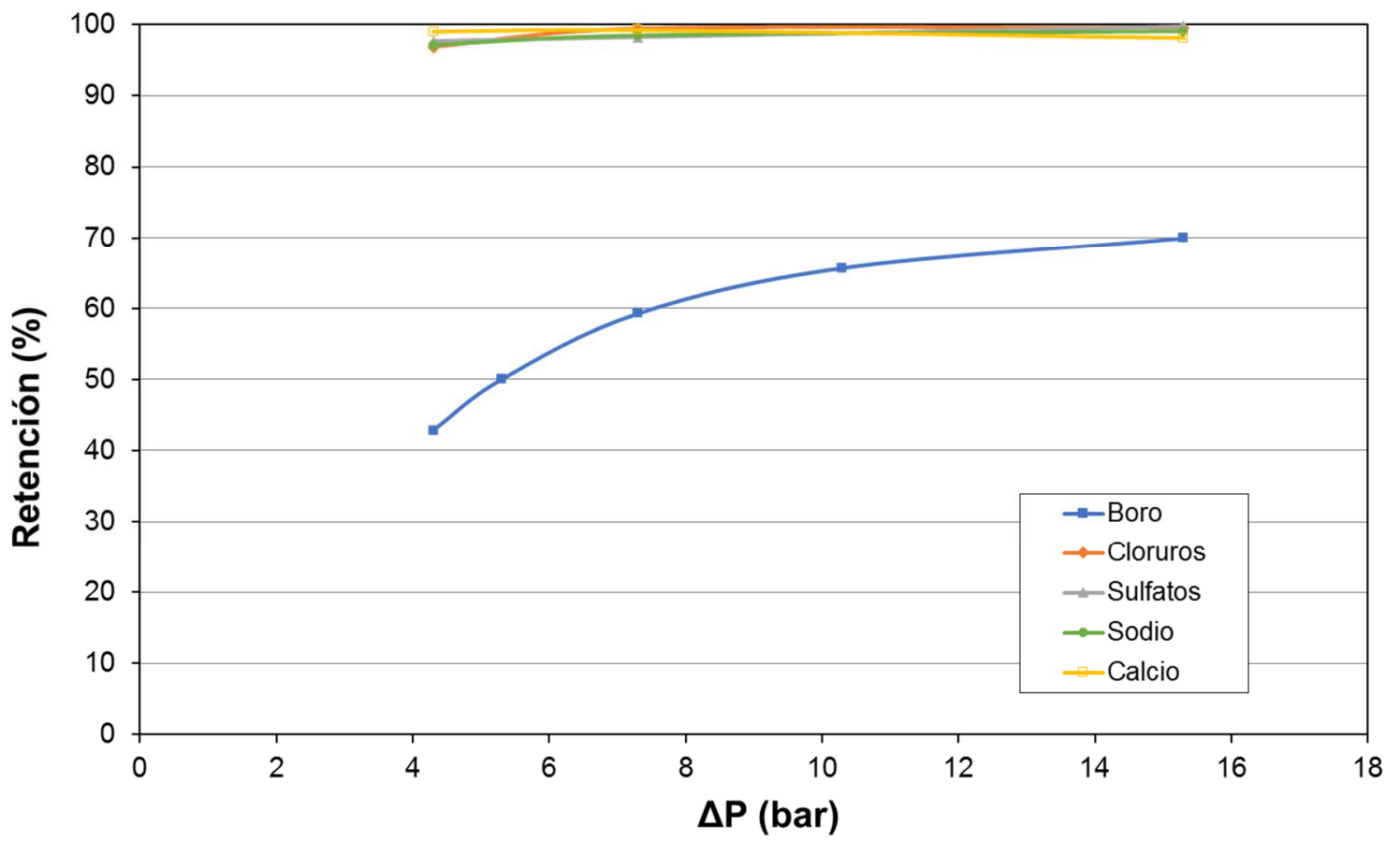

Figura 4.38. Representación de las retenciones obtenidas en función de la presión ensayada a pH 9,5.

En cuanto a la retención del boro, estos resultados concuerdan perfectamente con los obtenidos en los ensayos con aguas sintéticas, membranas planas y condiciones de trabajo similares (ver Figura 4.20 y Tabla 4.6), y siendo del mismo orden si se comparan con los que se han obtenido con las membranas en espiral y agua sintética (ver Figura 4.24 y Tabla 4.9). Además, los resultados de 
retención de los otros iones analizados concuerdan perfectamente con los resultados obtenidos durante la caracterización de las membranas cuando se realizaron los ensayos de retención a diferentes sales (ver Figura 4.11 y Figura 4.12).

Sin embargo, como era de esperar, si no existe una modificación del $\mathrm{pH}$ y se aumenta hasta alrededor de 11, los resultados de retención del boro no van a ser los esperados, ya que como máximo se alcanzan retenciones en torno al $70 \%$ y a presiones de trabajo muy elevadas (15 bar), sin poder bajar la concentración de boro por debajo de $3 \mathrm{mg} / \mathrm{L}$.

Por tanto, para aumentar la retención de este elemento se incrementó el pH hasta alrededor de 11 mediante la adición de $\mathrm{NaOH}$.

Tal y como se muestra en la Tabla 4.16 y en la Figura 4.39, la retención del boro, aunque ligeramente inferior, es del mismo orden que las retenciones obtenidas anteriormente con aguas sintéticas y membranas planas (ver Figura 4.20 y Tabla 4.6), así como las obtenidas con membranas en espiral con aguas sintéticas y aguas reales (ver Figura 4.24 y Tabla 4.9). Sin embargo, también se puede apreciar en la Tabla 4.16 y en la Figura 4.39, que una vez ajustado el $\mathrm{pH}$ a 11, a presión de 5,3 bar, el boro en el permeado ya se encuentra en 2,8 mg/L (sombreado en verde sobre la Tabla 4.16). Sabiendo que la concentración de este elemento debe ser inferior a 3 $\mathrm{mg} / \mathrm{L}$ para poder verter al alcantarillado (ver Tabla 1.2), ya se dispone de información de la presión que se tiene que utilizar en las pruebas en continuo. Por tanto, se eligió una presión de trabajo para realizar las pruebas en continuo de 6 bar, de esta forma se podría asegurar dicho límite de vertido.

Tabla 4.16. Ensayos a diferentes presiones con la membrana NF-90 y agua de balsa, aprox. pH 11.

\begin{tabular}{|c|c|c|c|}
\hline $\begin{array}{c}\text { Presión } \\
\text { (bar) }\end{array}$ & pH & $\begin{array}{c}\mathbf{B} \\
(\mathbf{m g} / \mathrm{L})\end{array}$ & $\begin{array}{c}\mathbf{R} \\
(\%)\end{array}$ \\
\hline N.A (Inicial) & 11 & 12,0 & --- \\
\hline 4,4 & 11 & 3,4 & 71,7 \\
\hline 5,3 & 11 & 2,8 & 76,7 \\
\hline 7,4 & 10,9 & 2,2 & 81,7 \\
\hline 10,3 & 10,8 & 1,9 & 84,2 \\
\hline 15,3 & 10,6 & 1,8 & 85,0 \\
\hline
\end{tabular}




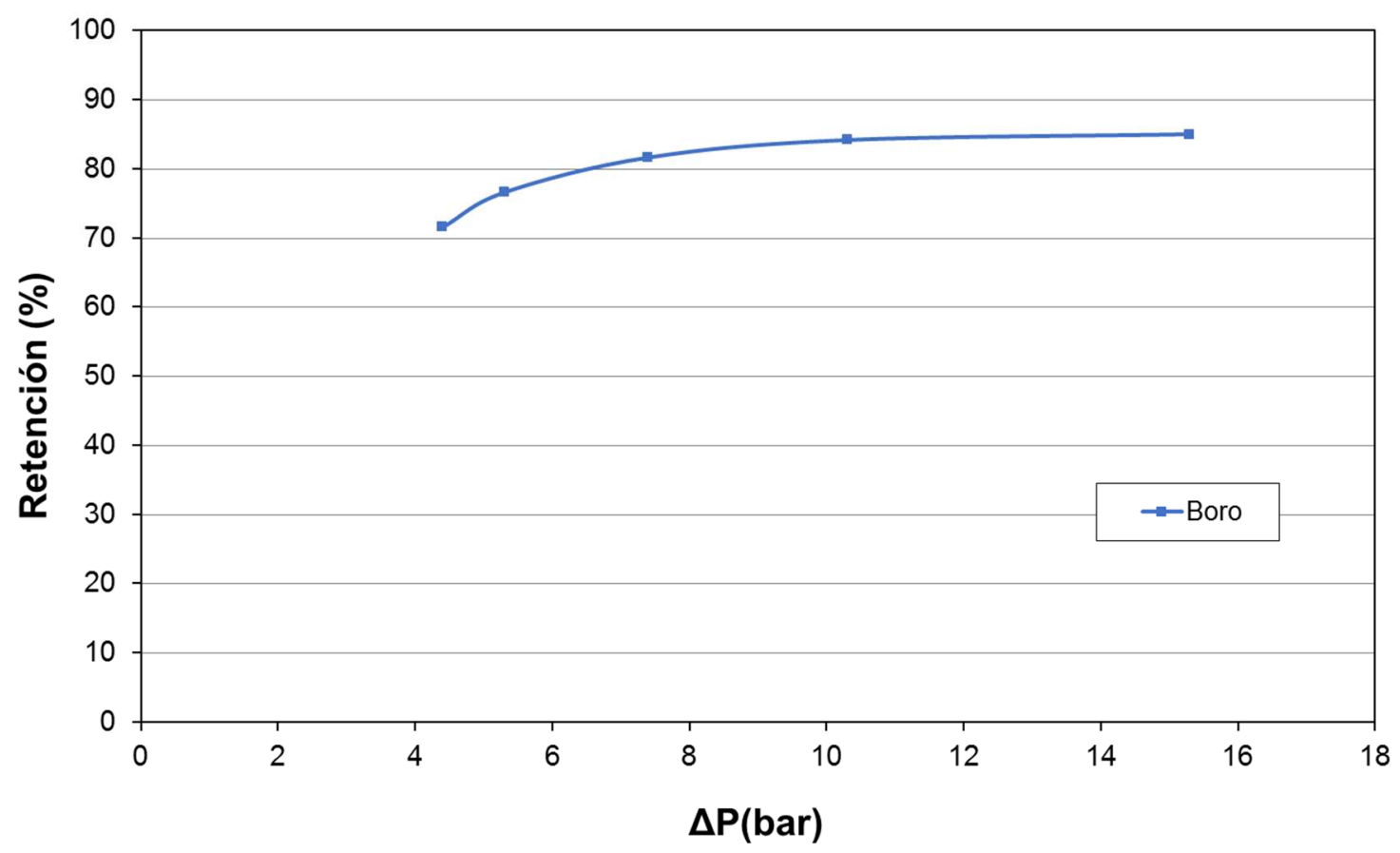

Figura 4.39. Representación de la retención del boro obtenida en función de la presión ensayada a pH 11.

\subsubsection{Ensayos en continuo con el pretratamiento y la nanofiltración en serie.}

Tras la realización de las pruebas en discontinuo para establecer las condiciones de trabajo más apropiadas, tanto para el pretratamiento de microfiltración, como el propio proceso de nanofiltración, se abordaron las pruebas de producción en continuo. En las pruebas en continuo se tiene que trabajar con la etapa de pretratamiento de microfiltración ( 7 membranas cerámicas KLEANSEPTM $300 \mathrm{kD}$ ) y el tratamiento propiamente dicho de nanofiltración (1 membrana polimérica NF-90 en espiral tipo 2540) en serie, tal y como se había descrito en el diagrama de flujo de la Figura 4.31. Es importante que el pretratamiento suministre a la nanofiltración toda el agua necesaria para que el tratamiento en continuo se lleve a cabo.

Para la realización de las pruebas en continuo se tiene que dejar en funcionamiento (en circuito cerrado) la parte de microfiltración varias horas (más de 12 h) antes de la puesta en marcha de la etapa de nanofiltración. De este modo, se puede asegurar un caudal constante del pretratamiento de microfiltración, ya que en las primeras horas de funcionamiento el caudal de la microfiltración sufre variaciones hasta que se estabiliza. Tras esa estabilización de las membranas de microfiltración es cuando se comienza la prueba en continuo, es decir, cuando entra en funcionamiento la parte de nanofiltración.

A continuación, en la Figura 4.40 se muestra un gráfico donde se representa la permeabilidad de las membranas de microfiltración en función del tiempo durante la estabilización de la membrana antes de comenzar con la prueba en continuo propiamente dicha. Como se puede observar, se obtiene una curva característica de un tratamiento de microfiltración igual a la obtenida en el apartado 4.2.3.1 Optimización del pretratamiento de microfiltración a escala piloto. La permeabilidad de la membrana en la meseta una vez estabilizada coincide con la obtenida en la optimización de 
este pretratamiento (en torno a los $20 \mathrm{~L} / \mathrm{h} \mathrm{m}^{2}$ bar, ver círculo naranja en la Figura 4.40 y Figura 4.34).

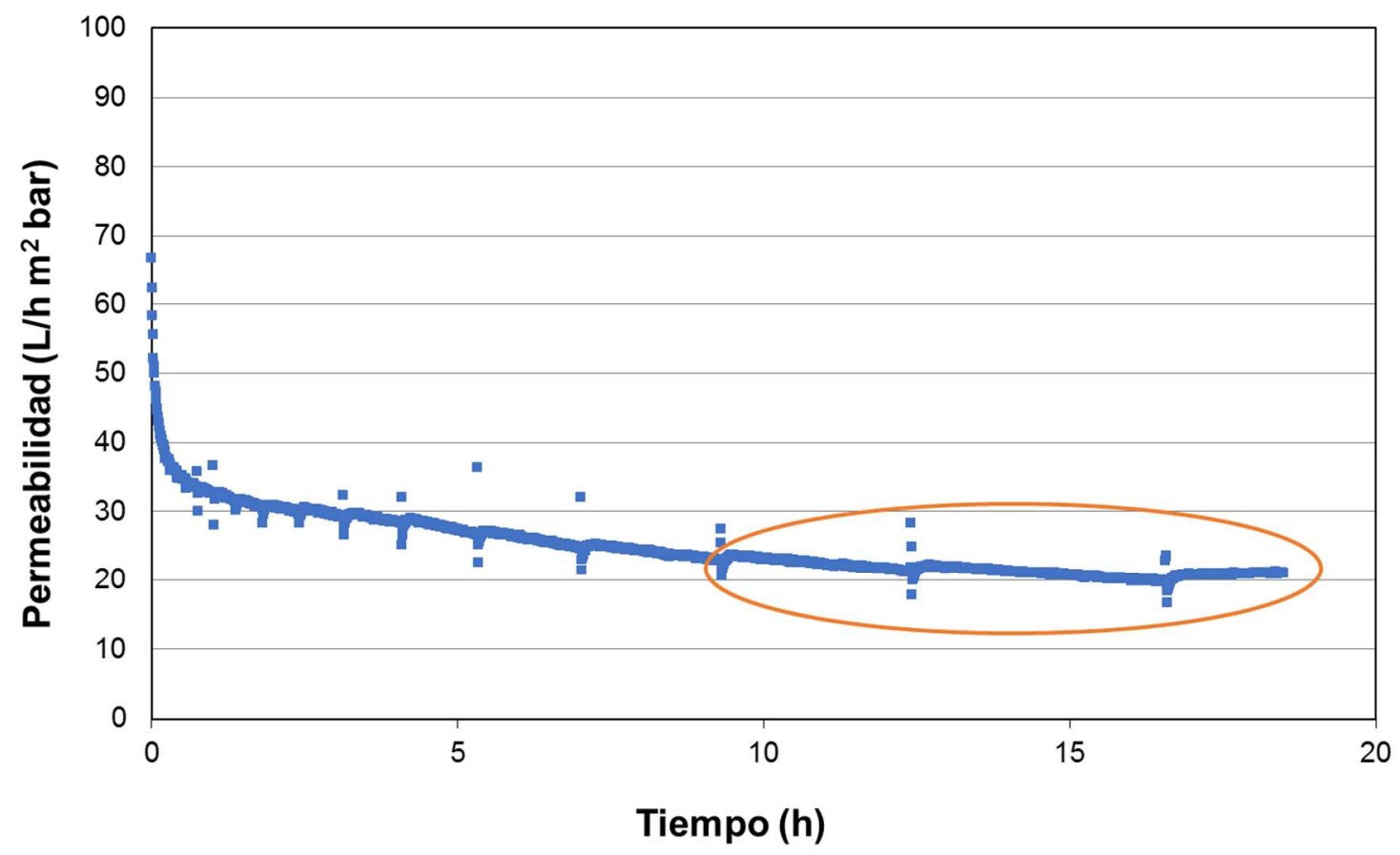

Figura 4.40. Estabilización de las membranas KLEANSEPTM $300 \mathrm{kD}$ previa a la prueba en continuo.

Como se observa en el gráfico anterior, la tendencia de la permeabilidad de las membranas es a disminuir, pues las membranas se van obturando con el paso del tiempo debido a la cantidad de sólidos que contiene el agua a tratar, pues a mayor cantidad de sólidos la obturación de las membranas será más rápida con el paso del tiempo.

En el gráfico también es posible observar el periodo en que las membranas cerámicas y su permeabilidad son estables, este es el momento óptimo para comenzar la prueba en continuo, es decir, en este momento se ha de llenar de agua microfiltrada la cuba que alimenta a la etapa de nanofiltración para iniciar la prueba de producción en continuo de agua nanofiltrada. 
A continuación, en la Tabla 4.17 se muestran las condiciones de trabajo de una de las pruebas en continuo:

Tabla 4.17. Condiciones de trabajo para una de las pruebas en continuo.

\begin{tabular}{|c|c|}
\hline \multicolumn{2}{|c|}{ Parámetros MF } \\
\hline Membranas & KLEANSEP ${ }^{T M} 300 \mathrm{kD}$ \\
\hline № de membranas & 7 \\
\hline Área de filtración & $7 \times 0,52 \mathrm{~m}^{2}=3,64 \mathrm{~m}^{2}$ \\
\hline Presión aplicada & 3 bar \\
\hline Conductividad alimentación & $7000 \mu \mathrm{S} / \mathrm{cm}$ \\
\hline Caudal de agua microfiltrada & $225 \mathrm{~L} / \mathrm{h}$ \\
\hline \multicolumn{2}{|c|}{ Parámetros NF } \\
\hline Membrana & NF-90 \\
\hline Presión & 6,4 bar \\
\hline № de membranas & 1 \\
\hline Área de filtración & $2,6 \mathrm{~m}^{2}$ \\
\hline Conductividad alimentación // permeado & $7000 \mu \mathrm{S} / \mathrm{cm} / / 880 \mu \mathrm{S} / \mathrm{cm}$ \\
\hline $\mathrm{pH}$ & 11,3 \\
\hline Caudal alimentación & $225 \mathrm{~L} / \mathrm{h}$ \\
\hline Caudal de permeado & $33 \mathrm{~L} / \mathrm{h}$ \\
\hline Conversión & $15 \%$ \\
\hline
\end{tabular}

Nota: Los valores son medias de los resultados obtenidos en los ensayos en continuo.

En la gráfica representada en la Figura 4.41 se pueden observar la producción obtenida en una de las pruebas en continuo para la etapa de nanofiltración. 


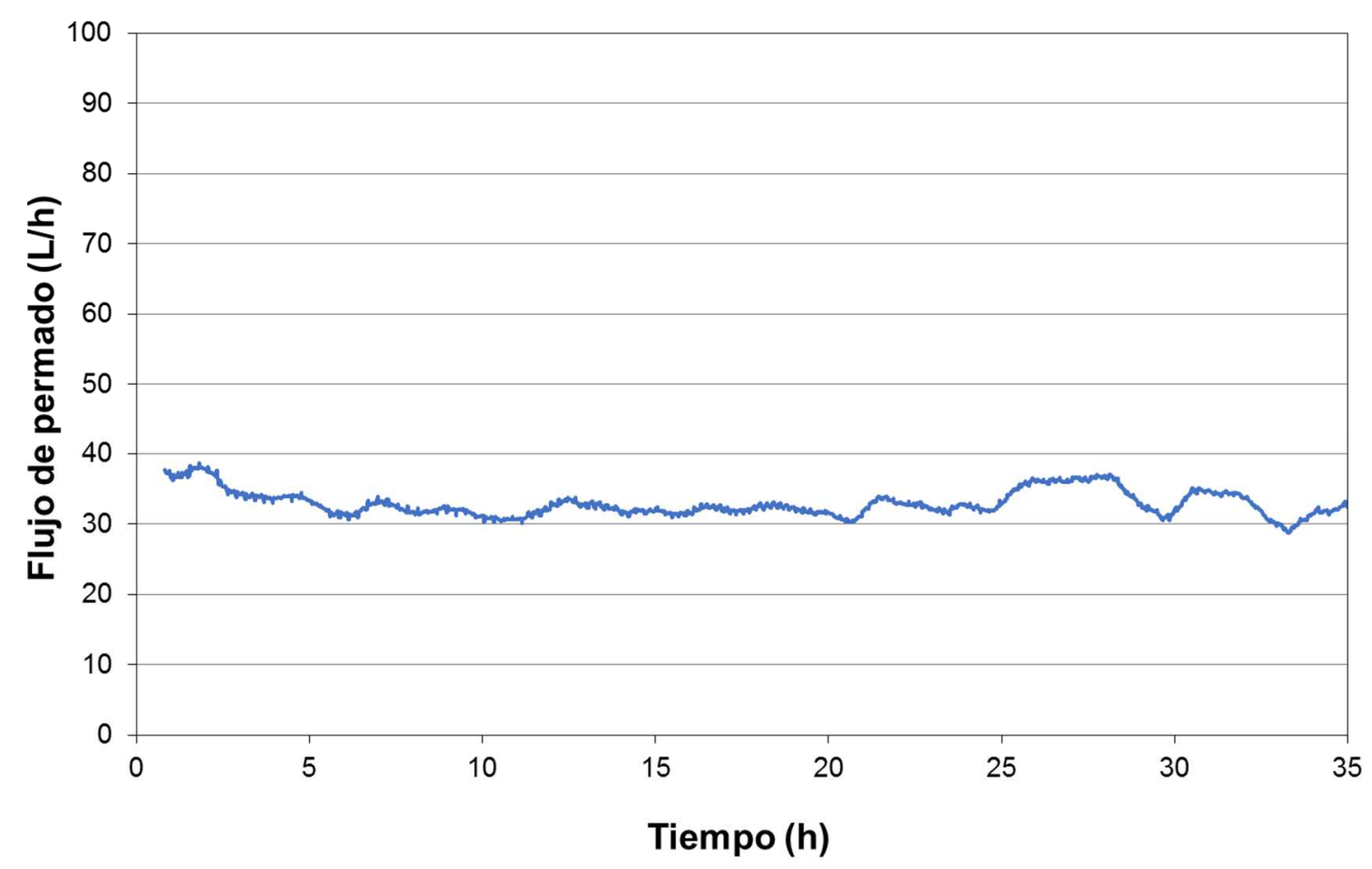

Figura 4.41. Representación gráfica de los datos de producción frente al tiempo de la etapa de NF.

Durante una de las pruebas en continuo se llenaron varios bidones de $50 \mathrm{~L}$ de agua nanofiltrada 0 permeado, para poder realizar pruebas de viabilidad de reutilización del agua en el propio proceso productivo a escala industrial. Además, se toman muestras de $0,5 \mathrm{~L}$, de agua de balsa y de agua nanofiltrada, para de este modo analizar el boro y obtener el rendimiento del proceso.

A continuación, en la Tabla 4.18 se muestra un resumen con las concentraciones obtenidas de boro en las muestras recogidas, además del rendimiento obtenido.

Tabla 4.18. Resultados de boro y rendimiento de la filtración en continuo.

\begin{tabular}{|l|c|}
\hline Muestra & Boro (mg/L) \\
\hline Agua de balsa & 3 \\
\hline Agua filtrada & 3 \\
\hline Rendimiento de retención del boro \\
\hline \multicolumn{2}{|c|}{$84 \%$} \\
\hline
\end{tabular}

Se decidió realizar las pruebas en continuo para obtener agua nanofiltrada justo en el límite de vertido ( $3 \mathrm{mg} / \mathrm{L}$ ), ya que si el objetivo final fuese el vertido, siempre tendría que realizarse un tratamiento que cumpliese con este límite pero que estuviese cercano al mismo, con el objetivo de optimizar el coste del tratamiento, ya que como se ha visto en la Tabla 4.16, para aumentar la retención sería necesario aumentar la presión de trabajo. 
Además, una vez conseguido el objetivo de obtener un agua que cumpla los requisitos para poder ser vertida cumpliendo todos los límites establecidos en la legislación vigente [16], en este trabajo se ha querido estudiar la posibilidad de reutilización del agua tratada en el propio proceso productivo de la empresa donde se ha realizado el tratamiento. Por tanto y por este motivo, una vez obtenida el agua nanofiltrada que cumple con los límites de vertido (sin necesidad de ir a condiciones de calidad más exigentes, con el objetivo de no encarecer el tratamiento) se han realizado varias pruebas para analizar la viabilidad de su reutilización. Para ello, tal como se ha comentado con anterioridad, se han cogido muestras del agua nanofiltrada en el proceso en continuo y se han realizado las pruebas oportunas para determinar si estas aguas son aptas para la elaboración de esmaltes y engobes utilizados en la fabricación de baldosas cerámicas.

\subsubsection{Reutilización del agua nanofiltrada en la elaboración de esmaltes y engobes}

Después de haber conseguido reducir la concentración de boro de un agua industrial por medio de un tratamiento nunca utilizado en el sector cerámico como es el de la nanofiltración, y consiguiendo concentraciones de este elemento que hacen aptas dichas aguas para ser vertidas, se decidió analizar la viabilidad de su reutilización en el propio proceso productivo. Por tanto, con las aguas obtenidas después de la nanofiltración, se elaboraron diferentes engobes y esmaltes cerámicos. Para determinar si los esmaltes y engobes elaborados con las aguas nanofiltradas eran aptos o no, se compararon baldosas cerámicas en las que se aplicaron los esmaltes y engobes elaborados con las aguas tratadas y otras en las que se aplicaron los mismos esmaltes y engobes pero esta vez elaborados con las aguas de suministro (aguas limpias) que la empresa utiliza habitualmente para esos propósitos.

Inicialmente, se realizaron pruebas a nivel de laboratorio y se fabricaron cantidades no demasiado elevadas de estos esmaltes (2-3 litros) que se aplicaron sobre piezas pequeñas de laboratorio.

Por lo tanto, se realizaron pruebas con un esmalte aplicado por pulverización elaborado con agua residual tratada mediante nanofiltración y con el mismo esmalte pero elaborado con agua limpia de suministro. Las piezas elaboradas con ambos esmaltes eran perfectamente comparables y en ninguna de ellas se percibió ningún defecto superficial que indicase que las piezas decoradas con el esmalte elaborado con las aguas limpias de suministro fueran mejores que las piezas decoradas con el esmalte elaborado con las aguas residuales nanofiltradas.

Además del esmalte aplicado por pulverización, también se elaboró otro esmalte, concretamente el esmalte de referencia (STD) que la empresa en la que se realizó el tratamiento tiene. Se realizaron las mismas pruebas que en el caso del esmalte aplicado por pulverización, comparando probetas decoradas con esmaltes elaborados con aguas después del tratamiento de nanofiltración y con esmaltes elaborados con aguas limpias de suministro.

Algunas de estas probetas pueden observarse en las fotografías recogidas en la Figura 4.42. En cada una de las fotografías, las aplicaciones que están más a la izquierda son las que han sido realizadas con los esmaltes elaborados con las aguas residuales nanofiltradas, mientras las que están a la derecha son las que se han realizado con agua limpia de proceso. 

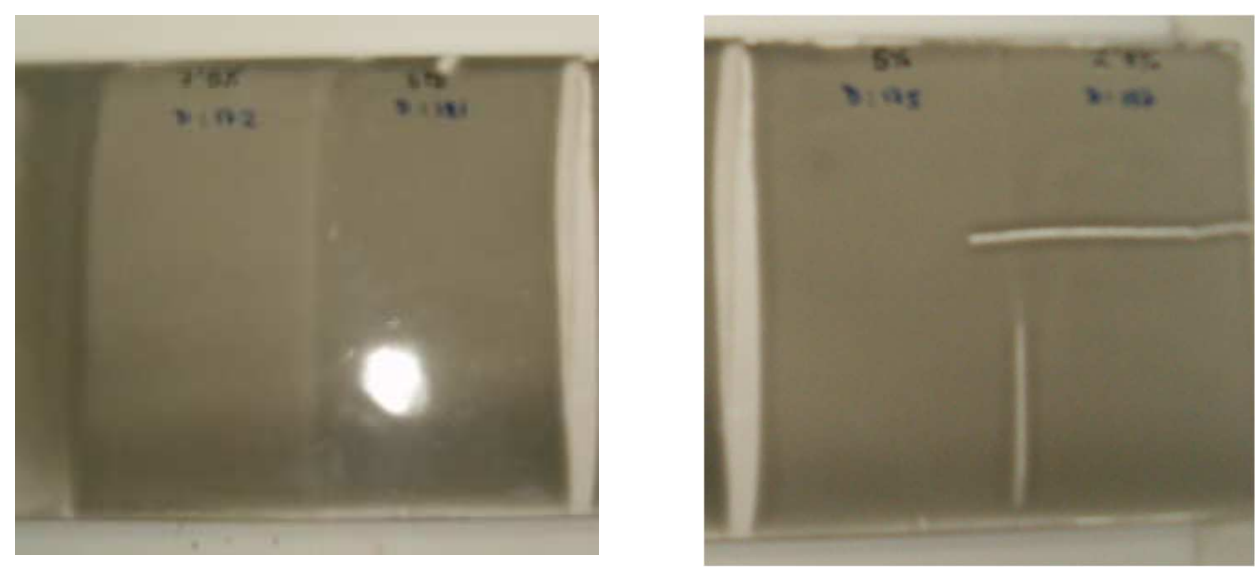

Figura 4.42. Piezas decoradas con el esmalte de referencia STD.

En todos los casos los resultados fueron totalmente comparables y no se detectó ningún defecto en las probetas decoradas con los esmaltes elaborados con las aguas residuales nanofiltradas.

Tras los buenos resultados obtenidos a escala de laboratorio, se decidió realizar una prueba a escala industrial, para lo cual se elaboraron 200 litros del engobe de referencia de la empresa donde se realizó el estudio. En este caso en concreto se utilizó 50\% de agua nanofiltrada y 50\% de agua limpia de suministro del total del agua necesaria para la elaboración del engobe. Además de analizar los resultados finales del engobe en las piezas cocidas, también se determinó la densidad del engobe y la cantidad del mismo aplicada a cada pieza $\left(1,85 \mathrm{~g} / \mathrm{cm}^{3}\right.$ y 10,5 g/pieza, respectivamente). Todos los controles fueron superados satisfactoriamente y en las piezas decoradas con los engobes elaborados con las aguas residuales nanofiltradas no apareció ningún defecto.
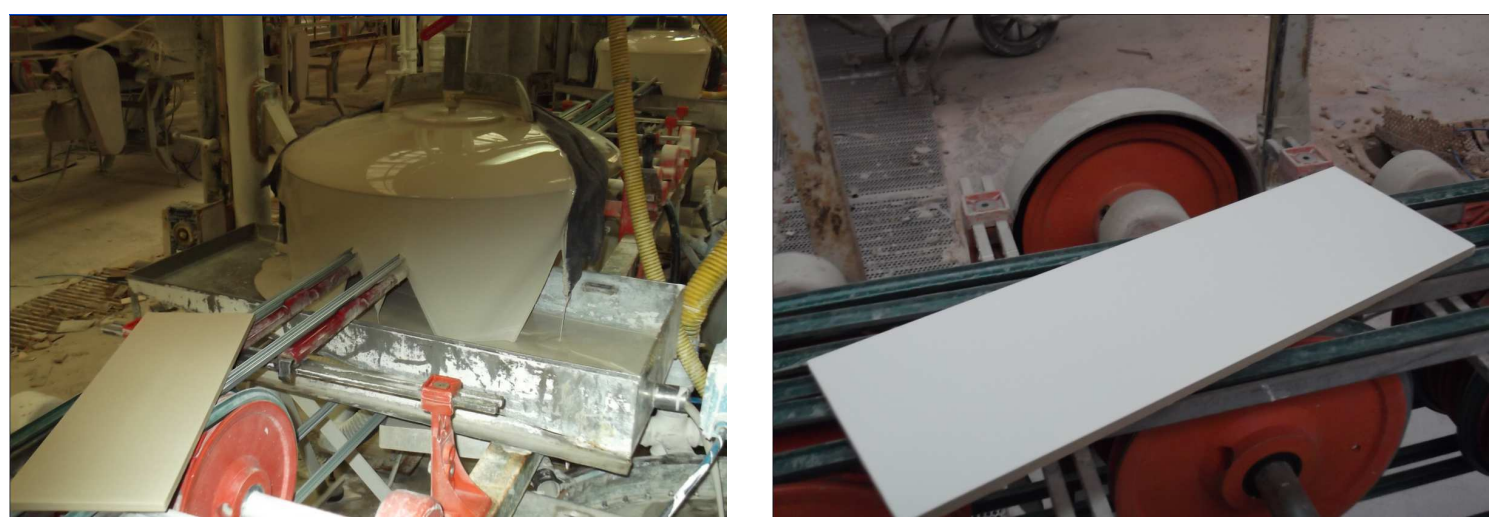

Figura 4.43. Proceso de aplicación del engobe elaborado con las aguas nanofiltradas.

Los resultados obtenidos han sido muy satisfactorios ya que las piezas decoradas con engobes y esmaltes elaborados con el agua nanofiltrada no presentan diferencias con las obtenidas con esmaltes elaborados con aguas de abastecimiento.

Por tanto, el agua tratada mediante nanofiltración, incluso pudiendo ser vertida al alcantarillado porque cumple con todos los límites establecidos por la legislación, podría ser reintroducida en el propio proceso productivo sin disminuir la calidad del producto final. Esto permitirá ahorrar en el 
consumo de agua limpia de suministro y retornar parte del gasto que supone un tratamiento de nanofiltración.

\subsubsection{Balance económico}

Si se compara el coste de un tratamiento comúnmente utilizado para la eliminación del boro como es la ósmosis inversa, con el coste asociado a los tratamientos de nanofiltración se puede observar que el coste de este último tratamiento puede ser prácticamente la mitad (ver Tabla 4.19), como consecuencia, en gran medida, de la mayor productividad que es posible alcanzar con las membranas de nanofiltración en comparación con las membranas de ósmosis inversa.

Tabla 4.19. Comparación entre los costes de un tratamiento de ósmosis inversa y uno de nanofiltración.

Ósmosis Inversa

\begin{tabular}{|c|c|c|}
\hline Parámetro & $\begin{array}{l}\text { Coste } \\
\left(€ / \mathrm{m}^{3}\right)\end{array}$ & $\begin{array}{c}\text { Porcentaje } \\
(\%)\end{array}$ \\
\hline Electricidad & 0,13 & 19,1 \\
\hline $\begin{array}{c}\text { Productos } \\
\text { (agentes de } \\
\text { limpieza, anti- } \\
\text { incrustantes...) }\end{array}$ & 0,48 & 70,6 \\
\hline Membranas & \multirow{2}{*}{0,07} & \multirow{2}{*}{10,3} \\
\hline Filtros & & \\
\hline Mantenimiento & - & - \\
\hline $\begin{array}{c}\text { Coste total del } \\
\text { permeado }\end{array}$ & 0,68 & - \\
\hline
\end{tabular}

Producción $=7665 \mathrm{~m}^{3} /$ año

Nanofiltración

\begin{tabular}{|c|c|c|}
\hline Parámetro & $\begin{array}{c}\text { Coste } \\
\left(€ / \mathrm{m}^{3}\right)\end{array}$ & $\begin{array}{c}\text { Porcentaje } \\
(\%)\end{array}$ \\
\hline Electricidad & 0,072 & 18,5 \\
\hline $\begin{array}{c}\text { Productos } \\
\text { (agentes de } \\
\text { limpieza, anti- } \\
\text { incrustantes...) }\end{array}$ & 0,215 & 55,3 \\
\hline $\begin{array}{c}\text { Membranas } \\
\text { Filtros }\end{array}$ & 0,043 & 11,1 \\
\hline $\begin{array}{c}\text { Mantenimiento } \\
\text { permeado }\end{array}$ & 0,031 & 8,28 \\
\hline Coste total del & 0,389 & - \\
\hline
\end{tabular}

Producción $=10000 \mathrm{~m}^{3} / \mathrm{año}$

Conversión $75-85 \%$

Los datos referentes a la ósmosis inversa han sido calculados para una instalación que está operando en el sector cerámico y está en línea con los costes que de esta tecnología se puede encontrar en la bibliografía [173][174]. 
Por lo que respecta a los costes de nanofiltración se han calculado para una hipotética planta que cubriese las necesidades de una empresa como la que ha proporcionado las aguas al presente estudio, para ello se contactó con la ingeniería que construyó la planta piloto. Los datos obtenidos en el coste de este tratamiento también se encuentran dentro de un orden de magnitud similar al coste que de este tratamiento recogen varios autores, que oscilan entre $0,11-0,37 € / \mathrm{m}^{3}[175][176]$ [177]. El coste de estos tratamientos decrece cuanto mayor es la producción de las instalaciones. En la bibliografía también se pueden encontrar varios autores que afirman que las técnicas de nanofiltración pueden ser una buena opción para reducir los costes de algunas actividades donde habitualmente se está utilizando la ósmosis inversa [50].

Aunque en este caso no solamente se pretende eliminar el boro, ya que también se persigue un agua con la suficiente calidad para poder ser reutilizada, también se puede encontrar en la bibliografía que el coste de la eliminación de este elemento es menor si se utilizan membranas de ósmosis inversa en vez de resinas de intercambio iónico cuando la concentración de boro tiene que reducirse hasta los $0,5 \mathrm{mg} / \mathrm{L}$ de boro [49]. Por tanto, si en los resultados obtenidos en este estudio el coste de la técnica de nanofiltración es menor que el calculado para la ósmosis inversa, se puede pensar que la tecnología de nanofiltración también puede tener unos costes asociados menores a los del intercambio iónico por resinas.

\subsection{Eliminación de sales divalentes de las aguas industriales de proceso mediante técnicas de nanofiltración}

El principal objetivo de esta parte del trabajo ha sido la optimización del proceso de preparación de las suspensiones cerámicas en una empresa de preparación de polvo atomizado para la elaboración de baldosas cerámicas (en adelante atomizador) tratando las aguas utilizadas como materia prima para la preparación de suspensiones cerámicas. Este objetivo se pretende conseguir mediante la nanofiltración de las aguas que se van a utilizar como aguas de proceso, para eliminar en la medida de lo posible los iones divalentes (en especial el $\mathrm{Ca}^{2+}$ y los $\mathrm{SO}_{4}{ }^{2-}$ ), iones floculantes, que impiden la buena desfloculación de las suspensiones cerámicas durante su elaboración (ver apartado 1.3.3. Desfloculación de las suspensiones cerámicas: influencia del agua utilizada) [11]. De esta forma se pretende optimizar el comportamiento reológico de las suspensiones cerámicas para conseguir una disminución de su viscosidad con el empleo de un menor porcentaje de productos desfloculantes. La disminución de la viscosidad debe permitir aumentar el contenido en sólidos en la suspensión cerámica y por tanto, lograr un incremento de la producción del atomizador, reduciendo el consumo energético de la empresa, y en consecuencia, también la cantidad de $\mathrm{CO}_{2}$ emitido a la atmósfera.

En esta parte del estudio se trabajó, tanto con aguas residuales después de un tratamiento físicoquímico, como con aguas limpias de pozo, ya que las empresas dedicadas a este fin utilizan estos dos tipos de aguas para la producción de polvo atomizado. Estas empresas en primer lugar, utilizan toda el agua residual que ellos mismos generan junto a las aguas residuales de otras empresas (clientes que les compran el polvo atomizado) que se dedican a la elaboración de baldosas cerámicas cuyo vertido es cero gracias a este tipo de empresas que les gestionan sus aguas residuales. Sin embargo, generalmente los atomizadores son deficitarios de agua y por tanto, 
además de utilizar todas las aguas residuales que poseen, necesitan de agua limpia de pozo para alcanzar la producción de polvo atomizado requerido. Debido a la cantidad de agua que se necesita y la importancia que sus características puede llegar a tener en el proceso, en este trabajo se ha considerado al agua de producción como una materia prima más, confiriéndole la importancia que realmente tiene. Por este motivo, el objetivo es tratar de mejorar la calidad, tanto de las aguas residuales que son introducidas al proceso, como la del agua de pozo. Hasta este momento, muchas empresas han considerado el agua para la preparación de las suspensiones cerámicas como una materia prima de segundo orden. Sin embargo, considerándola como una materia prima tan importante como las materias primas cerámicas y los desfloculantes necesarios para la composición cerámica, y por tanto mejorando su calidad, se pueden conseguir beneficios económicos considerables. Además, al mismo tiempo es posible conseguir empresas más sostenibles, ya que pueden aumentar su producción con menor consumo de aditivos y menor consumo de gas natural para el secado de la suspensión cerámica, con la consiguiente disminución de emisiones de $\mathrm{CO}_{2}$ a la atmosfera.

En la Figura 4.44 se representa el esquema general del proceso productivo de una empresa de atomización, así como el tratamiento que se ha estudiado en este trabajo y el punto donde se ha de introducir para obtener los mejores resultados posibles (las flechas verdes son los objetivos que se han perseguido).

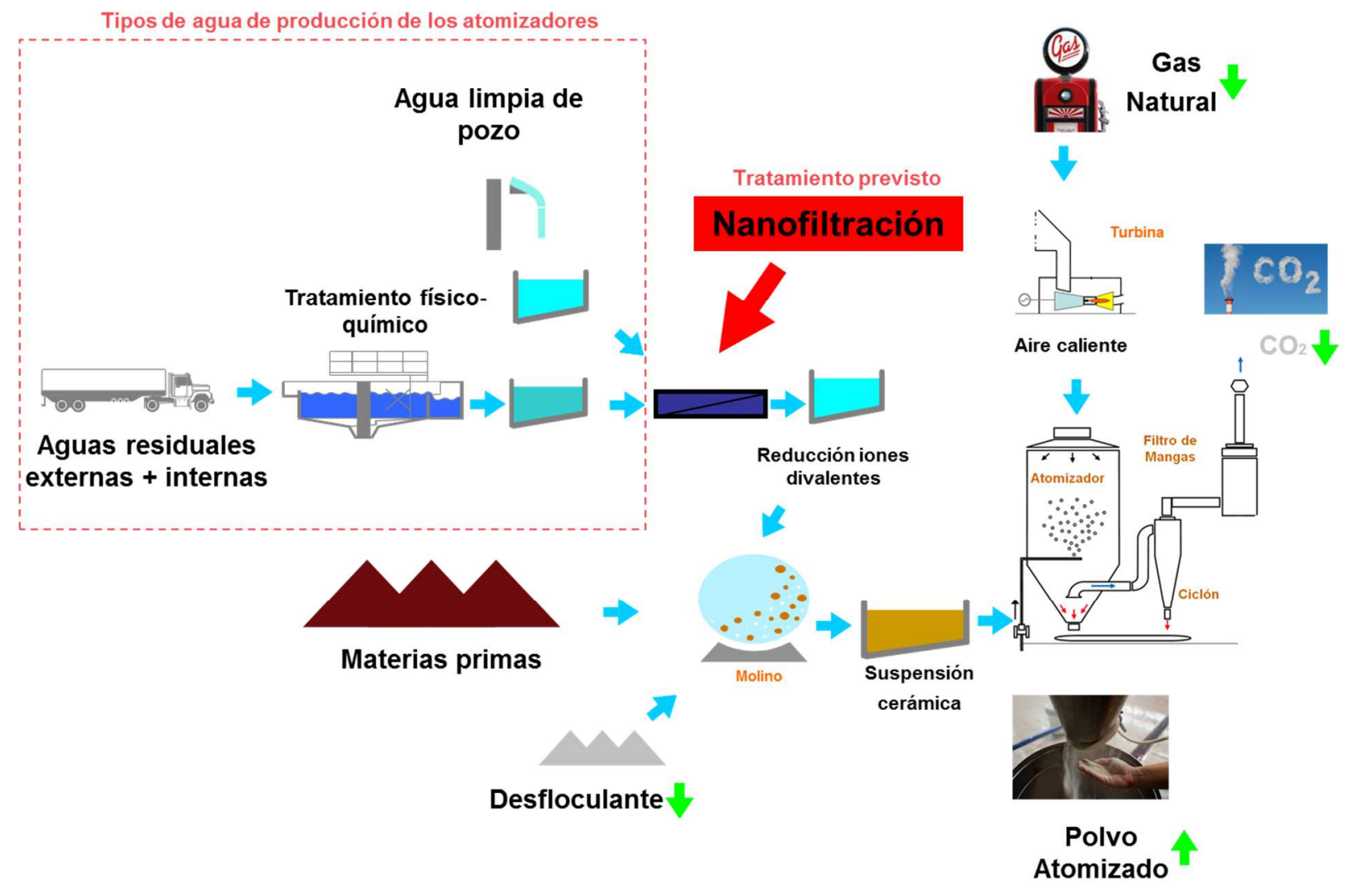

Figura 4.44. Esquema del proceso productivo de una empresa de producción de polvo atomizado, actuaciones previstas en el estudio y los resultados esperados (flechas verdes)

De la misma forma, en la Figura 4.45 se puede observar un diagrama de flujo donde se representan las cantidades de agua que necesita y gestiona una empresa modelo de producción de polvo 
atomizado. Una instalación de este tipo puede tener una producción de polvo atomizado de aproximadamente 600 t/día.

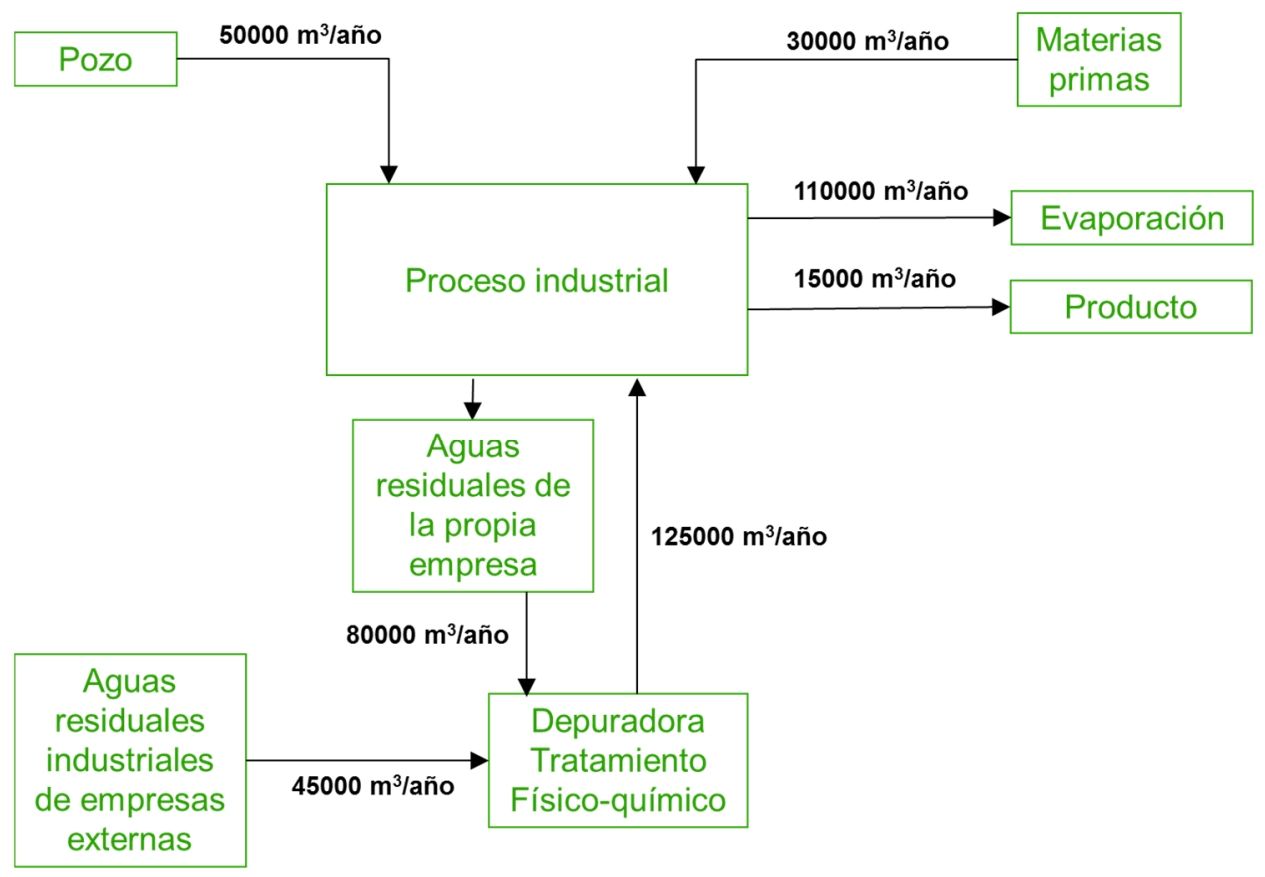

Figura 4.45. Diagrama de flujo de las aguas de una empresa tipo de preparación de polvo atomizado (producción: 600 t/día).

Por tanto, en este caso de estudio, se ha aplicado un tratamiento de nanofiltración con la membrana NF-270 para la eliminación de las especias divalentes de las aguas que este tipo de empresas utilizan en su proceso productivo. La elección de esta membrana ya se adelantó después de la caracterización de las mismas.

Para la realización de este trabajo, en primer lugar se ha realizado una caracterización de los dos tipos de agua que la empresa utiliza, de este modo se pretende conocer el punto de partida y las características de las diferentes aguas con las que se ha tenido que trabajar. Después de dicha caracterización, se han recopilado los resultados obtenidos a escala de laboratorio, tanto para la nanofiltración de aguas residuales después de un tratamiento físico-químico, como después del tratamiento de nanofiltración de las aguas de pozo.

Tras los ensayos de nanofiltración a escala de laboratorio con las aguas tratadas, se han preparado varias suspensiones cerámicas que se han caracterizado para determinar la viscosidad mínima $\left(\mu_{\text {min }}\right)$ y el contenido mínimo de desfloculante $\left(\right.$ desf $\left._{\min }\right)$ necesario (ver Figura 1.18), determinando así su comportamiento reológico. Además, se han preparado varias muestras (probetas) con el polvo atomizado obtenido a partir de estas suspensiones cerámicas con el objeto de realizar una caracterización cerámica que permita analizar el posible efecto del agua nanofiltrada empleada en la preparación del polvo atomizado sobre las características del producto cerámico fabricado.

Finalmente, se han realizado los ensayos de laboratorio mediante una prueba de concentración, operando de forma discontinua, es decir, recirculando el rechazo al tanque de alimentación para llegar a una conversión en torno al 85\% (ver Figura 1.34), ya que para alcanzar beneficios económicos es necesario trabajar a conversiones lo más elevadas posibles. 
Una vez obtenidos los resultados a escala laboratorio con ambos tipos de agua, se ha escalado la tecnología a nivel industrial. Se han realizado los ensayos en discontinuo para optimizar, tanto el pretratamiento de microfiltración, como el propio tratamiento de nanofiltración. También se han realizado ensayos industriales en continuo, para además de evaluar el comportamiento de esta técnica en condiciones reales, obtener grandes cantidades de agua nanofiltrada (10000 L) con los que realizar ensayos industriales con molinos discontinuos para escalar la producción de una suspensión cerámica, estudiar su comportamiento reológico y posteriormente atomizarla para obtener polvo atomizado.

Se ha finalizado con un estudio económico para estimar los ahorros conseguidos por una empresa con la implementación de la técnica, así como sus periodos de retorno una vez realizada la implementación.

En la Figura 4.46 se enumera los pasos seguidos en este segundo caso de estudio, para ello se ha elegido un diagrama flujo. 
PASOS SEGUIDOS DURANTE EL SEGUNDO CASO DE ESTUDIO

(ELIMINACIÓN DE IONES DIVALENTES)
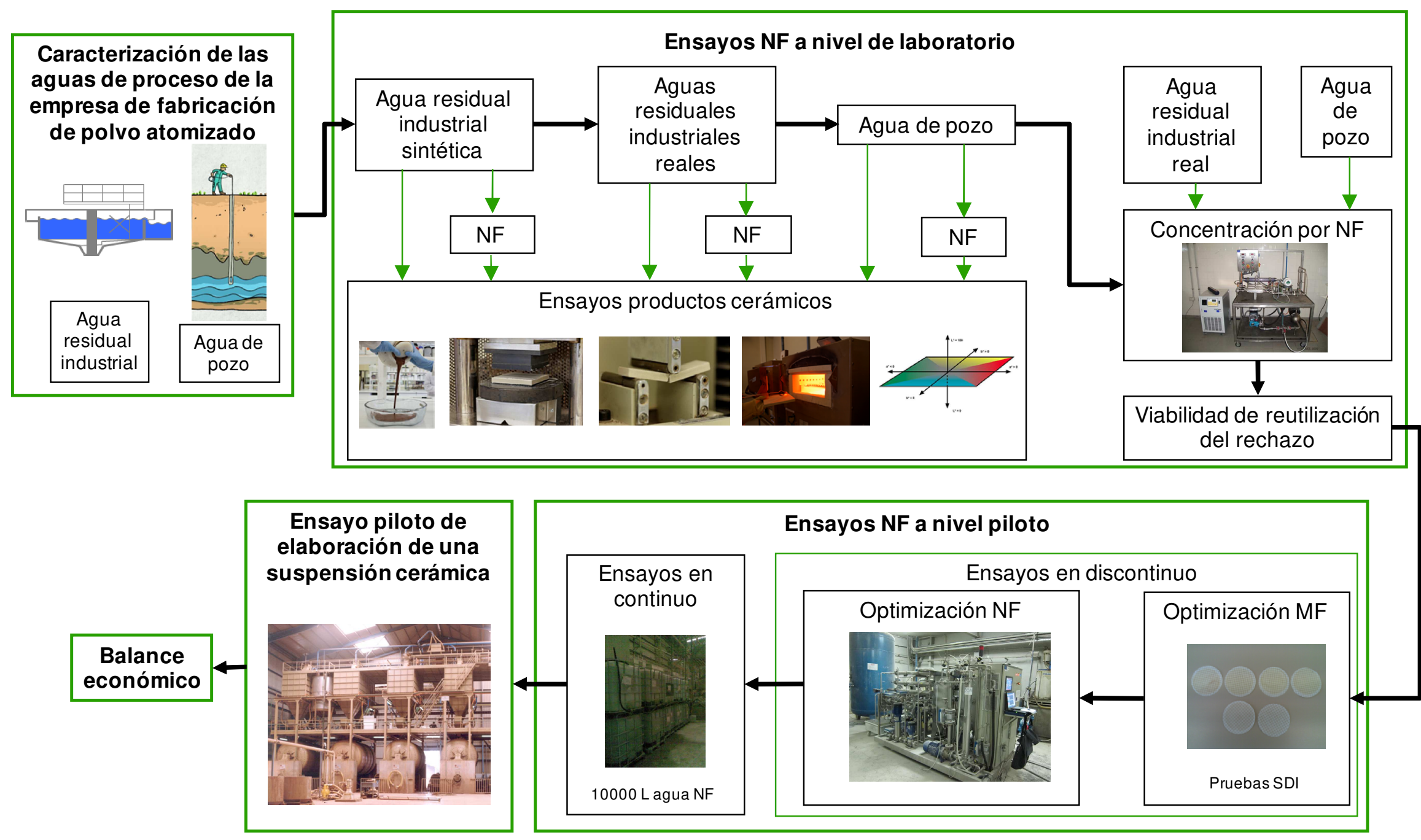

Figura 4.46. Diagrama de flujo de los pasos seguidos en el segundo caso de estudio (eliminación de sales divalentes) 


\subsubsection{Caracterización de las aguas de proceso de la empresa de producción de polvo atomizado}

Lo primero que se realizó en este segundo caso de estudio fue la caracterización de las aguas de la empresa, ya que es la materia prima con la que se va a trabajar.

Como se ha comentado, esta empresa de producción de polvo atomizado, al igual que prácticamente todas las empresas de este tipo, trabaja con dos tipos de agua. Por un lado se encuentran las aguas residuales, suma de sus aguas residuales más las aguas residuales de otras empresas que son gestionadas por ésta reintroduciéndolas en su proceso productivo en la etapa de molienda, tras un tratamiento físico-químico. Por otra parte, esta empresa también necesita abastecerse de agua de un pozo ubicado en la misma planta (ver Figura 4.45).

En la Tabla 4.20 y la Tabla 4.21 se recopilan los análisis químicos de los dos tipos de agua.

Tabla 4.20. Análisis químicos de varias muestras de aguas residuales recogidas a lo largo de varios meses.

\begin{tabular}{|c|c|c|c|c|c|c|c|}
\hline Parámetros & $\begin{array}{c}\text { Muestra } \\
\text { R2-1 }\end{array}$ & \begin{tabular}{|c} 
Muestra \\
R2-2
\end{tabular} & $\begin{array}{c}\text { Muestra } \\
\text { R2-3 }\end{array}$ & $\begin{array}{c}\text { Muestra } \\
\text { R2-4 }\end{array}$ & $\begin{array}{c}\text { Muestra } \\
\text { R2-5 }\end{array}$ & $\begin{array}{c}\text { Muestra } \\
\text { R2-6 }\end{array}$ & $\begin{array}{c}\text { Muestra } \\
\text { R2-7 }\end{array}$ \\
\hline $\mathrm{pH}$ & 7,4 & 7,3 & 7,8 & 7,7 & 7,6 & 7,9 & 7,6 \\
\hline Conductividad $(\mu \mathrm{S} / \mathrm{cm})$ & 1777 & 2010 & 4670 & 1371 & 1467 & 1564 & 1644 \\
\hline $\mathrm{DQO}\left(\mathrm{mg} / \mathrm{L} \mathrm{O}_{2}\right)$ & 48 & 234 & 324 & 123 & 17 & 264 & 304 \\
\hline $\begin{array}{c}\text { Sólidos en suspensión } \\
(\mathrm{mg} / \mathrm{L})\end{array}$ & 60 & 51 & 172 & 106 & 146 & 483 & 76 \\
\hline Cloruros (mg/L) & 266 & 337 & 1260 & 96 & 99 & 184 & 191 \\
\hline Sulfatos (mg/L) & 305 & 310 & 400 & 114 & 182 & 395 & 240 \\
\hline Boro (mg/L) & 0,52 & 3,6 & 0,09 & 3,3 & 1,4 & 6,3 & 9,1 \\
\hline Calcio (mg/L) & 320 & 360 & 440 & 48 & 126 & 380 & 240 \\
\hline Magnesio (mg/L) & - & - & - & 15 & 35 & - & - \\
\hline Sodio (mg/L) & - & - & - & 66 & 88 & - & - \\
\hline $\begin{array}{c}\text { Sales Totales } \\
\text { Disueltas (TDS) (mg/L) }\end{array}$ & 1422 & 1608 & 3736 & - & - & 1251 & 1315 \\
\hline Dureza $\left(\mathrm{mg} / \mathrm{L} \mathrm{CaCO}_{3}\right)$ & 420 & 530 & 530 & - & - & 430 & 460 \\
\hline $\begin{array}{l}\text { Carbonatos } \\
\left(\mathrm{mg} / \mathrm{L} \mathrm{CaCO}_{3}\right)\end{array}$ & $<20$ & $<20$ & $<10$ & 39 & $<20$ & $<10$ & $<10$ \\
\hline $\begin{array}{l}\text { Bicarbonatos } \\
\left(\mathrm{mg} / \mathrm{L} \mathrm{CaCO}_{3}\right)\end{array}$ & 530 & 330 & 630 & 123 & 425 & 413 & 425 \\
\hline
\end{tabular}


Tabla 4.21. Análisis químicos de dos muestras de agua de pozo recogidas a lo largo de varios meses.

\begin{tabular}{|c|c|c|}
\hline Parámetros & Muestra P2-1 & Muestra P2-2 \\
\hline $\mathrm{pH}$ & 7,2 & 7,2 \\
\hline Conductividad $(\mu \mathrm{S} / \mathrm{cm})$ & 1005 & 1013 \\
\hline $\mathrm{DQO}\left(\mathrm{mg} / \mathrm{L} \mathrm{O}_{2}\right)$ & $<10$ & $<10$ \\
\hline Sólidos en suspensión (mg/L) & 48 & 38 \\
\hline Cloruros (mg/L) & 71 & 71 \\
\hline Sulfatos (mg/L) & 220 & 215 \\
\hline Boro (mg/L) & 0,7 & 0,7 \\
\hline Calcio (mg/L) & 310 & 310 \\
\hline Magnesio (mg/L) & - & - \\
\hline Sodio (mg/L) & - & - \\
\hline $\begin{array}{l}\text { Sales Totales Disueltas (TDS) } \\
\text { (mg/L) }\end{array}$ & 804 & 810 \\
\hline Dureza (mg/L $\left.\mathrm{CaCO}_{3}\right)$ & 435 & 450 \\
\hline Carbonatos (mg/L $\left.\mathrm{CaCO}_{3}\right)$ & $<10$ & $<10$ \\
\hline Bicarbonatos (mg/L $\left.\mathrm{CaCO}_{3}\right)$ & 308 & 303 \\
\hline
\end{tabular}

Si se observa la Tabla 4.20 se puede apreciar que la composición química del agua residual con la que tiene que trabajar la empresa no es muy estable con el tiempo y se pueden encontrar diferencias muy notables de unos meses a otros. Aunque la empresa intenta que el agua residual se encuentre lo más homogénea posible, ésta no es una tarea fácil, ya que generalmente estas aguas son generadas en etapas de limpieza manual (ver apartado 1.1.3.1 Generación y características del agua residual).

En cambio, el agua limpia de pozo es muy estable en el tiempo, tal y como se puede apreciar en la Tabla 4.21. 


\subsubsection{Resultados de la nanofiltración a escala de laboratorio para la eliminación de iones divalentes}

Como se ha comentado con anterioridad y teniendo en cuenta los resultados obtenidos en el apartado 4.1.4 Elección de la membrana más adecuada para los tratamientos a realizar, se observó que la mejor membrana para conseguir los objetivos perseguidos en este segundo caso de estudio es la membrana NF-270, por su selectividad con los iones divalentes.

Las pruebas a escala de laboratorio se realizaron de forma discontinua, con una instalación de laboratorio capaz de albergar membranas planas poliméricas y que opera de forma tangencial, por tanto, se utilizó el equipo de filtración avanzada a escala de laboratorio que dispone en sus instalaciones el ITC (ver apartado 3.4.1 Plantas de filtración tangencial a escala de laboratorio).

La metodología utilizada en este apartado ha sido la de presentar los resultados conseguidos en las diferentes pruebas de nanofiltración a nivel de laboratorio, seguido de los resultados obtenidos en las pruebas de producto cerámico. De esta forma, se pretende comprobar directamente si la utilización de aguas nanofiltradas trae consigo beneficios en el comportamiento reológico de las suspensiones cerámicas elaboradas con estas aguas tratadas y el polvo atomizado obtenido con estas suspensiones es apto para la fabricación de baldosas cerámicas.

Para llevar a cabo las pruebas de nanofiltración se ha seguido la misma metodología que se ha descrito en el apartado 3.6 Procedimiento experimental. De la misma forma, tanto la caracterización de las muestras de las disoluciones de partida, como la de las muestras de permeado y rechazo tomadas a lo largo de la filtración se han realizado según lo establecido en el apartado 3.5 Análisis y determinación de diferentes parámetros.

\subsubsection{Resultados de las pruebas de nanofiltración realizadas con aguas sintéticas.}

Conocidos los análisis de las aguas características de este tipo de empresas y antes de entrar de lleno en la aplicación de la tecnología de nanofiltración en este tipo de aguas, se consideró oportuno realizar alguna prueba con aguas sintéticas, de esta forma poder estimar si los resultados que se obtenían eran beneficiosos para conseguir los objetivos marcados o no.

Por tanto, se realizaron pruebas de nanofiltración a escala de laboratorio con aguas sintéticas que simulasen las aguas industriales de una empresa. De las pruebas que se realizaron con agua sintética, a continuación se compilarán los resultados obtenidos con agua a una concentración de sales elevada, ya que se han planteado las condiciones más desfavorables (ver Tabla 4.20).

En la Tabla 4.22 se recogen los resultados obtenidos con las aguas sintéticas. Puede observarse que los iones divalentes son fuertemente retenidos incluso a presiones bajas, tal y como se persigue. En cambio, los iones monovalentes son mucho menos retenidos, situación que también es deseable en este trabajo, ya que estos iones no perjudican prácticamente al comportamiento reológico de las suspensiones cerámicas [51] y por tanto, es mejor que no sean retenidos para no aumentar la carga iónica de la corriente rechazo. 
Tabla 4.22. Resultados de las pruebas de nanofiltración con aguas sintéticas a diferentes presiones.

\begin{tabular}{|c|c|c|c|c|c|c|c|}
\hline \multirow{2}{*}{$\begin{array}{c}\text { Parámetros } \\
\text { Medidos }\end{array}$} & $\begin{array}{c}\text { Agua Sintética } \\
\text { sin tratar }\end{array}$ & \multicolumn{2}{|c|}{$\begin{array}{c}\text { Agua Sintética } \\
\text { Membr: NF270 } \\
\text { Presión: 5 bar }\end{array}$} & \multicolumn{2}{|c|}{$\begin{array}{c}\text { Agua Sintética } \\
\text { Membr: NF270 } \\
\text { Presión: 10 bar }\end{array}$} & \multicolumn{2}{|c|}{$\begin{array}{c}\text { Agua Sintética } \\
\text { Membr: NF270 } \\
\text { Presión: 15 bar }\end{array}$} \\
\cline { 2 - 9 } & Valor & $\begin{array}{r}\text { Retención } \\
(\%)\end{array}$ & Valor & $\begin{array}{c}\text { Retención } \\
(\%)\end{array}$ & Valor & $\begin{array}{c}\text { Retención } \\
(\%)\end{array}$ \\
\hline $\mathrm{pH}$ & 7,5 & 7,7 & - & 7,5 & - & 7,4 & - \\
\hline $\begin{array}{c}\text { Conductividad } \\
(\mu \mathrm{SS} / \mathrm{cm})\end{array}$ & 6845 & 4120 & 39,8 & 3205 & 53,2 & 2900 & 57,6 \\
\hline $\mathrm{Ca}^{2+}(\mathrm{mg} / \mathrm{L})$ & 365 & 99 & 72,9 & 54 & 85,2 & 43 & 88,2 \\
\hline $\mathrm{SO}_{4}{ }^{2-}(\mathrm{mg} / \mathrm{L})$ & 971 & 23 & 97,6 & 21 & 97,8 & 19 & 98,0 \\
\hline $\mathrm{Cl}^{-}(\mathrm{mg} / \mathrm{L})$ & 1254 & 1040 & 17,1 & 785 & 37,4 & 699 & 44,3 \\
\hline $\mathrm{Na}^{+}(\mathrm{mg} / \mathrm{L})$ & 861 & 560 & 35,0 & 445 & 48,3 & 400 & 53,5 \\
\hline
\end{tabular}

Tras la nanofiltración se ha elaborado una suspensión cerámica con el agua sintética sin nanofiltrar y otra con el permeado nanofiltrado a una presión de 15 bar. Las suspensiones se han preparado con una arcilla blanca comercial, por tanto, no es una composición cerámica sino una materia prima de la composición, sin embargo, esta prueba sirve para comparar las mejoras que un agua nanofiltrada puede aportar al comportamiento reológico de la suspensión, ya que la arcilla es la materia prima que consume mayor cantidad de desfloculante en la preparación de una suspensión. Los resultados obtenidos se recogen en la Tabla 4.23 y en la Figura 4.47.

Tabla 4.23. Resultados de las curvas de desfloculación de las suspensiones preparadas con aguas sintéticas.

\begin{tabular}{|c|c|c|}
\hline Parámetros & $\begin{array}{c}\text { Arcila + Agua } \\
\text { Sintética sin } \\
\text { tratar }\end{array}$ & $\begin{array}{r}\text { Arcila + Agua Sintética } \\
\text { Membr: NF270 } \\
\text { Presión: 15 bar }\end{array}$ \\
\hline $\begin{array}{c}\text { Contenido en sólidos (\%) } \\
\text { Contenido en desfloculante, } \\
\text { desf.min }(\%)\end{array}$ & 50,3 & 51,6 \\
\hline Viscosidad mínima, $\mu_{\min }(\mathrm{cP})$ & 2850 & 890 \\
\hline
\end{tabular}




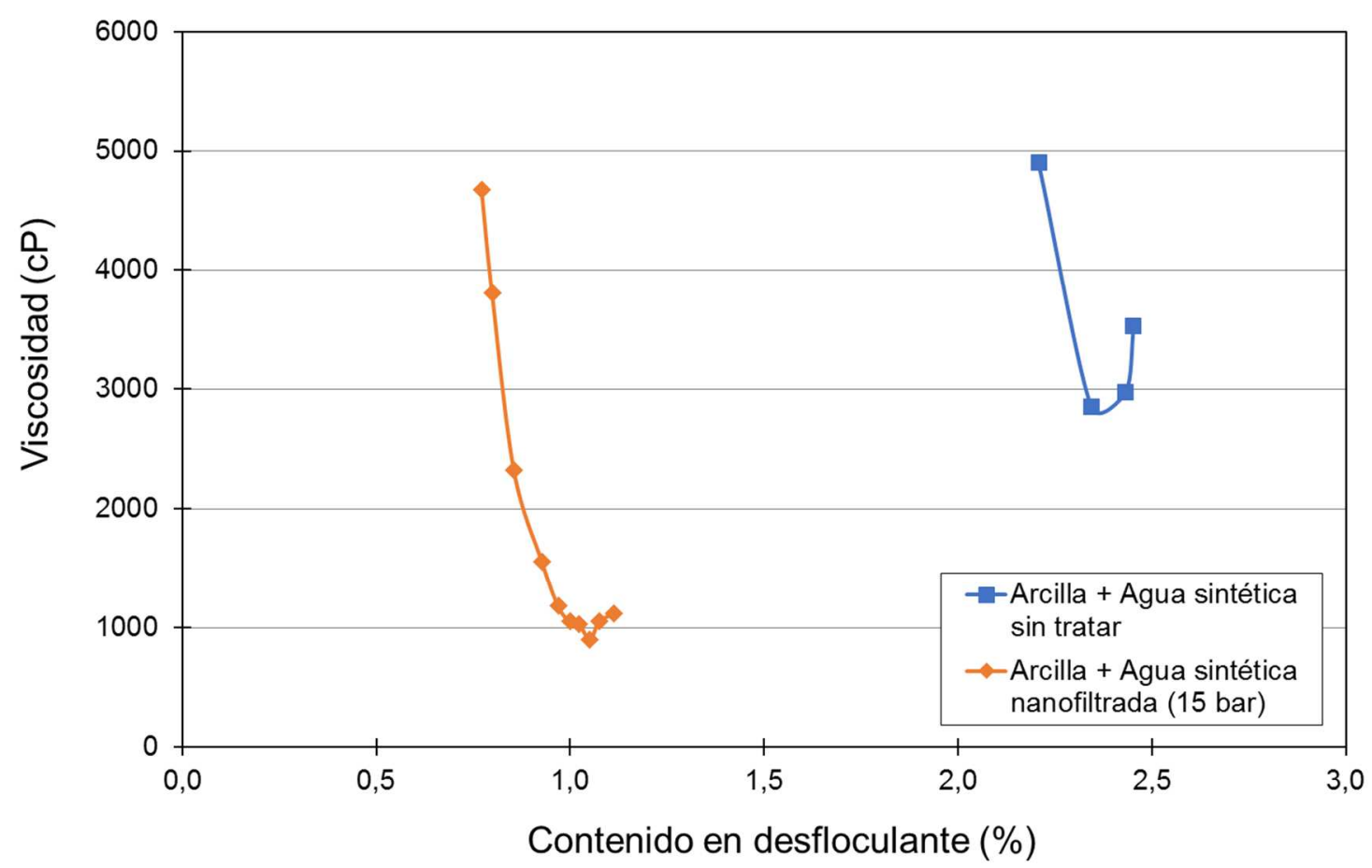

Figura 4.47. Viscosidad de las suspensiones preparadas con aguas sintéticas nanofiltradas y sin tratar frente al contenido en desfloculante.

Se puede observar que tanto la viscosidad mínima $\left(\mu_{\min }\right)$ como el contenido en desfloculante mínimo (desf $\left.f_{\min }\right)$ disminuyen enormemente $(68 \%$ y $55 \%$, respectivamente) si se utiliza agua nanofiltrada frente al agua sintética sin tratar. Mientras que el contenido en sólidos aumenta en más de 1 punto porcentual, lo que es también muy significativo. Estos resultados son extremadamente positivos para seguir adelante con el estudio, ya que los ahorros en desfloculante y el aumento en la producción del atomizador podrían ser muy importantes.

\subsubsection{Pruebas de nanofiltración con aguas residuales industriales y ensayos cerámicos utilizando el agua obtenida}

Después de obtener estos buenos resultados a nivel de laboratorio con aguas sintéticas se pensó en comprobar si las aguas residuales industriales nanofiltradas de esta empresa se comportarían de igual forma en la elaboración del polvo atomizado. Además, se pretende comprobar si las baldosas elaboradas con este polvo atomizado tendrían las mismas propiedades técnicas que las producidas con polvo atomizado obtenido con aguas sin nanofiltrar. En el caso contrario, no sería viable implementar este tratamiento con los fines propuestos. Por estas razones, se han realizado los ensayos reológicos con aguas residuales nanofiltradas y sin nanofiltrar pero en este caso con una composición característica de gres porcelánico. Hay que recordar (ver Figura 4.44) que esta empresa de elaboración de polvo atomizado somete las aguas residuales industriales que va a utilizar en su proceso productivo a un tratamiento físico-químico previo, por tanto, estas aguas obtenidas después del tratamiento mencionado son las que se han utilizado.

Además, después de las pruebas reológicas se han realizado otros ensayos del proceso cerámico para ver si existe alguna diferencia entre las piezas fabricadas con la suspensión cerámica 
elaborada con aguas tratadas por nanofiltración y las que han sido elaboradas con aguas no nanofiltradas (ver apartado 3.6.4.2 Pruebas de producto cerámico en el segundo caso de estudio).

Los resultados de la nanofiltración obtenidos con las aguas residuales de la empresa de elaboración de polvo atomizado son compilados en la Tabla 4.24:

Tabla 4.24. Resultados de la prueba de nanofiltración con las aguas residuales reales a varias presiones.

\begin{tabular}{|c|c|c|c|c|c|c|c|}
\hline \multirow[t]{2}{*}{ Parámetros } & \multirow{2}{*}{$\begin{array}{c}\begin{array}{c}\text { Agua } \\
\text { residual } \\
\text { sin } \\
\text { tratar }\end{array} \\
\text { Valor }\end{array}$} & \multicolumn{2}{|c|}{$\begin{array}{l}\text { Agua residual } \\
\text { Membr: NF270 } \\
\text { Presión: } 5 \text { bar }\end{array}$} & \multicolumn{2}{|c|}{$\begin{array}{l}\text { Agua residual } \\
\text { Membr: NF270 } \\
\text { Presión: } 10 \text { bar }\end{array}$} & \multicolumn{2}{|c|}{$\begin{array}{l}\text { Agua residual } \\
\text { Membr: NF270 } \\
\text { Presión: } 15 \text { bar }\end{array}$} \\
\hline & & Valor & $\begin{array}{l}\text { Retención } \\
(\%)\end{array}$ & Valor & $\begin{array}{l}\text { Retención } \\
\text { (\%) }\end{array}$ & Valor & $\begin{array}{l}\text { Retención } \\
(\%)\end{array}$ \\
\hline $\mathrm{pH}$ & 7,6 & $7,67-8,22$ & - & $7,92-8,31$ & - & $8,05-8,17$ & - \\
\hline $\begin{array}{c}\text { Conductividad } \\
(\mu \mathrm{S} / \mathrm{cm})\end{array}$ & 1467 & 505 & 66 & 379 & 74 & 335 & 77 \\
\hline $\mathrm{Cl}^{-}(\mathrm{mg} / \mathrm{L})$ & 99 & 64 & 35 & 49 & 51 & 52 & 47 \\
\hline $\mathrm{Na}^{+}(\mathrm{mg} / \mathrm{L})$ & 88 & 38 & 57 & 31 & 65 & 34 & 61 \\
\hline $\begin{array}{l}\text { Sólidos en } \\
\text { suspensión } \\
\text { (mg/L) }\end{array}$ & 146 & - & - & - & - & - & - \\
\hline $\mathrm{K}^{+}(\mathrm{mg} / \mathrm{L})$ & 3,6 & 1,5 & 58 & 1,1 & 69 & 1,2 & 67 \\
\hline $\mathrm{HCO}_{3}{ }^{-}(\mathrm{mg} / \mathrm{L})$ & 425 & 106 & 75 & 84 & 80 & 88 & 79 \\
\hline $\mathrm{SO}_{4}^{2-}(\mathrm{mg} / \mathrm{L})$ & 182 & 3,7 & 98 & 3,5 & 98 & 2,1 & 99 \\
\hline $\mathrm{Mg}^{2+}(\mathrm{mg} / \mathrm{L})$ & 35 & 5,7 & 84 & 4,4 & 87 & 4,3 & 88 \\
\hline $\mathrm{Ca}^{2+}(\mathrm{mg} / \mathrm{L})$ & 126 & 19 & 85 & 13 & 90 & 13 & 90 \\
\hline $\mathrm{CO}_{3}^{2-}(\mathrm{mg} / \mathrm{L})$ & $<20$ & $<20$ & - & $<20$ & - & $<20$ & - \\
\hline DQO (mg/L) & 17 & $<5$ & $>71$ & $<5$ & $>71$ & $<5$ & $>71$ \\
\hline
\end{tabular}

Al igual que en los casos anteriores, en la Tabla 4.24 se puede apreciar que los iones divalentes son fuertemente retenidos, incluso a presiones bajas, mientras que los iones monovalentes pasan más fácilmente a través de la membrana. Esto confirma los resultados obtenidos con anterioridad, además, sigue en la línea de los objetivos marcados en el estudio.

A continuación se van a mostrar los resultados obtenidos en la curva de desfloculación realizada a la suspensión cerámica elaborada con las aguas obtenidas en la prueba de nanofiltración, además de otras pruebas que habitualmente se efectúan a los materiales cerámicos y que se han realizado 
con las materias primas elaboradas con agua nanofiltrada y sin nanofiltrar, de esta forma se intentará detectar posibles diferencias. Las suspensiones cerámicas se han preparado esta vez con una mezcla de materias primas tipo utilizada en la fabricación de gres porcelánico de pasta blanca esmaltado denominada GPE, para que los resultados sean más próximos a la práctica industrial (ver Tabla 4.25).

Tabla 4.25. Composición de gres porcelánico esmaltado GPE.

\begin{tabular}{|c|c|}
\hline Materia prima & Cantidad (\% en peso) \\
\hline Arcilla blanca & 37,0 \\
\hline Caolín & 6,5 \\
\hline Feldespato I & 30,0 \\
\hline Feldespato II & 20,0 \\
\hline Arena Feldespática & 6,5 \\
\hline
\end{tabular}

Los resultados obtenidos en la curva de desfloculación se recogen en la Tabla 4.26 y en la Figura 4.48 .

Tabla 4.26. Resultados de las curvas de desfloculación de la suspensión (GPE) con el agua residual sin tratar y con el agua residual nanofiltrada.

\begin{tabular}{|c|c|c|c|}
\hline Parámetros & $\begin{array}{c}\text { GPE + Agua } \\
\text { residual sin } \\
\text { tratar }\end{array}$ & $\begin{array}{c}\text { GPE + Agua residual } \\
\text { Membrana: NF270 } \\
\text { Presión: 5 bar }\end{array}$ & $\begin{array}{c}\text { GPE + Agua residual } \\
\text { Membrana: NF270 } \\
\text { Presión: 15 bar }\end{array}$ \\
\hline $\begin{array}{c}\text { Contenido en } \\
\text { sólidos (\%) }\end{array}$ & 68,1 & 68,1 & 68,0 \\
\hline $\begin{array}{c}\text { Contenido en } \\
\text { desfloculante, } \\
\text { desf.min (\%) }\end{array}$ & 0,44 & 0,31 & 0,33 \\
\hline $\begin{array}{c}\text { Viscosidad mínima, } \\
\mu_{\text {min }}(\mathrm{cP})\end{array}$ & 670 & 350 & 370 \\
\hline
\end{tabular}




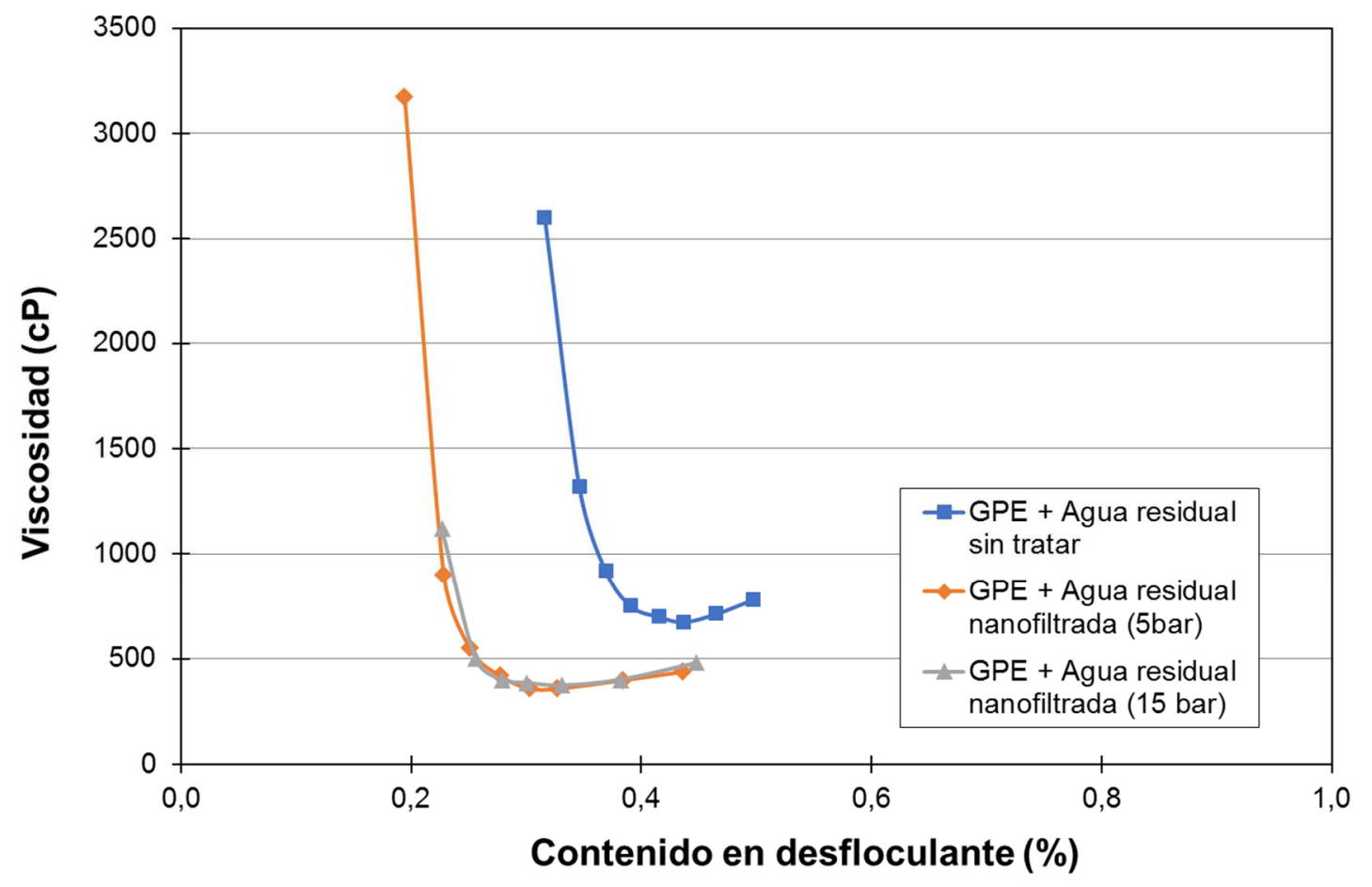

Figura 4.48. Viscosidad de suspensiones preparadas con aguas residuales frente al contenido en desfloculante.

Se puede observar, que tanto la viscosidad mínima $\left(\mu_{\min }\right)$, como el contenido en desfloculante mínimo (desf.min) disminuyen considerablemente (40-50\% y $25-30 \%$, respectivamente) si se utiliza agua nanofiltrada frente al agua residual real. Estos resultados siguen siendo muy positivos, ya que podrían dar lugar a un importante ahorro en desfloculante y a un aumento de la producción del atomizador.

Se puede apreciar que el comportamiento reológico de las suspensiones cerámicas elaboradas con agua nanofiltrada es el mismo y no depende de la presión a la que ha sido obtenida (los resultados son similares con las aguas obtenidas a 5 y 15 bar), por tanto, en principio, se puede trabajar a bajas presiones sin necesidad de realizar un gasto energético elevado.

Además, en esta ocasión se realizaron varios ensayos para comparar las propiedades de piezas cerámicas crudas (antes de cocer) obtenidas a partir de polvo atomizado que fue elaborado utilizando agua nanofiltrada y otras piezas obtenidas a partir de polvo atomizado elaborado con agua sin nanofiltrar.

Concretamente los ensayos que se realizaron fueron la elaboración de un diagrama de compactación y la determinación de la resistencia mecánica en seco (ver apartado 3.6.4.2 Pruebas de producto cerámico en el segundo caso de estudio). Los resultados obtenidos son recopilados en la Tabla 4.27, además la densidad aparente frente a la presión de prensado de las probetas se representa en la Figura 4.49. 
Tabla 4.27. Resultados de las pruebas con piezas crudas fabricadas con polvo atomizado proveniente de suspensiones cerámicas elaboradas con aguas nanofiltradas y sin tratar.

\begin{tabular}{|c|c|c|}
\hline Parámetros & $\begin{array}{c}\text { Atomizado (GPE) agua } \\
\text { residual sin tratar }\end{array}$ & $\begin{array}{c}\text { Atomizado (GPE) agua } \\
\text { nanofiltrada (NF270 5 bar) }\end{array}$ \\
\hline Humedad $(\%)$ & 5,5 & 5,5 \\
\hline Presión de prensado $\left(\mathrm{kg} / \mathrm{cm}^{2}\right)$ & 360 & 350 \\
\hline Densidad en seco $\left(\mathrm{g} / \mathrm{cm}^{3}\right)$ & 1,952 & 4,951 \\
\hline $\begin{array}{c}\text { Resistencia mecánica en seco } \\
\left(\mathrm{kg} / \mathrm{cm}^{2}\right)\end{array}$ & 50 & 43 \\
\hline
\end{tabular}

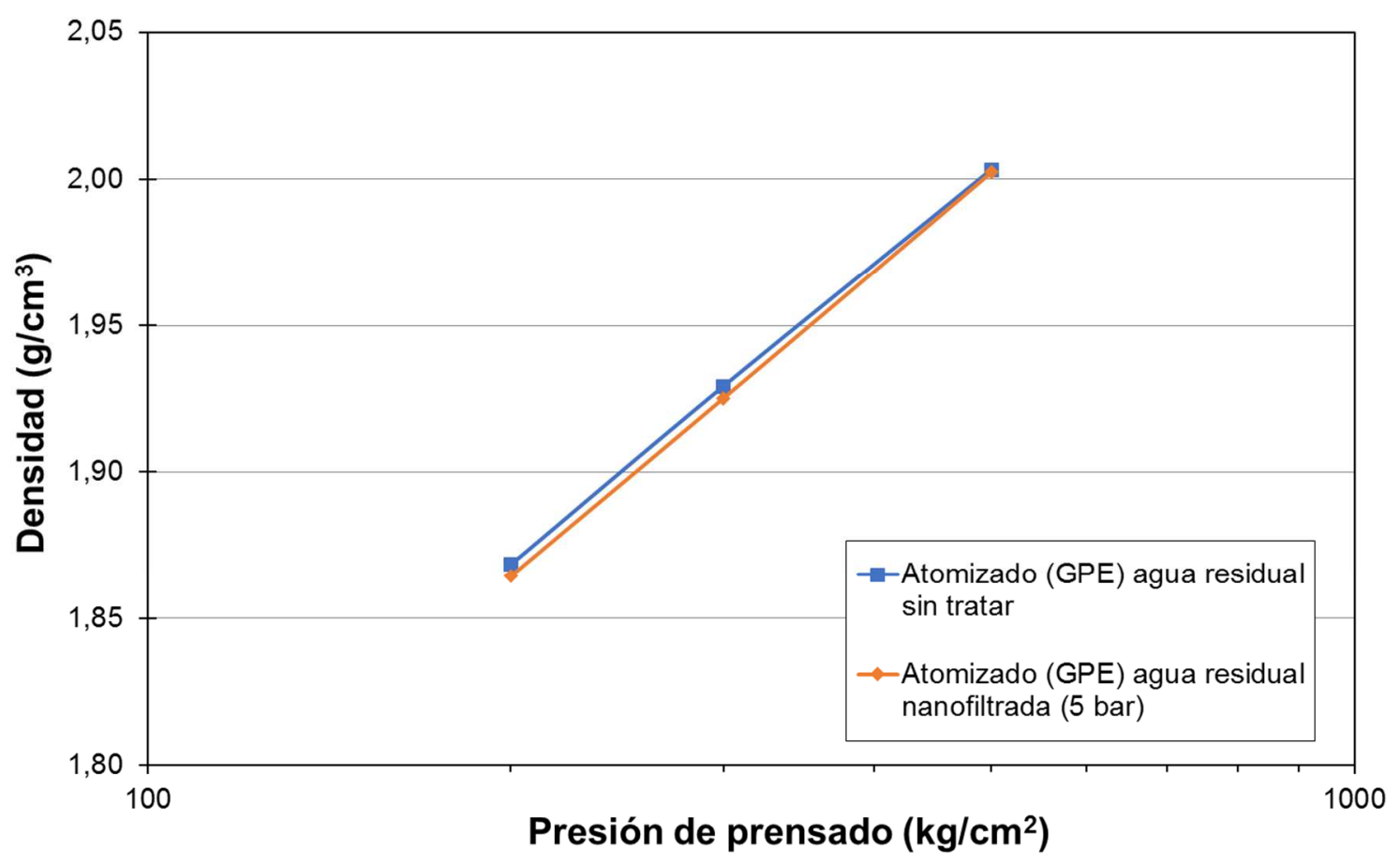

Figura 4.49. Densidad de la pieza en crudo frente a la presión de prensado.

Como puede observarse en los datos obtenidos, no existen diferencias significativas entre los resultados obtenidos en las probetas realizadas con agua nanofiltrada y agua sin nanofiltrar. La densidad en seco es prácticamente la misma en todas las presiones de prensado aplicadas (ver Figura 4.49). La resistencia mecánica es $7 \mathrm{~kg} / \mathrm{cm}^{2}$ superior en la probeta preparada con el polvo atomizado elaborado a partir del agua sin tratar, pero esta diferencia no es significativa, ya que la resistencia mecánica en crudo de las piezas de gres porcelánico de coloración blanca fluctúa entre $35-45 \mathrm{~kg} / \mathrm{cm}^{2}$ [11], por este motivo los valores obtenidos con ambas probetas están dentro del intervalo normal de resistencia mecánica. Por tanto, a este nivel no se ha detectado ningún tipo de 
problema para que no pueda utilizarse el agua nanofiltrada para la elaboración de baldosas cerámicas.

Una vez estudiado el comportamiento de las piezas en crudo, se ha procedido a realizar varios ensayos a piezas cocidas para ver si existen deficiencias en esta etapa del proceso (ver Figura 1.1). Concretamente, las pruebas realizadas han sido dos: Diagrama de gresificación y determinación de las coordenadas cromáticas (color de la pieza) (ver apartado 3.6.4.2. Pruebas de producto cerámico en el segundo caso de estudio).

En la Tabla 4.28 se han recopilado los resultados obtenidos con dos probetas cocidas (una preparada con agua sin nanofiltrar y la otra con agua nanofiltrada), los parámetros comparados han sido la densidad, la contracción lineal y sus coordenadas cromáticas, todos estos parámetros para dos probetas cocidas y a una absorción de agua del $1 \%$.

Tabla 4.28. Resultados de las pruebas realizadas en piezas cocidas fabricadas con polvo atomizado proveniente de suspensiones cerámicas elaboradas con aguas nanofiltradas y sin tratar (propiedades a una absorción de agua del 1\%).

\begin{tabular}{|c|c|c|c|}
\hline \multicolumn{2}{|c|}{ Parámetros } & $\begin{array}{l}\text { Atomizado (GPE) } \\
\text { agua residual sin } \\
\text { tratar }\end{array}$ & $\begin{array}{c}\text { Atomizado (GPE) } \\
\text { agua nanofiltrada } \\
\text { (NF270 } 5 \text { bar) }\end{array}$ \\
\hline \multicolumn{2}{|c|}{ Temperatura $\left({ }^{\circ} \mathrm{C}\right)$} & 1158 & 1154 \\
\hline \multicolumn{2}{|c|}{ Densidad $\left(\mathrm{g} / \mathrm{cm}^{3}\right)$} & 2,331 & 2,326 \\
\hline \multicolumn{2}{|c|}{ Contracción lineal (\%) } & 6,6 & 6,6 \\
\hline \multirow{3}{*}{$\begin{array}{c}\text { Coordenadas } \\
\text { cromáticas }\end{array}$} & $\mathrm{L}^{*}$ (blanco-negro) & 80,9 & 80,9 \\
\hline & $a^{*}$ (rojo-verde) & 2,5 & 2,5 \\
\hline & b* (azul-amarillo) & 11,3 & 11,1 \\
\hline
\end{tabular}

En la gráfica de la Figura 4.50 se ha representado la variación de la concentración lineal (\%) y la absorción de agua (\%) de las probetas cocidas a temperaturas que van desde $1140^{\circ} \mathrm{C}$ a $1200^{\circ} \mathrm{C}$. Donde puede observarse que a la temperatura típica de cocción del gres porcelánico $\left(1200^{\circ} \mathrm{C}\right)$ la contracción lineal de las piezas es del 7,5\% y la absorción del agua está por debajo del 0,1\%, valores que se encuentran dentro de los rangos establecidos para un gres porcelánico esmaltado de cocción blanca [11]. 


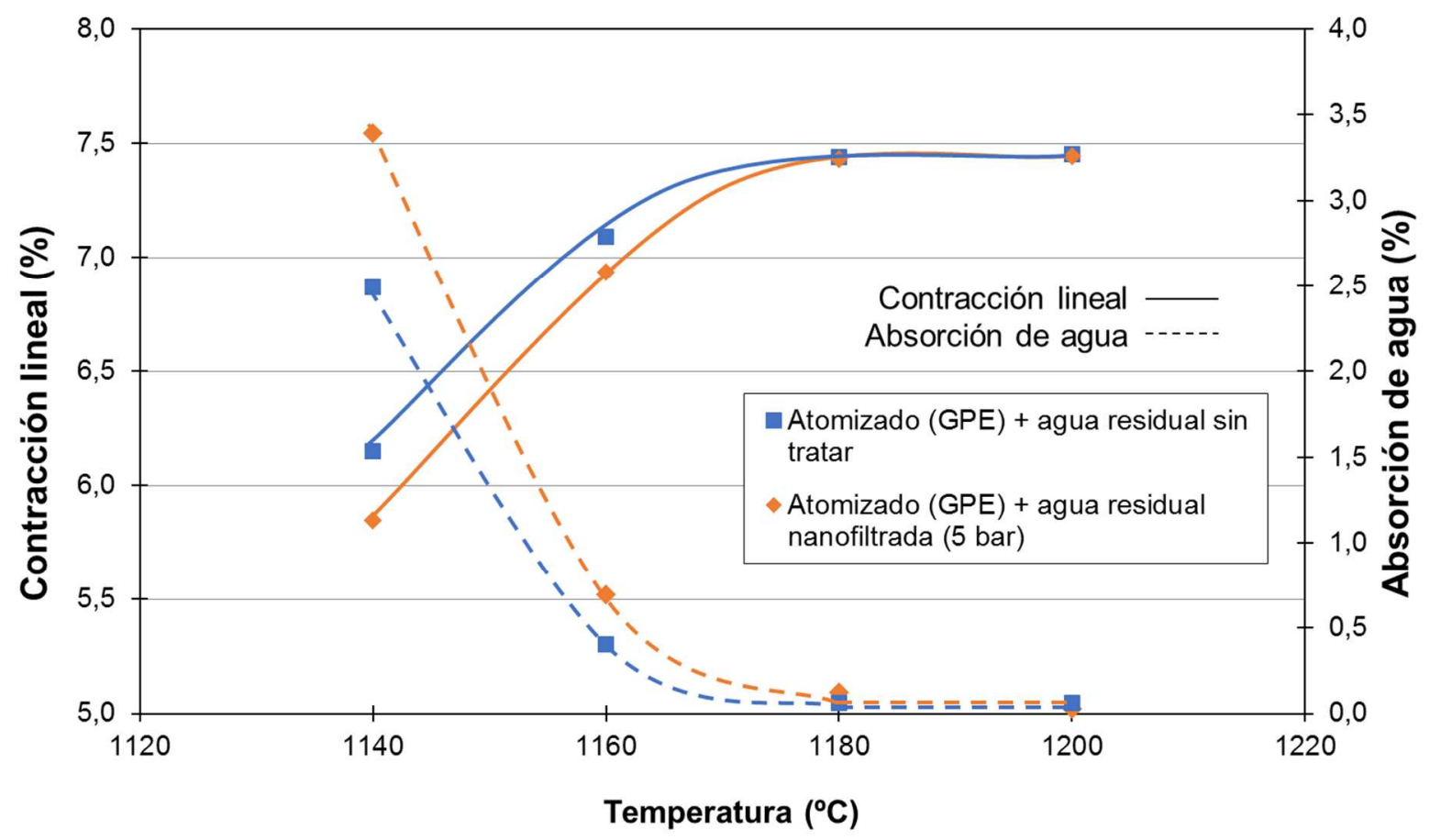

Figura 4.50. Contracción lineal y absorción de agua frente a la temperatura de cocción.

Al igual que en las pruebas realizadas con las piezas crudas, en el caso de piezas cocidas no se ha detectado ningún cambio significativo entre las piezas elaboradas con aguas nanofiltradas y las elaboradas con aguas sin nanofiltrar. Por tanto, se puede concluir que no existe ninguna razón que haga pensar que no pueda utilizarse agua nanofiltrada para la elaboración de baldosas cerámicas.

Tras haber comprobado que la utilización de aguas nanofiltradas para la elaboración de suspensiones cerámicas comporta importantes beneficios en el comportamiento reológico y no modifica prácticamente las propiedades ni el procesado del polvo atomizado, se repitió un ensayo de nanofiltración aumentando el número de presiones de trabajo (4, 5, 6, 8,10, 12 y 15 bar) utilizando el agua residual que la empresa de producción de polvo atomizado emplea en su proceso. De esta forma, se quiso observar el comportamiento de la membrana a una presión menor de 5 bar y a presiones intermedias hasta llegar a 15 bar, ya que hasta el momento solamente se había trabajado a 5, 10 y 15 bar para optimizar el número de ensayos a realizar. Sin embargo, es conveniente saber a qué presión se consigue llegar a la meseta de la retención constante, característica de los tratamientos de nanofiltración. De esta forma, se pretende saber a qué presión mínima se puede trabajar para obtener buenos resultados sin necesidad de gastar más energía.

Para cada presión se tomó una muestra de permeado y se midió la conductividad para utilizarla como parámetro de control de la filtración. Por tanto, con la conductividad de las muestras tomadas y conociendo la conductividad de la alimentación se puede calcular la retención de la membrana a este parámetro. En la Tabla 4.29 se recogen los resultados obtenidos en este ensayo con aguas residuales, mientras que en la gráfica de la Figura 4.51 se puede observar la retención o disminución de la conductividad frente a la presión aplicada en el tratamiento de nanofiltración. 
Tabla 4.29. Resultados de flujo y disminución de la conductividad en el ensayo de nanofiltración del agua residual.

\begin{tabular}{|c|c|c|c|}
\hline $\begin{array}{c}\text { Presión } \Delta \mathrm{P} \\
(\text { bar })\end{array}$ & $\begin{array}{c}\text { Flujo de permeado Jv } \\
\left(\mathrm{L} / \mathrm{h} \mathrm{m}^{2}\right)\end{array}$ & $\begin{array}{c}\text { Conductividad } \\
(\mu \mathrm{S} / \mathrm{cm})\end{array}$ & $\begin{array}{c}\text { Retención } \\
(\%)\end{array}$ \\
\hline- & - & $1544^{*}$ & - \\
\hline 4 & 37 & 460 & 77 \\
\hline 5 & 48 & 353 & 76 \\
\hline 6 & 58 & 367 & 78 \\
\hline 8 & 81 & 340 & 81 \\
\hline 10 & 104 & 326 & 84 \\
\hline 12 & 126 & 293 & 241 \\
\hline 15 & 156 & & 79 \\
\hline
\end{tabular}

* Conductividad inicial de la muestra alimento.

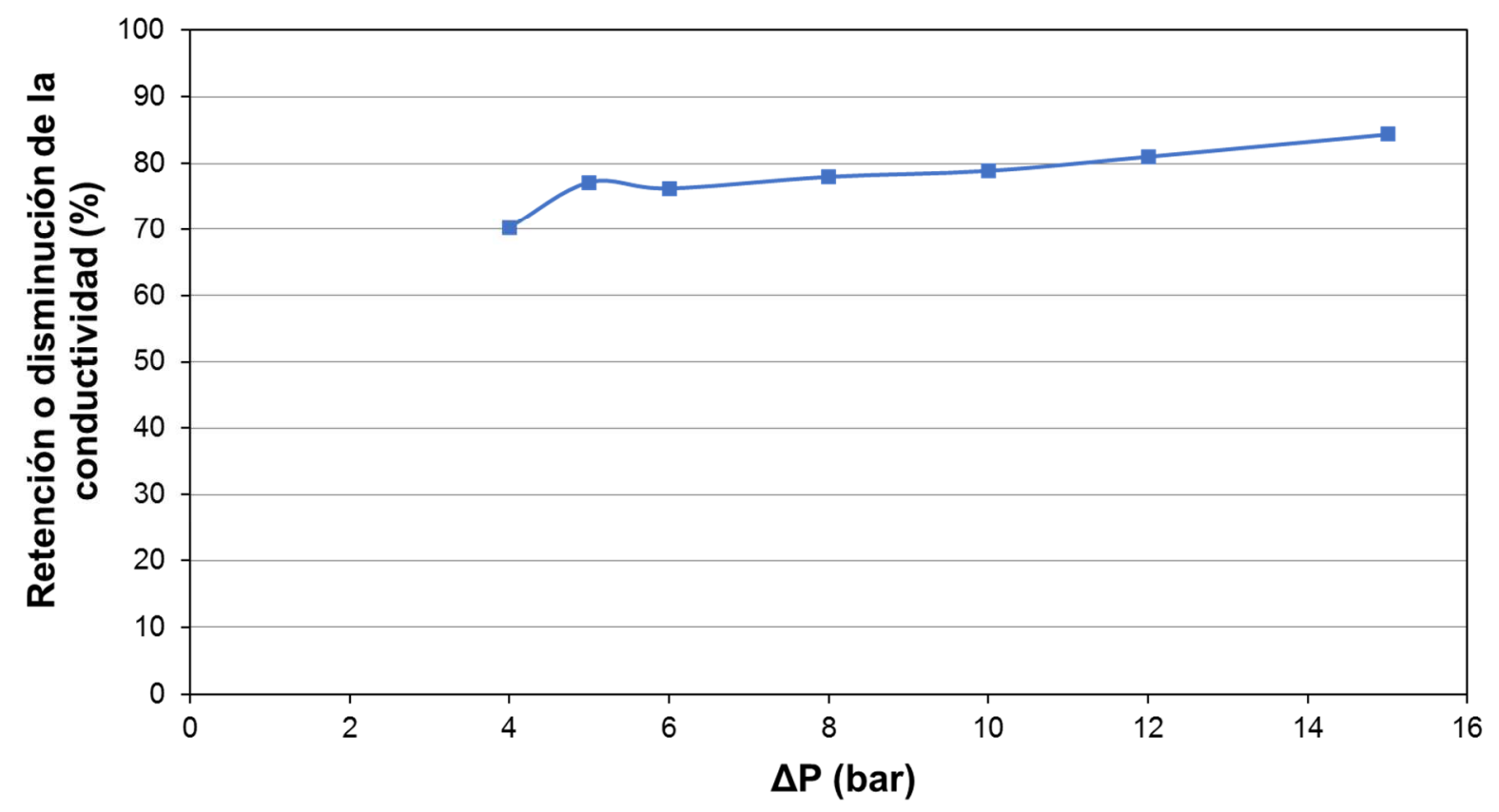

Figura 4.51. Disminución de la conductividad frente a la presión aplicada en la nanofiltración del agua residual.

El motivo de utilizar la conductividad como parámetro de control ha sido porque se puede medir directamente y por tanto no es necesario recurrir al laboratorio de análisis químico para analizar los iones divalentes que son los que verdaderamente se pretende eliminar. Además, si se comparan los resultados recogidos en la Tabla 4.29 y en la Figura 4.51 con los resultados obtenidos en la 
nanofiltración de aguas residuales recopilados en la Tabla 4.24, se puede observar que la disminución de la conductividad es del mismo orden que la disminución de la concentración de calcio (o incluso mejor), que es el principal catión floculante que se quiere eliminar de las aguas industriales. En posteriores ensayos se han realizado análisis más selectivos para saber exactamente la cantidad de iones divalentes que este tratamiento es capaz de retener. Como puede apreciarse en la Figura 4.51, a bajas presiones ya se pueden encontrar retenciones muy importantes. A una presión de 5 bar ya se encuentra la meseta que se sitúa en disminuciones de conductividad en torno al $80 \%$. Por tanto, para ahorrar energía, no es necesario trabajar a presiones más elevadas.

Una vez comprobado que la conductividad puede ser un parámetro sencillo de medir para controlar la evolución del tratamiento de nanofiltración, se pasó a realizar las pruebas con otros tipos de aguas.

\subsubsection{Pruebas de nanofiltración con aguas de pozo y pruebas reológicas}

En este apartado se recopilan los resultados obtenidos en las pruebas realizadas con las aguas de pozo, el otro tipo de agua que utiliza una empresa de producción de polvo atomizado (ver la Figura 4.44 y la Figura 4.45).

Se realizó un ensayo de nanofiltración a varias presiones y a concentración constante de un agua de pozo proporcionada por la empresa. En esta prueba se pudo determinar la disminución de la conductividad que mediante la aplicación de esta técnica se puede conseguir, además de la presión óptima de trabajo para conseguir la retención máxima. En la Tabla 4.30 se recogen los resultados.

Tabla 4.30. Resultados de flujo y disminución de la conductividad en el ensayo de nanofiltración del agua de pozo.

\begin{tabular}{|c|c|c|c|}
\hline $\begin{array}{c}\text { Presión } \Delta \mathrm{P} \\
(\text { bar })\end{array}$ & $\begin{array}{c}\text { Flujo de permeado } \mathrm{J}_{\mathrm{v}} \\
\left(\mathrm{L} / \mathrm{h} \mathrm{m}^{2}\right)\end{array}$ & $\begin{array}{c}\text { Conductividad } \\
(\mathrm{\mu S} / \mathrm{cm})\end{array}$ & $\begin{array}{c}\text { Retención } \\
(\%)\end{array}$ \\
\hline- & - & $910^{*}$ & 58 \\
\hline 4 & 38 & 379 & 63 \\
\hline 5 & 48 & 337 & 65 \\
\hline 6 & 60 & 321 & 67 \\
\hline 8 & 71 & 296 & 70 \\
\hline 10 & 102 & 273 & 70 \\
\hline 12 & 125 & 270 & 71 \\
\hline 15 & 153 & 261 & \\
\hline
\end{tabular}

* Conductividad inicial de la muestra alimento. 
En la Figura 4.52 se representa la disminución de la conductividad frente a la presión aplicada.

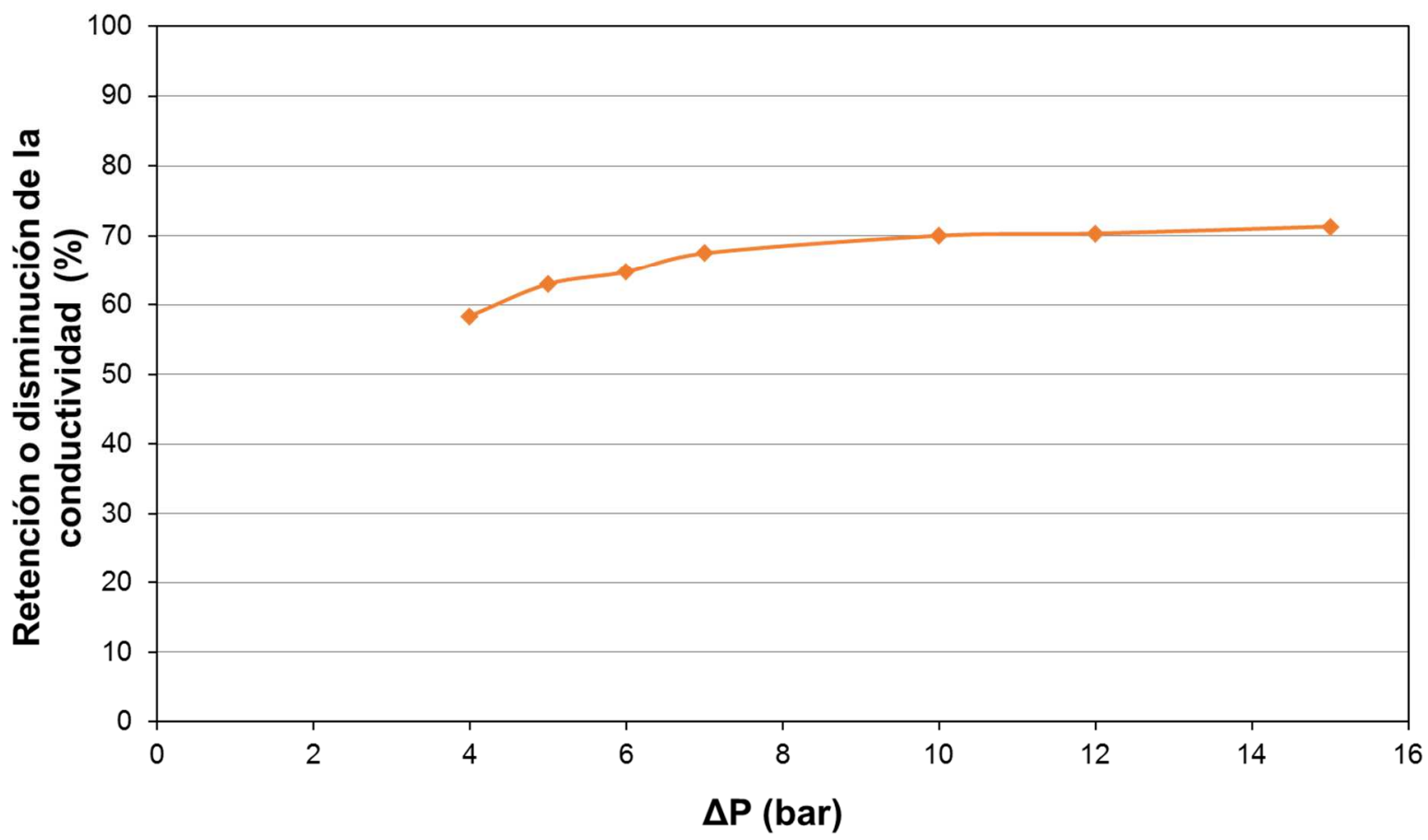

Figura 4.52. Disminución de la conductividad frente a la presión aplicada en la nanofiltración del agua de pozo.

Como se puede apreciar en la Figura 4.52, a partir de una presión de 6 bar la disminución de la conductividad se encuentra entre el 65 y $70 \%$. Por tanto, a bajas presiones ya se ha obtenido prácticamente la máxima retención, ya que se está muy cerca de la meseta.

Con las aguas obtenidas en este ensayo realizado con agua de pozo, se decidió hacer varias curvas de desfloculación, no siendo necesarias todo el resto de pruebas de producto cerámico, ya que como se ha visto en el punto anterior las aguas nanofiltradas son perfectamente aptas para la fabricación de baldosas cerámicas. Por tanto, solamente se realizó curvas de desfloculación con el agua de pozo y con el agua nanofiltrada. Los resultados se muestran en la Tabla 4.31 y en la Figura 4.53. 
Tabla 4.31. Resultados de las curvas de desfloculación de las suspensiones cerámicas con agua de pozo y agua nanofiltrada.

\begin{tabular}{|c|c|c|c|c|}
\hline \multirow{2}{*}{ Densidad } & \multicolumn{2}{|c|}{ Agua de pozo sin tratar } & \multicolumn{2}{c|}{ Agua de pozo nanofiltrada } \\
\cline { 2 - 5 } & $\begin{array}{c}\text { Desfloculante } \\
\text { mínimo } \\
\left(\text { desf.min }_{\text {. }}\right. \\
(\%)\end{array}$ & $\begin{array}{c}\text { Viscosidad } \\
\text { mínima }\left(\mu_{\text {min }}\right) \\
(\mathrm{cP})\end{array}$ & $\begin{array}{c}\text { Desfloculante } \\
\text { mínimo } \\
(\text { desf.min }) \\
(\%)\end{array}$ & $\begin{array}{c}\text { Viscosidad } \\
\text { mínima }\left(\mu_{\min }\right) \\
\text { (cP) }\end{array}$ \\
\hline $1,80 \mathrm{~g} / \mathrm{cm}^{3}$ & 0,6 & 398 & 0,5 & 353 \\
\hline $1,78 \mathrm{~g} / \mathrm{cm}^{3}$ & 0,6 & 311 & 0,5 & 272 \\
\hline $1,75 \mathrm{~g} / \mathrm{cm}^{3}$ & 0,6 & 157 & 0,4 & 145 \\
\hline
\end{tabular}
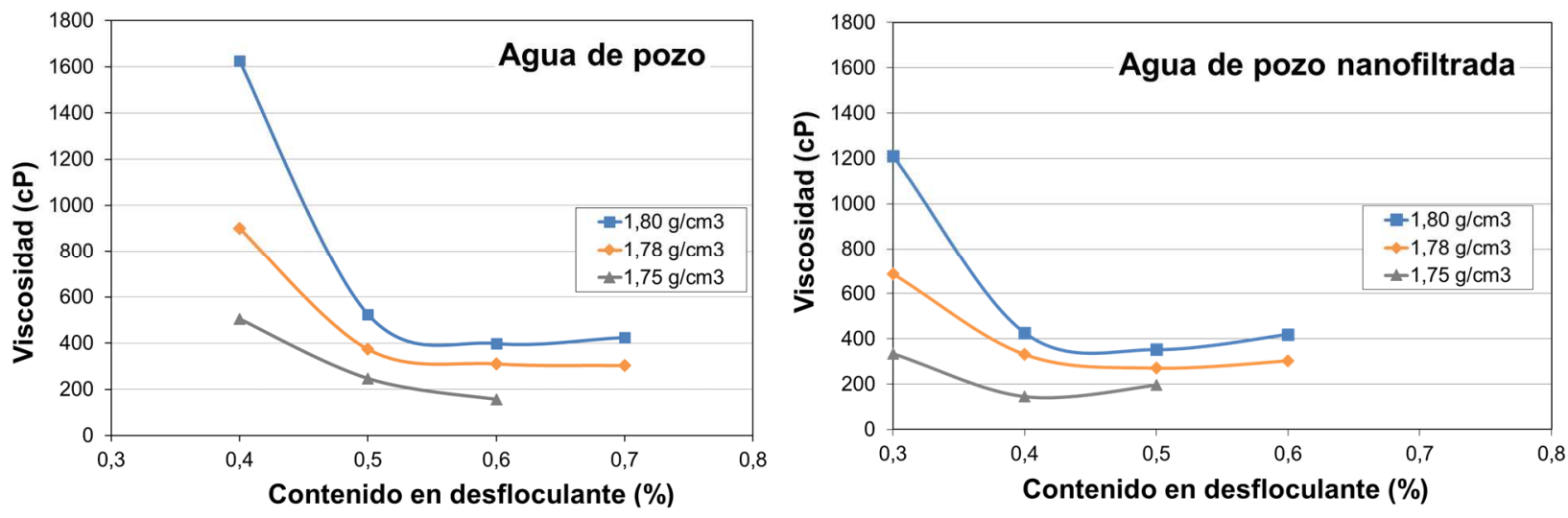

Figura 4.53. Viscosidad frente al contenido en desfloculante de las suspensiones elaboradas con agua de pozo.

Como se puede apreciar en las gráficas representadas en la Figura 4.53 se han comparado varias suspensiones cerámicas elaboradas con el agua nanofiltrada y con el agua de pozo sin nanofiltrar, y los resultados siguen siendo muy positivos, ya que tanto el desfloculante mínimo (desf.min) como la viscosidad mínima $\left(\mu_{\min }\right)$ de la suspensión cerámica disminuyen en las suspensiones elaboradas con agua tratada (todas las curvas se desplazan a la izquierda y hacia abajo).

\subsubsection{Pruebas de concentración de las muestras por nanofiltración y viabilidad de reutilización del rechazo obtenido}

Una vez comprobado que las aguas nanofiltradas aportan importantes beneficios reológicos y que eran perfectamente aptas para la fabricación de baldosas cerámicas, se continuó el estudio realizando pruebas de concentración de la disolución de partida para ver hasta qué punto puede concentrarse sin que la calidad del permeado se vea demasiado perjudicada, así como determinar si el rechazo puede ser reintroducido en el propio proceso de producción. De esta forma, se podrá determinar la máxima conversión que se puede alcanzar con estas membranas en el supuesto que el proyecto alcanzase una escala industrial. 
Por consiguiente, se realizaron pruebas, tanto con las aguas residuales, como con el agua de pozo. De esta forma se pretende determinar hasta qué nivel se podían concentrar cada una de ellas, o lo que es lo mismo, hasta que porcentaje de conversión se podía llegar sin que el permeado se viese afectado, ya que a mayor porcentaje de conversión la calidad del permeado disminuirá debido a que la concentración de la alimentación cada vez es mayor.

Como en todas las pruebas de laboratorio realizadas en este caso de estudio se utilizó el equipo de filtración tangencial que dispone el ITC capaz de albergar membranas planas (ver apartado 3.4.1 Plantas de filtración tangencial a escala de laboratorio). El régimen de circulación utilizado para llevar a cabo estos ensayos ha sido en discontinuo. Es decir, se extraía todo el permeado y el rechazo se volvía al tanque de alimentación en el que no se introducía ninguna otra corriente de alimentación nueva (ver Figura 1.34). De esta forma, se logra concentrar hasta el nivel deseado la disolución de partida. Las membranas utilizadas, como se ha mencionado en repetidas ocasiones en este caso de estudio, han sido las NF-270.

\section{Concentración de aquas residuales}

Para realizar esta prueba se partió de un volumen fijo de agua inicial de alimentación, al que se le fue extrayendo el permeado y recirculando el rechazo al tanque alimentación. A lo largo de la filtración se tomaron muestras del permeado y del rechazo, además de registrar la disminución del volumen del tanque de alimentación. La presión de trabajo fue de 5 bar, ya que como se ha visto con anterioridad (Tabla 4.24, Tabla 4.26, Figura 4.48 y Figura 4.51) no es necesario trabajar a presiones superiores para obtener retenciones de los compuestos que interesa eliminar y de esta forma consumir la menor energía posible.

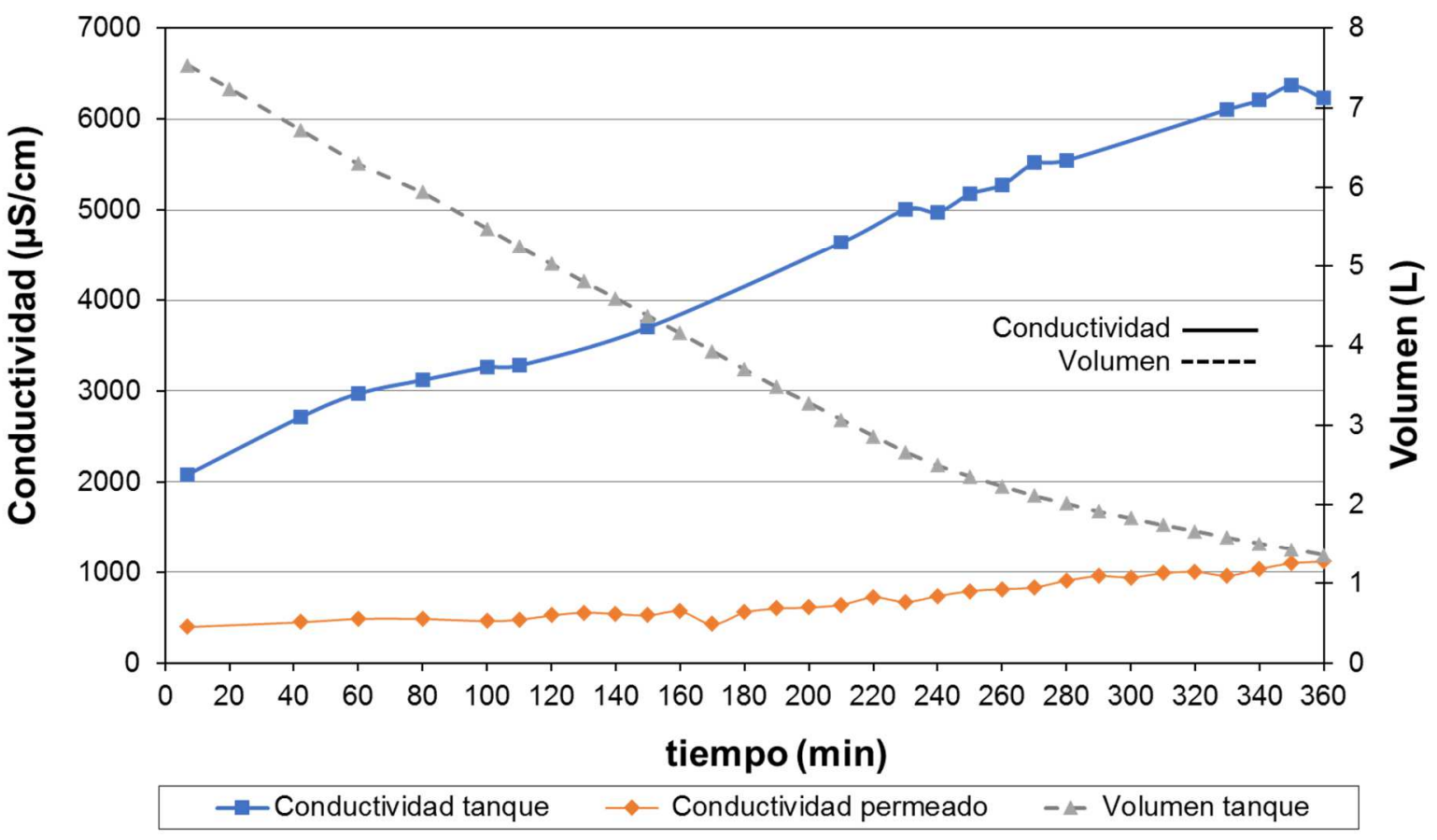

Figura 4.54. Prueba de concentración de una muestra de agua residual industrial mediante nanofiltración. 
Como se puede ver en la gráfica representada en la Figura 4.54 se partió de un volumen de disolución de alimentación de aproximadamente 7,5 litros y se detuvo el ensayo cuando se alcanzaron 1,2 litros, por tanto la concentración alcanzada es aproximadamente del 84\%.

Al finalizar la prueba se analizaron las muestras de permeado y rechazo, para poder calcular la retención obtenida. Los datos pueden observarse en la Tabla 4.32.

Tabla 4.32. Análisis de las aguas de inicio, el permeado y el rechazo de la prueba de concentración con aguas residuales.

\begin{tabular}{|c|c|c|c|c|}
\hline \multirow[t]{2}{*}{ Parámetro } & \multirow{2}{*}{$\begin{array}{c}\text { Agua residual } \\
\text { sin tratar } \\
\text { Valor }\end{array}$} & \multicolumn{2}{|c|}{$\begin{array}{l}\text { Agua residual nanofiltrada } \\
\text { Membr: NF270 } \\
\text { Presión: } 5 \text { bar }\end{array}$} & \multirow{2}{*}{ Rechazc } \\
\hline & & Valor & Retención (\%) & \\
\hline $\begin{array}{l}\text { Conductividad } \\
(\mu \mathrm{S} / \mathrm{cm})\end{array}$ & 1884 & 750 & 60 & 6450 \\
\hline $\mathrm{Cl}^{-}(\mathrm{mg} / \mathrm{L})$ & 100 & 94 & 6 & 114 \\
\hline $\mathrm{Na}^{+}(\mathrm{mg} / \mathrm{L})$ & 143 & 94 & 34 & 321 \\
\hline $\mathrm{SO}_{4}^{2-}(\mathrm{mg} / \mathrm{L})$ & 244 & 5,1 & 98 & 889 \\
\hline $\mathrm{Mg}^{2+}(\mathrm{mg} / \mathrm{L})$ & 33 & 6,2 & 81 & 131 \\
\hline $\mathrm{Ca}^{2+}(\mathrm{mg} / \mathrm{L})$ & 120 & 21 & 83 & 179 \\
\hline
\end{tabular}

Si se tiene en cuanta la conductividad, se puede apreciar que partiendo de una conductividad en torno a $1884 \mu \mathrm{S} / \mathrm{cm}$, la conductividad del permeado va aumentando desde $500 \mu \mathrm{S} / \mathrm{cm}$ hasta valores puntuales de algo más de $1000 \mu \mathrm{S} / \mathrm{cm}$ (ver Figura 4.54), siendo la conductividad final de todo el permeado obtenido de $750 \mu \mathrm{S} / \mathrm{cm}$. Por otra parte, la conductividad del rechazo aumenta desde 2000 $\mu \mathrm{S} / \mathrm{cm}$ hasta casi $6500 \mu \mathrm{S} / \mathrm{cm}$.

Se puede observar claramente en la Tabla 4.32 que los iones divalentes son fuertemente retenidos, en cambio la retención de los iones monovalentes es muy débil. Esta selectividad es la que se ha perseguido a lo largo de este estudio para alcanzar los objetivos previstos. Para finalizar esté ensayo de concentración, se realizaron varias curvas de desfloculación para verificar que, incluso con muestras de agua nanofiltrada con conductividades altas (debidas principalmente a los iones monovalentes) pero con bajos contenidos en iones divalentes, los beneficios reológicos se conservan.

En la Tabla 4.33, así como en las gráficas representadas en la Figura 4.55 puede observarse los resultados de las curvas de desfloculación obtenidas con el agua residual de la empresa de fabricación de polvo atomizado y el agua nanofiltrada tras el ensayo de concentración. 
Tabla 4.33. Resultados de las curvas de desfloculación de las aguas utilizadas en el ensayo de concentración.

\begin{tabular}{|c|c|c|c|c|}
\hline \multirow{2}{*}{ Densidad } & \multicolumn{2}{|c|}{ Agua residual sin tratar } & \multicolumn{2}{c|}{ Agua residual nanofiltrada } \\
\cline { 2 - 5 } & $\begin{array}{c}\text { Desfloculante } \\
\text { mínimo (desf.min) } \\
(\%)\end{array}$ & $\begin{array}{c}\text { Viscosidad } \\
\text { mínima }\left(\mu_{\text {min }}\right) \\
(\mathrm{cP})\end{array}$ & $\begin{array}{c}\text { Desfloculante } \\
\text { mínimo (desf.min) } \\
(\%)\end{array}$ & $\begin{array}{c}\text { Viscosidad } \\
\left.\text { mínima ( } \mu_{\text {min }}\right) \\
(\mathrm{cP})\end{array}$ \\
\hline $1,80 \mathrm{~g} / \mathrm{cm}^{3}$ & 0,65 & 370 & 0,5 & 342 \\
\hline $1,78 \mathrm{~g} / \mathrm{cm}^{3}$ & 0,7 & 310 & 0,6 & 237 \\
\hline $1,75 \mathrm{~g} / \mathrm{cm}^{3}$ & 0,6 & 200 & 0,4 & 160 \\
\hline
\end{tabular}
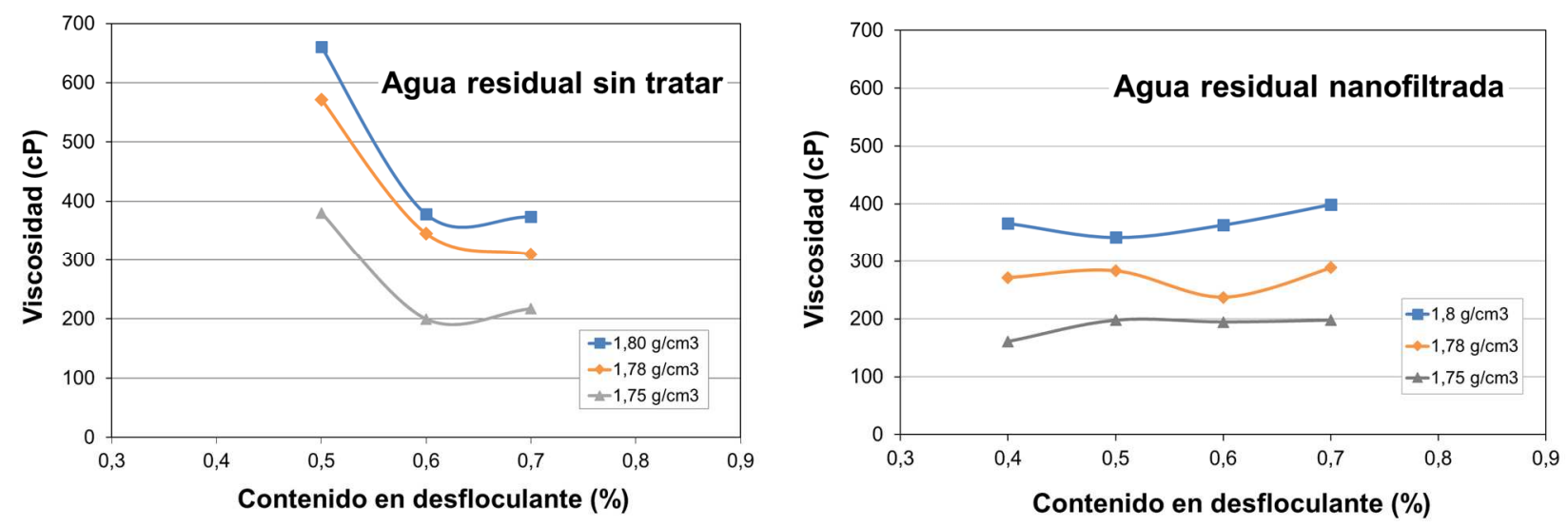

Figura 4.55. Viscosidad frente al contenido en desfloculante para diferentes densidades de las suspensiones cerámicas elaboradas con las aguas del ensayo de concentración de las aguas residuales.

Como puede apreciarse, siguen siendo positivos los resultados obtenidos con las aguas nanofiltradas, ya que las viscosidades de las suspensiones cerámicas son más bajas y el contenido en desfloculante también.

\section{Concentración de aqua de pozo}

Al igual que en el caso de las aguas residuales industriales, se realizó una prueba de concentración para determinar el máximo grado de conversión que se puede alcanzar, así como las características, tanto del permeado, como del rechazo que se obtienen a esa conversión máxima. La presión de trabajo fue de 5 bar. En la Figura 4.56 se puede observar los resultados. 


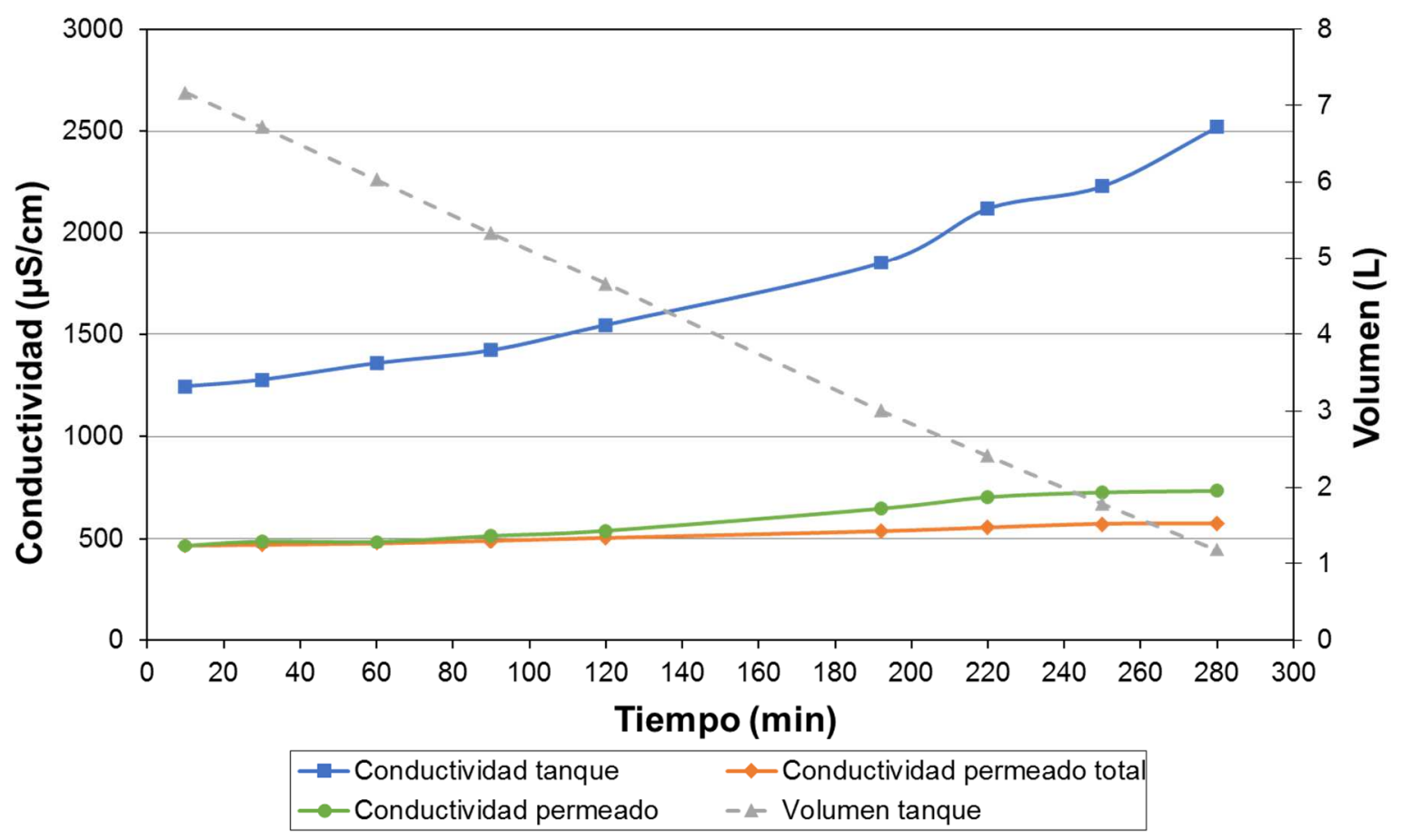

Figura 4.56. Prueba de concentración de una muestra de agua de pozo mediante nanofiltración.

Durante esta prueba se partió de una conductividad de $1242 \mu \mathrm{S} / \mathrm{cm}$ y se pudo llegar a una conversión del 85\%. La conductividad del rechazo ascendió a $2500 \mu \mathrm{S} / \mathrm{cm}$, mientras que la conductividad del permeado total se estabilizó en torno a $600 \mu \mathrm{S} / \mathrm{cm}$. Si se observa la conductividad obtenida en el rechazo, es perfectamente comparable con algunos de los análisis de las aguas residuales con las que las empresas de fabricación de polvo atomizado acostumbran a trabajar (ver Tabla 4.20). Estos datos hacen pensar que el rechazo obtenido en los tratamientos de nanofiltración podría ser reintroducido en el proceso de producción de polvo atomizado sin problema.

Con el fin de optimizar recursos, y observando que la conductividad del permeado se mantuvo en niveles tan bajos, no se consideró necesario repetir los ensayos reológicos con una suspensión cerámica elaborada con las aguas de pozo nanofiltradas, ya que es previsible obtener resultados similares a los ya observados anteriormente con este tipo de agua (ver Tabla 4.31 y Figura 4.57).

\section{Viabilidad de reutilización del rechazo}

Después de haber observado los buenos resultados obtenidos con el comportamiento reológico de las suspensiones realizadas con las aguas nanofiltradas, el factor clave para el posible escalado de la tecnología debe ser la viabilidad de reutilización de la corriente rechazo en el propio proceso productivo. La situación ideal sería que el rechazo pudiese ser reintroducido en el proceso de elaboración del polvo atomizado, durante la etapa de molienda. Por tanto, se ha creído oportuno estudiar el comportamiento reológico de suspensiones cerámicas elaboradas con los rechazos de las dos aguas nanofiltradas en los dos ensayos de concentración anteriores. Además, se ha comparado su comportamiento reológico con el de una suspensión elaborada con agua residual de proceso utilizada por la empresa. Los resultados se muestran en laTabla 4.34 y en la Figura 4.57. 
Tabla 4.34. Resultados de las curvas de desfloculación de las suspensiones cerámicas elaboradas con agua residual de proceso utilizada por la empresa y el rechazo obtenido después de los ensayos de nanofiltración (ensayos de concentración).

\begin{tabular}{|c|c|c|c|c|c|c|}
\hline \multirow[b]{2}{*}{ Densidad } & \multicolumn{2}{|c|}{ Agua residual sin tratar } & \multicolumn{2}{|c|}{$\begin{array}{c}\text { Rechazo de la } \\
\text { nanofiltración del agua de } \\
\text { pozo }\end{array}$} & \multicolumn{2}{|c|}{$\begin{array}{c}\text { Rechazo de la } \\
\text { nanofiltración del agua } \\
\text { residual }\end{array}$} \\
\hline & $\begin{array}{c}\text { Desfloculante } \\
\text { mínimo } \\
(\text { desf.min }) \\
(\%)\end{array}$ & $\begin{array}{c}\text { Viscosidad } \\
\text { mínima } \\
\left(\mu_{\min }\right) \\
(\mathrm{cP})\end{array}$ & $\begin{array}{c}\text { Desfloculante } \\
\text { mínimo } \\
(\text { desf.min) } \\
(\%)\end{array}$ & $\begin{array}{c}\text { Viscosidad } \\
\text { mínima } \\
\left(\mu_{\min }\right) \\
(\mathrm{cP})\end{array}$ & $\begin{array}{c}\text { Desfloculante } \\
\text { mínimo } \\
(\text { desf.min }) \\
(\%)\end{array}$ & $\begin{array}{c}\text { Viscosidad } \\
\text { mínima } \\
\left(\mu_{\text {min }}\right) \\
(\mathrm{cP})\end{array}$ \\
\hline $1,80 \mathrm{~g} / \mathrm{cm}^{3}$ & 0,6 & 530 & 0,6 & 600 & - & - \\
\hline $1,78 \mathrm{~g} / \mathrm{cm}^{3}$ & 0,6 & 405 & 0,6 & 500 & - & - \\
\hline $1,76 \mathrm{~g} / \mathrm{cm}^{3}$ & - & - & - & - & 1 & 661 \\
\hline $1,75 \mathrm{~g} / \mathrm{cm}^{3}$ & 0,7 & 225 & 0,6 & 235 & - & - \\
\hline $1,74 \mathrm{~g} / \mathrm{cm}^{3}$ & - & - & - & - & 0,9 & 499 \\
\hline
\end{tabular}

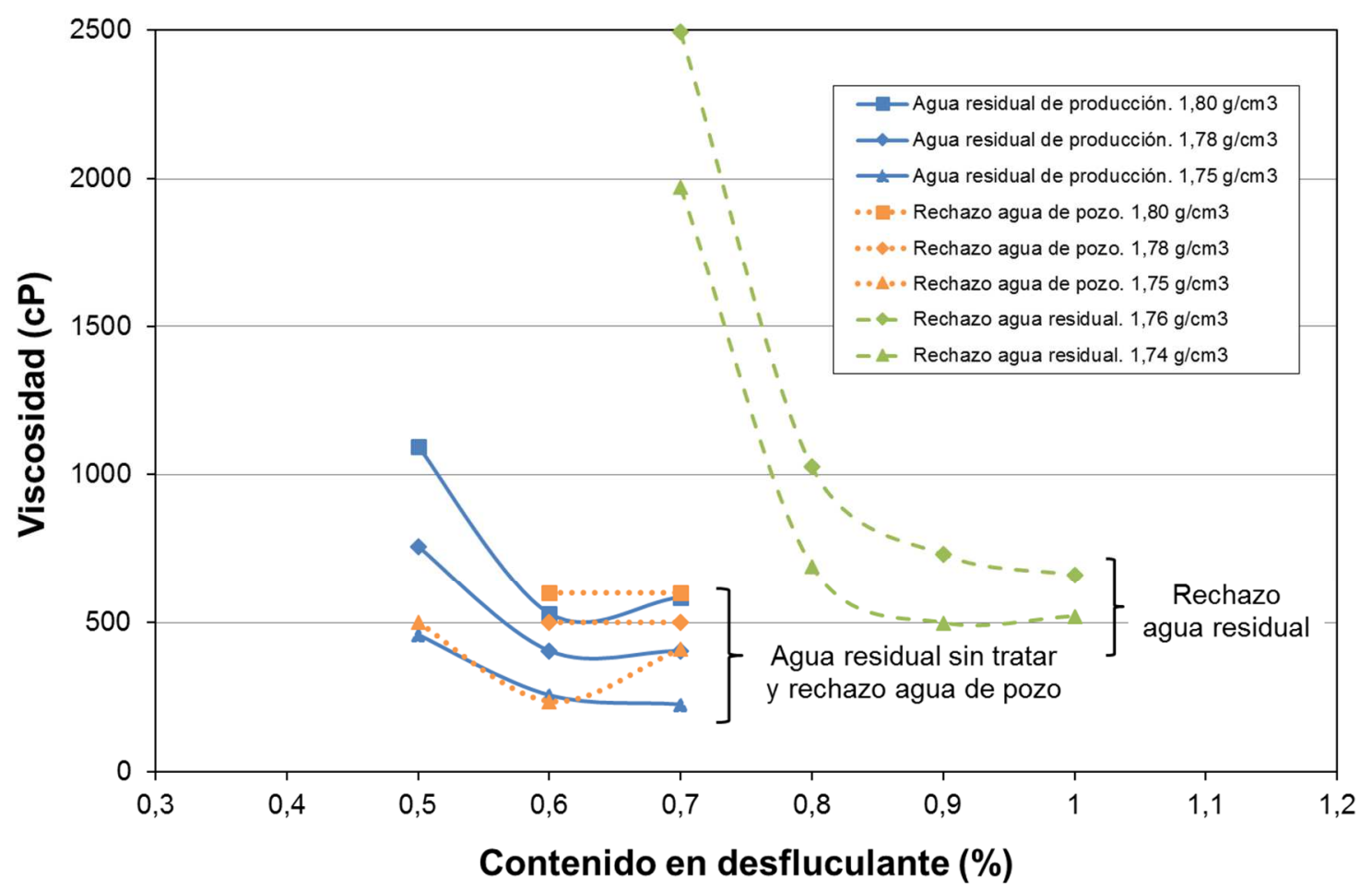

Figura 4.57. Viscosidad frente al contenido en desfloculante de las suspensiones elaboradas con agua residual y con los rechazos obtenidos de la nanofiltración del agua residual y del agua de pozo en los ensayos de concentración.

Como se puede apreciar en la Tabla 4.34 y en la Figura 4.57 las suspensiones cerámicas elaboradas con las aguas residuales que habitualmente son utilizadas por la empresa, tienen un comportamiento similar al de las suspensiones cerámicas elaboradas con el rechazo obtenido tras la nanofiltración de agua de pozo, por tanto el rechazo de las aguas de pozo podrá ser fácilmente reutilizado por la empresa, sin causarle ningún tipo de trastorno en su gestión. De esta forma, será posible aprovechar los beneficios que el agua nanofiltrada proporcionará a la empresa. 
En cambio, se ha podido comprobar que, cuando se filtran aguas residuales es más complejo reutilizar el rechazo obtenido después de la nanofiltración, ya que éste presenta conductividades muy elevas, por una mayor presencia de diferentes iones (una conductividad de $6450 \mu \mathrm{S} / \mathrm{cm}, 179$ $\mathrm{mg} / \mathrm{L}$ de $\mathrm{Ca}^{2+}$ o $889 \mathrm{mg} / \mathrm{L}$ de $\mathrm{SO}_{4}{ }^{2-}$ ). Como puede apreciarse en la Figura 4.57, las suspensiones elaboradas con el rechazo obtenido tras la nanofiltración de aguas residuales necesitan altos porcentajes de desfloculante para llegar a obtener viscosidades que no pueden bajar de $500 \mathrm{cP}$, incluso a densidades no demasiado altas. Este hecho hace que estas aguas no sean aptas para la elaboración de suspensiones cerámicas ya que las condiciones y coste de la operación de molienda excederían los de la práctica industrial. Por tanto, para trabajar con estas aguas residuales y la tecnología de nanofiltración, habría que pensar en combinar la tecnología de membranas con tecnologías de ablandamiento que permitieran realizar un tratamiento a esta corriente de rechazo para intentar bajar su conductividad y su dureza, de esta forma poder introducir este rechazo en el proceso productivo sin ningún cambio considerable en el producto final. También se podría trabajar con conversiones menos elevadas para no concentrar tanto el rechazo. Sin embargo, trabajar a conversiones mucho menores no aportaría los suficientes beneficios a una empresa para poder implementar la técnica de nanofiltración en su proceso productivo, ya que es previsible que los costes de operación superaran a los ahorros conseguidos. En cambio, se ha podido comprobar que, cuando se filtran aguas de pozo, la corriente de rechazo de la nanofiltración puede ser reutilizada fácilmente por la empresa para la elaboración de suspensiones cerámicas, ya que presenta características similares a las aguas residuales que las empresas de atomización gestionan (en cuanto a conductividad y dureza).

Por tanto, después de la obtención de estos resultados el estudio de este segundo caso de aplicación de la tecnología de nanofiltración en el sector se centrará en el tratamiento de las aguas de pozo para poder reutilizar también el rechazo en el propio proceso productivo, sin necesidad de ningún otro tipo de tratamiento.

\subsubsection{Resultados piloto en la empresa de producción de polvo atomizado con las aguas de pozo}

El objetivo específico de este punto ha sido recopilar toda la información resultante de las pruebas que se han realizado en las instalaciones industriales de una empresa de elaboración de polvo atomizado para ver si es posible el escalado a nivel industrial de los resultados que han sido obtenidos a escala de laboratorio, y demostrar, la viabilidad de la tecnología de nanofiltración en esta aplicación concreta.

Para la realización de las pruebas a escala piloto se ha utilizado la instalación del ITC (ver el apartado 3.4.2 Planta de filtración tangencial a escala piloto). Y para ello fue transportada con un camión grúa hasta la empresa de elaboración de polvo atomizado tal y como se muestra en las imágenes de la Figura 4.58. 

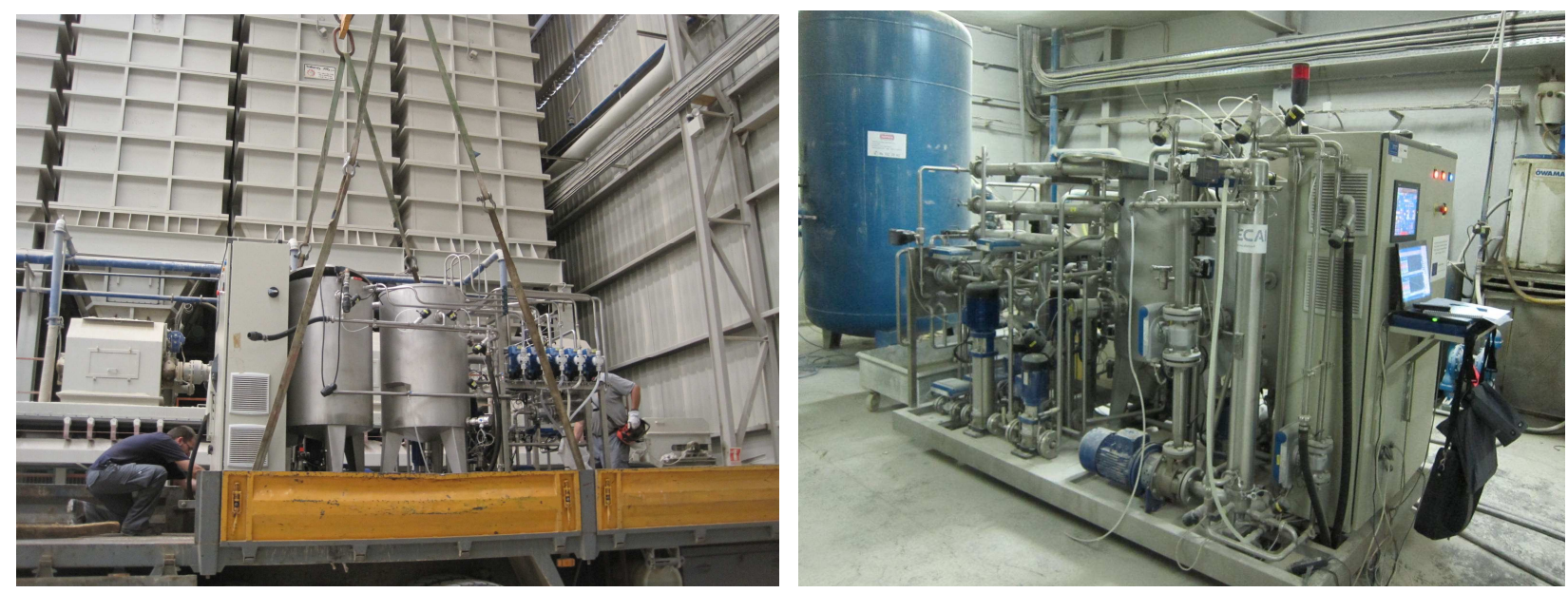

Figura 4.58. Traslado hasta la empresa de fabricación de polvo atomizado de la planta de nanofiltración del ITC y ubicación en la empresa.

Como se ha mencionado, el equipo consta de una primera etapa de pretratamiento o parte de microfiltración, en la cual se han utilizado 7 membranas cerámicas del tipo KLEANSEPTM 300 kD de la marca Orelis (ver apartado 3.3 Membranas), ya que estas membranas han sido las que mejores resultados ofrecieron en el anterior caso de estudio.

Sin embargo, el núcleo importante de la planta piloto es la parte de nanofiltración, donde se pueden utilizar simultáneamente tres membranas poliméricas en espiral de tipo 2540 en configuraciones muy diversas (en serie, en paralelo y combinaciones de ambas). En este caso se han utilizado 3 membranas tipo NF-270 2540 de la marca Dow Filmtec (ver apartado 3.3 Membranas y Anexo III).

Los distintos métodos de análisis y determinación de parámetros necesarios se recogen en el apartado 3.5 Análisis y determinación de diferentes parámetros.

A lo largo de esta parte del estudio se ha calculado varios parámetros en cada uno de los ensayos realizados con las membranas, ya que estos indicarán la idoneidad del tratamiento de nanofiltración para alcanzar los objetivos previstos. Estos parámetros han sido la retención ofrecida por la membrana a un determinado elemento y el grado de conversión (ver apartado 3.6.3 Cálculo de la retención ofrecida por las membranas y el grado de conversión).

Como se ha mencionado, en este caso el objetivo perseguido es que la retención de las membranas a los iones divalentes sea lo más elevada posible, por ese motivo se determinará la concentración de $\mathrm{Ca}^{2+}, \mathrm{Mg}^{2+}, \mathrm{SO}_{4}{ }^{2-} \ldots$ además de algunos iones monovalentes como por ejemplo $\mathrm{Na}^{+}, \mathrm{Cl}^{-} \ldots$, tanto en la disolución de alimentación como en el permeado, de esta forma calcular la retención para cada uno de estos elementos. Sin embargo, hay que poner de manifiesto que el análisis de estos elementos es muy laborioso y poco dinámico, por tanto, para agilizar los ensayos también se puede calcular indirectamente la retención de las membranas a estos iones, utilizando parámetros directamente relacionados con la concentración de dichos iones en una disolución como puede ser la conductividad, tal y como se verá a lo largo de los resultados obtenidos.

Por lo que respecta a la conversión, para lograr cumplir los objetivos marcados en el proyecto, interesa que este parámetro sea lo más alto posible, ya que esto significará que la cantidad de agua 
proveniente del rechazo será pequeña y la cantidad de agua libre de iones perjudiciales para la desfloculación o permeado será máxima.

Antes de la realización de las pruebas de nanofiltración realizadas en la empresa se puso a punto la etapa de microfiltración teniendo en cuenta los resultados obtenidos en el primer caso de estudio. Seguidamente se realizaron las pruebas de nanofiltración en la empresa que pueden dividirse en dos tipos. Por un lado, los ensayos de nanofiltración en discontinuo para determinar la retención de los iones que se quieren eliminar, la conversión del sistema y la configuración de membranas más adecuada. Y por otro lado, los ensayos de nanofiltración en continuo que han permitido estudiar el comportamiento de las membranas con el tiempo en condiciones de funcionamiento reales, además de obtener la suficiente agua nanofiltrada para realizar pruebas de producto a gran escala.

Para finalizar, en este apartado se han recopilado los resultados obtenidos en las pruebas reológicas que se han realizado a diferentes productos de la empresa de fabricación de polvo atomizado elaborados con las aguas tratadas. Se han realizado, tanto pruebas a escala laboratorio, como una prueba industrial a gran escala con un molino de bolas en discontinuo para la que se necesitaron $10000 \mathrm{~L}$ de agua permeada.

\subsubsection{Pruebas en discontinuo de la etapa de microfiltración.}

En primer lugar, antes de empezar con la nanofiltración propiamente dicha, se hicieron algunas pruebas con la etapa de microfiltración, que consistieron en poner a punto las membranas rehidratándolas y haciendo algunas pruebas de SDI (índice de ensuciamiento) para comprobar que esta etapa de pretratamiento estaba funcionando correctamente y que el SDI del agua era menor después de pasar por el pretratamiento. No se creyó necesario hacer un estudio muy exhaustivo a estas membranas porque ya se había realizado en el caso de estudio precedente (eliminación de boro) y no se iba a cambiar de membranas de microfiltración (ver apartado 4.2.3.1 Optimización del pretratamiento de microfiltración a escala piloto).

Durante las primeras pruebas de microfiltración se ha medido el SDI del agua antes y después de ser sometida a la microfiltración. Los resultados obtenidos se recogen en la Tabla 4.35, mientras que en la Figura 4.59 se pueden observar varios filtros utilizados en la determinación del SDI, tanto para aguas de pozo sin haber sido sometidas a ningún tipo de tratamiento, como los filtros utilizados con las aguas de pozo después del pretratamiento de microfiltración.

Tabla 4.35. Resultados de las pruebas de SDI y método de obtención.

\begin{tabular}{|c|c|c|}
\hline & SDI & Observaciones \\
\hline Agua de pozo & 5,95 & Medida realizada directamente en la empresa \\
\cline { 2 - 3 } & 6,05 & Medida realizada en el ITC \\
\hline $\begin{array}{c}\text { Agua después de MF } \\
\text { (KLEANSEPTM } 300 \mathrm{kD})\end{array}$ & 4,24 & Medida realizada en el ITC \\
\hline
\end{tabular}




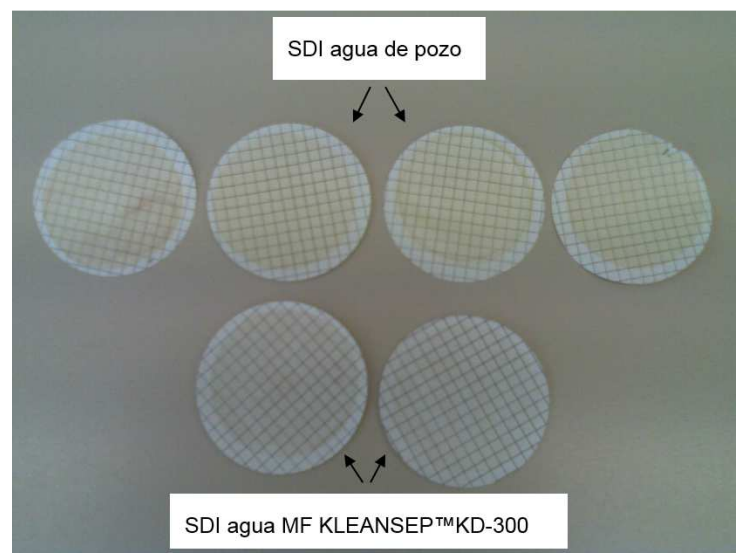

Figura 4.59. Filtros utilizados en el ensayo de SDI.

Se aprecia claramente una disminución del SDI después de la microfiltración, esto indica que el pretratamiento está siendo efectivo. Sin embargo, el SDI obtenido después del pretratamiento de microfiltración sigue siendo elevado. Este dato indica que las aguas, incluso siendo de pozo, tienen un índice de ensuciamiento importante, este dato tiene que estar presente durante la realización del estudio para efectuar las limpiezas pertinentes. También se deberá tener en cuanta si se tuviese que implementar una instalación industrial, tanto para una buena planificación de los ciclos de limpieza, como para la elección de un buen aditivo anti-incrustante, que mejore la nanofiltración y alargue la vida útil de las membranas.

\subsubsection{Pruebas en discontinuo de la etapa de nanofiltración}

Las primeras pruebas de nanofiltración realizadas en la empresa de producción de polvo atomizado fueron pruebas en circuito cerrado, es decir, tanto la corriente de permeado como la de rechazo se redirigían al tanque de alimentación. De esta forma se trabaja a concentración constante.

Con las pruebas en discontinuo a nivel de planta piloto se ha pretendido alcanzar varios objetivos. En primer lugar, analizar si los resultados que se habían obtenido a escala de laboratorio se repiten a escala piloto. Por otro lado, se ha analizado el comportamiento de las membranas con el tipo de agua con el que se tiene que trabajar para determinar cuáles son los parámetros de trabajo más indicados para la realización de las pruebas en continuo que simulen el funcionamiento de una instalación industrial. Y por último, se han probado varias configuraciones de membranas y varias condiciones de trabajo para optimizar al máximo el sistema de filtración, ya que en esta empresa se puede disponer de toda el agua necesaria para llevar a cabo los ensayos industriales. En este caso de estudio hubo la posibilidad de trabajar con 3 membranas de nanofiltración para obtener el máximo rendimiento de la planta piloto, ya que como se ha visto en el apartado de equipamiento (ver apartado 3.4.2 Planta de filtración tangencial a escala piloto), la planta piloto tiene 3 cárteres con capacidad para albergar 3 membranas de tipo 2540.

Por tanto, se han probado 4 configuraciones diferentes, ya que la planta piloto lo permite:

- Configuración 1: Una membrana individual.

- Configuración 2: Dos niveles. Dos membranas en serie.

- Configuración 3: Dos niveles. Dos membranas en paralelo + Una membrana en serie.

- Configuración 4: Tres niveles. Tres membranas en serie. 
La manera de proceder ha sido la de microfiltrar una cierta cantidad de agua que era conducida al tanque de alimentación de la parte de nanofiltración y ésta circulaba en circuito cerrado por el circuito de la nanofiltración hasta terminar con los ensayos previstos.

En los siguientes apartados se pueden observar los resultados obtenidos en cada una de las configuraciones estudiadas.

\section{Configuración 1: Una membrana individual}

En primer lugar, se optó por empezar haciendo pruebas con una sola membrana, de esta forma se podría estudiar si el comportamiento de la membrana en formato industrial (espiral y formato 2540) era el mismo que con las membranas planas que se habían utilizado durante las pruebas a escala de laboratorio.

En la Figura 4.60 se ilustra un esquema de la configuración de la membrana, donde a será la alimentación, p el permeado y $r$ el rechazo.

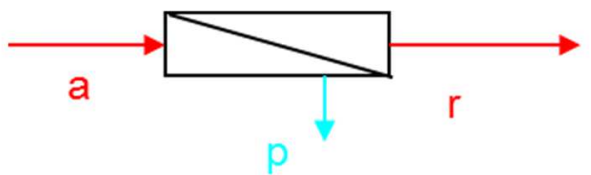

Figura 4.60. Un módulo, una membrana NF-270 2540.

Se han realizado varias pruebas con esta configuración. A continuación, en la Tabla 4.36 se recogen algunos de los resultados más representativos obtenidos.

Tabla 4.36. Prueba en discontinuo a diferentes presiones con agua de pozo y una configuración de 1 membrana NF-270 tipo 2540

\begin{tabular}{|c|c|c|c|c|c|c|c|c|c|}
\hline $\begin{array}{c}\Delta P \\
(\mathrm{bar})\end{array}$ & $\begin{array}{c}\text { Conduct } \\
(\mu \mathrm{S} / \mathrm{cm})\end{array}$ & $\begin{array}{c}\text { Conduct.p } \\
(\mu \mathrm{S} / \mathrm{cm})\end{array}$ & $\begin{array}{c}\text { Conduct.r } \\
(\mu \mathrm{S} / \mathrm{cm})\end{array}$ & $\begin{array}{c}R^{*} \\
(\%)\end{array}$ & $\begin{array}{c}Q_{a^{*}} \\
(\mathrm{~L} / \mathrm{h})\end{array}$ & $\begin{array}{c}Q_{p} \\
(\mathrm{~L} / \mathrm{h})\end{array}$ & $\begin{array}{c}J_{v^{*}} \\
\left(\mathrm{~L} / \mathrm{h} \cdot \mathrm{m}^{2}\right)\end{array}$ & $\begin{array}{c}Q_{r} \\
(\mathrm{~L} / \mathrm{h})\end{array}$ & $\begin{array}{c}S^{*} \\
(\%)\end{array}$ \\
\hline 4 & 1111 & 390 & 1175 & 65 & 1399 & 166 & 57,0 & 1233 & 12 \\
\hline 5 & 1080 & 367 & 1253 & 66 & 1400 & 190 & 65,3 & 1210 & 14 \\
\hline 7 & 1100 & 312 & 1250 & 72 & 1400 & 277 & 95,1 & 1123 & 20 \\
\hline 8 & 1099 & 297 & 1370 & 73 & 1400 & 316 & 108,5 & 1084 & 23 \\
\hline 9 & 1130 & 287 & 1350 & 75 & 1400 & 345 & 118,5 & 1055 & 25 \\
\hline 10 & 1093 & 294 & 1418 & 73 & 1400 & 389 & 130,9 & 1011 & 28 \\
\hline 11 & 1094 & 276 & 1344 & 75 & 1400 & 414 & 139,3 & 986 & 30 \\
\hline 12 & 1111 & 274 & 1383 & 75 & 1400 & 473 & 156,5 & 927 & 34 \\
\hline
\end{tabular}

Nota: $R$ es la retención o en este caso, la disminución de la conductividad y $S$ es la conversión alcanzada. 
Si se comparan estos datos con los obtenidos con la membrana plana (ver Tabla 4.30 y Figura 4.52) se puede observar que las retenciones coinciden bastante bien. Las retenciones de la membrana plana son ligeramente inferiores a las retenciones de la membrana en espiral, sin embargo estas variaciones son poco significativas.

\section{Configuración 2: Dos niveles. Dos membranas en serie}

En la Figura 4.61 puede observarse el esquema de esta configuración:

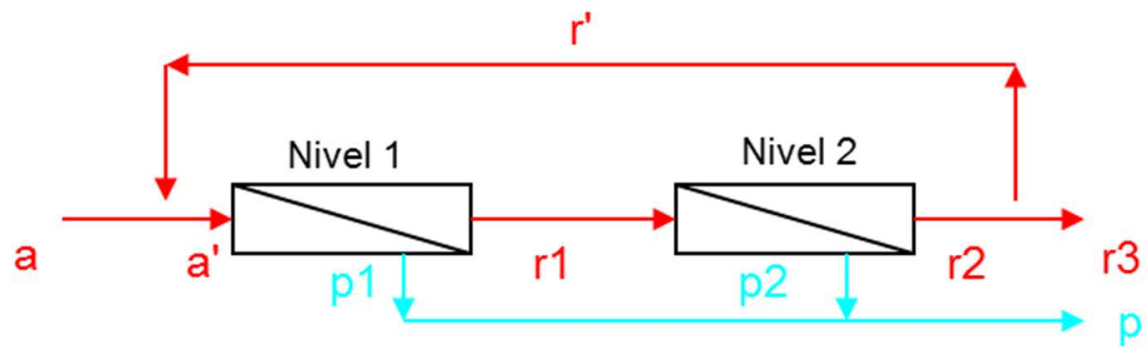

Figura 4.61. Dos módulos con dos membranas NF-270 2540 en serie con recirculación.

En este caso aparece la recirculación ( $\left.r^{\prime}\right)$, que simplemente es parte del rechazo que es recirculado a la cabeza del sistema de nanofiltración. La recirculación se realiza para aumentar la conversión del sistema y para que en todo momento haya un caudal óptimo de alimentación a las membranas para que estas funcionen de la forma más eficiente posible. Por tanto, a', será la corriente alimentación (a) más la corriente recirculación ( $r$ ’). Además, como en este caso existen dos niveles y dos membranas, p1 será el permeado de la membrana 1, mientras que p2 será el permeado de la 2. Por otro lado, al estar conectadas las dos membranas en serie, el rechazo de la membrana 1 (r1) será la alimentación de la membrana 2, mientras que el rechazo de la membrana 2 (r2) se bifurcará en el caudal de recirculación (r') y el rechazo que saldrá de la planta (r3). Los resultados obtenidos mediante esta configuración se recogen en la Tabla 4.37:

Tabla 4.37. Prueba en discontinuo a diferentes presiones con agua de pozo y una configuración de 2 membranas NF-270 en serie con recirculación.

\begin{tabular}{|c|c|c|c|c|c|c|c|c|c|}
\hline $\begin{array}{c}\Delta P \\
(\mathrm{bar})\end{array}$ & $\begin{array}{c}\text { Conduct.a } \\
(\mu \mathrm{S} / \mathrm{cm})\end{array}$ & $\begin{array}{c}\text { Conduct.p } \\
(\mu \mathrm{S} / \mathrm{cm})\end{array}$ & $\begin{array}{c}\text { Conduct.r } \\
(\mu \mathrm{S} / \mathrm{cm})\end{array}$ & $\begin{array}{c}R^{*} \\
(\%)\end{array}$ & $\begin{array}{c}Q_{a} \\
(\mathrm{~L} / \mathrm{h})\end{array}$ & $\begin{array}{c}Q_{p} \\
(\mathrm{~L} / \mathrm{h})\end{array}$ & $\begin{array}{c}Q_{r 3} \\
(\mathrm{~L} / \mathrm{h})\end{array}$ & $\begin{array}{c}Q_{r^{\prime}} \\
(\mathrm{L} / \mathrm{h})\end{array}$ & $\begin{array}{c}S^{*} \\
(\%)\end{array}$ \\
\hline 4 & 1029 & 427 & 1426 & 59 & 1002 & 288 & 714 & 95 & 29 \\
\hline 5 & 1025 & 412 & 1400 & 60 & 1004 & 356 & 648 & 69 & 35 \\
\hline 7 & 1011 & 397 & 1701 & 61 & 1000 & 502 & 498 & 100 & 50 \\
\hline 8 & 1003 & 398 & 1970 & 60 & 1005 & 574 & 431 & 103 & 57 \\
\hline 10 & 1010 & 430 & 2600 & 57 & 999 & 698 & 301 & 103 & 70 \\
\hline
\end{tabular}

Nota: $R$ es la retención o en este caso, la disminución de la conductividad y $S$ es la conversión alcanzada. 


\section{Configuración 3: Dos niveles. Dos membranas en paralelo + Una membrana en serie}

El esquema de esta configuración se puede observar en la Figura 4.62:

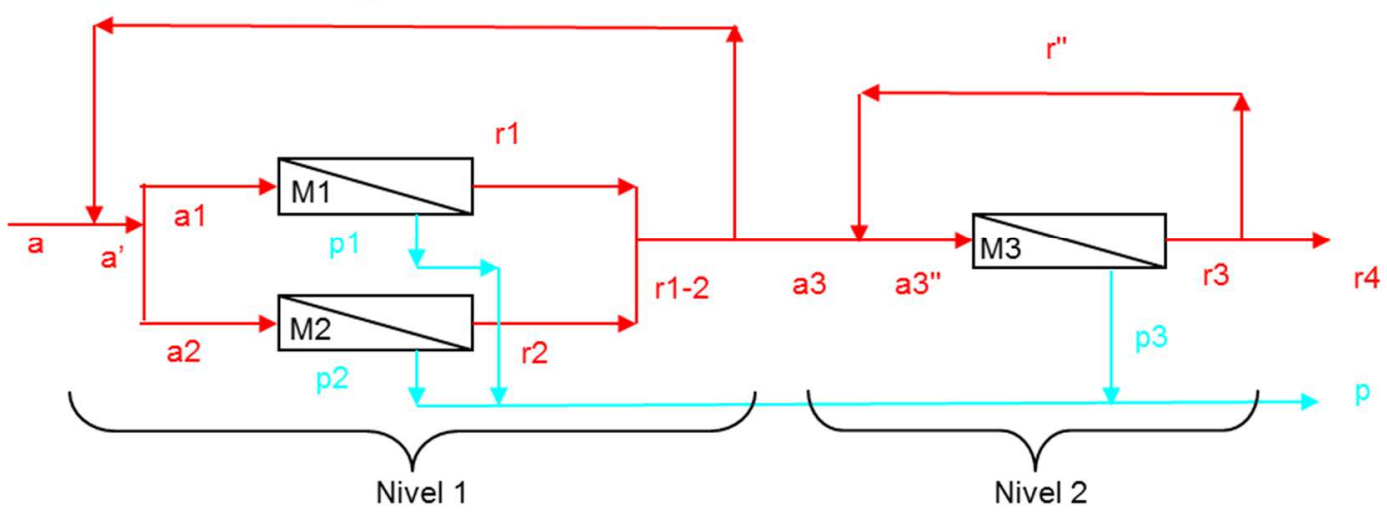

Figura 4.62. Tres módulos con tres membranas NF-270 2540, 2 membranas en paralelo + 1 en serie con recirculación.

En esta configuración, en el primer nivel se disponen dos membranas en paralelo, los permeados y rechazo se unirán por separado a la salida de cada membrana. La corriente rechazo unificada se bifurcará en la corriente recirculación ( $r$ ') que se reintroducirá en cabeza del sistema y en otra corriente que se dirigirá a la alimentación de la membrana 3 (M3). El permeado de la membrana 3 (M3) se unirá a la corriente que unía a su vez los permeados de las dos membranas situadas en el nivel $1(\mathrm{p} 1+\mathrm{p} 2)$. Por otro lado, el rechazo de la membrana 3 (M3) se dividirá en la corriente de recirculación (r") que se reintroducirá como alimento a la cabeza de la membrana 3 y en el rechazo que se extraerá de la planta piloto (r4). Por tanto, el alimento de la membrana 3 (a3") estará constituido por el rechazo de las membranas del nivel 1 (r1-2) menos la corriente de recirculación $(r$ ') que se introduce en cabeza del sistema, más la corriente de recirculación proveniente del rechazo de la membrana 3 ( $r$ ').

En la Tabla 4.38 se pueden observar los resultados obtenidos con esta configuración.

Tabla 4.38. Prueba en discontinuo a diferentes presiones con agua de pozo y una configuración de 2 membranas en paralelo + 1 membrana en serie $(2+1)$ con recirculación (membranas todas ellas NF-270 2540).

\begin{tabular}{|c|c|c|c|c|c|c|c|}
\hline $\begin{array}{c}\Delta P \\
(\text { bar })\end{array}$ & $\begin{array}{c}\text { Conduct.a } \\
(\mu S / c m)\end{array}$ & $\begin{array}{c}\text { Conduct.p } \\
(\mu S / c m)\end{array}$ & $\begin{array}{c}R^{*} \\
(\%)\end{array}$ & $\begin{array}{c}Q_{a} \\
(\mathrm{~L} / \mathrm{h})\end{array}$ & $\begin{array}{c}\mathbf{Q}_{p} \\
(\mathrm{~L} / \mathrm{h})\end{array}$ & $\begin{array}{c}\mathbf{Q}_{r 4} \\
(\mathrm{~L} / \mathrm{h})\end{array}$ & $\begin{array}{c}S^{*} \\
(\%)\end{array}$ \\
\hline 4 & 1091 & 476 & 56 & 1404 & 457 & 947 & 33 \\
\hline 5 & 1089 & 477 & 56 & 1401 & 537 & 864 & 38 \\
\hline 7 & 1089 & 494 & 55 & 1396 & 675 & 721 & 48 \\
\hline 8 & 1024 & 548 & 47 & 1398 & 745 & 653 & 53 \\
\hline 10 & 925 & 593 & 36 & 1401 & 815 & 586 & 58 \\
\hline
\end{tabular}

Nota: $R$ es la retención o en este caso, la disminución de la conductividad y $S$ es la conversión alcanzada. 


\section{Configuración 4: Tres niveles. Tres membranas en serie}

Para finalizar con las configuraciones que se pueden ensayar con esta planta piloto se ha realizado las pruebas utilizando tres membranas en serie. En este caso, la recirculación ha asegurado que el caudal de alimentación para cada membrana está dentro de los límites establecidos por el fabricante de las membranas para que éstas trabajen en condiciones ideales. El esquema de esta configuración puede observarse en la Figura 4.63. El rechazo de cada una de las membranas será la alimentación de la siguiente. Además, el rechazo de la membrana 2 (r2) se dividirá para extraer una corriente de recirculación que se retroalimentará en cabeza antes de la membrana 1 . De la misma manera, el rechazo de la membrana 3 (r3) se bifurcará para reintroducir una corriente de recirculación antes de la membrana 3 , el resto de la corriente formará el rechazo de la planta piloto (r4).

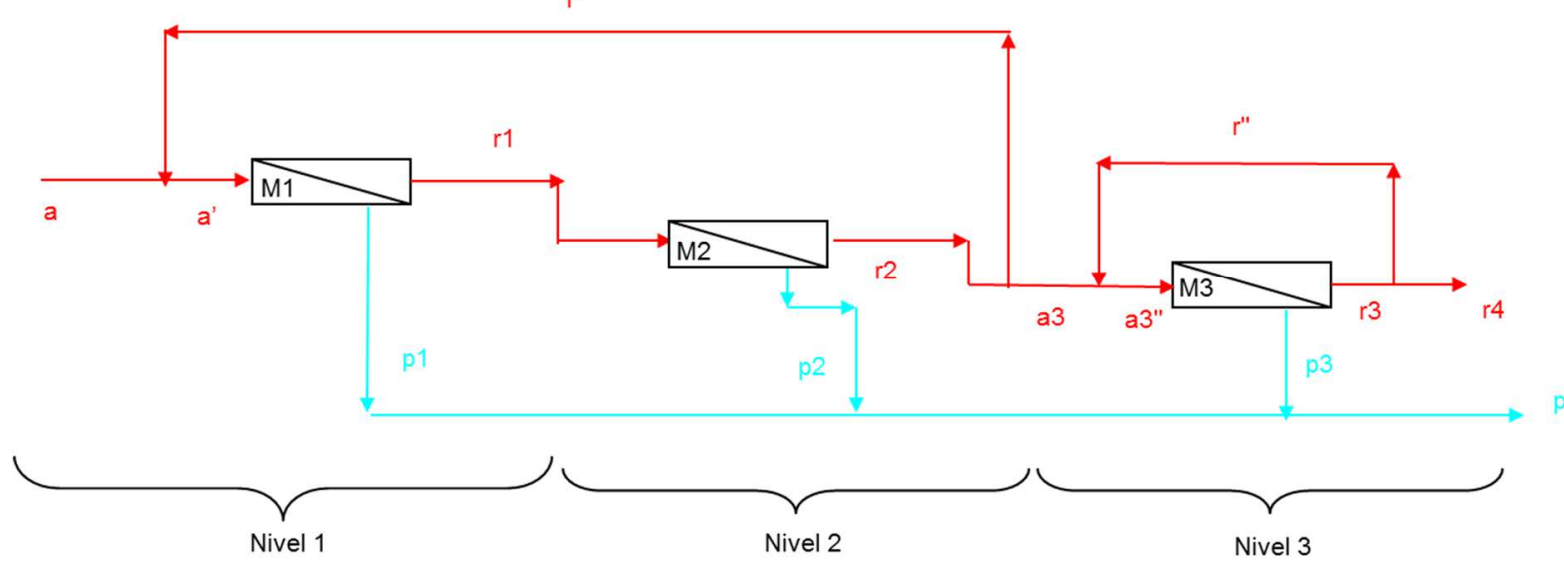

Figura 4.63. Tres módulos con tres membranas NF-270 2540 en serie con recirculación.

En la Tabla 4.39 se recogen los resultados obtenidos durante las pruebas realizadas con esta configuración

Tabla 4.39. Prueba en discontinuo a diferentes presiones con agua de pozo y una configuración de 3 membranas en serie NF-270 $(1+1+1)$ con recirculación.

\begin{tabular}{|c|c|c|c|c|c|c|c|}
\hline $\begin{array}{c}\Delta P \\
(\text { bar })\end{array}$ & $\begin{array}{c}\text { Conduct.a } \\
(\mu \mathrm{S} / \mathrm{cm})\end{array}$ & $\begin{array}{c}\text { Conduct.p } \\
(\mu \mathrm{S} / \mathrm{cm})\end{array}$ & $\begin{array}{c}\boldsymbol{R}^{*} \\
(\%)\end{array}$ & $\begin{array}{c}\boldsymbol{Q}_{a} \\
(\mathrm{~L} / \mathrm{h})\end{array}$ & $\begin{array}{c}\boldsymbol{Q}_{p} \\
(\mathrm{~L} / \mathrm{h})\end{array}$ & $\begin{array}{c}\mathbf{Q}_{r 4} \\
(\mathrm{~L} / \mathrm{h})\end{array}$ & $\begin{array}{c}S^{*} \\
(\%)\end{array}$ \\
\hline 4 & 936 & 373 & 60 & 999 & 411 & 595 & 41 \\
\hline 5 & 928 & 382 & 59 & 1001 & 490 & 530 & 49 \\
\hline 7 & 907 & 435 & 52 & 1000 & 636 & 375 & 64 \\
\hline 8 & 843 & 439 & 48 & 1005 & 708 & 308 & 70 \\
\hline 10 & 854 & 487 & 43 & 996 & 825 & 236 & 83 \\
\hline
\end{tabular}

Nota: $R$ es la retención o en este caso, la disminución de la conductividad y $S$ es la conversión alcanzada. 


\section{Comparación entre las diferentes configuraciones}

Después de observar los resultados obtenidos a lo largo de las diferentes pruebas realizadas se puede considerar que las mejores prestaciones (mayor retención y conversión) son alcanzadas con la configuración de 3 membranas en serie.

Por un lado, la disminución de la conductividad a baja presión (entre 4 bar y 7 bar), que es a la que interesa trabajar para no consumir mucha energía, en todos los casos es similar y se encuentra en torno al $60 \%$. Esta disminución se debe a la reducción de la concentración de iones en el permeado, sobre todo los iones divalentes que son los que interesa eliminar en este estudio. Esta reducción de conductividad, y por tanto, de iones divalentes que intervienen negativamente en la desfloculación de las suspensiones cerámicas, ya se ha visto que tiene importantes beneficios en el comportamiento reológico de las mismas (ver Tabla 4.31 y Figura 4.53). Por este motivo, no es necesario trabajar a presiones superiores.

Por otra parte, la conversión global obtenida con la configuración mencionada es la más elevada, variando a bajas presiones (entre 4 y 7 bar) en el intervalo de 40 a 64\%. Esta conversión global se consigue con una conversión individual de cada membrana no superior al $20 \%$, parámetro que según las especificaciones de los fabricantes de las membranas hay que tener en cuenta para no dañarlas [161]. Para aumentar la conversión del sistema hay que incrementar la superficie filtrante y utilizar la configuración de membrana más efectiva. La conversión alcanzada, junto con la retención de los iones no deseados (disminución de la conductividad), son los parámetros que se han tenido en cuenta para elegir esta configuración (3 membranas en serie). Configuración que será utilizada en las pruebas en continuo.

Una vez comprobado que los resultados conseguidos con las aguas obtenidas a escala piloto confirmaban los resultados observados en el laboratorio, se decidió realizar la nanofiltración para la obtención de 10000 L de agua permeada con el fin de elaborar suspensión cerámica a escala industrial. Para la obtención de esta cantidad de agua fueron necesarias las prueba en continuo con la planta piloto, que permitieron analizar el comportamiento del tratamiento en un ensayo de larga duración. Para ello, la configuración de la planta piloto ha sido de 3 membranas en serie y la presión de trabajo de 5,5 bar para intentar conseguir una reducción de la conductividad del $60 \%$ y una conversión lo más elevada posible, sin que las conversiones individuales de cada módulo excedieran el $20 \%$.

\subsubsection{Pruebas en continuo con la planta piloto}

En base a lo anterior, los pasos a seguir y las condiciones de trabajo utilizadas para realizar las pruebas en continuo fueron las siguientes:

- Alimentación de la cuba de microfiltración con agua de pozo.

- Microfiltración a través de membranas cerámicas KLEANSEPTM 300 kD. Para mantener el caudal de permeado, que será la alimentación de la siguiente etapa, en $1000 \mathrm{~L} / \mathrm{h}$, la presión de trabajo ha variado entre 2 y 4 bar (según ha ido progresando la obturación de las membranas).

- Alimentación de la cuba de nanofiltración con el agua microfiltrada. 
- Nanofiltración a través de 3 membranas NF-270 2540 conectadas en serie (ver Figura 4.63) y a una presión de aproximadamente 5,5 bar.

- Almacenamiento del agua nanofiltrada en tanques de $1000 \mathrm{~L}$ para su utilización en pruebas industriales. Para hacer la prueba de preparación de una suspensión cerámica a nivel industrial se han necesitado $10000 \mathrm{~L}$ de agua nanofiltrada (ver Figura 4.64).
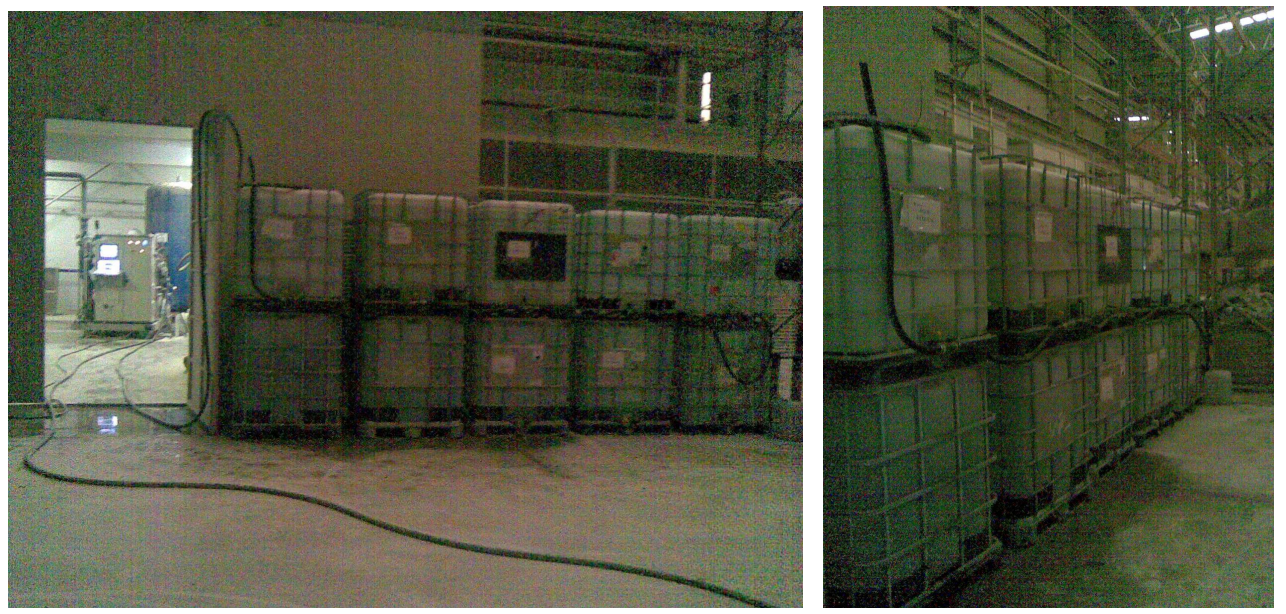

Figura 4.64. Planta piloto y tanques de almacenamiento del agua nanofiltrada.

En la Figura 4.65 se puede apreciar un esquema general del proceso en continuo:

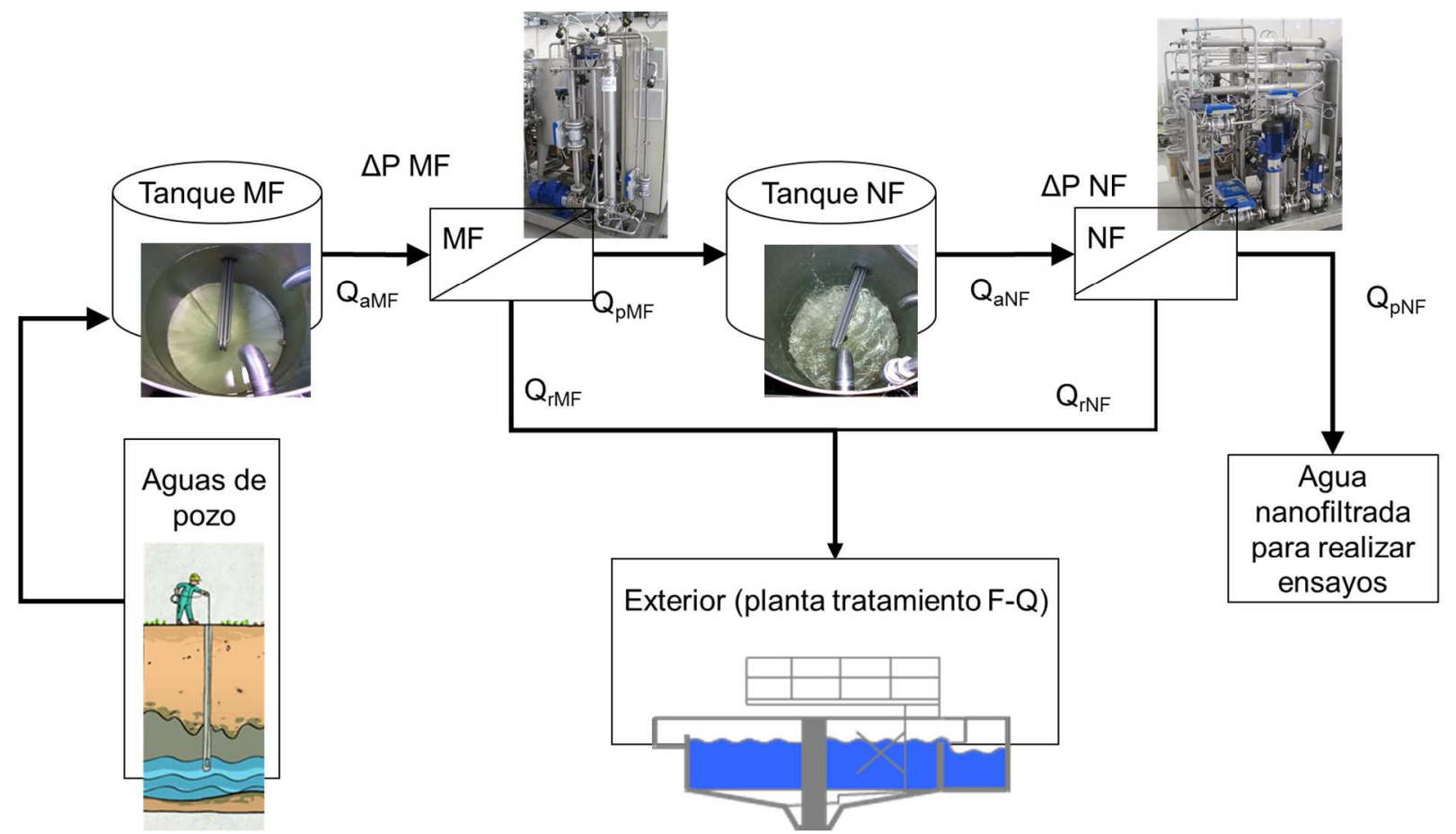

Figura 4.65. Esquema general del tratamiento en continuo de las aguas en la empresa de fabricación de polvo atomizado.

En los siguientes apartados se hará una recopilación de los resultados obtenidos en las pruebas realizadas en continuo. Se han realizado varias pruebas, sin embargo solamente se recopilarán los resultados de las pruebas más representativas.

Como se ha mencionado anteriormente, la parte de microfiltración se puede considerar como un pretratamiento, de esta forma alargar la vida útil de las membranas de nanofiltración y obtener su 
máximo rendimiento. Además, este pretratamiento tiene que proporcionar la suficiente agua microfiltrada a la etapa de nanofiltración. En el anterior caso de estudio (eliminación del boro) ya se abordó el funcionamiento de este pretratamiento, por lo que no se entrará en detalle para este segundo caso.

En cambio, sí que se abordarán los resultados obtenidos durante la nanofiltración propiamente dicha. Por lo tanto, durante la realización de las pruebas se han registrado todos los datos en continuo. En la Figura 4.66 se puede ver una representación del flujo de permeado y su conductividad obtenidos a lo largo de todo el ensayo en continuo.

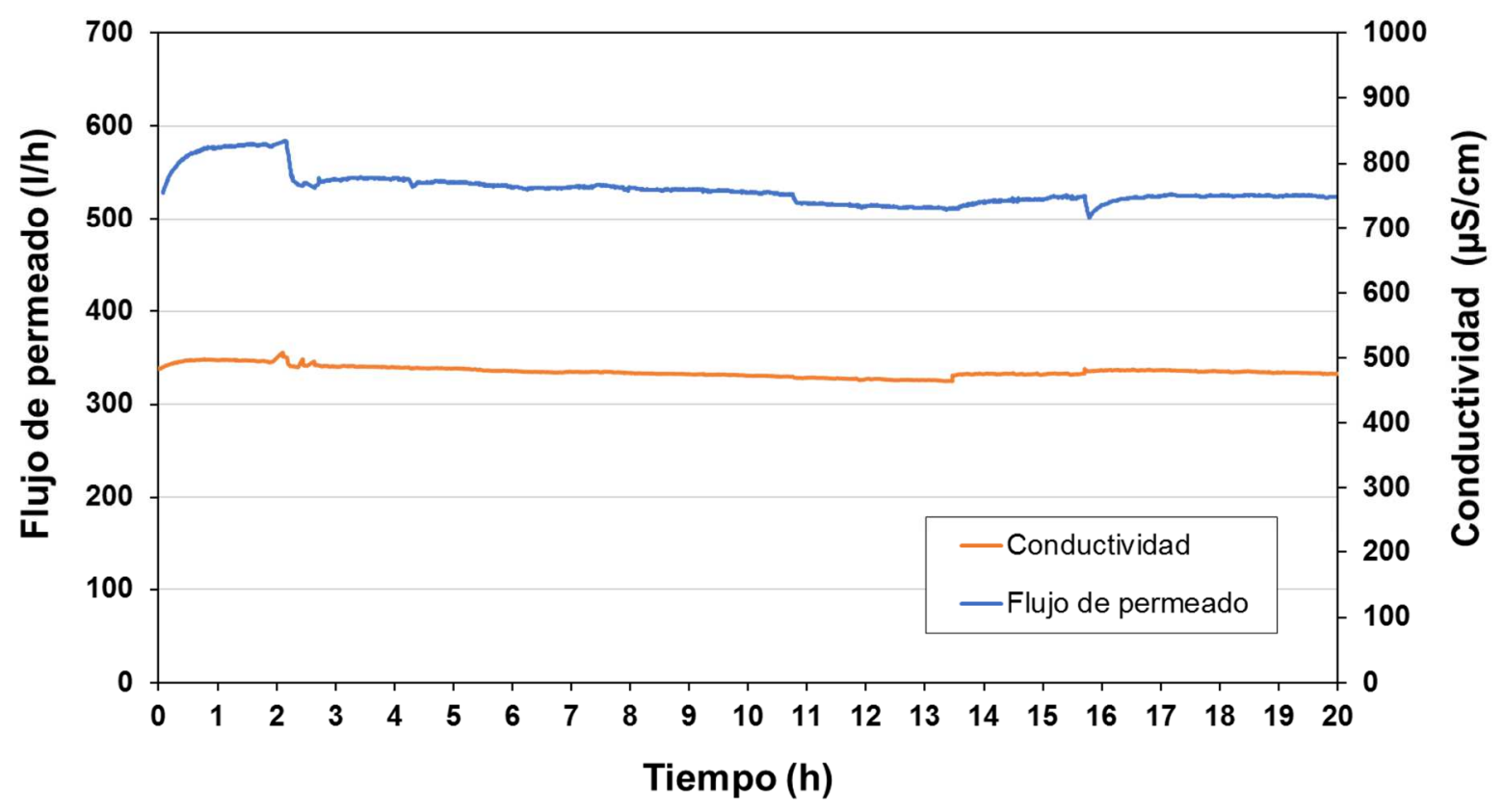

Figura 4.66. Flujo de permeado obtenido con las 3 membranas NF-270 en serie y conductividad del permeado en función del tiempo.

En la Tabla 4.40 se mostrarán algunos de los resultados puntuales, ya que las condiciones se mantuvieron constantes en todo momento, como se ha podido apreciar en la gráfica representada en la Figura 4.66.

Tabla 4.40. Condiciones de trabajo. Agua de pozo, sistema de 3 membranas en serie NF-270 (1+1+1) con recirculación.

\begin{tabular}{|c|c|c|c|c|c|c|c|}
\hline $\begin{array}{c}\Delta P \\
(\mathrm{bar})\end{array}$ & $\begin{array}{c}\text { Conduct.a } \\
(\mu \mathrm{S} / \mathrm{cm})\end{array}$ & $\begin{array}{c}\text { Conduct.p } \\
(\mu \mathrm{S} / \mathrm{cm})\end{array}$ & $\begin{array}{c}\boldsymbol{R}^{*} \\
(\%)\end{array}$ & $\begin{array}{c}\boldsymbol{Q}_{a} \\
(\mathrm{~L} / \mathrm{h})\end{array}$ & $\begin{array}{c}\boldsymbol{Q}_{p} \\
(\mathrm{~L} / \mathrm{h})\end{array}$ & $\begin{array}{c}\boldsymbol{Q}_{r 4} \\
(\mathrm{~L} / \mathrm{h})\end{array}$ & $\begin{array}{c}S^{*} \\
(\%)\end{array}$ \\
\hline 5,5 & 936 & 430 & 54 & 1000 & 522 & 478 & 52 \\
\hline
\end{tabular}

Nota: $R$ es la retención o en este caso, la disminución de la conductividad y $S$ es la conversión alcanzada.

Si se compara los resultados obtenidos en la prueba en continuo con los que se obtuvieron en las pruebas en discontinuo, se puede apreciar que son muy similares. Si se tiene en cuenta los resultados recogido en la Tabla 4.39 y en Tabla 4.40, se puede observar que el porcentaje de disminución de la conductividad es similar, bajando ligeramente en la prueba en continuo, ya que 
en la primera prueba se pudo conseguir una disminución de la conductividad del $59 \%$ y en esta segunda prueba en continuo la disminución ha sido del 54\%. Por lo que respecta a la conversión del sistema, ésta ha aumentado ligeramente, puesto que en la prueba en discontinuo se llegó a obtener una conversión del 49\%, mientras que en esta última prueba en continuo se ha llegado a conseguir una conversión del $52 \%$.

El parámetro que habitualmente se ha medido en continuo para calcular la retención de sales en la etapa de nanofiltración ha sido la conductividad, ya que es una medida simple y directa. Sin embargo, como en anteriores ocasiones, se ha realizado un análisis químico para conocer exactamente la retención de los iones más característicos, especialmente los iones divalentes. Los resultados de las muestras analizadas son los que se recogen en la Tabla 4.41.

Tabla 4.41. Análisis químicos de las muestras tomadas durante la realización de la prueba de nanofiltración en continuo. Agua de pozo, sistema 3 membranas NF-270 en serie $(1+1+1)$ con recirculación.

\begin{tabular}{|c|c|c|c|c|}
\hline Parámetro & $\begin{array}{c}\text { Alimentación } \\
(\mathrm{mg} / \mathrm{L})\end{array}$ & $\begin{array}{c}\text { Permeado } \\
(\mathrm{mg} / \mathrm{L})\end{array}$ & $\begin{array}{c}\text { Retención } \\
(\%)\end{array}$ & $\begin{array}{c}\text { Rechazo } \\
(\mathrm{mg} / \mathrm{L})\end{array}$ \\
\hline $\mathrm{Cl}^{-}(\mathrm{mg} / \mathrm{L})$ & 73 & 69 & 5 & 81 \\
\hline $\mathrm{SO}_{4}^{2-}(\mathrm{mg} / \mathrm{L})$ & 211 & 18 & 91 & 418 \\
\hline $\mathrm{Ca}^{2+}(\mathrm{mg} / \mathrm{L})$ & 73 & 24 & 67 & 126 \\
\hline $\mathrm{Na}^{+}(\mathrm{mg} / \mathrm{L})$ & 45 & 29 & 36 & 61 \\
\hline
\end{tabular}

Los iones divalentes son más retenidos que los iones monovalentes, tal y como se esperaba para poder cumplir los objetivos marcados. Si comparamos los resultados obtenidos en otras ocasiones con estas membranas (ver Tabla 4.32 y Tabla 4.41) se puede apreciar que la retención en el caso del calcio y de los sulfatos ha bajado ligeramente. Puede considerarse que están dentro de un mismo orden para el caso de los sulfatos, disminuyendo algo más en el caso del calcio. No obstante, se trata de una retención considerable (67\%). Al aumentar la conversión la efectividad del tratamiento tiende a disminuir ya que la concentración antes de la membrana aumenta considerablemente en las especies retenidas [43]. En cambio, la disminución en la efectividad del tratamiento si se comparan resultados de ensayos realizados a conversiones similares, podría ser debida a fenómenos de "fouling" o concentración de polarización, ya que ambos pueden influir negativamente en el funcionamiento de las membranas de nanofiltración [63][88]. Además, también hay que tener en cuenta si los resultados han sido obtenidos con membranas planas o en espiral, ya que como se ha visto en el apartado 4.2.2.2 Ensayos de nanofiltración realizados con membranas en espiral, existen factores hidrodinámicos y heterogeneidades entre varias membranas que pueden afectar ligeramente a su comportamiento.

El comportamiento de las membranas de nanofiltración es bastante estable en el tiempo, además la conductividad del permeado también lo es a lo largo del ensayo (ver la Figura 4.66). Por tanto, este comportamiento de las membranas hace pensar que sería viable la utilización de esta 
tecnología para conseguir los objetivos perseguidos en este trabajo. Por otro lado, hay que tener en cuenta que siempre hay que realizar una buena optimización de las etapas de lavado, así como un buen mantenimiento de la instalación de filtración y su pretratamiento.

Después de la realización de la prueba en continuo y de la obtención de los $10000 \mathrm{~L}$ de agua nanofiltrada ya se estuvo en disposición de realizar la prueba industrial de elaboración de una suspensión cerámica en un molino discontinuo de la empresa de elaboración de polvo atomizado en la que se han realizado las pruebas.

El comportamiento reológico de las suspensiones cerámicas elaboradas con las aguas nanofiltradas en la prueba en continuo se puede observar en la gráfica ilustrada en la Figura 4.67.

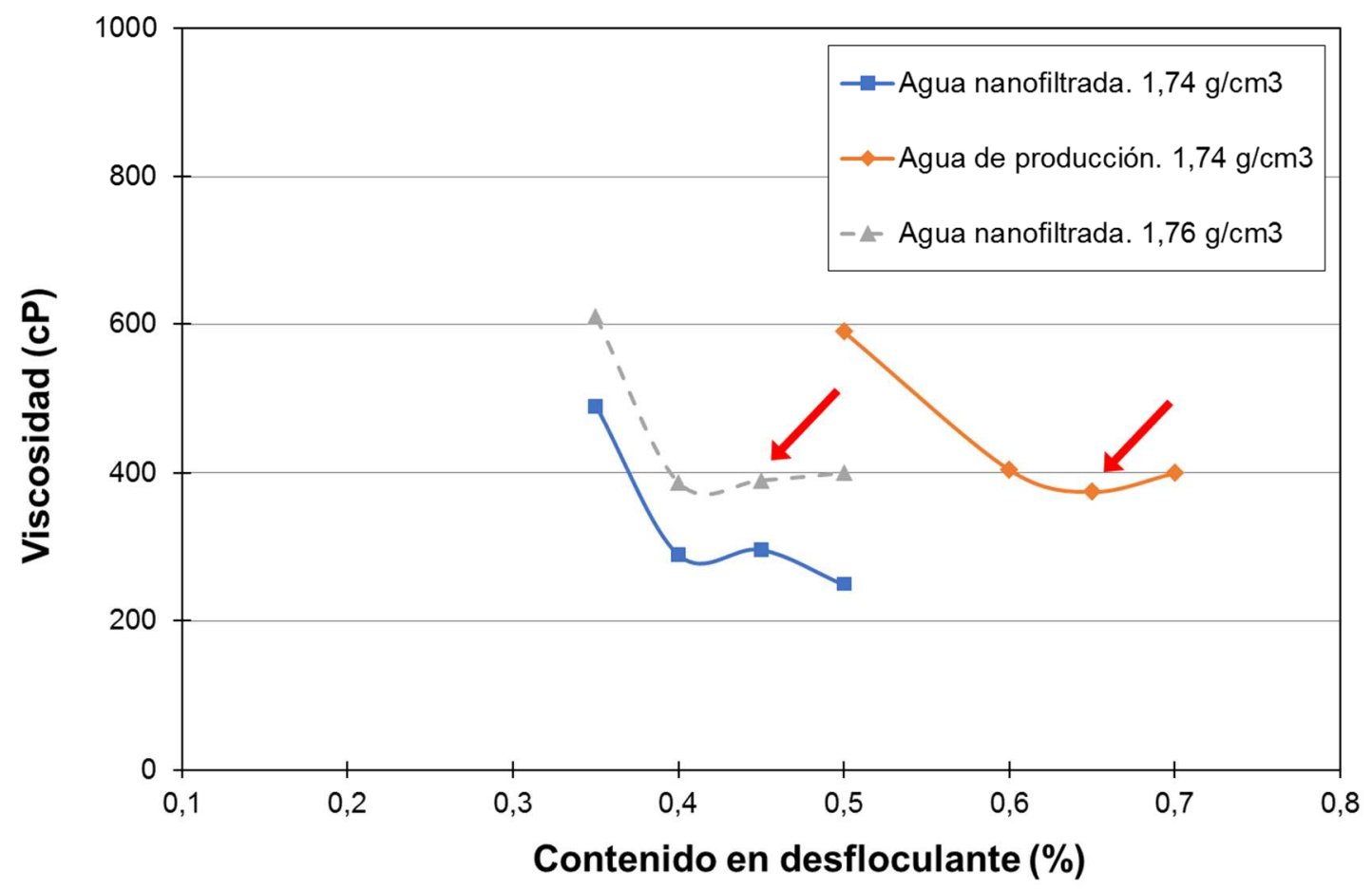

Figura 4.67. Comparativa de los resultados de las pruebas reológicas entre el agua de producción y el agua nanofiltrada en la prueba industrial.

Las flechas rojas de la gráfica indican el punto exacto al que se han llevado las suspensiones cerámicas elaboradas a nivel industrial. La suspensión elaborada con agua nanofiltrada se llevó a una densidad de $1,76 \mathrm{~g} / \mathrm{cm}^{3}$ con un contenido en desfloculante del 0,45\% y una viscosidad de 390 cP. Mientras que con el agua no tratada solamente se pudo llegar a una densidad de la suspensión cerámica de $1,74 \mathrm{~g} / \mathrm{cm}^{3}$ con un contenido de desfloculante del $0,65 \%$ y una viscosidad de $385 \mathrm{cP}$. Los resultados siguen siendo muy positivos ya que el contenido en desfloculante necesario para la obtención de la suspensión cerámica y la viscosidad de la misma han disminuido considerablemente. Este hecho ha permitido aumentar la densidad de la suspensión cerámica (y por tanto, el contenido en sólidos) de $1,74 \mathrm{~g} / \mathrm{cm}^{3}$ (densidad a la que acostumbra a trabajar la empresa donde se han realizado las pruebas) a $1,76 \mathrm{~g} / \mathrm{cm}^{3}$. Estos resultados muestran que con la utilización del agua nanofiltrada en las condiciones mencionadas pueden obtenerse importantes beneficios en la elaboración de suspensiones cerámicas. 


\subsubsection{Balance económico del tratamiento de las aguas de pozo}

En esta parte del estudio se han analizado, tanto los costes asociados a esta tecnología, como los posibles ahorros en producción que una empresa de fabricación de polvo atomizado puede alcanzar con la implementación del tratamiento de nanofiltración a sus aguas de pozo.

\section{Calculo del coste del tratamiento de nanofiltración}

Una empresa fabricante de equipamientos de filtración a través de membranas ha presupuestado el coste de una instalación de nanofiltración que cubriese las necesidades de una empresa de producción de polvo atomizado de este tipo. Por tanto, el coste de una planta de nanofiltración compuesta por un pretratamiento de microfiltración de membranas cerámicas más la etapa de nanofiltración a través de membranas poliméricas, así como todo el equipamiento necesario para el buen funcionamiento de la planta (caudalímetros, electroválvulas, pHmetros, conductímetros...), más los trabajos de instalación eléctrica y fontanería, ascendería a $70000 €$.

A su vez, esta empresa ha proporcionado los siguientes datos referentes a los costes de funcionamiento de esta instalación. Estos costes están calculados para una instalación capaz de tratar los $50000 \mathrm{~m}^{3}$ de agua de pozo que una empresa de polvo atomizado modelo puede consumir en un año y se recopilan en la Tabla 4.42.

Tabla 4.42. Datos desglosados de los costes de operación.

\begin{tabular}{|c|c|c|}
\hline Parámetro & $\begin{array}{c}\text { Coste } \\
\left(€ / \mathrm{m}^{3}\right)\end{array}$ & $\begin{array}{c}\text { Porcentaje del coste } \\
\text { respecto al total }\end{array}$ \\
\hline Electricidad & 0,072 & $26,20 \%$ \\
\hline Productos & 0,115 & $41,80 \%$ \\
\hline Membranas & 0,043 & $15,60 \%$ \\
\hline Filtros & 0,014 & $5,10 \%$ \\
\hline Mantenimiento & 0,031 & $11,30 \%$ \\
\hline Coste total agua tratada & $\mathbf{0 , 2 7 5}$ & - \\
\hline
\end{tabular}

\section{Cálculo del ahorro debido a la utilización de la nanofiltración en este caso de estudio}

Mediante la aplicación de la nanofiltración en este caso de estudio se pretende ahorrar en 3 puntos distintos:

\section{- Ahorro en el desfloculante}

Si se eliminan del agua que se ha de utilizar para la fabricación de la suspensión cerámica iones divalentes (iones muy floculantes), descenderá la cantidad de desfloculante necesario para que el 
comportamiento reológico y la densidad de la suspensión cerámica sean óptimos. Si se tiene en cuenta que el precio del desfloculante está en torno a los $250 € / t$, esto quiere decir que por cada punto porcentual de desfloculante que se disminuya en cada tonelada de gránulo atomizado se ahorrará 2,58 €/t.

\section{- Ahorro por el aumento de la densidad de la suspensión cerámica}

La disminución de iones divalentes en el agua de preparación de las suspensiones cerámicas además de la disminución del desfloculante necesario, también hace disminuir su viscosidad permitiendo aumentar su densidad, y por tanto, también su contenido en sólidos. Estas mejoras se traducirán en una mayor producción de gránulo atomizado y una menor cantidad de agua a evaporar, con el consiguiente ahorro en el consumo de gas. Teniendo en cuenta el precio del gas y todos los demás parámetros necesarios, se estima que por cada $0,01 \mathrm{~g} / \mathrm{cm}^{3}$ que se aumente la densidad de la suspensión cerámica se conseguirá un ahorro de 0,36 €/t de gránulo atomizado.

\section{- $\quad$ Ahorro en emisión de $\mathrm{CO}_{2}$}

Por otra parte, otro ahorro que va asociado a la disminución del consumo de gas es la disminución de la emisión de $\mathrm{CO}_{2}$ a la atmosfera. Si se considera que para evaporar el agua el Consumo Específico es de $825 \mathrm{kcal} / \mathrm{dm}^{3}$ agua evaporada y un factor de emisión de $56 \mathrm{t} \mathrm{CO}_{2} / \mathrm{TJ}$, se puede estimar que por cada $\mathrm{m}^{3}$ evaporado se generan $0,194 \mathrm{t}$ de $\mathrm{CO}_{2}$. Considerando un precio del derecho de emisión de $\mathrm{CO}_{2}$ de en torno a $5 € / t$ [178], se obtiene que por cada $\mathrm{m}^{3}$ de agua que se evite evaporar se ahorrará $0,969 € / \mathrm{m}^{3}$.

\section{Balance económico.}

Conociendo los costes asociados a la nanofiltración en este caso de estudio y también los ahorros que se pueden conseguir, se puede calcular el balance económico para dos de los escenarios conseguidos en este segundo caso. Concretamente se han analizado los resultados obtenidos en dos posibles situaciones:

- Situación 1: Pruebas a nivel planta piloto en continúo realizadas con tres membranas NF270 en espiral 2540 en serie, utilizando una presión de 5,5 bar. Conversión alcanzada del 52\% (ver apartado 4.3.3.3 Pruebas en continuo con la planta piloto).

- Situación 2: Pruebas de concentración a nivel laboratorio realizadas con membranas NF270 planas, utilizando una presión de 5 bar. Conversión alcanzada del 85\% (ver apartado 4.3.2.4 Pruebas de concentración de las muestras por nanofiltración y viabilidad de reutilización del rechazo obtenido). Conversiones en torno al $85 \%$ son típicas en los tratamientos de nanofiltración cuando se dispone de la instalación adecuada bien dimensionada [176][175], por tanto esta conversión será la utilizada en los cálculos. 
En la Tabla 4.43 se recogen los resultados de los balances económicos obtenidos para los dos escenarios comentados con anterioridad.

Tabla 4.43. Resultados de los balances económicos.

\begin{tabular}{|c|c|c|c|}
\hline & & Situación 1 & Situación 2 \\
\hline \multirow{3}{*}{$\begin{array}{c}\text { Datos de } \\
\text { nanofiltración }\end{array}$} & Total agua de pozo ( $\left.m^{3} / a n ̃ o\right)$ & 50000 & 50000 \\
\hline & Conversión alcanzada en la nanofiltración (\%) & 52 & 85 \\
\hline & Agua nanofiltrada (m³/año) & 26000 & 42500 \\
\hline \multirow{6}{*}{$\begin{array}{c}\text { Ahorro por aumento } \\
\text { de densidad }\end{array}$} & Densidad inicial $\left(\mathrm{g} / \mathrm{cm}^{3}\right)$ & \multicolumn{2}{|c|}{1,74} \\
\hline & Densidad final $\left(\mathrm{g} / \mathrm{cm}^{3}\right)$ & \multicolumn{2}{|c|}{1,76} \\
\hline & Contenido en sólido de la suspensión cerámica inicial (\%) & \multicolumn{2}{|c|}{68,16} \\
\hline & Contenido en sólido de la suspensión cerámica final (\%) & \multicolumn{2}{|c|}{69,21} \\
\hline & Producción de atomizado con la suspensión inicial (t/año) & 55668 & 85644 \\
\hline & Ahorro total por aumento de densidad $(€)$ & 40081 & 65517 \\
\hline \multirow{3}{*}{$\begin{array}{l}\text { Ahorro en } \\
\text { desfloculante }\end{array}$} & Desfloculante inicial (\%) & \multicolumn{2}{|c|}{0,65} \\
\hline & Desfloculante final (\%) & \multicolumn{2}{|c|}{0,45} \\
\hline & Ahorro total por desfloculante ( $€ /$ año) & 27834 & 45498 \\
\hline \multirow{2}{*}{$\begin{array}{c}\text { Ahorro por } \\
\text { derechos de } \\
\text { emisión de } \mathrm{CO}_{2}\end{array}$} & Ahorro de agua en este caso $\left(\mathrm{m}^{3}\right)$ & 1235 & 2019 \\
\hline & Ahorro total en emisión de $\mathrm{CO}_{2}$ ( $€ /$ año) & 1197 & 1956 \\
\hline $\begin{array}{l}\text { Gastos Planta } \\
\text { nanofiltración }\end{array}$ & Coste operación planta NF por año (€/año) & 7150 & 11688 \\
\hline \multirow{4}{*}{ Balance Total } & Ahorro total (€/año) & 69112 & 112971 \\
\hline & Gastos totales (€/año) & 7150 & 11688 \\
\hline & Ahorro neto (€/año) & 61962 & 101284 \\
\hline & Periodo de retorno: inversión/ahorro (años) & 1,1 & 0,7 \\
\hline
\end{tabular}

El ahorro conseguido con la implementación de esta tecnología es muy significativo, ya que incluso en las condiciones más desfavorables (conversión del 52\%) se ahorrarían más de $60000 €$ al año. Pudiendo amortizar el equipo en poco más de un año. 
Por otra parte, si se trabajase a conversiones del $85 \%$, porcentaje común en tratamientos de nanofiltración, el ahorro aún sería superior, y estaría por encima de los $100000 €$. Este ahorro permitiría amortizar el equipo en menos de un año.

En este caso, muy ligado al balance económico también existe un factor ambiental muy importante, ya que al trabajar con suspensiones cerámicas con un contenido en sólidos mayor, se necesita menos cantidad de agua para su elaboración y por lo tanto, una menor cantidad de energía para evaporarla. Por consiguiente, a menor consumo de gas natural, menores emisiones de $\mathrm{CO}_{2}$. En la Tabla 4.44 se recopilan los ahorros de agua y la disminución de la emisión de $\mathrm{CO}_{2}$ en las dos situaciones contempladas en el balance económico.

Tabla 4.44. Disminución de la emisión de $\mathrm{CO}_{2}$.

\begin{tabular}{|c|c|c|}
\hline & Situación 1 & Situación 2 \\
\hline Ahorro de agua de pozo (m³/año) & 1235 & 2019 \\
\hline Reducción de la emisión de $\mathrm{CO}_{2}$ (t/año) & 239 & 391 \\
\hline
\end{tabular}

El ahorro en el consumo de agua de pozo es muy importante, ya que los sectores cerámicos más importantes a nivel europeo están asentados en dos países (España e Italia) en los que existen muchas zonas con escasez de agua. Por tanto, extraer menos agua del subsuelo implica un menor estrés sobre los acuíferos, evitando su sobreexplotación y los problemas que ello conlleva. Además, no se gastan unas reservas de agua que pueden ser destinadas a otros usos, como el uso agrario o incluso el abastecimiento de la población.

Por otra parte, no menos importante que el ahorro de energía es la reducción de la emisión del $\mathrm{CO}_{2}$, compuesto que afecta negativamente al calentamiento global del planeta, por este motivo todos los países industrializados están luchando para disminuir sus emisiones.

Por tanto, con los aumentos de la producción por un lado, junto a la disminución del consumo de agua de pozo, de las emisiones de $\mathrm{CO}_{2}$ y del consumo de desfloculantes, por otro, las empresas que implementen estas técnicas además de poder recuperar sus inversiones obteniendo ahorros económicos importantes, estarán invirtiendo en sostenibilidad. 
5 CONCLUSIONES 

Los procesos avanzados basados en técnicas de separación mediante membranas de nanofiltración pueden ser utilizados por la industria cerámica para mejorar la gestión de sus aguas. Esta mejora puede permitir a las compañías una mayor reutilización de las aguas residuales y una mayor eficiencia en la utilización de sus aguas de proceso, dando lugar a importantes ahorros económicos y a una reducción del impacto ambiental.

Los resultados experimentales obtenidos en este estudio demuestran que la nanofiltración puede ser una buena técnica de purificación de las aguas residuales de la industria cerámica, ya que se alcanzan reducciones muy significativas de boro y de otros iones que pueden ser perjudiciales para la reutilización de estas aguas, sobre todo iones divalentes. Además, también es una técnica que puede utilizarse para el acondicionamiento de aguas de suministro así aumentar la eficiencia de los procesos que las utilizan.

Las presiones utilizadas por la técnica de nanofiltración abordada en este estudio son relativamente bajas si las comparamos con otros tratamientos similares como la ósmosis inversa, ya que utilizan presiones entre 4 y 8 veces menores, por tanto, esto significa que el consumo energético de la técnica propuesta será menor, con el consiguiente ahorro económico y medioambiental.

Por otra parte, estos resultados también prueban que Nanoflux ${ }^{\circledR}$ es una herramienta de modelización muy útil para la caracterización de las membranas de nanofiltración, que puede ayudar a entender mejor los tratamientos de nanofiltración y sus mecanismos de trasporte.

De las cuatro membranas de nanofiltración caracterizadas, todas ellas de la marca Dow-Filmtec, la NF-90 ha sido elegida para la eliminación de los compuestos del boro de un agua residual por su reducido radio de poro y su densidad de carga superficial ante las disoluciones utilizadas. Mientras que, para la eliminación de los iones divalentes, se ha elegido la membrana NF-270 por su mayor selectividad con este tipo de iones.

\subsection{Primer caso de estudio (eliminación del boro)}

Dentro del marco del primer caso de estudio se puede observar que la nanofiltración puede ser una tecnología aplicable para la eliminación del boro de un agua residual. Sin embargo, es necesario aumentar el pH de la disolución, para que de esta forma las especies que contienen el boro estén en forma de boratos. Estos boratos son moléculas cargadas cuando se encuentran en disolución y son más fácilmente retenidas por las membranas de nanofiltración. Por lo tanto, es posible ajustar la retención para cada membrana influyendo sobre el pH del efluente.

El agua residual industrial, incluso después del tratamiento físico-químico que realiza la empresa, presenta un índice de ensuciamiento de las membranas considerable. Este hecho lo demuestran los resultados obtenidos de SDI, que confirman que estas aguas son muy colmatantes. Por tanto, antes de un tratamiento de nanofiltración hará falta un pretratamiento, como por ejemplo un tratamiento de microfiltración. Los resultados de SDI del agua después de los pretratamientos de microfiltración, demuestran que este pretratamiento es efectivo y por tanto, debe ser realizado antes de someter las aguas al tratamiento de nanofiltración propiamente dicho. 
Por lo que respecta al tratamiento de microfiltración se pueden extraer las siguientes conclusiones:

- El comportamiento en cuanto a permeabilidad de las membranas KLEANSEPTM 0,1 $\mu$ m y de las membranas KLEANSEP ${ }^{\mathrm{TM}} 300 \mathrm{kD}$ de la compañía Orelis es similar frente a las aguas residuales utilizadas en este caso de estudio, sin embargo, las aguas obtenidas después del tratamiento con las membranas KLEANSEP ${ }^{\mathrm{TM}} 300 \mathrm{kD}$ presentan un SDI menor.

- La permeabilidad de las membranas no cambia demasiado con la variación del FCV ensayado.

- Las membranas sufren colmataciones importantes, pero después de las limpiezas correspondientes, se logra volver a recuperar parcialmente la permeabilidad inicial.

Por otra parte, por lo que respecta al tratamiento de nanofiltración, se pueden enumerar las siguientes conclusiones:

- Los mejores resultados han sido obtenidos sobre la membrana NF-90 de la compañía DowFilmtec trabajando a un $\mathrm{pH}=11$, a partir de una presión transmembrana de $\Delta P=5$ bar.

- La retención del boro (NF-90) ha sido más baja en los ensayos industriales que en los ensayos de laboratorio (de $99 \%$ a $80-85 \%$ ), aunque los valores obtenidos siguen siendo elevados y permiten obtener agua nanofiltrada que cumpla con los límites de vertido.

- Con las aguas tratadas se han preparado engobes y esmaltes cerámicos. Todos los ensayos industriales realizados con el agua nanofiltrada han sido positivos, por tanto, la reutilización del agua nanofiltrada es una alternativa viable a la gestión externa o al vertido al alcantarillado. Por tanto, el agua tratada mediante nanofiltración, incluso pudiendo ser vertida al alcantarillado porque cumple con todos los límites establecidos por la legislación, podría ser reintroducida en el propio proceso productivo sin disminuir la calidad del producto final. Esto permitirá ahorrar en el consumo de agua limpia de suministro y retornar parte del gasto que supone un tratamiento de nanofiltración.

- El coste del tratamiento con membranas de nanofiltración es prácticamente la mitad del coste de otras tecnologías utilizadas para la eliminación del boro, como por ejemplo puede ser la ósmosis inversa (ver Tabla 4.19).

- La nanofiltración podría considerarse una MTD (Mejor Técnica Disponible) para la eliminación del boro en las aguas residuales generadas en la industria cerámica.

\subsection{Segundo caso de estudio (eliminación de iones divalentes)}

En cuanto a las conclusiones del segundo caso de estudio:

- Se ha trabajado con las aguas denominadas aguas industriales, que son dos tipos: aguas residuales y aguas de pozo. Los análisis realizados a las aguas residuales reutilizadas por la empresa muestran que pueden existir variaciones importantes en la calidad de las aguas. En cambio, las aguas de pozo muestran una mayor estabilidad, sin cambios importantes a lo largo del tiempo. De todas formas, durante el proyecto se ha demostrado la gran flexibilidad del tratamiento de nanofiltración ante los cambios en la alimentación del sistema.

- Las membranas tipo NF-270 de la empresa Dow-Filmtec son las membranas indicadas para conseguir los objetivos del estudio, ya que son bastante selectivas. Muestran una gran 
selectividad para los iones divalentes $\mathrm{Ca}^{2+}$ y $\mathrm{SO}_{4}{ }^{2}$. En las diferentes pruebas realizadas, la retención de los iones divalentes mencionados ha sido de entre 60-70\% y $90-95 \%$ respectivamente. Además, se ha obtenido reducciones de la conductividad entre un $40-70 \%$.

- De todas las configuraciones ensayadas, la más eficiente que se puede conseguir con la instalación piloto disponible ha sido aquella en la que se disponen 3 membranas en serie y con recirculación para que todas las membranas funcionen con los caudales de alimentación necesarios.

- En cuanto a las conversiones a las que se ha trabajado, hay que decir que a una conversión de entre $50-60 \%$ la instalación piloto ha funcionado sin superar las conversiones individuales de las membranas y los resultados de retención han sido óptimos. Existe la posibilidad de aumentar la conversión con un incremento de la superficie filtrante y/o la presión de trabajo (85\%). Aunque hay que llegar a un equilibrio entre la conversión y la calidad del permeado, para que el aumento de la conversión no cause ningún perjuicio a los objetivos perseguidos.

- Los ensayos realizados a las piezas crudas y cocidas elaboradas con los polvos atomizados obtenidos a partir de las aguas reales y nanofiltradas muestran que no existen prácticamente diferencias entre ellas.

- Si se trata agua de pozo es posible reutilizar el 100\% del rechazo en el propio proceso productivo, sin necesidad de hacer ningún tratamiento adicional al rechazo.

- Se pueden alcanzar reducciones de más de un 30\% en el porcentaje de desfloculante añadido a la suspensión cerámica (pasar del 0,65\% al 0,45\%) y aumentar en 2 puntos la densidad de las suspensiones cerámicas (pasar de $1,74 \mathrm{~g} / \mathrm{cm}^{3}$ al 1,76 g/ $/ \mathrm{cm}^{3}$ ).

- Estas mejoras en el comportamiento reológico se traducen en importantes ahorros económicos (menos consumo de desfloculante y de gas natural, así como una mayor producción del atomizador) que pueden superar $1 € / t$ de polvo atomizado (concretamente $1,06 € / \mathrm{t}$ ). Para una empresa que consuma unos $50000 \mathrm{~m}^{3}$ de agua de pozo se podría traducir en un ahorro de más de 60000 €/año en el caso más desfavorable (conversión del 54 \%) y de más de 100000 €/año en el caso de llegar a una conversión del 85\%.

- Además de los ahorros económicos también se pueden conseguir importantes ahorros medioambientales ya que en el caso más desfavorable se podría reducir el consumo de agua de pozo en más de $1200 \mathrm{~m}^{3}$ /año y se podría reducir la emisión de $\mathrm{CO}_{2}$ procedente de la evaporación del agua de las suspensiones cerámicas en más de 200 t/año. 

6 LÍNEAS FUTURAS 

A raíz de los resultados conseguidos en el presente trabajo se pueden sugerir algunas líneas de investigación futuras que podrían continuar con el trabajo iniciado en este estudio. Algunas de estas líneas se describen a continuación:

- Concentración del rechazo de boro mediante técnicas de evaporación utilizando el calor residual que se pierde a través de las chimeneas de las empresas de producción de baldosas cerámicas.

- Combinación de técnicas de filtración a través de membranas con otras tecnologías para el tratamiento de las aguas residuales de las empresas de producción de polvo atomizado. Sobre todo para poder disminuir la concentración de iones divalentes de la corriente rechazo y poder reutilizarla en el propio proceso productivo sin afectar negativamente a las suspensiones cerámicas elaboradas con estas aguas.

- Nuevas aplicaciones de la nanofiltración en subsectores del sector cerámico como por ejemplo en la producción de fritas y esmaltes (eliminación de boro y metales pesados) o en la fabricación de tintas (recuperación de pigmentos y elementos de alto valor añadido).

- Reutilización de aguas residuales que no sean industriales en el sector cerámico. Se ha visto que el sector cerámico es capaz de reutilizar sus aguas residuales industriales en su propio proceso productivo, por tanto también podría estudiarse la viabilidad de utilizar, por ejemplo, aguas residuales urbanas después de ser tratadas en las EDAR y sometidas a tratamientos terciarios de filtración avanzada en la elaboración de suspensiones cerámicas para la fabricación de polvo atomizado. Esta posibilidad contribuiría al ahorro de agua limpia generalmente procedente de pozos, así como a disminuir la presión sobre los acuíferos existentes en el subsuelo de las regiones donde se asientan las empresas del sector cerámico y posibilitaría la reutilización del agua residual tratada en las EDAR más próximas a este sector.

- Caracterización y utilización de membranas de nanofiltración de otras compañías para estudiar si el comportamiento es similar o pueden incluso obtenerse mejores resultados. 

7 PROYECTOS DE INVESTIGACIÓN 

La línea de investigación en la que se ha basado esta tesis, ha sido subvencionada a cargo de diferentes proyectos de investigación apoyados por instituciones regionales, nacionales y europeas.

\begin{tabular}{|r|l|}
\hline Título & $\begin{array}{l}\text { Desarrollo de una tecnología de membranas para la mejora técnica y } \\
\text { medioambiental de la industria de la Comunidad Valenciana }\end{array}$ \\
\hline $\begin{array}{r}\text { Investigador } \\
\text { principal }\end{array}$ & Dr. Enrique Sánchez \\
\hline Duración & $2005-2007$ \\
\hline № de expediente & IMAETA/2005/11- IMAETB/2006/16 - IMAETB/2007/19 \\
\hline Entidad & IMPIVA - Instituto de la Pequeña y Mediana Industria \\
\hline
\end{tabular}

\begin{tabular}{|r|l|}
\hline Título & $\begin{array}{l}\text { Eliminación de compuestos orgánicos en aguas industriales cerámicas } \\
\text { mediante técnicas de filtración avanzadas (Ultra-nanofiltración) }\end{array}$ \\
\hline $\begin{array}{r}\text { Investigador } \\
\text { principal }\end{array}$ & Dra. Irina Celades \\
\hline Duración & 1 de Enero de 2007 - 20 de Febrero de 2009. \\
\hline № de expediente & IMCITA/2007/5 \\
\hline Entidad & IMPIVA - Instituto de la Pequeña y Mediana Industria \\
\hline
\end{tabular}

\begin{tabular}{|r|l|}
\hline Título & $\begin{array}{l}\text { Advanced membrane separation technologies for boron removal in waste } \\
\text { waters of ceramic and other manufacturing industries-NANOBORON }\end{array}$ \\
\hline $\begin{array}{r}\text { Investigador } \\
\text { principal }\end{array}$ & Dr. Enrique Sánchez \\
\hline Duración & 1 de Abril de 2008-30 de Abril de 2011 \\
\hline № de expediente & E!4121 \\
\hline Entidad & $\begin{array}{l}\text { European Eureka Project - IMPIVA - Instituto de la Pequeña y Mediana } \\
\text { financiadora }\end{array}$ \\
\hline
\end{tabular}




\begin{tabular}{|r|l|}
\hline Título & $\begin{array}{l}\text { Diseño y promoción de soluciones ambientales para el impulso de procesos } \\
\text { industriales sostenibles y competitivos en la Comunidad Valenciana- } \\
\text { PROSOCOM }\end{array}$ \\
\hline $\begin{array}{r}\text { Investigador } \\
\text { principal }\end{array}$ & Dra. Irina Celades \\
\hline Duración & 1 de enero de $2012-31$ de diciembre de 2013 \\
\hline № de expediente & IMDECA/2012/114 \\
\hline Entidad & IMPIVA - Instituto de la Pequeña y Mediana Industria \\
\hline
\end{tabular}

\begin{tabular}{|r|l|}
\hline Título & $\begin{array}{l}\text { Desarrollo de procesos avanzados de Nanofiltración para la reutilización de } \\
\text { las aguas residuales en la industria cerámica (NanoReCer). }\end{array}$ \\
\hline $\begin{array}{r}\text { Investigador } \\
\text { principal }\end{array}$ & Dr. Enrique Sánchez \\
\hline Duración & 1 de Octubre de $2009-31$ de Diciembre de 2011 \\
\hline $\begin{array}{r}\text { Entidad } \\
\text { financiadora }\end{array}$ & CDTI-Centro para el Desarrollo Tecnológico Industrial \\
\hline
\end{tabular}

\begin{tabular}{|r|l|}
\hline Título & $\begin{array}{l}\text { Diseño de un proceso que combine tratamientos tradicionales y avanzados } \\
\text { para optimizar la reutilización de aguas residuales en la fabricación de } \\
\text { gránulo atomizado (NanoCal) }\end{array}$ \\
\hline $\begin{array}{r}\text { Investigador } \\
\text { principal }\end{array}$ & Dra. Irina Celades López \\
\hline Duración & 1 de Enero de 2014 - 31 de Diciembre de 2014 \\
\hline Entidad & IVACE- Instituto Valenciano de Competitividad Empresarial \\
\hline
\end{tabular}


NOMENCLATURA 



\section{Símbolos}

a: Alimentación de un sistema

$A A$ : Absorción de agua (\%)

$b$ : Anchura de la probeta cerámica $(\mathrm{cm})$

$c_{i}$ : Concentración del compuesto $i$

$C L$ : Contracción lineal de una pieza cerámica (\%)

$\mathrm{CP}$ : Centipoise. La unidad cegesimal para la viscosidad dinámica es el poise (1 poise $(\mathrm{P})=0,1 \mathrm{~Pa} \cdot \mathrm{s}$

(Sistema Internacional)). Se suele usar más su submúltiplo el centipoise (cP) debido a que el agua tiene una viscosidad de $1,0020 \mathrm{cP}$ a $20^{\circ} \mathrm{C}$

Da: Símbolo de la unidad de masa atómica o Dalton

$D_{a p}$ : Densidad aparente de la probeta seca o cocida $\left(\mathrm{g} / \mathrm{cm}^{3}\right)$

des. $f_{\min }$ : Contenido en desfloculante mínimo (\%)

$d_{\mathrm{Hg}}$ : Densidad del mercurio $=13,53 \mathrm{~g} / \mathrm{cm}^{3}$

$D_{i}$ : Coeficiente de difusión en un medio continuo

$e$ : Espesor de la probeta cerámica $(\mathrm{cm})$

$e_{p}$ : Empuje probeta seca o cocida sumergida en el mercurio $(\mathrm{g})$

$F_{\text {max }}$ : Fuerza máxima antes de la rotura o carga de rotura $(\mathrm{kg})$

$J_{v}$ : Flujo volumétrico de permeado $\left(\mathrm{L} / \mathrm{h} \mathrm{m}^{2}\right)$

$L$ : Distancia entre apoyos $(\mathrm{cm})$

$L_{C}$ : Diámetro o longitud de la probeta cerámica cocida $(\mathrm{mm})$

$L_{p}$ : Permeabilidad al agua ( $\mathrm{L} / \mathrm{h} \mathrm{m}^{2}$ bar)

$L_{p}^{0}$ : Permeabilidad al agua pura $\left(\mathrm{L} / \mathrm{h} \mathrm{m}^{2}\right.$ bar $)$

$L_{S}$ : Diámetro o longitud de la probeta cerámica seca $(\mathrm{mm})$

$m$ : Masa de la probeta seca o cocida $(\mathrm{g})$

$m_{c}$ : Masa de la probeta cocida $(\mathrm{g})$

$m_{h}$ : Masa de la probeta húmeda $(\mathrm{g})$

p: Permeado

P: Presión (bar)

Q: Caudal (L/h)

r: Rechazo

$r_{p}:$ Radio de poro $(\mathrm{nm})$

$r_{i}$ : Radio de un elemento o ion

$R$ : Retención ofrecida por la membrana de un elemento o compuesto (\%)

$S$ : Grado de conversión o conversión (\%)

$t_{f}$ : Tiempo final requerido para recoger $500 \mathrm{~mL}$ de muestra después del tiempo de prueba en los ensayos de SDI (s)

$t_{i}$ : Tiempo inicial requerido para recoger $500 \mathrm{~mL}$ de muestra en los ensayos de SDI (s)

$t_{T}$ : Tiempo total transcurrido durante la prueba (generalmente son 15 minutos) en los ensayos de $\mathrm{SDI}(\mathrm{min})$

$X_{m}$ : Densidad de carga de la membrana o concentración de carga en la membrana $(\mathrm{mol} / \mathrm{L})$ 
$X_{i}$ : Densidad de carga de la membrana normalizada o concentración de carga en la membrana normalizada $X_{i}=X_{m} / \sum c_{a i}$

$z_{i}$ : Valencia o índice de coordinación de un elemento o ion

$\mu_{\min }$ : Viscosidad mínima

$\Delta P$ : Presión transmembrana o diferencia de presión (bar)

$\Delta \pi$ : Diferencia de presión osmótica (bar)

$\sigma$ : Coeficiente de reflexión

$\sigma_{m s}:$ Resistencia mecánica en seco $\left(\mathrm{kg} / \mathrm{cm}^{2}\right)$

\section{Subíndices}

a: Alimentación de un sistema

i: Un compuesto determinado

p: Permeado

r: Rechazo

\section{Acrónimos}

AAl: Autorización Ambiental Integrada

ANFFECC: Asociación Nacional de Fabricantes de Fritas, Esmaltes y Colores Cerámicos

ASCER: Asociación Española de Fabricantes de Azulejos y Pavimentos Cerámicos

DQO: Demanda Química de Oxígeno

EDAR: Estación de Depuración de Aguas Residuales

ENP: Ecuaciones Extendidas de Nernst-Planck

EPSAR: Entitat de Sanejament d'Aigües

FCV: Factor de Concentración Volumétrica

F-Q: Tratamiento físico-químico de coagulación-floculación de las aguas residuales

GPE: Gres Porcelánico Esmaltado

IEM: Instituto Europeo de Membranas de Montpellier (Francia)

ITC: Instituto de Tecnología Cerámica de Castellón (España)

IUPAC: "International Union of Pure and Applied Chemistry"

MEB: Microscopio Electrónico de Barrido

MF: Microfiltración

NDP: "Net Driving Pressure'[179]

NF: Nanofiltración

NTU: Unidades Nefelométricas de turbidez, o "Nephelometric Turbidity Unit"

OI: Ósmosis inversa 
PMC: Peso Molecular de Corte (Da)

RAE: Real Academia Española de la Lengua

SEC: Cromatografía de exclusión estérica

SDI: "Silt Density Index". Índice que una disolución posee para el "ensuciamiento" de una membrana

$\mathrm{SDI}_{15}$ : Índice que una disolución posee para el "ensuciamiento" de una membrana, cuando el tiempo total de la prueba ha sido de 15 minutos

STD: Esmalte de referencia

UF: Ultrafiltración 

GLOSARIO 

Anti-incrustante: Sustancia química que dosificada en la corriente de alimentación de un sistema de filtración evita las incrustaciones y deposiciones en la superficie de la membrana.

Atomización (secaderos por atomización): Este tipo de secaderos se utilizan en el proceso de fabricación de baldosas cerámicas para el secado de la suspensión de materias primas del soporte obtenida tras la molienda vía húmeda. El secado se realiza pulverizando la suspensión en una cámara en la que se introduce una corriente de gases a temperaturas del orden de $550-650^{\circ} \mathrm{C}$, para dar lugar a un material granulado adecuado para su prensado.

Autorización Ambiental Integrada (AAI): Documento que agrupa los permisos medioambientales de una instalación industrial en uno solo. Es la resolución del órgano competente de la Comunidad Autónoma en la que se ubique la instalación industrial. El permiso incluirá todas las medidas necesarias para conseguir un alto nivel de protección del medio ambiente en su conjunto y para asegurar que la explotación de la instalación se efectúe de acuerdo con los principios generales aplicables a las obligaciones fundamentales del titular. El permiso también incluirá valores límite de emisión para las sustancias contaminantes, o parámetros equivalentes o medidas técnicas, requisitos adecuados para la protección del suelo y las aguas subterráneas y requisitos para el control. Las condiciones del permiso se fijarán basándose en las mejores técnicas disponibles.

Baldosas cerámicas (pavimentos y revestimientos): Son placas de poco grosor generalmente utilizadas para revestimiento de suelos y paredes, fabricadas a partir de composiciones de arcillas y otras materias primas inorgánicas, que se someten a molienda y/o amasado, se moldean y seguidamente son secadas y cocidas a temperatura suficiente para que adquieran establemente las propiedades requeridas.

BREF (“BAT Reference Document”): Documento elaborado para determinadas actividades en el que se describen, en particular, las técnicas aplicadas, las emisiones actuales, los niveles de consumo, las consideraciones que se tienen en cuenta para determinar las MTD, así como las conclusiones sobre las MTD y las técnicas emergentes, tomando especialmente en consideración los criterios que se enumeran en el anexo III de la Directiva 2010/75/UE.

Cárter: Pieza o conjunto de piezas que protegen determinados mecanismos. En este trabajo es la pieza o conjunto de piezas que protegen y albergan la membrana.

Coeficiente de difusión: valor que representa la facilidad de migración de átomos, iones o moléculas de un gas, líquido o sólido desde una zona de concentración más alta a una más baja. Se expresa en $\mathrm{m}^{2} / \mathrm{s}$.

Coiones: lones del mismo signo que el de la carga superficial de la partícula o membrana.

Colmatar o colmatación: ver "fouling".

Coloide: Sistema de uno o varios componentes cuyas dimensiones se encuentran en el intervalo entre $1 \mathrm{~nm}$ y $1 \mu \mathrm{m}$.

Coloración blanca: Las suspensiones cerámicas o pastas blancas suelen formularse con materias primas con bajo contenido en hierro y otros elementos cromóforos. El resultado de la elección de estas materias primas es que después de la cocción las piezas cerámicas son blancas. 
Coloración roja: Las suspensiones cerámicas o pastas rojas suelen formularse a partir de mezclas de arcillas naturales de alto contenido en hierro de ahí su coloración roja después de la etapa de cocción.

Contraiones: Iones de signo opuesto a la carga superficial de una partícula o una membrana.

Densidad aparente: Magnitud que expresa la relación entre la masa y el volumen de un cuerpo poroso. Su unidad en el Sistema Internacional de unidades es el kilogramo por metro cúbico $\left(\mathrm{kg} / \mathrm{m}^{3}\right)$.

Desfloculación: Aumento de las fuerzas de repulsión entre partículas.

Desfloculante: Sustancia que dispersa los aglomerados de partículas de una suspensión cerámica para formar una suspensión más fluida.

Engobe: Debido a la diferente naturaleza química del soporte cerámico de las baldosas y del esmalte, se suele aplicar una capa de interfase entre ellos, con una composición química intermedia entre ambos. El producto destinado a este fin es un tipo de esmalte que se denomina engobe, y cumple principalmente las siguientes funciones: Crear una interfase entre el esmalte y el soporte que favorezca un adecuado acoplamiento entre ambos, ocultar el color del soporte para permitir un desarrollo óptimo del esmalte y de las decoraciones aplicadas sobre él, homogeneizar y eliminar las irregularidades superficiales del soporte para favorecer posteriores aplicaciones y formar una capa impermeable que evite problemas derivados de la porosidad del soporte.

Esmalte: Esmalte es todo compuesto, o mezcla de ellos, que funden total o parcialmente a temperaturas superiores a $650^{\circ} \mathrm{C}$ y que se une íntimamente con un soporte cerámico. Las materias primas que los componen son mezcladas y molturadas habitualmente vía húmeda, obteniéndose una suspensión similar a la preparada para el soporte, pero con un tamaño de partícula medio menor y un mayor porcentaje de agua. Los esmaltes son aplicados sobre las piezas cerámica en las líneas se esmaltado antes de su cocción.

“Fouling": Fenómeno de ensuciamiento de una membrana por la acumulación de moléculas y partículas en su superficie y/o dentro de los poros. Este fenómeno, provoca la modificación del rendimiento de la membrana. Esta palabra inglesa se podría traducir al castellano como colmatación o taponamiento de una membrana.

Frita: Material vítreo que resulta de un proceso de fundido de una mezcla de materias primas a alta temperatura en un horno de fusión. Las fritas se utilizan como materia prima para la preparación de esmaltes.

Gres porcelánico: Es la denominación de las baldosas cerámicas con muy baja porosidad (absorción de agua inferior al $0,5 \%$ en peso). Sus características permiten, además de los usos interiores en locales comerciales e incluso industriales, el uso en exteriores (pavimentos, fachadas...). En función de si están vidriadas o no se clasifican en dos tipos básicos: gres porcelánico no esmaltado (también denominado gres técnico) y gres porcelánico esmaltado.

Gresificación: La gresificación de una pieza cerámica, consiste en someterla a una temperatura donde la pieza obtenida presente un porcentaje de absorción de agua mínimo, coincidiendo con el 
máximo de contracción línea de la pieza en la cocción. A la representación de estas dos variables se le denomina diagrama de gresificación.

IPPC: Siglas en inglés de Prevención y Control Integrados de la Contaminación (Integrated Prevention Pollution Control), término que se aplica a la Directiva 1996/61/CE y a las leyes nacionales de transposición de dicha Directiva.

Líneas de esmaltado: La línea de esmaltado está compuesta por un sistema de correas (cintas transportadoras) movidas mediante poleas, encima de las cuales se depositan automáticamente los soportes cerámicos a la salida de la etapa de secado. A lo largo de esta línea se distribuyen los equipos necesarios para aplicar el engobe y el esmalte, ambos en forma de suspensión acuosa, sobre el soporte crudo, mediante el empleo de discos (pulverización) o de campanas (cortina continúa).

Meseta: se le denomina a la línea horizontal que forman los puntos de una representación gráfica donde la componente " $y$ " no varía con la componente " $x$ ".

Molinos de bolas: Equipo de molturación de materias primas que consiste en un cuerpo cilíndrico o cilíndrico-cónico, cuyas paredes interiores están protegidas, y que gira alrededor de un eje horizontal. En el interior del tambor se coloca una carga de molienda (que suelen ser bolos de sílex o bolas de alúmina), con una distribución de tamaños apropiados para optimizar la molturación.

MTD: Mejor Técnica Disponible, término utilizado en inglés como BAT: "Best Available Technique". Se entiende por la técnica más eficaz para proteger al medio ambiente en su conjunto, donde la tecnología empleada incluye el diseño, la construcción, el mantenimiento y la explotación, y debe ser viable técnica y económicamente.

Plasticidad: Capacidad de un material para ser moldeado y de retener su forma durante un cierto tiempo bajo fuerzas finitas.

Polvo atomizado: Producto obtenido en la etapa de secado por atomización en forma de aglomerados esféricos huecos de partículas con una humedad controlada que resultan muy adecuados para el prensado.

Potencial zeta: Potencial eléctrico en el plano de cizalla de la doble capa eléctrica. También conocido como potencial electrocinético. El plano de cizalla no se puede localizar exactamente pero está situado entre el plano de Stern y el plano de la denominada capa difusa.

Radio de Stokes: El radio de Stokes o el radio de Stokes-Einstein de un soluto es el radio de una esfera dura que se difunde a la misma velocidad que ese soluto, es decir que tiene el mismo comportamiento hidrodinámico.

Reología: estudio del flujo y deformación de la materia bajo la influencia de una fuerza mecánica. Se refiere especialmente, al comportamiento de material que no puede describirse por los modelos lineales simples de la hidrodinámica y elasticidad. Algunas de estas desviaciones son debidas a la presencia de partículas coloidales o a la influencia de superficies. Definición aceptada por la IUPAC [51]. 
Suspensión cerámica: Suspensión acuosa obtenida por molienda o desleído de las materias primas que componen el soporte de la baldosa cerámica junto con uno o varios aditivos (desfloculantes y en ocasiones ligantes).

Tortuosidad: Termino que define la complejidad geométrica de un medio poroso. En la mecánica de fluidos de los medios porosos, la tortuosidad es la relación del largo de la corriente natural de un fluido entre dos puntos y la distancia en línea recta entre esos puntos. Por consiguiente, la tortuosidad se relaciona con la relación entre el coeficiente de difusión de un fluido cuando no está confinado por un medio poroso y su coeficiente de difusión efectivo cuando está confinado en un medio poroso.

Velocidad tangencial: Velocidad media de circulación de un fluido paralelamente a una membrana. 
ANEXOS 



\section{ANEXO I. Desarrollo de modelos de transporte a través de membranas de nanofiltración}

Después del breve repaso histórico de la evolución de los modelos elaborados para dar una explicación teórica a los fenómenos de transporte que tiene lugar en la nanofiltración realizada en el apartado 1.4.2.1.2 Modelos de transporte a través de membranas de nanofiltración se ha creído conveniente profundizar en modelos de transporte simples en los que se considera a la membrana un medio poroso sin tener en cuenta el efecto carga. Estos modelos pueden ser los que utilizan la ecuación de Hagen-Poiseuille, basada en la ley de Darsy o también los que utilizan la ecuación de Kozeny-Carman [43]. Por otro lado, también se ahondará en otros modelos más complejos como son el modelo "Hindered Transport Theory" (HTT) y el modelo "Hindered Electro Transport" (HET), este último modelo tiene en cuanta tanto el efecto estérico, como el efecto carga de la membrana y de los solutos a eliminar [180]. Además, los modelos mencionados en último lugar son los que utiliza el programa de simulación que se ha utilizado en este estudio para la caracterización de las membranas.

Los modelos más básicos consideran la membrana como un medio poroso, por tanto existen microporos a través de los cuales se realiza el trasporte de materia. Se considera que estos poros son todos del mismo tamaño y el único parámetro del disolvente que se considera es la viscosidad. Estos modelos son muy utilizados para predecir el flujo volumétrico de disolvente que puede pasar atravesar la membrana. El flujo a través de estos poros puede ser descrito por la ecuación de Hagen-Poiseuille, ecuación basada en la ley de Darcy (cuya ecuación fenomenológica puede expresarse de la siguiente manera $J_{v}=L_{p} d P / d x$, donde $J_{v}$ es el flujo volumétrico, $L_{p}$ es la permeabilidad hidráulica, $d P$ es la diferencia de presión y $d x$ el espesor). Esta ecuación se observa a continuación:

$$
J_{v}=\frac{\varepsilon r^{2}}{8 \mu \tau} \frac{\Delta P}{\Delta x}
$$

donde $J_{v}$ es el flujo de disolvente $\left(\mathrm{L} \mathrm{h}^{-1} \mathrm{~m}^{-2}\right), r$ es el radio de poro $(\mathrm{m}), \varepsilon$ es la porosidad que puede calcularse de la siguiente forma $\varepsilon=\left(n p \pi r^{\wedge} 2\right) / A m$ ( $A m$ es el área de la membrana y $n p$ es el número de poros), $\mu$ es la viscosidad del fluido ( $\mathrm{Pa} \mathrm{s}$ ), $\tau$ es la tortuosidad, $\Delta P$ es la diferencia de presión (bar) y $\Delta x$ es el espesor de la membrana $(\mathrm{m})$. Esta ecuación muestra la relación que existe entre la estructura de la membrana con el transporte e indica que el flujo del disolvente es proporcional a la diferencia de presión que es la fuerza impulsora de la filtración. También le da sentido al parámetro $L_{p}$ permeabilidad hidráulica y la relaciona con determinados parámetros estructurales de la membrana. Por tanto la permeabilidad hidráulica puede expresarse:

$$
L_{p}=\frac{\varepsilon r^{2}}{8 \mu \tau}
$$

Este parámetro puede obtenerse experimentalmente utilizando por ejemplo agua pura y puede servir para caracterizar a la membrana. 
Si se considera a la membrana como un sistema de esferas empaquetadas, los poros resultantes no son poros lineales, por tanto la ecuación de Kozeny-Carman describe más exactamente el trasporte de disolvente [181]. Y esta ecuación se expresa de la siguiente forma:

$$
J_{v}=\frac{\varepsilon^{3}}{K \mu S^{2}(1-\varepsilon)^{2}} \frac{\Delta P}{\Delta x}
$$

donde $\varepsilon$ es la porosidad, $S$ es el área superficial interna, $K$ es la constante de Kozeny-Carman que depende de la forma de los poros y de la tortuosidad.

Como se ha comentado estos dos modelos descritos son modelos muy simples que consideran solamente el efecto estérico de las membranas, por tanto el transporte de soluto se daría por convección impedida y difusión. Por tanto, estos modelos simples no son los adecuados para explicar sistemas tan complejos. Por esta razón en este apartado se abordarán y se explicarán brevemente los dos modelos que el programa Nanoflux ${ }^{\circledR}$ utiliza para realizar sus cálculos y modelizaciones. Como se ha mencionado en el apartado 3.7 Programa de simulación NANOFLUX ${ }^{\circledR}$ el radio de poro $\left(r_{p}\right)$ y el espesor efectivo de la capa activa de la membrana es estimado por medio del modelo "Hindered Transport Theory" (HTT). Mientras que la densidad de carga de la membrana $\left(X_{m}\right)$ es obtenida por medio del modelo hibrido "Hindered ElectroTransport Theory" (HETT).

El modelo "Hindered Transport Theory" (HTT) ha sido desarrollado para solutos rígidos esféricos no cargados dentro de poros cilíndricos y más tarde aplicado por extensión a estructuras de poros complejos introduciendo el factor de tortuosidad. Este modelo solamente tiene en cuenta las interacciones hidrodinámicas y estéricas entre los solutos y los poros.

Se considera que la mecánica de medios continuos es aplicable en las membranas de nanofiltración debido a las dimensiones de los poros y la talla de los solutos estudiados. Si se supone que el transporte se realiza en una sola dirección siguiendo la dirección transversal a la membrana considerada como homogénea, el flujo volumétrico del soluto, $J_{i}$, viene dado por la ecuación siguiente [85]

$$
J_{i}=-\bar{D}_{l} \frac{d \bar{c}}{d x}+K_{c} \bar{C}_{l} J_{v}
$$

donde $\bar{C}_{l}$ es la concentración media del soluto $i$ en el interior de la membrana, $\bar{D}_{l}$ es el coeficiente de difusión efectivo del soluto, $K_{c}$ es el factor de fricción convectivo y $x$ es la distancia transversal que varía de 0 a $l_{m}$, parámetro este último que se puede considerar como el espesor medio de la capa activa de la membrana, y $J_{v}$ es el flujo de disolvente.

El coeficiente de difusión en el interior de la membrana se puede establecer mediante la siguiente ecuación:

$$
\bar{D}_{\iota}=\frac{D_{i}^{*} \phi_{i} K_{d}}{\tau_{i}}
$$


donde $D_{i}^{*}$ es el coeficiente de difusión aparente evaluado a partir de la ecuación de Stokes-Einstein, $K_{d}$ es el factor de fricción difusivo y $\tau_{i}$ es el factor de tortuosidad que es igual a 1 si se cumple la hipótesis de la hidrodinámica de los medios continuos en un conjunto de poros cilíndricos.

Las concentraciones del soluto en la membrana cerca de la interfase disolución membrana están ligadas a las concentraciones de la solución alimentación $\left(\bar{c}_{l}\left(0^{+}\right)=\phi_{i} c_{i a}\right)$ y a las del permeado $\left(\bar{c}_{l}\left(l_{m}{ }^{-}\right)=\phi_{i} c_{i p}\right)$, mediante el coeficiente de partición del soluto $\phi_{i}$.

Si se considera una concentración virtual del soluto dentro de la membrana $\overline{c_{l}}(x)=\phi_{i}(x)$ el flujo de soluto puede ser expresado bajo la forma descrita por Spiegler-Kedem [182] :

$$
J_{i}=-P_{i} \frac{d c_{i}}{d x}+\left(1-\sigma_{i}\right) c_{i} J_{v}
$$

donde $P_{i}$ es la permeabilidad local del soluto, mientras que $\sigma_{i}$ es el coeficiente de reflexión del soluto y puede expresarse como $\sigma_{i}=1-\phi_{i} K_{C}$.

La permeabilidad efectiva del soluto puede expresarse por medio de la siguiente expresión:

$$
L_{p i}=\phi_{i} \bar{D}_{\iota}=\phi_{i} D_{i} K_{d} \frac{l_{m}}{l_{\text {eff } i}}
$$

donde $l_{\text {eff } i}=\left(l_{m} \tau_{i} \mu_{p}\right) /\left(\mu \phi_{p}\right)$ es el espesor efectivo de la membrana para cada soluto.

Si se considera que $L_{p i}$ y $\sigma_{i}$ son independientes de la concentración, y teniendo en cuenta $J i=$ $J_{v} c_{p i}$, la integración de la expresión del flujo de soluto (I.6) proporciona la expresión de la retención del soluto [183]:

$$
R=1-\frac{c_{p i}}{c_{a i}}=\frac{(1-G) \sigma_{i}}{1-\sigma_{i} G}
$$

donde $G$ puede expresarse:

$$
G=e^{\left(-P_{e_{S}}\right)}
$$

en esta ecuación $P_{e_{s}}$ es el número de Peclet que se expresa de la siguiente manera:

$$
P_{e_{s}}=J_{v} l_{m}\left(\frac{1-\sigma_{i}}{L_{p i}}\right)=\frac{J_{v} l_{e f f i} K_{c}}{D_{i} K_{d}}
$$

Por tanto la retención es función de $P_{e_{s}}$ [182]. A flujo bajo, o sea número de Peclet pequeño, la retención será creciente con $J_{v}$ o con el $P_{e_{S}}$ :

$$
R \approx \frac{\sigma_{i} P_{e_{S}}}{1-\sigma_{i}}=\frac{\sigma_{i} l_{m} J_{v}}{L_{p i}}
$$


Para flujos grandes y número de Peclet elevados, la retención tiende a un valor límite independiente del número de Peclet e igual al coeficiente de reflexión:

$$
R^{\infty}=\sigma_{i}
$$

Los parámetros $K_{c}, K_{d}$ y $\phi_{i}$ se pueden estimar utilizando el modelo de poro cilíndrico. El coeficiente de partición estérico puede considerarse [85]:

$$
\phi_{i}=\left(1-\lambda_{i}\right)^{2}
$$

Los factores de fricción $K_{c}$ y $K_{d}$ depende únicamente de $\lambda_{i}=r_{i} / r_{p}$. Por tanto esto implica que para poros cilíndricos $\sigma_{i}$ y $L_{p i}$ dependen de las dimensiones del soluto y de los poros a través de $K_{c}$ y $K_{d}$.

Los modelos explicados hasta el momento no son por si solos adecuados para explicar sistemas tan complejos como son los que forman los solutos cargados y las membranas de nanofiltración, ya que en estos sistemas no solo hay que tener en cuenta la convección impedida o la difusión, son sumamente importantes las interacciones electroestáticas. Por consiguiente, estos modelos básicos solamente pueden proporcionar una información aproximada en el caso del trasporte del disolvente y de las moléculas neutras. Para el caso del transporte de los solutos se profundizará en el modelo "Hindered Electro Transport (HET)", que es el otro modelo utilizado por el programa informático Nanoflux ${ }^{\circledR}$.

El modelo “Hindered Electro Transport” (HET) es un caso particular del modelo general de transporte homogéneo que trata los iones como partículas esféricas cargadas y tiene en cuenta efectos estéricos en las actividades intra-membrana de los iones [184]. Este modelo describe el transporte de las sales a través de una membrana de nanofiltración, ya que tiene en cuanta tanto los efectos del trasporte impedido consecuencia del tamaño del soluto, así como los efectos electroestáticos de transporte causados por el efecto carga de los solutos así como de la propia membrana. Con este modelo también se puede modelizar perfectamente el transporte de los solutos sin carga, basta con no considerar interacciones electroestáticas para este tipo de solutos [180].

Como se ha comentado con anterioridad el modelo HET se basa en la ecuación del volumen medio de Stokes para el flujo del solvente e incorpora factores de impedimento estérico e hidrodinámicos en las ecuaciones extendidas de Nernst-Planck (ENP) de flujo de soluto y efectos estéricos/Donnan en la zona de la interfase disolución membrana. La ecuación del volumen medio de Stokes para el flujo de permeado puede expresarse de la siguiente forma:

$$
J_{v}=-L_{p}^{0}\left(\frac{d P}{d x}+R T \sum_{i} c_{i m} \frac{d\left[\ln \gamma_{i m}\right]}{d x}+\rho \frac{d \varphi}{d x}\right)
$$

donde $J_{v}$ es el flujo de permeado o la densidad de flujo volumétrico $\left(\mathrm{L} \mathrm{h}^{-1} \mathrm{~m}^{-2}\right), L_{p}^{0}$ es el coeficiente de permeabilidad $\left(\mathrm{L} \mathrm{h}^{-1} \mathrm{~m}^{-2}\right.$ bar $\left.{ }^{-1}\right), P$ es la presión (bar), $x$ es el espesor de la membrana $(\mu \mathrm{m}), R$ es la constante de los gases ideales, $T$ es la temperatura $\left({ }^{\circ} \mathrm{K}\right)$, el subíndice $i$ es el componente y el subíndice $m$ hace referencia a la membrana, $c_{i m}$ es la concentración del componente $i\left(\mathrm{~mol} \mathrm{~m}^{-3}\right)$ y 
$\gamma_{i m}$ el coeficiente de actividad efectivo del componente $i, \rho$ es densidad de carga iónica local, y $\varphi$ es el potencial eléctrico de la membrana (V). Si se integra esta ecuación entre el espesor de la membrana $0<x<\Delta x$, despreciando el gradiente de $\ln \gamma_{i m}$ ya que la variación de la concentración de los solutos en el interior de la membrana será muy pequeña, se alcanza la siguiente expresión:

$$
J_{v}=-L_{p}\left(\Delta P_{e}\right)
$$

En esta expresión $L_{p}$ es la permebilidad efectiva incluyendo los efectos de la electro-viscosidad, que también puede expresarse de la siguiente manera:

$$
L_{p}=\frac{L_{p}^{0}}{(1+\kappa) \Delta x}
$$

donde en esta expresión $k$ es un coeficiente relacionado con la electro-viscosidad. En el modelo HET se realiza una aproximación denominada buena exclusión del co-ion ("Good Co-ion Exclusión"GCE) donde este coeficiente relacionado con la electro-viscosidad se puede expresar de la siguiente forma:

$$
k=\frac{R T L_{p}^{0}\left|X_{m}\right| K_{1, c} l_{e f f}}{\left|z_{1}\right| K_{1, d} D_{1} \Delta x}
$$

donde el subíndice 1 indica el contra-ion, $X_{m}$ es la densidad de carga efectiva de la membrana (moles por unidad de volumen de poro-mol L-1), $K_{1, c}$ y $K_{1, d}$ son los factores de impedimento convectivo y difusivo, respectivamente, $l_{\text {eff }}$ es el espesor efectivo activo de la membrana de nanofiltración $(\mu \mathrm{m}), D_{1}$ es el coeficiente de difusión del contra-ion en la disolución $\left(\mathrm{m}^{2} \mathrm{~s}^{-1}\right)$. La aproximación GCE es válida cuando la concentración de las sales en la corriente alimento es baja $\left(c_{a}\right)$ o la densidad de carga de la membrana es alta, es decir cuando la relación $X_{m} / c_{a}>1$ [185].

En la ecuación (I.15), $\Delta P_{e}$ es la fuerza impulsora que en este caso es la presión efectiva (bar), esta presión se diferencia con la presión transmembrana $(\Delta P)$ porque en este caso se incluye la diferencia de presión osmótica a través de la membrana. Por tanto, esta presión efectiva se regirá por la siguiente expresión:

$$
\Delta P_{e}=\Delta P-\sigma \Delta \pi
$$

donde $\Delta \pi$ es la presión osmótica (bar) y $\sigma$ es el coeficiente de reflexión, parámetro que mide el grado de semi-permeabilidad de la membrana. Este parámetro expresa la capacidad de la membrana para dejar pasar a través de ella el disolvente con preferencia al soluto.

Como se ha comentado con anterioridad la aplicación de la ecuación extendida de Nernst-Planck, que originalmente fue propuesta para la descripción del transporte de electrolitos en ósmosis inversa a través de membranas de intercambio iónico [186], es particularmente útil para describir los mecanismos de trasporte de las membranas de nanofiltración. El modelo HET, basado en esta ecuación, además de contemplar la contribución del flujo correspondiente a la difusión, el flujo que corresponde a la migración eléctrica y el flujo correspondiente a la convección también tiene en 
cuenta la dimensión de los iones y otras interacciones del flujo de los iones. En la siguiente ecuación se recogen todos estos parámetros:

$$
J_{i}=-c_{i m} D_{i m} \frac{d\left[\ln \gamma_{i m}\right]}{d x}-D_{i m} \frac{d c_{i m}}{d x}-\frac{z_{i} c_{i m} D_{i m}}{R T} F \frac{d \varphi}{d x}+K_{i, c} C_{i m} J_{v}
$$

donde el subíndice $i$ hace referencia al ion y $m$ a la membrana, $D_{i m}$ es el coeficiente de difusión del ion $i$ en la membrana $\left(\mathrm{m}^{2} \mathrm{~s}^{-1}\right), z_{i}$ es la valencia del ion $i, F$ hace referencia a la constante de Faraday y $K_{i, c}$ es el factor relacionado con el impedimento para la convección del ion $i$.

Esta ecuación establece la ecuación extendida de Nernst-Planck y se utiliza para modelizar o predecir el transporte a través de una membrana de un ion en solución. En este caso, la ecuación se ha desarrollado específicamente para describir el transporte de un ion a través de un poro de la membrana, situación típica que se puede encontrar en las membranas de nanofiltración [187].

El flujo de un ion a través de una membrana de nanofiltración $J_{i}$ depende de la densidad del flujo volumétrico $J_{v}$ que atraviesa la membrana como puede apreciarse en la ecuación (I.19). También estará relacionados con la diferencia de presión $\Delta P$ a través de la densidad de flujo volumétrico $J_{v}$.

El flujo de un ion determinado puede expresarse también por medio de la siguiente expresión:

$$
J_{i}=c_{p i} J_{v}
$$

donde $c_{p i}$ es la concentración del ion $i$ en el permeado $\left(\mathrm{mol} \mathrm{m}^{-3}\right)$.

Teniendo en cuanta que el gradiente de $\ln \gamma_{i m}$ puede despreciarse y sustituyendo la ecuación (I.20) en la ecuación (I.19), se puede obtener la siguiente ecuación:

$$
\frac{d c_{i m}}{d x}=\frac{J_{v}}{D_{i m}}\left[K_{i c} c_{i m}-c_{p i}\right]-\frac{z_{i} c_{i m} D_{i m}}{R T} F \frac{d \varphi}{d x}
$$

Se puede suponer que en la proximidad de la membrana existe prácticamente electroneutralidad, condición perfectamente consistente con la ecuación de Poisson [188], por tanto se puede hacer la siguiente aproximación:

$$
\sum_{i=1}^{n} z_{i} c_{i m}+X_{m} \approx 0
$$

El gradiente de potencial eléctrico puede considerarse como el sumatorio de todos los iones y se podría expresar por la siguiente expresión:

$$
\frac{d \varphi}{d x}=\frac{\sum_{i=1}^{n} \frac{z_{i} J_{v}\left[K_{i c} c_{i m}-c_{p}\right]}{D_{i m}}}{\frac{F}{R T} \sum_{i=1}^{n} z_{i}^{2} c_{i m}}
$$

El proceso de cálculo basado en la integración de las ecuaciones (I.21) y (I.23) y considerando la aproximación enunciada como ecuación (I.22) permite modelizar la retención $(R)$ en función del flujo 
volumétrico $\left(J_{v}\right)$. Antes de seguir con la explicación, hay que tener en cuenta que la retención de un soluto se expresa de la siguiente forma:

$$
R_{i}=1-\frac{c_{p i}}{c_{a i}}
$$

Si se considera que por el momento la exclusión estérica es despreciable, el coeficiente límite de transmisión $(T)$ y la retención $(R)$ puede expresarse de una forma simple teniendo en cuenta la aproximación GCE [185]:

$$
\begin{gathered}
T=\frac{c_{p i}}{c_{a i}}=\frac{k_{2}^{a}}{t_{1}}=\left(1+\frac{\left|z_{2}\right| D_{2, m}}{\left|z_{1}\right| D_{1, m}}\right)\left(\frac{X_{i}}{v_{1}\left|z_{1}\right|}\right)^{-\frac{\left|z_{2}\right|}{\left|z_{1}\right|}} \\
R=1-T=1-\frac{k_{2}^{a}}{t_{1}}
\end{gathered}
$$

donde los subíndices 1 y 2 se refieren al contra ion y al co-ion respectivamente, $z$ y $v$ son la valencia electroquímica y el coeficiente estequiométrico de los iones también respectivamente, $t_{1}$ es un factor adimensional denominado número de transporte del contra ion, $k_{2}^{a}$ es el coeficiente de partición de Donnan del co-ion en la interfase disolución de alimentación - membrana que teniendo en cuanta la aproximación GCE [185] puede expresarse de la siguiente forma:

$$
k_{2}^{a}=\left(\frac{X_{i}}{v_{1}\left|z_{1}\right|}\right)^{-\frac{\left|z_{2}\right|}{\left|z_{1}\right|}}
$$

donde $X_{i}$ es la densidad de carga de la membrana normalizada (adimensional) y puede expresarse de la siguiente manera:

$$
X_{i}=\frac{X_{m}}{\sum c_{a i}}
$$

En la ecuación (I.25), el primer término entre paréntesis proviene de la convección del co-ion, el segundo término entre paréntesis proviene de la migración de los co-iones en la corriente del campo inducido por los contra iones y el último factor proviene de la relación de Donnan para los co-iones teniendo en cuenta la aproximación GCE [185].

En el modelo HET, el coeficiente de partición de Donnan depende de los efectos electrostáticos y los efectos de impedimento estérico y puede ser representado de la siguiente forma [180]:

$$
k_{i}=\frac{c_{i m}}{c_{i}}=\phi_{i} \exp \left(-\frac{z_{i} F}{R T} \Delta \varphi_{D}\right)
$$

En el coeficiente de partición de Donnan $\left(k_{i}\right)$ se puede introducir un parámetro de ajuste denominado coeficiente de partición residual $\left(\mathrm{k}^{\text {res }}\right)$, para que en ciertos solutos neutros se tengan en cuenta interacciones no estéricas (momento dipolar-membrana para solutos polares o polarizables, 
interacciones hidrófobas para las no polares...), o para ciertas especies iónicas a fin de tener en cuenta los efectos de exclusión distintos de los electrostáticos y estéricos (dieléctrico...) [77]. Este coeficiente puede introducirse en la ecuación (I.29) y se quedaría de la siguiente forma:

$$
k_{i}=\frac{c_{i m}}{c_{i}}=k_{i}^{r e s} \phi_{i} \exp \left(-\frac{z_{i} F}{R T} \Delta \varphi_{D}\right)
$$

donde $\Delta \varphi_{D}$ es el denominado potencial de Donnan $(\mathrm{V}), \phi_{i}$ es el coeficiente de impedimento estérico para el ion $i$. Este coeficiente puede definirse de la siguiente forma:

$$
\phi_{i}=\left(1-\frac{r_{i}}{r_{p}}\right)^{2}
$$

donde $r_{i}$ y $r_{p}$ son el radio del ion y del poro, respectivamente. El tamaño de los iones podrá ser calculada por la relación de Stokes-Einstein, tal y como se muestra en la siguiente ecuación:

$$
r_{i}^{S}=\frac{k_{B} T}{6 \pi \dot{\eta} D_{i}}
$$

donde $r_{i}^{S}$ es el radio del soluto $(\mathrm{m}), k_{B}$ es la constante de Boltzmann $\left(1.38 \times 10^{-23} \mathrm{JK}^{-1}\right)$, T es la temperatura $(\mathrm{K})$, y $\eta$ es el término que obedece a la viscosidad dinámica $\left(1.0019 \times 10^{-3} \mathrm{~Pa} \mathrm{~s}\right.$ a $\left.20^{\circ} \mathrm{C}\right)$. El radio de Stokes es el que se utiliza en el caso de los solutos neutros. Sin embargo, en el caso de los iones este método considera mejor opción utilizar el radio de la estructura cristalina (o de Pauling) [83]. Este es el radio que utiliza el programa informático Nanoflux ${ }^{\circledR}$ para las especias iónicas cuando tiene que realizar sus cálculos. 


\section{ANEXO II. Características técnicas de las membranas de microfiltración proporcionadas por el fabricante}

\section{Fiche Produit : MEMBRANE KLEANSEPTM}

Tout savoir sur les membranes tubulaires Kleansep ${ }^{\mathrm{TM}}$ en céramique

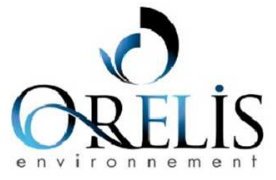

Pourquoi Penser Membranes ? La population mondiale est en pleine croissance. Cet essor conduit à un besoin accru en matière première, eau, énergie... C'est pourquoi Orelis Environnement, depuis les années 70 , a trouvé la solution pour limiter l'impact du besoin en eau et développer des procédés industriels pour son recyclage, en proposant des systèmes membranaires. Nous sommes au cœur du dispositif pour purifier, séparer, traiter, recycler... les précieuses ressources qui nous entourent.

Intérêt de la filtration par membrane Tout d'abord, la filtration tangentielle d'un liquide par un procédé à membrane Kleansep ${ }^{\mathrm{TM}}$ évite toute dénaturation du produit à filtrer. En effet, la séparation par membrane ne nécessite aucun additifs pour permettre le traitement et n'entraine pas de déchets. C'est un procédé propre. Le recyclage de la substance liquide est évalué à $95 \%$. La consommation d'eau est très nettement diminué comparé avec un autre système de purification (centrifugation...). La membrane sépare très finement, avec des perméabilités élevées, ce qui donne un très bon compromis entre la sélectivité et la perméabilité.

\section{Ses Avantages}

Lors de leur fonctionnement, les membranes peuvent subir de nombreuses sollicitations mécaniques, chimiques ou thermiques. C'est pourquoi Orelis Environnement préconise les membranes Kleansep ${ }^{\mathrm{TM}}$ car elles sont en céramique, ce qui leur confère une grande robustesse, et donc une longue durée de vie. Elles sont faciles à nettoyer et à régénérer. Les membranes peuvent travailler à des températures incroyablement élevées, seul leur environnement (sécurité, tuyauteries, joints d'étanchéité...) reste un facteur limitant. Certaines de nos membranes sont spécialement concues pour résister à un grand nombre de filtration de liquides très abrasifs.

\section{Ses Applications}

Elles sont utilisées pour la purification dans les procédés de la chimie, le traitement des effluents et/ou la séparation des eaux polluées, des huiles... mais pas que ! Alors n'hésitez pas à nous consulter ! Car nous proposons d'autres matériaux et design aussi bien en termes de membranes, de modules et de skids (unité de filtration).

\section{Respect de lenviróngement}

Exemple concret d'application

Les encres flexographiques, qui sont à

base d'eau, sont largement utilisées pour

l'impression de carton pour l'emballage. A chaque changement de couleur ou à la fin du processus d'impression, les machines d'impression sont lavées avec de l'eau pour enlever l'encre résiduelle. Le lavage des machines d'impression produisent des effluents aqueux et colorés.

La membrane céramique Kleansep ${ }^{T M}$ est en mesure de retirer la couleur de l'effluent générée par l'encre. Le perméat peut être recyclé pour le rinçage de la machine d'impression.

Le concentré d'encre peut être : - incinéré ou séchés (tambour rotatif), - recyclé dans les processus d'impression.

Plus de 98\% d'encre est retirée de l'effluent. Le perméat est utilisé pour le rinçage des machines à imprimer. Faible niveau de DCO dans le perméat (moins de $100 \mathrm{mg} / / \mathrm{O}_{2}$ ). La concentration d'encre est de plus de $25 \%$

Les encres concentrées peuvent être recyclées dans le process d'impression. Haut flux de perméat plus de $80 \mathrm{l} / \mathrm{h} \cdot \mathrm{m}^{2}$. L'unité entièrement automatisée comprend l'étape de nettoyage à haute température $\left(85^{\circ} \mathrm{C}\right)$.

L'eau et l'argent sont économisés - Green processus!

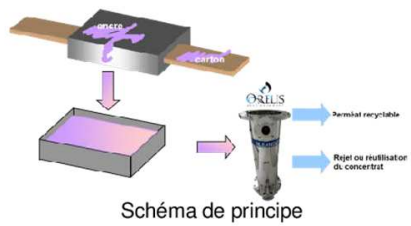

Notre équipe se tient à votre disposition pour définir avec vous la solution la mieux adaptée à vos besoins.

Tel +33 (0)466859536 contact@orelis.com

Le +

Orelis Environnement fournit les membranes déjà montées dans des modules. Mais aussi à l'unité, dans des emballages spécialement conçus pour elles, limitant ainsi l'impact environnemental. Tous nos emballages sont équipés de détecteur de chocs ou de de retournement, afin que le produit soit livré dans les meilleures conditions.
Présentation de CTI

Les membranes Kleansep ${ }^{\mathrm{TM}}$ sont produites, depuis plus de 20 ans, sur le site de Salindres (30) en France, par notre société sœur CTI.

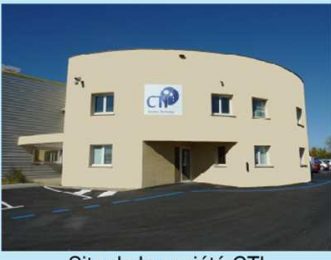

Site de la société CTI

"La fabrication des membranes minérales est maitrisée depuis le choix de la matière première jusqu'à la conception finale, dans un souci du respect de l'environnement." nous confie Mr Garcia, Président de CTI.

CTI développe et commercialise des céramiques techniques à haute valeur ajoutée pour les greentech industrielles:

Les membranes céramiques

Les filtres à particules

Catalyse et dépollution

Matériaux réfractaires Leader mondial en production de membranes céramiques pour la filtration des liquides, CTI innove également depuis plus de 10 ans dans la mise au point et l'industrialisation de nouveaux matériaux membranes pour les applications en pervaporation et en séparation / purification de gaz.

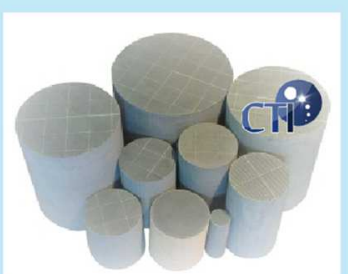

Membrane pour la filtration des gaz CTI a développé une expertise reconnue internationalement dans la conception et la production de matériaux céramiques fonctionnalisés, pour la catalyse et la dépollution des gaz d'émission.

CTI produit et commercialise également des matériaux céramiques pour applications à hautes températures $\left(>500^{\circ} \mathrm{C}\right)$ déclinés en supports poreux inertes dans de nombreuses géométries telles que les nids d'abeilles, mousses, tubes, vermicelles. www.ctisa.fr 
Fiche Produit : MEMBRANE KLEANSEPTM

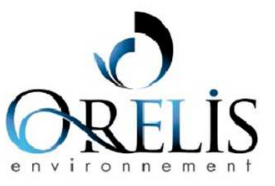

Tout savoir sur les membranes tubulaires Kleansep ${ }^{\mathrm{TM}}$ en céramique

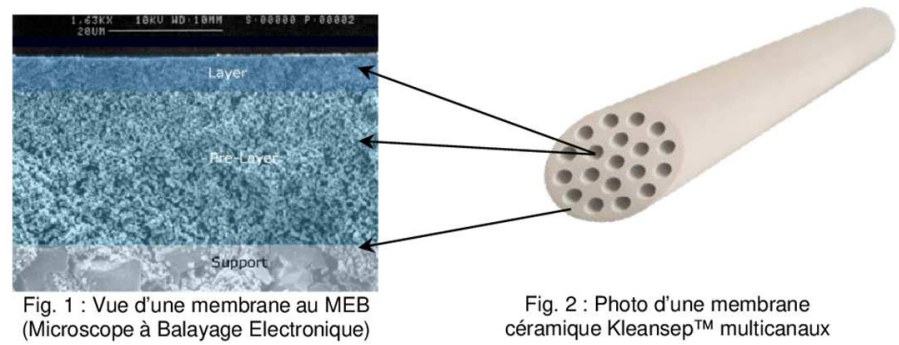

Définition d'une membrane

Une membrane est un dépôt de fine couche poreuse ou plusieurs sur un support (fig. 1). Dans le cas de la membrane céramique Kleansep ${ }^{\mathrm{TM}}$, le support (ou monolithe) est constitué d'oxyde de titane $\left(\mathrm{TiO}_{2}\right)$ et d'oxyde d'aluminium $\left(\mathrm{Al}_{2} \mathrm{O}_{3}\right)$ et les membranes sont soit en zircone $\left(\mathrm{ZrO}_{2}\right)$ soit en $\mathrm{TiO}_{2}$

Type de filtration

Orelis recommande la filtration tangentielle (cross-flow filtration), car contrairement à la filtration frontale, le rétentat circule à la surface de la membrane à haute vitesse (vitesse tangentielle). Cela évite la formation d'un gâteau à la surface de la membrane qui colmaterait cette dernière. Le liquide à traiter se divise en deux parties de concentrations distinctes, au niveau de la membrane. L'élément qui passe à travers la membrane : le perméat. La partie qui ne passe pas par la membrane s'appelle le rétentat. C'est cette partie qui contient les molécules retenues par la membrane. Dans le cas du traitement des eaux, c'est le perméat qui est valorisé.

\section{céramique Kleansep ${ }^{\mathrm{TM}}$ multicanaux}

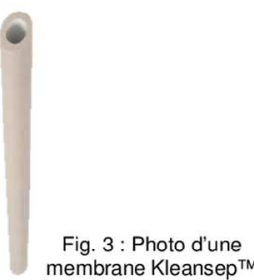

diamètre $10 \mathrm{~mm}$

Seuil de coupure (ou cut-off) La sélectivité d'une membrane est déterminée par son seuil de coupure. Pour la microfiltration, il est caractérisé par son débit à l'eau et son diamètre de pore. Pour l'ultrafiltration, il correspond

à la taille des éléments retenus par la membrane avec un taux de rétention de $90 \%$ et par son débit à l'eau. Et, pour finir pour la nanofiltration, les membranes sont caractérisées par leur débit à l'eau et leur aptitude à retenir des espèces spécifiques dans des conditions déterminées.

Orelis Environnement dispose de ces 3 techniques de séparation, et les décline dans un vaste éventail de seuil de coupure (tableau 1).

\section{Conception}

C'est un tube cylindrique de $1178 \mathrm{~mm}$ de long et de $25 \mathrm{~mm}$ de diamètre (fig. 2), pour les membranes utilisées en industrie il est composé de multiples canaux (fig. 4) en parallèle qui permettent le passage du liquide. II a une coloration blanche homogène. Afin d'assurer un suivi de la traçabilité et de l'intégrité des membranes, elles sont toutes identifiées par marquage (fig 5) de manière automatique et indélébile, avec l'indication de leur numéro de lot et de leur seuil de coupure (ou taille de pore).

Orelis Environnement dispose également de membrane en diamètre de $10 \mathrm{~mm}$ (fig. 3) pour les essais de faisabilité en laboratoire.

Durant les 5 dernières années, la moitié de la gamme de membranes céramiques a été conçue par nos équipes de recherches et développement pour satisfaire à la demande des clients.

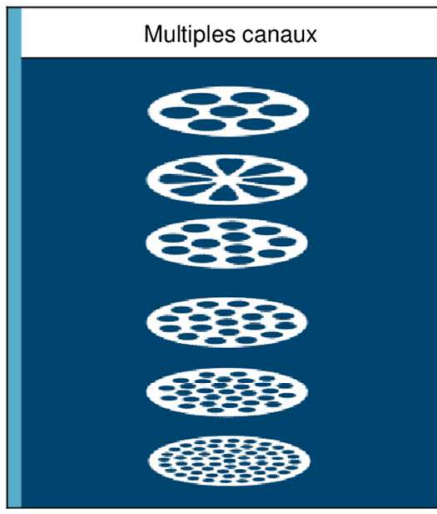

Fig. 4 : Illustration des géométries

\section{Seuils de coupure}

$\bullet 1,0 \mu \mathrm{m} \bullet 0,8 \mu \mathrm{m} \bullet 0,45 \mu \mathrm{m} \bullet$

$\bullet 0,2 \mu \mathrm{m} \bullet 0,1 \mu \mathrm{m} \mathrm{HR} \bullet$

- $300 \mathrm{kD} H F \bullet 150 \mathrm{kD} \bullet 50 \mathrm{kD} \bullet$

- $15 \mathrm{kD} \bullet 8 \mathrm{kD} \bullet$

- $5 \mathrm{kD} \bullet 1 \mathrm{kD} \bullet$

Tab. 1 : Tableau des cut-offs (liste non exhaustive)

\begin{tabular}{|ll|}
\hline Membrane : & $\mathrm{ZrO}_{2} / \mathrm{TiO}_{2}$ \\
\hline Résistance à la pression : & 80 bar \\
\hline Pression de service : & 10 bar \\
\hline Gamme de $\mathrm{pH}:$ & $0-14$ \\
\hline Stérilisation : & $121^{\circ} \mathrm{C}$ \\
\hline Stérilisation avec oxydants : & oui \\
\hline Solvants / Radiations : & Insensible \\
\hline Limite de température : & Jusqu'à $150^{\circ} \mathrm{C}$ \\
\hline
\end{tabular}

www.orelis.com

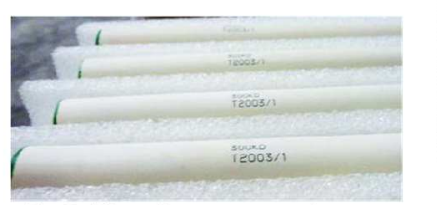

Fig. 5 : Photo du marquage au laser sur les membranes 


\section{ANEXO III. Características técnicas de las membranas de nanofiltración proporcionadas por el fabricante}

Product Information

FILMTEC Membranes

Desalting Nanofiltration Elements for Process Streams

Features

FILMTEC TM NF membrane elements are designed for process applications where a separation of solutes is desired.

- NF is a durable polypiperazine amide membrane designed to reject organics with a molecular weight above 200 while passing monovalent salts.

- FILMTEC NF membrane elements are used in a variety of applications such as desalting

organic compounds, acid processing, metal recovery and antifreeze recovery.

- FILMTEC NF membrane elements replace discontinued NF45 elements.

\section{Product Specifications}

\begin{tabular}{lll} 
Product & Part number & Active area $-\mathrm{ft}^{2}\left(\mathrm{~m}^{2}\right)$ \\
\hline $\mathrm{NF}-2540$ & 151538 & $28(2.6)$ \\
\hline $\mathrm{NF}-4040$ & 151543 & $82(7.6)$ \\
\hline $\mathrm{NF}-400$ (8040 style) & 151544 & $400(37.2)$ \\
\hline
\end{tabular}

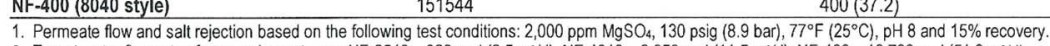

1. Permeate flow and salt rejection based on the following test conditions: $2,000 \mathrm{ppm} \mathrm{MgSO}, 130 \mathrm{psig}(8.9 \mathrm{bar}), 77^{\circ} \mathrm{F}\left(25^{\circ} \mathrm{C}\right), \mathrm{pH} 8$ and $15 \%$ recover.
2. Target water flow rates for new elements are: $\mathrm{NF}-2540-920 \mathrm{gpd}\left(3.5 \mathrm{~m}^{3} / \mathrm{d}\right), \mathrm{NF}-4040-3,050 \mathrm{gpd}\left(11.5 \mathrm{~m}^{3} \mathrm{~d}\right), \mathrm{NF}-400-13,700 \mathrm{gpd}\left(51.9 \mathrm{~m}^{3} / \mathrm{d}\right)$.

3. Minimum $\mathrm{MgSO}_{4}$ rejection is $98.0 \%$. Stabilized rejection is $>99 \%$.

4. Product specifications may vary slightly as improvements are implemented

Figure 1.
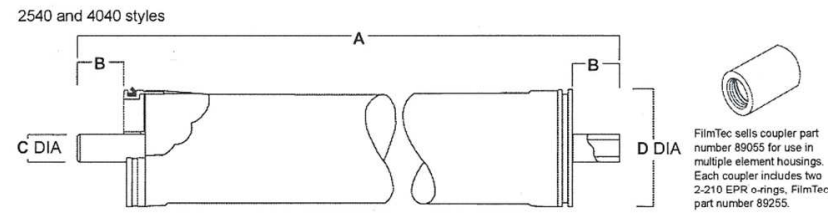

Figure 2.

$$
8040 \text { style }
$$
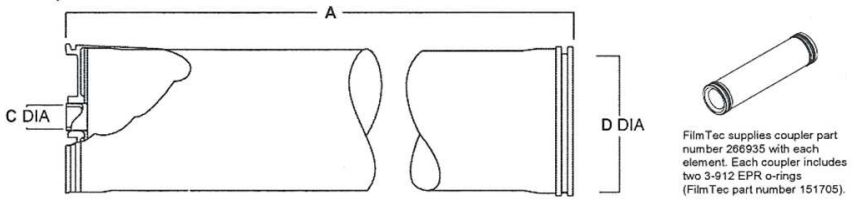

\begin{tabular}{|c|c|c|c|c|c|c|}
\hline Product & $\begin{array}{l}\text { Maximum feed flow } \\
\text { rate, } g \mathrm{gm}\left(\mathrm{m}^{3} / \mathrm{h}\right)\end{array}$ & $\begin{array}{l}\text { Typical recovery } \\
\text { rate (\%) }\end{array}$ & $\begin{array}{l}\text { Dimensions }-i \\
A\end{array}$ & $\begin{array}{l}\text { les (mm) } \\
\text { B }\end{array}$ & $c$ & D \\
\hline$N F-2540$ & $6(1.4)$ & 15 & $40.00(1,016)$ & $1.19(30.2)$ & $0.75(19)$ & $2.4(61)$ \\
\hline NF-4040 & $16(3.6)$ & 15 & $40.00(1,016)$ & $1.05(25.7)$ & $0.75(19)$ & $3.9(99)$ \\
\hline NF-400 (8040 style) & $70(16)$ & 15 & $40.00(1,016)$ & - & $1.13(28.6)$ & $7.9(200)$ \\
\hline
\end{tabular}

NF-400 (8040 style) $\quad 70(16)$

Typical recovery rate shown is for a single element. Recovery rate is calculated by dividing permeate flow rate by feed flow rate.

. NF-2540 elements have a tape outerwrap. NF-2540 elements fit nominal 2.5 inch I.D. pressure vessel.

. NF-4040 elements have a fiberglass outerwrap. NF-4040 elements fit nominal 4 inch I.D. pressure vessel. 


\begin{tabular}{|c|c|c|}
\hline Operating Limits & $\begin{array}{l}\text { - Membrane type } \\
\text { - Maximum operating temperaturea } \\
\text { - Maximum operating pressure } \\
\text { - Maximum pressure drop } \\
\text { - pH range, continuous operation } \\
\text { - pH range, short-term cleaninga } \\
\text { - Free chlorine concentration }{ }^{\mathrm{b}} \\
\text { - Hydrogen peroxide: } \\
\text { Continuous operation (@ } 77^{\circ} \mathrm{F} / 25^{\circ} \mathrm{C} \text { max.) } \\
\text { Short-term sanitizing (@ }\left(77^{\circ} \mathrm{F} / 25^{\circ} \mathrm{C} \text { max.) }\right. \\
\text { a Refer to Cleaning Guidelines in specification sheet } 609-00077 \text {. } \\
\text { - Under certain conditions, the presence of free chlorine and oth } \\
\text { failure. Since oxidation damage is not covered under warranty } \\
\text { pretreatment prior to membrane exposure. Please refer to tecl }\end{array}$ & $\begin{array}{l}\text { Polypiperazine amide thin-film composite } \\
113^{\circ} \mathrm{F}\left(45^{\circ} \mathrm{C}\right) \\
600 \mathrm{psig}(41 \text { bar }) \\
15 \mathrm{psig}(1.0 \text { bar }) \\
3-10 \\
1-12 \\
<0.1 \mathrm{ppm} \\
20 \mathrm{ppm} \\
1,000 \mathrm{ppm} \\
\text { F oxidizing agents will cause premature membrane } \\
\text { Film Tec recommends removing residual free chlorine by } \\
\text { nical bulletin } 609-22010 \text { for more information. }\end{array}$ \\
\hline
\end{tabular}

Important

Information

Operation

Guidelines

General

Information

FILMTEC TM Membranes For more information about FILMTEC membranes, call the Dow Liquid Separations business: North America: $\quad 1-800-447-4369$ Latin America: $\quad(+55)$ 11-5188-9222 Europe: $\quad(+32) 3-450-2240$ Pacific: $\quad+60379583392$ Japan: $\quad+81354602100$ http://wwww. filmtec.com $+862123019000$
Depending on the application requiremnts, new NF spiral elements may be cleaned prior to initial use. The cleaning procedure should be based on the application for which the elements are to be used. If cleaning with formulated agents is not available, an alkaline wash with wetting agent is recommended prior to initial use.

An appropriate alkaline wash consists of the following:

- Flushing with water (ensure water quality meets guidelines found in bulletin 609-00077).

- Heating water to $113^{\circ} \mathrm{F}\left(45^{\circ} \mathrm{C}\right)$ in recirculation made.

- Adding $0.2 \% \mathrm{Na}-\mathrm{EDTA}$ and $\mathrm{NaOH}$ to $\mathrm{pH} 11$ and recirculating for 30 minutes.

- Flushing with water until neutral $\mathrm{pH}$ is obtained.

Avoid any abrupt pressure or cross-flow variations on the spiral elements during start-up, shutdown, cleaning or other sequences to prevent possible membrane damage. During start-up, a gradual change from a standstill to operating state is recommended as follows:

- Feed pressure should be increased gradually over a 30-60 second time frame.

- Before initiating cross-flow at high permeate flux conditions (e.g., start-up with high-

temperature water), the set operating pressure should be maintained for 5-10 minutes.

- Cross-flow velocity at set operating point should be achieved gradually over 15-20 seconds.

- Keep elements moist at all times after initial wetting.

- If operating specifications given in this Product Information bulletin are not strictly followed, the limited warranty will be null and void.

- To prevent biological growth during system shutdowns, it is recommended that membrane elements be immersed in a preservative solution.

- The customer is fully responsible for the effects of incompatible chemicals and lubricants on elements.

- Maximum pressure drop across an entire pressure vessel (housing) is 50 psi (3.4 bar)

- Avoid permeate-side backpressure at all times.

Notice: The use of this product in and of itself does not necessarily guarantee the removal of cysts and pathogens from wate Effective cyst and pathogen reduction is dependent on the complete system design and on the operation and maintenance of the system.

Notice: No freedom from any patent owned by Seller or others is to be inferred. Because use conditions and applicable laws may differ from one location to another and may change with time, Customer is responsible for determining whether product and the information in this document are appropriate for Customer's use and for ensuring that Customer's workplace and disposal practices are in compliance with applicable laws and other governmental enactments. Seller assumes no obligation or liability for the information in this document. NO WARRANTIES ARE GIVEN; ALL IMPLIED WARRANTIES OF MERCHANTABILITY OR FITNESS FOR A PARTICULAR PURPOSE ARE EXPRESSLY EXCLUDED.

\section{E)}

Twe Trademark of The Dow Chemical Company ("Dow") or an affliated company of Dow

Form No. 609-00341-1106 


\section{DOW FILMTECTM Membranes}

DOW FILMTEC NF90 Nanofiltration Elements for Commercial Systems

Features

The DOW FILMTEC ${ }^{\text {TM }}$ NF90 membrane elements provide high productivity performance while removing a high percentage of salts, nitrate, iron and organic compounds such as pesticides, herbicides and THM precursors. The low net driving pressure of the NF90 membrane allows the removal of these compounds at low operating pressures.

\section{Product Specifications}

\begin{tabular}{lllll} 
Product & Part Number & $\begin{array}{l}\text { Applied Pressure } \\
\text { psig (bar) }\end{array}$ & $\begin{array}{l}\text { Permeate Flow Rate } \\
\left.\text { gpd (m } \mathbf{m}^{3 / \mathbf{d}}\right)\end{array}$ & $\begin{array}{l}\text { Stabilized Salt } \\
\text { Rejection (\%) }\end{array}$ \\
\hline NF90-2540 & 149982 & $70(4.8)$ & $680(2.6)$ & $>97.0$ \\
\hline NF90-4040 & 149983 & $70(4.8)$ & $2,000(7.6)$ & $>97.0$ \\
\hline
\end{tabular}

1. Permeate flow and salt rejection based on the following test conditions: $2,000 \mathrm{ppm} \mathrm{MgSO}_{4}, 77^{\circ} \mathrm{F}\left(25^{\circ} \mathrm{C}\right)$ and $15 \%$ recovery at the pressure specified above.

2. Permeate flows for individual NF90-2540 elements may vary by $-20 \% /+30 \%$. NF90-4040 individual elements may vary $-15 \% /+50 \%$.

3. Developmental products available for sale.

\section{Figure 1}
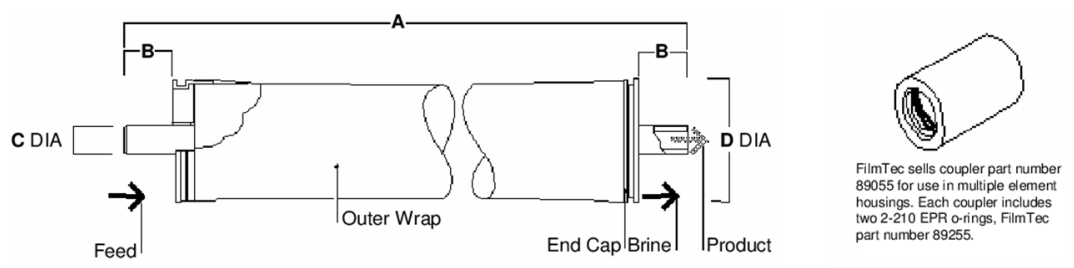

\begin{tabular}{|c|c|c|c|c|}
\hline \multirow[b]{2}{*}{ Product } & \multicolumn{4}{|c|}{ Dimensions - Inches (mm) } \\
\hline & A & B & $\mathrm{C}$ & D \\
\hline NF90-2540 & $40.0(1,016)$ & $1.19(30)$ & $0.75(19)$ & $2.4(61)$ \\
\hline NF90-4040 & $40.0(1,016)$ & $1.05(27)$ & $0.75(19)$ & $3.9(99)$ \\
\hline
\end{tabular}

2. NF90-2540 has a tape outer wrap. NF90-4040 has a fiberglass outer wrap.

Operating Limits

Page 1 of 2
- Membrane Type

- Maximum Operating Temperature

- Maximum Operating Pressure

- Maximum Feed Flow Rate - 4040 elements - 2540 elements

- Maximum Pressure Drop - tape wrapped - fiberglassed

- $p H$ Range, Continuous Operationa

- $\mathrm{pH}$ Range, Short-Term Cleaning (30 min. $)^{b}$

- Maximum Feed Silt Density Index

- Free Chlorine Tolerance ${ }^{c}$
Polyamide Thin-Film Composite

$113^{\circ} \mathrm{F}\left(45^{\circ} \mathrm{C}\right)$

600 psi (41 bar)

$16 \mathrm{gpm}\left(3.6 \mathrm{~m}^{3} / \mathrm{hr}\right)$

$6 \mathrm{gpm}(1.4 \mathrm{~m} / \mathrm{hr})$

13 psig ( 0.9 bar)

15 psig (1.0 bar)

$2-11$

$1-12$

SDI 5

$<0.1 \mathrm{ppm}$

a Maximum temperature for continuous operation above $\mathrm{pH} 10$ is $95^{\circ} \mathrm{F}\left(35^{\circ} \mathrm{C}\right)$

Refer to Cleaning Guidelines in specification sheet 609-23010 for NF90.

Under certain conditions, the presence of free chlorine and other oxidizing agents will cause premature membrane failure. Since oxidation damage is not covered under warranty, DOW FILMTEC recommends removing residual free chlorine by pretreatment prior to membrane exposure. Please refer to technical bulletin 609-22010 for more information. 


\section{Important} Information

\section{Operation \\ Guidelines}

\section{General}

Information
Proper start-up of reverse osmosis water treatment systems is essential to prepare the membranes for operating service and to prevent membrane damage due to overfeeding or hydraulic shock. Following the proper start-up sequence also helps ensure that system operating parameters conform to design specifications so that system water quality and productivity goals can be achieved.

Before initiating system start-up procedures, membrane pretreatment, loading of the membrane elements, instrument calibration and other system checks should be completed.

Please refer to the application information literature entitled "Start-Up Sequence" (Form No. 609-02077) for more information.

Avoid any abrupt pressure or cross-flow variations on the spiral elements during start-up, shutdown, cleaning or other sequences to prevent possible membrane damage. During start-up, a gradual change from a standstill to operating state is recommended as follows:

- Feed pressure should be increased gradually over a 30-60 second time frame.

- Cross-flow velocity at set operating point should be achieved gradually over 15-20 seconds.

- Permeate obtained from first hour of operation should be discarded.

- Keep elements moist at all times after initial wetting.

- If operating limits and guidelines given in this bulletin are not strictly followed, the limited warranty will be null and void.

- To prevent biological growth during prolonged system shutdowns, it is recommended that membrane elements be immersed in a preservative solution.

- The customer is fully responsible for the effects of incompatible chemicals and lubricants on elements.

- Maximum pressure drop across an entire pressure vessel (housing) is $30 \mathrm{psi}$ (2.1 bar).

- Avoid static permeate-side backpressure at all times.
DOW FILMTEC TM Membranes For more information about DOW FILMTEC membranes, call the Dow Water \& Process Solutions business: North America: $\quad 1-800-447-4369$ Latin America: $\quad$ (+55) 11-5188-9222 Europe: $\quad(+32) 3-450-2240$ Pacific: $\quad+60379583392$ Japan: $\quad+81354602100$ Japan: $\quad$ +81351002100 www. dowwaterandprocess.com
Notice: The use of this product in and of itself does not necessarily guarantee the removal of cysts and pathogens from water. Effective cyst and pathogen reduction is dependent on the complete system design and on the operation and maintenance of the system.

Notice: No freedom from any patent owned by Dow or others is to be inferred. Because use conditions and applicable laws may differ from one location to another and may change with time, Customer is responsible for determining whether products and the information in this document are appropriate for Customer's use and for ensuring that Customer's workplace and disposal practices are in compliance with applicable laws and other government enactments. Dow assumes no obligation or liability for the information in this document. NO WARRANTIES ARE GIVEN; ALL IMPLIED WARRANTIES OF MERCHANTABILITY OR FITNESS FOR A PARTICULAR PURPOSE ARE EXPRESSLY EXCLUDED.

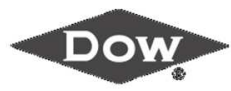


Product Information

FILMTEC ${ }^{\text {TM }}$ Membranes

FILMTEC NF200-400 Nanofiltration Element

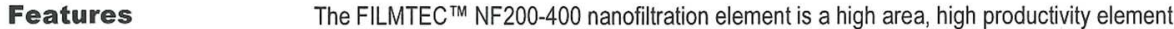
designed to remove a high percentage of TOC such as pesticides, herbicides and THM precursors while having a medium to high salt passage; medium hardness passage.

The FILMTEC NF200-400 element is an ideal element for surface and ground water applications where good organic removal is desired with partial softening in order to maintain a minimum level of hardness for organoleptic properties and preservation of distribution networks.

The high active area membrane combined with low net driving pressure of the membrane allows the removal of these compounds at low operating pressure.

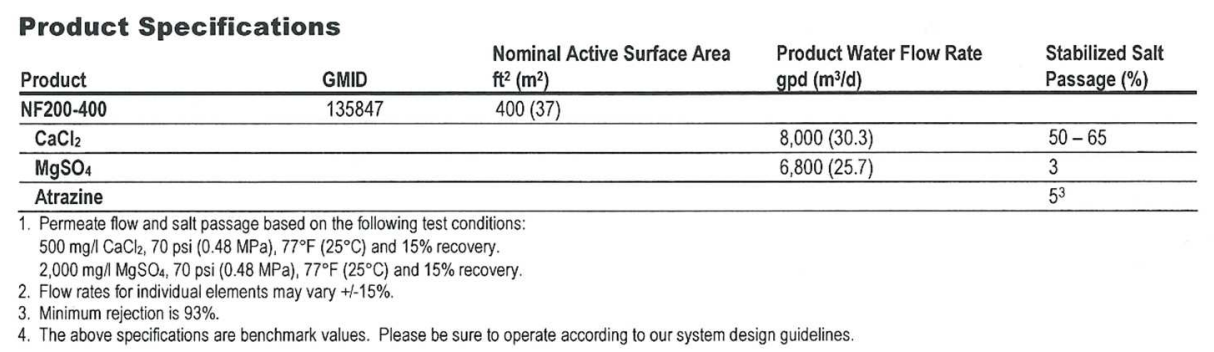

Figure 1

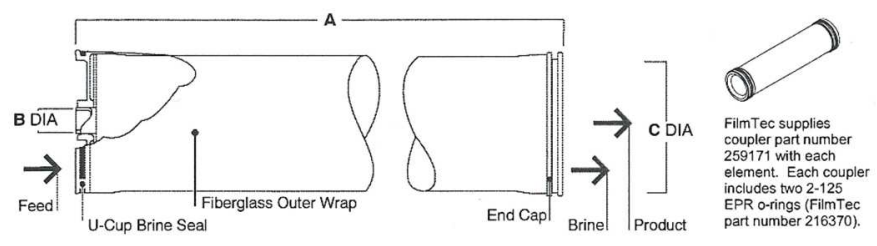

\begin{tabular}{|c|c|c|c|c|}
\hline \multirow{3}{*}{$\frac{\text { Product }}{\text { NF200-400 }}$} & \multicolumn{2}{|c|}{ Single-Element } & \multicolumn{2}{|c|}{ Dimensions - Inches (mm) } \\
\hline & Recovery & A & B & C \\
\hline & $15 \%$ & $40(1,016)$ & $1.5(38)$ & $7.9(201)$ \\
\hline
\end{tabular}

2. Element to fit nominal 8.00 -inch $(203 \mathrm{~mm}$ ) I.D. pressure vessel. 
Operating Limits

\section{Important}

Information

\section{Operation \\ Guidelines}

\section{General} Information

FILMTEC ${ }^{\text {TM Membranes }}$ For more information about FILMTEC membranes, call the Dow Liquid Separations business: North America: $\quad 1-800-447-4369$ Latin America: $\quad(+55)$ 11-5188-9222 Europe: $\quad(+32) 3-450-2240$ Pacilic: $\quad+60379583392$ Japan: $\quad$ +o1354602100 hitp://www. filmtec.com
- Membrane Type

- Maximum Operating Temperature

- Maximum Operating Pressure

- Maximum Pressure Drop

- pH Range, Continuous Operationa

- $\quad$ H Range, Short-Term Cleaning (30 min. $)^{b}$

- Maximum Feed Flow

- Maximum Feed Silt Density Index

- Free Chlorine Tolerancec

Maximum temperature for continuous operation above $\mathrm{pH} 10$ is $95^{\circ} \mathrm{F}\left(35^{\circ} \mathrm{C}\right.$.
Refer to Cleaning Guidelines in specification sheet $609-23010$.

Under certain conditions, the presence of free chlorine and other oxidizing agents will cause premature membrane failure. Since oxidation damage is not covered under warranty, Film Tec recommends removing residual free chlorine by

Proper start-up of reverse osmosis water treatment systems is essential to prepare the membranes for operating service and to prevent membrane damage due to overfeeding or hydraulic shock. Following the proper start-up sequence also helps ensure that system operating parameters conform to design specifications so that system water quality and productivity goals can be achieved.

Before initiating system start-up procedures, membrane pretreatment, loading of the membrane elements, instrument calibration and other system checks should be completed.

Please refer to the application information literature entitled "Start-Up Sequence" (Form No. 609-02077) for more information.

Avoid any abrupt pressure or cross-flow variations on the spiral elements during start-up, shutdown, cleaning or other sequences to prevent possible membrane damage. During start-up, a gradual change from a standstill to operating state is recommended as follows:

- Feed pressure should be increased gradually over a 30-60 second time frame.

- Cross-flow velocity at set operating point should be achieved gradually over 15-20 seconds.

- Permeate obtained from first hour of operation should be discarded.

- Keep elements moist at all times after initial wetting

- If operating limits and guidelines given in this bulletin are not strictly followed, the limited warranty will be null and void.

- To prevent biological growth during prolonged system shutdowns, it is recommended that membrane elements be immersed in a preservative solution.

- The customer is fully responsible for the effects of incompatible chemicals and lubricants on elements.

- Maximum pressure drop across an entire pressure vessel (housing) is $50 \mathrm{psi}$ (3.4 bar).

- Avoid permeate-side backpressure at all times.

Notice: The use of this product in and of itself does not necessarily guarantee the removal of cysts and pathogens from water. Effective cyst and pathogen reduction is dependent on the complete system design and on the operation and maintenance of the system.

Notice: No freedom from any patent owned by Seller or others is to be inferred. Because use conditions and applicable laws may differ from one location to another and may change with time, Customer is responsible for determining whether products and the information in this document are appropriate for Customer's use and for ensuring that Customer's workplace and disposal practices are in compliance with applicable laws and other governmental enactments. Seller assumes no obligation or liability for the information in this document. NO WARRANTIES ARE GIVEN; ALL IMPLIED WARRANTIES OF MERCHANTABILITY OR FITNESS FOR A PARTICULAR PURPOSE ARE EXPRESSLY EXCLUDED.

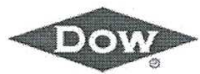


Product Information

FILMTECTM Membranes

FILMTEC NF270 Nanofiltration Elements for Commercial Systems

Features

The FILMTEC ${ }^{\text {TM }}$ NF270 membrane elements are ideal for removing a high percentage of TOC and THM precursors with medium to high salt passage and medium hardness passage. The FILMTEC NF270 membrane is an ideal choice for surface water and ground water where good organic removal is desired with partial softening.

\section{Product Specifications}

\begin{tabular}{|c|c|c|c|c|c|}
\hline Product & Part Number & $\begin{array}{l}\text { Active Area } \\
\mathrm{ft}^{2}\left(\mathrm{~m}^{2}\right)\end{array}$ & $\begin{array}{l}\text { Applied Pressure } \\
\text { psig (bar) }\end{array}$ & $\begin{array}{l}\text { Permeate Flow Rate } \\
\text { gpd }\left(\mathrm{m}^{3} / \mathrm{d}\right)\end{array}$ & $\begin{array}{l}\text { Stabilized Salt } \\
\text { Rejection (\%) }\end{array}$ \\
\hline NF270-2540 & 149986 & $28(2.6)$ & $70(4.8)$ & $850(3.2)$ & $>97.0$ \\
\hline NF270-4040 & 149987 & $82(7.6)$ & $70(4.8)$ & $2,500(9.5)$ & $>97.0$ \\
\hline
\end{tabular}

1. Permeate flow and salt rejection based on the following test conditions: $2,000 \mathrm{ppm} \mathrm{MgSO}_{4}, 77^{\circ} \mathrm{F}\left(25^{\circ} \mathrm{C}\right)$ and $15 \%$ recovery at the pressure specified above.

2. Permeate flows for individual NF270-2540 elements may vary by $-20 \% /+30 \%$. NF270-4040 individual elements may vary $-15 \% /+50 \%$.

3. Developmental products available for sale.

Figure 1
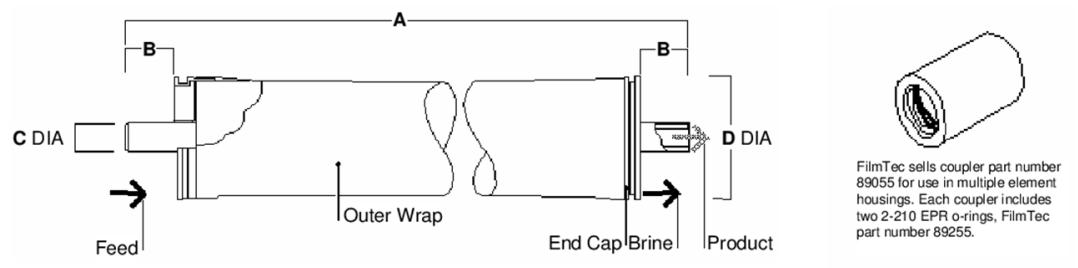

\begin{tabular}{|c|c|c|c|c|}
\hline \multirow[b]{2}{*}{ Product } & \multicolumn{4}{|c|}{ Dimensions - Inches (mm) } \\
\hline & A & B & C & D \\
\hline NF270-2540 & $40.0(1,016)$ & $1.19(30)$ & $0.75(19)$ & $2.4(61)$ \\
\hline NF270-4040 & $40.0(1,016)$ & $1.05(27)$ & $0.75(19)$ & $3.9(99)$ \\
\hline
\end{tabular}

2. NF270-2540 has a tape outer wrap. NF270-4040 has a fiberglass outer wrap.

Operating Limits

Page 1 of 2
- Membrane Type

- Maximum Operating Temperature

- Maximum Operating Pressure

- Maximum Feed Flow Rate - 4040 elements - 2540 elements

- Maximum Pressure Drop - tape wrapped - fiberglassed

- pH Range, Continuous Operation

- pH Range, Short-Term Cleaning (30 min. $)^{b}$

- Maximum Feed Silt Density Index

- Free Chlorine Tolerance ${ }^{c}$

Maximum temperature for continuous operation above $\mathrm{pH} 10$ is $95^{\circ} \mathrm{F}\left(35^{\circ} \mathrm{C}\right)$ Refer to Cleaning Guidelines in specification sheet 609-23010 for NF90.

Under certain conditions, the presence of free chlorine and other oxidizing agents will cause premature membrane failure. Since oxidation damage is not covered under warranty, FilmTec recommends removing residual free chlorine by pretreatment prior to membrane exposure. Please refer to technical bulletin 609-22010 for more information.
Polyamide Thin-Film Composite $113^{\circ} \mathrm{F}\left(45^{\circ} \mathrm{C}\right)$ $600 \mathrm{psi}(41 \mathrm{bar})$ $16 \mathrm{gpm}\left(3.6 \mathrm{~m}^{3} / \mathrm{hr}\right)$ $6 \mathrm{gpm}(1.4 \mathrm{~m} 3 / \mathrm{hr})$ 13 psig ( 0.9 bar $)$

$2-11$

$1-12$

SDI 5

$<0.1 \mathrm{ppm}$ 15 psig (1.0 bar) 
Important Information

\section{Operation \\ Guidelines}

\section{General}

Information
Proper start-up of reverse osmosis water treatment systems is essential to prepare the membranes for operating service and to prevent membrane damage due to overfeeding or hydraulic shock. Following the proper start-up sequence also helps ensure that system operating parameters conform to design specifications so that system water quality and productivity goals can be achieved.

Before initiating system start-up procedures, membrane pretreatment, loading of the membrane elements, instrument calibration and other system checks should be completed.

Please refer to the application information literature entitled "Start-Up Sequence" (Form No. 609-02077) for more information.

Avoid any abrupt pressure or cross-flow variations on the spiral elements during start-up, shutdown, cleaning or other sequences to prevent possible membrane damage. During start-up, a gradual change from a standstill to operating state is recommended as follows:

- Feed pressure should be increased gradually over a 30-60 second time frame.

- Cross-flow velocity at set operating point should be achieved gradually over 15-20 seconds.

- Permeate obtained from first hour of operation should be discarded.

- Keep elements moist at all times after initial wetting.

- If operating limits and guidelines given in this bulletin are not strictly followed, the limited warranty will be null and void.

- To prevent biological growth during prolonged system shutdowns, it is recommended that membrane elements be immersed in a preservative solution.

- The customer is fully responsible for the effects of incompatible chemicals and lubricants on elements.

- Maximum pressure drop across an entire pressure vessel (housing) is 30 psi (2.1 bar).

- Avoid static permeate-side backpressure at all times.
FILMTECTM Membranes membranes, call the Dow Liquid Separations business: North America: $\quad$ 1-800-447-4369 Latin America: (+55) 11-5188-9222 Europe: $\quad$ (+32) 3-450-2240 Pacific: $\quad+60379583392$ Japan: $\quad+81354602100$ China: $\quad+862123019000$ http://www.filmtec.com For more information about FILMTEC

Notice: The use of this product in and of itself does not necessarily guarantee the removal of cysts and pathogens from water Effective cyst and pathogen reduction is dependent on the complete system design and on the operation and maintenance of the system.

Notice: No freedom from any patent owned by Seller or others is to be inferred. Because use conditions and applicable laws may differ from one location to another and may change with time. Customer is responsible for determining whether products and the information in this document are appropriate for Customer's use and for ensuring that Customer's workplace and disposal practices are in compliance with applicable laws and other governmental enactments. Seller assumes no obligation or liability for the information in this document. NO WARRANTIES ARE GIVEN; ALL IMPLIED WARRANTIES OF MERCHANTABILITY OR FITNESS FOR A PARTICULAR PURPOSE ARE EXPRESSLY EXCLUDED.

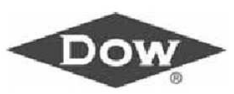

Form No. 609-00519-1206 
BIBLIOGRAFIA 

[1] G. Busani, C. Palmonari, G. Timellini, Piastrelle ceramiche \& ambiente. Emissioni gassose, acque, fanghi, rumore, Ed. EDI. CER, Sassuolo. (1995).

[2] R. Moliner-Salvador, A. Deratani, J. Palmeri, E. Sánchez, Use of nanofiltration membrane technology for ceramic industry wastewater treatment, Boletín la Soc. Española Cerámica y Vidr. 51 (2012) 103-110. doi:10.3989/cyv.152012.

[3] I. Celades, V. Sanfelix, V. Zahera, Guía de mejores técnicas disponibles para el sector de fabricación de baldosas cerámicas en la Comunidad Valenciana, Valencia, 2009.

[4] M.C. Minguillón, E. Monfort, A. Escrig, I. Celades, L. Guerra, G. Busani, A. Sterni, X. Querol, Air quality comparison between two European ceramic tile clusters, Atmos. Environ. 74 (2013) 311-319. doi:10.1016/j.atmosenv.2013.04.010.

[5] I. Celades, R. Moliner-Salvador, T. Ros-Dosdá, E. Monfort, V. Zaera, Environmental development of the Spanish ceramic tile manufacturing sector over the period 1992-2007, Bol. la Soc. Esp. Ceram. y Vidr. 51 (2012) 111-118. doi:10.3989/cyv.162012.

[6] ASCER, El sector del azulejo en España a través de 21 grandes empresas 2007-2011, (2016). http://www.ascer.es/verDocumento.ashx?documentold=928\&tipo=pdf (accedido 8 de febrero de 2016).

[7] VIGILANCER, Oportunidad: análisis competitivo internacional del sector cerámico, (2017). http://www.vigilancer.es/noticias/oportunidad-análisis-competitivo-internacional-del-sectorcerámico (accedido 9 de marzo de 2017).

[8] ASCER, Un sector competitivo, (2017). http://www.ascer.es/sectorDatos.aspx?lang=es-ES (accedido 9 de marzo de 2017).

[9] ANFFECC, Cifras del sector, (2017). http://www.anffecc.com/es/cifras-del-sector (accedido 9 de marzo de 2017).

[10] IPTS, Best available techniques (BAT) reference document for the manufacture of glass, (2013). doi:10.2791/69502.

[11] A. Barba, C. Feliu, V. Beltran, J. García, Materias primas para la fabricación de soportes de baldosas cerámicas, 2nd Editio, Instituto de Tecnología Cerámica, 2002.

[12] A. Blasco, A. Escardino, G. Busani, E. Monfort, J.L. Amorós, J. Enrique, V. Beltrán, P. Negre, Tratamiento de emisiones gaseosas, efluentes líquidos y residuos sólidos de la industria cerámica, Instituto de Tecnología Cerámica. Universitat Jaume I, 1992.

[13] G. Benveniste, C. Gazulla, P. Fullana, I. Celades, T. Ros, V. Zaera, B. Godes, B. Godes, Análisis de ciclo de vida y reglas de categoría de producto en la construcción. El caso de las baldosas cerámicas, Inf. la Construcción. 63 (2011) 71-81. doi:10.3989/ic.10.034.

[14] IPTS, Reference Document on Best Available Techniques in the Ceramic Manufacturing Industry, (2007). http://eippcb.jrc.ec.europa.eu/reference/BREF/cer_bref_0807.pdf.

[15] G. Mallol, E. Monfort, G. Busani, J. Lezaun, Depuración de los gases de combustión en la 
Industria Cerámica: guía técnica, (2001).

[16] EPSAR, Límites del modelo de ordenanza de vertidos a red municipal de saneamiento. Entitat Pública de Sanejament d'Aigües Residuals. Generalitar Valenciana, (2017). http://www.epsar.gva.es/sanejament/docs/118.pdf (accedido 8 de febrero de 2017).

[17] E. Andrés, V. Cases, C. M`Birek, M. Rodriguez, D. Prats, I. Celades, R. Moliner-Salvador, E. Sánchez, Removal of organic compounds from ceramic industry wastewater using nanofiltration - reverse osmosis, en: 11th Mediterranean Congress of Chemical Engineering, Barcelona, 2008.

[18] C. Palmonari, La depurazione delle acque nell'industria ceramica, EDI.CER, Sassuolo, 1990.

[19] G. Busani, La depurazione del boro nelle acque industriale ceramiche, TEIC, Modena, 1985.

[20] J.A. Díaz Lazaro-Carrasco, Depuración de aguas residuales, Centro de publicaciones del MOPU, Madrid, 1988.

[21] W.J. Weber, J. Bessa Feixas, R. Areal Guerra, Control de la calidad del agua: procesos fisicoquímicos, Reverté, 1979.

[22] E. Monfort, I. Celades, G. Mallol, Cuestiones sobre medio ambiente para un técnico del sector cerámico, Castellón, 1999.

[23] E. Sherwin, G.J. Weston, Química de los elementos no metálicos, Editorial Alhambra, Madrid, 1969.

[24] Y. Magara, A. Tabata, M. Kohki, M. Kawasaki, M. Hirose, Development of boron reduction system for sea water desalination, Desalination. 118 (1998) 25-33. doi:10.1016/S00119164(98)00076-9.

[25] A. Bick, G. Oron, Post-treatment design of seawater reverse osmosis plants: Boron removal technology selection for potable water production and environmental control, Desalination. 178 (2005) 233-246. doi:10.1016/j.desal.2005.01.001.

[26] M. Badruk, N. Kabay, M. Demircioglu, H. Mordogan, U. Ipekoglu, Removal of Boron from Wastewater of Geothermal Power Plant by Selective Ion-Exchange Resins. II. Column Sorption-Elution Studies, Sep. Sci. Technol. 34 (1999) 2981-2995. doi:10.1081/SS100100790 .

[27] J.L. Martínez, M. del M. de la Fuente, E. Muñoz Camacho, El boro en los vertidos industriales, Ing. química. 360 (1999) 163-169.

[28] M. del M. de la Fuente, E. Muñoz, Diseño y desarrollo de un sistema integrado de tratamiento de vertidos industriales borados, Residuos. 85 (2005) 38-46.

[29] A.J. Wyness, R.H. Parkman, C. Neal, A summary of boron surface water quality data throughout the European Union, en: Sci. Total Environ., 2003: pp. 255-269. doi:10.1016/S0048-9697(03)00106-2.

[30] M. Busch, W.E. Mickols, S. Jons, J. Redondo, J. De, W. Presenter, Boron removal in sea 
water desalination, Int. Desalin. Assoc. (2004) 3-39.

[31] E. Muñoz, J.M. Fernández, M.J. Rodríguez, M.M. de la Fuente, Efectos de la presencia de boro en aguas de riego, en: XXVII Reunión Bienal de la Real Sociedad Española de Química (Ed.), Real Sociedad Española de Química, La Laguna (Tenerife), 1999.

[32] Metcalf, Eddy, Ingeniería de aguas residuales : tratamiento, vertido y reutilización, McGrawHill, Interamericana de España, 1995. doi:10.1036/0070418780.

[33] L. Melnyk, V. Goncharuk, I. Butnyk, E. Tsapiuk, Boron removal from natural and wastewaters using combined sorption/ membrane process, Desalination. 185 (2005) 147-157. doi:10.1016/j.desal.2005.02.076.

[34] M. Rodríguez Pastor, A. Ferrándiz Ruiz, M.F. Chillón, D. Prats Rico, Influence of pH in the elimination of boron by means of reverse osmosis, Desalination. 140 (2001) 145-152. doi:10.1016/S0011-9164(01)00364-2.

[35] V. Bonnélye, M.A. Sanz, L. Francisci, F. Beltran, G. Cremer, R. Colcuera, J. Laraudogoitia, Curacao, Netherlands Antilles: A successful example of boron removal on a seawater desalination plant, Desalination. 205 (2007) 200-205. doi:10.1016/j.desal.2006.04.045.

[36] N. Kabay, I. Yilmaz, S. Yamac, S. Samatya, M. Yuksel, U. Yuksel, M. Arda, M. Salam, T. Iwanaga, K. Hirowatari, Removal and recovery of boron from geothermal wastewater by selective ion exchange resins I. Laboratory tests, React. Funct. Polym. 60 (2004) 163-170. doi:10.1016/j.reactfunctpolym.2004.02.020.

[37] C. Jacob, Seawater desalination: Boron removal by ion exchange technology, Desalination. 205 (2007) 47-52. doi:10.1016/j.desal.2006.06.007.

[38] S. Samatya, S.A. Tuncel, N. Kabay, Boron removal from RO permeate of geothermal water by monodisperse poly(vinylbenzyl chloride-co-divinylbenzene) beads containing N-methyl-dglucamine, Desalination. 364 (2015) 75-81. doi:10.1016/j.desal.2014.01.029.

[39] N. Geffen, R. Semiat, M.S. Eisen, Y. Balazs, I. Katz, C.G. Dosoretz, Boron removal from water by complexation to polyol compounds, J. Memb. Sci. 286 (2006) 45-51. doi:10.1016/j.memsci.2006.09.019.

[40] C. Bartels, S. Cioffi, S. Rybar, M. Wilf, E. Koutsakos, Long term experience with membrane performance at the Larnaca desalination plant, Desalination. 221 (2008) 92-100. doi:10.1016/j.desal.2007.01.070.

[41] D. Hasson, H. Shemer, I. Brook, I. Zaslavschi, R. Semiat, C. Bartels, M. Wilf, Scaling propensity of seawater in RO boron removal processes, J. Memb. Sci. 384 (2011) 198-204. doi:10.1016/j.memsci.2011.09.027.

[42] P. Dydo, M. Turek, J. Ciba, J. Trojanowska, J. Kluczka, Boron removal from landfill leachate by means of nanofiltration and reverse osmosis, Desalination. 185 (2005) 131-137. doi:10.1016/j.desal.2005.03.076.

[43] M. Mulder, Basic Principles of Membrane Technology, Springer Netherlands, 1996. 
[44] H.F. Ayyildiz, H. Kara, Boron removal by ion exchange membranes, Desalination. 180 (2005) 99-108. doi:10.1016/j.desal.2004.12.031.

[45] M. Turek, B. Bandura, P. Dydo, Electrodialytic boron removal from SWRO permeate, Desalination. 223 (2008) 17-22. doi:10.1016/j.desal.2007.01.181.

[46] P. Dydo, M. Turek, Boron transport and removal using ion-exchange membranes: A critical review, Desalination. 310 (2013) 2-8. doi:10.1016/j.desal.2012.08.024.

[47] M. Tagliabue, A.P. Reverberi, R. Bagatin, Boron removal from water: Needs, challenges and perspectives, J. Clean. Prod. 77 (2014) 56-64. doi:10.1016/j.jclepro.2013.11.040.

[48] M. Turek, P. Dydo, J. Trojanowska, A. Campen, Adsorption/co-precipitation-reverse osmosis system for boron removal, Desalination. $205 \quad$ (2007) 192-199. doi:10.1016/j.desal.2006.02.056.

[49] M.F. Chillón Arias, L. Valero i Bru, D. Prats Rico, P. Varó Galvañ, Approximate cost of the elimination of boron in desalinated water by reverse osmosis and ion exchange resins, Desalination. 273 (2011) 421-427. doi:10.1016/j.desal.2011.01.072.

[50] $H$. Jaeger, Nanofiltration membrane has the potential to reduce the cost of desalination, Membr. Technol. (2013) 9. doi:10.1016/S0958-2118(13)70104-6.

[51] R. Moreno, Reología de suspensiones cerámicas., Madrid, 2005. doi:10.1021/ie50668a007.

[52] E. Monfort, A. Mezquita, G. Mallol, R. Granel, E. Vaquer, Guía de ahorro energético en el sector de baldosas cerámicas de la Comunidad Valenciana, 2011.

[53] Hunter, R. J, R.J. Hunter, Hunter, R. J, Zeta potential in colloid science: principles and applications., Academic P, Academic Press, London, 1982. doi:10.1016/B978-0-12-3619617.50004-3.

[54] R.M. Pashley, M.E. Karaman, Applied colloid and surface chemistry, J. Wiley, 2004. doi:10.1002/0470014709.

[55] J. Marco, R. Gimeno, M. Rodríguez, P. Negre, C. Felíu, E. Sánchez, E. Bou, Comportamiento reológico de las suspensiones de esmalte. Influencia de la solubilidad de las fritas, pH, dureza del agua y aditivos empleados, Técnica Cerámica. (1996) 630-640. doi:0211-7290.

[56] D.E. Yates, S. Levine, T.W. Healy, Site-binding model of the electrical double layer at the oxide/water interface, J. Chem. Soc. 70 (1974) 1807. doi:10.1039/f19747001807.

[57] R.J. Pugh, L. 1959- Bergström, Surface and colloid chemistry in advanced ceramics processing, M. Dekker, 1994.

[58] Y.H. See Toh, X.X. Loh, K. Li, A. Bismarck, A.G. Livingston, In search of a standard method for the characterisation of organic solvent nanofiltration membranes, J. Memb. Sci. 291 (2007) 120-125. doi:10.1016/j.memsci.2006.12.053.

[59] H. Saidani, Influence des paramètres procédés sur les performances des membranes polymères de nanofiltration, Université Montpellier 2, 2009. 
[60] C. Bouchard, P. Kouadio, D. Ellis, M. Rahni, R. Lebrun, Les procédés à membranes et leurs applications en production d'eau potable, Vecteur Environ. (2000).

[61] WASSERLAB, El espectro de la filtración, (2017). http://www.wasserlab.com/es/aguapura/el-espectro-de-la-filtracion-2 (accedido 5 de marzo de 2017).

[62] B. Van Der Bruggen, C. Vandecasteele, T. Van Gestel, W. Doyen, R. Leysen, A review of pressure-driven membrane processes in wastewater treatment and drinking water production, Environ. Prog. 22 (2003) 46-56. doi:10.1002/ep.670220116.

[63] R.W. Baker, Membrane Technology and Applications, John Wiley \& Sons, Ltd, Chichester, UK, 2004. doi:10.1002/0470020393.

[64] A. Sagle, B. Freeman, Fundamentals of membranes for water treatment, Futur. Desalin. Texas. (2004) 1-17.

[65] S. Sales Pla, Intercambiadores iónicos inorgánicos nanoestructurados: síntesis e infiltración en membranas cerámicas, Universidad Jaume I de Castellón, 2015.

[66] R.R. Mccaffrey, R.E. Mcatee, A.E. Grey, C.A. Allen, D.G. Cummings, A.D. Appelhans, R.B. Wright, J.G. Jolley, Inorganic Membrane Technology, Sep. Sci. Technol. 22 (1987) 873-887. doi:10.1080/01496398708068987.

[67] R.R. Bhave, Inorganic Membranes Synthesis, Characteristics and Applications, Van Nostra, New York, 1991. doi:10.1007/978-94-011-6547-1.

[68] L. Palacio Martínez, Caracterización estructural y superficial de membranas microporosas, Universidad de Valladolid, 1999.

[69] C. Causserand, Filtration membranaire (OI, NF, UF): Caractérisation des membranes, Tech. l'ingénieur. 33 (2014) 0-16.

[70] G. Daufin, F. René, P. Aimar, Les séparations par membrane dans les procédés de l'industrie alimentaire, 1998.

[71] LIVING-WATER, Osmosis-Inversa, (2017). http://www.livingwater.org/osmosis_inversa_desmineralizacion_desalacion_agua_destilada.htm (accedido 24 de febrero de 2017).

[72] A. Maurel, Techniques séparatives à membranes: Osmose inverse, nanofiltration, ultrafiltration, microfiltration tangentielle considérations théoriques, Tech. l'ingénieur. Génie des procédés. (1993).

[73] ECLIPSE MEMBRANES, Hollow Fiber Porous PTFE Membranes, (2017). http://eclipsemembranes.com/custom-module-design/potting-technology.html (accedido 24 de febrero de 2017).

[74] C. Guizard, Guide de la Nanofiltration, Club Francais des membranes, Montpellier, 2000.

[75] R. Camarillo Blas, Separación selectiva de metales pesados en efluentes industriales mediante tecnología PSU, Universidad de Castilla-La Mancha, 2005. 
[76] R. Audinos, Membranes semi-perméables. Généralités, Tech. l'ingénieur. Matériaux Fonct. N1 (1999).

[77] J. Palmeri, N. Ben Amar, H. Saidani, A. Deratani, Process modeling of brackish and seawater nanofiltration, Desalin. Water Treatmen. 9 (2009) 263-271. doi:10.5004/dwt.2009.815.

[78] F. Yang, S. Zhang, D. Yang, X. Jian, Preparation and characterization of polypiperazine amide/PPESK hollow fiber composite nanofiltration membrane, J. Memb. Sci. 301 (2007) 8592. doi:10.1016/j.memsci.2007.06.009.

[79] A.I. Schäfer, A.G. Fane, T.D. Waite, Nanofiltration: Principles and Applications, Elsevier, 2005.

[80] K. V. Plakas, A.J. Karabelas, Removal of pesticides from water by NF and RO membranes A review, Desalination. 287 (2012) 255-265. doi:10.1016/j.desal.2011.08.003.

[81] S. V. Jadhav, K. V. Marathe, V.K. Rathod, A pilot scale concurrent removal of fluoride, arsenic, sulfate and nitrate by using nanofiltration: Competing ion interaction and modelling approach, J. Water Process Eng. 13 (2016) 153-167. doi:10.1016/j.jwpe.2016.04.008.

[82] P. Fievet, A. Szymczyk, Caractérisation des propriétés électriques des parois de pores d'une membrane, Comptes Rendus Chim. 5 (2002) 493-505. doi:10.1016/S1631-0748(02)01413-3.

[83] J. Palmeri, J. Sandeaux, R. Sandeaux, X. Lefebvre, P. David, C. Guizard, P. Amblard, J.-F. Diaz, B. Lamaze, Modeling of multi-electrolyte transport in charged ceramic and organic nanofilters using the computer simulation program NanoFlux, Desalination. 147 (2002) 231236. doi:10.1016/S0011-9164(02)00541-6.

[84] Y. Lanteri, P. Fievet, A. Szymczyk, Evaluation of the steric, electric, and dielectric exclusion model on the basis of salt rejection rate and membrane potential measurements, J. Colloid Interface Sci. 331 (2009) 148-155. doi:10.1016/j.jcis.2008.11.014.

[85] W.M. Deen, Hindered transport of large molecules in liquid-filled pores, AIChE J. 33 (1987) 1409-1425. doi:10.1002/aic.690330902.

[86] J.D. Ferry, Statistical evaluation of sieve constants in ultrafiltration, J. Gen. Physiol. 20 (1936) 95-104. doi:10.1085/jgp.20.1.95.

[87] A.E. Childress, M. Elimelech, Relating nanofiltration membrane performance to membrane charge (electrokinetic) characteristics, Environ. Sci. Technol. 34 (2000) 3710-3716. doi:10.1021/es0008620.

[88] M. Elimelech, W.H. Chen, J.J. Waypa, Measuring the zeta (electrokinetic) potential of reverse osmosis membranes by a streaming potential analyzer, Desalination. 95 (1994) 269-286. doi:10.1016/0011-9164(94)00064-6.

[89] J. Schaep, C. Vandecasteele, Evaluating the charge of nanofiltration membranes, J. Memb. Sci. 188 (2001) 129-136. doi:10.1016/S0376-7388(01)00368-4.

[90] M.R. Teixeira, M.J. Rosa, M. Nyström, The role of membrane charge on nanofiltration performance, J. Memb. Sci. 265 (2005) 160-166. doi:10.1016/j.memsci.2005.04.046. 
[91] T.A. Davis, J.S. Wu, B.L. Baker, Use of the donnan equilibrium principle to concentrate uranyl ions by an ion-exchange membrane process, AIChE J. 17 (1971) 1006-1008. doi:10.1002/aic.690170443.

[92] F.G. Donnan, The Theory of Membrane Equilibria., Chem. Rev. 1 (1924) 73-90. doi:10.1021/cr60001a003.

[93] M. Rieth, W. Schommers, Handbook of theoretical and computational nanotechnology, American Scientific Publishers, 2006.

[94] N. Hilal, H. Al-Zoubi, N.A. Darwish, A.W. Mohammad, M. Abu Arabi, A comprehensive review of nanofiltration membranes: Treatment, pretreatment, modelling, and atomic force microscopy, Desalination. 170 (2004) 281-308. doi:10.1016/j.desal.2004.01.007.

[95] X. Lefebvre, J. Palmeri, P. David, Nanofiltration theory: An analytic approach for single salts, J. Phys. Chem. B. 108 (2004) 16811-16824. doi:10.1021/jp048631t.

[96] O. Kedem, A. Katchalsky, Thermodynamic analysis of the permeability of biological membranes to non-electrolytes, Biochim. Biophys. Acta. 27 (1958) 229-246. doi:10.1016/0006-3002(58)90330-5.

[97] O. Kedem, A. Katchalsky, Permeability of composite membranes. Part 1. - Electric current, volume flow and flow of solute through membranes, Trans. Faraday Soc. 59 (1963) 19181930. doi:10.1039/TF9635901918.

[98] K.S. Spiegler, O. Kedem, Thermodynamics of hyperfiltration (reverse osmosis): criteria for efficient membranes, Desalination. 1 (1966) 311-326. doi:10.1016/S0011-9164(00)80018-1.

[99] X.L. Wang, T. Tsuru, S.I. Nakao, S. Kimura, The electrostatic and steric-hindrance model for the transport of charged solutes through nanofiltration membranes, J. Memb. Sci. 135 (1997) 19-32. doi:10.1016/S0376-7388(97)00125-7.

[100] X.L. Wang, T. Tsuru, S. ichi Nakao, S. Kimura, Electrolyte transport through nanofiltration membranes by the space-charge model and the comparison with Teorell-Meyer-Sievers model, J. Memb. Sci. 103 (1995) 117-133. doi:10.1016/0376-7388(94)00317-R.

[101] J.G. Wijmans, R.W. Baker, The solution-diffusion model: a review, J. Memb. Sci. 107 (1995) 1-21. doi:10.1016/0376-7388(95)00102-I.

[102] S. Bason, O. Kedem, V. Freger, Determination of concentration-dependent transport coefficients in nanofiltration: Experimental evaluation of coefficients, J. Memb. Sci. 326 (2009) 197-204. doi:10.1016/j.memsci.2008.09.054.

[103] S. Bason, Y. Kaufman, V. Freger, Analysis of ion transport in nanofiltration using phenomenological coefficients and structural characteristics, J. Phys. Chem. B. 114 (2010) 3510-3517. doi:10.1021/jp911615n.

[104] F.A. Morrison, J.F. Osterle, Electrokinetic Energy Conversion in Ultrafine Capillaries, J. Chem. Phys. 43 (1965) 2111-2115. doi:10.1063/1.1697081.

[105] R.J. Gross, J.F. Osterle, Membrane Transport Characteristics of Ultrafine Capillaries, J. 
Chem. Phys. 49 (1968) 228-234. doi:10.1063/1.1669814.

[106] J.C. Fair, J.F. Osterle, Reverse Electrodialysis in Charged Capillary Membranes, J. Chem. Phys. 54 (1971) 3307-3316. doi:10.1063/1.1675344.

[107] W.R. Bowen, A.W. Mohammad, N. Hilal, Characterisation of nanofiltration membranes for predictive purposes - Use of salts, uncharged solutes and atomic force microscopy, J. Memb. Sci. 126 (1997) 91-105. doi:10.1016/S0376-7388(96)00276-1.

[108] W.R. Bowen, H. Mukhtar, Characterisation and prediction of separation performance of nanofiltration membranes, J. Memb. Sci. 112 (1996) 263-274. doi:10.1016/03767388(95)00302-9.

[109] A. Szymczyk, P. Fievet, Investigating transport properties of nanofiltration membranes by means of a steric, electric and dielectric exclusion model, J. Memb. Sci. 252 (2005) 77-88. doi:10.1016/j.memsci.2004.12.002.

[110] S. Bouranene, Etude de la rétention de solutés neutres et ioniques par des membranes de nanofiltration, Université de Franche-Comté, 2008.

[111] X. Lefebvre, J. Palmeri, J. Sandeaux, R. Sandeaux, P. David, B. Maleyre, C. Guizard, P. Amblard, J.F. Diaz, B. Lamaze, Nanofiltration modeling: A comparative study of the salt filtration performance of a charged ceramic membrane and an organic nanofilter using the computer simulation program nanoflux, Sep. Purif. Technol. 32 (2003) 117-126. doi:10.1016/S1383-5866(03)00076-5.

[112] A.J.B. van Boxtel, Z.E.H. Otten, H.J.L.J. van der Linden, Evaluation of process models for fouling control of reverse osmosis of cheese whey, J. Memb. Sci. 58 (1991) 89-111. doi:10.1016/S0376-7388(00)80639-0.

[113] M. Mänttäri, L. Puro, J. Nuortila-Jokinen, M. Nyström, Fouling effects of polysaccharides and humic acid in nanofiltration, J. Memb. Sci. 165 (2000) 1-17. doi:10.1016/S03767388(99)00215-X.

[114] K.O. Agenson, T. Urase, Change in membrane performance due to organic fouling in nanofiltration (NF)/reverse osmosis (RO) applications, Sep. Purif. Technol. 55 (2007) 147156. doi:10.1016/j.seppur.2006.11.010.

[115] M. Fariñas Iglesias, Ósmosis inversa : fundamentos, tecnología y aplicaciones, McGraw-Hill Interamericana de España, 1999.

[116] G. Jonsson, C.E. Boesen, Concentration polarization in a reverse osmosis test cell, Desalination. 21 (1977) 1-10. doi:10.1016/S0011-9164(00)84104-1.

[117] J. Brun, Procédés de séparation par membranes: transport, techniques membranaires, applications, Masson, Paris, 1989.

[118] V. Geraldes, V. Semiao, M.N. Pinho, Hydrodynamics and concentration polarization in NF/RO spiral-wound modules with ladder-type spacers, Desalination. 157 (2003) 395-402. doi:10.1016/S0011-9164(03)00422-3. 
[119] J. Benavente, C. Fernandez-Pineda, Electrokinetic phenomena in porous membranes: Determination of phenomenological coefficients and transport numbers, J. Memb. Sci. 23 (1985) 121-136. doi:10.1016/S0376-7388(00)82214-0.

[120] A. Maurel, Dessalement de l'eau de mer et des eaux saumâtres et autres procédés non conventionnels d'approvisionnement en eau douce, Tec Doc. (2001).

[121] S.L. Li, C. Li, Y.S. Liu, X.L. Wang, Z.A. Cao, Separation of L-glutamine from fermentation broth by nanofiltration, J. Memb. Sci. 222 (2003) 191-201. doi:10.1016/S03767388(03)00290-4.

[122] D.X. Wang, L. Wu, Z.D. Liao, X.L. Wang, Y. Tomi, M. Ando, T. Shintani, Modeling the separation performance of nanofiltration membranes for the mixed salts solution with $\mathrm{Mg} 2+$ and Ca2+, J. Memb. Sci. 284 (2006) 384-392. doi:10.1016/j.memsci.2006.08.004.

[123] B. Van Der Bruggen, C. Vandecasteele, Removal of pollutants from surface water and groundwater by nanofiltration: Overview of possible applications in the drinking water industry, Environ. Pollut. 122 (2003) 435-445. doi:10.1016/S0269-7491(02)00308-1.

[124] X.L. Wang, C. Zhang, P. Ouyang, The possibility of separating saccharides from a $\mathrm{NaCl}$ solution by using nanofiltration in diafiltration mode, J. Memb. Sci. 204 (2002) 271-281. doi:10.1016/S0376-7388(02)00050-9.

[125] A.M. Hassan, A.M. Farooque, A.T.M. Jamaluddin, A.S. Al-Amoudi, M.A. Al-Sofi, A.F. AlRubaian, N.M. Kither, I.A.R. Al-Tisan, A. Rowaili, Demonstration plant based on the new NFSWRO process, Desalination. 131 (2000) 157-171. doi:10.1016/S0011-9164(00)90016-X.

[126] M. Turek, P. Dydo, R. Klimek, Salt production from coal-mine brine in NF - evaporation crystallization system, Desalination. 221 (2008) 238-243. doi:10.1016/j.desal.2007.01.080.

[127] F. Fu, Q. Wang, Removal of heavy metal ions from wastewaters: A review, J. Environ. Manage. 92 (2011) 407-418. doi:10.1016/j.jenvman.2010.11.011.

[128] M. Liu, Z. Lü, Z. Chen, S. Yu, C. Gao, Comparison of reverse osmosis and nanofiltration membranes in the treatment of biologically treated textile effluent for water reuse, Desalination. 281 (2011) 372-378. doi:10.1016/j.desal.2011.08.023.

[129] S.A. Avlonitis, I. Poulios, D. Sotiriou, M. Pappas, K. Moutesidis, Simulated cotton dye effluents treatment and reuse by nanofiltration, Desalination. 221 (2008) 259-267. doi:10.1016/j.desal.2007.01.082.

[130] W.J. Lau, A.F. Ismail, Polymeric nanofiltration membranes for textile dye wastewater treatment: Preparation, performance evaluation, transport modelling, and fouling control - a review, Desalination. 245 (2009) 321-348. doi:10.1016/j.desal.2007.12.058.

[131] E. Ellouze, N. Tahri, R. Ben Amar, Enhancement of textile wastewater treatment process using Nanofiltration, Desalination. 286 (2012) 16-23. doi:10.1016/j.desal.2011.09.025.

[132] J. Lin, C.Y. Tang, W. Ye, S.P. Sun, S.H. Hamdan, A. Volodin, C. Van Haesendonck, A. Sotto, P. Luis, B. Van der Bruggen, Unraveling flux behavior of superhydrophilic loose nanofiltration 
membranes during textile wastewater treatment, J. Memb. Sci. 493 (2015) 690-702. doi:10.1016/j.memsci.2015.07.018.

[133] M.D. Afonso, V. Geraldes, M.J. Rosa, M.N. de Pinho, Nanofiltration removal of chlorinated organic compounds from alkaline bleaching effluents in a pulp and paper plant, Water Res. 26 (1992) 1639-1643. doi:10.1016/0043-1354(92)90163-X.

[134] M. Mänttäri, T. Pekuri, M. Nyström, NF270, a new membrane having promising characteristics and being suitable for treatment of dilute effluents from the paper industry, J. Memb. Sci. 242 (2004) 107-116. doi:10.1016/j.memsci.2003.08.032.

[135] N. Ben Amar, N. Kechaou, J. Palmeri, A. Deratani, A. Sghaier, Comparison of tertiary treatment by nanofiltration and reverse osmosis for water reuse in denim textile industry, J. Hazard. Mater. 170 (2009) 111-117. doi:10.1016/j.jhazmat.2009.04.130.

[136] C.N. Lopes, J.C.C. Petrus, H.G. Riella, Color and COD retention by nanofiltration membranes, Desalination. 172 (2005) 77-83. doi:10.1016/j.desal.2004.07.030.

[137] K.S. Ashaghi, M. Ebrahimi, P. Czermak, Ceramic ultra and nanofiltration membranes for oilfield produced water treatment: A mini review, Open Environ. Sci. 1 (2008) 1-8. doi:10.2174/1876325100701010001.

[138] R. Ravindran Nair, E. Protasova, T. Bilstad, Smart xater for enhanced oil recovery by nanofiltration, J. Pet. Environ. Biotechnol. 7 (2016). doi:10.4172/2157-7463.1000273.

[139] X.-L. Wang, W.-J. Shang, D.-X. Wang, L. Wu, C.-H. Tu, Characterization and applications of nanofiltration membranes: State of the art, Desalination. 236 (2009) 316-326. doi:10.1016/j.desal.2007.10.082.

[140] F. Salehi, Current and future applications for nanofiltration technology in the food processing, Food Bioprod. Process. 92 (2014) 161-177. doi:10.1016/j.fbp.2013.09.005.

[141] G.S. Simate, J. Cluett, S.E. Iyuke, E.T. Musapatika, S. Ndlovu, L.F. Walubita, A.E. Alvarez, The treatment of brewery wastewater for reuse: State of the art, Desalination. 273 (2011) 235247. doi:10.1016/j.desal.2011.02.035.

[142] Y. Cengeloglu, G. Arslan, A. Tor, I. Kocak, N. Dursun, Removal of boron from water by using reverse osmosis, Sep. Purif. Technol. 64 (2008) 141-146. doi:10.1016/j.seppur.2008.09.006.

[143] J. Kim, H. Hyung, M. Wilf, J.-S. Park, J. Brown, Boron rejection by reverse osmosis membranes: national reconnaissance and mechanism study, Desalin. Water Purif. Res. (2009) 140.

[144] L.A. Richards, M. Vuachère, A.I. Schäfer, Impact of $\mathrm{pH}$ on the removal of fluoride, nitrate and boron by nanofiltration/reverse osmosis, Desalination. 261 (2010) 331-337. doi:10.1016/j.desal.2010.06.025.

[145] E. Curcio, X. Ji, A.M. Quazi, S. Barghi, G. Di Profio, E. Fontananova, T. Macleod, E. Drioli, Hybrid nanofiltration-membrane crystallization system for the treatment of sulfate wastes, J. Memb. Sci. 360 (2010) 493-498. doi:10.1016/j.memsci.2010.05.053. 
[146] H.M. Krieg, S.J. Modise, K. Keizer, H.W.J.P. Neomagus, Salt rejection in nanofiltration for single and binary salt mixtures in view of sulphate removal, Desalination. 171 (2005) 205-215. doi:10.1016/j.desal.2004.05.005.

[147] A. Bhattacharya, P. Ghosh, Nanofiltration and Reverse Osmosis Membranes: Theory and Application in Separation of Electrolytes, Rev. Chem. Eng. 20 (2004) 111-173. doi:10.1515/REVCE.2004.20.1-2.111.

[148] S.H. Yoon, C.H. Lee, K.J. Kim, A.G. Fane, Effect of calcium ion on the fouling of nanofilter by humic acid in drinking water production, Water Res. 32 (1998) 2180-2186. doi:10.1016/S0043-1354(97)00416-8.

[149] K. Košutić, I. Novak, L. Sipos, B. Kunst, Removal of sulfates and other inorganics from potable water by nanofiltration membranes of characterized porosity, Sep. Purif. Technol. 37 (2004) 177-185. doi:10.1016/S1383-5866(03)00206-5.

[150] J. Schaep, C. Vandecasteele, A. Wahab Mohammad, W. Richard Bowen, Modelling the retention of ionic components for different nanofiltration membranes, Sep. Purif. Technol. 2223 (2001) 169-179. doi:10.1016/S1383-5866(00)00163-5.

[151] L. Paduano, R. Sartorio, G. D'Errico, V. Vitagliano, Mutual diffusion in aqueous solution of ethylene glycol oligomers at $25^{\circ} \mathrm{C}$, J. Chem. Soc. Faraday Trans. 94 (1998) 2571-2576. doi:10.1039/a803567i.

[152] N. Ben Amar, H. Saidani, A. Deratani, J. Palmeri, Effect of temperature on the transport of water and neutral solutes across nanofiltration membranes, Langmuir. 23 (2007) 2937-2952. doi:10.1021/la060268p.

[153] M.A. Matthews, A. Akgerman, Infinite Dilution Diffusion Coefficients of Methanol and 2Propanol in Water, J. Chem. Eng. Data. 33 (1989) 122-123. doi:10.1021/je00052a018.

[154] E. Hawlicka, R. Grabowski, Self-Diff usion in Water-Alcohol Systems. 3. I-Propanol-Water Solutions of $\mathrm{Na}$, J. Phys. Chem. 96 (1992) 1554-1557.

[155] K.C. Pratt, W.A. Wakeham, The mutual diffusion coefficient for binary mixtures of water and the isomers of propanol, Proc. R. Soc. Lond. A. 342 (1975) 401-419. doi:10.1098/rspa.1975.0031.

[156] E.R. Nightingale, Phenomenological Theory of Ion Solvation. Effective Radii of Hydrated lons, J. Phys. Chem. 63 (1959) 1381-1387. doi:10.1021/j150579a011.

[157] M. Pennisi, R. Gonfiantini, S. Grassi, P. Squarci, The utilization of boron and strontium isotopes for the assessment of boron contamination of the Cecina River alluvial aquifer (central-western Tuscany, Italy), Appl. Geochemistry. 21 (2006) 643-655. doi:10.1016/j.apgeochem.2005.11.005.

[158] STERLITECH CORPORATION, SEPA CF Cell Assembly and Operation Manual | SEPA CF Cell Manual V1.2 https://www.sterlitech.com/media/wysiwyg/Manual/Manual_Sepa_CF_2016_1.pdf (accedido 24 de marzo de 2017). 
[159] GE Healthcare Life Sciences, Superose 12 10/300 GL, (2017). http://www.gelifesciences.com/webapp/wcs/stores/servlet/ProductDisplay?categoryld=1153 $8 \&$ catalogld=10101\&productld=23223\&storeld=11781\&langld=-1 (accedido 24 de enero de 2017).

[160] METRIX LABORATORIOS, Agua Ultrapura para la Analítica HPLC, (2017). http://www.metrixlab.mx/no-cat/agua-ultrapura-para-la-analitica-hplc/ (accedido 10 de enero de 2017).

[161] DOW-FILMTEC, FILMTEC ${ }^{\mathrm{TM}}$ Membranes System Design: Membrane System Design Guidelines for Commercial Elements Membrane System Design Guidelines Commercial Elements, http://msdssearch.dow.com/PublishedLiteratureDOWCOM/dh_08ca/0901b803808caf76.pdf ?filepath=liquidseps/pdfs/noreg/609-02054.pdf\&fromPage=GetDoc $r$ (accedido 24 de enero de 2017).

[162] J.L. Amorós, E. Sánchez, J. García-Ten, V. Sanz, M. Monzó, Manual para el control de la calidad de materias primas arcillosas, 2004.

[163] NanoFlux predicts and scales-up nano processes, Filtr. Sep. 42 (2005). doi:10.1016/S00151882(05)70722-9.

[164] J. Palmeri, X. Lefebvre, Modeling of neutral solute and ion transport in charged nanofiltration membranes using computer simulation programs, Handb. Theor. Comput. (2006).

[165] L.D. Nghiem, A.I. Schäfer, M. Elimelech, Removal of natural hormones by nanofiltration membranes: measurement, modeling and mechanisms, Environ. Sci. Technol. 38 (2004) 1888-1896. doi:10.1021/es034952r.

[166] M.J. López-M Noz, A. Sotto, J.M. Arsuaga, B. Van Der Bruggen, Influence of membrane, solute and solution properties on the retention of phenolic compounds in aqueous solution by nanofiltration membranes, Sep. Purif. Technol. 66 (2009) 194-201. doi:10.1016/j.seppur.2008.11.001.

[167] C. Ferreira Esmi, L. Schrive, Y. Barre, J. Palmeri, A. Deratani, Using nanofiltration in a «zerorejection» process: the removal of $\mathrm{Ni} 2+$ and $\mathrm{Co} 2+$ from salty wastewater, Desalin. Water Treat. (2012) 1-9. doi:10.1080/19443994.2012.714526.

[168] A. Simon, J.A. McDonald, S.J. Khan, W.E. Price, L.D. Nghiem, Effects of caustic cleaning on pore size of nanofiltration membranes and their rejection of trace organic chemicals, J. Memb. Sci. 447 (2013) 153-162. doi:10.1016/j.memsci.2013.07.013.

[169] L.D. Nghiem, S. Hawkes, Effects of membrane fouling on the nanofiltration of pharmaceutically active compounds (PhACs): Mechanisms and role of membrane pore size, Sep. Purif. Technol. 57 (2007) 176-184. doi:10.1016/j.seppur.2007.04.002.

[170] M.H. Davood Abadi Farahani, S.M. Borghei, V. Vatanpour, Recovery of cooling tower blowdown water for reuse: The investigation of different types of pretreatment prior nanofiltration and reverse osmosis, J. Water Process Eng. 10 (2016) 188-199. 
doi:10.1016/j.jwpe.2016.01.011.

[171] A. Alhadidi, A.J.B. Kemperman, R. Schurer, J.C. Schippers, M. Wessling, W.G.J. Van der Meer, Using SDI, SDI+ and MFI to evaluate fouling in a UF/RO desalination pilot plant, Desalination. 285 (2012) 153-162. doi:10.1016/j.desal.2011.09.049.

[172] I. Koyuncu, R. Sengur, T. Turken, S. Guclu, M.E. Pasaoglu, Advances in water treatment by microfiltration, ultrafiltration, and nanofiltration, en: Adv. Membr. Technol. Water Treat. Mater. Process. Appl., 2015: pp. 83-128. doi:10.1016/B978-1-78242-121-4.00003-4.

[173] E.S. Ali, A.S. Alsaman, K. Harby, A.A. Askalany, M.R. Diab, S.M. Ebrahim Yakoot, Recycling brine water of reverse osmosis desalination employing adsorption desalination: A theoretical simulation, Desalination. 408 (2017) 13-24. doi:10.1016/j.desal.2016.12.002.

[174] J.J. Sadhwani, J.M. Veza, Desalination and energy consumption in Canary Islands, Desalination. 221 (2008) 143-150. doi:10.1016/j.desal.2007.02.051.

[175] A.R. Costa, M.N. de Pinho, Performance and cost estimation of nanofiltration for surface water treatment in drinking water production, Desalination. 196 (2006) 55-65. doi:10.1016/j.desal.2005.08.030.

[176] A. Gorenflo, D. Velázquez-Padrón, F.H. Frimmel, Nanofiltration of a German groundwater of high hardness and NOM content: Performance and costs, Desalination. 151 (2003) 253-265. doi:10.1016/S0011-9164(02)01018-4.

[177] R. Liikanen, J. Yli-Kuivila, J. Tenhunen, R. Laukkanen, Cost and environmental impact of nanofiltration in treating chemically pre-treated surface water, Desalination. 201 (2006) 58-70. doi:10.1016/j.desal.2006.03.520.

[178] SENDECO2, Negociación de derechos de emisión de dióxido de carbono y créditos de carbono entre instalaciones, (2017). http://www.sendeco2.com/es/ (accedido 21 de abril de 2017).

[179] A. Zhu, P. Christofides, Y. Cohen, On RO membrane and energy costs and associated incentives for future enhancements of membrane permeability, J. Memb. Sci. (2009).

[180] X. Lefebvre, J. Palmeri, P. David, Nanofiltration theory: An analytic approach for single salts, J. Phys. Chem. B. 108 (2004) 16811-16824. doi:10.1021/jp048631t.

[181] A. Costa, Permeability-porosity relationship: A reexamination of the Kozeny-Carman equation based on a fractal pore-space geometry assumption, Geophys. Res. Lett. 33 (2006) L02318. doi:10.1029/2005GL025134.

[182] K.S. Spiegler, O. Kedem, Thermodynamics of hyperfiltration (reverse osmosis): criteria for efficient membranes, Desalination. 1 (1966) 311-326. doi:10.1016/S0011-9164(00)80018-1.

[183] S. Sarrade, G.M. Rios, M. Carlès, Dynamic characterization and transport mechanisms of two inorganic membranes for nanofiltration, J. Memb. Sci. 97 (1994) 155-166. doi:10.1016/03767388(94)00158-U.

[184] W.M. Deen, B. Satvat, J.M. Jamieson, Theoretical model for glomerular filtration of charged 
solutes., Am. J. Physiol. 238 (1980) F126-F139.

[185] X. Lefebvre, J. Palmeri, Nanofiltration theory: Good Co-lon exclusion approximation for single salts, J. Phys. Chem. B. 109 (2005) 5525-5540. doi:10.1021/jp0458710.

[186] R. Schlögl, Membrane permeation in systems far from equilibrium, Berichte der Bunsengesellschaft für Phys. Chemie. 70 (1966) 400-414. doi:10.1002/BBPC.19660700403.

[187] A.W. Mohammad, Y.H. Teow, W.L. Ang, Y.T. Chung, D.L. Oatley-Radcliffe, N. Hilal, Nanofiltration membranes review: Recent advances and future prospects, Desalination. 356 (2015) 226-254. doi:10.1016/j.desal.2014.10.043.

[188] V.M. Aguilella, Descripción de los procesos de transporte en disoluciones de electrolitos: modelo fenomenológico basado en las ecuaciones de Nerst-Planck, Universidad, Secretariado de Publicaciones, 1989. 
"Que la terra es vaja fent camí davant els teus passos. Que el vent bufe sempre a la teua esquena. Que el sol brille càlid sobre la teua cara. Que la pluja caiga suaument sobre els teus camps $i$, mentre tornem a trobar-nos, que Déu et guarde en la palma de les seues mans" (acomiadament templer) 